

$\mathbf{U}_{\text {NIVERSITAT }}$

JAUME•I

UNIVERSITAT JAUME I DE CASTELLÓ DEPARTAMENTO DE HISTORIA MODERNA

\title{
Fuentes para el estudio de la oligarquía y los cargos \\ municipales de Castellón en el s. XVII
}

Tesis Doctoral presentada por José Luis Lorenz Andrés

Director de la Tesis Doctoral Dra. Carmen Corona Marzol 
En general hay un grado de duda, de cautela y modestia que, en toda clase de investigaciones, debe acompañar siempre al razonador cabal (Hume)

La antítesis de la ciencia es el dogmatismo (Ortega y Gasset)

Dedicado muy especialmente a Vicente y a mi madre M.Soledad, así como a mi padre, mis hermanos Fernando y Esti, y a mi sobrino Marc. 


\section{Agradecimientos.}

Relatar la historia de la ciudad de Castellón es una labor que se ha venido desarrollando a lo largo del tiempo con pequeñas aportaciones de muchos autores, tarea que exige una curiosidad por comprender como fueron las diversas etapas de la villa. Para ello debe haber una pequeña chispa que incite la curiosidad del investigador. Exactamente eso es lo que provocaron mis profesores del Master en Historia e Identidades Hispánicas en el Mediterráneo Occidental (siglos XV-XIX), una necesidad de averiguar, comprender, justificar y explicar ciertos aspectos de la Edad Moderna en el municipio de Castellón. Fue así como nos planteamos este trabajo sobre las instituciones forales en la villa castellonense del siglo XVII y por eso mi primer agradecimiento solo puede ir dirigido a la Doctora Carmen Corona Marzol, pues además de despertar esa curiosidad, ha ido perfilando mi trabajo y me ha ayudado a superar los distintos obstáculos que han ido apareciendo durante estos cuatro años de investigación y que no han sido pocos.

Además he de agradecer la colaboración en la revisión y corrección de todo el trabajo de mi amiga y compañera Francisca Tenés. Una aportación desinteresada y cariñosa que me ha ayudado a perfeccionar un proyecto ambicioso y que no hubiese sido posible sin su participación.

Finalmente agradecer la inestimable ayuda del personal del Archivo Histórico Municipal de Castellón encabezado por su Directora Elena Sanchís y sus ayudantes Roberto Cruz, Manolita Febrer y Pepa Casino puesto que siempre han intentado ayudarme en todo lo que he solicitado. 


\section{Abreviaturas.}

AHMC: Archivo Histórico Municipal de Castellón.

AHPC: Archivo Histórico Municipal de Castellón.

ARV: Archivo del Reino de Valencia.

ACEQ: Bolsa de personas para el oficio de acequiero.

ALM: Bolsa de personas del brazo real para el oficio de almotacén.

CAB: Bolsa de caballeros o generosos.

CMM: Bolsa de personas para el oficio de consejero de mano mayor.

CMN: Bolsa de personas para el oficio de consejero de mano menor.

ESCR: Bolsa de personas para el oficio de escribano.

JBRA: Bolsa de personas para jurado primero.

J2A: Bolsa de personas para jurado segundo o de los artistas.

$\mathrm{J} 3 \mathrm{y} 4$ : Bolsa de personas para jurado tercero y cuarto o de los labradores.

JUST: Bolsa de personas del brazo real para el cargo de justicia. 


\section{3. Índice de contenido.}

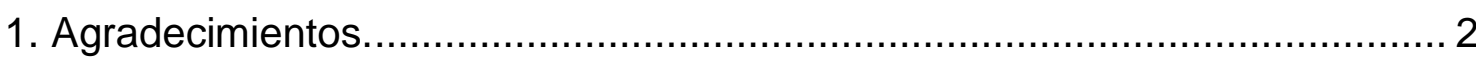

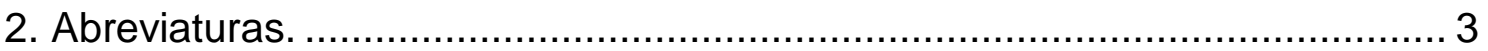

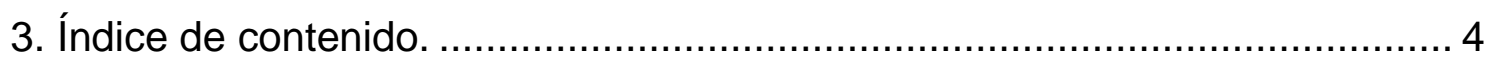

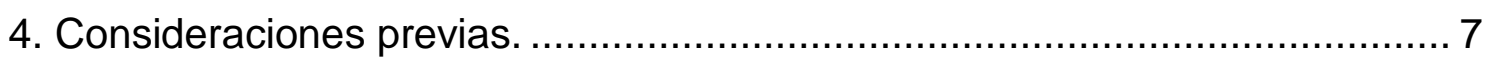

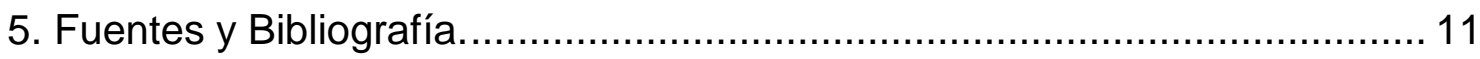

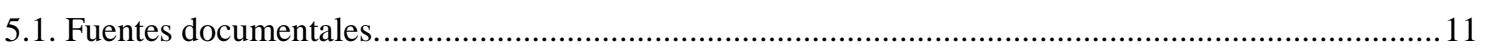

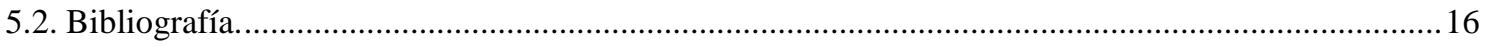

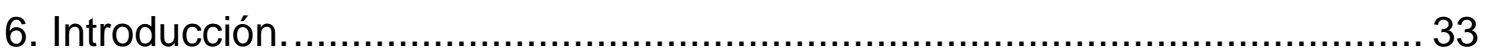

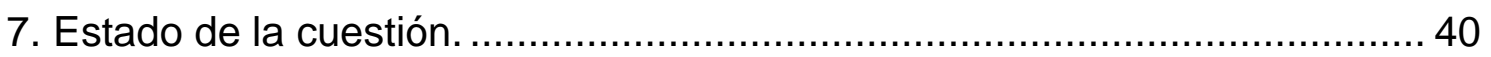

8. Metodología y objetivos...................................................................... 46

9. Aproximación al Castellón de la época moderna. .................................... 51

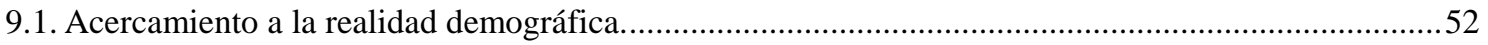

9.2. Análisis de la realidad económica de la villa............................................................................54

10. Evolución del proceso insaculatorio. ................................................... 56

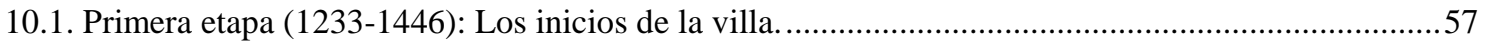

10.2. Segunda etapa (1446-1590): La introducción del sistema insaculatorio. ......................................57

10.3. Tercera etapa (1590-1707): Consolidación del sistema insaculatorio.........................................58

11. Estructura del poder local: El proceso insaculatorio, los oficios y el Consell.



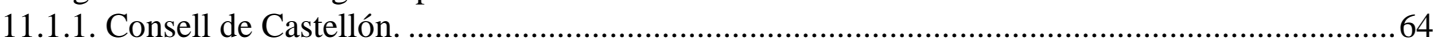



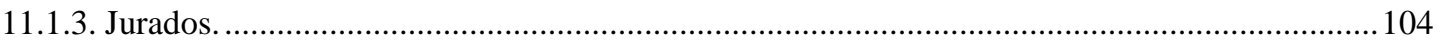

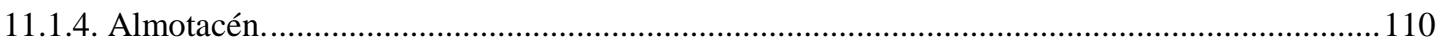

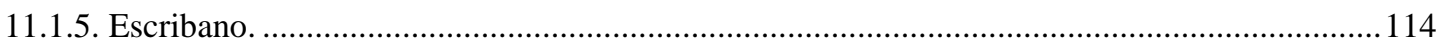

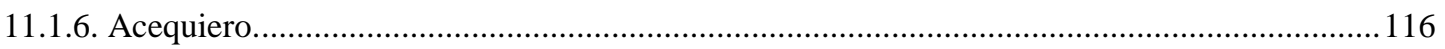

11.2. Oficios que no se elegían por el proceso insaculatorio........................................................... 119 
12. Las Insaculaciones: control y perpetuidad. 124

12.1. El límite en las bolsas de 1604: Una puerta abierta a cerrar el acceso al poder local.



12.2.1. Bolsa de caballeros o generosos. ..................................................................................... 128

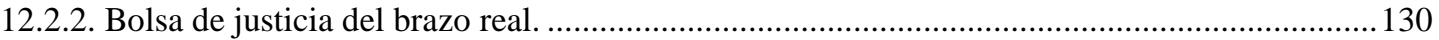

12.2.3. Bolsa de jurado primero del brazo real............................................................................ 132

12.2.4. Bolsa de jurado de segundo del brazo real o de los artistas. ................................................... 134

12.2.5. Bolsa de jurado tercero y cuarto del brazo real................................................................ 136

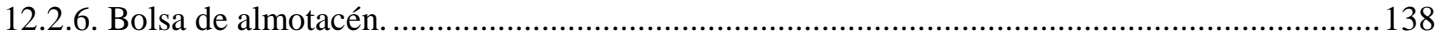

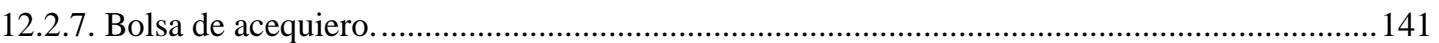

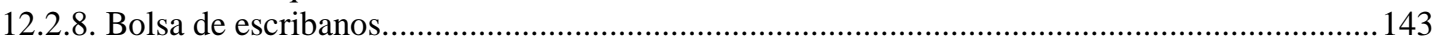

12.2.9. Bolsa de consejeros de mano mayor. ............................................................................ 145

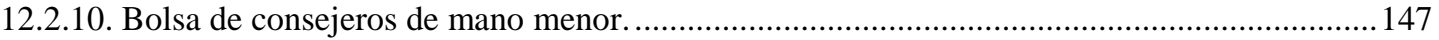

13. El poder de las familias en los cargos municipales y en el Consell.......... 150

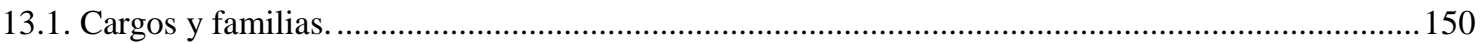



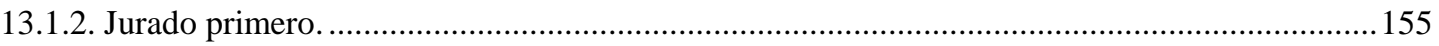



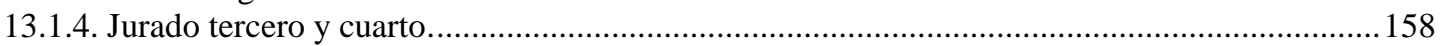

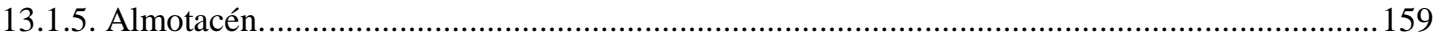

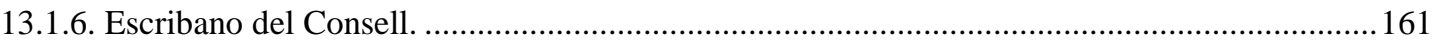

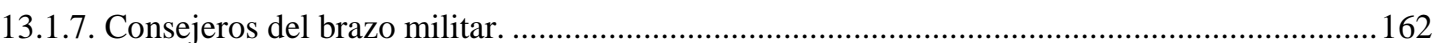

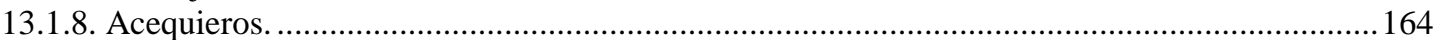

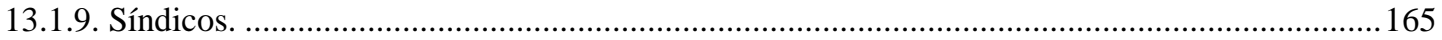

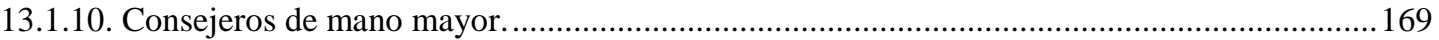

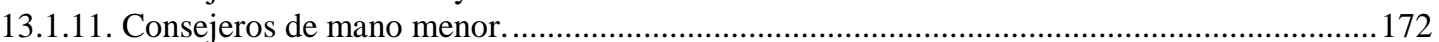

13.2. Perpetuidad en el poder a nivel individual........................................................................... 174

13.3. Las mismas familias en el Consell de Castellón..........................................................................175

14. La relación directa entre ser insaculado y el desempeño de un cargo en el Castellón del seiscientos.......................................................................... 179

15. El ayuntamiento borbónico y la disyuntiva entre ruptura o continuación. . 185

16. La influencia regia en las instituciones locales de Castellón tras el Privilegio de Felipe III de 1597

17. Castellón frente a otras villas de la Corona de Aragón: semejanzas y diferencias.

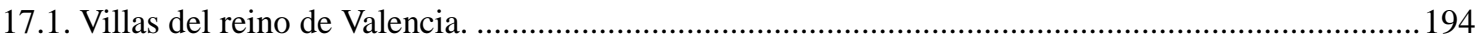

17.2. Otras villas de la Corona de Aragón.

18. Conclusiones.

19. Apéndice documental. 
19.1. Documento 1: Privilegio dado por Juan de Navarra en 1446 a la villa de Castellón

19.4. Documento 4: Privilegio real dado por Felipe III a la villa de Castellón, por el que se modifica la forma y el número de los que pueden ser insaculados en las bolsas para los oficios de gobierno del municipio.

19.5. Documento 5: Texto del Caballero D'Asfeld

19.6. Documento 6: Extracto del libro de Ayuntamientos y Concejos de la Villa de Castellón de la Plana del ano 1707 y 1708,1709 y 1710

19.7. Documento 7: Ejemplo de nombramiento de justicia y asesor de justicia. .269

19.8. Documento 8: Transcripción insaculaciones.

19.9. Documento 9: Familias en Castellón entre 1588 y 1769

19.10. Documento 10: Relación de asesores de justicia.

20. Relación de tablas. 


\section{Consideraciones previas.}

a) Limitación de los datos: Para realizar un análisis adecuado del periodo objeto de nuestro estudio hemos recurrido a archivos de la época foral. En ellos hemos encontrado lagunas en determinados intervalos temporales que nos gustaría poner de manifiesto.

En nuestra investigación, ha sido fundamental el estudio minucioso del Judiciari de la ciudad de Castellón entre 1590 y 1707, que en su mayoría se encuentra en buen estado. Sin embargo, los períodos de 1599-1602 y 1658-1661 se deshacen en las manos al consultarlos, provocado según el personal del archivo de Castellón, porque la tinta utilizada es corrosiva. Además, hay períodos de los que no hemos obtenido datos, bien porque existiendo el Judiciari no hay registro de las sesiones del Consell o bien porque simplemente con el paso de los años se ha extraviado. Esto solamente ocurre entre 1617 y 1620 y en dos años concretos como son 1603 y 1613.

A pesar de estas limitaciones podemos afirmar, bajo nuestro punto de vista, que los datos extraídos son bastante relevantes y que la falta de algunos de ellos en períodos muy concretos es insignificante y no altera las conclusiones que hemos formulado.

b) Criterios para nombres $\mathbf{y}$ apellidos: Es una práctica habitual en toda la documentación consultada de la época foral, citar el apellido o el nombre de las personas de forma diferente cada vez que estaba redactando un escribano distinto. Esto podía suponer un inconveniente para el lector por lo que hemos intentado homogeneizar el patrón de escritura, y de esta forma, hacer más fácil la lectura de este trabajo siguiendo siempre un rigor científico que no nos aparte de la realidad y que se asemeje más a la lengua catalana que era la lengua vehicular de la época foral en la villa de Castellón.

Miquel/Miguel: Utilizamos Miquel

Juceph/Joceph/Joseph/Josep: Utilizamos Josep

Juan/Joan/Johan: Utilizamos Joan

Thomas/Tomàs: Utilizamos Tomàs

Matheu/Mateu/Mateo: Utilizamos Mateu 
Hierony/Gerony/Geroni: Utilizamos Gerony

Mathia/Macià: Utilizamos Macià

Francesc/Francés: Utilizamos Francesc

Cristòfol/Cristòfol: Utilizamos Cristòfol

Eiximeno/Ximeno: Utilizamos Eiximeno

Arcís/Narcís: Utilizamos Narcís

Egual/Igual: Utilizamos Igual

Berthomeu/Bertomeu: Utilizamos Bertomeu

Lois/Lluís/Luis: Utilizamos Lluís

Anthoni/Anthony/Antoni: Utilizamos Antoni

\section{c) Criterios para la transcripción:}

- Respeto a la grafía original, aunque restituyendo las palabras a su propio contexto y haciendo homogéneo el uso de la i latina propia de la lengua catalana frente a la y griega que aparece en algunos casos.

- Separación de palabras y uso de l'apostrofació.

- Aplicación criterios actuales de puntuación, mayúsculas y acentos.

- Desarrollo de las abreviaturas.

- Texto con corchetes recoge anotaciones marginales en el original.

- Paréntesis con puntos suspensivos (...) indican palabras ilegibles.

- Anotaciones en cursiva y paréntesis indican aclaraciones propias.

\section{d) Criterios para la elaboración de los cuadros de los cargos anuales:}

Justicia: Consideramos que si es elegido en diciembre ocupa el cargo todo el ejercicio siguiente. El asesor del justicia se elige a continuación del oficio de justicia por lo que se ha seguido el mismo criterio.

Jurados, consejeros, escribanos y síndico del Consell: Consideramos que como su elección es en la Pascua de Pentecostés y casi siempre es en el mes de mayo, el cargo lo ocupan durante seis meses y unos días de ese año y cinco meses y unos días del año siguiente, por tanto se le ha asignado el año de ejercicio del cargo el mismo que el de nombramiento. Este criterio es más práctico para la elaboración de los cuadros y su posterior interpretación. 
Almotacén: Consideramos que como su elección es a finales de septiembre y sólo ejerce su cargo tres meses en ese año y la mayor parte es en el siguiente, se le ha asignado en las tablas el año siguiente a la elección.

Acequiero: Es un caso similar al de justicia ya que también es elegido en diciembre.

e) Apellidos y familias: En este apartado nos gustaría hacer una aclaración respecto a las familias y los apellidos ya que hemos englobado a las personas que ocuparon cualquiera de los cargos del Consell en función de su apellido. Esto supone un sesgo importante porque puede ocurrir que el mismo apellido lo compartan dos consejeros de familias distintas. Como nuestro objetivo es que el trabajo refleje lo más fielmente posible la realidad de la época hemos tenido en cuenta para la agrupación de las familias los siguientes criterios:

1. Agrupación por apellidos.

2. Revisión de protocolos notariales en aquellos casos que considerábamos más importantes ya que la reconstrucción de todos los árboles familiares nos hubiera llevado toda una vida.

3. Valorar la pertenencia al mismo grupo oligárquico y su presencia en las mismas bolsas.

4. Contrastar nuestros datos con el estudio realizado por Sánchez Adell sobre el número de familias que había en Castellón en el siglo XVII y que se ofrece de forma resumida en el documento nueve del apéndice documental.

f) Palabras en cursiva: En el texto se cita en cursiva aquellos cargos, oficios y órganos que mantienen su nombre en la lengua que se utiliza en la época para una mejor comprensión de todo el trabajo.

g) Apéndice documental: En el apéndice se han incluido las transcripciones del Privilegio de Don Juan de Navarra de 1446, la Ordinación de Covarrubias de 1590, el Privilegio del joven heredero al trono Felipe III y el de 1604 que limitaba el número de 
integrantes de las bolsas. Estos ya habían sido transcritos por otros autores como Arroyas Serrano o Bernabé Gil, por lo que nuestra intención es incorporarlos al trabajo para una mejor comprensión de toda la explicación. 


\section{Fuentes y Bibliografía.}

\subsection{Fuentes documentales.}

\section{Archivo Histórico Municipal de Castellón}

Manuscritas

1) Actas capitulares de 1710-1729.

2) Actas del Judiciari

1587-1590, 1591, 1595-1596, 1597-1599, 1599-1602 (Muy dañado), 1604-1608, 1607-1611, 1608-1611, 1611-1614, 1614-1617, 1620-1623, 1621-1625, 1626-1628, 1629-1631, 1631-1634, 1634-1637, 1636, 1637-1640, 1640-1643, 1642, 1643-1646, 1646-1648, 1650, 1650-1653, 1653-1655, 1654-1657, 1656-1659, 1658-1661 (Muy dañado), 1662-1665, 1666-1668, 1668-1671, 1671-1674, 1674-1677, 1677-1680, 1681-1683, 1683-1686, 1686-1689, 1689-1692, 1692-1695, 1696-1698, 1698-1701, 1701-1704, 1704-1707 y 1707-1710.

3) Protocolos notariales.

ALONSO, Francesc: 329.1680, 82; 330.1683; 331. 1684;332. 1685, 86; 333. 1687, 88; 334. 1689, 92; 335. 1693-1694.

APARICI, Miquel: 355. 1700; 356. 1693-1694.

ARMELLES, Cristóbal: 1. 1644-1645, 46, 47.

ARRUFAT, Francescc: 2. 1644-1645,49.

ARRUFAT, Joan: 3. 1579.

ARRUFAT, Joan: 4. 1690

ARRUFAT, March: 5. 1551-1554, 56, 59, 61; 6. 1562, 63, 64-65, 67; 7. 1568, 69, 70, 71; 8. 1572, 73, 74; 9. 1575, 77; 10. 1580, 81; 11. 1585, 86; 12. 1587, 88-89, 92; 13. 1593, 96-97, 98-99.

BAYOT, Pere: 14. 1667; 15. 1668; 16. 1669; 17. 1670; 18. 1671; 19. 1672.

BE, Tomàs: 20. 1705.

BELTRAN, Domingo: 21. 1569-70; 22. 1574, 76-77; 23. 1578-1579, 82, 85; 24. $1587,88,89 ; 25$. 1591, 92, 93; 26. 1596, 97, 98; 27. 1599, 1605-1606.

BELTRAN, Nicolau: 28. 1611, 14. 1608-09-10.

BLASCO, Cristóbal: 29. 1696-98, 99-1702; 30. 1703-1707, 11-13. 
BLASCO, Josep: 31. 1662-1664, 63, 64, 65-67; 32. 1668, 69, 70, 71-72; 33. 1673, 74, 75, 76; 34. 1677, 77-78, 78; 35. 1679, 81, 82-83; 36. 1684-1686, 87, 90; 37. 1691-1699, 1699-1702.

BREVA, Felip: 349. 1670-1675; 350. 1680, 88-96.

BREVA, Pere: 336. 1674, 75, 76; 38. 1676, 1705, 06; 337. 1677, 78; 338. 1679, 80, 81; 339. 1683, 84, 85; 340, 1687, 88; 341. 1691, 96; 342. 1698-99, 1700; 343. 1702. CAPERO, Pau: 39. 1605, 06, 11, 13, 15, 16, 17, 18; 40. 1619, 20, 21.

CASES, Jaume: 280. 1662; 281. 1663; 282. 1664; 283. 1665; 284. 1666; 286. 1667; 287. 1668; 288. 1669; 289. 1670; 290. 1675-80, 84; 291. 1693; 292. 1694; 293. 1695; 294, 1696, 98.

CASTELL, Joan: 41. 1554, 57, 59-60; 42. 1561-62, 63-64; 43. 1565, 66; 44. 15671568; 45. 1569, 72, 73; 46. 1574, 75, 76; 47. 1577, 78; 48. 1579-80, 81, 82; 49. $1583,84,85$; 50. 1586-87, 88-89; 51. 1590-1591, 92; 52. 1593-94, 95-96; 53. 15991600.

CASTELLET, Jaume 54. 1602, 05, 06; 253. 1608, 10, 11; 55. 1612-13, 14; 357. 1616-17. 18; 56. 1622-23, 27-28, 29-30, 31; 57. 1632-34, 36, 37; 58. 1640-43, 44. CEBRIA, Josep: 59. 1681, 81-83; 60. 1684-85-86, 87; 61. 1687-88-89, 89; 62. 1690-92, 91; 63. 1693-94, 94; 64. 1695, 95-96; 65. 1700, 01, 02; 66. 1703, 04, 05, 06-07.

CUCALA, Gregori: 68. 1606-09, 18, 20.

EXARQUE, Valerià: 69. 1637, 38, 39, 40, 41; 70. 1641, 42; 71. 1643, 45; 72. 1646, 47; 73. 1648, 49; 74. 1650; 75. 1651; 76. 1652; 77. 1653, 54; 78. 1656, 57; 79. 1658, 59; 80. 1660, 61; 81. 1663; 82. 1664; 83. 1665; 84.1666; 85. 1667, 68; 86. 1669,$71 ; 87.1672,73 ; 88.1675,76$.

FERRER, Vícent: 305. 1645, 48; 306. 1652; 307. 1653; 308. 1654; 309. 1655; 310. 1656; 311. 1658, 60; 312. 1659; 313. 1661, 62; 314. 1663, 64; 99. 1665-67; 315. 1675-76, 1687.

FOLCH, Joan Jerònim: 100. 1579, 80-84, 85-87; 101. 1588, 91, 92; 102. 1593, 95, 96; 103. 1598; 104. 1599; 105. 1600, 01; 106. 1602, 03; 107. 1604, 05, 09; 108. 1611,$13 ; 109.1615,17,18,21-22$.

FOLCH, Pare: 110. 1566, 67, 68-69; 111. 1570, 73, 74; 112. 1576, 77, 78; 113. 1579, 80-81, 82-83-84; 114. 1586, 88-89-90, 91-92-93-94.

FRANCH, Josep: 347. 1652, 69-70; 348. 1671-79.

GALI, Josep: 115. 1649. 
GIL, Bte.: 116. 1672-73-74-75-76, 74-77, 77-78; 117. 1679-80, 81, 82-84.

GINER, Jaume 230. 1564, 66, 67; 118. 1565, 74; 231. 1572, 73; 232. 1577, 98; 233. 1600; 119. 1603; 234. 1604; 120. 1607; 121. 1610; 235. 1612; 122. 1613, 15.

GINER, Pere: 254. 1623, 28; 255. 1630; 256. 1633; 257. 1633; 258. 1637; 259. 1638; 260. 1639; 261. 1640; 262, 1641; 263. 1642; 264. 1643; 265. 1643; 266. 1644; 267. 1645; 268. 1649; 269. 1650; 270. 1652; 271. 1653; 272. 1654; 273. 1655; 274. 1656; 275. 1657; 276. 1658; 277. 1658; 278. 1659, 63; 279. 1666, 72.

GRAU, Josep: 123. 1648-49-50-51; 124. 1652-53; 125. 1654-55; 126. 1656; 127. 1657-58, 59-60; 128. 1661-65-66; 129. 1664, 69; 130. 1667; 131. 1670.

JOVER, Francescc: 132. 1571, 80, 83, 84, 87-88; 133. 1589-90-91, 92-93, 94-95; 134. 1596, 97-98; 135. 1599-1600, 01-02; 136. 1603-04, 07; 137. 1608, 09-10; 138. $1612 ; 139.1613,14 ; 140.1616,18-19-20$.

LLORENS DE CLAVELL, Josep: 316. 1683-84; 317. 1686; 318. 1689, 90; 141. 1690; 319. 1691: 320. 1692; 321. 1693; 322. 1694; 323. 1695; 324. 1696; 325. 1697; 326. 1698; 327. 1700; 328. 1701, 329. 1702; 330. 1703; 331. 1704; 332. 1707. MARTÍ, Alejandro: 142. 1682, 1703.

MARTÍNEZ, Tomás: 143. 1685, 85-86-87; 144. 1688-89-90-91-92-93, 97-98-99; 145. 1702-03, 04-05; 146. 1707.

MAS, Francescc: 351. 1658-59; 352. 1660.

MAS, Josep: 147. 1574-78, 91-92; 148. 1593-94-95, 96-97-98-99.

MICO, Jerònim: 224. 1576; 225. 1578, 79; 226. 1579; 227. 1580, 81; 149. $1584 ; 228.1585 ; 229.1586$.

MOLINER, Bertomeu: 150. 1605.

MOLINER, Narcís: 151. 1598.

PLANELL, Joan: 171. 1625-26-27, 28-29-30; 172. 1628-31, 32-33-34, 35-36-37.

RAMOS, Bertomeu: 353. 1704.

ROMEU, Pere: 236. 1605, 07, 09; 237. 1610, 13; 238. 1615; 239. 1617; 240. 1618; 241. 1619; 242. 1620; 243. 1622; 174. 1623; 244. 1624; 245. 1625; 246. 1627; 247. 1629; 248. 1630; 249. 1633; 250. 1634; 251. 1639; 252. 1646, 49; 175. 1648.

RUNA, Bertomeu: 176. 1612-16.

SALA, Domingo: 177. 1582-83-84, 89-90; 178. 1591-92; 179. 1594, 95-96; 180. 1606-10; 181. 1611-12; 182. 1613, 14; 183. 1612-16, 21.

SALVADOR, Melchor: 184. 1614.

SANCHÍS, Josep: 344. 1697-98; 345. 1699-1700, 01-02; 346. 1703-04. 
SEVERACH, Gaspar: 197. 1666-71; 198. 1671-74; 199. 1676-78; 200. 1680-82; 201. 1683, 84, 85, 86; 202. 1688, 89-90, 90, 91; 203. 1694, 98, 1700, 02, 03, 05, 06, 07, 08; 204. 1710, 11, 13.

SOLDEVILLA, Joan: 205. 1617-18-19, 21; 206. 1622, 23; 207. 1624, 25, 26; 208. 1627, 28; 209. 1629, 31, 32, 34; 210. 1635, 36, 37.

TIMOR, Francescc: 211. 1659-62.

TIRADO, Joan: 212. 1642-46, 48, 50, 51.

TOSQUELLA, Vicent: 295. 1652, 55: 296. 1656; 297. 1657, 58; 298. 1659, 60; 213. 1661; 299. 1662; 300. 1663-64-65; 301. 1675, 77, 78; 302. 1679-80-81-82, 8586-87-88; 303. 1689-90-91-92, 93-94-95-96-97; 304. 1650-91.

TRAVER, B. F.: 214. 1639-40, 43-44, 45-47; 215. 1650-51, 53; 216.1654.

TRAVER, Francescc: 354. 1641-42, 1648-49.

TRAVER, Joan B.: 217. 1608, 27, 30, 32, 39.

VICENT, Pere Joan: 218. 1653-54, 60, 63.

4) Llibre de les Insaculacions.

5) Llibre dels Privilegis.

6) Llibre de les Ordinacions.

7) Libre Vert.

8) Variarum de Clavell.

\section{Archivo Histórico Provincial de Castellón}

Manuscritas

1) Protocolos notariales

ALMELLA, Miguel: Caja 1 (1742-1745).

AVINENT, José: Caja 25 (1739-1741).

BENEDITO, Joaquín: Caja 28 (1750-1751).

BREVA, Luis: Caja 34 (1732-1735) y (1736-1738). Caja 35 (1740-1740), (17411741) у (1743-1742). Caja 36 (1743-1743) sin foliar, (1744-1744), (1745-1745) y (1747-1747). Caja 37 (1748-1748), (1749-1749), (1750-1750) y (1751-1751). Caja 38 (1752-1752), (1753-1753), (1754-1754) у (1755-1755). Caja 39 (1756-1756), (1757-1757) y (1758-1758). Caja 40 (1759-1760), (1761-1761) у (1762-1763). Caja 41 (1764-1765) sin foliar, (1766-1767) y (1768-1769). Caja 42 (1770-1770), (17711771) у (1772-1772).

MAÑÉS, Francisco: Caja 55 (1725-1725). 
MELIA y TRAVER, Felip: Caja 55 (1758-1758) y (1759-1759). Caja 56 (17601760). Caja 57 (1772-1778). Caja 58 (1780-1785). Caja 59 (1786-1789). Caja 60 (1790-1793). Caja 61 (1794-1797) sin foliar.

PEREZ, Francisco: Caja 63 (1749-1749).

PEREZ, Juan: Caja 62 (1743-1744), (1745-1746) y (1747-1748). Caja 63 (17511751) у (1752-1752). Caja 64 (1753-1754), (1755-1755) у (1756-1756). Caja 65 (1757-1757), (1758-1759) у (1760-1761). Caja 66 (1762-1763), (1768-1769) у 1770-1771). Caja 67 (1772-1773).

ROCA, Francisco: Caja 82 (1782-1782)

SALES, Miguel: Caja 82 (1787-1795).

SEBARRA, Domingo: Caja 34 (1733-1734).

SEGARRA, Domingo: Caja 83 (1739-1741) y (1742-1743).

SIDRO Y PÉREZ, Manuel: Caja 84 (1752-1755), (1756-1758) y (1759-1760). Caja 85 (1761-1761) y (1762-1764). Caja 86 (1765-1768) y (1769-1771). Caja 87 (17821791).

VICENTE, Bernando: Caja 88 (1759-1761). Caja 89 (1762-1762), (1763-1764) y (1765-1766). Caja 90 (1767-1767), (1768-1768), (1769-1769) у (1770-1770). Caja 91 (1771-1771), (1772-1772) у (1773-1773). Саја 92 (1774-1774), (1775-1775) у (1776-1776). Caja 93 (1777-1777), (1778-1778) у (1779-1779). Caja 94 (17801780), (1781-1781) у (1782-1782). Caja 95 (1784-1784) у (1785-1785). Caja 96 (1786-1786), (1787-1787) у (1788-1788). Caja 97 (1790-1790), (1791-1791), (1792-1792) у (1793-1793). Caja 98 (1794-1794). 


\subsection{Bibliografía.}

Alberola RomÀ, A. (1984): Jurisdicción y propiedad de la tierra de Alicante. Ayuntamiento/Universidad de Alicante.

AlBerola RomÀ, A. (1990): "La organización del municipio en la época foral”. Historia de la ciudad de Alicante. Ayuntamiento de Alicante. Tomo III. pp. 185-212.

Alberola RomÀ, A. (1992): "Autoridad real y poder local. Reflexiones en tomo al desarrollo del procedimiento insaculatorio en los municipios valencianos durante la época foral moderna". Pedralbes. Revista d'Història Moderna, $\mathrm{n}^{\mathrm{o}}$ vol. 12. Universidad de Barcelona. Barcelona.

Alberola RomÀ, A. (1992): "Els muncipis reialencs valencians durant l'època foral moderna: estructura política i funcionament”. Dels Furs al Estatut. Actes del I Congrés d'Administració Valenciana: De la Història a la Modernitat. València. pp. 443-456.

Alberola RomÀ, A. (1997): "Élites urbanas en el gobierno municipal de Alicante durante los siglos XV y XVI". Familia, Parentesco y Linaje. Historia de la Familia. Una perspectiva sobre la sociedad europea. Seminario familia y ente en el poder en el reino de Múrcia siglos XV al XIX. Universidad de Murcia, pp.121-130.

Alberola RomÀ, A. (1999): “Oligarquías urbanas en las ciudades y villas alicantinas durante el reinado de Felipe II". Felipe II y el Mediterráneo/coord. por Ernest Belenguer Cebrià, Vol. 2. Valencia, pp. 295-310.

Alfaro Pérez, F.J. y Domínguez Cavero B. (2002): "La organización municipal de Navarra en el Antiguo Régimen (1512-1841). El sistema inseculatorio y su relación con Aragón”. Revista de Historia J. Zurita, I.F.C. (C.S.I.C.), 75-2000, Zaragoza, pp. 7-36.

AMElANG, J.S. (1986): La formación de una clase dirigente: Barcelona 1490-1714. Ariel. Barcelona.

ANDRÉS RoBRES, F. (1986): Estructura y crisis de las finanzas municipales en el Castellón del Setecientos. Ayuntamiento de Castellón de la Plana. Castellón.

ARroyas SERrano, M. (1986): "Insaculación y oligarquía municipal. Aportación al estudio del gobierno municipal de Castellón a finales del siglo XVI". Revista de Historia Jerónimo Zurita. IFC, Zaragoza, pp. 353-361. 
Arroyas Serrano, M. (1989): El Consell de Castellón en el siglo XVII: Ordenamiento jurídico y estructura institucional. Diputación de Castellón. Castellón.

AzacARAte, G. (1979): "El municipio en la Edad Media". Municipalismo y regionalismo. Instituto de Estudios de Adiministración Local, Madrid.

Balbas CruZ, J.A. (1883): Castellonenses ilustres. Establecimiento Tipográfico de José Armengot. Castellón.

Balbas CRuz, J.A. (1982): El libro de la provincia de Castellón.Castellón. Caja de Ahorros y Monte de Piedad de Castellón.

Balcells, A. y otros Eds. (1980-1981): Historia de los Países Catalanes. Edhasa. Barcelona.

BALDÓ LACOMBA, M. (1992): Introducció a la història. Universitat de Valencia.Valencia.

BAREL, Y. (1981): La ciudad medieval. Sistema social - sistema urbano. Instituto de Estudios de la Administración local. Madrid.

BARRERA AYMERIC, M. (1996): La mort barroca: ritus $i$ rendes. Universidad Jaime I y Diputación de Castellón. Castellón. Castellón.

BARRIO BARRIO, J.A. (1992): "La introducción de la insaculación en el Antiguo Reino de Valencia. Xàtiva, 1427” Dels furs al estatut. Actes del I Congrés d'Administració Valenciana: De la Història a la Modernitat. Generalitat Valenciana. València, pp. 499-505.

Belenguer i CEBrià, E. (1972): Fernando el Católico y la ciudad de Valencia. Estudis I. Valencia.

Belenguer i CEBriÀ, E. (1976): València en la crisi del segle XV. Ediciones 62. Barcelona.

Belenguer i Cebrià, E. (1992): “La ciutat de València a l'època foral : algunes reflexions “. Dels Furs al Estatut. Actes del I Congrés d'Administració Valenciana: De la història a la Modernitat. Generalitat Valenciana. València, pp. 433-442.

Belenguer i CeBrià, E. (1993): “La Monarquía Hispànica i la Corona d'Aragón: El progressiu qüestionament del pactisme a Catalunya”. Revista Pedralbes $\mathrm{n}^{\circ} 13$. Barcelona, pp. 207-216.

Belenguer i CeBriÀ, E. (1994): “La Monarquía Hispánica vista desde Aragón”. Revista Estudis n²0. Valencia, pp. 57-82.

Belenguer i CEBrì̀, E. (2001): La Corona de Aragón en la Monarquía Hispánica: del apogeo del siglo XV a la crisis del XVII. Península. Barcelona. 
BenAssar, B. (1983): La España del siglo de oro. Crítica. Barcelona.

Benassar, B. (1989): Valladolid en el siglo de oro. Una ciudad de Castilla y su entorno agrario en el siglo XVI. Ámbito. Valladolid.

Berenguer BARCELó, J. (1977). Historia de Alcoy. Selbstverl. Alcoy.

BERnABÉ GIL, D. (1982): Oligarquía municipal e intereses agrarios. Orihuela en la coyuntura subsiguiente a la peste de 1648. Anales de la Universidad de Alicante. Historia Moderna, 1. Alicante.

BERnABÉ GIL, D. (1985/1986) : “Centralismo y autonomía municipal en Orihuela: De Fernando el Católico al "Viraje Filipino" ". Revista de Historia Moderna. no 12. Universidad de Alicante. Alicante, pp. 29-54.

BERNABÉ GIL, D. (1986)"La administración municipal", (Antonio MESTRE SANCHÍS, dir.), Historia de la provincia de Alicante, vol. IV: Edad Moderna, Ediciones Mediterráneo, Murcia, pp. 239-268.

BERnABÉ GIL, D. (1986/1987): “Universidades y villas.Notas sobre el proceso de segregación municipal en el realengo valenciano". Revista de Historia Moderna, 6/7. Universidad de Alicante. Alicante, pp. 11-38.

BERNABÉ GIL, D. (1989): "Los juristas en la burocracia municipal. Abogados y asesores ordinarios de la ciudad de Orihuela en el siglo XVII". Homentage al Dr. en Sebastià García Martínez, II. Generalitat Valenciana. Valencia, pp. 133-145.

Bernabé Gil, D. (1989): Hacienda y mercado urbano en la Orihuela foral moderna. Instituto de Cultura Juan Gil-Albert. Diputación de Alicante. Alicante.

BernabÉ GIL, D. (1990): Monarquía y patriciado urbano en Orihuela, 1445-1707, Universidad-Caja de Ahorros Provincial de Alicante, Alicante.

BERNABÉ GIL, D. (1991): "La insaculación como instrumento de reproducción social y familiar de una élite de poder urbana. La clase dirigente oriolana entre 1445 y 1705”, Familia, Grupos Sociales y Mujer en España (ss. XV-XIX), en F.Chacón, H.Hernández, A. Peñafiel (eds.), Universidad de Murcia, pp. 95-115.

BERNABÉ GIL, D. (1992): "El control de la insaculación en los municipios de realengo". Dels Furs al Estatut. Actes del I Congrés d'Administració Valenciana: De la Història a la Modernitat. Generalitat Valenciana. València, pp. 505-510.

BERNABÉ GIL, D. (1994): "Las oligarquías urbanas del Reino de Valencia en el tránsito a la Edad Moderna", El Mediterráneo europeo y las ciudades en el tránsito a la Edad Moderna, Generalitat Valenciana, Valencia, pp. 205-231. 
BernabÉ GIL, D. (1999): "Els procediments de control reial sobre els municipis valencians (segles XVI-XVII)". Recerques: Història, economia i cultura. $N^{o} 38$. Valencia, pp. 27-46.

BERnABÉ GIL, D. (1999): “Insaculación y oligarquía municipal en Guardamar del Segura durante el siglo XVII “, en J. M. De Bernando Ares y J. M. GonZÁlez BELTRÁn (Eds.): La administración municipal en la Edad Moderna, Universidad de Cádiz-Asociación Española de Historia Moderna, Cádiz, pp. 501-508.

BERNABÉ GIL, D. (2001): “Insaculación, Oligarquía e intervencionismo regio en la villa de Xixona (ss. XVI-XVII)". Estudis: Revista de Historia Moderna. Anales de la Universidad de Alicante $n^{\circ} 19$. Alicante, pp. 79-122.

BERnABÉ GIL, D. (2003): "El baile en las insaculaciones de los municipios valencianos", XVII Congreso de Historia de la Corona de Aragón, Universidad de Barcelona, vol. III, pp. 81-92.

BERNABÉ GIL, D. (2005): "Elites de poder municipal en el Reino de Valencia durante la época foral moderna", Cheiron, no 41, Roma, pp. 135-156.

BERNABÉ GIL, D. (2006): “Ámbitos de relación entre el poder real y los municipios de la Corona de Aragón durante la época foral moderna”. Estudis: Revista de Historia Moderna. n³2. Valencia, pp. 49-72.

BERNABÉ GIL, D. (2007): El municipio en la corte de los Austrias: síndicos y embajadas de la ciudad de Orihuela en el siglo XVII. Institución Alfonso el Magnánimo. Valencia.

BERNABÉ GIL, D. (2008): “Insaculación y participación vecinal en el consistorio ibense (1578-1706)". Estudios de historia moderna: en homenaje a la profesora Emilia Salvador Esteban / coordinado por Ricardo Franch Benavent y Rafale SánchezBlanco. Vol. 1 (Política). Universidad de Valencia. Valencia, pp. 55-72.

Bernabé GiL, D. (2012): Privilegios de insaculación otorgados a municipios valencianos de realengo en época foral, Instituto Juan Gil-Albert, Alicante.

Bernabé GIL, D. (2013): Almoradí en la Edad Moderna. Ayuntamiento de Almoradí. Almoradí.

BERnABÉ GIL, D. (2014): "L'oposició dels municipis valencians a les visites del governador durant la segona meitat del segle XVII". Revista Recerques nº6. Universidad de Valencia. Valencia, pp. 63-80. 
BernabÉ GIL, D. (2014): "La Lugartenencia y las Subrogaciones locales de la Gobernación General de Orihuela en la Edad Moderna". Anales de la Universidad de Alicante $\mathrm{n}^{\circ}$ 32. Universidad de Alicante. Alicante, pp.33-60.

Bernabeu SAnchís, A. (1992). Ontinyent, Vila-reial: De les Germanies a la Nova Planta. Servicio de Publicaciones del Ayuntamiento de Onteniente. Onteniente.

Bernardo De ARES, J.M. (1996): "El régimen municipal en la Corona de Castilla". Studia Histórica, Histórica Moderna, $\mathrm{n}^{\circ}$ 15. Universidad de Salamanca. Salamanca, pp. 23-61.

Bernat i MARtí, J. S. y BAdEnes Martín, M. A. (1994): Crecimiento de la población valenciana. Ediciones Alfonso el Magnánimo. Institució Valenciana d'Estudis e Investigació. Generalitat Valenciana y Diputación de Valencia. Valencia.

BRINES BLASCO J. Y OTROS (1995): Formación y disolución de los grandes patrimonios castellonenses en el Antiguo Régimen. Ediciones Fundación Dávalos Fletcher. Castellón.

Burgos EstebAn, F.M. (1994): Los lazos de poder. Obligaciones y parentescos en la élite local castellana, siglos XVI-SVII. Universidad de Valladolid. Valladolid.

Burriel de Orueta, E. (1971): "Desarrollo urbano de Castellón de la Plana”. Estudios Geográficos nº9. CSIC. Valencia, pp.189-290.

CANet Aparisi, T. (1983): "Derecho y administración de justicia en la formación del Reino de Valencia”. Estudis, revista de historia moderna, 10, Universidad de Valencia. Valencia, pp. 7-31.

CANET APARISI, T. (1986): La Audiencia valenciana en la época foral moderna. Alfons el Magnànim. Valencia.

CANET APARISI, T. (1987): "Procedimiento de control de los oficiales regios en la Corona de Aragón. Consideraciones sobre su tipología y evolución en la época foral moderna". Estudis, revista de historia moderna,13,Universidad de Valencia. Valencia, pp. 131-150.

CANET APARISI, T. (1990): La magistratura valenciana (s. XVI-XVII). Revista Estudis. Monografía. Universitat de Valencia.

CASEY, J. (1970): "La crisis general del s. XVII a València. 1646-1648”. Boletín de la Sociedad Castellonense de Cultura, XLVI, Vol. II. Castellón, pp. 96-173.

CASEY, J. (1975): "La situación económica de la nobleza valenciana en vísperas de la expulsión de los moriscos”. Homenaje al Dr. Juan Reglà Campistol. Tomo I. Universidad de Valencia. Valencia, pp. 27-34. 
CAsey, J. (1980): “Tierra y Sociedad en Castellón de la Plana. 1608-1702”. Estudis 7. Valencia, pp. 14-46.

CASEY, J. (1982): “La crisi del Pais Valencià durante el segle XVII”. Debats I. Alfons el Mangànim. Valencia, pp. 27-34.

CASEY, J. (1983): El reino de Valencia en el siglo XVII. Siglo XXI. Madrid.

CASEY, J. Chacon y otros (1987): Familia y sociedad en el Mediterráneo Occidental siglos XV-XIX. Crítica. Barcelona.

CísCAR Pallarés, E. (1979): “Las Cortes valencianas de Felipe III”, Revista Estudis. Monografía. Universitat de Valencia. Valencia.

COlOM, G. Y GARCIA, A. (1970): Furs de València. Volum I. Editorial Barcino. Barcelona.

Colom, G. Y GARCiA, A. (1974): Furs de València. Volum II. Editorial Barcino. Barcelona.

COlOM, G. Y GARCIA, A. (1978): Furs de València Volum III. Editorial Barcino. Barcelona.

COLOM, G. Y GARCIA, A. (1983): Furs de València IV. Editorial Barcino. Barcelona.

Corona Marzol, C. (1985): "Edad Moderna". La Provincia de Castellón de la Plana. Tierras y Gentes. Confederación Española de Cajas de Ahorro. Madrid, pp. 341-372.

Corona Marzol, C. (1997): "La historia moderna en Castellón. Reflexiones temáticas y bibliográficas" en Revista Millars. Espai i Història. Dos décadas de historiografía Castellonense $\mathrm{n}^{\mathrm{o}} \mathrm{XX}$. Universitat Jaume I. Castellón, pp. 235-242.

Corona MARzol, C. (1999): "El municipio de Castellón: Entre la historia foral y la centralización borbónica”. La ciudad de Castellón de la Plana. Ortells Chabrera, V. (Coord.). Ayuntamiento de Castellón de la Plana. Castellón. pp. 235-242.

DANTE Y RIU, J. (2001): “El govern de la ciutat de Barcelona a l'època moderna: estabilitat institucional, dificultats financeres i relació amb el poder reial". Cuaderns d'Història 5. Barcelona, pp. 127-145.

De Cadenas y Vicent, V. (1971): "El empleo de "Don "en los documentos hasta el siglo XVIII y su presunción de calificación nobiliaria”. Cuadernos de doctrina nobiliaria 3. Ediciones Hidalguía. Madrid. pp. 9-12.

De Lario Ramírez, D. (1974): Cortes del reinado de Felipe IV: Cortes valencianas de 1626. Universidad de Valencia. Valencia. 
DE LARIO RAMÍREZ, D. (1975): "Cortes valencianas de 1626: problemas en torno al pago del servicio ofrecido", Revista Estudis, n²4. Universitat de Valencia. Valencia. pp. 115-128.

De MaríA, R. (1928): Colección de cartas pueblas. Boletín de la Sociedad Castellonenese de Cultura. ${ }^{\circ}$ XIX. Castelló, pp. 86-89.

Dedieu, P. (2000): "Procesos y redes. La historia de las instituciones administrativas de la Época Moderna, hoy”. La pluma, la mitra y la espada. Estudios de Historia Institucional en la Edad Moderna. Castellano, J.L. Et al. (eds.). Madrid-Barcelona, pp. 13-30.

DíAz MantecA, E. (1979): "El "llibre de Peyta" de 1721". Societat Castellonenca de Cultura. Estudios Económicos IX. Castelló.

Domínguez Ortiz, A. (1973): Las clases privilegiadas del Antiguo Régimen. Akal. Madrid.

Domínguez Ortiz, A. (1978): El Antiguo Régimen: Los Reyes Católicos y los Austrias. Alfaguara. Madrid.

DOMÍNGUEZ PÉREZ, C. (1982): "Evolución y movilidad de la población en la Plana (nuevos datos para los siglos XV-XVIII)”, Saitabi. Valencia, pp. 185-202.

Elliot, J.H. (1982): Poder y sociedad en la España de los Austrias. Crítica. Barcelona.

Elliot, J.H. (2010): “A Europe of Composite Monarchies”. España, Europa y el mundo de ultramar [1500-1800] Taurus. Madrid, pp. 29-54.

FARFÁn NAVARro, M.C. (1973): "Inventario de los Protocolos notariales existentes en el archivo histórico provincial de Castellón de la Plana". Actas I Congreso de Historia del País Valenciano Vol.1. Generalitat Valenciana. Valencia. pp. 325-332.

FAYARD, J. (1982): Los miembros del Concejo de Castilla (1621-1746). Siglo XXI. Madrid.

FELIPO ORTS, A. (1985/1986): "Felipe IV y el Reino de Valencia (1621-1634). Relaciones con la monarquía, orden público y problemática de la Ciudad”. Estudis, 12. Valencia.

FELIPO ORTS, A. (1988): El centralismo de nuevo cuño y la política de Olivares en el País Valenciano. Ayuntamiento de Valencia. Valencia.

FELIPO ORTS, A. (1993): "L'accés de la noblesa titulada al govern de la ciutat de València. (1652-1707)". Pedralbes: Revista de Historia Moderna. (Ejemplar dedicado al Congreso de Historia Moderna de Catalunya III). Universidad de Barcelona. Barcelona, pp. 469-483. 
FELIPO ORTS, A. (1996): Insaculación y élites de poder en la ciudad de Valencia. Edicions Alfons el Magnànim. Institut Valenciá d'Estudis i Investigació. Generalitat Valenciana. Diputació de València. Valencia.

FELIPO ORTS, A. (1999): “Oligarquía y corrupción en la Valencia de Felipe II: Los desfalcos de la Taula de Canvis" Estudis: Revista de Historia Moderna. $N^{o} 25$. Universidad de Valencia. Valencia, pp. 37-54.

FELIPO ORTS, A. (2000): “Corona y oligarquía en la ciudad de Valencia durante el reinado de Carlos V’. Estudis: Revista de Historia Moderna. №26. Valencia, pp. 5994.

FELIPO ORTS, A. (2001/2002): "El síndico de la ciudad de Valencia: De las Germanías a la Insaculación" Revista de Historia Moderna: Anales de la Universidad de Alicante. (Ejemplar dedicado a : Oligarquías y municipio en la España de los Austrias). $N^{o}$ 19. Alicante, pp. 51-78.

FELIPO ORTS, A. (2002): La oligarquía municipal en la ciudad de Valencia: de las germanías a la insaculación. Diputación de Valencia. Valencia.

FELIPO ORTS, A. (2004): Autoritarismo monárquico y reacción municipal: la oligarquía urbana de valencia desde Fernando el Católico a las germanías. Universidad de Valencia. Valencia.

FEliPO ORTS, A. (2014): La Nobleza Valenciana en la Edad Media. Patrimonio, Poder y Cultura. Universidad de Valencia. Valencia.

FERnÁNDEZ NADAL, C.M. (2003): El Corregimiento en Castellón en Época de Carlos III. Ayuntamiento de Castellón. Castellón.

FERNÁNDEZ Ros, J.M. (1994): “Oligarquía y estructura familiar en el Antiguo Régimen: Carcaixent, 1604- 1609”. Historia de la Familia. Parentesco y linaje. Universidad de Murcia. Murcia, pp. 961-970.

FloRENSA I SOLER, N. (1993): “La insaculació pactada: Barcelona 1640”. Pedralbes: Revista d'Història Moderna. (Ejemplar dedicado a les institucions Catalanes (segles XV-XVII)).Universidad de Barcelona. Barcelona, pp. 447-456.

Gacto, E. (1987): "El grupo familiar de la Edad Moderna en los terriorios del Mediterráneo hispánico: una visión jurídica". La familia en la España Mediterránea (siglos XV-XIX). Crítica. Barcelona, pp. 36-64.

GARCíA CÁRCEl, R. (1973): “Cortes del reinado de Carlos I”, Revista Estudis. Universidad de Valencia. Monografía. Universitat de Valencia. 
García MARTíneZ, S. (1968): Valencia bajo Carlos II. Universidad de Valencia. Valencia.

GELABERT GONZÁLEZ, J.E. (1978): “Fuentes fiscales y estructuración socioeconómica. Siglos XVI y XVII". Revista de Historia Moderna. Actas de las II Jornadas de Didáctica de la Historia. Universidad de Extremadura. Cáceres.

Generalitat Valenciana (1992): Dels Furs al Estatut. Actes del I Congrés d’Administració Valenciana : De la història a la Modernitat. Generalitat Valenciana. Valencia.

GIMENEZ LÓPEZ, E. (1988): “Los corregidores de Alicante, Perfil sociológico y político de una élite militar. Municipios y poder en el Antiguo Régimen Valenciano". Revista de Historia Moderna. Anales de la Universidad de Alicante, 6. Alicante, pp. 67-86.

Gimeno Michavila, V. (1926): Del Castellón Viejo Est. tip. hijo de J.Armengot. Castellón de la Plana.

Gimeno Michavila, V. (1930): Las calles de Castellón. Castellón. Imprenta J.Bas. Castellón.

GIMENO SANFELIU, M.J. (1982): "Defensa y consolidación del patrimonio familiar de la oligarquía urbana de Castellón en el siglo XVIII". Universidad Nacional de Educación a Distancia en la Provincia de Castellón. Castellón, pp. 3-12.

Gimeno SANFELIU, M.J. (1990): La oligarquía urbana de Castellón en el siglo XVIII. Ayuntamiento de Castellón. Castellón.

GiMeno SANFELIU, M.J. (1993): "La baronía de Benicássim en el siglo XVI". Millars XVI. Universitat Jaume I. Castelló, pp. 109-124.

Gimeno Sanfeliu, M.J. (1998): Patrimonio, Parentesco y poder. Castellón (XVI-XIX). Universitat Jaume I y Diputación de Castellón. Castellón.

GIMENO SANFELIU, M.J. (2003): Llinatge i poder. Generalitat Valenciana. Castellón.

GONZÁLEZ HERNÁNDEZ, M. A. (2009-2010): “Intervención regia y fraude electoral en el patriciado urbano de la ciudad valenciana. Orihuela 1458-1479”. Anales de la Universidad de Alicante. Historia Medieval. No 16. Alicante, pp. 238-317.

Graullera Sanz, V. (1992): "Los Regentes de la Audiencia Valenciana en la época foral". Dels furs a l'Estatut. Actes del I Congrés d'Administració Valenciana: De la Historia a la Modernitat. Generalitat Valenciana.Valencia, pp. 691-700.

Guerrero Mayllo, A. (1991): Oligarquía y gobierno municipal en la Corte de la monarquía hispánica. El Concejo de Madrid entre 1560 y 1606. UNED. Madrid. 
Guía MARÍN, LL. (1984): "Cortes del reinado de Felipe IV, II. Cortes valencianas de 1645”, Revista Estudis. Monografía. Universitat de Valencia. Valencia.

Hernández Benítez, M. (1995): A la sombra de la corona. Poder local y oligarquía urbana (Madrid 1606-1808). Siglo XXI. Madrid.

JARQUE MARTínEZ, E. (1993): "El precio de la fiscalidad real: poder monárquico y oligarquía municipal en Zaragoza (1628-1650)”, en FORTEA, J. I. y CREMADES, C., eds. Política y hacienda en el Antiguo Régimen, Murcia, Universidad de Murcia, pp. 333-342.

JARQUe MARTíneZ, E. (1986): “Monarquía y poder urbano en Aragón (1487-1565)”, Estudios. Zaragoza, pp. 78-103.

JARQUE MARTínEZ, E. (1996): “La oligarquía urbana de Zaragoza en los siglos XVI y XVII: Estudio comparativo con Barcelona”. Revista de Historia J.Zurita, no 69-70. Zaragoza, pp. 148-167.

JARQue MartíneZ, E. (2000): "El poder municipal aragonés en tiempos de Felipe II", en E. Martínez Ruiz (Dir.), Madrid, Felipe II y las ciudades de la monarquía, vol. I Poder y dinero, Actas editorial. Madrid, , pp. 199-215.

JARQUE MARTínEZ, E. (2001); "Monarquía, comisarios insaculadores y oligarquías municipales en el Aragón de la segunda mitad del siglo XVII", Revista de Historia Moderna, n¹9. Universidad de Alicante. Alicante, pp. 239-268.

LALINDE BADÍA, J. (1961): La problemática histórica del heredamiento. A.H.D.E. Zaragoza.

LALINDE BADÍA, J. (1963): La gobernación general de la Corona de Aragón. CSIC. Madrid-Zaragoza.

LALINDE BADÍA, J. (1964): La institución virreinal en Cataluña (1479-1716). Instituto Español de Estudios Mediterráneos. Barcelona.

LALINDE BADÍA, J. (1980): "El pactismo en los reinos de Aragón y Valencia". El pactismo en la historia de España. Instituto de España, Cátedra "Francisco Vives". Madrid, pp. 113-139.

LeÓN NAVARRo, V. (1990): Del sistema austracista al borbónico: Los protocolos testamentarios. Estudis. Universidad de Valencia. Valencia, pp. 57-73.

Llistar EsCRIG, A. (1987): Historia de Castellón. Caja de ahorros y monte de piedad de Castellón. Castellón.

LublinskaYA, A.D. (1979): La crisis del siglo XVII y la Sociedad del Absolutismo. Crítica. Barcelona. 
LYNCH, J. (1992): Los Austrias, 2 vol. Crítica. Barcelona.

MADRANy y CALATAyUd, M. (1788): Tratado de la nobleza de la Corona de Aragón, especialmente del Reino de Valencia, comparada con la de Castilla. Josef y Tomás de Orga. Valencia.

Maravall, J.A. (1972): Estado Moderno y mentalidad social. Tomo II. Revista Occidente. Madrid.

Maravall, J.A. (1979): Poder, honor y élites en el siglo XVII. Siglo XXI. Madrid.

Martí i Villaplana, C.L. (1990). "La insaculació a Alcoi al segle XVII". Actes del Congrés d'Estudis de l'Alcoià-Comtat. Alcoi, pp. 93-96.

Martínez Millán, J. (1989): "Élites de poder en tiempos de Felipe II (1539-1572)". Hispania 171. Madrid, pp. 111-149.

MARTíneZ Millán, J. (ed.) (1992): Instituciones y élites de poder en la monarquía hispánica durante el siglo XVI. Universidad Autónoma. Madrid.

Mateos Royos, J.A. (2001): "La ciudad con el rey: municipio, monarquía y ritual cívico en Zaragoza bajo Felipe III (1598-1621)”. Revista d'Història Moderna. Anales de la Universidad de Alicante. N²1. Alicante, pp. 137-164.

MERCADER RIBA, J. (1957): "El fin de la Insaculación Fernandina en los Municipios y Gremios Catalanes”. Estudios del V Congreso de Historia de la Corona de Aragón. Barcelona.

Mercader RibA, J. (1961): “Del 'Consell de Cent' al Ayuntamiento borbónico. La transformación del municipio catalán bajo Felipe V". Hispania, XXI, CSIC. Madrid, pp. 232-297, pp. 420-465.

MERCHAN FERNÁNDEZ, C. (1988): Gobierno municipal y administración local en la España del Antiguo Régimen. Tecnos. Madrid.

Molas Ribalta, P. (1980): “La Historia Social de la Administración”. Historia Social de la Administración española. Estudios sobre los siglos XVII y XVIII. Barcelona, pp. 9-20.

Molas Ribalta, P. (1984): "Política e institucions". Primer Congrés d'Història Moderna a Catalunya. Tomo II, pp. 11-18.

Molas Ribalta, P. (1989): “Títulos de hidalguía en el setecientos valenciano". Hidalgos \& Hidalguía dans l'Espagne des XVIe-XVIIIe siècles. Theories, pratiques e representations. Paris, pp. 189-205. 
NARbona VizCAÍnO, R. (1989): "Los Rabassa, un linaje patricio de Valencia medieval". Anales de la Universidad de Alicante. Historia Medieval, no 7. Alicante, pp. 111-136.

ORTIZ GARCÍA-BuStELlo, Ma L. (1991): “Albaida, vila y señorío: administración municipal y oligarquía urbana en el siglo XVII". Estudis 17, Universidad de Valencia. Valencia, pp. 229-240.

PAGÉS, P. (1985): “Aproximació metodològica a l'estudi de l'estructura del poder local. La vida cuotidiana dins la perspectiva històrica". III jornades d'estudis històrics locals. Palma de Mallorca, pp. 75-82.

PALOP RAMOS, J.M. (1975): “Centralismo borbónico y reivindicaciones políticas en la Valencia del setecientos. El caso de 1760". Homenaje al doctor Juan Reglà Campistol, II. Estudis. Universidad de Valencia. Valencia, pp. 65-78.

Passola i Tejedor, A. (1984): "La insaculación en la Paería de Lérida en el siglo XVII". Actas del primer congreso de Historia Moderna en Cataluña. Ediciones universitarias. Barcelona, pp. 133-139.

Passola i TeJedor, A. (1985): Clases sociales y gobierno municipal en Lledia en el siglo XVII (1680-1690) .Tesis licenciatura inédita. Lleida.

PAssola i TeJedor, A. (1986): "Una oligarquía municipal: La Pahería de Lleida en el siglo XVII”. Manuscrits 3. Bellaterra, pp. 151-173.

PASsOla I TEJEDOR, A. (1996): "Insaculación, monarquía y élites urbanas". El poder real de la Corona de Aragón: (siglos XIV-XVI) Vol. 2 . Congreso de Historia de la Corona de Aragón. Jaca, pp. 291-310.

Passola i TEJEDOR, A.(1997): La historiografía sobre el municipio en la España Moderna. Universitat de Lleida. Lleida.

Passola i Tejedor, A. (1997): “ Poder, parentesco y linajes en la Lleida de los Austrias". Familia, Parentesco y Linaje. Historia de la Familia. Una perspectiva sobre la sociedad europea. Seminario familia y ente en el poder en el reino de Múrcia siglos XV al XIX. Universidad de Murcia. Murcia, pp. 131-150.

Passola i Tejedor, A. (1999): Oligarquía, municipio y corona en la Lleida de los Austrias. Tesis Doctoral. Biblioteca digital Miguel de Cervantes. Universidad de Alicante. Alicante.

PAssola i Tejedor, A. (2001): "La élite municipal leridana bajo los Austrias". Revista de Historia Moderna. Anales de la Universidad de Alicante. №19. Universidad de Alicante. Alicante, pp. 269-312. 
PAssola I TEJEDOR, A. (2002): “Poder real y poder local: un pacto tácito". Espacios de poder: Cortes, ciudades y villas (s. XVI-XVIII). Universidad Autónoma de Madrid. Madrid, pp. 45-71.

PASSOla I TeJedor, A. (2008): "Las tensiones en torno al control electoral urbano en la Corona de Aragón (siglos XVI-XVII)". Ciudades en conflicto: (siglos XVI-XVIII). Coord.: José Ignacio Fortea Pérez y Juan Eloy Gealbert González. Junta de Castilla y León. Consejería de Cultura y Turismo:Marcial Pons. Valladolid, pp. 13-36.

PÉrez ApARICIO, C. (1993): “Austrias y Borbones. Las repercusiones del cambio dinástico en el País Valenciano". Saitabi. Valencia, pp. 231-242.

PÉrez APARICIO, C. (2006): “Cataluña y Valencia en las postrimerías del sistema pactista (1665-1714)". La Corona de Aragón de los siglos XII al XVIII.Generalitat de Catalunya. Departament de Cultura. Barcelona, pp. 337-370.

Pèrez García, P. (1989): "Los ciudadanos de Valencia. Estatuto jurídico y jerarquía social de un grupo privilegiado: memoriales y tratados de los siglos XVI, XVII y XVIII”. Estudis no 15. Universidad de Valencia. Valencia, pp. 145-188.

Pèrez Martín, A. (1989): “Génesis del Estado Moderno”. Actas del I Symposium Internacional: Estado y fiscalidad en el Antiguo Régimen. Múrcia, pp. 15-32.

Pèrez MoredA, V. y ReHER, D.S. (1988): Demografía Histórica en España. El Arquero. Madrid.

PESET, J.L. (1975): "El "carácter" de los valencianos y el fin del Antiguo Régimen". Homenaje al Dr. D. Juan Reglà Campistol. Tomo II. Estudis. Universidad de Valencia. Valencia, pp. 24-259.

Peset, M. (1972); "Notas sobre la abolición de los fueros de Valencia”. Anuario de Historia del Derecho Español. XLII. Madrid, pp. 657-715.

PIRENNE, H. (1972); Las ciudades de la Edad Media. Alianza. Madrid.

PorCAR RIPOLles, J. (1931): "La primitiva plaça de Castelló”. Boletín Sociedad Castellonense de Cultura. Tomo 12. Cuaderno VI, pp. 354-358.

Porres MARIJUÁN, M.R. (1996): "Élites sociales y poder local en el País Vasco durante el Antiguo Régimen: estado de la cuestión y perspectivas”. Élites, poder y red social. Imízcoz BeunZA, J.M. (director). Universidad del País Vasco. Bilbao, pp. 101-118.

PorRes MARIJUÁN, M.R. (2001): “Oligarquías y poder municipal en las villas vascas en tiempos de los Austrias". Revista de Historia Moderna. Anales de la Universidad de Alicante $n^{\circ} 19$. Alicante. 
PosAdA, A. (1979): Escritos municipalistas y de la vida local. Instituto de Estudios de Administración local. Madrid.

RAMOS Bosisini, F. (1981): "El municipio y la vida municipal en Castilla". Ordenanzas de Loja. Universidad de Granada. Granada, pp. 5-28.

REDONDO Veintenillas, G. (1978): “La censura política de los Austrias en Aragón. (Una aportación al conocimiento de la selección de cargos concejiles y del control municipal en Aragón durante el siglo XVII)". Cuadernos de Zaragoza $n^{o} 27$. Zaragoza.

REglÀ I CAMPISTOL, J. (1967): "Notas sobre la política municipal de Fernando el Católico en la Corona de Aragón”. Homenaje a Vicens Vives. Vol. II. Barcelona, pp. $521-533$.

REvest y CORZO, L. (1957): Llibre de les Ordenacions de la vila de Castelló. Hijos de F. Armengol. Castellón de la Plana.

Roca Traver, F.A. (1952): Ordenaciones municipales de Castellón de la Plana durante la Baja Edad Media. Instituto Alfonso el Magnánimo. Diputación de Valencia. Valencia.

Roca Traver, F.A. (1983): "El Mustassaf de Castellón y el "Llibre de Mustaçafia". Sociedad Castellonense de Cultura, Castellón.

RoCAFORT, J. (1945): Libro de cosas notables. Eduardo Codina Armengol. Castellón.

Salvador Esteban, E. (1979): “Cortes valencianas del reinado de Felipe II", Revista Estudis. Monografía. Universidad de Valencia. Valencia

SALVADOR EstebAN, E (1984): "La Gobernación valenciana durante la edad moderna. Cuestiones en torno a su singular estructura territorial". Studia Historica et Philologica in honores M. Batllori. Roma.

SALVADOR ESTEBAN, E (1985-1986): “Poder central y poder territorial. El virrey y las Cortes en el Reino de Valencia". Estudis, 12. Universidad de Valencia. Valencia.

SÁNCHEZ AdELl, J. (1952): "Llorens de Clavell y sus memorias históricas de Castellón”. Sociedad Castellonense de Cultura. Castelló de la Plana.

SÁNCHEZ AdELl, J. (1965): “Cognoms castellonencs de 1588 i 1769”. Butlletí de la Societat Castellonenca de Cultura. Quadern IV. Octubre-Desembre de 1965. Castelló de la Plana, pp. 205-320.

SÁNCHEZ AdELl, J. (1978): “Onomástica y movilidad de población en la villa de Castellón de la Plana. (XIV-XVIII)”, Revista de la facultad de geografía e historia de la Universidad de Valencia. Volumen XXVIII. Valencia, pp. 33-67. 
SÁnchez Adell, J. (1982): Castellón de la Plana en la Baja Edad Media. Sociedad Castellonense de Cultura. Castellón.

SÁnChez Adell, J. (1993): Llibre dels Privilegis de Castelló de la Plana. Ayutamiento de Castellón. Castellón.

SÁnchez Almela, E. (1989): Guía del Archivo Histórico Municipal de Castellón. Ajuntament de Castelló. Castellón de la Plana.

SÁnCHEZ LeÓn, P. (1991): "Nobleza, Estado y clientelas en el feudalismo. En los límites de la Historia Social”. La Historia Social en España. Actualidades y perspectivas. Asociación de Historia Social: s. XXI de España Editores. Madrid, pp. $197-215$.

SANTAMARÍA ARÁndeZ, A. (1981): "Los consells municipales de la Corona de Aragón a mediados del siglo XIII. El sistema de cooptación”. Anuario de Historia del Derecho Español. 51. Ministerio de Justicia. Madrid, pp. 291-394.

SANTAMARÍA ARÁNDEZ, A. (2000): El consell General de Valencia en el tránsito a la modernidad. Ed. Generalitat Valenciana. Valencia.

SCHOlZ, J.M. Y PÉREZ MARTíN, A. (1978): Legislación y jurisprudencia en la España del Antiguo Régimen. Universidad de Valencia. Valencia.

SERRANO MARÍn, E. (1989): “Aragón en la Monarquía de los Austrias. Las Instituciones políticas". Historia de Aragón. Vol. 1. Generalidades. Ed. Insituto Fernando el Católico. Zaragoza, pp. 211-220.

SERRANO MARÍn, E. (1996): "Nobleza en España en la Edad Moderna. Líneas de estudio a partir de la Sociedad Española del siglo XVII de Don Antonio Domínguez Ortiz”. Revista d'Història Moderna $n^{\circ}$ 14. Barcelona, pp. 15-38.

Sevillano Colom, F. (1953): "De la institución del mustaçaf de Barcelona, de Mallorca y de Valencia". A.H.D.E. XXIII. Ministerio de Justicia. Madrid, pp. 525538.

Simo Santoja, V.L. (1975): Valencia en la época de los corregidores. Ayuntamiento de Valencia. Valencia.

Solano Camón, E. (1987): Poder Monárquico y Estado pactista (1626-1652). Los Aragonenses ante la Unión de Armas. Institución Fernando el Católico. Zaragoza.

Solano CAmón, E. y SANZ CAMAÑÉS P. (1996): “Aragón y la Corona durante el gobierno de los Austrias. Relaciones políticas e institucionales", Actas del Congreso: El Estado Moderno a uno y otro lado del Atlántico, Ius Fugit, Revista 
interdisciplinar de Estudios Histórico-Jurídicos. Vols.3-4 (1994-1995). Institución Fernando el Católico. Zaragoza, pp. 203-243.

SOlAnO CAMÓN, E. (2005): "Milicia, fueros y acción del poder real sobre Aragón entre 1562 y 1642”. Pedralbes, Revista d'Història Moderna, Universitat de Barcelona. $n^{o}$ 25. Barcelona, pp. 191-230.

SOlAnO CAMÓn, E. (2005): "Proyección del poder real sobre la corona de Aragón en la España del Quijote”. La Monarquía hispánica en tiempos del Quijote. Ediciones Silex. Madrid, pp. 463-492.

SOLANO CAMÓN, E. (2007): "Las instituciones postmedievales". Estudios sobre Aragón en el Umbral del siglo XXI, Edición digital. Instituto de Ciencias de la Educación, Universidad de Zaragoza. Zaragoza.

TOMÁs y VALIENTE, F. (1975): "Las ventas de oficios de regidores y la formación de oligarquías urbanas en Castilla (siglos XVII y XVIII)". Actas I Jornadas de Metodología Aplicada a las Ciencias Históricas. Santiago, pp. 551-568.

TOMÁS Y VALIENTE, F. (1982): "El gobierno de la monarquía y la administración de los reinos en la España del siglo XVII". Historia de España de Menéndez Pidal. Vol $X X V$. Madrid, pp. 21-82.

Tomás y VAliente, F. (1982): Gobierno e instituciones en la España del Antiguo Régimen. Alianza Editorial. Madrid.

TORRAS I RIBÉ, J.M. (1983): "El procedimiento insaculatorio en los reinos de la Corona de Aragón, entre la Renovación Institucional y el sometimiento a la monarquía (1427-1714)".Congreso sobre Jerónimo Zurita. Zaragoza.

TORRAS I RIBÉ, J.M. (1983): Els municipis catalans a l'Antic Régim (1453-1808). Curial. Barcelona.

TORRAS I RIBÉ, J.M. (1983): “El municipi català durant els segles XVI y XVII”. El govern de les ciutats catalanes. Institut Municipal d'Història. Barcelona, pp. 83-101.

TORRAS I RIBÉ, J.M. (1986): "El procedimiento insaculatorio en los municipios de los reinos de la Corona de Aragón entre la renovación institucional y el sometimiento a la monarquía (1427-1714)". Congreso Jerónimo Zurita: su época y su escuela. Ediciones Fernando el Católico. Zaragoza, pp.341-352.

TORRAS I RiBÉ, JM. (1996): “La desnaturalización del proceso insaculatorio en los municipios aragoneses bajo los Austrias". Revista de Historia Moderna, $n^{o} 15$. Universidad de Salamanca. Salamanca, pp. 243-258. 
Traver Tomàs, V. (1982): Antigüedades de Castellón de la Plana . Excelentísimo Ayuntamiento de Castellón la Plana. Castellón de Plana.

VAÑO SilvestRe, F. (1976): "Bocairente. La designación de autoridades por insaculación”. Primer Congreso de Historia del País Valenciano. Valencia, pp. 189199.

Vicens ViVes, J. (1974): "Estructura Administrativa estatal en los siglos XVI y XVII". Coyuntura económica y reformismo burgués. Barcelona. pp. 99-141.

VILAR, J.B. (1977): Los siglos XIV y XV en Orihuela. Patronato García Regel. Murcia.

VILAR, J.B. (1981): Orihuela, una ciudad valenciana en la España Moderna. Patronato García Regel. Orihuela.

Villalonga Villalba, I. (1916): Régimen municipal foral valenciano, los jurados y el Consejo. Tip. Moderna, AC de Gimeno, Valencia.

Villamarín Gómez, S. (2014): Castellón de la Plana 1700-1710. Último consistorio foral. Guerra de Sucesión y Nueva Planta. Universitat de València. València.

Voltes, P. (1962): "Mercedes nobiliarios otorgados por el Archiduque Carlos de Austria”. Documentos y Estudios X, pp. 65-106. 


\section{Introducción.}

La realización del Trabajo Final de Máster en Historia e Identidades del Mediterráneo Occidental entre el s. XV y el s. XIX sobre el proceso inaculatorio en el Castellón del seiscientos fue la primera aproximación a las élites locales. En áquel estudio solamente se exponían las insaculaciones de final del s. XVII y se dejaba entrever la especial importancia de algunas familias en la ciudad de Castellón. Sin embargo, ya en su momento fuimos conscientes que debíamos ampliar ese estudio para poder corroborar como fue ese comportamiento. Un estudio que se centrara principalmente en la exhumación de fuentes para poder sacar a la luz quienes eran las élites que ocuparon los puestos de gobierno municipales. De esta forma nuestra principal aportación es fundamentalmente de carácter documental con un trabajo exhaustivo de vaciado de fuentes. Una labor ardua y compleja que ha requerido la inversión de mucho tiempo para poder revisar todas las actas del judiciari entre 1597 y 1707 así como los protocolos notariales de los siglos XVI, XVII y XVIII para tener una visión completa de las familias castellonenses en el poder. Ha sido este nuestro objetivo durante los cinco años en que hemos intentando desempolvar los númerosos datos que nos aportan los registros locales de la ciudad de la Plana. Un próposito centrado en poner de manifiesto los nombres de todas las personas que ocuparon los cargos relevantes de la villa y los entresijos familiares para poder realizar una valoración de su vinculación con las autoridades. Pero la verdadera finalidad es ir mucho más allá y se centra en poner a disposición de futuras investigaciones unos datos de carácter fundamental para entender el poder de las oligarquías urbanas en el s. XVII en Castellón.

Fue éste el motivo por el que decidimos titular este proyecto de investigación Fuentes para el estudio de la oligarquía y los cargos municipales de Castellón en el s. $X V I I$. Es sin duda, un resumen exacto y fehaciente de la pretensión que nos habíamos marcado cuando empezamos este sinuoso camino que se inició con la obra de Corona 
Marzol $^{1}$, una aproximación a su artículo servía como punto de partida para entender el Castellón del seiscientos.

El análisis de las relaciones de poder que configuraron el sistema político de las monarquías de agregación de la Europa Moderna, y entre ellas, la monarquía hispánica de los Austrias ha sido uno de los temas más relevantes de la historiografía moderna. En ello ha jugado un papel fundamental el estudio de las villas y municipios de todos los reinos que formaban parte del poder de los Habsburgo en la Península Ibérica cuya diversidad ha centrado el análisis de numerosos historiadores.

Una de nuestras prioridades es contribuir a que la historiografía valenciana en general, y la municipal en particular, se reaproximen un poco más para poder entrelazarse y retroalimentarse. Para ello hay líneas generales que es preciso abordar como: la incidencia del proceso de centralización que llevó a cabo la monarquía tanto en la composición de las oligarquías urbanas como en el régimen municipal, el grado de autonomía de que gozaban las distintas villas, qué capacidad tenían para resistir la presión del rey, el uso que hacían del poder las clases dominantes, el beneficio que estas clases extraían de la institución municipal o los cambios que se originaron en las oligarquías entre otros.

En la Corona de Aragón las corporaciones locales venían desarrollando desde la época medieval un espacio político propio, cuya vigencia les permitía maniobrar bajo el amparo de la autoridad del monarca pero con la libertad que les podían conceder los fueros. Esto configuraba un sistema urbano en el que las injerencias externas no eran acogidas de buen agrado.

Las instituciones constituyen esencias de poder, y en la Edad Moderna en el Reino de Valencia esto se veía plasmado en los consejos municipales, dotados de mayor o menor poder en función de la independencia conseguida respecto a la autoridad real. Las oligarquías urbanas de las villas valencianas eran conscientes de que la intervención

\footnotetext{
${ }^{1}$ Corona Marzol, C. (1999): "El municipio de Castellón: Entre la historia foral y la centralización borbónica”. La ciudad de Castellón de la Plana. .Ortells Chabrera, V. (Coord.). Ayuntamiento de Castellón de la Plana, pp. 235-242.
} 
regia podía restringirles el control político del municipio, por lo que sabían que debían actuar en convivencia con los representantes del rey.

Estos consejos eran las estructuras básicas de estos municipios, de su funcionamiento político interno y de su grado de dependencia respecto de la Corona en una coyuntura de creciente control de los resortes del poder local por parte de ésta. En su composición influían las élites urbanas y se establecía el papel que ellas desempeñaban. Es evidente que estas instituciones eran esencias de poder y ellas se nutrían de las insaculaciones a través de la inclusión en las bolsas de las personas que se consideraban idóneas para ocupar los cargos y oficios de la villa. El proceso se iniciaba con la elección por parte del monarca de una lista de personas notables, siempre tras la concesión del privilegio insaculatorio, las cuales decidían quiénes pasaban a formar parte de las bolsas en primera instancia y a partir de ahí era el propio Privilegio el que dictaminaba cómo se debían cubrir las bajas que se producían, así como las nuevas incorporaciones. Es precisamente en este apartado donde encontramos diferencias entre unos municipios u otros dentro del Reino de Valencia e incluso en la Corona de Aragón, y por ello dedicaremos un capítulo en el que expondremos las líneas generales de funcionamiento de las diversas villas tomando como punto de referencia a Castellón. No podemos olvidar que una vez se había logrado entrar en las bolsas, su permanencia era vitalicia, siempre y cuando no fuera declarado inhabilitado por edad, es decir, jubilado. El proceso insaculatorio o de sach y sort comenzaba con el reparto de habas blancas y negras entre los miembros del Consell, a continuación se nombraban los candidatos y era incluido en las bolsas si el número de habas blancas superaba el de negras. Después, anualmente para la elección de los cargos, se leían las listas de las personas insaculadas en cada bolsa certificando que todas eran hábiles para el oficio que se iba a cubrir y a continuación se sacaban las bolsas del archivo del palacio del Consell y se metían las cédulas con los nombres de las personas en vasijas de agua. Acto seguido, un niño de unos diez años extraía las cédulas una a una y las depositaba en las manos del jurado primero que extraía el pergamino con el nombre y era el baile quién lo hacía público.

Era de esta manera como se determinaba quiénes iban a formar parte del aparato del poder de la villa, por lo que era imprescindible la participación en este proceso insaculatorio para consolidarse y mantenerse en estas bolsas. Ello posibilitaba decidir 
qué personas iban a ocupar los diversos oficios municipales y participar en la elección de los nuevos integrantes de las bolsas, es decir, perpetuarse entre las élites dominantes.

Como historiadores nuestro laboratorio es el pasado, y como historiadores sociales que aspiramos a ser, nuestro interés primordial es el estudio del ser humano inmerso en un grupo social. Además nos parece muy adecuado que los grupos gobernantes deben ser estudiados con meticulosidad y con cierta preferencia. Son estas élites de poder las que establecen e implantan el sistema político-económico que determinará la estructura social. Si llevábamos este tema al ámbito local o municipalista implicaba el análisis de aquellas instituciones que reflejaban el perfil socioeconómico del Castellón del seiscientos, y por tanto el estudio de las clases dominantes que gobernaban la ciudad.

El Consell de la ciudad y su riqueza documental ha sido la principal fuente de la mayor parte de las informaciones utilizadas en la investigación, tanto en lo referente al conocimiento del funcionamiento institucional como a la identificación de la oligarquía y sus actitudes económicas y políticas.

Es fundamental pues, realizar un análisis de cómo fueron estas relaciones de poder en el municipio castellonense durante la época foral y conseguir culminar el estudio sobre el Consell iniciado por Arroyas $S$ errano ${ }^{2}$ y el realizado por Gimeno Sanfeliu ${ }^{3}$ sobre las familias poderosas de la época, para tener una visión completa de la estructura oligárquica en la ciudad de la Plana, en una etapa histórica que como hemos citado anteriormente se establecía un difícil equilibrio entre la autoridad real y local.

Debe entenderse que como todo estudio histórico meritorio uno de los aspectos básicos debe ser la limitación temporal puesto que sin ello sería inabarcable y perdería su razón de ser. Ante ello nosotros hemos decidido centrarnos en la época comprendida entre 1597 y 1707, es decir, entre la aprobación del Privilegio de Felipe III y el fin de la

\footnotetext{
2 Arroyas Serrano, M. (1989): El Consell de Castellón en el siglo XVII. Diputación de Castellón. Castellón. En este trabajo plantea la necesidad de un estudio sobre el desempeño del poder en el s. XVII en Castellón y ese guante es el que hemos intentado recoger en este trabajo.

${ }^{3}$ Gimeno Sanfeliu, M.J. (1998): Patrimonio, Parentesco y poder. Castellón (XVI-XIX). Universitat Jaume I y Diputación de Castellón. Castellón.
} 
época foral. La causa es muy evidente, ya que es a partir del citado privilegio cuando se consolida el sistema insaculatorio en la ciudad de Castellón y nos permite realizar un estudio en profundidad de las consecuencias que tuvo y qué relaciones se establecieron ante el nuevo sistema de elección. Es verdad que no era precisamente una novedad, porque ya se había puesto en práctica con el Privilegio de Juan de Navarra en 1446, pero sí que se habían modificado determinados aspectos que lo podían hacer un sistema apetecible para las oligarquías urbanas y que perduró hasta la llegada de la dinastía borbónica, lo que supuso el fin de las instituciones forales.

El proceso de investigación ha resultado bastante laborioso porque sólo ha sido posible mediante la revisión sistemática de los miles de folios que comprende el Llibre del Consell durante todo el período comprendido ente 1597 y 1707, los primeros años del ayuntamiento borbónico, junto con los protocolos notariales de la época.

De esta forma, el presente trabajo lo iniciamos con una pequeña aproximación a la villa de Castellón en la época moderna desde la perspectiva política, demográfica y económica. Estos aspectos son de vital importancia para poder tener una visión del municipio que nos permita entender la vida diaria del s. XVII en el villa castellonense. Continuaremos realizando una descripción de la evolución del proceso insaculatorio y cómo se fue consolidando hacia un sistema de poder y una vez entendido, analizarlo y explicar su funcionamiento.

Hemos dedicado un apartado a describir cómo era esta proceso insaculatorio que nutría al Consell de Castellón y algunos oficios de la villa, puesto que se han corregido ciertos errores mantenidos por la historiografía anterior y que era muy importante dejar claros para una mejor comprensión de los datos extraídos.

Una vez esclarecido el marco en el que se puede entender el funcionamiento de las instituciones políticas municipales, se detallan todas las insaculaciones que hubo y se especifica en cada cargo una tabla con las familias que tuvieron más peso y por tanto, estaban más presentes en las bolsas. Esto mismo se muestra para los consejeros de mano mayor y menor. 
Seguidamente, realizamos un análisis de cuáles fueron las familias que ocuparon los cargos una vez ya habían entrado en las bolsas, puesto que aún quedaba el trámite de las inhabilitaciones y después que la suerte les acompañase en la extracción de los redolines de las vasijas. Los hechos producidos en 1707 tras la guerra de Sucesión podían haber generado un cambio importante en las oligarquías de Castellón, por tanto era fundamental observar si se habían producido alguna transformación tras la llegada de los Borbones. Para poder observarlo acompañamos el estudio de las familias que ocuparon los puestos relevantes del municipio en la época foral junto a un cuadro en el que se puede observar las personas que formaron parte del nuevo ayuntamiento borbónico en los primeros años.

Todo este estudio es el que más tiempo ha requerido ya que ha supuesto el análisis de muchos datos para poder realizar una completa enumeración de todas las personas que formaron parte del Consell de Castellón entre 1597 y 1707, y todas aquellas que ocuparon los oficios y cuya relación se puede observar en las diferentes tablas.

A continuación y puesto que la villa de Castellón era de realengo, se analiza la influencia regia en el proceso insaculatorio y en los resortes de poder del municipio. Esto hace suponer que el monarca intentará influir a través de todos los mecanismos posibles, aunque cómo veremos fue bastante escasa, dejando que la oligarquía marcara los cauces de la ciudad castellonense.

Finalmente y antes de obtener las conclusiones comparamos el funcionamiento de la villa de Castellón con otros municipios del Reino de Valencia como pueden ser Jijona, Valencia, Orihuela o Alicante y a su vez también realizamos esta comparación con otros municipios de la Corona de Aragón como Barcelona, Zaragoza o Lérida, para indagar si hubo un patrón homogéneo o si aquellos aspectos que se han dado por genéricos de la época moderna en las monarquías europeas se cumplían en la villa de Castellón.

En la parte final del trabajo exponemos una serie de conclusiones que perfilan, desde nuestro modesto punto de vista, el funcionamiento de un municipio importante por su tamaño en el reino de Valencia en la época foral, algo que no se ve reflejado en el 
intereses de la monarquía ni de las élites aristocráticas que sí estaban instaladas en la ciudad de Valencia, capital del reino. Esta situación invitaba a las esferas oligárquicas municipales a mantener su poder y consolidar su dominio con el consentimiento regio para que no se viese alterado, es decir, un juego de equilibrios en el cual Castellón participó y permitió a estos grupos dominantes no ver reducido su dominio de las instituciones locales. 


\section{Estado de la cuestión.}

La ponencia de Vicens Vives en el $\mathrm{XI}^{\circ}$ Congreso de Ciencias Históricas celebrado en Estocolmo en 1960, podemos considerarla como el inicio del estudio de las instituciones locales como parte de la estructuración del poder a nivel estatal, y que más tarde publicará en $1974^{4}$, y donde expone como fundamental el estudio de los cuerpos burocráticos, los funcionarios de lo componían, su extracción social, su preparación profesional, su comportamiento, etc.

Las ideas que plasmó Vicens Vives pretendían romper con la interpretación ideológica y que la historiografía romántica nacionalista había extendido respecto a la introducción del sistema insaculatorio fernandino, defendiendo la idea que la actitud del rey Católico era preservar la pluralidad social e ideológica del municipio.

Mientras el profesor Reglá Campistol ${ }^{5}$ al final de la década de los años sesenta manifestaba: "Hasta cierto punto, el sistema insaculatorio en los municipios de la Corona de Aragón es equivalente a la institución de los Corregidores en Castilla, ya que en ambos casos se persigue un mismo objetivo: la sumisión de los municipios a los designios de la monarquía autoritaria", por tanto se inclinaba por una línea distinta a la que había plasmado en sus investigaciones el profesor Vicens Vives.

Es entonces cuando aparecen los estudios de Belenguer Cebrià, con su libro "València en la crisi del segle $X V^{\text {,6 }}$ y que era la plasmación de su tesis doctoral en la que ya manejaba el juego de equilibrios entre la monarquía de Fernando el Católico y las oligarquías de la ciudad de Valencia, pero simplemente se planteaba una pequeña apertura al papel que podían haber jugado las élites ciudadanas, incidiendo en los problemas financieros.

\footnotetext{
${ }^{4}$ Vicens Vives, J. (1974): "Estructura Administrativa estatal en los siglos XVI y XVII". Coyuntura económica y reformismo burgués. Ariel. Barcelona, pp. 99-141.

${ }^{5}$ Reglà Campistol, J. (1967): "Notas sobre la política municipal de Fernando el Católico en la Corona de Aragón”. Homenaje a Vicens Vives. Vol. II. Barcelona, pp. 521-533.

${ }^{6}$ La obra original se publicó en 1976, pero en el año 2012 se publica una nueva edición bajo el título original Fernando el Católico y la ciudad de Valencia en el que se amplia y se incorporan nuevas referencias bibliográficas.
} 
En los años ochenta encontramos los estudios de Torras i Ribé ${ }^{7}$ que profundizan en el papel que juegan los municipios en la Corona de Aragón, centrándose en Cataluña y en el Reino de Aragón. Su argumentación se centra en defender que la monarquía intentó aumentar su control sobre los municipios a través del sistema insaculatorio, tanto con los Reyes Católicos como con la llegada de los Austrias. Para ello la concesión de un privilegio u ordenación y la designación de los insaculados eran las herramientas más útiles de intervención. Y además explica como en Aragón se plasmará con el intento continuo de la revisión periódica de las bolsas y al final del seiscientos con el secuestro directo de ellas. Mientras, en Cataluña lo conseguirá después de la Guerra dels Segadors.

Sin embargo las aportaciones de este autor no penetraban hasta los entramados de las oligarquías municipales, pese a que su obra Els municipis catalans de l'Antic Règim 1453-1808 permitía tener una visión global del funcionamiento del Principado. Sus estudios se fueron completando en los años noventa defendiendo la no existencia de ese supuesto neoforalismo a finales del s. XVII con Carlos II y que plasmará en su artículo La desnaturalización del procedimiento insaculatorio en los municipios aragoneses bajo los Austrias $^{8}$, defendiendo el reforzamiento de la autoridad monárquica.

En la misma época Amelang publica en su obra La formación de una clase dirigente: Barcelona 1490-1714 ${ }^{9}$, en la que defiende la existencia en Barcelona de una clase dirigente que monopoliza el poder ciudadano, y que la Corona había favorecido pero cuyo papel se centraba en intentar desbloquear el acceso. Niega ese pretendido objetivo de la monarquía de relevar a la oligarquía existente por una más afín a sus intereses.

\footnotetext{
${ }^{7}$ Torras i Ribé , J.M. (1983): Els municipis catalans a l’Àntic Règim (1453-1808). Curial. Barcelona.

${ }^{8}$ Torras i Ribé, J.M. (1996): "La desnaturalización del proceso insaculatorio en los municipios aragoneses bajo los Austrias”. Revista de Historia Moderna, $n^{\circ} 15$. Universidad de Salamanca, pp. 243-252.

${ }^{9}$ Amelang, J. (1983): La formación de una clase dirigente: Barcelona 1490-1714. Ariel. Barcelona.
} 
Mientras en Valencia Casey ${ }^{10}$ presentaba en 1983 su estudio en los archivos de la Corona de Aragón y los municipales de Castellón de la Plana, Valencia, Alcira y Orihuela. En sus conclusiones defendía que en el Reino de Valencia las oligarquías eran más excluyentes y la reducción de la base de reclutamiento había llevado al faccionalismo y a las disputas, de forma que había una especie de pacto tácito. Por un lado la oligarquía local apoyaba la política real a cambio de mantener sus derechos y cierta autonomía de gestión. La contrapartida era evidente, la Corona conseguía mantener la tranquilidad de la ciudad y de forma indirecta la de todo el reino.

“...la tranquilidad política de la ciudad descansaba simplemente en un entendimiento entre la élite gobernante y la Monarquía, ninguna de las cuales debía ejercer demasiada presión sobre la otra...". "El gobierno municipal valenciano descansaba en una sutil interdependencia entre el rey y la oligarquía: ninguna de las dos partes podía actuar sin contar con la otra. La base de esta alianza era que el pueblo no estaba preparado para gobernar" ${ }^{\prime 1}$.

A partir de mediados de la década de los ochenta e inicios de los noventa, en la universidad de Alicante, empiezan a surgir un grupo de investigadores que profundizan en las relaciones de poder municipales con la corona. Dentro de este grupo encontramos a Bernabé Gil, el cual defiende en su obra Relaciones entre la monarquía y patriciado urbano de Orihuela como el proceso insaculatorio permitía el afianzamiento de la élite gobernante y el mantenimiento de ese pacto entre la monarquía y la élite local de los municipios. " La Corona legitima a la oligarquía y actúa como garante de su privilegia situación obteniendo a cambio su colaboración para la gobernabilidad del reino y en las exigencias de servicios militares y monetarios" 12 .

En la misma línea defiende que la monarquía intentó aprovechar aquellos momentos de desgobierno o rivalidades, para afianzar su autoridad aunque nunca llegando a comprometer el papel político de esta oligarquía.

\footnotetext{
${ }^{10}$ Casey, J. (1983): El reino de Valencia en el siglo XVII. Siglo XXI. Madrid.

${ }^{11}$ Casey, J. (1983): El reino... op cit. pp. 171 y 173-174.

12 Bernabé Gil, D. (1990): Monarquía y patriciado urbano en Orihuela, 1445-1707. Universidad-Caja de Ahorros Provincial del Alicante. Alicante, pp.195-196.
} 
Alberola Romà realiza estudios de la misma cuestión pero insistiendo en la suspensión del poder insaculatorio para los municipios lo que reforzaría ese autoritarismo regio y esa desnaturalización del sistema que ya también proponía Torras i Ribé para el reino aragonés.

Tanto Bernabé Gil como Alberola Romà realizarán valoraciones globales de todo el proceso insaculatorio y de las instituciones municipales del Reino de Valencia que quedarán plasmadas entre otros en el I Congreso de la Administración Valenciana y que se recogerá después en la obra Dels Furs al Estatut. Han sido dos de los autores que más han insistido en argumentar e intentar realizar una explicación de cómo eran estas relaciones institucionales en la época de la Edad Moderna y por tanto sus investigaciones han sido continuas lo que ha supuesto la publicación de muchos artículos durante las últimas dos décadas, y lo podemos ver ampliamente recopilado en la bibliografía ${ }^{13}$. Destacando la recopilación de los Privilegios de Insaculación


recientemente por Bernabé Gil y que es una obra de inestimable valor, ya que nos permite tener una visión global de cómo fueron las pautas que marcaron el funcionamiento de las instituciones locales y hasta que punto se daba ese equilibrio teórico entre oligarquía urbana y monarca.

Paralelamente y por el interés que suscitaba el tema se publica en esta época el libro de Arroyas Serrano sobre Castellón ${ }^{15}$, y los trabajos de Bernabeu Sanchís sobre Onteniente $^{16}$, Barrio Barrio sobre Jàtiva ${ }^{17}$, Martí Villaplana ${ }^{18}$ y Berenguer Barceló ${ }^{19}$

\footnotetext{
${ }^{13}$ Alberola Roma, A. (1992, pp. 443-456) y Bernabé Gil, D. (1992, pp.505-510). Estas aportaciones están recogidas en la obra editada por la Generalitat Valenciana en 1992 Dels Furs al Estatut. Actes del I Congrés d'Administració Valenciana: De la Història a la Modernitat.

${ }^{14}$ Bernabé Gil, D. (2012): Privilegios de insaculación otorgados a municipios valencianos de realengo en la época foral. Instituto Juan Gil-Albert, Alicante.

${ }^{15}$ Arroyas Serrano, M. (1989): El Consell... op.cit.

${ }^{16}$ Bernabeu Sanchís, A. (1992): Ontinyent, Vila- reial: De les Germanies a la Nova Planta. Servicio de Publicaciones del Ayuntamiento de Onteniente.

${ }^{17}$ Barrio Barrio, J.A. (1992): Aportación recogida en la misma obra Dels Furs.... op.cit., pp. 499-504.

${ }^{18}$ Martí y Villaplana, C.L. (1990): "La insaculació a Alcoi al segle XVII". Actes del Congrés d'Estudis de l'Alcoià-Comtat. Alcoi, pp. 93-96.

${ }^{19}$ Berenguer Barceló, S. (1973): Historia de Alcoy. Alcoy.
} 
sobre Alcoy, Vaño Silvestre sobre Bocairente ${ }^{20}$ y Ortiz García-Bustelo sobre Albaida ${ }^{21}$. Evidentemente esto hacía que la historia de las instituciones municipales se fuese completando y nos permitiese tener una visión de conjunto más amplia. Ahora bien habría que esperar a las aportaciones de Amparo Felipo a mediados de los años noventa $^{22}$ y en el 2004 para tener una visión completa del sistema insaculatorio en la ciudad de Valencia ${ }^{23}$.

Posteriormente en Castellón, Corona $\mathrm{Marzol}^{24}$ realizaba diversas publicaciones que nos permitían actualizar los estudios de Arroyas Serrano sobre el municipio castellonense centrándose en todo el periodo de la Edad Moderna, mientras que Gimeno Sanfeliu $^{25}$ enfocaba su estudio en las familias castellonenses que obtuvieron títulos con la llegada de la nueva casa borbónica.

Mientras en el Principado de Cataluña era Passola i Tejedor el que tomaba el relevo de Torras i Ribé en los años noventa para realizar un estudio detallado del funcionamiento de la Paheria en la ciudad de Lleida ${ }^{26}$, poniendo en duda algunas de las afirmaciones del profesor Reglà Campistol y siguiendo una línea más próxima a autores como Bernabé Gil o Vicens Vives respecto a ese pacto tácito o equilibrio monarquía y oligarquía municipal.

\footnotetext{
${ }^{20}$ Vaño Silvestre, F. (1976): “Bocairente. La designación de autoridades por insaculación”. Primer Congreso de Historia del País Valenciano. Valencia, pp. 189-199.

${ }^{21}$ Ortiz García-Bustelo ,M ${ }^{\mathrm{a}}$ L. (1991): “Albaida, vila y señorío: administración municipal y oligarquía urbana en el siglo XVII". Estudis $n^{\circ} 17$, pp. 229-240.

${ }^{22}$ Felipo Orts, A. (1996): Insaculación y élites de poder en la ciudad de Valencia. Edicions Alfons el Magnànim. Institut Valenciá d’Estudis i Investigació. Generalitat Valenciana. Diputació de València.

${ }^{23}$ Felipo Orts, A. (2004): Autoritarismo monárquico y reacción municipal: la oligarquía urbana de valencia desde Fernando el Católico a las germanías. Universidad de Valencia. Valencia.

${ }^{24}$ Corona Marzol, C. (1999): "El municipio... op. cit., pp. 235-242.

${ }^{25}$ Gimeno Sanfeliu, M.J. (1990): La oligarquía urbana de Castellón en el siglo XVIII. Ayuntamiento de Castellón. Castellón. y Gimeno Sanfeliu, M.J. (2003): Llinatge i poder. Generalitat Valenciana. Castellón.

26 Passola Tejedor, A. (2001): "La élite municipal leridana bajo los Austrias". Revista de Historia Moderna. Anales de la Universidad de Alicante. № 19. Universidad de Alicante, pp. 269-312.
} 
En Aragón, Jarque Martínez iba completando el estudio municipalista de la época moderna centrando su estudio en el reino de Aragón con diversas aportaciones y en las que defiende también ese pacto tácito de las oligarquías de las urbes y la autoridad regia que beneficiaba a ambas $\operatorname{partes}^{27}$.

Ante todos estos análisis partíamos de dos cuestiones diferentes y que era preciso abordar. En primer lugar el vacío en el estudio del municipio castellonense en el seiscientos, pese a que las aportaciones de Arroyas Serrano nos habían mostrado como era el funcionamiento del Consell y una descripción pormenorizada de los oficios que se ocupaban por el sistema insaculatorio, faltaba por determinar quiénes ocupaban esos puestos y que podía suponer para el municipio. Este aspecto no había sido estudiado por Gimeno Sanfeliu porque ella se había centrado en las familias que habían obtenido la hidalguías en el s. XVIII con la llegada de los Borbones. Su argumentación partía de la base de aquellas personas relevantes del municipio castellonense que tenían la ciudadanía. Es decir cuando ella habla de élites de poder, se refiere a aquellas que se ennoblecieron o que ya lo habían hecho. Quedaba pues un período de la historia local que debíamos abordar para ver los entresijos de la institución referente de la villa en la época foral, el Consell, desde el punto de vista de las personas y su relación con el sistema insaculatorio.

En segundo lugar debíamos plantearnos en qué punto estaba la historia social de la época moderna y que podíamos aportar nosotros a las diferentes tendencias que se han planteado. Era necesario intentar averiguar que representaba para la ciudad la estratificación propia del Antiguo Régimen en función de las características socioeconómicas y como eran estas relaciones con la corona, de forma que pudiésemos aportar algunas reflexiones sobre el tema que convergiesen o no con las tendencias en el estudio municipalista en la Corona de Aragón, bien en el Reino de Valencia, el Reino de Aragón o en el Principado de Cataluña.

\footnotetext{
27 Jarque Martínez, E. (1996): "La oligarquía urbana de Zaragoza en los siglos XVI y XVII: Estudio comparativo con Barcelona”. Revista de Historia J.Zurita, nº 69-70. Zaragoza, pp. 148-167.
} 


\section{Metodología y objetivos.}

Al enfrentamos a un trabajo de investigación que pretende aportar un enfoque nuevo o algún aspecto no tratado sobre una realidad investigada, hemos de tener en cuenta que no podemos dejar de lado en ningún caso el rigor científico, ya que la realidad histórica debe enfrentarse al método científico al igual que cualquier otra disciplina tal como la física, y debe partir de unas hipótesis para llegar a unas conclusiones que nos sirvan para un mejor entendimiento de los hechos pasados. Fue así como decidimos que la Edad Moderna dejaba una puerta abierta a profundizar en el estudio del funcionamiento de unos entramados de poder que sugerían ciertas matizaciones, concretamente en la villa de Castellón de la Plana donde no se había profundizado en el control oligárquico por los grupos de poder no pertenecientes a las familias de caballeros o generosos. Sin embargo, es evidente que nuestra formación establecía una serie de limites que afectaban a la interpretación de los datos obtenidos, pero que no eran ningun inconveniente para realizar una profunda investigación de archivo. Ésta permitiría obtener una recopilación de todas las insaculaciones de la ciudad de Castellón del siglo diecisiete y todas las personas que ocuparon los cargos relevantes del municipio castellonense, lo cual podría servir como fuente inestimable de futuros trabajos de investigación.

Cuando nos planteamos por primera vez como eran las relaciones institucionales en la Edad Moderna, éramos conscientes de las peculiaridades que se daban en la Península Ibérica por tener una monarquía formada por varios reinos, ${ }^{28}$ los cuales tenían sus instituciones propias que los hacían más interesantes. Sin embargo, nuestro interés se centraba en la historia local, la cual ya contaba con aportaciones muy relevantes que habían descrito cómo eran estas relaciones en la época moderna. Para ello, una lectura detenida de la obra de Arroyas Serrano nos permitía tener una visión de qué supuso el sistema insaculatorio en Castellón al final de la época foral y cómo funcionaban los diversos oficios del municipio así como la institución que dirigía la ciudad, el Consell

\footnotetext{
${ }^{28}$ Esta bastante arraigado la utilización del concepto de Monarquía Compuesta acuñado por Elliot, J. H. (2010): “A Europe of Composite Monarchies”. España, Europa y el mundo de ultramar [1500-1800] Taurus. Madrid, pp. 29-54.
} 
de Castellón. Al igual que las aproximaciones certeras que realizaba Corona Marzol ${ }^{29}$ sobre la villa castellonense en la Edad Moderna. Sin embargo, creíamos necesario completar estos estudios analizando quiénes eran los que ocupaban estos puestos y si se trataba de un control oligárquico de pocas familias que servía como argumento para los teóricos de la defensa del equilibrio entre monarquía y municipio o si por el contrario fue el poder de la Corona el que controlaba la ciudad de Castellón.

Antes de empezar a analizar la documentación de la época era necesario hacer una lectura minuciosa de los estudios realizados por Gimeno Sanfeliu ya que establecía el poder de las familias que consiguieron ennoblecerse gracias a su pertenencia a las bolsas de ciudadanos honrados, así como el estudio de la evolución de estas familias desde el siglo XVI al XIX. Pero además, nosotros queríamos saber quiénes eran las personas con más relevancia en los oficios municipales, cuáles eran los apellidos que los dominaban y cómo interactuaban los distintos grupos de poder en el municipio castellonense.

En la misma línea que Gimeno Sanfeliu, Fernández Nadal ${ }^{30}$ nos aportaba una visión muy enriquecedora de la nueva situación política en la ciudad de Castellón con la llegada de los Borbones. Este estudio nos facilitaba la labor para poder demostrar si existía el mantenimiento en el poder local, o por el contrario aparecían nuevos grupos oligárquicos.

El inicio fue consultar el Llibre dels Privilegis al que hace referencia Arroyas Serrano para consultar minuciosamente en qué consistía el proceso insaculatorio, y delimitar muy bien la época en la que se iba a centrar nuestro estudio. Evidentemente decidimos centrarnos en el período comprendido entre la concesión del Privilegio de Felipe III, que consolidaba el proceso insaculatorio, y el fin de la época foral. Así, una vez consultado este libro nos dedicamos a revisar el Llibre de les Insaculacions, donde están recogidas todas las insaculaciones desde 1590 hasta 1700, y las transcribimos todas para poder comprobar quiénes eran las personas y los apellidos que entraban en

\footnotetext{
${ }^{29}$ Corona Marzol, C. (1999): "El municipio... op. cit.

${ }^{30}$ Fernández Nadal, C.M. (2003): El corregimiento de Castellón en la época de Carlos III: Entre continuidad y reforma. Ayuntamiento de Castellón. Castellón.
} 
las bolsas. Nos dimos cuenta que había algunas insaculaciones que no estaban reflejadas en este libro por lo que recurrimos al Judiciari, en concreto a las actas del Consell y allí obtuvimos todas las insaculaciones que faltaban. Esta parte supuso gran dedicación puesto que la trascripción y la lectura de todas las insaculaciones y la posterior clasificación conllevaron un análisis muy meticuloso. Sin embargo, la tarea más ardua se presentó cuando revisamos todas las actas del Consell desde 1590 hasta 1707, de las cuales extrajimos todos los consejeros; tanto los de mano mayor como los de mano menor; los justicias, los acequieros, los escribanos, los jurados primero, segundo, tercero y cuarto, los consejeros militares, los síndicos y el oficio de almotacén. Ello implicó la revisión de todas las sesiones del Consell $^{31}$ para todo el período estudiado, y nos permitió rechazar algunas afirmaciones tradicionales del funcionamiento del Consell de Castellón, como la alternancia anual de los militares y el brazo real en la ocupación de algunos cargos como el justicia, jurado primero o almotacén. Comprendimos que para contrastar o rechazar las hipótesis que todo historiador plantea hay que acudir a los documentos, en este caso las actas del Consell, donde se puede comprobar si aquello que dicen los Privilegios o las Ordenaciones o las peticiones de alguno de los brazos en las Cortes se cumple o no, y que después nos permite enunciar una serie de conclusiones con suficiente argumentario analítico.

A continuación, nuestro siguiente paso fue revisar la documentación de los protocolos notariales del archivo de Castellón para comprender las relaciones familiares que se establecían entre los miembros del Consell. La revisión nos ofreció una visión completa de quiénes eran los que desempeñaban oficios de la villa de Castellón, ocupaban los asientos del Consell y decidían los aspectos de la vida diaria de sus habitantes. Pero tampoco hay que olvidar que era precisamente este órgano el que establecía las relaciones con el monarca, aunque estuviera presente en la villa el lugarteniente del gobernador o el baile.

Con toda la información obtenida elaboramos una base de datos de la cual obtuvimos las tablas resumen aportadas en el trabajo para así empezar a redactar las

\footnotetext{
${ }^{31}$ Se puede hacer una estimación de unas veinticuatro reuniones anuales, dos mensuales por año, por ciento siete años. Esto supone alrededor de 2600 folios. Sin embargo, hemos de considerar que esto es una aproximación arbitraria, ya que el número de reuniones del Consell dependía de los asuntos que se tenían que tratar, y por supuesto que estaba en función de las circunstancias de la villa.
} 
conclusiones. Pero primero era necesario hacer una revisión de toda la bibliografía que se había escrito sobre la historia social de la época moderna de Castellón y fue de inestimable valor el estudio realizado por Sánchez Adell sobre las familias en la villa en el siglo XVII. Allí pudimos ver qué familias habitaban en el municipio y que se correspondían con los datos que habíamos obtenido. Además era muy importante analizar todo lo escrito sobre la insaculación en el Reino de Valencia por Bernabé Gil y Alberola Romà o por Felipo Orts en Valencia, para después analizar otras ciudades y villas de la Corona de Aragón como Zaragoza, estudiado por Jarque Martínez, o la ciudad de Lleida por Passola Tejedor o en Barcelona los trabajos de Torrás i Ribé que también lo enfoca para todos los municipios catalanes. Llegado a este punto, estábamos en condición de realizar un estudio comparativo entre Castellón y las demás villas de la Corona de Aragón que nos mostraba las similitudes y diferencias en el régimen municipal del seiscientos.

Para completar nuestra tarea indagamos en los primeros años del ayuntamiento borbónico. Tuvimos que revisar las actas comprendidas entre 1710 y 1729 donde hubo que volver a analizar las sesiones diarias para ver quiénes ocupaban los nuevos cargos creados después de la desaparición de las instituciones forales. Ahora sí que teníamos una visión completa de todo el período y contábamos con la información necesaria para intentar responder a las cuestiones que nos planteamos al inicio del trabajo que se podían resumir en las siguientes:

En primer lugar, la matización de algunos aspectos relevantes del funcionamiento del Consell de Castellón desde la aprobación del Privilegio de Felipe III en 1597 hasta el final de la época foral y conseguir con ello una aproximación más exacta a la configuración de las personas que formaban parte de él.

En segundo lugar determinar quiénes fueron las personas insaculadas en las distintas bolsas durante este período y a su vez relacionarlo con los nombres propios de quienes ocuparon los cargos municipales como los justicias, los jurados, almotacén, escribano, consejeros militares, y los de mano mayor y menor, es decir, quiénes se reunían en la casa de la villa en el Consell para regir la vida diaria de los habitantes de Castellón de la Plana. A partir de aquí estaba construido el escenario que nos permitía argumentar si eran las mismas familias las que ocupaban los cargos y extraer 
conclusiones sobre las relaciones endogámicas de poder y la relación existente entre las insaculaciones y el desempeño efectivo de los cargos.

Después nos centramos en describir el nuevo ayuntamiento borbónico creado a partir de 1708 y si esto supuso una ruptura con las oligarquías anteriores.

Plantear qué papel jugaron las instituciones regnícolas en el funcionamiento del Consell y en el procedimiento insaculatorio a partir de la aprobación del citado Privilegio de 1597 constituía una cuestión que queríamos aclarar. Sin embargo, nos interesaba profundizar más para describir como fueron estas relaciones, ya que el Privilegio establecía que el proceso insaculatorio quedaba en manos de la ciudad, es decir del Consell, pero era fundamental entender el papel que tomaron a partir de ese momento las instituciones regnícolas como la Real Audiencia, el baile o el lugarteniente del gobernador.

Finalmente creíamos fundamental, y lo determinamos como aspecto a tratar, realizar una comparación de la villa de Castellón con otros municipios del Reino de Valencia y con otros de la Corona de Aragón para ver las semejanzas y diferencias que aparecían y que eran la prueba palpable de una realidad institucional, social y económica propia del Antiguo Régimen en una Monarquía Compuesta. Esto invitaba a entender las peculiaridades de cada uno de los municipios de la Corona de Aragón, entroncado con las estructuras socio-económicas de las villas y que contrastaba con ese intento centralista de las postrimerías de la época foralista.

La tarea que nos propusimos era muy voluminosa en cuánto a la documentación que era necesario revisar y por tanto requería unas pautas de trabajo que llevaran por el camino de la rigurosidad científica. El objetivo era lograr un estudio que fuera crítico y sobre todo que mostrará una parte de la historia de Castellón que aún no se había completado, y que estaba demandando una exhumación de fuentes para realizar un análisis sobre las oligarquías que determinaron el devenir de la ciudad de Castellón en el último tramo de la época foral en el Reino de Valencia. 


\section{Aproximación al Castellón de la época moderna.}

La villa de Castellón en la época moderna estaba integrada en la gobernación deça Xexona, es decir, en las tierras del reino de Valencia que quedaban al norte de la ciudad de Jijona. Esta gobernación quedaba a cargo de uno de los dos portanveus con residencia en Valencia que ejercían sus funciones en nombre del gobernador general, el príncipe heredero a la corona.

Por tanto, encontramos en el Reino de Valencia dos portanveus, uno para las tierras al norte de la ciudad de Jijona y otro para las que quedaban al sur. Como acabamos de comentar, Castellón quedaba bajo el control del portanveus de la zona norte, y que a su vez se dividía en tres partes: una con capitalidad en Valencia, otra en Játiva y otra en Castellón. Esto implicaba el nombramiento de dos lugartenientes del portanveus que ejercían funciones delegadas y que residían en ambas villas. Por tanto nos encontramos con el representante real en la ciudad de Castellón en la figura del lugarteniente del portanveus no constreñido solamente al municipio castellonense sino que su límite territorial se establecía della Uxò, donde acababa la demarcación de la ciudad de Valencia hasta la zona norte del reino.

El lugarteniente debía acudir a los actos de nombramiento de los oficios de la villa, e incluso a las insaculaciones, pero su presencia en la villa de Castellón no era siempre posible por lo que muchas veces tenía que suplirlo su subrogado, y como comentaremos en un apartado posterior, éste normalmente estaba relacionado con las oligarquías locales.

La autoridad real en el municipio se complementaba con el baile, encargado del control y administración de los bienes de la monarquía y que además intervenía en el proceso de insaculación y la elección de los cargos y oficios de la villa. Como ocurría con el gobernador, también existía la figura del subrogado para las situaciones en las que se tenía que ausentar.

La participación de estos dos cargos en las insaculaciones se limitó, a partir del Privilegio del joven heredero al trono de la monarquía hispánica Felipe III, a votar en el 
proceso pero sin tener potestad para determinar los candidatos de forma unilateral tal y como explicaremos más adelante.

El gobierno de la villa quedaba en manos del Consell de Castellón que estaba formado por los consejeros, los jurados y presidido por el justicia. Todos ellos eran los encargados de gestionar los aspectos más importantes del municipio, aunque la corte de jurados realizaba las labores más concretas del quehacer diario hasta el fin de la época foral. Fue la llegada de los Borbones la que supuso la sustitución del Consell de Castellón por el ayuntamiento borbónico según el modelo castellano.

Estas indicaciones son aspectos que pueden servir para una mejor comprensión a la hora de analizar y leer de una forma pormenorizada nuestro trabajo.

\subsection{Acercamiento a la realidad demográfica.}

Para entender cómo era la villa de Castellón de la Plana en la Edad Moderna es necesario realizar una aproximación a la realidad demográfica del municipio castellonense del siglo XVII, para lo cual tomamos los datos ya publicados por autores como Bernat i Martí y Badenes Martín o los recogidos por Gimeno Sanfeliu, puesto que no es objetivo de este trabajo realizar un análisis crítico de los estudios demográficos. Eso supone tomar los datos de las diversas fuentes, aplicarles los coeficientes correctores y de ocultación propuestos por ellos y mostrar cual es la estimación poblacional en la villa de Castellón. En el cuadro siguiente se recoge un resumen del recuento de habitantes de diferentes fuentes ${ }^{32}$ desde 1609 a 1713 que es aproximadamente el período objeto de nuestro estudio.

\footnotetext{
${ }^{32}$ Bernat i Martí y Badenes Martín (1994): Crecimiento de la población valenciana. Ediciones Alfonso el Magnánimo. Institució Valenciana d’Estudis e Investigació. Generalitat Valenciana y Diputación de Valencia, pp. 133 a 173.

Gimeno Sanfeliu, M. J. (1998): Patrimonio, Parentesco y poder. Castellón (XVI-XIX). Universitat Jaume I y Diputación de Castellón. Castellón, pp. 46.
} 
Tabla 1: Censos de población de diversos autores ${ }^{33}$ :

\begin{tabular}{|l|c|c|c|c|}
\hline \multicolumn{1}{|c|}{ Fuente } & Vecinos & Vecinos*4,1 & $\begin{array}{c}\text { Coeficiente } \\
\text { ocultación }\end{array}$ & Total \\
\hline Caraçena 1609 & 1152 & 4777 & - & 4777 \\
\hline G.J. Escolano 1609 & 1260 & 5166 & - & 5166 \\
\hline Vecindario de 1646 & 1152 & 4723 & $21,70 \%$ & 5748 \\
\hline Real Pragmática 1692 & 1446 & 5929 & $14,90 \%$ & 6812 \\
\hline Vecindario 1712/1713 Campoflorido & 1072 & 4395 & $57,1 \%$ & 6905 \\
\hline
\end{tabular}

Elaboración propia.

En la tabla se muestra la evolución de la población durante el siglo XVII y hay aspectos que nos llaman poderosamente la atención. En primer, lugar el incremento paulatino de la población durante este siglo llegando a principios de 1700 a acercarse a la cifra de 7000 habitantes. Este proceso fue similar al del resto del Reino de Valencia y se justifica por una fuerte natalidad complementada por una nupcialidad temprana y una mortalidad moderada ${ }^{34}$. Castellón era la ciudad más poblada de la zona norte pero sin un peso específico dentro del reino, una ciudad "rural" con una economía agraria y sin un estamento nobiliario importante en el que solo encontramos las baronías de Benicásim y la Puebla Tornesa y algunos caballeros pero no muy numerosos. A continuación se situaban los ciudadanos honrados junto a doctores en leyes, notarios, médicos, apotecaris, cirujanos, mercaderes y labradores enriquecidos que eran los verdaderos protagonistas del poder en Castellón. Por tanto parece que el interés de la nobleza por ubicarse en la villa era prácticamente inexistente, con preferencia por situarse en la capital del reino.

Posteriormente compararemos los datos poblacionales expuestos aquí con el número de familias que ocuparon los cargos de la villa para poder deducir hasta qué punto el sistema era representativo, si había cierta regeneración o si se mantenían las mismas personas y familias.

\footnotetext{
${ }^{33}$ Los datos de 1609 están tomados de los recuentos poblaciones de Caraçena y G.J. Escolano que aparecen en la obra de Bernat i Martí y después añadimos los datos recogidos por Gimeno Sanfeliu para 1642, 1692 y 1712 y 1713. Le hemos aplicado el coeficiente de 4,1 que recomiendan los autores para estimar el número de habitantes por hogar y también se aplica un coeficiente de ocultación. Este último no se ha estimado para los recuentos de 1609.

${ }^{34}$ Bernat y Martí y Badenes Martín (1994): Crecimiento... op. cit. , pp. 131.
} 


\subsection{Análisis de la realidad económica de la villa.}

Castellón era una villa básicamente agrícola donde el 59\% de la población se dedicaba al sector primario, el $23 \%$ de la población activa al sector secundario, un $12 \%$ al sector terciario y un $6 \%$ de $\operatorname{criados}^{35}$. El territorio dedicado al cultivo era en 1608 de 66.511 hanegadas y paso a ser en 1702 de 70.144,25 hanegadas ${ }^{36}$. Mientras la ganadería tuvo un escaso peso restringida al ganado ovino y caprino ${ }^{37}$. El dominio de la actividad agrícola, sin embargo, no cubría muchas veces las necesidades alimenticias de sus habitantes debido a que la producción no podía satisfacerlas cuando había un aumento de la población. Los cultivos que dominaban el campo castellonense incluían la vid, olivos, algarrobo (que había ganado terreno a otros cultivos), el trigo, cultivos de huerta y el cáñamo, en torno al cual se creó una actividad comercial y artesana de una relevancia importante. Sin embargo, la artesanía se dedicaba básicamente a producir vestidos, zapatos, casas y muebles para los naturales de la ciudad. Solamente el incremento de la producción de cañamo en la huerta de Castellón incentivó una pequeña industria de exportación ${ }^{38}$. Por tanto la economía castellonense seguía siendo rural y agrícola e incluso los llamados labradores enriquecidos que nutrían las bolsas de jurados terceros y cuartos y la de los consejeros de mano menor, eran pequeños propietarios de tierras que no trabajaban las tierras y habían conseguido cierto nivel socioeconómico en la villa de Castellón por su acumulación de tierras. Fue de este grupo de donde surgieron gran parte de los notarios, ya que muchos de ellos eran los hijos de estos labradores enriquecidos que pasaron a formar parte de la bolsa de artistas o jurado segundo, e incluso algunos consiguieron formarse como doctores en leyes o en medicina lo que supuso su ascenso a las bolsas de jurado primero donde estaban los ciudadanos honrados.

Todo ello presenta en el s. XVII una villa de Castellón con una economía agrícola donde las actividades comerciales y artesanales juegan un papel secundario que complementa las labores agrícolas. Destacó el incremento del cultivo del algarrobo, más

\footnotetext{
${ }^{35}$ Gimeno Sanfeliu, M.Jesús (1998): Patrimonio... op. cit. , pp. 47.

${ }^{36}$ Casey, J. (1980): “Tierra y Sociedad en Castellón de la Plana. 1608-1702”. Estudis 7. Valencia, pp. 18.

${ }^{37}$ Villamaría Gómez, S. (2014): Castellón de la Plana 1700-1714: Último consistorio foral, Guerra de Sucesión y Nueva Planta. Universidad de Valencia. Valencia, pp. 27-28.

${ }^{38}$ Casey, J. (1980): “Tierra y ...” op. cit. ,pp. 31.
} 
utilizado como alimento para los caballos, mulas y burros, animales que habían sustituido a bueyes como fuerza de tiro y arrastre. El municipio castellonense era pues, de carácter rural y sin un gran interés económico para las fuerzas poderosas de la ciudad de Valencia ni para las regnícolas, lo cual le da a la ciudad cierto alejamiento de determinadas batallas de poder, aunque no resta su importancia como villa más relevante de la zona norte del reino. Nos encontramos ante un municipio altamente estratificado, según Casey ${ }^{39}$, compuesto por una élite, que como veremos a posteriori en el trabajo, es la que copa los puestos de las instituciones municipales y una clase más baja que prácticamente sobrevive. Sin embargo, el citado autor mantiene que dentro de la premisa de una sociedad del Antiguo Régimen en que la movilidad social es bastante complicada, se puede pasar de la pobreza al prestigio social con más o menos riqueza. Esta afirmación no la compartimos, ya que los ejemplos que él cita son los hijos de labradores enriquecidos a través del oficio de notario que conseguían ascender y posicionarse dentro de las oligarquías municipales. Hemos de recordar que estos labradores enriquecidos ya se encuentran en esos círculos que detentan el poder y que a través de las redes clientelares matrimoniales se van manteniendo e incluso escalando, pero ya están dentro de esas élites. No queremos extendernos mucho en este apartado y en las conclusiones intentaremos volver a esta premisa para perfilar esas clases dirigentes que, con más o menos riqueza, se movían en un círculo bastante cerrado.

\footnotetext{
${ }^{39}$ Casey, J. (1980): “Tierra y ...” op. cit., pp. 45-46.
} 


\section{Evolución del proceso insaculatorio.}

El quehacer diario de la villa de Castellón, como en muchos municipios del Reino de Valencia en la época foral, giraba entorno al consejo de la ciudad que en este caso era el Consell de Castellón. Esta institución se había formado en la Baja Edad Media en los municipios de la Corona de Aragón y en el caso de Castellón ha sido estudiada por historiadores clásicos locales como Traver Tomás ${ }^{40}$, Gimeno Michavila ${ }^{41}$, Roca Traver ${ }^{42}$, Sáncez Adell ${ }^{43}$ o Revest Corzo $^{44}$. Es evidente la relevancia que tiene determinar quiénes eran las personas encargadas de elegir los miembros de este Consell, que dirigía los asuntos de la villa y que a su vez era el que decidía quién ocupaba los distintos cargos y oficios del municipio.

El análisis y estudio del Consell de Castellón en la Edad Moderna implica delimitar el origen y estructura de este órgano desde el inicio de la reconquista. Para ello hemos de realizar un examen previo de la evolución de las instituciones locales en la villa de Castellón hasta el fin de la época foral, para lo cual seguimos la clasificación propuesta por Arroyas Serrano en la que distingue tres etapas muy claras que nos sirven para centrar nuestro trabajo y que inciden en la introducción del sistema insaculatorio como determinante a la hora de establecerlas. La primera etapa comprendería desde la toma de Castellón por Jaime I en 1233 hasta el Privilegio de Don Juan de Navarra como Lugarteniente del Reino en 1446, la segunda etapa desde el citado Privilegio hasta la Ordinación de Covarrubias de 1590 y la tercera etapa se puede establecer desde ésta hasta el fin de la época foral en 1707.

\footnotetext{
${ }^{40}$ Traver Tomás, V. (1982): Antigüedades de Castellón de la Plana. Ayuntamiento de Castellón. Castellon.

${ }^{41}$ Gimeno Michavila, V. (1926): Del Castellón Viejo. Hijo de J. Armengol. Castellón de la Plana.

${ }^{42}$ Roca Traver, F.A. (1952): Ordenaciones municipales de Castellón de la Plana durante la Baja Edad Media. Instituto Valenciano de Estudios Históricos. Institución Alfonso el Magnánimo. Diputación de Valencia. Valencia.

${ }^{43}$ Sánchez Adell, J. (1982): Castellón de la Plana en la Baja Edad Media. Sociedad Castellonense de Cultura. Castellón.

${ }^{44}$ Revest y Corzo, Ll. (1957): Llibre de les Ordenacions de la vila de Castelló. Hijos de F. Armengol. Castellón de la Plana.
} 


\subsection{Primera etapa (1233-1446): Los inicios de la villa.}

Recordemos que Jaime I toma Castellón de la Plana en el año 1233 y que durante los primeros años no se hace mención a ninguna institución hasta los privilegios obtenidos de Pedro III como villa de realengo y que establecen que la institución municipal pase a regirse con las mismas normas dictadas para Valencia. Sin embargo, la primera información completa que tenemos sobre la institución municipal la encontramos en la Ordinación de 1335 de la Reina Doña Leonor bajo cuyo señorío está la villa de Castellón y que establecía la normativa de la composición del Consell. Éste estaba formado por treinta y seis consejeros, entre los cuales se incluyen doce de mano menor, doce de mano mediana y doce de mano mayor y los cuatro jurados. Por tanto encontramos la primera composición del Consell muy similar a la estructura en número que tendrá en la época de final del seiscientos. Además se establece la normativa para los otros oficios de la villa como el Taulatger o tesorero. Este conjunto de normas generó problemas entre las distintas manos, lo que conllevó una nueva regulación, la Ordinación de Micer Rabasa del año 1341. Ésta permitía mantener las mismas personas en el poder municipal, sin embargo la rivalidad entre bandos opuestos dentro de este sistema de cooptación hacía necesaria una modificación que llegó con el sistema insaculatorio y que parece ser que se enmarcó dentro de ese mayor control sobre los municipios de la monarquía.

\subsection{Segunda etapa (1446-1590): La introducción del sistema insaculatorio.}

El Privilegio de Don Juan de Navarra de 1446 supone la introducción del sistema insaculatorio, una nueva forma de elección de los órganos y oficios que han de regir el funcionamiento de la villa de Castellón. No hemos de olvidar que la introducción de este Privilegio no anulaba la Ordinación anterior de Micer Rabasa sino que la complementó. Los aspectos más relevantes de la nueva reglamentación $\operatorname{son}^{45}$ :

\footnotetext{
${ }^{45}$ Bernabé Gil, D. (2012): Privilegios de insaculación otorgados a municipios del Reino de Valencia en la Época Foral. Instituto Alicantino de Cultura Juan Gil-Albert y Diputación de Alicante. Alicante, pp. 205-224. Para un análisis más detallado se puede consultar en el apéndice el documento 1 dónde se transcribe el Privilegio de Don Juan de Navarra de 1446.
} 
deben existir tres bolsas para el brazo militar, una para el oficio de justicia, una para el almotacén y otra para el oficio de jurado y se establecen las condiciones que se deben cumplir para entrar en ellas. Esto mismo se fija para el brazo real en el que se crean nueve bolsas: las de jurado primero, jurado segundo, jurado tercero y cuarto, clavario, escribano de jurado y Consell, consejeros, almotacén, justicia y mensajero excepto si es de Cortes, así como las condiciones para entrar en ellas. Además explica detalladamente quiénes han de poseer las llaves de la caja, donde se guardan las bolsas con los insaculados, que serán los mismos en toda la época foral, es decir, el lugarteniente de portantveus de gobernador, el baile, el justicia y el jurado primero. Se expone que el proceso de elección se realizará con la introducción de los nombres de los insaculados en redolines de cera en una vasija de agua y un niño será el encargado de extraerlos y depositarlos en manos de la autoridad competente ya sea el baile, el justicia o el jurado primero.

La vigencia de este sistema era de diez años, pero desde el inicio las oligarquías municipales se opusieron puesto que no podían mantener el poder que habían conseguido anteriormente. Esto supuso intentar la revocación del sistema insaculatorio mediante continuas peticiones del Consell de Castellón, primero para que no se cumplieran los diez años y después con las modificaciones de las Ordinaciones de 1467 y 1476, logrando que no se consolide el sistema y que simplemente exista de una manera marginal.

\subsection{Tercera etapa (1590-1707): Consolidación del sistema insaculatorio.}

Marca el inicio la petición de la villa para que no sea el baile el que decida la graduación de los jurados previamente extraídos por el proceso insaculatorio de una vasija. La sentencia de la Real Audiencia de Valencia ante la petición de la villa de Castellón de retornar al sistema insaculatorio es enviar a Diego de Covarrubias para que haga la insaculación y redacte una nueva Ordinación ${ }^{46}$. Destacamos como aspecto

\footnotetext{
${ }^{46}$ Bernabé Gil, D. (2012): Privilegios de insaculación otorgados a municipios del Reino de Valencia en la Época Foral. Instituto Alicantino de Cultura Juan Gil-Albert y Diputación de Alicante. Alicante, pp.
} 
fundamental de esta nueva reglamentación el establecimiento de nuevo de los dos brazos: nobiliario y real. En el nobiliario se creaba un saco para ocupar el cargo de justicia, jurado primero, almotacén y consejero, los años en que se tenía que hacer la elección de estas bolsas, mientras que en el brazo real se establecían nueve bolsas: jurado primero, jurado segundo, jurado tercero y cuarto, almotacén, escribano del Consell, acequiero, justicia, consejeros de mano mayor y consejeros de mano menor. Esto ya nos deja entrever qué oficios serán los que serán elegidos por el sistema de insaculación, aspecto que detallaremos después.

En la Ordinación establece los requisitos que se deben cumplir para poder entrar a formar parte de las bolsas y señala que será anual la duración de los oficios que se cubren por el sistema insaculatorio, excepto el de escribano que lo será por dos años y haciendo especial mención de los consejeros, que no lo podrán serlo más de dos años consecutivos $^{47}$. Sin embargo, el aspecto quizás más relevante y que iniciará la reivindicación más importante de la villa es la cuestión de quién era el encargado de insacular. En esta Ordinación de Covarrubias se establece que esta potestad recae en el Rey o Virrey o Real Audiencia como se puede leer en el capítulo cuyo título "que nos faça insaculació sinó per la Audiència Real” y que concretamente cita:

“....statuix, ordena, i mana dita promoció, o nova inseculatió, haverse de fer i que es fasa en lo modo i forma i de les persones per sa Magestat, o son Loctinent general i Real Audiència nomenadores è ordenadora, e no de altra manera per convenir eixa al bé comú de dita vila, sots decret de nullitat e mil florins d'or applicadors ut supra è altres penes a arbitre de sa Excellencia i Real Consell imposadores" ${ }^{48}$.

Esto supuso que fuera el poder real el que controlara el acceso a las instituciones locales de Castellón que se proveían por el sistema insaculatorio, lo cual no gustó a las élites e iniciaron una serie de peticiones para que esto no fuera así.

225-240. Para un análisis más detallado de la Ordinación de Covarrubias de 1590 remitirse al documento 2 del apéndice.

${ }^{47}$ Bernabé Gil, D. (2012): Privilegios... op. cit., pp. 225-250. Para un análisis más detallado de la Ordinación de Covarrubias de 1590 remitirse al documento 2 del apéndice. Este aspecto será modificado con el Real Privilegio de 1597 que se puede consultar en documento 3 del apéndice.

48 Bernabé Gil, D. (2012): Privilegios.. op. cit., pp. 231-232. Para un análisis más detallado de la Ordinación de Covarrubias de 1590 remitirse al documento 2 del apéndice. 
El resultado de estas reivindicaciones se plasma en el nuevo privilegio otorgado a la villa de Castellón por el heredero al trono de la Monarquía Hispánica. El Privilegio de Felipe III de 1597 supone una novedad puesto que deja en manos del municipio el poder de insacular a las personas para los oficios e instituciones que rigen la ciudad. Aspecto que, como comenta Arroyas Serrano, supone una novedad en la Corona de Aragón ya que ciudades como Valencia, Orihuela o Jijona siempre tuvo especial relevancia la intervención regia directa a través del baile, virrey o racional, e incluso en ciudades que no pertenecían al reino de Valencia como Zaragoza, las listas de posibles candidatos fueron supervisadas por la corona. Mientras, en la ciudad de Castellón el papel del baile o del lugarteniente del portanveus de la zona norte con residencia en la villa de la Plana no fue relevante, siendo, como analizaremos en un apartado posterior, un factor más en ese equilibro con la Corona pues priorizaba el interés de las oligarquías municipales, que aseguraba a su vez la tranquilidad del monarca.

Incidiendo en esta línea, dedicaremos un epígrafe para ver si a partir de la concesión del citado Privilegio y hasta el fin de la época foral hubo injerencias relevantes de la Corona en el proceso insaculatorio o sin embargo, se cumplió la delegación de esa potestad para insacular en el municipio.

Con la concesión del Privilegio de Felipe III ya nos adentramos en la tercera etapa que establece el marco del presente trabajo. Es en este punto donde es muy importante detallar el funcionamiento del sistema insaculatorio con el nuevo privilegio, así como los oficios y órganos que dirigían la vida diaria en el municipio castellonense y cuya definición viene determinada por la aprobación de la Ordinación de Covarrubias de 1590. En 1597 con el nuevo privilegio solo se modifican algunos aspectos relevantes que se mantendrán durante toda la época foral y que solo se verán puntualizados levemente con el Privilegio de Felipe III de $1604^{49}$ que establece el límite del número de componentes de las bolsas o la polémica sobre la entrada de los oficios mecánicos en las bolsas de mano menor en 1626 y 1627 . Este último aspecto fue muy bien estudiado por Arroyas Serrano, por lo que solo le dedicaremos después una pequeña valoración.

\footnotetext{
${ }^{49}$ AHMC. Variarum de Clavell. En el apéndice documento 4 se puede consultar el citado Privilegio.
} 
Ilustración 1: Redolines de cera de la insaculación ${ }^{50}$.



${ }^{50}$ AHMC. Foto obtenida del archivo donde aún se pueden contemplar los redolines que se utilizaban para la insaculación, aunque no se conservan en muy buen estado. 


\section{Estructura del poder local: El proceso insaculatorio, los oficios y el Consell.}

El sistema insaculatorio sólo era utilizado para los cargos de justicia, jurados, almotacén, acequiero, consejeros y escribano por lo que no incluyen todos los oficios del municipio ya que otros como los de síndico del consejo, el clavario de forments, el asesor de justicia (por citar algún ejemplo) serán elegidos por los miembros del Consell. Por tanto, es fundamental entender el proceso insaculatorio y la importancia que tenía conseguir ser miembro de las distintas bolsas, ya que ello iba a suponer la posibilidad de entrar a formar parte del Consell de Castellón donde se repartían los cargos de la villa. Si una familia quería ostentar poder a nivel local era imprescindible que estuviese presente en las distintas bolsas y después, una vez dentro, ya era cuestión de tiempo en que tuviese la posibilidad de salir elegido para cualquier cargo y a partir de ahí intentar ejercer este poder para favorecer sus intereses.

Las cantidades que se exigían para poder entrar en las distintas bolsas que nutrían los cargos municipales dependían del oficio y de si la persona era natural de la ciudad de Castellón. Para el caso de los consejeros se les exigía unas posesiones de renta de 10.000 sueldos que se duplicaba en el caso de que no se fuese natural de Castellón. Si se quería entrar en las bolsas de justicia, jurado, almotacén, escribano o acequiero la cantidad pasaba a ser 20.000 sueldos y también se duplicaba si no se era de la ciudad.

El Consell tenía su ubicación entre las plazas de la hierba y la de les Corts frente al ábside de la iglesia y Traver Tomás lo describe como un caserón con cuatro naves de ancho y un patio interior adornado con naranjos. En su interior tenía la sala, el archivo, más otras dependencias, y en sus fachadas arcos apuntados de sillería y ventanas ajimezadas con las columnillas, capitel y dinteles tribolados, cuyos restos fueron encontrados al derribar las casas que sobre su solar se edificaron en el siglo XVIII ${ }^{51}$.

\footnotetext{
${ }^{51}$ Traver Tomas, V. (1982): Antigüedades...op.cit pp. 197.
} 


\section{Ilustración 2: Simulación del edificio del antiguo Consell de Castellón:}

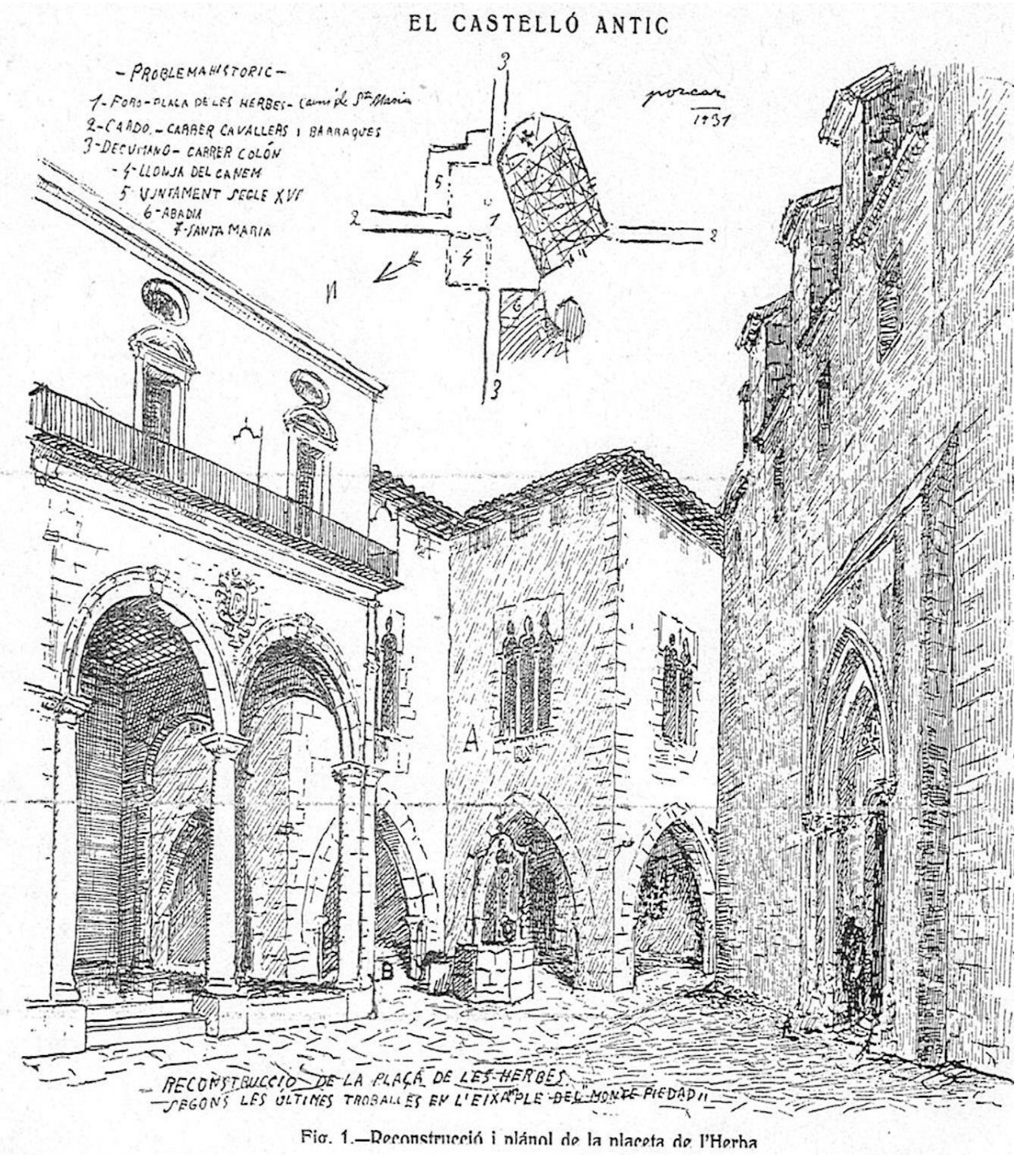

Reconstrucción de la llamada placeta de l'Herba realizada por Porcar en 1931 basándose en los restos encontrados en la reforma del Monte de Piedad y que publicó en el Boletín de la Sociedad Castellonense de Cultura ${ }^{52}$.

Es muy importante realizar una descripción previa de los oficios que determinaban la organización municipal de Castellón en el período comprendido entre 1590, con la concesión de la Ordinación de Covarrubias, hasta el fin de la época foral. Este aspecto ha sido muy bien detallado por autores como Arroyas Serrano ${ }^{53}$ en los años que hemos citado anteriormente y Roca Traver ${ }^{54}$ o Sánchez Adell ${ }^{55}$ en la Baja

\footnotetext{
52 Porcar Ripolles, J. (1931): "La primitiva plaça de Castelló”. Boletín Sociedad Castellonense de Cultura. Tomo 12. Cuaderno VI, pp. 354-355.

53 Arroyas Serrano, M.(1989): El Consell ... op.cit., p.102.

${ }^{54}$ Roca Traver, F. (1952): Ordenaciones... op.cit., pp. 41 a 49.
} 
Edad Media para la ciudad de Castellón. En la ciudad de Valencia encontramos a Felipo Orts ${ }^{56}$ y a Bernabé Gil $^{57}$ para el Reino de Valencia y para los casos concretos de Alicante y Orihuela. Pese a la rigurosidad de todos ellos, merece la pena que nos detengamos para perfilar algunos aspectos que no estaban suficientemente aclarados y que nos permiten hacer una nueva clasificación en función de aquellos oficios que se determinaban por el sistema insaculatorio y aquellos que no, pero que recaían en las personas que designaba el Consell. Tradicionalmente los autores anteriormente citados distinguían entre oficios mayores y menores. Sin embargo, nosotros queremos centrarnos en lo que representaba la insaculación como llave de entrada al Consell para poder decidir a quién se nombraba funcionario del municipio. Eso solo se podía conseguir si se formaba parte del órgano de decisión de Castellón. Esto suponía que la fuente de poder nacía de esa institución e implicaba que la presencia en el citado órgano colegiado permitía mover los resortes del poder local y su defensa frente a la autoridad real, y realza la verdadera importancia que tiene el conocimiento de las personas que lo ocuparon durante el período comprendido entre 1597 y el fin de la época foral.

\section{1. Órganos u oficios elegidos por el sistema insaculatorio.}

\subsubsection{Consell de Castellón.}

Era la institución fundamental para dirigir el municipio y desde donde se gestionaba la villa. La elección de sus miembros se realizaba en la víspera Pascua de Pentecostés. Su composición viene determinada en el capítulo referido a la graduación de los jurados de la Ordinación de Covarrubias de 1590 en la que textualmente se puede leer:

“... e lo mateix orde se guarde en la extractió de concellers, que és lo dispost en los sobre dits officis, los quals sien i ajen de ser trenta hu en número, ço és los quatre jurats vells, síndich vell i novell, justicia, mustassaf i scrivà vells, e les demés sien trets dels sachs de consellers, ço és generosos cascun any, o cavallers, de la bosa o sach de generosos sia trobats hi seran no impedits, e los demés sien estrets dels sachs dels concellers, ço és la mitad de concellers de mà major e l'atra mitad de concellers

\footnotetext{
${ }^{55}$ Sánchez Adell, J. (1982): Castellón de la Plana... op. cit., pp. 45 a 50.

${ }^{56}$ Amparo Felipo (2004): Autoritarismo ... op. cit., pp. 24 a 147. En este caso es importante destacar que la autora explica la organización municipal de la ciudad de Valencia pero centrándose en el siglo XVI.

${ }^{57}$ Bernabé Gil, D. (2012): Privilegios... op. cit., pp. 12 a 14.
} 
de mà menor, e si no seran pares los que ha de ser (...) extrets lo hu que ha de ser de demés sia pres dels de mà major, tots los quals han de ser convocats i ab que sien presents vintuhu..."

Este texto establece un Consell de Castellón formado por treinta y seis miembros, el justicia y jurados de ese año en concreto, y treinta y un consejeros como especifica la citada Ordenación. Los consejeros que son elegidos por oficio por haber ocupado un cargo en el ejercicio anterior, se incluyen dentro de los dos consejeros del brazo militar ${ }^{59}$ o dentro de los de mano mayor o de mano menor. La práctica habitual durante todo el período estudiado es que sean elegidos los dos del brazo militar, quince de mano mayor y catorce de mano menor. Las excepciones que encontramos en esta composición son: en los años 1599 y 1629 en los que se elige un consejero más de mano mayor y uno menos de mano menor, en 1607 ocurre el caso contrario, un consejero menos de mano mayor y uno más de mano menor, en el año 1695 encontramos un consejero más de mano menor, es decir quince, mientras que 1635 hay uno menos. En 1600, 1602 y 1650 se elige un consejero menos de mano menor. En todos estos casos no especifica ningún motivo pero como podemos ver son muy pocas las ocasiones en que esto sucede.

El resto del período estudiado se mantiene la composición de veintinueve consejeros, quince de mano mayor y catorce de mano menor, e incluso encontramos años como 1624, 1627, 1645, 1653, 1654, 1657, 1674, 1675, 1676/1677, 1677, 1678 у 1688 en los que no se llega a esa cifra porque no hay suficientes candidatos hábiles entre los insaculados ${ }^{60}$. Como es de suponer estos años se encuentran próximos aquellos en los que hubo insaculaciones en la villa de Castellón. Así, 1624 y 1627 se encuentran muy cercanos a la insaculación de 1630, 1645 a las de 1647-1648 y 1653 a las

\footnotetext{
${ }^{58}$ Bernabé Gil, D. (2012): Insaculación... op. cit., pp. 233. Para un análisis más detallado de la Ordinación de Covarrubias de 1590 remitirse al documento 2 del apéndice.

${ }^{59}$ Arroyas Serrano, M. (1989): El Consell... op. cit., pp. 59. En este libro el autor especifica cuando se refiere a la composición del Consell, que los consejeros militares aunque no se nombra en número son dos. Esto lo hemos podido corroborar al analizar todos los consejeros militares desde el Privilegio de Felipe III hasta el fin de la época foral y la instauración del ayuntamiento borbónico.

De Lario Ramírez, D. (1974): Cortes del reinado de Felipe IV: Cortes valencianas de 1626. Universidad de Valencia. Valencia, capítulo 38, también se plasma la misma idea.

${ }^{60}$ Véase la tabla 2 en la cual se pueden observar los consejeros del período estudiado.
} 
insaculaciones de ese mismo año. También 1654 y 1658, que están próximos a las insaculaciones de 1660 y 1662, pero el más relevante es la falta de personas hábiles en 1674, 1675, 1676, 1677 y 1678 que lleva a las insaculaciones de 1677 y 1679. Finalmente es evidente que la falta de personas hábiles de 1688 y 1695 no son cubiertas con las insaculaciones de 1685, 1686 y 1694 y para ello se insacula de nuevo y por última vez en 1700 .

Hemos de hacer una mención especial a la afirmación de Arroyas Serrano en la que indicaba que a partir de 1626 se incorporan al Consell dos consejeros más, uno de cada mano, y el acequiero viejo al cesar sus funciones, es decir, que pasaría a formar parte por oficio el acequiero que había ejercido su cargo en el año anterior. Esto suponía que pasasen a ser treinta y cuatro más el justicia y jurados de ese año (en total treinta y nueve) ${ }^{61}$.

Para realizar esta afirmación se apoyaba en los actos de Cortes de $1626^{62}$ y concretamente en el capítulo treinta y ocho donde dice textualmente:

“... 18 de Febrer del any 1604, fonch servit concedir als justicia, jurats, i consell de la vila de Castelló de la Plana lliure facultat pera insacular les persones quels paregues per als oficis de justicia, jurats, mustassaf, cequier, escrivà i consellers, ab que en la insaculació faedora asistis lo lloctinent de governador, que asistis en dita vila, juntament ab lo batle a soles, los quals haguesen de donar son $\operatorname{vot}^{63}$; i que lo numero dels insaculats foren, es a saber, en la bosa de jurat en cap vint persones, en la de jurat segon altres vint, en la de jurat tercer i quart quaranta; en la de justicia trenta, en la de mustassaf quaranta, en la de cequier cinquanta, i en la de escrivà deu; i que havent en les dites boses lo dit número complet, no puga ningún altre ser insaculat, no promogut a dits officis, com se veu per dit Real Privilegi, al qual sia haguda relació. I per no haver suplicat a sa Magestat lo syndich de dita vila en dita ocasió ques designarà lo numero de consellers, aquell no fonch expressat en dit Real Privilegi, si bé dita vila desde llavors ençà ha observat que lo número dels consellers sia de huytanta persones, i no més, que són les mateyxes que estan insaculades en les dites boses de justicia,

\footnotetext{
${ }^{61}$ Arroyas Serrano, M. (1989): El Consell... op. cit., pp. 103.

${ }^{62}$ De Lario Ramírez, D. (1974): Cortes del... op. cit., p. 183.

${ }^{63}$ Esta afirmación sobre el papel del lugarteniente del gobernador y el baile la retomaremos después para delimitar el papel que jugó la corona en las instituciones locales.
} 
jurats, mustassaf, cequier, i escrivà, estrahentne cada un any trenta un Conseller, pera que exercisquen dit ofici; es a saber, dos militars, quinze de la bosa de mà major, y catorze de bosa de mà menor, incloent en dit numero de trenta hu, los justicia, jurats, mustaçaf i escrivà que han regit dits oficis en lo any antecedent. I convenga per al bon regiment de dita vila, que açó se observe i guarde; i que lo cequier de la mateixa manera acabat lo dit ofici, reste també conseller per a l'any següent. Perçó lo dit braç real ab acte de la present Cort suplica a Vostra Magestat, sia de son Real servici confermar lo dit Real privilegi, i lo dit costum i observància d'extraure los consellers en la forma i número de sus dit; i que (com està dit) lo cequier reste també Conseller acabat son ofici per al any següent, com ho resten les demés oficials; i que no puguen eser extrets, ni nomenants Consellers en altra forma, ni de altres persones. $\mathrm{Sa}$ Magestat remet a son Lloctinent general pera que informe lo que se li suplica en aquest capitol, per a que avent-ho vist puga determinar lo que més convenga a son Real Servici".

Como podemos observar la petición se hace pero queda claramente establecido que se deja en manos del lugarteniente general para que emita un informe sobre el asunto. Y si observamos lo que ocurre en los años siguientes en la composición del Consell de Castellón queda patente como semejante petición nunca fue aceptada. Nunca se amplio el número de consejeros en el resto de la época foral y el acequiero tampoco fue miembro del Consell por ejercer dicho oficio en el año anterior. Si revisamos todos las elecciones de consejeros de todo el periodo comprendido entre la petición en las Cortes de 1626 hasta el fin de la época foral, no hay ni un solo caso en el que se especifique que el acequiero viejo entra a formar parte del Consell por haber ostentado ese cargo. Esto, sin embargo, sí que ocurre en los oficios como jurados, justicia, almotacén, síndico o escribano, aunque tampoco se detalla todos los años, ya que algunas veces aparecen en el Consell del año siguiente sin hacer mención a que forman parte de él por el cargo ostentado en el período previo. Pero en el caso de los acequieros nunca se cita y los únicos años en que es elegido miembro del Consell y no por su cargo son: Francesc Mas que fue el acequiero de 1641 y es elegido consejero en 1642; Miquel Romeu acequiero de 1652 elegido como consejero en 1653; Joan Navarro acequiero de 1660 elegido consejero para 1661; Gerony Rubert acequiero de 1665 elegido consejero para 1666; Josep Avinent menor acequiero de 1676 elegido consejero para 1677; Pere Museros de Vicent acequiero de 1677 elegido consejero para 1678; Gerony Castell acequiero de 1679 es elegido consejero en 1680; Andreu Ribalta acequiero de 1682 es 
elegido consejero de 1683; Josep Amposta acequiero de 1683 elegido consejero para 1684; Gerony Castell acequiero de 1689 elegido consejero para 1690; Miquel Català de Pere acequiero de 1691 es elegido consejero para 1692; March Casalís acequiero de 1694 es elegido consejero para 1695; Gaspar Rubert acequiero de 1695 es elegido consejero para 1696; Vicent Pasqual de Miquel acequiero de 1697 es elegido consejero para 1698; Joan Safont acequiero de 1700 es elegido consejero para 1701; Andreu Castellet acequiero de 1703 es elegido consejero para el 1704; Pere Museros acequiero de 1704 es elegido consejero para 1705 y Josep Rubert acequiero de 1705 es elegido consejero para 1706. Los datos reales nos muestran que desde el acto de Cortes de 1626 hasta 1707 pasan ochenta y un años de los cuales solo hay dieciocho ocasiones en las que el acequiero del año anterior es elegido consejero y en ninguna de ellas se especifica que lo es por oficio ${ }^{64}$.Sin embargo parece que en los últimos años del régimen foral se instaura como algo oficial.

Además, es importante hacer una mención a la limitación de la bolsa de mano mayor y mano menor que deja su composición en ochenta miembros en total, aspecto con una gran relevancia ya que son estas bolsas el origen de la mayor parte del Consell. Debido a su importancia en un apartado posterior realizaremos un pequeño análisis de las consecuencias que tuvo su cumplimiento o incumplimiento.

Otro aspecto que deberíamos aclarar es la posibilidad que tenían los consejeros de repetir en su cargo y que según la Ordinación de Covarrubias de $1590^{65}$ sólo podía ser de dos años consecutivos. El Privilegio de Felipe III en $1597^{66}$ lo modifico para permitir que se pudiera ocupar el cargo durante tres años consecutivos. Esta afirmación se consideró en su momento como válida por Arroyas Serrano pero hemos podido comprobar al obtener el listado de miembros del Consell entre los años 1597 y 1707 que no es cierta y podemos citar como ejemplo a Pau Capero que fue consejero de mano

\footnotetext{
${ }^{64}$ Véase el listado de acequieros en el tabla 8.

${ }^{65}$ Bernabé Gil, D. (2012): Privilegios... op. cit., pp. 235. Veáse el documento 2 del apéndice, el apartado de "vacacio de officis"de la Ordenación de Covarrubias.

66 Bernabé Gil, D. (2012): Privilegios... op. cit., pp. 243-244. Véase el documento 3 del apéndice el apartado de "que los Consellers pugue esser compellits a servir tres anys". Pese a que no está númerado podríamos suponer que es el capítulo o apartado tercero, puesto que a continuación se expone una asunto diferente en un apartado cuarto.
} 
mayor en los años 1605, 1606, 1607, 1608, 1609 y 1610, es decir, nada más y nada menos que seis años consecutivos. Éste no es un caso aislado puesto que es fácil encontrar otros casos entre los consejeros de mano mayor como Joan Gerony Folch que lo fue entre 1606 a 1611(seis años consecutivos) o Antoni Joan Lleó que lo fue entre 1608 y 1616 (nueve años seguidos), teniendo en cuenta que suponemos que también lo fue el año 1612 del que no tenemos datos. Podríamos citar muchos casos más que demostrarían como prevalecían los intereses de las oligarquías municipales frente a los fueros o incluso frente al ordenamiento jurídico real. Lo mismo ocurre con los consejeros de mano menor donde encontramos a Francesc Navarro que fue consejero de forma consecutiva desde 1598 a 1605, es decir, durante ocho años seguidos si suponemos que también lo fue en 1603 año del que no tenemos datos, o Pere Segarra, de 1666 a 1669 también cuatro años seguidos, o Francesc Pasqual de Joan desde 1672 a 1676 o Pere Calbo desde 1689 a 1692. Sin embargo, la repetición en el cargo, se solía producir más en los consejeros de mano mayor que en los de mano menor donde lo encontramos en menos ocasiones. Esto no es una novedad en la Corona de Aragón ya que en ciudades como Lleida ${ }^{67}$ o Alicante ${ }^{68}$ tampoco se podía ejercer el cargo de ésta forma y aparecen consejeros en años consecutivos.

La composición de los consejeros queda establecida en los del brazo militar y los del brazo real, quedando estos últimos divididos en mano mayor y mano menor. Los miembros de mano mayor son: los ciudadanos honrados, doctores en leyes, notarios, doctores en medicina, cirujanos, apotecaris, pintores y mercaderes, es decir, los miembros de las bolsas de jurados primero y segundo. Mientras que las personas que integran la mano menor son los labradores, salvo la excepción del periodo comprendido entre de 1624 a 1636 en que se introdujeron algunos miembros de los oficios mecánicos de la ciudad (Perayres, Sastres, Teixidors, Corders, Espardenyers, Esparter $i$ Çabaters). Este aspecto está muy bien explicado en el libro de Arroyas Serrano donde expone que desde la sentencia de la Real Audiencia de Valencia del 2 de febrero de 1624 y la confirmación con el Privilegio Real de 1626 dado a la ciudad de Castellón se permite el acceso a las bolsas de mano menor de los oficios mecánicos durante diez

\footnotetext{
${ }^{67}$ Passola i Tejedor, A. (1999): Oligarquía, municipio y corona en la Lleida de los Austrias. Tesis Doctoral. Biblioteca digital Miguel de Cervantes. Universidad de Alicante, pp. 328.

${ }^{68}$ Alberola Romà, A. (1990): “La organización del municipio en la época foral”. Historia de la ciudad de Alicante. Ayuntamiento de Alicante. Tomo III, pp. 193.
} 
años, pero tal y como comenta el citado autor y nosotros hemos corroborado, las oligarquías del Consell intentaron frenar la habilitación de miembros de estos al declarar muy pocas personas hábiles ${ }^{69}$. No reproduciremos aquí la elección de habas blancas y negras que expone Arroyas Serrano para cada uno de los candidatos, sino que citaremos cómo en 1624 tras las sentencia de la Real Audiencia de Valencia entra a formar parte del Consell como consejero de mano menor Joan Ferrer teixidor, en 1625 Gaspar Ferrer teixidor y Andreu Duenyes sastre y en 1626 otra vez Joan Ferrer teixidor y Francesc Montarda sastre. A partir de esa fecha, es decir una vez se ha confirmado con el nuevo Privilegio Real de 1626 se reduce su presencia en las bolsas de mano menor y desaparecen del Consell y nunca más volverán a formar parte ni de él ${ }^{70}$, ni de las bolsas.

Los miembros del Consell son elegidos por el sistema insaculatorio y entre los miembros del brazo real, es decir entre los consejeros de mano mayor y mano menor se elige el cargo de síndico. Hemos de aclarar que este término engloba a varios oficios que hemos de discernir para un mejor entendimiento de la exposición. El síndico al cual nos referimos era el tesorero del Consell. A su vez existía el síndico procurador de pobres y el síndico o mensajero, oficios que explicaremos un poco más adelante.

Es importante destacar el papel que juegan las inhabilitaciones a la hora de optar a los cargos que se nutren del sistema insaculatorio. Antes de elegir a los candidatos para ocupar los distintos oficios de la villa, se leen las personas que están insaculadas en la bolsa correspondiente $\mathrm{y}$ en ese momento se enumeran los inhabilitados. La Ordinación de Covarrubias de $1590^{71}$ que confirmaba el Privilegio de 1446 de Don Juan de Navarra, ${ }^{72}$ ya dejaba muy claros los motivos que podían suponer inhabilitación para ejercer los oficios de la villa, y el Privilegio de 1597 de Felipe III asumirá lo expuesto

\footnotetext{
${ }^{69}$ Arroyas Serrano, M. (1989): El Consell... op.cit., pp. 79-84.

${ }^{70}$ Veáse el listado de consejeros en la tabla 2.

${ }^{71}$ Bernabé Gil, D. (2012): Privilegios... op. cit., pp. 225-240. Véase el documento 2 del apéndice sobre la Ordinación de Covarrubias.

${ }^{72}$ Bernabé Gil, D. (2012): Privilegios... op. cit., pp. 205-223. Véase el documento 1 del apéndice sobre el Privilegio dado por el rey Juan II de Navarra en 1446.
} 
en $1590 .{ }^{73}$ Para ello podemos leer lo siguiente en la Ordinación de Covarrubias en el apartado referido que no puedan ser oficiales en un mismo año ${ }^{74}$ :

"ITTEM statuix, ordena i mana que un mateix any para e fill, ne dos germans, ne dos cuñats, ne marits de dos germanes, ni sogre ni gendre no puixen esser jurats, ans si aprés que lo hu sera tret e publicat ixques lo altre en lo qual sia lo dit impediment, tornat en lo dit redolí e tornat a posar en lo sach de hon sera estat tret e sia tret altre redolí”.

Esto deja bastante claro que para el oficio de jurados no podrán optar a ese cargo el mismo año dos personas con lazos familiares, pero parece ser que eso se extiende a la elección de consejeros. Ello lo vemos en 1688 donde el justicia es Jaume Cases y el jurado segundo Francesc Joan Cases quiénes por oficio deberían ser elegidos consejeros para el año 1689, sin embargo en la elección de cargos de veintiocho de mayo de 1689 se cita lo siguiente ${ }^{75}$ :

“... i en primer lloch foren donats per hàbils i quedaren consellers per offici per a lo dit any primer vinent i havent-se duptant si quedaria Jaume Cases notari per haver exercit lo offici de justicia en lo any propassat o si quedaria el Doctor Francesc Joan Cases per acabar lo offici de jurat i ser major de edad, i com segons ordinacions de la present vila dos germans no poden ser consellers en el mateix any es convocaren los assessors i foren de vots per saber que devia quedar Jaume Cases notari en conseller i no lo dit Doctor Francesc Joan Cases per ser lo offici de justicia més preheminent que no lo de jurat. No obstant, per lo dit Consell de fer lo que se votase amb faves blanques i negres per haver suscitat dit dubte. I per lo dit escrivà foren donades faves blanques i negres a tots los dits consellers i penjaren lo sach en lo calaix davant de dits oficials i en primer lloch es votà per lo dit Doctor Francesc Joan Cases i foren atrobades en dit sach vint faves blanques i deu negres. (Simili) modo fonch votat per lo dit Jaume Cases i buidades les faves del dit sach, després d'haver votat los dits consellers foren atrobades i contades onse faves blanques i denou negre a lo que quedà per offici el doctor Francesc Joan Cases...”.

\footnotetext{
${ }^{73}$ Bernabé Gil, D. (2012): Privilegios... op. cit., pp. 241-250.Véase el documento 3 del apéndice sobre el Privilegio de Felipe III en 1597.

74 Bernabé Gil, D. (2012): Privilegios... op. cit., pp. 235 . Véase el documento 2 del apéndice sobre la Ordinación de Covarrubias.

75 AHMC. Judiciari de 1686-1689. Sesión celebrada el 28 de junio de 1689.
} 
Por tanto, la incompatibilidad por parentesco se extiende a los consejeros y en caso de duda se vota en el Consell con el método habitual de las habas blancas y negras. Llama poderosamente la atención como pese a decir expresamente que es más relevante el cargo de justicia, la decisión del Consell es que el jurado segundo anterior Francesc Joan Cases es consejero por oficio. Contrariamente hay casos en los que sí son consejeros en el mismo año de la misma familia como en 1598 que son elegidos Jaume Serra y Melchor Serra o Miquel Mas y Josep Mas, los cuatro para la mano mayor y Miquel Navarro y Pere Navarro para mano menor. Esto ocurre más veces y no vamos a hacer una enumeración detallada sino que a modo de ejemplo citaremos para mano mayor en 1611 Miquel Giner y Jaume Giner, en 1616 Tomàs March y Pere March, en 1620 Batiste Gascó y Bernat Gascó, en 1637 Gaspar Luis Brunell y Gaspar Joan Brunell, en 1650 Miquel Giner y Jaume Giner, en 1651 Joan Andreu y Jaume Andreu, en 1673 Pere Giner y Tomás Giner y en 1674 Josep Avinent major y menor. Si realizamos el mismo análisis en mano menor encontramos a Francesc Navarro y Miquel Navarro en 1605, a Jaume Alegre y a Nicolau Alegre en 1615, a Miquel Vilarroig, Joan Vilarroig y Francesc Vilarroig en 1623 y a Miquel Castell y Martí Castell en 1626.

El que no se cumplan las inhabilitaciones por parentesco no es un aspecto nuevo porque ya lo había detectado Alberola Romà en la ciudad de Alicante ${ }^{76}$. Este hecho nos da la imagen que los fueros eran respetados por la villa siempre que se adecuaran a sus intereses y que muchas veces los incumplimientos se originaban para la perpetuación en el poder.

A continuación mostramos los consejeros entre 1597 y 1707 (no se incluyen los consejeros militares).

Tabla 2: Consejeros de mano mayor y menor entre 1597 y $1707^{77}$ :

\begin{tabular}{ll|ll}
\multicolumn{1}{c|}{$1597-1598$} & \multicolumn{1}{c}{$\mathbf{1 5 9 8 - 1 5 9 9}$} \\
\hline \multicolumn{1}{c}{ Mano mayor } & \multicolumn{1}{c}{ Mano menor } & \multicolumn{1}{c}{ Mano mayor } & Mano menor \\
\hline Tomàs March & Nicolau Alegre & Jaume Serra & Batiste Coll \\
Tomàs Moliner & Gabriel Agramunt & Josep Mas & Jaume Alegre \\
Francesc Jover & Bertomeu Bonet & Melchor Serra & Gabriel Agramunt \\
Melchor Salvador & Francesc Romeu & Nicolau Feliu & Pere Vilarroig \\
Antoni Lleó & Pere Figuerola & Cristòfol Gascó & Pere Figuerola
\end{tabular}

\footnotetext{
${ }^{76}$ Generalitat Valenciana (1992): Dels Furs al Estatut. Actes del I Congrés d'Administració Valenciana: De la història a la Modernitat. Valencia , pp. 452.

77 AHMC. Extraído de la revisión de todas las actas del Judiciari de las reuniones del Consell de Castellón entre 1597 y 1707.
} 


\begin{tabular}{ll|ll} 
Antoni Pedro & Martí Castell & Miquel Carnicer & $\begin{array}{l}\text { Joan Figuerola de } \\
\text { Francesc } \\
\text { Cristofol Gascó }\end{array}$ \\
Joan Castell & Andreu Pasqual & Antoni Pedro & Miquel Flors major \\
Nicolau Feliu & Bertomeu Giner & Tomàs March & Nicolau Coll \\
Gaspar Brunell & Pere Mas & Cristòfol Sisternés & Miquel Navarro \\
Agostí Llorach & Joan Giner & Bertomeu Moliner & Pere Navarro \\
Jaume Sabera & Pere Museros & Miquel Mas & Francesc Navarro \\
Lluís Agramunt de & Pere Vilarroig & Miquel Giner & Agostí Molinos \\
Sisternés & Joan Vilarroig de & Francesc Jover menor & Andreu Figuerola \\
Baltazar Peris & Bertomeu & Batiste Gisbert & Miquel Pasqual \\
Joan Ferrer & Andreu Figuerola & Melchor Salvador &
\end{tabular}

\begin{tabular}{|c|c|c|c|}
\hline \multicolumn{2}{|c|}{ 1599-1600 } & \multicolumn{2}{|c|}{ 1600-1601 } \\
\hline Mano mayor & Mano menor & Mano mayor & Mano menor \\
\hline Antoni Joan Lleó & Joan Vilarroig & Martí Arrufat & Francesc Navarro \\
\hline Martí Arrufat & $\begin{array}{l}\text { Francesc Navarro de } \\
\text { Francesc }\end{array}$ & Tomàs March & Joan Figuerola de Joan \\
\hline Gaspar Brunell & $\begin{array}{l}\text { Joan Vilarroig de } \\
\text { Bertomeu }\end{array}$ & Joan Bernat & Miquel Pasqual \\
\hline Domingo Beltrán & Pere Museros & Melchor Salvador & $\begin{array}{l}\text { Joan Bosch menor de } \\
\text { Pere }\end{array}$ \\
\hline Melchor Serra & Martí Castell & Joan Castell & Gabriel Agramunt \\
\hline Miquel Giner & Miquel Sanchís & Cristòfol Sisternés & Bertomeu Mas \\
\hline Cosme Feliu & Bertomeu Giner & Antoni Joan Lleó & $\begin{array}{l}\text { Joan Vilarroig de } \\
\text { Bertomeu }\end{array}$ \\
\hline Miquel Mas & Antoni Figuerola & Tomàs Moliner & Nicolau Alegre \\
\hline Llorens Sisternés & Nicolau Coll & Domingo Beltran & Pere Mas \\
\hline Jaume Sabera & & Joan Ferrer & \\
\hline Tomàs Moliner & & Baltazar Peris & \\
\hline Josep Mas & & & \\
\hline
\end{tabular}

\begin{tabular}{ll|ll}
\multicolumn{1}{c}{ Mano mayor } & \multicolumn{1}{c}{ Mano menor } & \multicolumn{1}{c}{ Mano mayor } & Mano menor \\
\hline Josep Mas & Martí castell & Francesc Jover menor & \multicolumn{1}{c}{ Bertomeu Giner } \\
Llorens Sisternés & Pere Vilarroig & Joan Castell & Francesc Navarro \\
Antoni Lleó & Joan Sanchís & Melchor Salvador & Jaume Bonet \\
Joan Bernat & Pere Museros & Bertomeu Moliner & Miquel Museros \\
Miquel Carnicer & Joan Figuerola de Joan & Josep Tomàs & Martí Castell \\
Francesc Jover major & Andreu Pasqual & Miquel Giner & Agostí Molinos \\
Baltazar Peris & Francesc Navarro de & Tomàs March & Joan Sanchís \\
& Francesc & & Miquel Navarro \\
Miquel Mas & Domingo Molina & Cristòfol Sisternés & Bertomeu Mas \\
Miquel Jaume Serra & Nicolau Alegre & Miquel Mas & Miquel Pascual \\
Miquel Giner & Bertomeu Bonet & Miquel Carnicer & Pere Museros \\
Domingo Beltrán & Baltazar & Cosme Martí & Domingo Molina \\
Narcís Feliu & Gisbert & Jaume Sabera & Gabriel Agramunt \\
Gaspar Brunell & Pere Navarro & Narcís Feliu &
\end{tabular}

\begin{tabular}{ll|ll}
\multicolumn{1}{c|}{ Mano mayor } & \multicolumn{1}{c}{ Mano menor } & \multicolumn{1}{c}{ Mano mayor } & \multicolumn{1}{c}{ Mano menor } \\
\hline Cosme Martí & Bertomeu Mas & Melchor Salvador & \multicolumn{1}{c}{ Francesc Navarro } \\
Bertomeu Moliner & Nicolau Coll & Narcís Feliu & Joan Vilarroig \\
Tomàs March & Andreu Figuerola & Gaspar Brunell & Miquel Planell \\
Cristòfol Sisternés & Domingo Molina & Antoni Lleó & Gerony Vidal \\
Miquel Giner & Joan Bosch & Miquel Aragonés & Joan Figuerola \\
Baltazar Peris & Pere Navarro & Jaume Giner & Miquel Navarro \\
Joan Bernat & Miquel Museros & Pau Capero & Joan Moràn \\
Antoni Lleó & Pere Figuerola & Miquel Mas & Monserrat Martí
\end{tabular}


Francesc Jover Miquel Aragonés Domingo Beltran Miquel Mas Jaume Sabera Cristòfol Gascó Miquel Jaume Serra
Pere Museros

Pere Vilarroig

Gabriel Agramunt

Joan Vilarroig

Francesc Navarro

Bertomeu Bonet
Antoni Fabregat

Tomàs Moliner

Jaume March

Francesc Jover menor

Gaspar Gombau

Joan Moreno

Miquel Carnicer
Agostí Molinos Jaume Roig major

Bertomeu Giner

Pere Ribalta

Nicolau Alegre

Bertomeu Mas

\begin{tabular}{ll|ll}
\multicolumn{1}{c|}{ Mano mayor } & \multicolumn{1}{c}{ Mano menor } & \multicolumn{1}{c}{ Mano mayor } & Mano menor \\
\hline Cristòfol Sisternés & Pere Figuerola & Gaspar Mascarós & Bertomeu Mas \\
Cristòfol Gascó & Domingo Molina & Miquel Giner & Pere Vilarroig \\
Gaspar Mascarós & Francesc Alegre & Tomàs March & Antoni Navarro \\
Jaume Giner & Berenguer Castell & Francesc Jover menor & Agostí Molinos \\
Joan Gerony Folch & Joan Sanchís & Gaspar Gombau & Joan Sanchís \\
Jaume Sabera & Joan Vilarroig & Pau Capero & Antoni Castell \\
Pau Capero & Miquel Museros & Miquel Aragonés & Miquel Planell \\
Narcís Feliu & Gerony Vidal & Antoni Fabregat & Pere Figuerola \\
Miquel Carnicer & Lluís Mas de Pere & Miquel Carnicer & Nicolau Coll \\
Joan Bernat & Pere Museros & Gaspar Brunell & Batiste Gisbert \\
Gaspar Brunell & Antoni Navarro & Joan Gerony Folch & Gerony Vidal \\
Melchor Salvador & Pere Eiximeno & Tomàs Moliner & Miquel Alberich \\
Baltasar Gombau & Antoni Pastor & Melchor Salvador & Bertomeu Bonet \\
Tomàs Moliner & Pere Vilarroig & Martí Castell & Francesc Alegre \\
Antoni Fabregat & & & Jaume Roig \\
& & & Joan Moran
\end{tabular}

\begin{tabular}{ll|ll}
\multicolumn{1}{c}{ Mano mayor } & \multicolumn{1}{c}{ Mano menor } & \multicolumn{1}{c}{ Mano mayor } & \multicolumn{1}{c}{ Mano menor } \\
\hline Francesc Jover & $\begin{array}{l}\text { Francesc Navarro de } \\
\text { Antoni }\end{array}$ & Miquel Giner ciutadà & Miquel Navarro \\
Jaume Sabera & Bertomeu Giner & $\begin{array}{l}\text { Gaspar Brunell } \\
\text { Cristòfol Sisternés }\end{array}$ & Miquel Pasqual \\
Pau Capero & Joan Sanchís & Cosme Martís Mas & Pere Eiximeno \\
Bertomeu Moliner & Joan Figuerola & Jaume Sabera & Pere Museros \\
Jaume March & Antoni Pastor & Francesc Joan Bou & Francesc Navarro \\
Miquel Aragonés & Nicolau Coll & Jaume March & Antoni Castell \\
Gaspar Gombau & Jaume Bonet & Micer Gerony Jover & Pere Ribalta \\
Melchor Salvador & Pere Ribalta & Tomàs Moliner & Bertomeu Mas \\
Miquel Mas & Miquel Sanchís & Melchor Salvador & Miquel Alberich \\
Cosme Martí & Gabriel Agramunt & Miquel Carnicer & Bertomeu Giner \\
Gaspar Mascarós & Pere Museros & Antoni Lleó & Joan Vilarroig de \\
Antoni Fabregat & Martí Castell & Pau Capero & Bertomeu \\
Joan Gerony Folch & Lluís Mas & Joan Gerony Folch & Antoni Pastor \\
Cristòfol Sisternés & Pere Marqués & Baltazar Gombau & Miquel Museros \\
Antoni Joan Lleó & &
\end{tabular}

\begin{tabular}{ll|ll}
\multicolumn{1}{c|}{ Mano mayor } & \multicolumn{1}{c}{ Mano menor } & \multicolumn{1}{c}{ Mano mayor } & \multicolumn{1}{c}{ Mano menor } \\
\hline Tomàs March & Batiste Gisbert & Miquel Giner & \multicolumn{1}{c}{ Francesc Alegre } \\
Francesc Jover & Gabriel Agramunt & $\begin{array}{l}\text { Francesc Bou } \\
\text { Gerony Jover }\end{array}$ & \multicolumn{1}{c}{ Antoni Ribes } \\
$\begin{array}{l}\text { Miquel Aragonés } \\
\text { Baltazar Gombau }\end{array}$ & Pere Museros & Jaume Sabera & Francesc Navarro de \\
& Miquel Planell & & Antoni \\
Bertomeu Moliner & Antoni Ribes & Jaume Giner & Joan Figuerola de Joan \\
Antoni Fabregat & Bertomeu Bonet & Cristòfol Sisternés & Berenguer Castell \\
Francesc Joan Bou & Francesc Mas & Baltazar Gombau & Miquel Planell \\
Antoni Joan Lleó & Antoni Castell & Antoni Fabregat & Miquel Pasqual \\
Cosme Martí & Antoni Navarro & Miquel Carnicer & Miquel Alberich \\
Melchor Salvador & Pere Vilarroig & Miquel Aragonés & Francesc Mas \\
Gaspar Brunell & Pere Eiximeno & Tomàs Moliner & Gabriel Agramunt \\
Joan Gerony Folch & Agostí Moliner & Joan Gerony Folch & Pere Marques \\
Miquel Carnicer & Gerony Vidal & Melchor Salvador & Miquel Museros \\
Cristòfol Sisternés & Miquel Museros & Gaspar Brunell & Monserrat Martí \\
Pau Capero & Antoni Joan Lleó &
\end{tabular}




\begin{tabular}{ll|ll}
\multicolumn{1}{c|}{ Mano mayor } & \multicolumn{1}{c}{ Mano menor } & \multicolumn{1}{c}{ Mano mayor } & \multicolumn{1}{c}{ Mano menor } \\
\hline Miquel Moliner & Gabriel Segarra & Cosme Martí & \multicolumn{1}{c}{ Bertomeu Bonet } \\
Joan Batiste Vallés & Nicolau Coll & Tomàs Moliner & \multicolumn{1}{c}{ Nicolau Alegre } \\
Melchor Salvador & Francesc Mas & Pere March & Andreu March \\
Jaume Giner & Miquel Alberich & Francesc Jover & Antoni Castell \\
Miquel Carnicer & Miquel Sanchís de Joan & Antoni Fabregat & Pere Marqués \\
Pau Capero & Monserrat Martí & Miquel Giner & Miquel Pasqual \\
Bernat Gascó & Miquel Vicent Pasqual & Gerony Quevedo & Miquel Pasqual de Vicent \\
Miquel Aragonés & Gabriel Agramunt & Pere Joan Vicent & Miquel Sanchís de Joan \\
Antoni Joan Lleó & Pere Vilarroig major & Antoni Lleó & Miquel Vilarroig \\
Francesc Joan Bou & Jaume Bonet & Pau Capero & Gabriel Agramunt \\
Miquel Giner & Antoni Ribes & Llorens Gascó & Pere Figuerola \\
Gerony Quevedo & Gerony Vidal & Jaume Sabera & Miquel Sanchís de Martí \\
Francesc Jover & Miquel Planell & Pere Joan Martí & Miquel Museros \\
Pere March & Andreu Pasqual & Jaume Bonet & Joan Vilarroig de \\
Tomàs March & & & Bertomeu
\end{tabular}

\begin{tabular}{ll|ll}
\multicolumn{1}{c|}{ 1615-1616 } & \multicolumn{1}{c}{ 1616-1617 } \\
\hline \multicolumn{1}{c}{ Mano mayor } & \multicolumn{1}{c}{ Mano menor } & \multicolumn{1}{c}{ Mano mayor } & \multicolumn{1}{c}{ Mano menor } \\
\hline $\begin{array}{l}\text { Gerony Jover } \\
\text { Tomàs March }\end{array}$ & Jaume Bonet & Baltazar Gombau & \multicolumn{1}{c}{ Bertomeu Bonet } \\
Francesc Joan Bou & Pere Figuerola & Pere Joan Vicent & Miquel Sanchís de Joan \\
Cosme Martí menor & Gabriel Agramunt & Francesc Jover & Francesc Mas \\
Jaume Sabera & Jaume Alegre & Pau Capero & Pere Museros de Narcís \\
Miquel Aragones & Antoni Ribes & Francesc Bou & Pere Figuerola \\
Gerony Quevedo & Joan Bosch & Miquel Moliner & Gerony Vidal \\
Miquel Moliner & Joan Figuerola & Jaume Bonet & Miquel Planell \\
Pere Joan Martí & Miquel Vilarroig & Gerony Quevedo & Miquel Reboll \\
Antoni Joan Lleó & Pere Museros & Miquel Carnicer & Miquel Vicent Pasqual \\
Llorens Gascó & Pere Vilarroig & Miquel Aragonés & Antoni Ribes \\
Jaume Blasco & Nicolau Alegre & Tomàs March & Miquel Sanchís \\
Jaume Giner & Miquel Reboll & Antoni Lleó & Pere Museros major \\
Pere March & Miquel Navarro & Jaume Blasco & Pere Marques \\
Miquel Carnicer & Francesc Mas & Pere Joan Martí & Miquel Lluch Sanchís \\
& & Pere March &
\end{tabular}

\begin{tabular}{ll|ll}
\multicolumn{1}{c|}{$\mathbf{1 6 2 0}-\mathbf{1 6 2 1}$} & \multicolumn{1}{c}{$\mathbf{1 6 2 1 - 1 6 2 2}$} \\
\hline \multicolumn{1}{c}{ Mano mayor } & \multicolumn{1}{c}{ Mano menor } & \multicolumn{1}{c}{ Mano mayor } & \multicolumn{1}{c}{ Mano menor } \\
\hline Bernat Gascó & Miquel Planell & Cosme Martí & Francesc Alegre \\
Francesc Joan Bou & Gabriel Ferrer & Batiste Moliner & Jaume Alegre \\
Pere March & Joan Bosch & Gerony Quevedo & Pere Figuerola \\
Jaume Bonet & Lluís Mas & Bertomeu Giner & Miquel Lluch Sanchís \\
Batiste Serra & Francesc Mas & Batiste Serra & Gabriel Segarra \\
Melchor Salvador & Gabriel Agramunt & Pau Pavia & Antoni Navarro \\
Batiste Gascó & Pere Vilarroig & Joan Batiste Vallés & Miquel Rubert \\
Baltazar Gombau & Miquel Vicent Pasqual & Gabriel Ferrer & Miquel Planell \\
Miquel Aragonés & Nicolau Coll & Martí Giner & Pere Museros \\
Bertomeu Giner & Monserrat Martí & Bernat Gascó & Lluís Mas \\
Antoni Joan Lleó & Antoni Navarro & Francesc Jover & Andreu Pasqual \\
Francesc Jover & Miquel Sanchís de Joan & Llorens Gascó & Monserrat Martí \\
Pere Figuerola & Andreu Pasqual & Jaume Bonet & Miquel Navarro \\
Lluís Mas & Miquel Lluch Sanchís & Pere Joan Vicent & Nicolau Coll \\
Martí Giner & & Pere March &
\end{tabular}

\begin{tabular}{ll|ll}
\multicolumn{1}{c|}{ 1622-1623 } & \multicolumn{1}{c}{$\mathbf{1 6 2 3 - 1 6 2 4}$} \\
\hline \multicolumn{1}{c}{ Mano mayor } & \multicolumn{1}{c}{ Mano menor } & \multicolumn{1}{c}{ Mano mayor } & \multicolumn{1}{c}{ Miquel Alberich } \\
\hline Baltazar Gombau & Pere Eiximeno & Miquel Giner & Miquel Navarro \\
Cristòfol Bou & Miquel Lluch Sanchís & Batiste Gascó & Francesc Mas \\
Batiste Serra & Miquel Pasqual & Jaume Castellet & Francesc Alegre \\
Lluís Mas & Francesc Vilarroig & Pau Capero & Mateu Sanchís \\
Geroni Quevedo & Miquel Vilarroig & Batiste Moliner & Monserrat Martí \\
Gabriel Ferrer & Miquel Vicent Pasqual & Baltazar Gombau & Miquel Vilarroig \\
Antoni Joan Lleó & Miquel Rubert & Lluís Mas & Jaume Alegre \\
Cosme Martí & Mateu Sanchís & Tomàs March &
\end{tabular}


Melchor Salvador Bertomeu Giner Pere March Jaume Bonet Francesc Jover Martí Giner Jaume Blasco
Gabriel Segarra

Joan Bosch

Pere Marqués

Andreu March

Nicolau Alegre

Francesc Mas
Melchor Salvador Gerony Quevedo Cristòfol Bou Macia Gascó Batiste Serra Llorens Gascó Bernat Gascó
Nicolau Coll Lluís Mas Francesc Vilarroig Pere Eiximeno Joan Vilarroig Miquel Museros

\begin{tabular}{ll|ll}
\multicolumn{1}{c|}{ 1624-1625 } & \multicolumn{1}{c}{$\mathbf{1 6 2 5 - 1 6 2 6}$} \\
\hline Mano mayor & \multicolumn{1}{c}{ Mano menor } & \multicolumn{1}{c}{ Mano mayor } & \multicolumn{1}{c}{ Mano menor } \\
\hline Jaume Bonet & Antoni Ribes & Tomàs March & Miquel Forés \\
Pere Joan Vicent & Joan Bosch & Cristòfol Sisternés & Miquel Alberich \\
Miquel Giner & Francesc Monterde & Miquel Giner & Monserrat Martí \\
Cristòfol Sisternés & Cosme Segarra & Batiste Serra & Miquel Vicent Pasqual \\
Baltazar Gombau & Andreu March & Nicolau Serra & Miquel Museros \\
Cristòfol Bou & Andreu Pasqual & Pere March & Francesc Alegre \\
Miquel Moliner & Lluís Mas & Pere Joan Vicent & Miquel Vilarroig \\
Dionís Jover & Joan Ferrer & Martí Giner & Andreu Duenyes \\
Macià Gascó & Miquel Sanchís de Joan & Gabriel Bonet & Gaspar Ferrer \\
Pere Nicolau Figuerola & Nicolau Coll & Pau Capero & Francesc Mas \\
Pau Capero & & Cristòfol Bou & Joan Vilarroig \\
Jaume Castellet & & Gaspar Martí Serer & Antoni Castell \\
Gaspar Martí & & Batiste Moliner & Andreu Pasqual \\
Melchor Salvador & & Gabriel Ferrer & Pere Alegre \\
Llorens Gascó & & Francesc Jover &
\end{tabular}

\begin{tabular}{|c|c|c|c|}
\hline \multicolumn{2}{|c|}{ 1626-1627 } & \multicolumn{2}{|c|}{$1627-1628$} \\
\hline Mano mayor & Mano menor & Mano mayor & Mano menor \\
\hline Bernat Gascó & Batiste Llorens & Pau Capero & Pere Museros de Narcís \\
\hline Jaume Castellet & Miquel Castell & Batiste Gascó & Pere Eiximeno \\
\hline Cristòfol Bou & Joan Vilarroig de Pere & Melchor Amiguet & Jaume Alegre de Jaume \\
\hline Gaspar Martí & Nicolau Coll & Martí Giner & Miquel Lluch Sanchís \\
\hline Bertomeu Giner & Francesc Mas & Melchor Salvador & Joan Giner \\
\hline Gabriel Bonet & Martí Castell & Dionís Jover & Lluís Mas \\
\hline Pere Joan Vicent & Gaspar Navarro & Nicolau Figuerola & Miquel Castell de Antoni \\
\hline Nicolau Serra & Monserrat Martí & Miquel Moliner & Joan Bosch de Joan \\
\hline Pere March & $\begin{array}{l}\text { Joan Vilarroig de } \\
\text { Bertomeu }\end{array}$ & Cristòfol Bou & Miquel Forés \\
\hline Tomàs March & Andreu March & Batiste Serra & $\begin{array}{l}\text { Joan Vilarroig de } \\
\text { Bertomeu }\end{array}$ \\
\hline Miquel Pasqual & Cosme Segarra & Tomàs March & Antoni Ribes \\
\hline Martí Giner & Jaume Alegre de Jaume & Gabriel Bonet & Miquel Museros \\
\hline Nicolau Figuerola & Francesc Monterde & Bertomeu Giner & Miquel Sanchís de Joan \\
\hline Francesc Jover & Joan Ferrer & Gaspar Martí & Nicolau Alegre \\
\hline Melchor Salvador & & & \\
\hline
\end{tabular}

1628-1629

\begin{tabular}{ll}
\hline \multicolumn{1}{c}{ Mano mayor } & \multicolumn{1}{c}{ Mano menor } \\
\hline Batiste Gascó & Miquel Vilarroig \\
Batiste Serra & Martí Castell \\
Batiste Vallés & Lluís Mas \\
Cristòfol Bou & Mateu Sanchís \\
Cristòfol Sisternés & Francesc Mas \\
& \\
Nicolau Figuerola & Francesc Vilarroig \\
Bertomeu Giner & Miquel Rubert \\
Pere Joan Vicent & Francesc Alegre \\
Miquel Moliner & Gaspar Navarro \\
Melchor Amiguet & Cosme Segarra \\
Melchor Salvador & Pere Eiximeno \\
Dionís Jover & Berenguer Ribalta \\
Llorens Gascó & Francesc Castell \\
Batiste Moliner & Miquel Pasqual de \\
& Miquel
\end{tabular}

\section{Nicolau Serra}

1629-1630

\begin{tabular}{ll}
\multicolumn{1}{c}{ Mano mayor } & \multicolumn{1}{c}{ Mano menor } \\
Cristòfol Sisternés & Nicolau Alegre \\
Cristòfol Bou & Antoni Ribes \\
Batiste Gascó & Francesc Vilarroig \\
Pere March & Andreu March \\
Jaume Castellet & Joan Vilarroig de \\
& Bertomeu \\
Miquel Moliner & Berenguer Ribalta \\
Gabriel Bonet & Miquel Pasqual \\
Cosme Martí & Nicolau Coll \\
Batiste Moliner & Cosme Segarra \\
Nicolau Serra & Pere Eiximeno \\
Bertomeu Giner & Pere Marques \\
Tomàs March & Miquel Sanchís \\
Melchor Amiguet & Joan Bosch \\
Miquel Bonaventura & \\
& \\
Nicolau Figuerola & \\
Dionís Jover &
\end{tabular}




\begin{tabular}{ll|ll}
\multicolumn{1}{c|}{ 1630-1631 } & \multicolumn{2}{c}{ 1631-1632 } \\
\hline \multicolumn{1}{c}{ Mano mayor } & \multicolumn{1}{c}{ Mano menor } & \multicolumn{1}{c}{ Mano mayor } & Mano menor \\
\hline Joan Planell & Miquel Sanchís & Pere Joan Vicent & Francesc Alegre \\
Dionís Jover & Pere Marqués & Miquel Vicent Pasqual & Miquel Rubert \\
Joan Batiste Vallés & Cosme Vidal & Batiste Moliner & Francesc Pasqual \\
Cosme Martí & Joan Navarro & Batiste Serra & Berenguer Ribalta \\
Pere Giner & Pere Museros & Batiste Gascó & Joan Vilarroig de Pere \\
Fulgenci Mascarós & Cosme Reboll & Miquel Moliner & Monserrat Martí \\
Jaume Aragonés & Nicolau Alegre & Jaume Andreu & Martí Castell \\
Jaume Andreu & Monserrat Museros & Batiste Traver & Gaspar Navarro \\
Gaspar Brunell & Miquel Giner & Jaume Aragonés & Joan Vilarroig de Miquel \\
Batiste Serra & March Casalís & Joan Planell & Pere Alegre \\
Bernat Gascó & Miquel Rubert & Cosme Feliu & Joan Navarro \\
Pere Joan Vicent & Miquel Vicent Pasqual & Gabriel Ferrer & Francesc Castell \\
Gabriel Bonet & Pere Castellet & Francesc Bou & Andreu Mas \\
Agostí Agramunt & Pere Alegre & Agostí Agramunt & Francesc Mas \\
Francesc Romeu & & Pau Capero &
\end{tabular}

\begin{tabular}{ll|ll}
\multicolumn{1}{c|}{ Man2-1633 } & \multicolumn{1}{c}{ 1633-1634 } \\
\hline Gaspar Joan Brunell & \multicolumn{1}{c}{ Mantoni Castell } & \multicolumn{1}{c}{ Mano mayor } & \multicolumn{1}{c}{ Mano menor } \\
Fulgenci Mascarós & Pere Alegre & Jaume Castellet & \multicolumn{1}{c}{ Miquel Vicent Pasqual } \\
Melchor Amiguet & Cosme Segarra & Cosme Feliu & Nicolau Coll \\
Jaume Aragonés & Joan Bosch & Francesc Bou & Pere Museros de Narcís \\
Nicolau Figuerola & Miquel Boix & Nicolau Figuerola & Pere Figuerola \\
Pau Capero & Francesc Mas & Agostí Agramunt & Cosme Vidal \\
Agostí Agramunt & Jaume Rubert & Gaspar Joan Brunell & Joan Vilarroig de Pere \\
Gerony Feliu & Pere Museros de Narcís & Pere Giner & Cosme Segarra \\
Joan Martí & Pere Figuerola & Miquel Moliner & Pere Castellet \\
Pere Joan Vicent & Cosme Reboll & Melchor Amiguet & Baltazar Avinent \\
Batiste Moliner & March Casalís & Batiste Gascó & Francesc Pasqual \\
Micer Miquel Moliner & Joan Granyana & Jaume Andreu & Francesc Moliner \\
Gabriel Bonet & Joan Vilarroig de Miquel & Joan Planell & Joan Navarro de Miquel \\
Joan Planell & Cosme Vidal & Cosme Martí & Joan Bosch de Bou \\
Gaspar Martí & & Batiste Moliner &
\end{tabular}

\begin{tabular}{ll|ll}
\multicolumn{1}{c|}{ Mano mayor } & \multicolumn{1}{c}{ Mano menor } & \multicolumn{1}{c}{ Mano mayor } & \multicolumn{1}{c}{ Mano menor } \\
\hline Nicolau Serra & Francesc Alegre & Nicolau Serra & \multicolumn{1}{c}{ Nicolau Alegre } \\
Batiste Traver & Martí Castell & Pere Nicolau Figuerola & Miquel Giner \\
Batiste Gascó & Batiste Llorens & Francesc Bou & Antoni March \\
Cristòfol Bou & Miquel Pasqual & Jaume Aragonés & Monserrat Museros \\
Pere Romeu & Baltazar Avinent & Nicolau Pauner & Joan Vilarroig de Joan \\
Cosme Martí & Cosme Vidal & Jaume Jover & Miquel Lluch Sanchís \\
Melchor Amiguet & Bertomeu Navarro & Miquel Mur & Joan Navarro \\
Batiste Serra & Andreu March & Pere Giner & Joan Vilarroig de Miquel \\
Cosme Feliu & Pere Castellet & Joan Martí & Jaume Muntanyés \\
Salvador Martí & Mateu Tormo & Batiste Moliner & Miquel Vicent Pasqual \\
Jaume Aragonés & Miquel Rubert & Guillem Sanchís & Batiste Llorens menor \\
Vicent Albiol & Francesc Moliner & Joan Tormo & Melchor Capero \\
Batiste Moliner & Francesc Castell de & Pere Romeu & Nicolau Pauner \\
Gabriel Bonet & Francesc & Lluís Mas & \\
Pere Roig & Francesc Mas & &
\end{tabular}

\begin{tabular}{ll|ll}
\multicolumn{1}{c|}{ Mano mayor } & \multicolumn{1}{c}{ Mano menor } & \multicolumn{1}{c}{ Mano mayor } & \multicolumn{1}{c}{ Mano menor } \\
\hline Pere Joan Vicent & Joan Bosch & Gaspar Lluís Brunell & \multicolumn{1}{c}{ Mateu Sanchís } \\
Melchor Capero & Gaspar Navarro & Cristòfol Bou & Joan Vilarroig de Pere \\
Lluís Mas & Joan Granyana & Jaume Jover & Francesc Moliner \\
Jaume Aragonés & Miquel Pasqual & Jaume Andreu & Cosme Segarra \\
Nicolau Figuerola & Nicolau Alegre & Batiste Moliner & Miquel Lluch Sanchís \\
Melchor Amiguet & Francesc Castell & Gaspar Joan Brunell & Pau Castellet \\
Vicent Albiol & Francesc Mas & Joan Batiste Gascó & Mateu Tormo \\
Nicolau Serra & Pere Alegre & Pere Romeu & Antoni Castell
\end{tabular}


Miquel Mur Joan Tormo Jaume March Joan Planell Joan Martí Jaume Jover Gaspar Joan Brunell
Martí Castell

Monserrat Museros

Francesc Moliner

Cosme Vidal

Baltazar Avinent

Nicolau Coll
Batiste Traver

Melchor Capero

Batiste Serra

Salvador Martí

Lluís Mas

Miquel Mur

Jaume Castellet
Joan Navarro

Jaume Muntanyés

Pere Figuerola

Baltazar Avinent

Pere Alegre

Joan Bosch

\begin{tabular}{|c|c|c|c|}
\hline \multicolumn{2}{|c|}{ 1638-1639 } & \multicolumn{2}{|c|}{$1639-1640$} \\
\hline Mano mayor & Mano menor & Mano mayor & Mano menor \\
\hline Nicolau Serra & Francesc Vilarroig & Jaume Jover & Nicolau Alegre \\
\hline Joan Martí & Bertomeu Navarro & Batiste Jover & Berenguer Ribalta \\
\hline Miquel Mur & Miquel Giner & Pere Joan Vicent & Antoni Navarro \\
\hline Miquel Romeu & Joan Granyana & Vicent Martí & Cosme Reboll \\
\hline Jaume Castellet & Joan Navarro & Batiste Gascó & Mateu Sanchís \\
\hline Jaume Andreu & $\begin{array}{l}\text { Francesc Castell de } \\
\text { Francesc }\end{array}$ & Miquel Mur & Jaume Muntanyés \\
\hline Jaume March & Pere Castellet & Melchor Amiguet & March Casalís \\
\hline Gabriel Bonet & Francesc Mas & Joan Batiste Traver & $\begin{array}{l}\text { Francesc Castell de } \\
\text { Francesc }\end{array}$ \\
\hline Batiste Serra & Cosme Segarra & Joan Martí & Cristòfol Castellet \\
\hline Joan Batiste Gascó & Cosme Reboll & Lluís Mas & Francesc Mas \\
\hline Melchor Capero & March Casalís & Jaume Andreu & Miquel Giner \\
\hline Gaspar Lluís Brunell & Jaume Muntanyés & Joan Tormo & Francesc Moliner \\
\hline Vicent Martí & Antoni Castell & Gabriel Bonet & Miquel Castell \\
\hline $\begin{array}{l}\text { Melchor Amiguet } \\
\text { Joan Tormo }\end{array}$ & Joan Vilarroig de Miquel & $\begin{array}{l}\text { Francesc Bou } \\
\text { Jaume Castell }\end{array}$ & Francesc Vilarroig \\
\hline
\end{tabular}

\begin{tabular}{ll|ll}
\multicolumn{1}{c|}{ 1640-1641 } & \multicolumn{1}{c}{$\mathbf{1 6 4 1 - 1 6 4 2}$} \\
\hline \multicolumn{1}{c}{ Mano mayor } & \multicolumn{1}{c}{ Mano menor } & \multicolumn{1}{c}{ Mano mayor } & \multicolumn{1}{c}{ Mano menor } \\
Jaume Castellet & Baltazar Avinent & Miquel Mur & Francesc Vilarroig \\
Francesc Bou & Joan Vilarroig de Miquel & Matiste Serra & Monserrat Museros \\
Pere Giner & Miquel Giner & Miquel Giner \\
& Francesc Castell de & Pere Roig & Francesc Castell de \\
Batiste Traver & Francesc & Batiste Moliner & Francesc \\
Melchor Amiguet & Andreu March & Batiste Traver & Berenguer Ribalta \\
Gabriel Bonet & Batiste Llorens menor & Jaume Navarro \\
Batiste Moliner & Miquel Castell de Antoni & Jaume March & Cristòfol Castellet \\
Lluís Mas & Francesc Mas & Melchor Amiguet & Francesc Moliner \\
Batiste Jover & Antoni Navarro de Miquel & Cristòfol Bou & Francesc Mas \\
Melchor Capero & Pere Alegre & Melchor Capero & Joan Granyana \\
Nicolau Serra & Berenguer Ribalta & Batiste Gascó & Pere Alegre \\
Pere Joan Vicent & Cosme Segarra & Joan Martí & Cosme Segarra \\
Jaume Castell & Mateu Sanchís & Jaume Castell & Antoni Navarro \\
Pere Roig & Mateu Tormo & Jaume Jover & Cosme Reboll \\
& & Salvador Martí &
\end{tabular}

1642-1643

\begin{tabular}{llll}
\hline \multicolumn{1}{c}{ Mano mayor } & \multicolumn{1}{c}{ Mano menor } & \multicolumn{1}{c}{ Mano mayor } & \multicolumn{1}{c}{ Mano menor } \\
\hline $\begin{array}{l}\text { Francesc Bou } \\
\text { Miquel Romeu }\end{array}$ & Miquel Castell & Pere Joan Vicent & \multicolumn{1}{c}{ Francesc Moliner } \\
Lluís Mas & Andreu March & $\begin{array}{l}\text { Joan Granyana } \\
\text { Batiste Moliner }\end{array}$ & Andreu Castellet \\
Salvador Martí & Francesc Castell de & Jaume Andreu & Joan Castell de Miquel \\
Jaume Castell & Monserrat Museros & Cristòfol Bou & Joan Vilarroig de Pere \\
Melchor Amiguet & Francesc Vilarroig & Jaume March & Pere Alegre \\
Gaspar Lluís Brunell & March Casalís & Joan Andreu & Jaume Montanyés \\
Miquel Mur & Francesc Mas & Jaume Giner & Joan Navarro de Miquel \\
Melchor Capero & Berenguer Ribalta & Miquel Batiste Gascó & Andreu Pasqual de Joan \\
Batiste Jover & Joan Navarro & Miquel Mur & Vicent Marqués \\
Pere Giner & Antoni Navarro & Joan Tormo & Miquel Llansola \\
Jaume Castellet & Baltazar Avinent & Gaspar Brunell & Martí Castell \\
Jaume Jover & Batiste Llorens menor & Vicent Castellet & Monserrat Museros \\
Batiste Traver & Miquel Giner & Baltazar Gombau & Francesc Mas \\
Joan Tormo & Jaume Muntanyés & Jaume Castell &
\end{tabular}




\begin{tabular}{ll|ll}
\multicolumn{1}{c|}{ 1644-1645 } & \multicolumn{1}{c}{$\mathbf{1 6 4 5 - 1 6 4 6}$} \\
\hline \multicolumn{1}{c}{ Mano mayor } & \multicolumn{1}{c}{ Mano menor } & \multicolumn{1}{c}{ Mano mayor } & \multicolumn{1}{c}{ Mano menor } \\
\hline $\begin{array}{l}\text { Melchor Capero } \\
\text { Melchor Amiguet }\end{array}$ & March Casalís & Baltazar Gombau & \multicolumn{1}{c}{ Batiste Llorens } \\
Jaume Giner & Baltazar Avinent & Jaume March & Joan Marqués \\
Vicent Porta & Berenguer Ribalta & Gaspar Lluís Brunell & Baltazar Avinent menor \\
Gaspar Brunell & Mateu Tormo & Miquel Mur & Monserrat Museros \\
& Miquel Castell de & Jaume Castell & March Casalís major \\
Vicent Castellet & Berenguer & Vicent Castellet & Agostí Reboll \\
Miquel Alberich & Pere Navarro de Joan & Vicent Porta & Josep Castell de Antoni \\
Pere Romeu notari & Andreu March & Melchor Capero & Vicent Marqués \\
Jaume Castell & Joan Vilarroig de Miquel & Vicent Musseros \\
Lluís Giner & Miquel Castell de Antoni & Batiste Jover & Joan Granyana \\
Batiste Moliner & Jaume Roig & Joan Tormo & Josep Segarra \\
Batiste Jover & Cosme Segarra & Melchor Amiguet & Pere Vilarroig de \\
& Joan Navarro de Miquel & Joan Andreu & Bertomeu \\
Lluís Cristòfol Bou & Miquel Giner & Vicent Martí & Joan Navarro \\
Lluís Mas & Francesc Moliner & Cristòfol Bou & \\
Vicent Martí & & Baltazar Gombau &
\end{tabular}

\begin{tabular}{ll|ll}
\multicolumn{1}{c|}{ 1646-1647 } & \multicolumn{1}{c}{ 1647-1648 } \\
\hline \multicolumn{1}{c}{ Mano mayor } & \multicolumn{1}{c}{ Mano menor } & \multicolumn{1}{c}{ Mano mayor } & \multicolumn{1}{c}{ Mano menor } \\
Lluís Giner & Cosme Reboll & Gaspar Martí & \multicolumn{1}{c}{ Joan Vilarroig de Pere } \\
Pere Giner & Agostí Reboll & Miquel Romeu & \multicolumn{1}{c}{ Pertarroig de } \\
& & Bertou & Berenguer Ribalta \\
Vicent Vilar & Joan Vilarroig de Miquel & Josep Alberich & Josep Castell de Antoni \\
Vicent Porta & Gaspar Eiximeno & Vicent Castellet & Gaspar Eiximeno \\
Salvador Martí & Vicent Museros & Salvador Martí & Francesc Figuerola \\
Gaspar Brunell & Joan Castellet de Miquel & Jaume Castell & Joan Vilarroig de Miquel \\
Batiste Moliner & Batiste Llorens menor & Melchor Gaspar & Francesc Moliner \\
Pere Joan Vicent & Josep Segarra & Gaspar Lluís Brunell & Josep Segarra \\
Miquel Mur & Baltazar Avinent menor & Jaume Giner & Andreu Castellet \\
Cristòfol Bou & Andreu Pasqual de Joan & Joan Andreu & Batiste Llorens menor \\
Miquel Alberich & Francesc Figuerola & Jaume March & Batiste Avinent menor \\
Vicent Castellet & Francesc Llansola & Batiste Moliner & Cosme Reboll \\
Pere Romeu & Miquel Sanchís de Miquel & Pere Joan Vicent & Joan Navarro de Miquel \\
Melchor Capero & Josep Castell & Melchor Amiguet & \\
Baltazar Gombau & & Pere Romeu &
\end{tabular}

\begin{tabular}{ll|ll}
\multicolumn{1}{c|}{ 1648-1649 } & \multicolumn{1}{c}{$\mathbf{1 6 4 9 - 1 6 5 0}$} \\
\hline \multicolumn{1}{c}{ Mano mayor } & \multicolumn{1}{c}{ Mano menor } & \multicolumn{1}{c}{ Mano mayor } & \multicolumn{1}{c}{ Manonor } \\
\hline Miquel Mur & Baltazar Avinent & Gaspar Brunell & Batiste Llorens menor \\
Miquel Romerich & Miquel Llansola & Jaume Giner & Francesc Figuerola \\
Pere Joan Vicent & Mateu Tormo & Melchor Amposta & Vicent Museros \\
Lluís Giner & Pere Navarro de Joan & Vicent Martí & Gaspar Eiximeno \\
Pere Giner & Pere Reboll & Vicent Vilar & Berenguer Ribalta \\
Vicent Vilar & Josep Segarra & Cristòfol Bou & Miquel Llansola \\
Jaume Castell & Miquel Boix & Vicent Porta & Matéu Tormo \\
Joan Andreu & Pere Vilarroig & Joan Andreu & Joan Navarro major \\
Baltazar Gombau & Joan Navarro menor & Baltazar Gombau & Francesc Moliner \\
Batiste Moliner & Joan Marqués & Jaume Castell & Baltazar Avinent \\
Melchor Capero & Francesc Llansola & Melchor Amiguet & Andreu March \\
Melchor Amiguet & Francesc Alegre & Miquel Romeu & Pere Vilarroig \\
Vicent Porta & Joan Vilarroig & Miquel Alberich & Agostí Reboll \\
Vicent Castellet & Vicent Museros & Vicent Castellet & Joan Castell de Miquel
\end{tabular}

\begin{tabular}{ll|ll}
\multicolumn{1}{c|}{$\mathbf{1 6 5 0 - 1 6 5 1}$} & \multicolumn{1}{c}{$\mathbf{1 6 5 1 - 1 6 5 2}$} \\
\hline \multicolumn{1}{c}{ Mano mayor } & \multicolumn{1}{c}{ Mano menor } & \multicolumn{1}{c}{ Mano mayor } & Mano menor \\
\hline Vicent Vilar & Joan Navarro de Joan & Vicent Martí & Matheu Sanchís \\
Gaspar Lluís Brunell & Vicent Figuerola & Vicent Castellet & Vicent Marqués \\
Miquel Giner & Andreu Castellet & Jaume Andreu & Batiste Llorens \\
Melchor Amiguet & Nicolau Moliner & Jaume March & Francesc Alegre \\
Miquel Alberich & Vicent Museros & Salvador Martí & Josep Avinent \\
Melchor Amposta & Miquel Castell de Antoni & Baltazar Gombau & Josep Segarra \\
Miquel Romeu & Josep Segarra & Vicent Porta & Miquel Boix
\end{tabular}


Jaume Giner

Salvador Martí

Baltazar Gombau

Batiste Jover

Miquel Mur

Jaume March

Jaume Castell

Joan Andreu
Miquel Boix

Joan Vilarroig

Josep Avinent

Monserrat Museros

Batiste Llorens

Pere Reboll
Melchor Amiguet

Jaume Giner

Josep Alberich

Tomàs Giner

Miquel Mur

Joan Andreu

Miquel Romeu

Jaume Castell
Jaume Roig

Monserrat Museros

Francesc Pasqual de Joan

Jaume Ferrer

Joan Navarro de Miquel

Andreu Castellet

Joan Vilarroig

\begin{tabular}{ll|ll}
\multicolumn{1}{c|}{ Mano mayor } & \multicolumn{1}{c}{ Mano menor } & \multicolumn{1}{c}{ Mano mayor } & \multicolumn{1}{c}{ Mano menor } \\
\hline Batiste Jover & Vicent Museros & $\begin{array}{l}\text { Melchor Amiguet } \\
\text { Tomàs Giner }\end{array}$ & \multicolumn{1}{c}{ Vicent Figuerola } \\
Vicent Vilar & Francesc Figuerola & Joan Narro de Joan \\
Melchor Amposta & Andreu Castellet & Josep Alberich & Miquel Boix \\
Miquel Mur & Gaspar Eiximeno & Jaume Andreu & Miquel Llansola \\
Baltazar Gombau & Francesc Moliner & Vicent Vilar & Monserrat Museros \\
Joan Andreu & Josep Castell de Francesc & Nicolau Moliner de \\
Miquel Romeu & Pere Navarro de Joan & Miquel Romeu & Francesc \\
& & & Andreu Castellet \\
Jaume Giner & Vicent Marqués & Jaume Castell & Josep Avinent \\
Jaume Andreu & Mateu Tormo & Miquel Mur & Vicent Museros \\
Vicent Martí & Miquel Boix & Pere Giner & Vicent Marqués \\
Vicent Porta & Jaume Roig & & Francesc Alegre \\
Salvador Martí & Josep Castell de Antoni & & Mateu Tormo \\
Jaume March & Miquel Llansola & & Jaume Roig \\
Gaspar Brunell & Josep Segarra & &
\end{tabular}

\begin{tabular}{|c|c|c|c|}
\hline \multicolumn{2}{|c|}{ 1654-1655 } & \multicolumn{2}{|c|}{$1655-1656$} \\
\hline Mano mayor & Mano menor & Mano mayor & Mano menor \\
\hline Batiste Jover & Josep Castell de Antoni & Vicent Vilar & Josep Segarra \\
\hline Vicent Porta & Gaspar Eiximeno & Miquel Mur & Vicent Marqués \\
\hline Baltazar Gombau & Mateu Tormo & Pere Giner & Miquel Giner \\
\hline Melchor Amiguet & Francesc Pasqual de Joan & Jaume Andreu & Vicent Rubert \\
\hline Jaume Andreu & Josep Castell de Francesc & Josep Alberich & Andreu Ribalta \\
\hline Miquel Romeu & Josep Avinent & Dionís Aragonés & Andreu Pasqual de Andeu \\
\hline Joan Andreu & Joan Navarro & Francesc Mercer & $\begin{array}{l}\text { Miquel Llansola de } \\
\text { Miquel }\end{array}$ \\
\hline Josep Alberich & Pere Navarro de Joan & Gaspar Martí & Miquel Català \\
\hline Jaume Giner & Vicent Figuerola & Vicent Figuerola & Jaume Roig \\
\hline Tomàs Giner & Batiste Llorens menor & Joan Andreu & Vicent Figuerola \\
\hline Jaume Castell & Monserrat Museros & Gaspar Brunell & $\begin{array}{l}\text { Miquel Vilarroig gendre } \\
\text { de Viciano }\end{array}$ \\
\hline & Francesc Alegre & Jaume Castell & Josep Castell de Francesc \\
\hline & Jaume Roig & Batiste Jover & Miquel Sanchís \\
\hline & Miquel Llansola & $\begin{array}{l}\text { Joan Cases } \\
\text { Vicent Pasqual }\end{array}$ & Josep Castell de Antoni \\
\hline
\end{tabular}

\begin{tabular}{ll|ll}
\multicolumn{1}{c|}{ Mano mayor } & \multicolumn{1}{c}{ Mano menor } & \multicolumn{1}{c}{ Mano mayor } & Mano menor \\
\hline Tomàs Giner & Vicent Rubert & Vicent Figuerola & \multicolumn{1}{c}{ Vicent Museros } \\
Gerony Vidal & Martí Viciano & Mateu Tormo \\
Josep Alberich & Francesc Pasqual de & Melchor Amposta & Josep Castell de Antoni \\
Melchor Amiguet & Joan & Tomàs Giner & Josep Albiol \\
Vicent Martí & Vicent Castellet & Dionís Aragonés & Vicent Eiximeno \\
Vicent Figuerola & Josep Avinent & Pere Giner & Miquel Llansola menor \\
Gaspar Martí & Josep Castell de Francesc \\
Miquel Romeu & Andreu Pasqual de Andreu & Joan Cases & Jaume Roig \\
Pere Giner & Miquel Vilarroig gendre & Melchor Amiguet & Andreu Pasqual \\
Jaume Castell & de Francesc Castell & & Joan Navarro \\
Baltazar Gumbau & Miquel Sanchís de Miquel & Baltazar Gombau & Andreu Castellet \\
Vicent Pasqual & Miquel Vilarroig gendre & Aleixandre Martí & \\
de Viciano & March Castellet & Josep Alberich & Vicent Marqués \\
Dionís Aragonés & Pere Navarro & Vicent Martí & Pere Vilarroig de \\
& Miquel Llansola menor & Gerony Vidal & Bertomeu
\end{tabular}


\begin{tabular}{l|l} 
Francesc Mercer menor & Pere Segarra \\
Jaume Andreu & Jaume Andreu \\
Vicent Pasqual
\end{tabular}

\begin{tabular}{ll|ll}
\multicolumn{1}{c|}{ Mano mayor } & \multicolumn{1}{c}{ Mano menor } & \multicolumn{1}{c}{ Mano mayor } & Mano menor \\
\hline Joan Andreu & Josep Segarra & Miquel Romeu & $\begin{array}{l}\text { Pere Vilarroig de } \\
\text { Bertomeu } \\
\text { Vicent Martí }\end{array}$ \\
& $\begin{array}{l}\text { Francesc Pasqual de } \\
\text { Joan }\end{array}$ & Tomàs Giner & Muel Vilarroig gendre \\
de Viciano & Gaspar Eximeno \\
Melchor Amiguet & Andreu Pasqual & Jaume Andreu & Martí Viciano \\
Gaspar Lluís Brunell & Gerony Reboll & Vicent Pasqual & Miquel Giner \\
Baltazar Gombau & Josep Avinent & Vicent Porta & Josep Castell de Antoni \\
Vicent Pasqual & Andreu Ribalta & Josep Alberich & Vicent Castellet \\
Gerony Vidal & Miquel Català & Aleixandre Martí & Miquel Llansola major \\
Josep Alberich & Josep Castell de Antoni & Vicent Figuerola & Josep Avinent \\
Melchor Amposta & Mateu Tormo & Joan Andreu & Vicent Marqués \\
Jaume Giner & Miquel Giner & Jaume Giner & Vicent Museros \\
Pere Museros & Jaume Roig & Melchor Amposta & Andreu Ribalta \\
Dionís Aragonés & Andreu Castellet & Pere Museros & Vicent Rubert \\
Francesc Mercer menor & Miquel Llansola major & Jaume Castell & Josep Castell de Francesc \\
Aleixandre Martí & Vicent Marqués & Melchor Amiguet &
\end{tabular}

\begin{tabular}{|c|c|c|c|}
\hline \multicolumn{2}{|c|}{$1660-1661$} & \multicolumn{2}{|c|}{ 1661-1662 } \\
\hline Mano mayor & Mano menor & Mano mayor & Mano menor \\
\hline Melchor Amiguet & Vicent Museros & Baltazar Gombau & Miquel Llansola major \\
\hline Gerony Vidal & Vicent Figuerola & Vicent Figuerola & $\begin{array}{l}\text { Josep Castell de } \\
\text { Francesc }\end{array}$ \\
\hline Pere Giner & Francesc Pasqual & Vicent Porta & Vicent Marqués \\
\hline Dionís Aragonés & Vicent Eiximeno & Tomàs Giner & Miquel Giner \\
\hline Miquel Mur & Francesc Amiguet & Pere Giner & $\begin{array}{l}\text { Pere Castell gendre de } \\
\text { Granyana }\end{array}$ \\
\hline Miquel Romeu & Andreu Ribalta & Joan Andreu & $\begin{array}{l}\text { Miquel Vilarroig gendre } \\
\text { de Castell }\end{array}$ \\
\hline Vicent Pasqual & Joan Navarro & Melchor Amiguet & Josep Vilarroig major \\
\hline Jaume Andreu & Miquel Giner & Vicent Pasqual & March Castellet \\
\hline Melchor Amposta & Andreu Castellet & Pere Museros & Gaspar Eiximeno \\
\hline Pere Museros & Martí Viciano & Miquel Romeu & $\begin{array}{l}\text { Pere Vilarroig de } \\
\text { Bertomeu }\end{array}$ \\
\hline Tomàs Giner & Vicent Marqués & Melchor Amposta & Josep Avinent \\
\hline Josep Alberich & Josep Vilarroig & Joan Cases & Joan Navarro \\
\hline Jaume Castell & Miquel Vilarroig de Joan & Dionís Aragonés & Vicent Rubert \\
\hline Joan Andreu & Pere Castell & Miquel Mur & Francesc Pasqual \\
\hline Francesc Mercer & & Francesc Mercer & \\
\hline
\end{tabular}

\begin{tabular}{|c|c|c|c|}
\hline \multicolumn{2}{|c|}{$1662-1663$} & \multicolumn{2}{|c|}{ 1663-1664 } \\
\hline Mano mayor & Mano menor & Mano mayor & Mano menor \\
\hline Gaspar Brunell & $\begin{array}{l}\text { Miquel Vilarroig de Joan } \\
\text { gendre de Viciano }\end{array}$ & Gerony Vidal & Francesc Figuerola \\
\hline Josep Alberich & $\begin{array}{l}\text { Miquel Sanchís de } \\
\text { Miquel }\end{array}$ & Tomàs Capero & Andreu Castellet \\
\hline Vicent Martí & Francesc Pasqual de Joan & Vicent Pasqual & $\begin{array}{l}\text { Miquel Vilarroig de } \\
\text { Viciano }\end{array}$ \\
\hline Pere Museros & Josep Vilarroig de Josep & Macià Compte & Pere Vilarroig \\
\hline Macià Compte & Josep Avinent de Baltazar & Francesc Mercer & $\begin{array}{l}\text { Joan Museros de } \\
\text { Monserrat }\end{array}$ \\
\hline Dionís Aragonés & Gabriel Segarra de Josep & Vicent Tosquella & $\begin{array}{l}\text { Miquel Pasqual de } \\
\text { Francesc }\end{array}$ \\
\hline Batiste Orts & Vicent Marqués & Miquel Romeu & Miquel Llansola menor \\
\hline Vicent Figuerola & Miquel Giner & Francesc Andreu & Miquel Navarro de Joan \\
\hline Francesc Mercer & Gaspar Eiximeno & Batiste Orts & Francesc Amiguet \\
\hline Melchor Calbo & Josep Rubert major & Vicent Ferrer & Pere Navarro de Joan \\
\hline Gerony Vidal & $\begin{array}{l}\text { Joan Museros de } \\
\text { Monserrat }\end{array}$ & Tomàs Giner & Andreu Pasqual de Andreu \\
\hline Vicent Pasqual & Francesc Viciano major & Francesc Grau & Vicent Rubert \\
\hline Joan Cases & Antoni Castell de Josep & Melchor Amiguet & Vicent Museros \\
\hline Francesc Grau & Pere Museros de Vicent & Joan Cases & Vicent Eximeno \\
\hline
\end{tabular}


Jaume Castell

| Vicent Figuerola

\begin{tabular}{|c|c|c|c|}
\hline \multicolumn{2}{|c|}{$1664-1665$} & \multicolumn{2}{|c|}{$1665-1666$} \\
\hline Mano mayor & Mano menor & Mano mayor & Mano menor \\
\hline Aleixandre Martí & Joan Navarro & Vicent Ferrer & Pere Bonet \\
\hline Joan Andreu & Vicent Castellet & Vicent Tosquella & Vicent Rubert \\
\hline Jaume Castell & $\begin{array}{l}\text { Joan Museros de } \\
\text { Monserrat }\end{array}$ & Pere Giner & $\begin{array}{l}\text { Miquel Vilarroig de } \\
\text { Viciano }\end{array}$ \\
\hline Vicent Martí & Miquel Llansola menor & Vicent Pasqual & Pere Vilarroig \\
\hline Melchor Amiguet & Gaspar Eiximeno & Jaume Castell & Miquel Navarro de Gaspar \\
\hline Miquel Romeu & Joan Pasqual de Joan & Vicent Figuerola & Vicent Castellet \\
\hline Francesc Andreu & $\begin{array}{l}\text { Miquel Vilarroig de } \\
\text { Castell }\end{array}$ & Vicent Porta & Antoni Castell \\
\hline Macià Compte & Francesc Amiguet & Josep Alberich & Vicent Museros \\
\hline Josep Alberich & Josep Avinent major & Pere Joan Vicent & Vicent Eiximeno \\
\hline Melchor Calbo & Miquel Catalá & Francesc Mercer & Gabriel Segarra de Josep \\
\hline Francesc Joan Casses & Miquel Sanchís & Gaspar Brunell & Andreu Castellet \\
\hline Vicent Pasqual & Miquel Navarro de Gaspar & Miquel Romeu & Josep Castell de Francesc \\
\hline Vicent Tosquella & Andreu Castellet & Francesc Andreu & Pere Navarro \\
\hline Pere Museros & Martí Viciano & Miser Joan Cases & Andreu Pasqual \\
\hline Tomàs Giner & & Macià Compte & \\
\hline \multicolumn{2}{|c|}{$1666-1667$} & \multicolumn{2}{|c|}{$1667-1668$} \\
\hline Mano mayor & Mano menor & Mano mayor & Mano menor \\
\hline Tomàs Giner & Pere Segarra & Gaspar Brunell & Vicent Marqués \\
\hline Vicent Tosquella & Martí Viciano & Vicent Figuerola & Francesc Pasqual \\
\hline Aleixandre Martí & Andreu Pasqual de Andreu & Francesc Mercer & Antoni Castell \\
\hline Joan Andreu & $\begin{array}{l}\text { Joan Museros de } \\
\text { Monserrat }\end{array}$ & Vicent Porta & Pere Segarra \\
\hline Josep Alberich & Francesc Viciano major & Vicent Tosquella & Gerony Rubert \\
\hline Pere Giner & Pere Calbo & Josep Alberich & Andreu Ribalta \\
\hline Pere Museros & $\begin{array}{l}\text { Miquel Vilarroig de } \\
\text { Viciano }\end{array}$ & Aleixandre Martí & Miquel Català \\
\hline Francesc Andreu & Miquel Català & Joan Andreu & Miquel Navarro \\
\hline Vicent Pasqual & Antoni Castell de Josep & Francesc Grau & Josep Avinent \\
\hline Joan Cases & Vicent Museros & Joan Cases & Miquel Llansola \\
\hline Miquel Romeu & Gerony Rubert & Macià Compte & Pere Calbo \\
\hline Vicent Porta & Pere Bonet & Francesc Andreu & Martí Viciano \\
\hline Lluís Pauner & Josep Avinent & Pere Giner & Pere Vilarroig \\
\hline Francesc Grau & Josep Castell de Francesc & Miquel Romeu & Gaspar Eiximeno \\
\hline Jaume Castell & & Pere Museros & \\
\hline
\end{tabular}

\begin{tabular}{ll|ll}
\multicolumn{1}{c|}{ 1668-1669 } & \multicolumn{1}{c}{$\mathbf{1 6 6 9 - 1 6 7 0}$} \\
\hline \multicolumn{1}{c}{ Mano mayor } & \multicolumn{1}{c}{ Mano menor } & \multicolumn{1}{c}{ Mano mayor } & \multicolumn{1}{c}{ Mano menor } \\
\hline $\begin{array}{l}\text { Tomàs Capero } \\
\text { Vicent Pasqual } \\
\text { Francesc Andreu }\end{array}$ & $\begin{array}{l}\text { Vicent Museros } \\
\text { Josep Avinent major } \\
\text { Miquel Vilarroig de } \\
\text { Viciano }\end{array}$ & $\begin{array}{l}\text { Joan Cases } \\
\text { Miquel Romeu } \\
\text { Pere Giner }\end{array}$ & $\begin{array}{l}\text { Miquel Llansola } \\
\text { Pere Navarro }\end{array}$ \\
$\begin{array}{l}\text { Tomàs Giner } \\
\text { Aleixandre Martí }\end{array}$ & Francesc Amiguet & Aleixandre Martí & Jaume Viciano de Miquel \\
Felip Sorrando & Josep Castell de Francesc & Felip Sorrando & Andreu Pasqual de Andreu \\
Vicent Martí & Miquel Català & Tomàs Capero & Josep Avinent major \\
Macià Compte & Gerony Alegre & Francesc Andreu & Andreu Ribalta \\
& Vicent Rubert & Josep Alberich & Miquel Vilarroig de \\
Josep Alberich & Gaspar Eximeno & Macià Compte & Castell \\
Joan Andreu & Andreu Pasqual & Francesc Pasqual de Joan \\
Francesc Mercer & Tabriel Segarra de Josep & Vicent Figuerola & Joan Navarro de Joan \\
Jaume Cases & Joan Andreu & Pere Segarra de Cosme \\
Pere Museros & March Casalís & Antoni Castell de Josep \\
Vicent Figuerola & Pere Segarra & Martí Viciano \\
Pere Palanques & Miquel Navarro & Francesc Mercer & Gabriel Segarra de Josep \\
& & Vicent Pasqual &
\end{tabular}

\begin{tabular}{cc|cc}
\multicolumn{2}{c|}{$1670-1671$} & \multicolumn{2}{c}{$1671-1672$} \\
\hline Mano mayor & \multicolumn{1}{c}{ Mano menor } & Mano mayor & Mano menor \\
\hline Gaspar Brunell & $\begin{array}{l}\text { Josep Castell de } \\
\text { Francesc }\end{array}$ & Francesc Andreu & Gaspar Eiximeno
\end{tabular}


Vicent Martí

Macià Compte

Tomàs Capero

Pere Giner

Aleixandre Martí

Josep Alberich

Miquel Romeu

Vicent Figuerola

Pere Museros

Felip Sorrando

Joan Andreu

Jaume Cases

Miquel Mur

Vicent Pasqual

\section{Gerony Alegre}

Miquel Vilarroig de

Breva

Miquel Navarro de Gaspar

Martí Viciano

Josep Avinent major

Vicent Eiximeno

Francesc Figuerola de

Vicent

Joan Pasqual de Joan

Vicent Rubert

March Casalís

Josep Avinent menor

Joan Museros de

Monserrat

Jaume Viciano de Miquel

Francesc Mercer
Vicent Tosquella
Felip Sorrando
Vicent Martí
Cosme Martí
Josep Alberich
Tomàs Capero
Miquel Mur
Pere Museros
Pere Giner
Gaspar Brunell
Aleixandre Martí
Joan Andreu
Francesc Joan Cases

\author{
Miquel Pasqual de \\ Francesc \\ Jaume Viciano de \\ Miquel \\ Vicent Rubert \\ Joan Navarro de Joan \\ Miquel Navarro de Gaspar \\ Gabriel Segarra \\ Josep Albiol
}

Josep Avinent maior Josep Castell de Francesc Pere Segarra de Cosme

Pere Calbo

Pere Navarro

March Casalís

\begin{tabular}{|c|c|c|c|}
\hline \multicolumn{2}{|c|}{$1672-1673$} & \multicolumn{2}{|c|}{ 1673-1674 } \\
\hline Mano mayor & Mano menor & Mano mayor & Mano menor \\
\hline Tomàs Giner & March Casalís & Cosme Martí & $\begin{array}{l}\text { Miquel Vilarroig de } \\
\text { Castell }\end{array}$ \\
\hline Vicent Ferrer & Gaspar Eiximeno & Vicent Martí & Francesc Figuerola \\
\hline Joan Andreu & Gerony Rubert & Pere Palanques & $\begin{array}{l}\text { Miquel Llansola de } \\
\text { Miquel }\end{array}$ \\
\hline Macià Compte & Pere Navarro de Joan & Miquel Sanchís & Pere Navarro de Joan \\
\hline Felip Sorrando & Miquel Navarro de Gaspar & Vicent Tosquella & Pere Calbo \\
\hline Vicent Figuerola & Pere Roig de Jaume & Francesc Joan Cases & Miquel Vilarroig de Breva \\
\hline Vicent Tosquella & Francesc Pasqual de Joan & Vicent Ferrer & Gaspar Eiximeno \\
\hline Francesc Andreu & Andreu Pasqual & Pere Giner & Joan Vilarroig major \\
\hline Joan Cases & $\begin{array}{l}\text { Miquel Vilarroig de } \\
\text { Viciano }\end{array}$ & Tomàs Giner & Andreu Pasqual de Andreu \\
\hline Tomàs Capero & $\begin{array}{l}\text { Miquel Pasqual de } \\
\text { Francesc }\end{array}$ & Francesc Andreu & Pere Roig de Jaume \\
\hline Vicent Martí & Francesc Amiguet & Macià Compte & Andreu Ribalta \\
\hline Pere Giner & Vicent Museros & Joan Andreu & Francesc Pasqual de Joan \\
\hline Francesc Mercer & Miquel Llansola & Vicent Figuerola & Vicent Rubert \\
\hline Pere Museros & Josep Villaroig & Pere Museros & Pere Segarra de Cosme \\
\hline Vicent Pasqual & & Francesc Mercer & \\
\hline
\end{tabular}

\begin{tabular}{|c|c|c|c|}
\hline \multicolumn{2}{|c|}{$1674-1675$} & \multicolumn{2}{|c|}{$1675-1676$} \\
\hline Mano mayor & Mano menor & Mano mayor & Mano menor \\
\hline Felip Sorrando & Vicent Museros & Joan Cases & $\begin{array}{l}\text { Miquel Pasqual de } \\
\text { Francesc }\end{array}$ \\
\hline Jaume Cases & Miquel Català & Pere Museros & Josep Avinent major \\
\hline Vicent Figuerola & Pere Roig de Jaume & Felip Sorrando & Josep Rubert major \\
\hline Pere Giner & Miquel Navarro de Gaspar & Francesc Mercer & Pere Segarra de Cosme \\
\hline Vicent Ferrer & Francesc Pasqual de Joan & Francesc Andreu & Antoni Castell de Josep \\
\hline Macià Compte & Pere Calbo & Miquel Sanchís & Pere Navarro \\
\hline Miquel Sanchís & $\begin{array}{l}\text { Joan Museros de } \\
\text { Monserrat }\end{array}$ & Macià Compte & Gaspar Eiximeno \\
\hline Dionís Aragonés & Josep Avinent menor & Vicent Ferrer & Miquel Català \\
\hline Vicent Martí & Josep Avinent major & Dionís Aragonés & Miquel Navarro de Gaspar \\
\hline Vicent Pasqual & March Casalís & Pere Giner & $\begin{array}{l}\text { Miquel Vilarroig de } \\
\text { Viciano }\end{array}$ \\
\hline Francesc Mercer & $\begin{array}{l}\text { Antoni Castell de Josep } \\
\text { Josep Rubert major } \\
\text { Vicent Eiximeno } \\
\text { Pere Navarro }\end{array}$ & Vicent Pasqual & $\begin{array}{l}\text { Josep Vilarroig major } \\
\text { Francesc Pasqual de Joan } \\
\text { Josep Avinent menor } \\
\text { Andreu Ribalta }\end{array}$ \\
\hline
\end{tabular}

\begin{tabular}{|c|c|c|c|}
\hline \multicolumn{2}{|c|}{$1676-1677$} & \multicolumn{2}{|c|}{$1677-1678$} \\
\hline Mano mayor & Mano menor & Mano mayor & Mano menor \\
\hline Francesc Andreu & Vicent Museros & Felip Sorrando & Pere Segarra \\
\hline Jaume Cases & Pere Calbo & Vicent Tosquella & $\begin{array}{l}\text { Miquel Vilarroig de } \\
\text { Castell }\end{array}$ \\
\hline Pere Giner & Andreu Ribalta & Vicent Ferrer & Miquel Pasqual de \\
\hline
\end{tabular}




$\begin{array}{ll}\text { Pere Figuerola } & \begin{array}{l}\text { Josep Albiol } \\ \text { Jaume Viciano de } \\ \text { Miquel Timor }\end{array} \\ \text { Mosep Casalís } & \begin{array}{l}\text { Miquel Pasqual de } \\ \text { Francesc }\end{array} \\ \text { Macià Compte } & \text { Pere Roig de Jaume } \\ \text { Miquel Bonet } & \text { Miquel Llansola } \\ \text { Josep Amposta } & \text { Gerony Alegre } \\ \text { Pere Museros } & \text { Gerony Castell } \\ & \text { Miquel Vilarroig } \\ \text { Tomàs Mercer } & \text { Miquel Vilarroig de } \\ \text { Vicent Ferrer } & \text { Nicolau } \\ & \text { Joan Museros de } \\ & \text { Monserrat } \\ & \text { Miquel Boix de Miquel }\end{array}$

Francesc Andreu
Pere Museros
Pere Giner
Josep Casalís
Josep Amposta
Tomàs Mercer
Pere Figuerola
Miquel Bonet

Francesc

Pere Roig de Jaume

Miquel Llansola

Josep Avinent menor

Gerony Castell

Andreu Ribalta

Pere Museros de Vicent

Miquel Vilarroig de

Nicolau

Miquel Vilarroig de Breva

Miquel Català

Vicent Eiximeno

Pere Calbo

\begin{tabular}{|c|c|c|c|}
\hline \multicolumn{2}{|c|}{ 1678-1679 } & \multicolumn{2}{|c|}{$1679-1680$} \\
\hline Mano mayor & Mano menor & Mano mayor & Mano menor \\
\hline Batiste Jover & Antoni Castell & Francesc Andreu & $\begin{array}{l}\text { Jaume Viciano de } \\
\text { Miquel }\end{array}$ \\
\hline Joan Timor & Gerony Castell & Vicent Tosquella & $\begin{array}{l}\text { Miquel Vilarroig de } \\
\text { Nicolau }\end{array}$ \\
\hline Macià Compte & Josep Avinent major & Ignacio Figuerola & Pere Calbo \\
\hline Miquel Bonet & Pere Museros de Vicent & Macià Compte & Andreu Ribalta \\
\hline Pere Museros & Josep Albiol & Miquel Bonet & $\begin{array}{l}\text { Josep Vilarroig de } \\
\text { Francesc }\end{array}$ \\
\hline Josep Amposta & $\begin{array}{l}\text { Miquel Pasqual de } \\
\text { Francesc }\end{array}$ & Pere Giner de Vilarroig & Pere Segarra \\
\hline Vicent Ferrer & Gerony Alegre & Martí Viciano & Vicent Eiximeno \\
\hline Francesc Ferrer & Miquel Vilarroig de Breva & Pere Figuerola & Pere Navarro de Joan \\
\hline Felip Sorrando & $\begin{array}{l}\text { Miquel Vilarroig de } \\
\text { Castell }\end{array}$ & Felip Sorrando & Miquel Llansola \\
\hline Vicent Figuerola & Miquel Llansola & Vicent Ferrer & Andreu Castellet \\
\hline Pere Figuerola & Gabriel Segarra de Josep & Tomàs March & Josep Albiol \\
\hline Josep Casalís & Pere Calbo & Joan Timor & Josep Rubert menor \\
\hline & Pere Navarro de Joan & Josep Amposta & Pere Museros de Vicent \\
\hline & Pere Segarra & Jaume Giner & Josep Avinent major \\
\hline & & Josep Casalís & \\
\hline
\end{tabular}

\begin{tabular}{|c|c|c|c|}
\hline \multicolumn{2}{|c|}{$1680-1681$} & \multicolumn{2}{|c|}{ 1681-1682 } \\
\hline Mano mayor & Mano menor & Mano mayor & Mano menor \\
\hline Batiste Jover & $\begin{array}{l}\text { Joan Museros de } \\
\text { Monserrat }\end{array}$ & Pere Giner de Vilarroig & Pere Roig de Jaume \\
\hline Pere Breva & Domingo Vilarroig & Josep Amposta & Andreu Ribalta \\
\hline Vicent Ferrer & Miquel Llansola & Vicent Tosquella & Pere Navarro de Joan \\
\hline Jaume Cases & Francesc Vilarroig & Ignacio Figuerola & Félix Vilarroig \\
\hline Martí Viciano & Gerony Castell & Pere Figuerola & Josep Albiol \\
\hline Joan Timor & Josep Albiol & Pere Breva & $\begin{array}{l}\text { Miquel Vilarroig de } \\
\text { Nicolau }\end{array}$ \\
\hline Felip Sorrando & Josep Rubert menor & Batiste Jover & Vicent Museros \\
\hline Pere Figuerola & $\begin{array}{l}\text { Miquel Pasqual de } \\
\text { Francesc }\end{array}$ & Tomàs March & Josep Vilarroig de Jaume \\
\hline Ignacio Figuerola & Pere Reboll & Martí Viciano & Gabriel Segarra \\
\hline Vicent Tosquella & Vicent Museros & Macià Compte & Miquel Català \\
\hline Francesc Andreu & Miquel Boix de Miquel & Vicent Ferrer & Josep Goterris \\
\hline Macià Compte & Gabriel Segarra de Josep & Josep Casalís & Pere Segarra \\
\hline Tomàs March & Andreu Castellet & Francesc Ferrer & Pere Reboll \\
\hline Miquel Sanchís & Jaume Viciano de Miquel & Dionís Aragonés & Miquel Boix de Miquel \\
\hline Josep Casalís & & Joan Timor & \\
\hline \multicolumn{2}{|c|}{$1682-1683$} & \multicolumn{2}{|c|}{$1683-1684$} \\
\hline Mano mayor & Mano menor & Mano mayor & Mano menor \\
\hline Francesc Andreu & Josep Rubert menor & Tomàs March & Miquel Català \\
\hline Jaume Cases & Francesc Vilarroig & Felip Sorrando & Josep Albiol \\
\hline Pere Figuerola & Félix Vilarroig & Miquel Bonet & Vicent Eiximeno \\
\hline
\end{tabular}


Vicent Ferrer

Batiste Jover

Martí Viciano

Joan Timor

Josep Amposta

Macià Compte

Vicent Tosquella

Pere Breva

Ignacio Figuerola

Dionís Aragonés

Vicent Figuerola

Pere Giner de Vilarroig
Andreu Castellet

Miquel Boix

Miquel Llansola

Josep Museros de Vicent

Miquel Pasqual de

Francesc

Jaume Viciano de Miquel

March Casalís

Pere Navarro de Jaume

Gabriel Segarra de Josep

Pere Roig de Jaume

Pere Calbo

\begin{tabular}{|l} 
Macià Compte \\
Josep Amposta \\
Batiste Jover \\
Vicent Tosquella \\
Pere Breva \\
\\
Vicent Ferrer \\
Martí Viciano \\
Miquel Sanchís \\
Pere Giner de Vilarroig \\
Dionís Aragonés \\
Felip Breva \\
Joan Timor
\end{tabular}

Miquel Navarro de Gaspar Miquel Boix de Miquel Jaume Viciano de Miquel

Pere Reboll

Gerony Castell

Pere Roig de Jaume

Gabriel Segarra

Josep Museros

Joan Museros de

Monserrat

Félix Vilarroig

Francesc Vilarroig

\begin{tabular}{|c|c|c|c|}
\hline \multicolumn{2}{|c|}{$1684-1685$} & \multicolumn{2}{|c|}{$1685-1686$} \\
\hline Mano mayor & Mano menor & Mano mayor & Mano menor \\
\hline Francesc Andreu & March Casalís & Tomàs March & $\begin{array}{l}\text { Jaume Viciano de } \\
\text { Miquel }\end{array}$ \\
\hline Ignacio Figuerola & Francesc Amiguet menor & Batiste Jover & Pere Roig de Jaume \\
\hline Pere Figuerola & Gabriel Segarra de Josep & Macià Compte & $\begin{array}{l}\text { Jaume Breva de } \\
\text { Vilarroig }\end{array}$ \\
\hline Vicent Ferrer & Francesc Vilarroig & Vicent Figuerola & March Casalís \\
\hline Vicent Tosquella & Josep Vilarroig de Jaume & Pasqual Avinent & Josep Museros de Vicent \\
\hline Josep Amposta & Pere Museros de Vicent & Jaume Giner & Vicent Pasqual de Miquel \\
\hline Pere Giner Vilarroig & Gerony Castell & Josep Amposta & Miquel Català de Pere \\
\hline Felip Sorrando & Josep Avinent menor & Miquel Bonet & $\begin{array}{l}\text { Joan Museros de } \\
\text { Monserrat }\end{array}$ \\
\hline Miquel Bonet & Andreu Castellet & Vicent Martí & Josep Albiol major \\
\hline Pere Breva & Vicent Eiximeno & Gaspar Rubert & Gerony Castell \\
\hline Martí Viciano & Domingo Vilarroig & Vicent Tosquella & Domingo Vilarroig \\
\hline Felip Breva & Pere Calbo & Martí Viciano & Miquel Boix de Miquel \\
\hline Dionís Aragonés & $\begin{array}{l}\text { Joan Museros de } \\
\text { Monserrat }\end{array}$ & Pere Museros & Pere Calbo \\
\hline Miquel Sanchís & $\begin{array}{l}\text { Miquel Vilarroig de } \\
\text { Nicolau }\end{array}$ & Pere Figuerola & Joan Vilarroig de Miquel \\
\hline Joan Timor & & Ignacio Figuerola & \\
\hline
\end{tabular}

\begin{tabular}{ll|ll}
\multicolumn{1}{c|}{ 1686-1687 } & \multicolumn{1}{c}{ 1687-1688 } \\
\hline Mano mayor & \multicolumn{1}{c}{ Mano menor } & \multicolumn{1}{c}{ Mano mayor } & \multicolumn{1}{c}{ Mano menor } \\
Cristòfol Vilar & Miquel Vilarroig de & Vicent Martí & \multicolumn{1}{c}{ Joan Museros de } \\
Pere Museros & Nicolau & Monserrat \\
Vicent Ferrer & Andreu Castellet & Francesc Mercer & Francesc Amiguet menor \\
Jaume Cases & Jaume Viciano de Miquel & Gaspar Rubert & Félix Vilarroig \\
Macià Compte & Jaume Breva de Vilarroig & Joan Safont & Josep Avinent menor \\
Miquel Bonet & Pere Roig de Jaume & Pere Museros & Andreu Ribalta \\
Batiste Jover & Josep Albiol major & Cristofol Vilar & Vicent Eiximeno \\
Vicent March & Vicent Eiximeno & Ignacio Figuerola & Miquel Boix de Miquel \\
Miquel Garcés & Vicent Pasqual de Miquel & Josep Llorens de Prima & Miquel Catalá de Pere \\
Josep Amposta & Gabriel Segarra de Josep & Jaume Cases & Francesc Vilarroig \\
Vicent Tosquella & Miquel Navarro de Gaspar & Miquel Garces & Miquel Avinent de Josep \\
Pasqual Avinent & Francesc Vilarroig & Tomàs March & Ignacio Breva \\
& Josep Vilarroig de Jaume & Macià Compte & Miquel Pascual de \\
Francesc Andreu & & & Francesc \\
Ignacio Figuerola & Pere Calbo & Vicent Llorens & Antoni Castell \\
Jaume Giner & March Casalís & Pere Breva & Josep Pasqual de Francesc \\
Gaspar Rubert & & Vicent Ferrer &
\end{tabular}

\begin{tabular}{ll|ll}
\multicolumn{2}{c|}{$1688-1689$} & \multicolumn{2}{c}{$1689-1690$} \\
\hline \multicolumn{1}{c}{ Mano mayor } & \multicolumn{1}{c}{ Mano menor } & \multicolumn{1}{c}{ Mano mayor } & \multicolumn{1}{c}{ Mano menor } \\
\hline Vicent Figuerola & Gerony Castell & Francesc Joan Cases & Josep Rubert \\
Pascual Avinent & Andreu Castellet & Macià Compte & Antoni Castell \\
Tomàs March & Miquel Vilarroig de & Vicent Ferrer & Jaime Viciano
\end{tabular}


Pere Breva

Batiste Jover

Miquel Garcés

Francesc Mercer

Joan Safont

Cristofol Vilar

Josep Amposta

Martí Viciano

Ignacio Figuerola

Josep Llorens de Prima
Nicolau

Miquel Navarro de Gaspar

Domingo Vilarroig

Josep Museros

Josep Avinent

Vicent Eiximeno

Jaume Viciano de Miquel

Josep Albiol major

Ignacio Breva

Miquel Llansola

Francesc Vilarroig

Gabriel Segarra de Josep
Vicent Martí

Ignacio Figuerola

Pere Figuerola notari

Pere Breva

Joan Safont

Pere Museros

Martí Viciano

Miquel Garcés

Cristofol Vilar

Josep Amposta

Gaspar Rubert

Jaume Giner
Vicent Pascual de Miquel

Miquel Llansola

Miquel Avinent

Miquel Vilarroig de

Nicolau

Gerony Castell

Félix de Vilarroig

Andreu Ribalta

Josep Albiol

Francesc Vilarroig

Pere Roig de Jaume

Pere Calbo

\begin{tabular}{ll|ll}
\multicolumn{1}{c|}{ 1690-1691 } & \multicolumn{1}{c}{ 1691-1692 } \\
\hline \multicolumn{1}{c}{ Mano mayor } & \multicolumn{1}{c}{ Mano menor } & \multicolumn{1}{c}{ Mano mayor } & \multicolumn{1}{c}{ Mano menor } \\
\hline Pascual Avinent & Francesc Amiguet & Vicent Figuerola & $\begin{array}{l}\text { Josep Avinent de } \\
\text { Baltazar } \\
\text { Miquel Bonet }\end{array}$ \\
& Josep Vilarroig de Jaime & Pere Figuerola & $\begin{array}{l}\text { Fosep Pal de } \\
\text { Francesc }\end{array}$ \\
Josep Amposta & Antoni Castell & Cristòfol Vilar & Josep Museros de Vicent \\
Francesc Mercer & Jaume Viciano de Miquel & Pere Breva & Ignacio Breva \\
Cristòfol Vilar & Gerony Castell & Pere Museros & Pere Calbo \\
Josep Llorens de Prima & Pere Calbo & Pascual Avinent & Miquel Boix de Miquel \\
Vicent Ferrer & Josep Museros de Vicent & Francesc Mercer & Domingo Vilarroig \\
Tomàs March & Andreu Ribalta & Martí Viciano & Antoni Castell \\
Miquel Garcés & Josep Albiol major & Joan Safont & Joan Museros de Joan \\
Vicent Martí & Ignacio Breva & Miquel Bonet & Joan Breva \\
Francesc Andreu & Domingo Vilarroig & Tomàs March & Miquel Llansola \\
Jaime Giner & Miquel Llansola & Miquel Garcés & Josep Albiol \\
Francesc Andreu Cases & Miquel Navarro de Gaspar & Vicent Llorens & Vicent Pascual de Miquel \\
Macià Compte & Francesc Vilarroig & Francesc Andreu & Gabriel Segarra de Josep \\
Pere Museros & \multicolumn{2}{l}{} &
\end{tabular}

\begin{tabular}{ll|ll}
\multicolumn{1}{c|}{ 1692-1693 } & \multicolumn{1}{c}{ 1693-1694 } \\
\hline \multicolumn{1}{c}{ Mano mayor } & \multicolumn{1}{c}{ Mano menor } & \multicolumn{1}{c}{ Mano mayor } & \multicolumn{1}{c}{ Mano menor } \\
\hline Tomàs March & March Casalís & Ignacio Figuerola & \multicolumn{1}{c}{ Domingo Vilarroig } \\
Josep Llorens & Pere Roig de Jaime & Pasqual Avinent & \multicolumn{1}{c}{ Andreu Castellet } \\
Miquel Bonet & Agostí Reboll & Josep Llorens & Viximeno \\
Pere Breva & Ignacio Breva \\
Martí Viciano & Joan Muserosquella & Miquel Pasqual de \\
& & Francesc Andreu & Francesc \\
Jaume Cases & Josep Vilarroig de Jaume & Jaume Giner & Josep Rubert \\
Cristòfol Vilar & Josep Rubert menor & Vicent Figuerola & Miquel Navarro de Gaspar \\
Miquel Garcés & Joan Breva & Miquel Bonet & March Casalís \\
Gaspar Rubert & Félix Vilarroig & Macià Compte & Gabriel Segarra de Josep \\
Josep Amposta & Pere Calbo & Josep Amposta & Gerony Castell \\
Joan Safont notari & Vicent Eiximeno & Francesc Joan Cases & Andreu Ribalta \\
Jaime Giner & Josep Avinent de Baltazar & Cristòfol Vilar & Josep Pasqual de Francesc \\
Pasqual Avinent & Miquel Català de Pere & Tomàs March & Jaume Viciano de Miquel \\
Francesc Mercer & Vicent Pasqual de Miquel & Miquel Garcés & Antoni Castell \\
Vicent Ferrer & & Pere Museros &
\end{tabular}

\begin{tabular}{ll|ll}
\multicolumn{1}{c|}{$1694-1695$} & \multicolumn{2}{c}{$1695-1696$} \\
\hline \multicolumn{1}{c}{ Mano mayor } & \multicolumn{1}{c}{ Mano menor } & \multicolumn{1}{c}{ Mano mayor } & \multicolumn{1}{c}{ Mano menor } \\
\hline $\begin{array}{l}\text { Batiste Jover } \\
\text { Gaspar Rubert }\end{array}$ & $\begin{array}{l}\text { Francesc Amiguet } \\
\text { Agusti Reboll }\end{array}$ & $\begin{array}{l}\text { Miquel Garcés } \\
\text { Josep Amposta }\end{array}$ & $\begin{array}{l}\text { Josep Rubert } \\
\text { Miquel Vilarroig de } \\
\text { Nicolau }\end{array}$ \\
Martí Viciano & Felip Vilarroig & Pasqual Avinent & Josep Castell de Anton \\
Cristòfol Vilar & Francesc Vilarroig & Jacint March & Joan Museros de Monserra \\
Jaume Cases & Jaume Viciano de Miquel & Vicent Figuerola & Miquel Navarro de Antoni \\
Francesc Andreu & Andreu Ribalta & Ignacio Figuerola & Josep Vilarroig de \\
Ignacio Figuerola & Jaume Breva de Vilarroig & Pere Breva & Francesc \\
& & & Joan Breva
\end{tabular}


Pasqual Avinent Tomàs March Miquel Bonet Pere Museros Joan Safont Macià Compte Vicent Figuerola Francesc Mercer
Miquel Pasqual

Pere Calbo

Miquel Llansola

Josep Vilarroig de Jaume

Miquel Navarro de Gaspar

Josep Pasqual de Francesc

Josep Avinent
Jaume Giner Joan Montañes Pere Mercer Pintor Aleixandre Martí Joan Safont Cristòfol Vilar Batiste Jover Jaume Cases
Vicent Pasqual de Miquel Josep Museros de Vicent

Pere Calbo

Pere Roig de Francesc

Jaume Catala

March Casalís

Miquel Llansola

Francesc Amiguet

\begin{tabular}{ll|ll}
\multicolumn{1}{c|}{ 1696-1697 } & \multicolumn{1}{c}{ 1697-1698 } \\
\hline \multicolumn{1}{c}{ Mano mayor } & \multicolumn{1}{c}{ Mano menor } & \multicolumn{1}{c}{ Mano mayor } & \multicolumn{1}{c}{ Manonor } \\
\hline Josep Museros & Andreu Ribalta & Jaume Giner & March Casalís \\
Pere Vidal & Andreu Castellet & Tomàs March & Joan Museros de Joan \\
Francesc Andreu & Francesc Amiguet & Pere Museros & Miquel Boix de Miquel \\
Ignacio Figuerola & Miquel Boix de Miquel & Josep Segarra & Miquel Avinent de Josep \\
Aleixandre Martí & Miquel Pasqual de & Pere Vidal & Josep Avinent de \\
& Francesc & Jacint March & Jalthazar \\
Batiste Jover & Joan Breva & Batiste Jover & Francesc Amiguet \\
Vicent Figuerola & Josep Avinent de Baltasar & Miquel Navarro de Gaspar \\
Joan Safont & Félix Vilarroig & Josep Amposta & Josep Castell de Antoni \\
Jaume Cases & Agusti Reboll & Vicent Figuerola & Josep Museros de Vicent \\
Cristòfol Vilar & Miquel Navarro de Antoni & Gaspar Rubert & Andreu Ribalta \\
Pere Breva & Jaume Català & Miquel Bonet & Josep Rubert de Josep \\
Gaspar Rubert & Francesc Vilarroig & Joan Safont & Domingo Vilarroig \\
Miquel Bonet & Josep Vilarroig & Josep Blasco & Miquel Pasqual de \\
Josep Segarra & Gerony Castell & Ignacio Figuerola & Francesc \\
Martí Viciano & & &
\end{tabular}

Martí Viciano

1698-1699

\begin{tabular}{|c|c|c|c|}
\hline \multicolumn{2}{|c|}{ 1698-1699 } & \multicolumn{2}{|c|}{ 1699-1700 } \\
\hline Mano mayor & Mano menor & Mano mayor & Mano menor \\
\hline Cristòfol Vilar & Francesc Vilarroig & Josep Segarra & Agustí Reboll \\
\hline Jaume Cases & $\begin{array}{l}\text { Josep Pasqual de } \\
\text { Francesc }\end{array}$ & Tomàs March & Vicent Figuerola \\
\hline Pere Museros & $\begin{array}{l}\text { Joan Museros de } \\
\text { Monserrat }\end{array}$ & Batiste Jover & March Casalís \\
\hline Joan Muntanyés & $\begin{array}{l}\text { Miquel Vilarroig de } \\
\text { Nicolau }\end{array}$ & Josep Amposta & Miquel Vilarroig \\
\hline Jaume Giner & Vicent Pasqual de Miquel & Joan Safont & Pere Roig \\
\hline Pere Vidal & Francesc Amiguet & Gaspar Rubert & Baltasar Avinent \\
\hline Ignacio Figuerola & Andreu Castellet & Jacint March & Miquel Navarro de Miquel \\
\hline Aleixandre Martí & Jaume Breva menor & Pere Mercer & Ignacio Breva \\
\hline Miquel Bonet & Miquel Navarro de Antoni & Pere Vidal & Josep Pasqual \\
\hline Gaspar Rubert & Josep Vilarroig de Jaume & Miquel Bonet & Josep Rubert \\
\hline Jacint March & Josep Rubert de Josep & Joan Montanyés & Francesc Vilarroig \\
\hline Martí Viciano & Josep Museros de Josep & Cristòfol Vilar & Josep Vilarroig \\
\hline Joan Safont & Josep Avinent de Baltazar & Jaume Giner & Domingo Vilarroig \\
\hline Josep Blasco & Miquel Boix & Martí Viciano & Miquel Navarro de Gaspar \\
\hline Batiste Jover & & Josep Blasco & \\
\hline \multicolumn{2}{|c|}{ 1700-1701 } & \multicolumn{2}{|c|}{ 1701-1702 } \\
\hline Mano mayor & Mano menor & Mano mayor & Mano menor \\
\hline Ignacio Figuerola & $\begin{array}{l}\text { Josep Museros de } \\
\text { Avinent }\end{array}$ & Josep Segarra & $\begin{array}{l}\text { Miquel Navarro de } \\
\text { Antoni }\end{array}$ \\
\hline Aleixandre Martí & Miquel Navarro de Gaspar & Jacint March & Tomàs Breva \\
\hline Pere Mercer & Francesc Vilarroig & Gaspar Rubert & Josep Pasqual de Francesc \\
\hline Joan Andreu & Josep Castell de Gerony & Pere Breva & $\begin{array}{l}\text { Miquel Pasqual de } \\
\text { Miquel }\end{array}$ \\
\hline Francesc Andreu & $\begin{array}{l}\text { Vicent Figuerola de } \\
\text { Francesc }\end{array}$ & Joan Andreu & Vicent Figuerola \\
\hline Tomàs March & Antoni Castell & Jaume Giner & Baltazar Avinent \\
\hline Joan Montanyés & Tomàs Blasco & Josep Blasco & March Casalís \\
\hline Martí Viciano & Josep Pasqual de Francesc & Vicent Anglés & Joan Breva \\
\hline Pere Museros & Miquel Pasqual de Miquel & Martí Viciano & Miquel Avinent \\
\hline Félix Roig & Miquel Vilarroig & Miquel Bonet & Andreu Ribalta \\
\hline Batiste Jover & Jaume Breva de Jaume & Cristòfol Vilar & Francesc Amiguet \\
\hline Cristòfol Vilar & March Casalís & Josep Llorens de Clavell & Miquel Vilarroig de \\
\hline
\end{tabular}


Vicent Anglès

Josep Amposta

Jaume Giner
Josep Vilarroig de Josep

Félix Tirado
Aleixandre Martí

Pere Museros

Joan Safont
Nicolau

Agusti Reboll

Andreu Castellet

\begin{tabular}{ll|ll}
\multicolumn{1}{c|}{ Mano mayor } & \multicolumn{1}{c}{ Mano menor } & \multicolumn{1}{c}{ Mano mayor } & Mano menor \\
\hline Tomàs March & $\begin{array}{l}\text { Joan Museros de } \\
\text { Monserrat }\end{array}$ & Miquel Bonet & Joan Breva notari \\
Josep Amposta & Josep Castell de Antoni & Joan Sanchís & Tomàs Blasco notari \\
Batiste Jover & Josep Vilarroig de Jaume & Joan Safont & Jaume Breva de Jaume \\
Joan Andreu & Miquel Navarro de Gaspar & Jaume Giner & Antoni Castell \\
Jaume Giner & Ignacio Breva & Severino Museros & Pere Museros de Pere \\
Gaspar Rubert & Pere Museros de Pere & Ignacio Figuerola & Pere Roig de Jaume \\
Pere Breva & Francesc Amiguet & Francesc Andreu & Félix Vilarroig \\
Severino Museros & Félix Vilarroig & Jacint March & Josep Museros de Vicent \\
Josep Blasco & Miquel Vilarroig de & Josep Segarra & Andreu Castellet \\
Jaume Pasqual & Nicolau & Josep Llorens de Clavell & Vicent Figuerola de \\
Josep Llopis & Josep Museros de Vicent & & Francesc \\
Pere Mercer & Josep Avinent Balthazar & Aleixandre Martí & Josep Vilarroig de Josep \\
Ignacio Figuerola & Vicent Figuerola de & Pau Mercer & Josep Pasqual de Francesc \\
Vicent Tosquella & Francesc & Pere Breva & Josep Avinent de Baltazar \\
Francesc Andreu & Josep Pasqual de Francesc & Jaume Pasqual & Andréu Ribalta \\
& Gosep Rubert & &
\end{tabular}

Francesc Andreu

1704-1705

\begin{tabular}{|c|c|c|c|}
\hline \multicolumn{2}{|c|}{ 1704-1705 } & \multicolumn{2}{|c|}{ 1705-1706 } \\
\hline Mano mayor & Mano menor & Mano mayor & Mano menor \\
\hline Vicent Tosquella & Baltazar Avinent & Jaume Giner & $\begin{array}{l}\text { Miquel Navarro de } \\
\text { Gaspar }\end{array}$ \\
\hline Tomàs March & Josep Castell de Gerony & Batiste Jover & $\begin{array}{l}\text { Jaume Breva de } \\
\text { Vilarroig }\end{array}$ \\
\hline Josep Llopis & Josep Castell de Antoni & Severino Museros & Miquel Navarro de Antoni \\
\hline Josep Segarra & Miquel Avinent & Vicent Tosquella & Josep Pasqual de Francesc \\
\hline Félix Breva & Josep Vilarroig de Josep & Félix Roig & $\begin{array}{l}\text { Vicent Figuerola de } \\
\text { Francesc }\end{array}$ \\
\hline Pere Vidal & Jaume Breva de Jaume & Josep Llorens de Clavell & Josep Vilarroig Josep \\
\hline Pere Mercer & Miquel Pasqual de Miquel & Joan Safont & Pere Museros de Pere \\
\hline Félix Roig & $\begin{array}{l}\text { Miquel Vilarroig de } \\
\text { Nicolau }\end{array}$ & Pere Vidal & Josep Museros de Vicent \\
\hline Gaspar Rubert & Andreu Castellet & Josep Llopis & Andreu Castellet \\
\hline Pere Breva & Pere Museros de Pere & Miquel Bonet & Domingo Vilarroig \\
\hline Joan Safont & $\begin{array}{l}\text { Joan Museros de } \\
\text { Monserrat }\end{array}$ & Josep Segarra & Agostí Reboll \\
\hline Francesc Andreu & Agostí Reboll & Gaspar Rubert & $\begin{array}{l}\text { Miquel Pasqual de } \\
\text { Francesc }\end{array}$ \\
\hline Jacint March & Félix Vilarroig & Josep Amposta & Miquel Avinent \\
\hline Joan Andreu & Josep Museros de Vicent & Ignacio Figuerola & Tomàs Blasco \\
\hline Pere Museros & & Pere Mercer & \\
\hline \multicolumn{2}{|c|}{ 1706-1707 } & \multicolumn{2}{|c|}{ 1707-1708 } \\
\hline Mano mayor & Mano menor & Mano mayor & Mano menor \\
\hline Francisco Andreu & Tomàs Breva & Miquel Bonet & March Casalís \\
\hline Jaume Pasqual & Joan Museros de Joan & Batiste Jover & Josep Castell de Antoni \\
\hline Pere Breva & Vicent Pasqual de Miquel & Doctor Félix Roig & Miquel Pasqual de Miquel \\
\hline Joan Andreu & Pere Museros de Pere & Joan Safont & Ignacio Breva \\
\hline Josep Llopis & Félix Vilarroig & Josep Llopis & Félix Tirado \\
\hline Ignacio Figuerola & Josep Avinent de Baltazar & Aleixandre Martí & Miquel Navarro de Gaspar \\
\hline Pere Museros & Josep Vilarroig de Josep & Josep Segarra & Andreu Ribalta \\
\hline Josep Amposta & $\begin{array}{l}\text { Miquel Vilarroig de } \\
\text { Nicolau }\end{array}$ & Josep Amposta & Baltazar Avinent \\
\hline Gaspar Rubert & Josep Rubert & Pere Vidal & Josep Castell de Gerony \\
\hline Felip Breva & Josep Castellet de Gerony & Joan Andreu & $\begin{array}{l}\text { Miquel Vilarroig de } \\
\text { Nicolau }\end{array}$ \\
\hline Vicent Tosquella & Tomàs Blasco & Vicent Anglés & Pere Museros \\
\hline Josep Segarra & Miquel Avinent & Vicent Tosquella & Josep Vilarroig de Josep \\
\hline
\end{tabular}


Félix Roig

Josep Llorens de Planell Jacint March
Miquel Navarro de Antoni Félix Tirado

\section{Felip Breva}

Josep Llorens de Clavell

Pere Breva
Josep Rubert major

Josep Pasqual de Francesc

Elaboración propia ${ }^{78}$.

Ilustración 3: Escudo del Consell de Castellón:

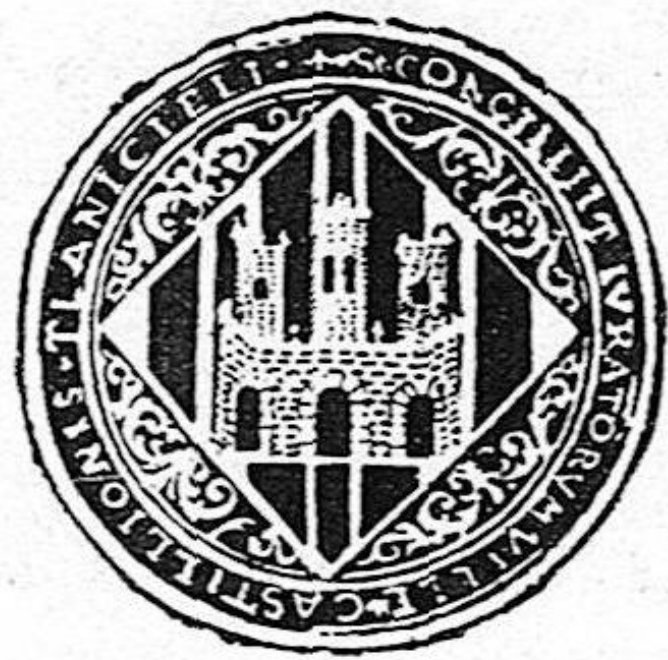

En la imagen podemos observar el sello del Consell en el siglo XVII. Imagen extraída del libro de Vicente Traver Tomas: "Antigüedades de Castellón de la Plana"79.

Una vez mostrados quiénes fueron los consejeros de mano mayor y de mano menor aportamos la tabla con los consejeros militares:

Tabla 3: Consejeros militares en la ciudad de Castellón entre 1597 y $1707^{\mathbf{8 0}}$ :

\begin{tabular}{|c|c|c|}
\hline Año & Consejero & Consejero \\
\hline $\mathbf{1 5 9 7}$ & Gerony Miquel /Pere Miquel & Pere Reus /Nicolau Reus \\
$\mathbf{1 5 9 8}$ & Pere Reus & Pere Miquel \\
$\mathbf{1 5 9 9}$ & Gerony Miquel & Cristòfol Miralles \\
$\mathbf{1 6 0 0}$ & Pere Miquel & Cristòfol Miralles \\
$\mathbf{1 6 0 1}$ & Pere Miquel & Pere Reus \\
$\mathbf{1 6 0 2}$ & & \\
$\mathbf{1 6 0 3}$ & & \\
$\mathbf{1 6 0 4}$ & Cristòfol Miralles & Nicolau Reus \\
$\mathbf{1 6 0 5}$ & Mateu Ros & Gerony Miquel \\
$\mathbf{1 6 0 6}$ & Nicolau Reus & Pere Morales \\
$\mathbf{1 6 0 7}$ & Pere Miquel & Nicolau Reus \\
$\mathbf{1 6 0 8}$ & Nicolau Reus & Pere Miquel \\
$\mathbf{1 6 0 9}$ & Pere Miquel & Gerony Arrufat \\
$\mathbf{1 6 1 0}$ & Nicolau Reus & Pere Morales \\
\hline
\end{tabular}

\footnotetext{
${ }^{78}$ En negrita se señalan los consejeros que entran en el Consell por su cargo en el ejercicio anterior. Además, en este caso no se realiza una valoración en cifras puesto que no es nuestro objetivo repetir los argumentos. Dedicaremos un apartado posterior a explicar el peso individual de las personas en el Consell.

${ }^{79}$ Través Tomás, V. (1982): Antigüedades... op. cit. pp.16.

${ }^{80}$ AHMC. Los datos se han obtenido de las reuniones del Consell de Castellón reflejadas en el Judiciari entre 1597 y 1707.
} 


\begin{tabular}{|c|c|c|}
\hline Año & Consejero & Consejero \\
\hline 1611 & Nicolau Reus & Gerony Arrufat \\
\hline 1612 & Gerony Arrufat & Joan Arrufat \\
\hline 1613 & Nicolau Reus & Gerony Arrufat \\
\hline 1614 & Pere Morales & Pere Miquel \\
\hline 1615 & Joan Arrufat & Pere Miquel \\
\hline 1616 & Joan Arrufat & Gerony Arrufat \\
\hline 1617 & & Mateu Ros \\
\hline 1618 & & \\
\hline 1619 & & \\
\hline 1620 & Nicolau Reus & Pere Miquel \\
\hline 1621 & Nicolau Reus & Mateu Ros \\
\hline 1622 & Mateu Ros & Pere Morales \\
\hline 1623 & Mateu Ros & Pere Morales \\
\hline 1624 & Mateu Ros & Pere Morales \\
\hline 1625 & Pere Arrufat & Mateu Ros menor \\
\hline 1626 & Pere Morales & Pere Arrufat \\
\hline 1627 & Mateu Ros & Gerony Arrufat \\
\hline 1628 & Gerony Arrufat & Mateu Ros menor \\
\hline 1629 & Pere Morales & Joan Arrufat \\
\hline 1630 & Mateu Ros & Pere Reus \\
\hline 1631 & Gerony Arrufat & Pere Reus \\
\hline 1632 & Pere Morales & Pere Reus \\
\hline 1633 & Pere Morales & Gerony Arrufat \\
\hline 1634 & Pere Reus & Cristòfol Sisternés \\
\hline 1635 & Pere Miquel & Nicolau Reus \\
\hline 1636 & Jaume Miquel & Francesc Sisternés \\
\hline 1637 & Cristòfol Sisternés & Pere Morales \\
\hline 1638 & Cristòfol Sisternés & Gerony Arrufat \\
\hline 1639 & Cristòfol Sisternés & Gerony Arrufat \\
\hline 1640 & Pere Reus & Francesc Sisternés \\
\hline 1641 & Cristòfol Sisternés & Pere Reus \\
\hline 1642 & Gerony Arrufat & Pere Reus \\
\hline 1643 & Joan Ros & Gerony Arrufat \\
\hline 1644 & Cristòfol Sisternés & Pere Reus \\
\hline 1645 & Joan Ros & Pere Reus \\
\hline 1646 & Gerony Arrufat & Cristòfol Sisternés \\
\hline 1647 & Pere Reus & Francesc Bou \\
\hline 1648 & Nicolau Serra & Francesc Sisternés \\
\hline 1649 & Cristòfol Sisternés & Francesc Bou \\
\hline 1650 & Francesc Bou & Pere Giner de Bou \\
\hline 1651 & Francesc Bou & Pere Giner de Bou \\
\hline 1652 & Pere Giner de Bou & Francesc Bou \\
\hline 1653 & Pere Giner de Bou & \\
\hline 1654 & Francesc Bou & Pere Giner de Bou \\
\hline 1655 & Joan Castell & Basilio Reus \\
\hline 1656 & March Antoni Jordà & Pere Giner de Bou \\
\hline 1657 & Gerony Mas & Joan Ros \\
\hline 1658 & Francesc Bou & Joan Ros \\
\hline 1659 & Andreu Jordà & Gerony Mas \\
\hline 1660 & Joan Castell & Joan Ros \\
\hline 1661 & Pere Serra & Felip Sisternés \\
\hline 1662 & Joan Castell & Martí Mas \\
\hline 1663 & Felip Jover & Joan Ros \\
\hline 1664 & Narcís Feliu & Basilio Reus \\
\hline 1665 & Miquel Vallés & Gerony Mas \\
\hline 1666 & Basilio Reus & Martí Mas \\
\hline 1667 & Fernando Miralles & Felip Sisternés \\
\hline 1668 & Carlos Jover & Josep Igual \\
\hline 1669 & Felip Sisternés & Felip Jover \\
\hline
\end{tabular}




\begin{tabular}{|c|c|c|}
\hline Año & Consejero & Consejero \\
\hline 1670 & Joan Ros de Ursins & Josep Igual \\
\hline 1671 & Josep Feliu & Miquel Vallés \\
\hline 1672 & Miquel Vallés & Felip Sisternés \\
\hline 1673 & Josep Igual & March Antoni Jordà \\
\hline 1674 & Joan Ros de Ursins & Basilio Reus \\
\hline 1675 & Felip Sisternés & March Antoni Jordà \\
\hline 1676 & Gerony Mas & Carlos Jover \\
\hline 1677 & Joan Castell & Macià Igual \\
\hline 1678 & Carlos Jover & Cristòfol Castell \\
\hline 1679 & Cristòfol Castell & Basilio Reus \\
\hline 1680 & Josep Igual & Basilio Reus \\
\hline 1681 & March Antoni Jordà & Carlos Jover \\
\hline 1682 & Pere Serra i Dols & March Antoni Jordà \\
\hline 1683 & March Antoni Jordà & Felip Mas \\
\hline 1684 & Basilio Reus & Jaume Vallés \\
\hline 1685 & Jaume Vallés & Josep Igual \\
\hline 1686 & Joachim Gombau & Baltazar Ripoll \\
\hline 1687 & Josep Castell de Museros & Cristòfol Castell \\
\hline 1688 & Basilio Reus & Jaume Vallés \\
\hline 1689 & March Antoni Jordà & Gerony Vallés \\
\hline 1690 & Fernando Miralles & Jaume Vallés \\
\hline 1691 & Josep Castell de Museros & Gerony Vallés \\
\hline 1692 & March Antoni Jordà & Martí Mas \\
\hline 1693 & Jaume Vallés & Fernando Miralles \\
\hline 1694 & Josep Igual & Martí Mas \\
\hline 1695 & Martí Mas & Gerony Bou de Monsonís \\
\hline 1696 & Josep Igual & Josep Castell de Romeu \\
\hline 1697 & Joachim Gombau & Martí Igual \\
\hline 1698 & Gerony Bou de Monsonís & Gerony Vallés \\
\hline 1699 & Fernando Miralles & Gerony Vallés \\
\hline 1700 & Joachim Gombau & Macià Igual \\
\hline 1701 & Gerony Vallés & Gerony Bou de Monsonís \\
\hline 1702 & Cosme Feliu i Pastor & Gerony Bou de Monsonís \\
\hline 1703 & Martí Mas & Gerony Vallés \\
\hline 1704 & Josep Castell de Museros & Martí Mas \\
\hline 1705 & Cosme Feliu & Martí Mas \\
\hline 1706 & Fernando Miralles & Macià Igual \\
\hline 1707 & Gerony Vallés & Macià Igual \\
\hline 1708 & & \\
\hline
\end{tabular}

Hemos de hacer ciertas matizaciones para entender los datos. En noviembre de 1597 son sustituidos Gerony Miquel y Pere Reus por Pere Miquel y Nicolau Reus. El motivo de dicho cambio no está especificado. En 1617 no tengo un consejero militar porque no hay datos, y he podido suponer el otro porque era el justicia del año anterior. Esa suposición sería correcta siempre y cuando no haya sido declarado no hábil. En 1653 solamente hay un consejero del brazo militar porque solo hay cuatro más en bolsa, de ellos tres son impedidos y el otro es el justicia.

\footnotetext{
${ }^{81}$ En negrita los consejeros que son elegidos por haber ocupado un cargo el año anterior y dejamos en blanco los años que no poseemos datos.
} 
Si analizamos qué personas repitieron más veces en el cargo podemos observar como Gerony Arrufat y Pere Reus ocuparon el cargo en catorce ocasiones. A continuación se sitúa Pere Morales con trece veces y le sigue Nicolau Reus y Pere Miquel con once. Es muy importante reseñar como la mayoría de estas veces la encontramos en la primera mitad del siglo XVII, ya que después hay una tendencia a qué no esté tan concentrado.

A continuación realizamos una explicación del funcionamiento del Consell en todos los años estudiados, es decir si estuvo compuesto por los quince consejeros de mano mayor, los catorce de mano menor, los dos consejeros militares y el justicia y los cuatro jurados del año en cuestión. Debemos dejar claro que el justicia, jurados, almotacén, síndico del Consell y escribano del año anterior entraban a formar parte de él por oficio.

Los años 1597, 1603, 1612, 1617, 1618 y 1619 no hemos podido obtener datos puesto que no existe el Judiciari o está muy dañado y no se puede extraer ninguna conclusión. En los años 1604, 1606, 1609, 1610, 1611, 1615, 1620, 1621, 1622, 1630, 1632, 1633, 1634, 1635, 1640, 1642, 1643, 1644, 1646, 1647, 1648, 1655, 1656, 1657, 1661, 1667, 1669, 1670, 1672, 1681, 1684, 1691, 1693, 1697, 1699, 1700, 1703 у 1704 el Consell está compuesto por treinta y seis miembros y dentro de los consejeros están los oficios del año anterior. Sin embargo, está composición no se cumple siempe y ahora vamos a detallar los años en los que hay alteraciones y sus motivos.

En 1598 no es elegido como consejero militar Cristòfol Miralles que era el justicia anterior porque es nombrado jurado primero. En 1599 no se explica el motivo de porque se elige un consejero más de mano mayor. En 1600 y 1602 no hay explicación de la causa de elegir un consejero menos de mano menor. En 1601 Antoni Pedro era jurado anterior pero no entra en el Consell por su fallecimiento. En 1605 no podemos saber si el almotacén del año anterior ha entrado en el órgano decisorio del Castellón del seiscientos puesto que no sabemos quién fue. En 1607 no tenemos nombramiento por tanto no sabemos el motivo que justifica los catorce consejeros de mano mayor y dieciséis de mano menor. No es elegido consejero el almotacén anterior Gerony Jover pero no especifica ningún motivo. En 1608 no sale elegido como consejero Jaume Giner justicia anterior ya que es el escribano de ese año. No tenemos el nombramiento del año anterior del almotacén por lo que no sabemos si entra por oficio. En 1613 destacamos que Joan Batiste Vallés es nombrado miembro del Consell y en septiembre es elegido almotacén. En 1614 se cita expresamente como son consejeros 
por oficio Cosme Martí, Pere March y Francesc Jover. Sin embargo, no se cita que Tomàs Moliner sea consejero por su cargo anterior de jurado segundo, aunque después si que es elegido como miembro del Consell. Asimismo, el almotacén anterior Gerony Arrufat no es elegido como consejero militar por su oficio anterior y no especifica el motivo. Además los consejeros militares Pere Miquel y Mateu Ros son inhabilitados, el primero por ser señor de molino y el segundo por ser deudor de la villa. Se vuelve a repetir el caso anterior, Francesc Jover que ha sido elegido consejero en mayo es nombrado en septiembre almotacén. En 1616 no se incorpora al Consell el justicia anterior Bernat Gascó como consejero puesto que es impedido en votaciones de habas blancas y negras. En 1623 el síndico anterior Bertomeu Giner no es elegido consejero porque lo es su suegro Miquel Giner y entonces es inhabilitado por parentesco familiar, pero aún así esta decisión se toma con las habas blancas y negras. El jurado anterior Miquel Sanchís tampoco es elegido consejero y no explica el motivo pero probablemente hay que buscarlo en la elección de Mateu Sanchís como miembro del Consell, y por razones familiares inhabilita al otro. En 1624 Antoni Joan Lleó no es elegido consejero pese a que fue el justicia ya que es inhabilitado por ser deudor de su majestad. Son elegidos cuatro consejeros menos de mano menor porque no hay suficientes en la bolsa ya que algunos han sido declarados no hábiles con las habas blancas y negras. En 1625 no es elegido consejero Francesc Joan Bou que ejerce como escribano solo dos años, por lo que todo nos parece indicar que ha fallecido. En 1626 queda muy claro como en mano menor solo son elegidas dos personas de los oficios y doce del resto y además el justicia anterior Dionís Jover no es elegido consejero porque esta impedido. En 1627 no especifica el motivo de que sean solo catorce de mano mayor. En esta elección son declarados no hábiles Andreu Duenyes sastre y Pere Lleonart espardenyer por tener pleito pendiente con la Real Audiencia de Valencia, por lo que no es elegido ningún oficio. En 1628 no es elegido consejero Joan Arrufat porque es justicia del año corriente. En 1629 se produce una elección un poco algo confusa ya que ocurren varias cosas no habituales. No es elegido el almotacén anterior Melchor Salvador sin que se especifique motivo. Se elige un consejero más de mano mayor y uno menos de mano menor, pero no directamente si no que nos hemos dado cuenta cuando hemos comprobado las reuniones posteriores del Consell y aparecía Dionís Jover que no había sido elegido en mayo. Además en mano mayor no se cita a Miquel Bonaventura ni a Nicolau Figuerola como parte de los consejeros de mano mayor sino que los podemos ver después en las reuniones del Consell. Esto mismo ocurre con el 
consejero de mano menor Joan Bosch. No es elegido consejero Gerony Quevedo por su fallecimiento. Destacar como se declara inhábil a Antoni Ribes por haber sido dos años consejero. En 1636 Jaume Miquel es justicia anterior pero no entra como consejero por tener un pleito en la Real Audiencia de Valencia. En 1637 no es elegido consejero el almotacén anterior Martí Castell pero no sabemos el motivo. Además no es elegido el justicia anterior Pere Giner como consejero porque es el escribano. En 1638 no es elegido consejero el jurado anterior Pere Eximeno por su fallecimiento. En 1639 Francesc Vilarroig es consejero y acequiero en este año. En 1641 Nicolau Serra no es elegido consejero pese a que es almotacén anterior y no se especifica el motivo en el Judiciari. En 1645 hay un consejero menos de mano menor pero no específica el motivo. No ha sido elegido consejero ni el jurado primero anterior Francesc Josep Bou que está impedido, ni Batiste Moliner almotacén anterior pero no hemos podido averiguar la causa ya que no la cita. En 1649 no es elegido consejero el almotacén anterior Batiste Jover por ser capitán de la leva corriente. En 1650 no es elegido el almotacén anterior Berenguer Ribalta. Como no tenemos el nombramiento no podemos averiguar las causas. En 1651 se deja muy claro que son quince puestos de mano mayor y catorce de mano menor por lo que la pretendida ampliación de 1634 no es cierta. En 1652 el almotacén anterior Josep Alberich no es elegido consejero porque es jurado. En 1653 solo hay diez consejeros de mano mayor porque el resto de las personas de la bolsa están impedidas. El almotacén anterior Vicent Martí no es elegido consejero porque es elegido escribano. En 1654 solo hay doce consejeros de mano mayor porque no hay más personas hábiles en la bolsa. En 1658 hay un consejero menos de mano menor porque no hay personas hábiles. Gaspar Martí jurado anterior no es elegido consejero porque se le declara inhabilitado por su avanzada edad y no desempeñar bien su cargo. Es importante citar como en mano menor se dice que se quiere elegir quince consejeros pero solo se citan en la elección catorce cargos y se deja un espacio en blanco para nombrar otro consejero. Sin embargo, en el margen donde se citan todos los elegidos solo hay catorce. Además revisando todas las reuniones del Consell posteriores no aparece ninguno nuevo. En 1659 al estar muy dañado no podemos averiguar cual es el motivo por lo el que no es elegido consejero militar el almotacén anterior Pere Giner, aunque es muy probable que por su muerte. En 1662 hay un consejero menos de mano menor. No es elegido consejero el almotacén anterior Vicent Museros por ser clavario. En 1663 no es elegido consejero el justicia anterior Joan Andreu porque es elegido jurado y se específica claramente que todos los consejeros de mano menor son 
labradores. En 1664 no es elegido consejero militar el almotacén anterior don Fernando Miralles y no tenemos ninguna explicación. En 1665 no es elegido consejero el jurado anterior Batiste Orts por haber fallecido. En 1666 el justicia anterior Melchor Amiguet no es elegido consejero por su fallecimiento. En 1668 no es elegido consejero militar el almotacén anterior don Fernando Miralles ya que además era consejero militar del año anterior por lo que repetiría. En 1671 no es elegido consejero el almotacén anterior Jaume Cases porque es el escribano de ese año. En 1673 no es elegido consejero el justicia anterior Josep Alberich porque falleció y fue sustituido en noviembre por Vicent Martí que si que es elegido consejero. Gaspar Brunell almotacén anterior ha fallecido por lo que no es elegido consejero. En 1674 solo hay once consejeros en mano menor porque no hay más hábiles en la bolsa. No es elegido Tomàs Capero jurado anterior por su fallecimiento. En 1675 no es elegido consejero Cosme Martí que era el almotacén anterior porque pasa a ocupar el cargo de baile. Como en mano mayor hay muy pocos se habilitan aunque no lo eran a Vicent Pasqual, Miquel Sanchís y Dionís Aragonés. Se realiza la extracción en noviembre por el pleito que tiene Miquel Bonet y que obligó a suspender la extracción en mayo. En 1676 solo hay doce consejeros de mano mayor por no haber más personas hábiles. No son elegidos consejeros ni el justicia anterior Vicent Martí por su fallecimiento, ni el síndico anterior Francesc Mercer por no haber pagado sus deudas de su ejercicio de la sindicatura. En mayo solo se cambian jurados. En enero de 1677 por el pleito de Miquel Bonet se hace la extracción de acequiero, jurado de la bolsa segunda de los artistas, consejeros militares y consejeros de mano mayor y menor. Vicent Figuerola, Pere Segarra y Miquel Vilarroig de Castell son los jurados primero, tercero y cuarto respectivamente extraídos en mayo 1676. En 1677 solo hay once consejeros de mano mayor ya que no hay más hábiles y no es elegido consejero militar el justicia anterior Francesc Bou ya que es jubilado para todos los cargos. Tampoco es elegido consejero el jurado anterior Vicent Figuerola por estar impedido por ejercer el cargo de jurado dos años consecutivos. En 1678 solo hay doce consejeros de mano mayor porque no hay más hábiles. En 1679 no es elegido consejero el justicia anterior Joan Museros de Monserrat porque es elegido jurado. En 1680 Macià Igual es almotacén anterior y no es elegido consejero militar y no explica ningún motivo pero podría ser porque el justicia anterior es Josep Igual y es familiar de Macià Igual. En 1682 no es elegido consejero Felipe Sorrando justicia anterior porque es jurado. En 1683 no es elegido consejero militar Macià Igual pese a que es el justicia anterior porque esta ausente de la villa. En 1685 se celebra la extracción en agosto por el pleito a 
la Real Audiencia de Valencia. En 1686 es elegido Gaspar Rubert síndico que no es consejero, por lo que hay un consejero más. En 1687 el justicia anterior Felip Sorrando no es elegido consejero porque ya ha ocupado el cargo dos años consecutivos. En 1688 solo hay trece consejeros de mano mayor porque no hay más personas hábiles. No es elegido consejero March Antoni Jordà ya que es jurado primero. En 1689 por oficio deben ser elegidos consejeros tanto Jaume Cases justicia anterior como su hermano Francesc Joan Cases por ser jurado, pero como eso no lo permiten las ordenaciones se decide votar con habas blancas y negras y el resultado es que este último es el que debe ser elegido por oficio. En 1690 no es elegido consejero el jurado anterior Batiste Jover y no específica ningún motivo. En 1692 no es elegido consejero Vicent Martí jurado anterior, por estar impedido. La elección de jurado segundo y escribano no se realiza junto a las demás por pleito en la Real Audiencia lo cual hace que tanto Macià Compte jurado como el escribano viejo Vicent Tosquella no sean elegidos consejeros. La sustitución de estos se realiza el 6 de junio de 1692. En 1694 no es elegido consejero el almotacén viejo Miguel Garcés porque es jurado. En 1695 el síndico Francesc Amiguet no es elegido entre los consejeros por lo que hay uno más de mano mayor. En 1696 no es elegido consejero Tomàs March justicia anterior porque es jurado. En 1698 no es elegido consejero el escribano viejo Macià Compte por su fallecimiento pero si que lo es el escribano que lo sustituye hasta la elección, Pere Museros. No es elegido consejero militar el justicia anterior Josep Igual, puesto que fallece en noviembre de 1697 y es sustituido por Gerony Bou que si es elegido consejero militar. El almotacén anterior Pere Breva es el nuevo escribano por lo que no es elegido como consejero. En 1701 no es elegido consejero el almotacén anterior Josep Amposta porque es jurado. En 1702 no es elegido consejero el síndico anterior Vicent Anglés por estar impedido por ser Gobernador de Nules. En 1705 no es elegido consejero el almotacén anterior Felip Breva por ser sacristà de la llumenaria. En 1706 no es elegido consejero el justicia anterior March Casalís labrador, porque es jurado. En 1707 el almotacén anterior Gaspar Rubert no es elegido consejero porque es jurado. El justicia anterior Tomàs March no es elegido consejero porque es jurado primero. 


\subsubsection{Justicia.}

Es el encargado de presidir el Consell de Castellón y es elegido por el sistema insaculatorio alrededor del 22 de diciembre a partir de la Ordinación de Covarrubias de $1590^{82}$

Tradicionalmente se daba por sentado en el procedimiento de elección de cargos de la villa de Castellón, la alternancia anual entre el brazo militar y real para los oficios de justicia, jurado primero y almotacén. De esta forma, reproduciendo las palabras de Arroyas Serrano $^{83}$ :”... La elección del oficio se hacía el 22 de Diciembre, desde 1590 por el sistema de insaculación entre los hábiles de la bolsa correspondiente, alternándose anualmente la bolsa de caballeros y generosos con la del brazo real...". Esta afirmación no es del todo cierta ya que en la Ordinación de Covarrubias hace referencia en el capítulo titulado "any de militars" 84 al fuero veintiocho de "curia et Baiulo in novis" sobre el nombramiento de justicias en la ciudad de Valencia y se puede leer lo siguiente:

“... E les villes majors del regne, çó és Xàtiva, Morverdre, Algezira, Castelló e Burriana, la I any sia justitia cavaller o generós, e l'altre I prohom de la vila, si hi seran atrobats VI cavallers o generosos suffitiens al dit ofici; e l'any que serà justitia lo prohom de la vila, que hi haja I jurat cavaller o generós; e cascun any hi haya II consellers cavallers o generosos. E si no i seran atrobats sinó V, IIII o III cavallers o generosos sufficients al dit offici de justicia, que hi sia elet la I d'aquells de IIII en IIII anys; e si no i seran atrobats sinó dos sufficients al dit offici, la I d'aquells sia justitia de VI en VI anys. Emperò, tota hora hi haja II consellers generosos, si atrobats hi seran; e en cas que no i sien atrobats sinó V, IIII, III, o II generosos sufficients al dit offici de justitia, l'any següent, aprés que serà estat justítia lo cavaller o generòs, sia jurat o generós.

E açò mateix sia entès en les altres viles on haurà compliment de generosos II en II.

\footnotetext{
82 AHMC. Judiciari. 1620-1623. Se adjunta en el documento 8 del apéndice la transcripción de la elección de justicia y asesor de justicia de 22 de diciembre de 1622.

${ }^{83}$ Arroyas Serrano, M. (1989): El Consell ...op. cit., pp.106.

${ }^{84}$ Bernabé Gil, D. (2012): Privilegios...op. cit., pp. 233. Véase en el documento 2 del apéndice la Ordinación de Covarrubias.
} 
Semblantment sia servat del mostaçaf, ço és que, si i seran trobats VI cavallers o generosos homens suffitiens al dit offici de mostaçaf, que sia I any mostaçaf cavaller o generós e l'altre prohom de la vila. E si i seran trobats V, IIII o III sufficients al dit offici, que sia elet en mostaçaf cavaller o generós de IIII en IIII anys. E si seran II suffitiens al dit offici, sia hi elet cavaller o generós de VI en VI anys. Així, emperò: que aquell cavaller o generòs qui haurà tengut alcun offici dels dessús dits en cas que n’hi haja VI o més, no puxa ésser elet en aquell offici dels dessús dits que haurà tengut per II anys següents...” 85 .

Como se puede observar el texto deja muy claro que la alternancia en los oficios de justicia y almotacén será anual siempre y cuando existan suficientes personas en la bolsa militar, tal como cita Bernabé Gil ${ }^{86}$, aclarando que será cada seis años si hay dos y cada cuatro si oscila entre tres y cinco. En la villa de Castellón prácticamente nunca será de alternancia anual para los oficios de justicia, almotacén y jurado porque no habían suficientes personas en las bolsas y además muchas veces eran declarados no hábiles para los cargos. Esto hizo que la alternancia anual no se cumpliera.

En el caso del oficio de justicia la tendencia general en el período entre 1597 y 1707 será de alternancia cada cuatro años, es decir, tres años ocupa el cargo un miembro de la bolsa del brazo real y al cuarto lo ocupa alguien de la bolsa del brazo militar. Las excepciones las encontramos en $1603^{87}$ y 1653 , en las que han pasado seis años, en 1608 y 1687 han pasado cinco años, en 1635, 1664, 1667, 1676, 1679 y 1682 y 1697 han pasado tres años, y a partir de 1701 hasta 1707 ya no aparece ningún justicia del brazo militar ${ }^{88}$. Por tanto la evidencia de la no alternancia anual entre brazo militar y real es innegable.

Asimismo esta conclusión se puede extender al oficio de jurado primero en el cual tampoco existía la alternancia anual con el brazo real. El proceso habitual en el

\footnotetext{
${ }^{85}$ Colom, G. y Garcia, A. (1970): Furs de València I. Editorial Barcino. Barcelona, pp. 174-175.

${ }^{86}$ Bernabé Gil, D. (2001): "Insaculación, Oligarquía e intervencionismo regio en la villa de Xixona (ss. XVI-XVIII)". Estudis: Revista de Historia Moderna. Anales de la Universidad de Alicante nº19. Alicante, pp. 87.

${ }^{87}$ Del 1603 no hemos podido encontrar datos sobre el Consell de Castellón ya que no hay Judiciari y por deducción suponemos que ese año el justicia correspondió elección del brazo militar.

${ }^{88}$ Véase tabla 4 con el cuadro de justicias desde 1597 a 1707.
} 
período comprendido entre 1597 y 1707 es cada cuatro años pero también encontramos casos en los que el jurado primero es del brazo militar pasados seis años, es decir, cinco años consecutivos lo ocupa una persona elegida del brazo real, y el sexto lo ocupa una persona del brazo militar, así como casos de cada tres años ${ }^{89}$.

En el oficio de almotacén ocurre lo mismo siendo la práctica más habitual que se intercale brazo militar cada cuatro años aunque encontramos algunas excepciones significativas. La elección de Pere Giner de Bou en 1655 después de ocho años seguidos extrayendo este oficio de la bolsa de brazo real o la elección del mismo Pere Giner de Bou en 1658 después de tres años. Es en el período de 1663 a 1673 cuando sí que encontramos alternancia entre el brazo militar y el brazo real con los militares Fernando Miralles (1663), Martí Mas (1665), Fernando Miralles (1667), Joan Ros de Ursins (1669), Miquel Vallés (1671), Basilio Reus (1673) y para el siguiente ya han pasado tres años con la elección de Joan Castell en 1676 al igual que la elección de Macià Igual 1679. En 1689 es elegido Fernando Miralles cuando solo han pasado dos años desde la última elección del brazo de militar. También nos llama la atención como el siguiente caballero que ocupa el cargo después de Fernando Miralles es Joachim Gombau pero han pasado cinco años, período que tampoco es muy habitual.

La última vez que ocupa el cargo un militar es en el año 1703 y a partir de esa fecha y hasta el final de la época foral será ocupado por una persona del brazo real ${ }^{90}$.

Para completar la corroboración de la no alternancia anual del jurado primero entre brazo real podemos leer el siguiente extracto de la elección de cargos fechada el diez de mayo de 1636 :

"... digueren Pere Morales i Francesc de Sisternés cavallers, que pretenen que a de fer la extracció de jurats de Jurat primer del bras militar segons furs del present regne. E prosedint a fer extracció de Bras real disentiren y protestaren, i que espressament disentirán en que es fes extracció de Jurats del Bras Real, per quant se ha de fer del bras militar conforme los furs del present regne per ser prou en número, i Melchor Capero síndich de la present vila diu que no són prou en número al faltar ab dos

\footnotetext{
${ }^{89}$ Véase tabla 5 con el cuadro de jurados desde 1597 a 1707.

${ }^{90}$ Véase tabla 6 con el cuadro de almotacén desde 1597 a 1707.
} 
segons furs del present regne i que per consegüent s'ha de fer extracció del Bras Real..."91.

Y la elección del almotacén fechada el veintiocho de septiembre de 1633:

“... Fonch proposat per lo doctor Pere Nicolau Figuerola que en semblant dia se

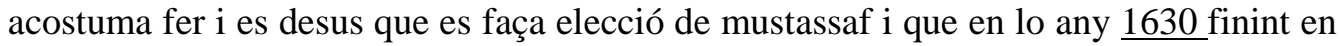
trenta hu fonch elect en mustassaf del bras militar Pere Morales cavaller i en los tres anys inmediate següents s'ha de fer elecció de Mustassaf del bras Real que vegen furs si es farà elecció de Mustassaf i si es farà del bras militar o real guardant les ordinacions de dita vila. Fonch provehit clos e determinat per lo dit Consell (...)emine discrepante ques farà extracció de mustassaf de la boça e bras militar guardant les ordinacions de dita vila e impediment ussos i bons costums de aquella..."92.

En la siguiente tabla se muestra la relación de los que ocuparon este puesto entre 1597 y 1707.

Tabla 4: Justicias de la ciudad de Castellón entre 1597 y 1707³:

\begin{tabular}{|l|c|c|}
\hline Año & Justicias & Grupo oligárquico \\
\hline 1597 & Cristòfol Miralles & Cavaller \\
1598 & Antoni Lleó & Ciutadà \\
1599 & Joan Castell & Ciutadà \\
1600 & Francesc Jover & Ciutadà \\
1601 & Melchor Salvador & Notari \\
1602 & Bertomeu Bonet & Llaurador \\
1603 & & \\
1604 & Melchor Salvador & Notari \\
1605 & Cristòfol Sisternés & Ciutadà \\
1606 & Gaspar Gombau & Ciutadà \\
1607 & Jaume Giner & Notari \\
1608 & Gerony Arrufat & Cavaller \\
1609 & Tomàs March & Doctor en Dret \\
1610 & Miquel Giner & Ciutadà \\
1611 & Jaume March & Ciutadà \\
1612 & Nicolau Reus & Cavaller \\
1613 & Bertomeu Bonet & Llaurador \\
\hline
\end{tabular}

\footnotetext{
${ }^{91}$ AHMC. Judiciari. 1634-1635-1636-1637. Sesión del Consell del 10 de mayo de 1636.

${ }^{92}$ AHMC. Judiciari 1631-1632-1633-1634. Sesión del Consell del 28 de mayo de 1633.

93 AHMC. Elaborado a partir de todas las reuniones del Consell reflejadas en el Judiciari entre 1597 y 1707.
} 


\begin{tabular}{|c|c|c|}
\hline Año & Justicias & Grupo oligárquico \\
\hline 1614 & Joan Gerony Folch/Jaume March/Joan Gerony Folch & Notari/ciutadà/notari \\
\hline 1615 & Bernat Gascó & Ciutadà \\
\hline 1616 & Mateu Ros & Cavaller \\
\hline 1617 & Miquel Giner & Ciutadà \\
\hline 1618 & & \\
\hline 1619 & & \\
\hline 1620 & Mateu Ros & Cavaller \\
\hline 1621 & Francesc Mas & Llaurador \\
\hline 1622 & Miquel Giner & Ciutadà \\
\hline 1623 & Antoni Lleó & Ciutadá \\
\hline 1624 & Pere Arrufat & Cavaller \\
\hline 1625 & Dionís Jover & Doctor en dret \\
\hline 1626 & Pau Capero & Notari \\
\hline 1627 & Bernat Gascó & Ciutadà \\
\hline 1628 & Joan Arrufat & Cavaller \\
\hline 1629 & Batiste Serra & Ciutadà \\
\hline 1630 & Francesc Mas & Llaurador \\
\hline 1631 & Gaspar Joan Brunell & Ciutadà \\
\hline 1632 & Gerony Arrufat & Cavaller \\
\hline 1633 & Francesc Alegre & Llaurador \\
\hline 1634 & Pere Joan Vicent & Cirurgià \\
\hline 1635 & Jaume Miquel & Cavaller \\
\hline 1636 & Pere Giner & Notari \\
\hline 1637 & Gabriel Bonet & Notari \\
\hline 1638 & Batiste Jover & Ciutadà \\
\hline 1639 & Pere Reus & Cavaller \\
\hline 1640 & Miquel Mur & Doctor en dret \\
\hline 1641 & Francesc Bou & Ciutadà \\
\hline 1642 & Pere Joan Vicent & Cirurgià \\
\hline 1643 & Cristòfol Sisternés & Cavaller \\
\hline 1644 & Baltazar Gombau & Ciutadà \\
\hline 1645 & Lluís Giner & Ciutadà \\
\hline 1646 & Gaspar Martí & Mercader \\
\hline 1647 & Nicolau Serra & Cavaller \\
\hline 1648 & Gaspar Brunell & Ciutadà \\
\hline 1649 & Miquel Castell de Antoni & Llaurador \\
\hline 1650 & Vicent Martí & Notari \\
\hline 1651 & Batiste Jover & Ciutadà \\
\hline 1652 & Melchor Amiguet & Notari \\
\hline
\end{tabular}




\begin{tabular}{|c|c|c|}
\hline Año & Justicias & Grupo oligárquico \\
\hline 1653 & Francesc Bou & Cavaller \\
\hline 1654 & Micer Vicent Vilar & Ciutadà \\
\hline 1655 & Tomàs Giner & Cirurgià \\
\hline 1656 & Vicent Figuerola & Ciutadà \\
\hline 1657 & Francesc Bou & Cavaller \\
\hline 1658 & Miquel Romeu & Ciutadà \\
\hline 1659 & Joan Cases & Ciutadà \\
\hline 1660 & Baltazar Gombau & Ciutadà \\
\hline 1661 & Martí Mas & Cavaller \\
\hline 1662 & Joan Andreu & Ciutadà \\
\hline 1663 & Aleixandre Martí & Notari \\
\hline 1664 & Gerony Mas & Cavaller \\
\hline 1665 & Melchor Amiguet & Notari \\
\hline 1666 & Gaspar Brunell & Ciutadà \\
\hline 1667 & Carlos Jover & Generós \\
\hline 1668 & Joan Cases & Doctor en Dret \\
\hline 1669 & Josep Castell de Francesc & Llaurador \\
\hline 1670 & Josep Feliu & Generós \\
\hline 1671 & Tomàs Giner & Ciutadà \\
\hline 1672 & Josep Alberich /Vicent Martí & Mercader/notari \\
\hline 1673 & Joan Ros de Ursins & Cavaller \\
\hline 1674 & Francesc Andreu & Ciutadà \\
\hline 1675 & Vicent Martí /Vicent Museros & Notari/Llaurador \\
\hline 1676 & Francesc Bou & Cavaller \\
\hline 1677 & Batiste Jover & Ciutadà \\
\hline 1678 & Joan Museros de Monserrat & Llaurador \\
\hline 1679 & Josep Igual & Generós \\
\hline 1680 & Pere Roig de Jaume & Llaurador \\
\hline 1681 & Felip Sorrando & Mercader \\
\hline 1682 & Macià Igual & Generós \\
\hline 1683 & Francesc Andreu & Ciutadà \\
\hline 1684 & Tomàs March & Ciutadà \\
\hline 1685 & Felip Sorrando & Mercader \\
\hline 1686 & Felip Sorrando & Mercader \\
\hline 1687 & Basilio Reus & Cavaller \\
\hline 1688 & Jaume Cases & Notari \\
\hline 1689 & Pasqual Avinent & Notari \\
\hline 1690 & Josep Castell de Museros & Cavaller \\
\hline 1691 & Pere Roig de Jaume & Llaurador \\
\hline
\end{tabular}




\begin{tabular}{|c|c|c|}
\hline Año & Justicias & Grupo oligárquico \\
\hline 1692 & Francesc Andreu & Ciutadà \\
\hline 1693 & Martí Viciano & Doctor en medicina \\
\hline 1694 & Basilio Reus/Gerony Bou de Monsonís & Cavaller/Cavaller \\
\hline 1695 & Tomàs March & Ciutadà \\
\hline 1696 & Jaume Giner & Doctor en dret \\
\hline 1697 & Josep Igual/Gerony Bou de Monsonís & Cavaller/Cavaller \\
\hline 1698 & Tomàs March & Ciutadà \\
\hline 1699 & Francesc Andreu & Ciutadà \\
\hline 1700 & Josep Segarra & Ciutadà \\
\hline 1701 & Cosme Feliu & Generós \\
\hline 1702 & Miquel Bonet & Notari \\
\hline 1703 & Tomàs March & Ciutadà \\
\hline 1704 & Batiste Jover & Ciutadà \\
\hline 1705 & March Casalís & Llaurador \\
\hline 1706 & Tomàs March & Ciutadà \\
\hline 1707 & Francesc Andreu/Jacint March & Ciutadà/Doctor en dret \\
\hline
\end{tabular}

La mayoría de veces el nombramiento del justicia ocurre según lo establecido en los privilegios pero en algunos casos hay ciertas anomalías que se explican a continuación. En abril de 1598 Bernat Pardo sustituye Antoni Joan Lleó que había sido nombrado en marzo. A partir de octubre vuelve a aparecer Antoni Joan Lleó por pleito en la Real Audiencia de Valencia. En 1613 se elige a Joan Gerony Folch justicia para el 1614, pero en marzo después de pleito en la Real Audiencia de Valencia es elegido Jaume March. Sin embargo, al finalizar el año vuelve a ocupar el cargo Joan Gerony Folch y no sabemos el motivo. En noviembre de 1673 fallece el justicia Josep Alberich y es elegido para acabar el año Vicent Martí. En octubre de 1675 vuelve a ocurrir un caso similiar ya que fallece el justicia Vicent Museros por lo que es sustituido por Vicent Martí. En 1686 se prorroga el justicia del año anterior por el pleito en la Real Audiencia de Valencia. La extracción de justicia para el año 1691 se hace en marzo por pleito en la Real Audiencia de Valencia. En 1694 fallece Basilio Reus y lo sustituye Gerony Bou de Monsonís, al igual que en 1697, ya que el 8 de noviembre muere Josep Igual y su sustituto hasta diciembre es Gerony Bou de Monsonís. En agosto de 1707 fallece Francesc Andreu y se nombra justicia a Jacint March.

\footnotetext{
${ }^{94}$ En la tabla se han dejado en blanco aquellos años que no hemos podido obtener datos porque se ha extraviado el Judiciari de ese período o porque si lo hay se encuentra en muy mal estado. Los años en que la elección corresponde al brazo militar se ha resaltado el nombre en negrita.
} 
Si analizamos los resultados que hemos obtenido en el cuadro se observa como no hemos obtenido personas que repitan muchas veces en el cargo. Solamente hemos de destacar el caso de Francesc Andreu y Tomàs March que al final de la centuria lo ocuparon hasta cinco veces, Francesc Bou lo ocupó cuatro veces o Miquel Giner al principio de siglo tres veces. Estos casos si que consiguieron repetir en el cargo pero la tónica generalizada es que no hay ninguna persona que se establezca en el puesto de una forma permanente. La comprobación más evidente es que hasta ochenta y tres personas diferentes desempeñaron el oficio de los ciento diez años de los que tenemos datos ${ }^{95}$. Si hacemos una distinción entre brazo militar y real dado que se elegían de bolsas diferentes, obtenemos que de las veintinueve veces que el oficio lo desempeño un cavaller o militar solo hubo encontramos a Francesc Bou que lo hizo en tres ocasiones. Gerony Bou de Monsonís, Basilio Reus, Josep Igual, Mateu Ros y Gerony Arrufat lo hicieron en dos ocasiones. Y el resto de personas lo ocuparon una sola vez. Por tanto encontramos hasta veintiuna personas diferentes en el oficio, y dado que esta bolsa constaba de muy pocos miembros es evidente la no personalización del puesto. Este primer análisis nos muestra como no hubo un control del desempeño de este puesto a nivel individual, más bien familiar como veremos más adelante. Si que sirvió para formar parte del Consell y después ocupar otro cargo ya sea el de consejero, almotacén, jurado o síndico. Pero esta argumentación la expondremos más tarde cuando veamos la valoración individual de los treinta y seis puestos del Consell.

\subsubsection{Jurados ${ }^{96}$.}

Eran los verdaderos ejecutores de las decisiones tomadas en el Consell y se enfrentaban a la gestión diaria del municipio. Su elección, al igual que la de los consejeros, se realizaba en la víspera de la Pascua de Pentecostés por el procedimiento de insaculación y el número de elegidos era de cuatro. Para el jurado primero se tomaba la bolsa de jurado primero del brazo real o del brazo militar, aspecto que ya se ha explicado anteriormente. En el caso que fuera elegido del brazo real, el jurado segundo se extraía de la bolsa llamada de jurado segundo o de los artistas, y los jurados tercero y

\footnotetext{
${ }^{95}$ Hemos de matizar que algunos años se produjeron sustituciones por fallecimiento o por pleito en la Real Audiencia de Valencia y se han considerado las dos personas. Esto solo ocurre en cinco ocasiones por tanto no distorsiona nuestros resultados.

${ }^{96}$ Formaban la corte de jurados para gestionar los asuntos diarios y no tener que convocar al Consell continuamente.
} 
cuarto de la última bolsa llamada bolsa de los jurados tercero y cuarto, siendo jurado tercero el que más veces ha sido jurado y cuarto el otro. En el caso de que ninguno de ellos haya sido jurado será elegido tercero el de más edad ${ }^{97}$. Si la elección correspondía al brazo militar no se extraía de la bolsa de jurado segundo o de los $\operatorname{artistas}^{98}$. Sin embargo, este aspecto se modifico con el Privilegio de Felipe III de 1597 y en los años que se extraía jurado primero del brazo militar se decidió que los otros tres fueran de la bolsa del brazo real de jurado primero, de la bolsa de los artistas o jurado segundo y el último de la bolsa de jurados tercero y cuarto. Por tanto no se extraían dos sino uno de la última bolsa y se conseguía la representación de los tres grupos de poder de la villa ${ }^{99}$.

Consideramos de una especial relevancia concretar la tipología de personas que formaban parte de las tres bolsas de jurados. En la bolsa de jurado primero del brazo real se encontraban los ciudadanos honrados ${ }^{100}$, doctores en leyes y doctores en medicina. En la bolsa de jurado segundo o artistas se encontraban cirujanos, apotecaris, notarios, pintores y mercaderes. Finalmente, la bolsa de jurados tercera y cuarta era monopolio de los labradores.

\section{Ilustración 4: Jurado primero de la villa de Castellón}

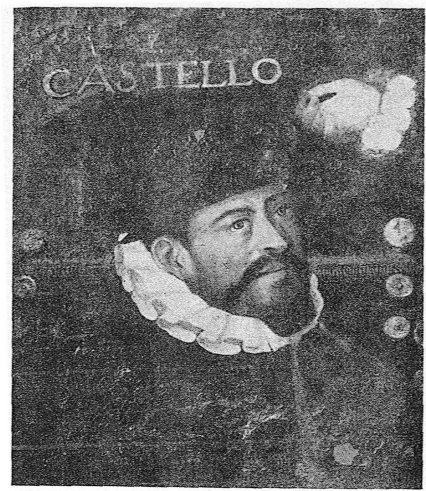

En la imagen podemos ver a Narcís Feliu, jurado primero de la villa de Castellón en agosto de 1592. La imagen está extraída del libro de Vicente Traver Tomas: "Antigüedades de Castellón de la Plana”, y a su vez ésta ha sido tomada del Salón de la Generalitat en Valencia, cuyo autor es Juan de Sariñena.

\footnotetext{
${ }^{97}$ Bernabé Gil, D. (2012): Privilegios...op. cit., pp. 233. Véase documento 2 en el apéndice la Ordinación de Covarrubias de 1590 en lo referente a "Agraduació de jurats".

${ }^{98}$ Ibidem.

${ }^{99}$ Bernabé Gil, D. (2012): Privilegios...op. cit., pp. 247. Véase documento 3 en el apéndice el Privilegio de Felipe III de 1597 en lo referente a "Extractió de jurats, en anys de militars".

${ }^{100}$ Bernabé Gil, D. (2001): "Insaculación...” op.cit., pp. 90. Explica que eran ciudadanos los vecinos de una ciudad que, sin haber obtenido privilegio militar, gozaban de una elevada estima social, vivían de rentas y no se dedicaban a oficios mecánicos ni trabajaban “de sus manos”.
} 
En el siguiente cuadro se muestran las personas que ocuparon el cargo entre 1597 y 1707.

Tabla 5: Jurados de la ciudad de Castellón entre 1597 y $1707^{101}$ :

\begin{tabular}{|c|c|c|c|c|}
\hline Año & Jurado primero & Jurado segundo & Jurado tercero & Jurado cuarto \\
\hline 1597 & Miquel Jaume Serra & Josep Mas & Batiste Gisbert & Jaume Alegre \\
\hline 1598 & Cristòfol Miralles & Martí Arrufat & Gaspar Brunell & Joan Vilarroig \\
\hline 1599 & Francesc Jover & Melchor Salvador & Nicolau Alegre & Joan Bosch \\
\hline 1600 & Antoni Pedro & Josep Mas & Martí Castell & Pere Vilarroig \\
\hline 1601 & Francesc Jover menor & Bertomeu Giner & Joan Castell & Francesc Navarro \\
\hline $\begin{array}{l}1602 \\
1603\end{array}$ & Miquel Jaume Serra & Tomàs Moliner & Francesc Navarro & Joan Vilarroig \\
\hline 1604 & Gerony Miquel & Narcís Feliu & Gaspar Brunell & Francesc Navarro \\
\hline 1605 & $\begin{array}{l}\text { Miquel Giner/Gaspar } \\
\text { Mascarós }\end{array}$ & $\begin{array}{l}\text { Domingo Beltran/Joan } \\
\text { Gerony Folch }\end{array}$ & Pere Figuerola & Domingo Molina \\
\hline 1606 & Francesc Jover menor & Miquel Aragonés & Batiste Gisbert & Martí Castell \\
\hline 1607 & Francesc Jover & Jaume Sabera & Francesc Navarro & Bertomeu Giner \\
\hline 1608 & Miquel Giner & Miquel Navarro & Gaspar Brunell & Miquel Pasqual \\
\hline 1609 & Francesc Jover menor & Miquel Aragonés & Batiste Gisbert & Gabriel Agramunt \\
\hline 1610 & Gerony Arrufat & Gerony Jover & Jaume Sabera & Francesc Alegre \\
\hline 1611 & Tomàs March & Pau Capero & Pere Vilarroig & Joan Figuerola \\
\hline 1612 & Miquel Moliner & Nicolau Coll & Joan Batiste Vallés & Gabriel Segarra \\
\hline 1613 & Cosme Martí & Tomàs Moliner & Nicolau Alegre & Andreu March \\
\hline 1614 & Joan Arrufat & Tomàs March & Francesc Joan Bou & Jaume Bonet \\
\hline 1615 & Baltazar Gombau & Miquel Sanchís & Bertomeu Bonet & Pere Joan Vicent \\
\hline 1616 & Bertomeu Giner & Nicolau Alegre & Joan Gerony Folch & Antoni Castell \\
\hline 1617 & & & & \\
\hline 1618 & & & & \\
\hline 1619 & & & & \\
\hline 1620 & Cosme Martí & Batiste Moliner & Francesc Alegre & Jaume Alegre \\
\hline 1621 & Pere Morales & Baltazar Gombau & Cristòfol Bou & Pere Eiximeno \\
\hline 1622 & Tomàs March & Jaume Castellet & Miquel Sanchís & Miquel Alberich \\
\hline 1623 & Jaume Bonet & Pere Joan Vicent & Antoni Ribes & Joan Bosch \\
\hline 1624 & Pere March & $\begin{array}{l}\text { Francesc Jover de } \\
\text { Sunyer }\end{array}$ & Antoni Castell & Monserrat Martí \\
\hline 1625 & Pere Morales & Jaume Castellet & Bernat Gascó & Batiste Llorens \\
\hline 1626 & Batiste Gascó & Melchor Amiguet & Pere Eiximeno & Pere Museros \\
\hline 1627 & Nicolau Serra & Batiste Moliner & Francesc Castell & $\begin{array}{l}\text { Miquel Pasqual de } \\
\text { Miquel }\end{array}$ \\
\hline 1628 & Pere March & $\begin{array}{l}\text { Miquel Bonaventura } \\
\text { Pasqual }\end{array}$ & $\begin{array}{l}\text { Miquel Sanchís de } \\
\text { Joan }\end{array}$ & Joan Bosch \\
\hline 1629 & Mateu Ros & Bernat Gascó & Pere Joan Vicent & Miquel Rubert \\
\hline 1630 & Cosme Feliu & Gabriel Ferrer & Andreu March & Francesc Castell \\
\hline 1631 & Fulgenci Mascarós & Melchor Amiguet & Antoni Castell & Cosme Segarra \\
\hline 1632 & Batiste Serra & Vicent Pasqual & Jaume Castellet & Berenguer Ribalta \\
\hline 1633 & Pere Reus & Nicolau Serra & Joan Batiste Traver & Batiste Llorens menor \\
\hline 1634 & Nicolau Figuerola & Joan Martí & Pere Alegre & Batiste Llorens menor \\
\hline 1635 & Gaspar Joan Brunell & Pere Joan Vicent & Joan Bosch & Gaspar Navarro \\
\hline 1636 & Gaspar Lluís Brunell & Mateu Sanchís & Lluís Cristòfol Bou & Joan Vilarroig de Pere \\
\hline 1637 & Gerony Arrufat & Nicolau Serra & Joan Martí & Pere Eiximeno \\
\hline 1638 & Jaume Jover & Pere Joan Vicent & Nicolau Alegre & Berenguer Ribalta \\
\hline 1639 & Gaspar Brunell & Jaume Castellet & Baltazar Avinent & Jaume Vilarroig \\
\hline 1640 & Batiste Serra & Vicent Martí & Francesc Vilarroig & Monserrat Museros \\
\hline
\end{tabular}

${ }^{101}$ Elaborada a partir de la revisión de las reuniones del Consell reflejadas en el Judiciari entre 1597 y 1707. 


\begin{tabular}{|c|c|c|c|c|}
\hline Año & Jurado primero & Jurado segundo & Jurado tercero & Jurado cuarto \\
\hline 1641 & Gerony Arrufat & Miquel Romeu & Lluís Mas & Miquel Castell \\
\hline 1642 & Batiste Gascó & Batiste Moliner & Francesc Moliner & Joan Granyana \\
\hline 1643 & Melchor Capero & Melchor Amiguet & March Casalís & Baltazar Avinent \\
\hline 1644 & Francesc Josep Bou & Jaume March & Batiste Llorens & Joan Marqués \\
\hline 1645 & Gerony Arrufat & Pere Giner & Vicent Vilar & Cosme Reboll \\
\hline 1646 & Miquel Romeu & Josep Alberich & Joan Vilarroig & Pere Vilarroig \\
\hline 1647 & Miquel Mur & Miquel Alberich & $\begin{array}{l}\text { Baltazar Avinent } \\
\text { major }\end{array}$ & Miquel Llansola \\
\hline 1648 & Jaume Giner & Melchor Amposta & Batiste Llorens & Francesc Figuerola \\
\hline 1649 & Gerony Arrufat & Miquel Giner & Jaume March & Josep Segarra \\
\hline 1650 & Vicent Castellet & Jaume Andreu & Mateu Sanchís & Vicent Marqués \\
\hline 1651 & Vicent Vilar & Melchor Amposta & Francesc Figuerola & Vicent Museros \\
\hline 1652 & Tomàs Giner & Josep Alberich & Vicent Figuerola & Joan Navarro de Joan \\
\hline 1653 & Batiste Jover & Vicent Porta & Josep Castell & Gaspar Eiximeno \\
\hline 1654 & Miquel Mur & Pere Giner & Josep Segarra & Vicent Marqués \\
\hline 1655 & March Antoni Jordà & Gerony Vidal & Melchor Amiguet & Monserrat Museros \\
\hline 1656 & Batiste Jover & Melchor Amposta & Vicent Museros & Mateu Tormo \\
\hline 1657 & Joan Andreu & Gaspar Martí & Josep Segarra & $\begin{array}{l}\text { Francesc Pasqual de } \\
\text { Joan }\end{array}$ \\
\hline 1658 & Tomàs Giner & Jaume Andreu & Pere Vilarroig & $\begin{array}{l}\text { Miquel Vilarroig de } \\
\text { Viciano }\end{array}$ \\
\hline 1659 & Joan Castell & Gerony Vidal & Pere Giner & Vicent Figuerola \\
\hline 1660 & Vicent Figuerola & Vicent Porta & $\begin{array}{l}\text { Miquel Llansola } \\
\text { major }\end{array}$ & $\begin{array}{l}\text { Josep Castell de } \\
\text { Francesc }\end{array}$ \\
\hline 1661 & Gaspar Brunell & Josep Alberich & $\begin{array}{l}\text { Miquel Vilarroig de } \\
\text { Joan }\end{array}$ & $\begin{array}{l}\text { Miquel Sanchís de } \\
\text { Miquel }\end{array}$ \\
\hline 1662 & Felip Jover & Tomàs Capero & Melchor Amiguet & Francesc Figuerola \\
\hline 1663 & Joan Andreu & Jaume Castell & Joan Navarro & Vicent Castellet \\
\hline 1664 & Batiste Orts & Vicent Ferrer & Pere Bonet & Vicent Rubert \\
\hline 1665 & Basilio Reus & Tomàs Giner & Aleixandre Martí & Pere Segarra \\
\hline 1666 & Vicent Figuerola & Francesc Mercer & Vicent Marqués & Francesc Pasqual \\
\hline 1667 & Tomàs Capero & Vicent Pasqual & Vicent Museros & Josep Avinent \\
\hline 1668 & Felip Sisternés & Miquel Romeu & Pere Giner & Josep Rubert \\
\hline 1669 & Gaspar Brunell & Vicent Martí & $\begin{array}{l}\text { Miquel Vilarroig de } \\
\text { Breva }\end{array}$ & Gerony Alegre \\
\hline 1670 & Francesc Andreu & Francesc Mercer & Gaspar Eiximeno & $\begin{array}{l}\text { Miquel Pasqual de } \\
\text { Francesc }\end{array}$ \\
\hline 1671 & Felip Sisternés & Vicent Figuerola & Macià Compte & Josep Vilarroig \\
\hline 1672 & Cosme Martí & Pere Palanques & Francesc Figuerola & $\begin{array}{l}\text { Miquel Vilarroig de } \\
\text { Castell }\end{array}$ \\
\hline 1673 & Tomàs Capero & Felip Sorrando & Vicent Museros & Miquel Català \\
\hline 1674 & Felip Sisternés & Joan Cases & Pere Museros & $\begin{array}{l}\text { Miquel Pasqual de } \\
\text { Francesc }\end{array}$ \\
\hline 1675 & Vicent Figuerola & Jaume Cases & $\begin{array}{l}\text { Jaume Viciano de } \\
\text { Miquel }\end{array}$ & Pere Calbo \\
\hline 1676 & Vicent Figuerola & Felip Sorrando & Pere Segarra & $\begin{array}{l}\text { Miquel Vilarroig de } \\
\text { Castell }\end{array}$ \\
\hline 1677 & Carlos Jover & Joan Timor & Macià Compte & Antoni Castell \\
\hline 1678 & Francesc Andreu & Vicent Tosquella & $\begin{array}{l}\text { Jaume Viciano de } \\
\text { Miquel }\end{array}$ & $\begin{array}{l}\text { Miquel Vilarroig de } \\
\text { Nicolau }\end{array}$ \\
\hline 1679 & Batiste Jover & Pere Breva & $\begin{array}{l}\text { Joan Museros de } \\
\text { Monserrat }\end{array}$ & Domingo Vilarroig \\
\hline 1680 & March Antoni Jordà & Pere Giner de Vilarroig & Josep Amposta & Andreu Ribalta \\
\hline 1681 & Francesc Andreu & Jaume Cases & Josep Rubert menor & Francesc Vilarroig \\
\hline 1682 & Tomàs March & Felip Sorrando & Miquel Català & Josep Albiol \\
\hline 1683 & Ignacio Figuerola & Pere Figuerola & March Casalís & $\begin{array}{l}\text { Francesc Amiguet } \\
\text { menor }\end{array}$ \\
\hline 1684 & Batiste Jover & Macià Compte & $\begin{array}{l}\text { Jaume Viciano de } \\
\text { Miquel }\end{array}$ & Pere Roig de Jaume \\
\hline
\end{tabular}




\begin{tabular}{|c|c|c|c|c|}
\hline Año & Jurado primero & Jurado segundo & Jurado tercero & Jurado cuarto \\
\hline 1685 & Joachim Gombau & Cristòfol Vilar & Vicent Ferrer & $\begin{array}{l}\text { Miquel Vilarroig de } \\
\text { Nicolau }\end{array}$ \\
\hline 1686 & Vicent Martí & Francesc Mercer & $\begin{array}{l}\text { Joan Museros de } \\
\text { Monserrat }\end{array}$ & $\begin{array}{l}\text { Francesc Amiguet } \\
\text { menor }\end{array}$ \\
\hline 1687 & Vicent Figuerola & Pasqual Avinent & Gerony Castell & Andreu Castellet \\
\hline 1688 & March Antoni Jordà & Francesc Joan Cases & Macià Compte & Josep Rubert \\
\hline 1689 & Batiste Jover & Miquel Bonet & Francesc Amiguet & Josep Vilarroig \\
\hline 1690 & Vicent Figuerola & Pere Figuerola & $\begin{array}{l}\text { Josep Avinent de } \\
\text { Baltazar }\end{array}$ & $\begin{array}{l}\text { Josep Pasqual de } \\
\text { Francesc }\end{array}$ \\
\hline 1691 & March Antoni Jordà & Vicent Martí & Macià Compte & March Casalís \\
\hline 1692 & Ignacio Figuerola & Pasqual Avinent & Domingo Vilarroig & Andreu Castellet \\
\hline 1693 & Batiste Jover & Gaspar Rubert & Francesc Amiguet & Agostí Reboll \\
\hline 1694 & Miquel Garcés & Josep Amposta & Josep Rubert & $\begin{array}{l}\text { Miquel Vilarroig de } \\
\text { Nicolau }\end{array}$ \\
\hline 1695 & Josep Castell de Romeu & Josep Museros & Pere Vidal & Andreu Ribalta \\
\hline 1696 & Tomàs March & Pere Museros & March Casalís & Joan Museros de Joan \\
\hline 1697 & Cristòfol Vilar & Jaume Cases & Francesc Vilarroig & $\begin{array}{l}\text { Josep Pasqual de } \\
\text { Francesc }\end{array}$ \\
\hline 1698 & Josep Segarra & Josep Amposta & Agostí Reboll & $\begin{array}{l}\text { Vicent Figuerola de } \\
\text { Francesc }\end{array}$ \\
\hline 1699 & Macià Igual & Ignacio Figuerola & Aleixandre Martí & $\begin{array}{l}\text { Josep Museros de } \\
\text { Avinent }\end{array}$ \\
\hline 1700 & Jacint March & Gaspar Rubert & $\begin{array}{l}\text { Miquel Navarro de } \\
\text { Antoni }\end{array}$ & Tomàs Breva \\
\hline 1701 & Tomàs March & Josep Amposta & $\begin{array}{l}\text { Joan Museros de } \\
\text { Monserrat }\end{array}$ & $\begin{array}{l}\text { Josep Castell de } \\
\text { Antoni }\end{array}$ \\
\hline 1702 & Joan Sanchís & Joan Safont & Joan Breva & Tomàs Blasco \\
\hline 1703 & Vicent Tosquella & Josep Llopis & Baltazar Avinent & $\begin{array}{l}\text { Josep Castell de } \\
\text { Gerony }\end{array}$ \\
\hline 1704 & Jaume Giner & Severino Museros & $\begin{array}{l}\text { Miquel Navarro de } \\
\text { Gaspar }\end{array}$ & $\begin{array}{l}\text { Jaume Breva de } \\
\text { Vilarroig }\end{array}$ \\
\hline 1705 & Fernando Miralles & Francesc Andreu & Jaume Pasqual & Tomàs Breva \\
\hline 1706 & Batiste Jover & Miquel Bonet & March Casalís & $\begin{array}{l}\text { Josep Castellet de } \\
\text { Antoni }\end{array}$ \\
\hline 1707 & Tomàs March & Gaspar Rubert & Domingo Vilarroig & $\begin{array}{l}\text { Jaume Breva de } \\
\text { Francesc }\end{array}$ \\
\hline
\end{tabular}

Elaboración propia ${ }^{102}$

Las anómalias que presenta son varias: En primer lugar en mayo de 1605 Gaspar Mascarós y Joan Gerony Folch son declarados inhábiles para jurados primero y segundo. Esto hace que sean elegidos Miquel Giner y Domingo Beltrán. Sin embargo, son sustituidos por Gaspar Mascarós y Joan Gerony Folch en octubre de 1605 porque la Real Audiencia de Valencia los declara hábiles. En segundo lugar el hecho de que Vicent Figuerola es el jurado primero en 1675 y 1676 por tanto repite dos años consecutivos.

Para analizar los datos de esta tabla a nivel individual hemos de desglosar entre las personas que ocuparon el puesto de jurado primero, segundo, tercero y cuarto. En el caso del jurado primero era cubierto por personas procedentes del brazo militar y brazo

\footnotetext{
${ }^{102}$ Hemos marcado el nombre en negrita cuando el jurado primero es militar y los años 1603, 1617, 1618 y 1619 que no tenemos datos se han dejado en blanco.
} 
real. La alternancia ya hemos explicado que no era anual, más bien cada cuatro o cinco años porque no había personas disponibles en la bolsa del brazo militar. Las personas que ocuparon el puesto de jurado primero de este brazo podemos ver que no fueron muy numerosas, pero ello se debe fundamentalmente a la existencia de una bolsa de caballeros o generosos con pocas personas. Si además tenemos en cuenta que algunos podían ser inhabilitados u ocupar algún cargo incompatible con el oficio, entonces es evidente que se reducirá la lista de candidatos. Los resultado obtenidos nos muestra que de las veintiséis ocasiones en que el oficio de jurado primero correspondió al brazo militar, solo repitieron más de una vez: Gerony Arrufat que lo hizo en cinco ocasiones, March Antoni Jordà en tres, Felip Sisternés en tres y Pere Morales en dos. En total encontramos dieciséis personas diferentes ocupando el cargo. Esto nos deja entrever un aspecto que se mostrará en todos los oficios. La aparición de personas concretas que lo ocupan más de una vez pero no hay un dominio en el oficio, más bien, hay una consolidación de que esas personas iran sentándose en el Consell por desempeñar distintos oficios. Por tanto las mismas personas pero moviéndose por los distintos cargos.

En el puesto de jurado primero del brazo real también encontramos un ábanico bastante amplio de personas que lo ocupan, puesto que dentro de las ochenta veces que le corresponde aparecen cincuenta y ocho personas diferentes. Destacamos que la mayoría la ocupan una sola vez, aunque hay personas como Vicent Figuerola o Batiste Jover que lo llegaron a ocupar hasta siete veces, seguidos por Francesc Andreu con cinco y Tomàs March y Francesc Jover con cuatro. En este caso si que vemos que hay personas que copan el cargo durante bastantes años, pero esto no quiere decir que monopolizaron el cargo. Este dato va a reforzar nuestra idea de la permanencia en el Consell de algunas personas como Batiste Jover y Vicent Figuerola y que podremos comprobar en un apartado posterior.

El puesto de jurado segundo continúa en la línea de lo expuesto anterioremente. En los ciento nueve años de los que tenemos datos ${ }^{103}$ llegan a ocupar el puesto de jurado segundo sesenta y tres personas diferentes. Esto es una novedad respecto a otros oficios ya que aquí la diversidad es menor, pero hemos de tener muy claro que tampoco hay

\footnotetext{
${ }^{103}$ Recordemos que los años en que se elegía el jurado primero del brazo militar, los artistas o miembros de la bolsa de jurado segundo ocupan el puesto de jurado tercero. Esto se ha tenido en cuenta para establecer exactamente las personas de la bolsa de jurado segundo que ocuparon el puesto. Además se incluye las dos personas que lo ocuparon en 1605.
} 
una o varias personas que lo ostenten durante muchos años. Tan sólo encontramos a Melchor Amiguet y Macià Compte que lo hicieron en cinco ocasiones, y a Josep Amposta y a Pere Joan Vicent en cuatro. Sin embargo, si que aparecen muchas personas que lo ocupan dos veces. Esto nos vuelve a demostrar la no personalización del cargo, pero si que sirve para que todas las personas que lo ocupan puedan estar en el Consell año tras año.

El oficio de jurado tercero correspondía a los labradores enriquecidos de la ciudad de Castellón excepto los años que había elección de jurado primero del brazo militar. En este caso el puesto era para los miembros de la bolsa de los artistas. En los ciento siete años estudiados encontramos a sesenta y ocho personas diferentes destacando Tomàs March que lo ocupó en cinco ocasiones. Pero volvemos a las mismas conclusiones anteriores ya que no había personas ancladas en un oficio, lo que ocurría es que iban ocupando diferentes para estar en el Consell.

El oficio de jurado cuarto también era ocupado por labradores todos los años, sin que se le afectase la elección de jurado primero del brazo militar. Los datos sirven para seguir confirmando nuestra conclusión sobre la no perpetuación a nivel individual en un puesto concreto. En este caso concreto en los ciento seis años estudiados aparecen hasta ochenta y cinco personas distintas siendo de todos los oficios en el que hay menos repeticiones ya que solo encontramos a Miquel Vilarroig de Nicolau con tres presencias. Ahora bien hay que tener en cuenta que como podían ocupar el puesto de jurado tercero o el de cuarto lo que realmente les interesaba era estar en uno de los dos puestos, o mejor dicho en uno de los treinta y seis puestos del Consell.

\subsubsection{Almotacén.}

La elección de este cargo se realizaba la víspera del día de San Miguel y su función era la vigilancia y el control del sistema de pesas y medidas utilizado en tiendas, tabernas y demás puntos de venta, así como la supervisión del mercado ${ }^{104}$. Tal y como hemos explicado anteriormente había alternancia entre el brazo militar y brazo real para su desempeño aunque ya hemos aportado pruebas que no era anualmente. Este cargo se elegía por el procedimiento insaculatorio ${ }^{105}$, y se podía ocupar aunque fuese consejero como ocurrió en 1613, año en el cual es elegido en mayo Joan Batiste Vallés consejero

\footnotetext{
${ }^{104}$ Bernabé Gil, D. (2012): Privilegios... op. cit., pp. 13.

${ }^{105}$ Véase tabla 6 con el listado del almotacén.
} 
de mano mayor y en septiembre también es nombrado almotacén. Al año siguiente vuelve a ocurrir lo mismo con Francesc Jover.

Solo hemos encontrado estos dos casos pero en estos primeros años de la insaculación el poder se centra en un muy pocas personas y pese a que es azaroso que coincida en la misma persona dos cargos ya que es el resultado del sorteo de la vasija, sí que es muy importante tener en cuenta que esto ha sido previa existencia de las mismas personas en las bolsas de consejero y almotacén, y como en el momento que se ha producido el nombramiento no se ha planteado ninguna incompatibilidad. Esto sin lugar a dudas, restringe los resortes de poder aunque sea de forma mínima.

En el cuadro que exponemos a continuación podemos ver una relación de todas las personas que ocuparon el cargo entre 1597 y 1708.

Tabla 6: Almotacén de la ciudad de Castellón entre 1597 y $1707^{106}$ :

\begin{tabular}{|c|c|c|}
\hline Año & Almotacén & Grupo oligárquico \\
\hline 1598 & Cristòfol Gascó & Ciutadà \\
\hline 1599 & Bertomeu Bonet & Llaurador \\
\hline 1600 & Llorens Sisternés & Ciutadà \\
\hline 1601 & Jaume Bonet & Llaurador \\
\hline 1602 & & \\
\hline 1603 & & \\
\hline 1604 & & \\
\hline 1605 & Cristòfol Gascó & Ciutadà \\
\hline 1606 & Gerony Jover & Doctor en dret \\
\hline 1607 & & \\
\hline 1608 & Cosme Martí & Ciutadà \\
\hline 1609 & Nicolau Reus & Cavaller \\
\hline 1610 & Bertomeu Bonet & Llaurador \\
\hline 1611 & Melchor Salvador & Notari \\
\hline 1612 & Jaume Giner & Notari \\
\hline 1613 & Gerony Arrufat & Cavaller \\
\hline 1614 & Joan Batiste Vallés & Notari \\
\hline 1615 & Francesc Jover & Notari \\
\hline 1616 & Miquel Aragonés & Notari \\
\hline 1617 & Joan Arrufat & Cavaller \\
\hline 1618 & & \\
\hline 1619 & & \\
\hline 1620 & Pere Figuerola & Llaurador \\
\hline 1621 & Jaume Blasco & Mercader \\
\hline 1622 & Antoni Joan Lleó & Ciutadà \\
\hline 1623 & Mateu Ros & Cavaller \\
\hline 1624 & Cristòfol Sisternés & Ciutadà \\
\hline 1625 & Miquel Giner & Ciutadà \\
\hline 1626 & Nicolau Figuerola & Doctor en dret \\
\hline 1627 & Joan Arrufat & Cavaller \\
\hline
\end{tabular}

\footnotetext{
${ }^{106}$ AHMC. Elaborada a partir de la revisión de todas las reuniones del Consell reflejadas en el Judiciari entre 1597 y 1707.
} 


\begin{tabular}{|c|c|c|}
\hline Año & Almotacén & Grupo oligárquico \\
\hline 1628 & Melchor Salvador & Notari \\
\hline 1629 & Miquel Vicent Pasqual & Llaurador \\
\hline 1630 & Cristòfol Bou & Notari \\
\hline 1631 & Pere Morales & Cavaller \\
\hline 1632 & Francesc Josep Bou & Ciutadà \\
\hline 1633 & Martí Castell & Llaurador \\
\hline 1634 & Batiste Moliner & Notari \\
\hline 1635 & Francesc Sisternés & Cavaller \\
\hline 1636 & Martí Castell & Llaurador \\
\hline 1637 & Melchor Amiguet & Notari \\
\hline 1638 & Batiste Gascó & Doctor en dret \\
\hline 1639 & Francesc Sisternés & Cavaller \\
\hline 1640 & Nicolau Serra & Ciutadà \\
\hline 1641 & Andreu March & Llaurador \\
\hline 1642 & Cristòfol Bou & Notari \\
\hline 1643 & Pere Reus & Cavaller \\
\hline 1644 & Batiste Moliner & Notari \\
\hline 1645 & Vicent Castellet & Doctor en dret \\
\hline 1646 & Melchor Amiguet & Notari \\
\hline 1647 & Francesc Sisternés & Cavaller \\
\hline 1648 & Batiste Jover & Ciutadà \\
\hline 1649 & Berenguer Ribalta & Llaurador \\
\hline 1650 & Joan Vilarroig de Miquel & Llaurador \\
\hline 1651 & Josep Alberich & Notari \\
\hline 1652 & Vicent Martí & Notari \\
\hline 1653 & Vicent Vilar & Doctor en dret \\
\hline 1654 & Miquel Giner & Llaurador \\
\hline 1655 & Pere Giner & Cavaller \\
\hline 1656 & Josep Castell de Antoni & Llaurador \\
\hline 1657 & Vicent Martí & Notari \\
\hline 1658 & Pere Giner & Cavaller \\
\hline 1659 & Josep Alberich & Notari \\
\hline 1660 & Miquel Giner & Llaurador \\
\hline 1661 & Vicent Museros & Llaurador \\
\hline 1662 & Vicent Pasqual & Notari \\
\hline 1663 & Fernando Miralles & Generós \\
\hline 1664 & Pere Vilarroig & Llaurador \\
\hline 1665 & Martí Mas & Cavaller \\
\hline 1666 & Gaspar Eiximeno & Llaurador \\
\hline 1667 & Fernando Miralles & Generós \\
\hline 1668 & Aleixandre Martí & Notari \\
\hline 1669 & Joan Ros de Ursins & Cavaller \\
\hline 1670 & Jaume Cases & Notari \\
\hline 1671 & Miquel Vallés & Generós \\
\hline 1672 & Gaspar Brunell & Cirugià \\
\hline 1673 & Basilio Reus & Cavaller \\
\hline 1674 & Cosme Martí & Ciutadà \\
\hline 1675 & Andreu Ribalta & Llaurador \\
\hline 1676 & Joan Castell & Cavaller \\
\hline 1677 & Miquel Llansola & Llaurador \\
\hline 1678 & Andreu Ribalta & Llaurador \\
\hline 1679 & Macià Igual & Generós \\
\hline 1680 & Pere Navarro de Joan & Llaurador \\
\hline 1681 & Miquel Pasqual de Francesc & Llaurador \\
\hline 1682 & Macià Compte & Notari \\
\hline 1683 & Basilio Reus & Cavaller \\
\hline 1684 & Felip Sorrando & Mercader \\
\hline 1685 & Miquel Pasqual de Francesc & Llaurador \\
\hline 1686 & Miquel Pasqual de Francesc & Llaurador \\
\hline
\end{tabular}




\begin{tabular}{|l|c|c|}
\hline Año & Almotacén & Grupo oligárquico \\
\hline $\mathbf{1 6 8 7}$ & March Antoni Jordà & Cavaller \\
$\mathbf{1 6 8 8}$ & Vicent Ferrer & Notari \\
$\mathbf{1 6 8 9}$ & Fernando Miralles & Generós \\
$\mathbf{1 6 9 0}$ & Gabriel Segarra de Josep & Llaurador \\
$\mathbf{1 6 9 1}$ & Miquel Bonet notari & Notari \\
$\mathbf{1 6 9 2}$ & Jaume Giner & Doctor en dret \\
$\mathbf{1 6 9 3}$ & Miquel Garcés & Doctor en medicina \\
$\mathbf{1 6 9 4}$ & Ignacio Figuerola & Doctor en dret \\
$\mathbf{1 6 9 5}$ & Josep Igual & Generós \\
$\mathbf{1 6 9 6}$ & Miquel Pasqual de Francesc & Llaurador \\
$\mathbf{1 6 9 7}$ & Pere Breva & Notari \\
$\mathbf{1 6 9 8}$ & March Casalís & Llaurador \\
$\mathbf{1 6 9 9}$ & Joachim Gombau & Generós \\
$\mathbf{1 7 0 0}$ & Josep Amposta & Cirurgià \\
$\mathbf{1 7 0 1}$ & Jaume Giner & Doctor en dret \\
$\mathbf{1 7 0 2}$ & Antoni Castell & Llaurador \\
$\mathbf{1 7 0 3}$ & Josep Castell de Museros & Cavaller \\
$\mathbf{1 7 0 4}$ & Felip Breva & Notari \\
$\mathbf{1 7 0 5}$ & Joan Andreu & Doctor en dret \\
$\mathbf{1 7 0 6}$ & Gaspar Rubert & Notari \\
$\mathbf{1 7 0 7}$ & Vicent Figuerola & Ciutadà \\
\hline
\end{tabular}

La única anomalía que hemos encontrado es que en septiembre de 1686 no se hace elección de almotacén por pleito en la Real Audiencia de Valencia y se mantiene en el cargo Miquel Pasqual de Francesc.

Los datos de la tabla nos muestran como tampoco hubo una repetición en la ocupación del cargo. Podemos destacar el caso de Miquel Pasqual de Francesc que lo ocupó cuatro veces, dos de ellas de forma consecutiva, o los caballeros Francesc Sisternés y Fernando Miralles con tres veces. También lo ocupó tres veces Miquel Giner.

Se vuelve a repetir lo que habíamos visto en el oficio de justicia, es decir, que no hay una repetición de personas en este cargo, puesto que en los ciento cuatro años estudiados encontramos a ochenta y dos personas diferentes. Volvemos a obtener las mismas conclusiones que en el caso anterior y en las que insistiremos más adelante. No es poder a nivel individual de un oficio, es cuestión de ir desempeñando oficios que permitan siempre tener un puesto en el Consell, y como las mismas personas ya aparecen en los oficios estudiados y después como consejeros.

\footnotetext{
${ }^{107}$ Los nombres que aparecen en negrita corresponden al año en que el almotacén es elegido del brazo militar y los años que están en blanco es o porque el Judiciari está en muy mal estado o porque se ha extraviado.
} 


\subsubsection{Escribano.}

Este oficio se elegía en la víspera de la Pascua de Pentecostés junto a los jurados y consejeros. Desde la Ordinación de Covarrubias y hasta el final de la época foral se elegirá por el procedimiento de insaculación. La única modificación relevante se produce con el Privilegio de Felipe III de 1597 en el que se amplía el período en que pueden ejercer su cargo dejándolo en tres años consecutivos frente a los dos que reflejaba la Ordinación de 1590. Este hecho se ha podido comprobar como se produce en todo el período objeto de nuestro estudio y solo se ve modificado cuando hay algún fallecimiento $^{108}$. Su función consistía en dar fe de todas las reuniones del Consell y de los jurados, así como de todos los oficiales de la villa, formando un conjunto de documentación que recibe el nombre de Judiciari. El cargo fue ocupado, como es lógico pensar, por los notarios que ejercían en la villa, puesto que podemos definir el cargo como el notario oficial del municipio. Además es fundamental su papel en el procedimiento de insaculación ya que es el encargado de la custodia del archivo local donde se encuentra la caja de las insaculaciones y el libro de registro de las personas insaculadas ${ }^{109}$. A continuación podemos ver detallados todos los escribanos de la ciudad.

Tabla 7: Escribanos de la ciudad de Castellón entre 1597 y $1707^{110}$ :

\begin{tabular}{|c|c|}
\hline Año & Escribano \\
\hline 1597-1598 & Domingo Beltran \\
$\mathbf{1 5 9 9 - 1 6 0 1}$ & Bertomeu Moliner \\
$\mathbf{1 6 0 2 - 1 6 0 4}$ & Francesc Jover \\
$\mathbf{1 6 0 5 - 1 6 0 7}$ & Bertomeu Moliner \\
$\mathbf{1 6 0 8 - 1 6 1 0}$ & Jaume Giner \\
$\mathbf{1 6 1 1 - 1 6 1 3}$ & Francesc Jover \\
$\mathbf{1 6 1 4 - 1 6 1 6}$ & Melchor Salvador \\
$\mathbf{1 6 1 7 - 1 6 1 9}$ & \\
$\mathbf{1 6 2 0 - 1 6 2 2}$ & Pau Capero \\
$\mathbf{1 6 2 3 - 1 6 2 4}$ & Francesc Joan Bou \\
$\mathbf{1 6 2 5 - 1 6 2 7}$ & Gerony Quevedo \\
$\mathbf{1 6 2 8 - 1 6 3 0}$ & Pau Capero \\
$\mathbf{1 6 3 1 - 1 6 3 3}$ & Lluís Cristòfol Bou \\
$\mathbf{1 6 3 4 - 1 6 3 6}$ & Jaume Castellet \\
$\mathbf{1 6 3 7 - 1 6 3 9}$ & Pere Giner \\
$\mathbf{1 6 4 0 - 1 6 4 2}$ & Jaume Andreu \\
$\mathbf{1 6 4 3 - 1 6 4 5}$ & Jaume Castellet \\
\cline { 2 - 2 }
\end{tabular}

\footnotetext{
108 Véase en la tabla 7 el listado de escribanos.

${ }^{109}$ AHMC. Llibre de les Insaculacions.

${ }^{110}$ AHMC. Elaborado a partir de todas las reuniones del Consell reflejadas en el Judiciari entre 1597 y 1707.
} 


\begin{tabular}{|c|c|}
\hline Año & Escribano \\
\hline $\mathbf{1 6 4 6 - 1 6 4 8}$ & Vicent Martí \\
$\mathbf{1 6 4 9}$ & Pere Romeu \\
$\mathbf{1 6 5 0}$ & Pere Romeu/Pere Giner \\
$\mathbf{1 6 5 1 - 1 6 5 2}$ & Pere Giner \\
$\mathbf{1 6 5 3 - 1 6 5 5}$ & Vicent Martí \\
$\mathbf{1 6 5 6 - 1 6 5 8}$ & Vicent Porta \\
$\mathbf{1 6 5 9 - 1 6 6 1}$ & Vicent Martí \\
$\mathbf{1 6 6 2 - 1 6 6 4}$ & Pere Giner \\
$\mathbf{1 6 6 5 - 1 6 6 7}$ & Vicent Martí \\
$\mathbf{1 6 6 8 - 1 6 7 0}$ & Vicent Tosquella \\
$\mathbf{1 6 7 1 - 1 6 7 3}$ & Jaume Cases \\
$\mathbf{1 6 7 4 - 1 6 7 6}$ & Vicent Tosquella \\
$\mathbf{1 6 7 7 - 1 6 7 9}$ & Jaume Cases \\
$\mathbf{1 6 8 0 - 1 6 8 2}$ & Miquel Bonet \\
$\mathbf{1 6 8 3 - 1 6 8 5}$ & Jaume Cases \\
$\mathbf{1 6 8 6 - 1 6 8 8}$ & Pere Figuerola \\
$\mathbf{1 6 8 9 - 1 6 9 1}$ & Vicent Tosquella \\
$\mathbf{1 6 9 2 - 1 6 9 4}$ & Pere Breva \\
$\mathbf{1 6 9 5 - 1 6 9 6}$ & Macià Compte \\
$\mathbf{1 6 9 7}$ & Macià Compte/Pere Museros \\
$\mathbf{1 6 9 8 - 1 7 0 0}$ & Pere Breva \\
$\mathbf{1 7 0 1 - 1 7 0 3}$ & Pere Vidal \\
$\mathbf{1 7 0 4 - 1 7 0 6}$ & Aleixandre Martí \\
$\mathbf{1 7 0 7}$ & Pere Museros \\
\hline \multicolumn{2}{|c|}{ Elaboración propia ${ }^{I I I}}$. \\
\hline
\end{tabular}

No hemos podido averiguar el motivo de la sustitución de Francesc Joan Bou en 1624 en el cargo de escribano porque no tenemos los nombramientos de 1625. El escribano de 1628 era Gerony Quevedo pero a su muerte ocupó el puesto Pau Capero que después fue elegido escribano. En 1650 fue sustituido Pere Romeu por Pere Giner. Como no tenemos el nombramiento no podemos averiguar cual es la causa. En 1697 Macià Compte fue sustituido por Pere Museros por el fallecimiento del primero.

Como ocurría anteriormente no hay un control de una persona o varias que copen este oficio. Destacan Vicent Martí con cuatro ocasiones, Vicent Tosquella con tres y Pere Giner también con tres. Pero hemos de tener en cuenta que hay hasta veinticuatro personas diferentes que ocupan el cargo y si lo comparamos con las treinta y nueve ocasiones en que se ocupó el puesto, obtenemos que había mucha diversidad. Esto mantiene nuestra argumentación anterior que defendía la no existencia de personas aposentadas en un oficio en concreto, sin embargo, si que aparecen los mismos nombres que en el resto de oficios, lo que nos lleva a pensar que no se repetía en un cargo concreto pero si que se movían de un oficio a otro para estar siempre presentes en el Consell.

${ }^{111}$ Los años que no tenemos datos, los dejamos en blanco. 


\subsubsection{Acequiero.}

Este oficio se encargaba de los asuntos relacionados con el riego y tenía bajo su jurisdicción la acequia mayor. Su elección se realizaba a finales de diciembre y empezó a realizarse por el procedimiento de insaculación a partir de la Ordinación de Covarrubias de 1590. Ya se ha aclarado anteriormente la afirmación errónea sobre su inclusión en el Consell por haber ejercido el cargo en el año anterior que exponía Arroyas Serrano en su libro ${ }^{112}$. Además se podrá ejercer este cargo y el de consejero como el caso de Francesc Vilarroig que en diciembre de 1638 es elegido acequiero y en mayo de 1639 consejero.

La relación de acequieros la exponemos detallada a continuación:

Tabla 8:Acequieros de la ciudad de Castellón entre 1597 y $1707^{113}$ :

\begin{tabular}{|c|c|c|}
\hline Año & Acequiero & Grupo oligárquico \\
\hline 1597 & Joan Vilarroig & Llaurador \\
\hline 1598 & Pere Figuerola (desde marzo) & Llaurador \\
\hline 1599 & Miquel Pasqual & Llaurador \\
\hline 1600 & Joan Sanchís & Llaurador \\
\hline 1601 & Joan Vilarroig & Llaurador \\
\hline 1602 & Joan Alegre de Bertomeu & Llaurador \\
\hline 1603 & & \\
\hline 1604 & & \\
\hline 1605 & Batiste Gisbert & Llaurador \\
\hline 1606 & Joan Vilarroig & Llaurador \\
\hline 1607 & & \\
\hline 1608 & Joan Figuerola & Llaurador \\
\hline 1609 & & \\
\hline 1610 & Francesc Mas & Llaurador \\
\hline 1611 & & \\
\hline 1612 & Miquel Sanchís & Llaurador \\
\hline 1613 & Miquel Navarro & Llaurador \\
\hline 1614 & Gabriel Segarra & Llaurador \\
\hline 1615 & Nicolau Coll & Llaurador \\
\hline 1616 & Andreu Pasqual & Llaurador \\
\hline 1617 & Pere Vilarroig & Llaurador \\
\hline 1618 & & \\
\hline 1619 & & \\
\hline 1620 & Gabriel Segarra & Llaurador \\
\hline 1621 & Andreu Pasqual & Llaurador \\
\hline 1622 & Joan Vilarroig de Bertomeu & Llaurador \\
\hline 1623 & Nicolau Alegre & Llaurador \\
\hline 1624 & Miquel Forés & Llaurador \\
\hline 1625 & & \\
\hline 1626 & Batiste Serra & Ciutadà \\
\hline
\end{tabular}

\footnotetext{
${ }^{112}$ Para una mejor comprensión de esta afirmación recomendamos revisar el listado de acequieros desde 1597 hasta 1707 de la tabla 8, la lista de miembros del Consell en el mismo período de la tabla 2 y las anotaciones sobre su estructura de la tabla 3.

${ }^{113}$ AHMC. Elaborado a partir de las reuniones del Consell reflejadas en el Judiciari entre 1597 y 1707.
} 


\begin{tabular}{|c|c|c|}
\hline Año & Acequiero & Grupo oligárquico \\
\hline 1627 & Joan Bosch & Llaurador \\
\hline 1628 & Miquel Rubert & Llaurador \\
\hline 1629 & Batiste Moliner & Cirugià \\
\hline 1630 & Pere Eiximeno & Llaurador \\
\hline 1631 & Miquel Vicent Pasqual & Llaurador \\
\hline 1632 & Francesc Castell de Francesc & Llaurador \\
\hline 1633 & Miquel Rubert & Llaurador \\
\hline 1634 & Monserrat Martí & Llaurador \\
\hline 1635 & Francesc Josep Bou & Ciutadà \\
\hline 1636 & Jaume Montanyés & Llaurador \\
\hline 1637 & Berenguer Ribalta & Llaurador \\
\hline 1638 & Lluís Mas & Llaurador \\
\hline 1639 & Francesc Vilarroig & Llaurador \\
\hline 1640 & Mateu Sanchís & Llaurador \\
\hline 1641 & Francesc Mas & Llaurador \\
\hline 1642 & Bertomeu Navarro & Llaurador \\
\hline 1643 & Jaume Montanyés & Llaurador \\
\hline 1644 & Mateu Sanchís & Llaurador \\
\hline 1645 & Francesc Moliner & Llaurador \\
\hline 1646 & Joan Navarro de Joan & Llaurador \\
\hline 1647 & Joan Castell & Cavaller \\
\hline 1648 & Mateu Sanchís & Llaurador \\
\hline 1649 & Jaume Roig & Llaurador \\
\hline 1650 & Miquel Giner & Doctor en Dret \\
\hline 1651 & Francesc Moliner & Llaurador \\
\hline 1652 & Miquel Romeu & Ciutadà \\
\hline 1653 & Miquel Boix & Llaurador \\
\hline 1654 & Josep Avinent & Llaurador \\
\hline 1655 & Gaspar Brunell & Ciutadà \\
\hline 1656 & Francesc Amiguet & Llaurador \\
\hline 1657 & Vicent Castellet & Doctor en Dret \\
\hline 1658 & Miquel Giner & Doctor en Dret \\
\hline 1659 & Miquel Sanchís & Llaurador \\
\hline 1660 & Joan Navarro & Llaurador \\
\hline 1661 & Martí Viciano & Llaurador \\
\hline 1662 & Pere Castell de Francesc & Llaurador \\
\hline 1663 & Miquel Sanchís & Llaurador \\
\hline 1664 & Francesc Amiguet & Llaurador \\
\hline 1665 & Gerony Rubert & Llaurador \\
\hline 1666 & Vicent Eiximeno & Llaurador \\
\hline 1667 & Josep Castell & Llaurador \\
\hline 1668 & Gerony Rubert & Llaurador \\
\hline 1669 & Pere Calbo & Llaurador \\
\hline 1670 & Antoni Castell & Llaurador \\
\hline 1671 & Miquel Vilarroig & Llaurador \\
\hline 1672 & Miquel Català & Llaurador \\
\hline 1673 & Gerony Rubert & Llaurador \\
\hline 1674 & Miquel Llansola & Llaurador \\
\hline 1675 & Vicent Eiximeno & Llaurador \\
\hline 1676 & Josep Avinent menor & Llaurador \\
\hline 1677 & Pere Museros de Vicent & Llaurador \\
\hline 1678 & Miquel Boix de Miquel & Llaurador \\
\hline 1679 & Gerony Castell & Llaurador \\
\hline 1680 & Miquel Vilarroig de Nicolau & Llaurador \\
\hline 1681 & Vicent Eiximeno & Llaurador \\
\hline 1682 & Andreu Ribalta & Llaurador \\
\hline 1683 & Josep Amposta & Cirurgià \\
\hline 1684 & Pere Museros de Vicent & Llaurador \\
\hline 1685 & March Casalís & Llaurador \\
\hline
\end{tabular}




\begin{tabular}{|l|c|c|}
\hline Año & Acequiero & Grupo oligárquico \\
\hline $\mathbf{1 6 8 6}$ & Domingo Vilarroig & Llaurador \\
$\mathbf{1 6 8 7}$ & Pere Calbo & Llaurador \\
$\mathbf{1 6 8 8}$ & Miquel Pasqual de Francesc & Llaurador \\
$\mathbf{1 6 8 9}$ & Gerony Castell & Llaurador \\
$\mathbf{1 6 9 0}$ & Francesc Vilarroig & Llaurador \\
$\mathbf{1 6 9 1}$ & Miquel Català de Pere & Llaurador \\
$\mathbf{1 6 9 2}$ & Gaspar Rubert & Notari \\
$\mathbf{1 6 9 3}$ & Josep Museros de Vicent & Llaurador \\
$\mathbf{1 6 9 4}$ & Gabriel Segarra de Josep/March & Llaurador/Llaurador \\
& Casalís & \\
$\mathbf{1 6 9 5}$ & Gaspar Rubert & Notari \\
$\mathbf{1 6 9 6}$ & Josep Museros de Vicent & Llaurador \\
$\mathbf{1 6 9 7}$ & Vicent Pasqual & Notari \\
$\mathbf{1 6 9 8}$ & Jacint March & Doctor en dret \\
$\mathbf{1 6 9 9}$ & Miquel Pasqual de Francesc & Llaurador \\
$\mathbf{1 7 0 0}$ & Joan Safont & Notari \\
$\mathbf{1 7 0 1}$ & Felip Roig & Llaurador \\
$\mathbf{1 7 0 2}$ & Francesc Amiguet & Llaurador \\
$\mathbf{1 7 0 3}$ & Andreu Castellet & Llaurador \\
$\mathbf{1 7 0 4}$ & Pere Museros & Notari \\
$\mathbf{1 7 0 5}$ & Josep Rubert & Llaurador \\
$\mathbf{1 7 0 6}$ & Joan Breva & Llaurador \\
$\mathbf{1 7 0 7}$ & Miquel Avinent & Llaurador \\
\hline
\end{tabular}

Elaboración propia ${ }^{114}$.

El cambio que se produce en agosto de 1694 en el que se nombra a March Casalís, es debido al fallecimiento de Gabriel Segarra de Josep.

Las conclusiones a nivel individual que podemos extraer de la tabla siguen la misma línea que los oficios anteriores. No hay alguna persona que ocupó el cargo de una forma sistemática, siendo tres el máximo número de veces que lo ocupan Francesc Amiguet, Vicent Eiximeno, Gerony Rubert, Miquel Sanchís, Mateu Sanchís y Joan Vilarroig. Al igual que ocurre en los cargos de justicia y almotacén en los ciento tres años que hemos estudiado, han aparecido setenta y ocho personas diferentes, por tanto, no encontramos personas ancladas en el oficio, sino que serán personas que iran ocupando los distintos puestos para seguir en el Consell. Por este motivo seguimos viendo a las mismas personas en cada uno de los oficios. En este caso si que nos gustaría mencionar el aspecto curioso de 1647 cuando Joan Castell del brazo militar ocupa el cargo de acequiero, pero no hemos podido averiguar en el Judiciari cuál fue el motivo.

\footnotetext{
${ }^{114}$ Los años 1603, 1604, 1607, 1609, 1611, 1618 y 1619 no tenemos datos y se dejan en blanco. Además en 1625 letra ilegible por lo que no podemos averiguar quién es el acequiero.
} 


\subsection{Oficios que no se elegían por el proceso insaculatorio.}

A continuación se citan algunos oficios municipales que no eran elegidos por el proceso insaculatorio pero sí que eran elegidos por el Consell, por tanto son los miembros de éste los que deciden qué personas los ocupan. Es pues de vital importancia entrar a formar parte de la institución municipal para elegir los distintos cargos, participar en la elección de los nuevos insaculados y poder formar parte de las élites de poder. Hemos de tener en cuenta que una vez dentro del Consell era mucho más fácil extender los tentáculos familiares en los diversos oficios y cargos.

$\mathrm{El}$ asesor de justicia era el encargado de ayudar al justicia en materia legal. $\mathrm{Su}$ elección se realizaba en el mes de diciembre, momentos después de haber elegido a la persona que ocuparía el cargo de justicia. La terna de candidatos se proponía al Consell y eran éstos los que decidían quién iba a ocupar el cargo. Es pues evidente que las oligarquías locales representadas en el órgano de poder local eran las que decidían este oficio. A modo de ejemplo se adjunta una relación de todos los asesores entre 1597 y $1707^{115}$.

El síndico o mensajero tenía como función acudir a Valencia o Madrid en representación de la villa de Castellón para defender sus intereses y cuya elección no tenía una fecha concreta puesto que dependía del asunto que se debía tratar. Podemos citar como ejemplo al doctor en leyes Joan Batiste Gascó que es enviado a Valencia en noviembre de 1639 para resolver un asunto relacionado con la acequia de la villa. Era de especial relevancia el nombramiento del síndico que acudía a la convocatoria de cortes $^{116}$. Sin embargo, hemos de hacer una mención aparte al síndico o tesorero del Consell también llamado clavario o taulatger que es un consejero más entre los elegidos en la insaculación en la víspera de la Pascua de Pentecostés ${ }^{117}$. Era el encargado de las cuentas municipales y debía prestar un juramento de buen uso de las rentas que iba a manejar. Es precisamente este oficio el que tendrá derecho a ocupar un asiento del Consell en el siguiente ejercicio por haber formado parte de él.

\footnotetext{
115 Véase en el apéndice el documento 11 el listado de asesores de justicia.

${ }^{116}$ Arroyas Serrano, M. (1989): El Consell.. op. cit. pp.117. Magín nos explica la función que tenía este enviado de la villa de Castellón y como se realizaba una elección secreta.

${ }^{117}$ Véase en la tabla 32 la lista de síndicos del Consell.
} 
El Clavari de forments surgió porque Castellón se vió afectada en muchos casos por problemas de abastecimiento de trigo por lo que su función se centró principalmente en este ámbito. Su elección se realizaba una vez los jurados elegidos en la víspera de la Pascua de Pentecostés habían prestado su juramento. Encontramos otro cargo que dependía expresamente de los miembros del Consell, en la misma línea que el asesor del justicia y el síndico del Consell. Como ejemplos citamos a Jaume Jover elegido en junio de $1639^{118}$ y a Martí Viciano elegido en mayo de $1668^{119}$.

El asesor de los jurados y asesor de pobres era el encargado de ayudar a los jurados en temas de leyes por lo que siempre será un doctor en esta materia. Su elección también se realiza después del juramento de los jurados y síndico. Otro cargo que es directamente nombrado por los miembros del Consell y que recaerá evidentemente en personas relacionadas con la esfera de poder de los insaculados y recién elegidos consejeros. Como ejemplos citamos a micer Joan Batiste Gascó elegido en junio de $1639^{120}$ o a Josep Miralles elegido en mayo de $1668^{121}$.

El síndico procurador de pobres tenía como función la defensa de las gentes que no tenían representación en el Consell y su elección se realizaba al final del mes de diciembre. El Consell elige entre los miembros aptos una terna de tres que le son propuestos al jurado primero, y éste designa el que cree más oportuno. Para optar a este oficio se debía tener bienes por valor de mil libras y además se exigía que si se había ocupado un año se debía esperar dos para volver a ocuparlo. Volvemos a encontrarnos su nombramiento como parte del poder del Consell de Castellón. Podemos citar como ejemplos de personas que ocuparon este cargo a Cristòfol Bou notario, que lo ocupó en $1640^{122}$ o a Jaume Cases, también notario, que lo ocupó en $1669^{123}$.

El sacristán se encargaba de los asuntos religiosos que quedaban en manos de la villa y no del obispado, entre los cuales se encontraba la custodia de las joyas y alhajas

\footnotetext{
${ }^{118}$ AHMC. Judiciari 1637-1638-1639-1640. Sesión del Consell de 9 de junio de 1639.

${ }^{119}$ AHMC . Judiciari. 1668-1669-1670-1671. Sesión del Consell de 27 de mayo de 1668.

${ }^{120}$ AHMC. Judiciari. 1637-1638-1639-1640. Sesión del Consell de 9 de junio de 1639.

${ }^{121}$ AHMC. Judiciari. 1668-1669-1670-1671. Sesión del Consell de 27 de mayo de 1668.

${ }^{122}$ AHMC. Judiciari. 1637-1638-1639-1640. Sesión del Consell de 26 de diciembre de 1639.

${ }^{123}$ AHMC. Judiciari. 1668-1669-1670-1671. Sesión del Consell de 27 de diciembre de 1668.
} 
de la iglesia mayor. Su elección se realizaba a finales de diciembre y aunque no era elegido por el sistema insaculatorio si que tenía ciertas peculiaridades. En primer lugar se exigía la posesión de bienes por valor de mil libras y no tener ninguno de los impedimentos generales. Una vez constatados estos aspectos, se procedía a introducir los nombres de los candidatos que se habían ofrecido en la vasija y se extraían tres nombres de entre los cuales el justicia elegía a uno. Evidentemente el justicia, miembro de las oligarquías tomaba la decisión final que se ajustaba a sus intereses. Como ejemplos citamos a Pere Alegre que lo fue en el año $1640^{124}$ o a Miquel Navarro de Gaspar para el año $1669^{125}$.

El taulager dels bons segrets centraba sus funciones en los asuntos económicos de la corte del justicia y se elegía en diciembre. Como ejemplos citaremos a Batiste Jover para $1640^{126}$ y a Jaume Cases notario para $1669^{127}$. Y es en este punto donde nos gustaría resaltar que este último ocupa dos cargos en el mismo ejercicio, el de síndico procurador de pobres y el taulager de bons segrets.

A los verguers les correspondían las labores de alguaciles, siendo su función específica actuar de testigo en los actos notariales del Consell y de los jurados y entregar las notificaciones de éstos. Su nombramiento no se determina en una época del año en concreto. Su elección se produce dentro del Consell por lo que sigue siendo fundamental estar bien relacionado con las oligarquías del municipio representadas en él. Como ejemplo citamos a Jaume Fortuny y Baltazar Martíns, testigos de la insaculación de $1686^{128}$.

El nuncio o trompeta público era el encargado de dar a conocer a los habitantes de la villa de Castellón aquellos asuntos o decisiones de interés general y que le habían entregado el oficio correspondiente. La comunicación pública se hacía en los lugares habituales del municipio. Es evidente que su elección también dependía del organismo

\footnotetext{
${ }^{124}$ AHMC. Judiciari. 1637-1638-1639-1640. Sesión del Consell de 26 de diciembre de 1639.

${ }^{125}$ AHMC. Judiciari. 1668-1669-1670-1671. Sesión del Consell de 27 de diciembre de 1668.

${ }^{126}$ AHMC. Judiciari. 1637-1638-1639-1640. Sesión del Consell de 26 de diciembre de 1639.

${ }^{127}$ AHMC. Judiciari. 1668-1669-1670-1671. Sesión del Consell de 27 de diciembre de 1668.

${ }^{128}$ AHMC. Llibre de les Insaculacions. Insaculación de 17 de octubre de 1686. En el documento número 9 del apéndice documental se recoge la transcripción de todas las insaculaciones y entre ellas la de 1686.
} 
municipal. Como ejemplo podemos citar a Pere López que ocupa el puesto en abril de 1668 y convoca públicamente al Consell para realizar la insaculación o mejor dicho la introducción de nuevas personas insaculadas.

Los caps de guayta se encargaban de auxiliar al justicia en sus funciones y no eran elegidos por el Consell, sino que su elección se delegaba en una comisión que se nombraba en el mes de diciembre junto al justicia. Eran dos personas respetables y naturales de la villa, que debían llevar insignia como ocurría en la ciudad de Valencia y que consistía en un bastón. Evidentemente la comisión que los elegía estaba formada por personas de las oligarquías municipales. Esto nos lleva a pensar de nuevo que serán personas muy cercanas al poder de la villa emanado del Consell.

La función dels Prohoms de Canet y Mediona está ligada a estas acequias y se elegían en diciembre por el Consell. La importancia de ocupar estos cargos la podemos ver reflejada en los nombres que lo ocuparon, ya que al igual que ocurrió con el oficio de acequiero, serán los labradores enriquecidos quiénes lo detenten. Como ejemplos podemos citar a Pere Font y Pere Vilarroig de Bertomeu para $1640^{129}$ y Pere Avinent y Tomàs Moliner para $1669^{130}$.

Además en el Consell existían las elecciones de prohoms encargados de un tema concreto, como la del primero de octubre de 1668 en la que hay dos representantes de los caballeros Pere Serra i Dols y Josep Igual, dos representantes de los ciudadanos Gaspar Brunell y Joan Andreu, dos representantes de los artistas Vicent Pasqual notari y Josep Alberich mercader y finalmente dos representantes de los labradores Josep Castell de Francesc y Gaspar Eiximeno. En el caso que exponemos como ejemplo consistía en ${ }^{131}$ :

“...tractar les cosses que es poden oferir en la fàbrica de la Torre de la vora de la mar de este terme, cossa que necessita esta vila. Per a que no siga menester cada vegada que suscite alguna dificultat, ajuntar Consell donantlos per a dit effecte bastant poder

\footnotetext{
${ }^{129}$ AHMC. Judiciari. 1637-1638-1639-1640. Sesión del Consell de 27 de diciembre de 1639.

${ }^{130}$ AHMC. Judiciari. 1668-1669-1670-1671. Sesión del Consell de 27 de diciembre de 1668.

${ }^{131}$ AHMC. Judiciari. 1668-1669-1670-1671. Sesión del Consell de 1 de octubre de 1668.
} 
per a delliberar i concertar les cosses que es poden offerir en la fábrica de dita Torre, sens consulta del Consell". 


\section{Las Insaculaciones: control y perpetuidad.}

\subsection{El límite en las bolsas de 1604: Una puerta abierta a cerrar el acceso al poder local.}

La historiografía tradicional ha supuesto que el proceso insaculatorio era una herramienta para que las clases dirigentes de las villas se mantuvieran en el poder y que, a su vez, se restringiese el acceso a las bolsas que suponían al fin y al cabo la remesa de donde se nutrían los candidatos a los cargos u oficios de la villa de Castellón. En este apartado vamos a realizar un análisis pormenorizado de las personas que fueron insaculadas para los distintos oficios del municipio durante el siglo XVII, de forma que podamos comprender qué familias se perpetúan en el poder, y cuales tienen una presencia más marginal o aquellas que, con solo un representante, consiguen situarse siempre en la élite municipal.

Esta tarea exige un estudio meticuloso de todas y cada una de las insaculaciones realizadas en el municipio castellonense, y que en muchas ocasiones no se encuentra detallado en el Llibre de les Insaculacions, por lo que hemos tenido que recurrir al Judiciari donde se recogen las actas del Consell, institución que realizaba los procesos insaculatorios.

Antes de desmenuzar todos los datos obtenidos adjuntamos una tabla en la que podemos ver el número de personas insaculadas durante en siglo XVII, y que ya ha había aportado Arroyas Serrano ${ }^{132}$, pero que requería ciertas matizaciones y puntualizaciones.

${ }^{132}$ Arroyas Serrano, M. (1989): El Consell... op. cit., pp. 77. 
Tabla 9: Las insaculaciones y el número de personas insaculadas ${ }^{133}$ :

\begin{tabular}{|c|c|c|c|c|c|c|c|c|c|c|}
\hline & CAB & JUST & JBR & J2A & J3y4 & ESCR & ACEQ & ALM & CMM & CMN \\
\hline 1590 & 2 & 25 & 15 & 15 & 30 & 11 & 36 & 36 & 33 & 39 \\
\hline 1598 & 5 & - & 15 & 10 & 29 & - & - & - & 1 & 8 \\
\hline 1600 & 9 & 34 & 23 & 21 & 40 & 13 & 51 & 46 & 48 & 55 \\
\hline 1604 & - & 30 & 20 & 20 & 40 & 10 & 50 & 40 & $40^{134}$ & 40 \\
\hline 1623 & 10 & 29 & 20 & 20 & 40 & 8 & 50 & 40 & 43 & 41 \\
\hline 1630 & 7 & 30 & 21 & 18 & 40 & 6 & 50 & 40 & 42 & 53 \\
\hline 1634 & 8 & 30 & 20 & 20 & 39 & 9 & 49 & 39 & 45 & 53 \\
\hline $1638-1643$ & 9 & 29 & 20 & 18 & 40 & 7 & 49 & 38 & 39 & 51 \\
\hline $1647-1648$ & 8 & 31 & 21 & 16 & 40 & 6 & 50 & 40 & 37 & 45 \\
\hline 1653 & 10 & 27 & 17 & 13 & 37 & - & 45 & 37 & 30 & 44 \\
\hline 1662 & 19 & 28 & 18 & 19 & 41 & 4 & 51 & 38 & 37 & 48 \\
\hline 1666 & 19 & 28 & 18 & 19 & 41 & 10 & 51 & 38 & 37 & 48 \\
\hline 1668 & 1 & 4 & 1 & 3 & 8 & 6 & 8 & 8 & - & - \\
\hline 1677 & 16 & 22 & 13 & 15 & 23 & 8 & 50 & 31 & 27 & 36 \\
\hline 1679 & 20 & 29 & 17 & 15 & 40 & 9 & 48 & 37 & 32 & 41 \\
\hline 1685 & 20 & - & 20 & 20 & 39 & - & - & - & 40 & 39 \\
\hline 1686 & - & 30 & - & 19 & 40 & 10 & 50 & 40 & 41 & 40 \\
\hline 1694 & 15 & 30 & 20 & 20 & 40 & 10 & 50 & 40 & 40 & 40 \\
\hline 1700 & 13 & 30 & 20 & 20 & 39 & 10 & 50 & 40 & 40 & 40 \\
\hline
\end{tabular}

La insaculación de 1598 viene reflejada en el judiciari pero más que una insaculación en si misma para todas las bolsas, supone una actualización de algunas de ellas, puesto que no se insacula ni la bolsa de justicias del brazo real, ni la de almotacén, ni la de acequieros ni la escribanos y en las de consejeros de mano mayor y menor son elegidos uno de mano mayor y ocho de mano menor, por lo que podría ser una ampliación de los que ya había. En 1600 hay una ampliación al final de la insaculación propiamente dicha en las bolsas de jurado tercero y cuarto (13), consejeros de mano mayor (9) y menor (20). Las hojas están en mal estado y en la bolsa de almotacén puede haber un nombre más pero lamentablemente no podemos confirmarlo. En la bolsa de acequieros suman 51 teniendo en cuenta un nombre tachado ilegible.

A partir de 1604 entra en vigor el límite de las bolsas, y de la insaculación que se produce en ese mismo año no tenemos listas, y no se fija límite para las bolsas de mano mayor y menor, sin embargo la práctica habitual es que sean cuarenta de cada mano, lo

\footnotetext{
${ }^{133}$ Se ha elaborado a partir de los datos de Arroyas Serrano citado anteriormente y del AHMC con el Llibre de les Insaculacions y aquellas insaculaciones que hemos encontrado en el Judiciari.

134 El número máximo de consejeros de mano menor y mano mayor que deben haber en las bolsas no se establece en 1604. En 1626 la villa realiza petición para que se establezca en 80 miembros, 40 de mano mayor y 40 de mano menor, que es lo que se venía haciendo desde 1604. Sin embargo esta petición no será confirmada al igual que incorporar al acequiero viejo en el Consell. Pese a eso podemos afirmar que el límite en las bolsas de mano mayor y menor siempre estuvo alrededor de 40 personas cada una.
} 
que supone un total de ochenta que es la suma de los veinte de jurado primero, más los veinte de jurado segundo más los cuarenta de jurado tercero y cuarto. En la insaculación de 1662 incluimos las tres personas introducidas en la bolsa militar en 1660. La insaculación ocurrida en 1668 genera un poco de problemática, ya que Arroyas Serrano establece unas cifras que nosotros no hemos encontrado en el Llibre de les Insaculacions, aunque si que hemos encontrado en el Judiciari de 1668 una insaculación que más parece una ampliación. Sin embargo, tampoco esto queda muy claro ya que en algunos casos solamente se repiten nombres de 1666. Por ello aportamos las cifras de las nuevas personas insaculadas pero no las consideramos para nuestras conclusiones porque no se aclara el origen. La insaculación de 1685 se complementa en 1686 por un pleito. La insaculación de 1700 incluye una ampliación al final por lo que hemos reflejado el total, sin embargo es significativo como se cita expresamente lo siguiente: ciutadans (20) refiriéndose a la bolsa de jurado primero; artistes (20) refiriéndose a la bolsa de jurado segundo; llaurador $3^{\circ}$ y $4^{\circ}$ refiriéndose a la bolsa de jurado tercero y cuarto; justicia (30) refiriéndose evidentemente a la bolsa de justicia de brazo real; Mustassaf(40) refiriéndose a la bolsa de Almotacén; Cequier(50) refiriéndose a la bolsa de acequiero; Escrivans(10) refiriéndose a la bolsa de escribanos, y que los nombres que aparecen son simplemente los mismos que hay en la insaculación del principio.

Como podemos observar hay variaciones respecto a lo aportado por Arroyas Serrano sin embargo no son significativas, y mantendríamos la misma argumentación expuesta por él, puesto que la limitación de las bolsas con el Privilegio de 1604 concedido por Felipe III, supuso la consolidación del control del acceso por parte de las oligárquicas de la ciudad de Castellón. Este método aseguraba que los posibles candidatos fueran del agrado de los que ya estaban en el poder, que habían accedido por medio de las bolsas que se habían creado en un inicio en 1590 y que las mismas élites se esforzaron por mantener.

Al observar la evolución de número de miembros en las distintas bolsas, se puede ver claramente como se respetó el límite establecido en la mayoría de los casos, evidentemente por intereses locales, pero hay dos insaculaciones en las que el número de miembros fue muy inferior, en 1653, donde solamente en mano menor se supera el límite de cuarenta miembros, y en 1677, lo que supondrá una nueva insaculación en 
1679. Es en esta segunda mitad de la centuria cuando se puede ver como se cumple de una forma estricta los límites establecidos en las bolsas, y de la cual podemos deducir una tendencia a que se mantengan el número de personas establecidas en el Privilegio de 1604 complementado con una mayor escrupulosidad a la hora de tener en cuenta las incompatibilidades e inhabilitaciones, tales como el parentesco o la repetición en los cargos. Podemos ver en el cuadro anterior como a partir de la insaculación de 1685 se cumplen los límites casi al cien por cien. 


\subsection{Las familias y el control de las bolsas.}

Como hemos comentado en el apartado anterior el número de miembros de las bolsas vino limitado con la concesión del Privilegio de 1604, en el que se establecía el número máximo de miembros en cada una de ellas, excepto en la de consejeros de mano mayor y menor que por costumbre se situó en cuarenta para cada una de ellas y que se intentó confirmar en 1626 por la monarquía por petición de la villa pero no se materializó. Este límite supuso un control por parte de las familias y personas poderosas de la villa para que no pudiesen entrar aquellas que se consideraban no gratas o no cualificadas, sin embargo, aún quedaba la posibilidad de recurrir a la Real Audiencia de Valencia que muchas veces fue la vía que se utilizó para entrar pero que implicó una injerencia de la autoridad real.

\subsubsection{Bolsa de caballeros o generosos.}

La existencia de caballeros o generosos en el municipio castellonense era muy residual, puesto que como ha estudiado muy bien Gimeno Sanfeliu ${ }^{135}$ no había en Castellón un interés de la nobleza por establecerse en la villa. Esto lo podemos ver en la bolsa de generosos o caballeros donde no encontramos muchos miembros (ver en el apartado anterior). Sin embargo, sí que es muy interesante realizar un pequeño análisis de aquellas familias que coparon la insaculación de estas bolsas y que tuvieron en sus manos los puestos a los que se optaban según establecían los fueros, es decir, el de justicia, el de almotacén, el de jurado primero y dos consejeros, puesto que al ser pocos sus posibilidades de estar en los hilos de poder del municipio eran muy altas.

Tabla 10: Insaculaciones bolsa generosos o caballeros ${ }^{136}$ :

\begin{tabular}{|ccc|ccc|}
\hline Apellido & Periodo & Miembros & Apellido & Periodo & Miembros \\
\hline Arrufat & $1600-1630$ & 4 & Miquel & $1598-1638$ & 3 \\
Bou & $1638-1662$ y $1685-\ldots$ & 3 & Miralles & $1590-\ldots$ & 3 \\
Bou de Monsonis & $1662-1685$ & 1 & Morales & $1600-1638$ & 1 \\
Castell & $1653-\ldots$ & 4 & Muñoz & $1679-1685$ & 1
\end{tabular}

\footnotetext{
135 Gimeno Sanfeliu, M.J. (1998). Patrimonio,... op. cit.

${ }^{136}$ AHMC. Datos extraídos de la todas las insaculaciones realizadas desde 1597 hasta 1707 que se pueden consultar en el documento 8 del apéndice.
} 


\begin{tabular}{|c|c|c|c|c|c|}
\hline Castell de Museros & $1685-\ldots$ & 1 & Reus & $1590-\ldots$ & 5 \\
\hline Escorcia y Ladrón & $1685-\ldots$ & 1 & Ripio & $1685-1694$ & 1 \\
\hline \multirow[t]{2}{*}{ Feliu } & $1662-\ldots$ & 5 & Ros & $1600-1647 y$ & 4 \\
\hline & & & & 1677-1685 & \\
\hline \multirow[t]{2}{*}{ Giner de Bou } & $1647-1662$ & 1 & Ros de & $1662-1677$ & 1 \\
\hline & & & Ursins & & \\
\hline Gombau & $1679-\ldots$ & 2 & Serra & $1638-1666$ & 1 \\
\hline Igual & $1662-\ldots$ & 2 & Serra i Dols & 1666-1685 & 1 \\
\hline Jordà & $1653-1694$ & 1 & Sisternés & 1634-1685 & 3 \\
\hline Jover & $1662-\ldots$ & 2 & Valles & $1662-\ldots$ & 3 \\
\hline \multirow[t]{2}{*}{ Mas } & $1653-\ldots$ & 3 & Vich de & $1630-1638$ & 1 \\
\hline & & & Gombau & & \\
\hline
\end{tabular}

La tabla de insaculaciones del brazo militar nos muestra como hay dos familias que se mantuvieron en ella durante prácticamente toda la centuria, los Reus y los Miralles, lo que nos deja una realidad palpable sobre su influencia en la villa. Mientras todas las demás que aparecen insaculadas no se mantienen durante todo el período siendo el caso más llamativo el de los Arrufat o los Miquel cuya influencia parece diluirse a partir de 1630 los primeros, o 1638 los segundos, desapareciendo de las insaculaciones. Se puede observar también como se incrementa el número de familias conforme transcurre la centuria (vid supra: análisis del número de componentes de las bolsas). En cuánto a peso en las insaculaciones de las distintas familias es evidente que los Feliu o Reus son las que tuvieron más miembros insaculados, hasta cinco y una de ellas coincide con aquellas que tuvieron algún miembro durante toda la época objeto de nuestro estudio. Pero no podemos obviar la relevancia de los Arrufat, los Ros o los Castell que tuvieron cuatro miembros insaculados con relación de parentesco, ya que todos se concentran en las primeras décadas del siglo XVII en las que el número de miembros de la bolsa eran muy reducido, entorno a diez, y situarse con tres o cuatro personas muestra claramente la influencia en el poder local en la villa de Castellón. Seguidamente tenemos a los Bou, Mas, Miquel, Miralles, Sisternés, Vallés con tres miembros siendo familias relevantes a la hora de desempeñar los oficios y de tener un asiento del Consell.

\footnotetext{
${ }^{137}$ En la tabla el intervalo del periodo establece desde la primera insaculación en la que aparecen hasta la que ya no son citados. En el caso de los puntos suspensivos indica que estuvieron hasta el final de la época foral.
} 
Para acabar el análisis de la bolsa del brazo militar, nos gustaría hacer mención a las familias que solo tuvieron un miembro, y que muchas veces lo podemos considerar un paso testimonial como es el caso de Ripio, Muñoz o Vich que solo estuvieron en una insaculación o el caso de Escorcia y Ladrón que estaba emparentado con el lugarteniente portanveus del gobernador de 1673-1677. Caso diferente es el Giner de Bou, Jordà y Morales que aunque solo tuvieron un representante en las insaculaciones si que eran familias relevantes de Castellón.

\subsubsection{Bolsa de justicia del brazo real.}

Esta bolsa estaba compuesta por miembros del brazo real que incluían a los ciudadanos honrados que optaban a la bolsa de jurado primero, artistas que optaban a la bolsa de jurados segundo y labradores enriquecidos que estaban integrados en la bolsa de jurados tercero y cuarto. Por tanto en ella encontramos ciudadanos, doctores en leyes, doctores en medicina, mercaderes, apotecaris, cirujanos, notarios, pintores y labradores enriquecidos.

La composición de esta bolsa durante todas las insaculaciones se distribuía de la siguiente forma: alrededor de dos tercios para los ciudadanos o componentes de la bolsa de jurado primero, y después el otro tercio se repartía entre los de la bolsa de jurado segundo y los labradores enriquecidos que formaban parte de la bolsa de jurados tercero y cuarto.

Tabla 11: Insaculaciones bolsa de justicia del brazo real ${ }^{138}$ :

\begin{tabular}{|ccc|ccc|}
\hline Apellido & Periodo & Miembros & Apellido & Periodo & Miembros \\
\hline Agramunt & $1600-1623$ y 1634-1653 & 2 & Lleó & $1600-1630$ & 1 \\
Alberich & $1600-1623$ & 1 & March & $1590-1647$ y $1694-\ldots$ & 6 \\
Albiol & $1590-1623$ y 1666-1677 & 2 & Martí & $1590-\ldots$ & 7 \\
Alegre & $1630-1677$ & 2 & Mas & $1600-1638$ & 3 \\
Amiguet & $1630-1666$ & 1 & Mascarós & $1600-1638$ & 2 \\
Amposta & $1679-\ldots$ & 1 & Mercer & $1694-\ldots$ & 2 \\
Andreu & $1638-\ldots$ & 3 & Moliner & $1590-1662$ & 3 \\
Anglés & A partir de 1700 & 1 & Muntanyés & Solamente 1700 & 1
\end{tabular}

\footnotetext{
${ }^{138}$ AHMC. Datos extraídos de la todas las insaculaciones realizadas desde 1597 hasta 1707 que se pueden consultar en el documento 8 del apéndice.
} 


\begin{tabular}{|c|c|c|c|c|c|}
\hline Aragonés & $1653-1700$ & 2 & Mur & $1634-1677$ & 1 \\
\hline Arrufat & $1590-1623$ & 1 & Museros & $1623-1630$ у $1647-\ldots$ & 3 \\
\hline Avinent & $1686-1700$ & 1 & Nuñez & $1647-1653$ & 1 \\
\hline Beltrán & $1590-1623$ & 1 & Orts & $1662-1677$ & 1 \\
\hline Bernat & $1600-1623$ & 1 & Pardo & $1600-1623$ & 1 \\
\hline Bonaventura & $1630-1638$ & 1 & Pasqual & $1590-1600$ у $1662-\ldots$ & 2 \\
\hline Bonet & $\begin{array}{c}1600-1638 \text { y a partir de } \\
1700\end{array}$ & 4 & Pauner & $1630-1677$ & 2 \\
\hline Bosch & $1590-1600$ & 1 & Pedro & $1600-1623$ & 1 \\
\hline Brito & $1647-1653$ & 2 & Peris & $1590-1623$ & 1 \\
\hline Brunell & $1590-1677$ & 2 & Porta & $1662-1677$ & 1 \\
\hline Calbo & $1686-1700$ & 2 & Quevedo & $1623-1630$ & 1 \\
\hline Capero & $1623-1638$ у $1662-1677$ & 3 & Roig & $1677-\ldots$ & 2 \\
\hline Casalís & $1677-\ldots$ & 2 & Romeu & $1590-1662$ & 2 \\
\hline Cases & $1653-1700$ & 2 & Rubert & Solamente 1700 & 1 \\
\hline Castell & $1590-1623$ у $1638-\ldots$ & 7 & Salvador & $1623-1630$ & 1 \\
\hline Castellet & $1638-1677$ & 1 & Sanchís & $1677-\ldots$ & 1 \\
\hline Compte & $1679-1700$ & 1 & Segarra & $1694-1700$ & 1 \\
\hline Feliu & $1590-1638$ & 2 & Serra & $1590-1638$ & 7 \\
\hline Ferrer & $\begin{array}{c}1600-1623,1634-1638 \text { y } \\
1677-\ldots\end{array}$ & 3 & Sisternés & $1590-1647$ & 3 \\
\hline Figuerola & $1630-\ldots$ & 6 & Sorrando & $1677-1685$ & 1 \\
\hline Fores & $1590-1600$ & 1 & Timor & $1677-1694$ & 1 \\
\hline Garces & $1694-1700$ & 1 & Tosquella & $1677-\ldots$ & 1 \\
\hline Gasco & $1590-1653$ & 6 & Vallés & $1623-1634$ & 1 \\
\hline Giner & $1590-\ldots$ & 11 & Vicent & $1630-1653$ & 1 \\
\hline Gombau & $1623-1653$ & 2 & Viciano & $1677-\ldots$ & 1 \\
\hline Grañana & $1600-1623$ & 1 & Vidal & $1653-1677$ & 1 \\
\hline Jover & $1590-1662$ у $1677-\ldots$ & 8 & Vilar & $1638-1677$ у $1686-\ldots$ & 2 \\
\hline
\end{tabular}

Elaboración propia ${ }^{139}$.

Hemos querido hacer una mención especial a su composición para reflejar que las familias que más miembros presentan en las insaculaciones son los Giner con once personas insaculadas, los Jover con ocho, los Castell, los Martí y los Serra con siete o los Figuerola y los March con seis. Todos ellos tienen, entre las personas insaculadas, notarios, doctores en leyes, ciudadanos o labradores enriquecidos. Sin embargo, es

\footnotetext{
${ }^{139}$ En la tabla el intervalo del periodo establece desde la primera insaculación en la que aparecen hasta la que ya no son citados. En el caso de los puntos suspensivos indica que estuvieron hasta el final de la época foral. Además hemos de tener en cuenta que en la insaculación de 1630 hay un nombre ilegible que no se puede leer pero que no es relevante para la extracción de conclusiones.
} 
mucho mayor la presencia de doctores en leyes en familias como los Giner que en los Castell, cuya mayor parte proviene de los labradores enriquecidos. Esto lo veremos con más detalle cuando analicemos la bolsa de jurado primero en la que la presencia de los Giner es muy notoria mientras que los Castell o los Serra es más escasa.

Los datos de la tabla anterior muestran como los Giner son los que más representación tuvieron en las insaculaciones y a su vez que estuvieron durante todo el periodo estudiado lo cual nos indica el poder que pudieron adquirir en la villa por su presencia en esta bolsa. A continuación, son relevantes familias como los Martí que acumulan siete presencias pero, además, están presentes en todas las insaculaciones del período. El caso de los Jover y los Castell sería similar aunque hay un intervalo en el que hay ausencias en las insaculaciones.

A partir de ahí nos gustaría resaltar varios casos llamativos como son los Serra que, pese a sus siete presencias, desaparecen de las insaculaciones a partir de 1638 lo cual indica que su poder en la villa se concentró en la primera parte de la centuria al igual que ocurrió con los Gascó que presentan a seis miembros en las insaculaciones pero desaparecen a partir de las insaculación de 1653. Mientras en el lado opuesto encontramos a los Figuerola, familia que como podremos estudiar en apartados posteriores, ocuparon cargos municipales a partir de 1630 y coincide con su aparición en esta bolsa a partir de este año y consiguen estar presentes con seis miembros.

\subsubsection{Bolsa de jurado primero del brazo real.}

Esa bolsa estaba formada por los ciudadanos honrados, doctores en leyes y en medicina que ya hemos definido anteriormente y que a su vez eran los que más peso específico tenían en la bolsa de justicia del brazo real.

Tabla 12: Insaculaciones bolsa de jurado primero del brazo real ${ }^{140}$

\begin{tabular}{|ccc|ccc|}
\hline Apellido & Periodo & Miembros & Apellido & Periodo & Miembros \\
\hline Agramunt & $1590-1623$ y 1630- & 2 & Jover & $1590-1662$ y & 7 \\
& 1653 & & & $1677-\ldots$ & 1 \\
Albiol & $1600-1677$ & 2 & Lleó & $1598-1630$ & 1 \\
Andreu & $1623-\ldots$ & 3 & March & $1590-1630$ y & 3
\end{tabular}

\footnotetext{
${ }^{140}$ AHMC. Datos extraídos de la todas las insaculaciones realizadas desde 1597 hasta 1707 que se pueden consultar en el documento 8 del apéndice.
} 


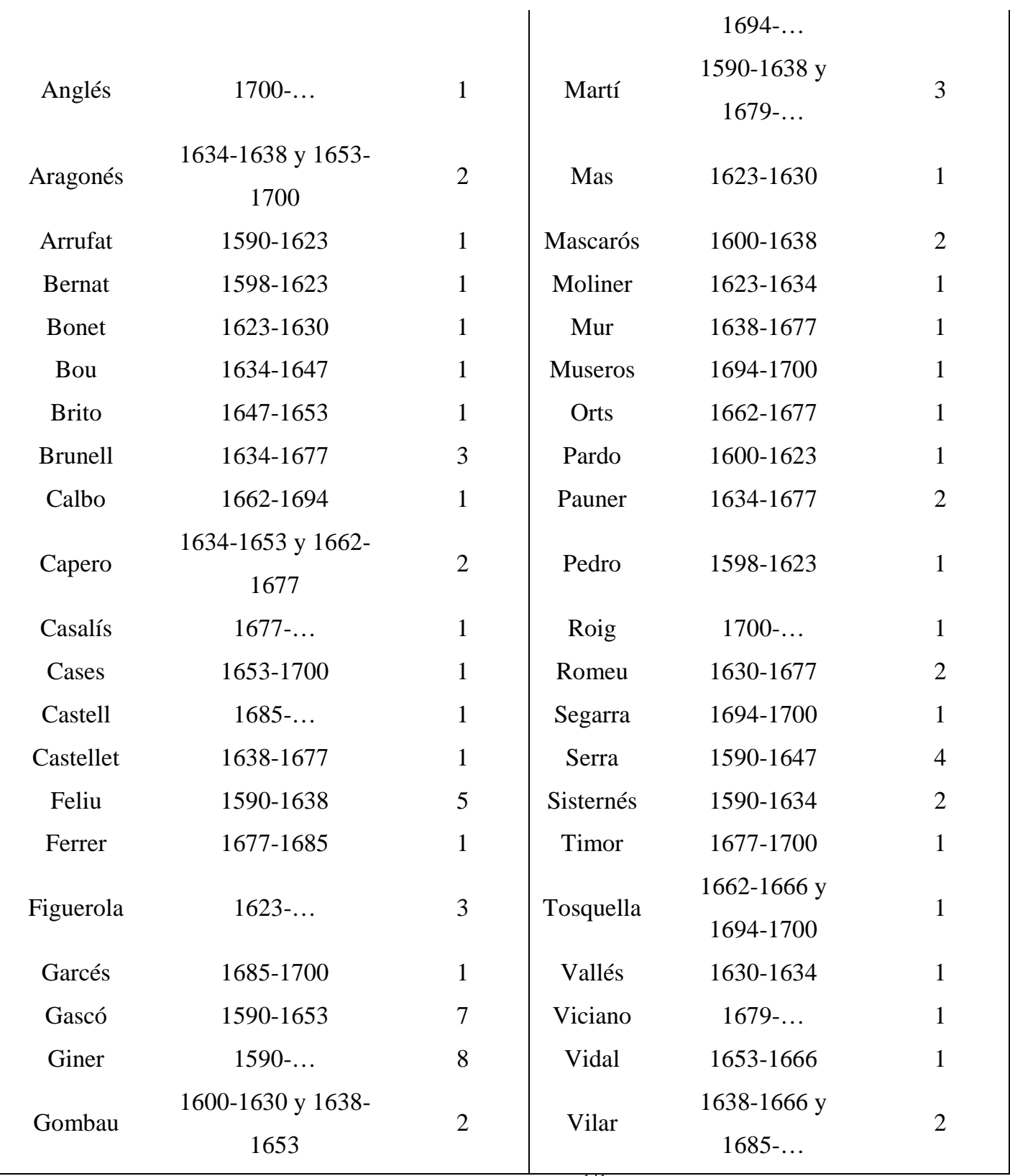

Elaboración propia ${ }^{141}$.

Los resultados que obtenemos al observar de forma resumida las insaculaciones del jurado primero del brazo real, son muy parecidos a lo que ocurría con la bolsa de justicia ya que, como podemos ver, las familias con más presencia son los Giner, que tuvieron a ocho miembros, los Gascó y los Jover con siete personas, seguidos por los Feliu con cinco insaculados y cuatro los Serra ${ }^{142}$.

\footnotetext{
${ }^{141}$ En las insaculaciones de 1600 y la de 1647-1648 hay un nombre ilegible en cada una de ellas. Además en la insaculación de 1700 hay una ampliación o anotación al final del texto en la que se cita ciutadans (20) y se nombra a ocho personas ya insaculadas anteriormente.

142 Cuando nos referimos a ocho personas en la bolsa queremos decir que estuvieron ocho distintos aunque algunos de ellos aparecieran en varias insaculaciones.
} 
La familia de los Giner va estar presente en las insaculaciones del jurado primero durante todo el período, mientras que los Feliu desaparecen a partir de 1638 y los Gascó y los Serra dejan de aparecer en la bolsa a mediados del s. XVII. Esto nos indica que el hecho de estar insaculados con tantas personas en la primera mitad de la centuria acrecenta su peso específico en el control de estas bolsa para después tener una pérdida de poder muy relevante. Mientras, los Jover se mantendrán aunque de una forma más intermitente que los Giner.

\subsubsection{Bolsa de jurado de segundo del brazo real o de los artistas.}

En esta segunda bolsa de jurado se encontraban los notarios, mercaderes, apotecaris, pintores y cirujanos, y en su composición se puede ver como, tal y como va avanzando la centuria, se incrementa el número de notarios y su peso específico cada vez es mayor.

Tabla 13: Insaculaciones bolsa de jurado segundo del brazo real ${ }^{143}$ :

\begin{tabular}{|ccc|ccc|}
\hline Apellido & Periodo & Miembros & Apellido & Periodo & Miembros \\
\hline Alberich & $1638-1653$ & 2 & Llorach & $1600-1623$ & 1 \\
Albiol & $1647-1653$ y $1666-1677$ & 2 & Llorens & $1677-\ldots$ & 2 \\
Alfagueri & $1590-1600$ & 1 & March & $1634-1653$ & 1 \\
Amiguet & $1630-1666$ & 1 & Martí & $1623-1677$ y $1694-\ldots$ & 5 \\
Amposta & $1647-1666$ y $1677-1700$ & 2 & Mas & $1590-1623,1634-1647$ & 4 \\
Andreu & $1630-1662$ & 1 & Mercer & $1653-\ldots$ & 3 \\
Aragonés & $1590-1623$ & 1 & Moliner & $1590-1653$ & 4 \\
Avinent & $1685-1700$ & 1 & Moreno & $1600-1623$ & 1 \\
Beltrán & $1623-1638$ & 1 & Muntanyes & $1694-\ldots$ & 1 \\
Blasco & $1623-1638$ y $1685-\ldots$ & 2 & Museros & $1653-\ldots$ & 3 \\
Bonaventura & $1630-1634$ & 1 & Navarro & $1600-1623$ & 1 \\
Bonet & $1623-1638$ y $1677-\ldots$ & 2 & Palanques & $1662-1677$ & 1 \\
Bou & $1600-1653$ & 2 & Pasqual & $1623-1630$ y $1653-\ldots$ & 3 \\
Breva & $1679-\ldots$ & 2 & Pavia & $1623-1634$ & 1 \\
Brunell & $1590-1623$ & 2 & Peris & $1590-1623$ & 1
\end{tabular}

\footnotetext{
${ }^{143}$ AHMC. Datos extraídos de la todas las insaculaciones realizadas desde 1597 hasta 1707 que se pueden consultar en el documento 8 del apéndice.
} 


\begin{tabular}{|ccc|ccc|} 
Capero & $1600-1634$ & 1 & Planell & $1630-1638$ & 1 \\
Carnicer & $1598-1623$ & 1 & Porta & $1638-1666$ & 1 \\
Cases & $1666-1700$ & 1 & Romeu & $1634-1653$ & 1 \\
Castell & $1590-1623$ y $1634-1677$ & 2 & Rubert & $1694-\ldots$ & 1 \\
Castellet & $1623-1647$ & 1 & Sabera & $1598-1630$ & 1 \\
Compte & $1662-1700$ & 1 & Safont & $1686-\ldots$ & 1 \\
Fabreó & $1590-1600$ & 1 & Salvador & $1600-1630$ & 1 \\
Ferrer & $1623-1647$ y $1662-\ldots$ & 2 & Sanchís & $1666-\ldots$ & 1 \\
Figuerola & $1677-1694$ & 1 & Serra & $1590-1623$ y $1679-$ & 1 \\
Folch & $1590-1630$ & 1 & Sorrando & $1666-1685$ & 1 \\
Fores & $1590-1600$ & 1 & Timor & $1662-1666$ & 1 \\
Gascó & $1623-1630$ & 1 & Tosquella & $1662-\ldots$ & 1 \\
Giner & $1600-1623$ y $1634-1679$ & 3 & Traver & $1630-1638$ & 1 \\
Grau & $1662-1677$ & 1 & Vallés & $1623-1630$ & 1 \\
Jover & $1623-1630$ & 1 & Vicent & $1623-1647$ y $1662-$ & 1 \\
Llopis & Solamente 1700 & & Vidal & $1694-\ldots$ & 2 \\
\hline
\end{tabular}

Se observa en la tabla que no hay un dominio tan claro de unas familias en concreto sino que hay un reparto más equitativo entre un mayor número de ellas. Es fundamental aquí poner de manifiesto la existencia en esta bolsa de los notarios, muchos de ellos hijos de labradores enriquecidos que supusieron el núcleo más importante de esta bolsa y que fueron adquiriendo más relevancia conforme iba transcurriendo el siglo XVII. Así encontramos en cabeza de la lista a los Martí tanto al inicio de la centuria como en el tramo final con cinco miembros, seguidamente los Mas y los Moliner con cuatro miembros y los Giner, Museros y Mercer tuvieron tres miembros. De estas tres familias hemos de destacar el caso de los Giner puesto como iremos viendo a lo largo del trabajo estuvieron presentes en todas las bolsas, llegando a ocupar todos los cargos y podemos decir que fueron una de las familias con más poder en la villa de Castellón, de los Mercer comentar que aparecen en la insaculación de 1653 y permanecerán hasta el final, sucediéndose en las bolsas por ser pintores y la familia Museros también expandirá sus tentáculos por más bolsas de jurados terceros y cuartos y la de consejeros de mano menor.

La interrelación entre las élites de Castellón se hace evidente cuando analizamos el origen de determinadas familias castellonenses y ello lo comprobamos en el caso de 
la familia Mas que como hemos visto ya estaba presente en varias bolsas y al igual que los Giner estaban entroncados con miembros de otras familias.

\subsubsection{Bolsa de jurado tercero y cuarto del brazo real.}

La bolsa de jurados tercero y cuarto se cubría con los labradores enriquecidos ${ }^{144}$ que también formaban parte de la bolsa de consejeros de mano menor, justicia, almotacén y acequiero. Sin embargo, pese a estar insaculados en todas las citadas anteriormente, aquellas donde estaban integradas solamente por ellos eran las de jurados tercero y cuarto y la de consejeros de mano menor.

La presencia en esta bolsa suponía el equilibrio de poder en el Consell castellonense ya que se conseguía que hubiera un representante del brazo militar cuando correspondía a este ser nombrado jurado primero, uno del brazo real que incluía a los ciudadanos honrados, doctores en leyes y en medina y otro de los artistas. Esto se complementaba con los labradores enriquecidos que formaban parte de esta bolsa.

Tabla 14: Insaculaciones bolsa de jurado terceros y cuarto del brazo real ${ }^{145}$ :

\begin{tabular}{|ccc|ccc|}
\hline Apellido & Periodo & Miembros & Apellido & Periodo & Miembros \\
\hline Agramunt & $1598-1623$ & 1 & Llansola & $1638-1677$ y 1684- & 3 \\
Agullo & $1590-1630$ & 1 & March & $1623-1653$ & 1 \\
Alberich & $1600-1630$ & 1 & Marqués & $1623-1677$ & 3 \\
Albiol & $1600-1623$ y $1662-1700$ & 2 & Martí & $1630-1638$ & 1 \\
Alegre & $1590-1685$ & 5 & Mas & $1590-1647$ & 4 \\
Amiguet & $1679-\ldots$ & 1 & Micó & $1590-1623$ & 1 \\
Andreu & $1590-1623$ & 1 & Miralles & $1590-1600$ & 1 \\
Avinent & $1630-.$. & 5 & Moliner & $1600-1623$ y $1634-$ & 2 \\
Bernat & $1590-1600$ & 1 & Molinos & $1598-1623$ & 1 \\
Blasco & Solamente 1700 & 1 & Muntanyés & $1638-1662$ & 1
\end{tabular}

144 Cuando hablamos de labradores nos referimos a propietarios enriquecidos, es decir, le damos el significado que se usa en la Edad Moderna como propietario de tierras y no como persona que trabaja directamente la tierra.

145 Datos extraídos de la todas las insaculaciones realizadas desde 1597 hasta 1707 que se pueden consultar en el documento 8 del apéndice. 


\begin{tabular}{|c|c|c|c|c|c|}
\hline Boix & $1647-1653$ у $1677-1700$ & 2 & Museros & $1590-\ldots$ & 10 \\
\hline Bonet & $1590-1623$ у $1653-1677$ & 3 & Navarro & $1590-\ldots$ & 10 \\
\hline Bosch & $1590-1638$ & 2 & Pasqual & $1590-\ldots$ & 13 \\
\hline Breva & $1679-\ldots$ & 6 & Pastor & $1600-1623$ & 1 \\
\hline Calbo & $1666-1700$ & 1 & Planell & $1600-1623$ & 1 \\
\hline Casalís & $1630-1647$ у $1666-\ldots$ & 2 & Reboll & $1630-\ldots$ & 4 \\
\hline Castell & $1590-\ldots$ & 14 & Ribalta & $1623-\ldots$ & 2 \\
\hline Castellet & $1638-\ldots$ & 6 & Ribes & $1600-1634$ & 1 \\
\hline Català & $1653-1700$ & 2 & Roig & $1647-\ldots$ & 2 \\
\hline Coll & $1600-1647$ & 1 & Romeu & $1590-1600$ & 1 \\
\hline Eiximeno & $1623-1700$ & 3 & Rubert & $\begin{array}{c}1623-1647 \text { y } 1653- \\
\ldots\end{array}$ & 5 \\
\hline Figuerola & $1590-1623$ y $1647-1700$ & 8 & Sanchís & $1590-1666$ & 4 \\
\hline Flors & $1598-1600$ y $1638-1647$ & 2 & Segarra & $1623-1694$ & 5 \\
\hline Giner & $1590-1666$ & 5 & Tirado & Solamente 1700 & 1 \\
\hline Gisbert & $1590-1623$ & 2 & Tormo & $1638-1662$ & 1 \\
\hline Goterris & $1679-1685$ & 1 & Ventura & $1623-1630$ & 1 \\
\hline Grañana & $1634-1653$ & 1 & Viciano & $\begin{array}{c}1600-1623 \text { y } 1666- \\
\ldots\end{array}$ & 1 \\
\hline Jover & $1590-1623$ & 1 & Vidal & $\begin{array}{c}1600-1623 \text { y } 1630- \\
1634\end{array}$ & 2 \\
\hline Llorens & $1623-1666$ & 2 & Vilarroig & $1590-\ldots$ & 19 \\
\hline
\end{tabular}

Elaboración propia ${ }^{146}$.

En la tabla observamos como la familia por excelencia que tuvo mayor número de representantes fue la de los Vilarroig con diecinueve miembros y que se extendieron desde la primera insaculación hasta el final de la época foral. La consecuencia palpable era el incremento en las probabilidades de ocupar este cargo, cosa que, como veremos a posteriori en otro apartado, se produjo. Esta posición predominante en la presencia en esta bolsa nos deja entrever la importancia que tenía esta familia entre los labradores enriquecidos y como fue habitual su mezcla con otras familias de su misma estratificación social. En segundo lugar a los Castell con catorce miembros y durante todo el período estudiado, después encontramos a los Pasqual con trece miembros, los cuales se moverán siempre entre las bolsas de jurado tercero y cuarto y manteniéndose desde el inicio hasta el final de la época foral. A continuación encontramos dos familias muy relevantes en estas bolsas como son los Museros y los Navarro con diez miembros

\footnotetext{
${ }^{146}$ En 1600 hay dos nombre ilegibles.
} 
en bolsas y con presencia desde 1590 hasta el final de la institución, por lo que nos encontramos con dos casos similares a los anteriores. Los Figuerola son los que ocupan el quinto lugar por número de representantes en las bolsas, pero ya no están presentes durante todo el período que estamos analizando puesto que se produce un vacío entre 1623 y 1647 retomando después hasta 1707. Sin embargo es relevante destacar de esta familia como al contrario de las citadas anteriormente, como ascendieron en la escala social puesto que a partir de 1623 los encontramos en la bolsa de jurado primero y destacamos al Doctor Ignacio Figuerola o al ciudadano Vicent Figuerola que ocuparon el citado cargo a partir de la segunda mitad del siglo XVII. Este hecho nos deja una muestra evidente de la relación intrínseca que había entre las familias que formaban parte de las distintas bolsas y que en muchos casos se entroncaban y extendían sus intereses en todas ellas.

Ilustración 5: Bolsa de jurado tercero y cuarto ${ }^{147}$.

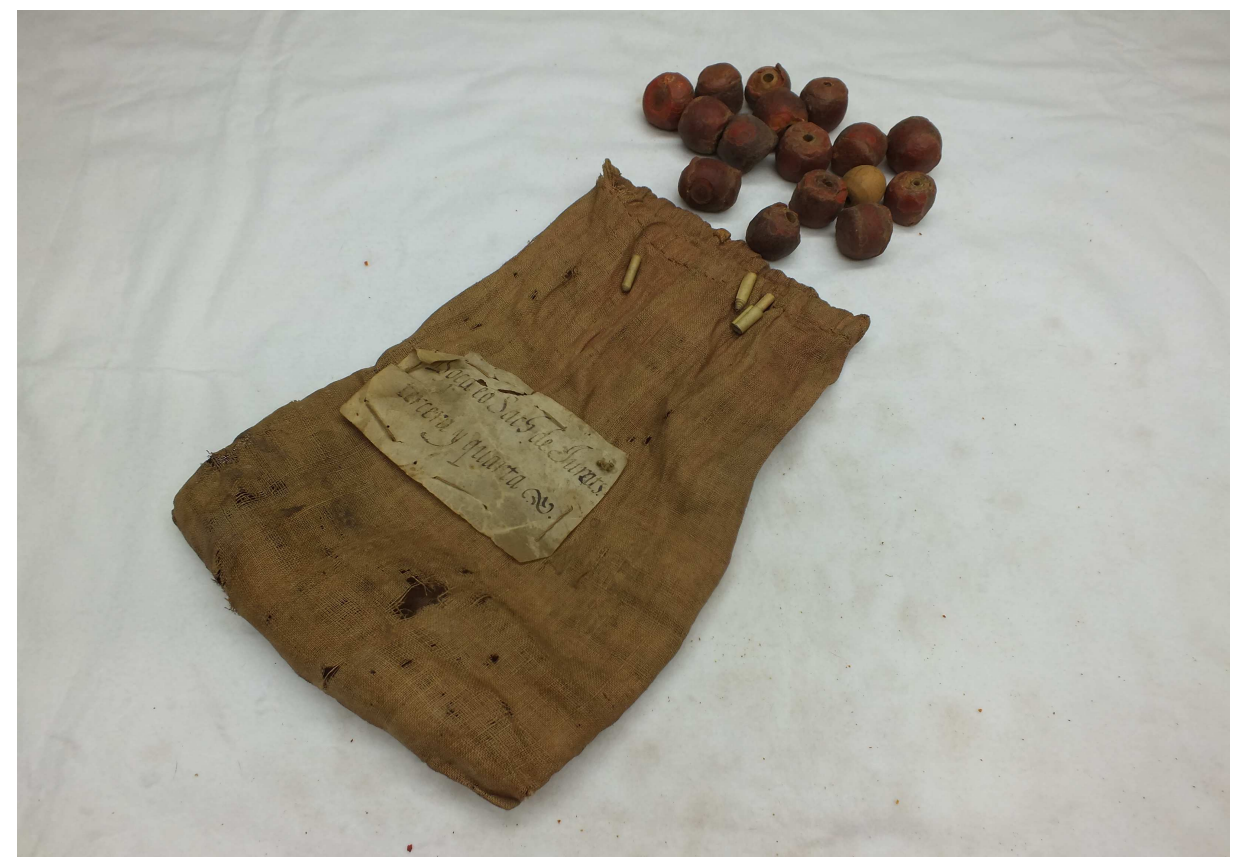

\subsubsection{Bolsa de almotacén.}

La bolsa de almotacén incluía a miembros de los tres grandes núcleos de poder del brazo real del municipio castellonense, es decir de los ciudadanos, doctores en leyes

\footnotetext{
147 AHMC. Fotografía obtenida del archivo en la cual podemos ver la bolsa donde se depositaban las cédulas de los candidatos a jurado tercero y cuarto, es decir, los labradores enriquecidos.
} 
y en medicina de la bolsa de jurado primero, de los artistas de la bolsa de jurados segundos y de los labradores enriquecidos de los jurados tercero y cuarto. Por tanto en esta bolsa encontramos una mezcla de las familias que hemos obtenido anteriormente y no podemos olvidar que (como hemos explicado en un apartado anterior) este puesto lo ocupaban cada tres, cuatro, cinco o seis años, una persona de la bolsa del brazo militar.

Tabla 15: Insaculaciones bolsa de almotacén del brazo real ${ }^{148}$ :

\begin{tabular}{|c|c|c|c|c|c|c|c|c|}
\hline Apellido & Periodo & Miembros & Apellido & Periodo & Miembros & Apellido & Periodo & Miembros \\
\hline & $1590-1623$ & & & $1630-1638$ & & & & \\
\hline Agramunt & $\begin{array}{c}\text { y } 1634- \\
1647\end{array}$ & 2 & Eiximeno & $\begin{array}{c}\text { y } 1662- \\
1700\end{array}$ & 3 & Pascual & $\begin{array}{l}1623-1638 \\
\text { у } 1653-\ldots\end{array}$ & 4 \\
\hline Alberich & $1647-1677$ & 1 & Feliu & $1590-1638$ & 4 & Pauner & $1634-1677$ & 2 \\
\hline Albiol & $\begin{array}{c}1600-1623 \\
\text { y } 1634- \\
1666\end{array}$ & 4 & Ferrer & $\begin{array}{l}1600-1623, \\
1630-1647 \\
\text { у } 1677-\ldots\end{array}$ & 5 & Pavia & $1630-1634$ & 1 \\
\hline Alegre & $1623-1647$ & 2 & Figuerola & $1590-\ldots$ & 6 & Pedro & $1600-1623$ & 1 \\
\hline Alfaseri & $1590-1600$ & 1 & Folch & $1590-1630$ & 1 & Peris & $1590-1623$ & 1 \\
\hline Amiguet & $1630-1666$ & 1 & Fores & $1590-1600$ & 1 & Planell & $1634-1638$ & 1 \\
\hline Amposta & $\begin{array}{l}1653-1677 \\
\text { у } 1679-\ldots\end{array}$ & 2 & Garces & $1685-1700$ & 1 & Porta & $1647-1677$ & 1 \\
\hline Andreu & $1623-1677$ & 6 & Gascó & $1590-1653$ & 9 & Reboll & $1647-1653$ & 1 \\
\hline Anglés & $\begin{array}{c}\text { Solamente } \\
1700\end{array}$ & 1 & Gaspar & $1638-1647$ & 1 & Ribalta & $1638-1677$ & 1 \\
\hline Aragonés & $\begin{array}{c}1590-1598 \\
1630-1647 \\
\text { y } 1653- \\
1700\end{array}$ & 4 & Giner & $\begin{array}{l}1590-1634 \\
\text { у } 1638-\ldots\end{array}$ & 12 & Roig & $\begin{array}{c}1653-1666 \\
\text { y } 1700\end{array}$ & 2 \\
\hline Arrufat & $1590-1623$ & 1 & Gisbert & $1590-1600$ & 1 & Romeu & $\begin{array}{c}1590-1600 \\
\text { y } 1630- \\
1677\end{array}$ & 5 \\
\hline Avinent & $1694-1700$ & 1 & Gombau & $\begin{array}{c}1600-1630 \\
\text { y } 1638- \\
1653\end{array}$ & 2 & Sabera & $1600-1623$ & 1 \\
\hline Beltrán & $1590-1623$ & 1 & Jover & $1590-\ldots$ & 9 & Safont & $\begin{array}{c}\text { Solamente } \\
1700\end{array}$ & 1 \\
\hline Bernat & $1630-1638$ & 1 & Llansola & $1666-1700$ & 1 & Salvador & $1600-1630$ & 1 \\
\hline
\end{tabular}

\footnotetext{
${ }^{148}$ AHMC. Datos extraídos de la todas las insaculaciones realizadas desde 1597 hasta 1707 que se pueden consultar en el documento 8 del apéndice.
} 


\begin{tabular}{|c|c|c|c|c|c|c|c|c|}
\hline Blasco & $\begin{array}{c}1634-1638 \\
\text { у } 1700\end{array}$ & 2 & Lleó & $1600-1630$ & 1 & Sanchís & $\begin{array}{l}1600-1653 \\
\text { у } 1677-\ldots\end{array}$ & 6 \\
\hline Bonet & $\begin{array}{l}1590-1638 \\
\text { у } 1679-\ldots\end{array}$ & 4 & Llorens & $1653-1662$ & 1 & Segarra & $\begin{array}{c}1600-1623 \\
1653-1662 \\
\text { у } 1694-. .\end{array}$ & 2 \\
\hline Bosch & $1590-1600$ & 1 & March & $\begin{array}{l}1590-1653 \\
\text { у } 1679-\ldots\end{array}$ & 6 & Serra & $1590-1647$ & 5 \\
\hline Bou & $1600-1653$ & 3 & Martí & $1590-\ldots$ & 9 & Sisternés & $1590-1634$ & 2 \\
\hline Breva & $1686-\ldots$ & 3 & Mas & $\begin{array}{l}1590-1647 \\
1590-1600\end{array}$ & 5 & Sorrando & $1677-1685$ & 1 \\
\hline Brito & $1647-1653$ & 1 & Mascaros & $\begin{array}{c}\text { y } 1630- \\
1634\end{array}$ & 2 & Timor & $1677-1700$ & 1 \\
\hline Brunell & $1590-1666$ & 3 & Mercer & $\begin{array}{l}1653-1685 \\
\text { у } 1694-\ldots\end{array}$ & 3 & Tormo & $1653-1662$ & 1 \\
\hline Calbo & $\begin{array}{l}1666-1694 \\
1623-1653\end{array}$ & 1 & Moliner & $1590-1647$ & 5 & Tosquella & $1662-\ldots$ & 1 \\
\hline Capero & $\begin{array}{c}\text { y } 1662- \\
1677\end{array}$ & 3 & Mur & $1638-1677$ & 1 & Vallés & $1623-1634$ & 1 \\
\hline Casalís & & 2 & Museros & $\begin{array}{l}1653-1685 \\
\text { у 1694-... }\end{array}$ & 3 & Vicent & $1623-1653$ & 2 \\
\hline Cases & $\begin{array}{c}1590-1600 \\
\text { y } 1653- \\
1700\end{array}$ & 3 & Navarro & $\begin{array}{l}1600-1623 \\
\text { у } 1653-\ldots\end{array}$ & 5 & Viciano & $1679-\ldots$ & 3 \\
\hline Castell & $\begin{array}{c}1590-1623 \\
\text { y } 1630- \\
1677 \text { y } \\
1679-. .\end{array}$ & 7 & Nuñez & $1647-1653$ & 1 & Vidal & 1653-1666 & 1 \\
\hline Castellet & $1630-1677$ & 2 & Orts & $1662-1666$ & 1 & Vilar & $\begin{array}{c}1638-1666 \\
\text { y } 1686-. . \\
1590-1600 \\
1638-\end{array}$ & 2 \\
\hline Compte & $1666-1700$ & 1 & Pardo & $1600-1623$ & 1 & Vilarroig & $\begin{array}{c}1653,1662- \\
1679 y \\
1700\end{array}$ & 7 \\
\hline
\end{tabular}

Elaboración propia $^{149}$.

El análisis de los datos obtenidos nos muestra una evidencia que ya se había dado en las bolsas anteriores y es que la familia Giner es la que más miembros tuvo

\footnotetext{
${ }^{149}$ En 1600 hay un nombre que no se puede leer porque se ha desgastado el papel.
} 
llegando a doce y como prácticamente estuvieron durante todo el periodo. Repetimos que eso nos da una idea del poder que tuvo dentro del Consell. En segundo lugar encontramos a los Gascó, Jover y Martí con nueve miembros cada una y en las que destacamos como la primera no tiene lazos con el brazo militar y se concentró su presencia en la primera mitad del siglo XVII mientras que las otras dos estuvieron durante todo el período y los Jover si que tenían lazos con el brazo militar. A continuación aparecen los Castell y los Vilarroig con siete miembros y que hemos de recordar que ya dominaban la bolsa de jurados tercero y cuarto, los Figuerola con seis durante todo el periodo y los Andreu y March que también tuvieron a seis miembros pero no fueron tan constante puesto que desaparecen en algunos periodos.

\subsubsection{Bolsa de acequiero.}

El control de esta bolsa podía suponer el acceso al oficio de acequiero que suponía influencia en la distribución de las aguas, por tanto era de un interés evidente para los labradores enriquecidos para intentar favorecerse del reparto de las mismas para sus tierras. Por tanto en esta bolsa vamos a encontrar una presencia masiva de aquellos que están en las bolsas de jurado tercero y cuarto y en las de consejeros de mano menor.

Tabla 16: Insaculaciones bolsa de acequiero ${ }^{150}$

\begin{tabular}{|c|c|c|c|c|c|c|c|c|}
\hline Apellido & Periodo & Miembros & Apellido & Periodo & Miembros & Apellido & Periodo & Miembros \\
\hline Agramunt & $1600-1623$ & 1 & Compte & $1677-1700$ & 1 & Muntanyés & $\begin{array}{c}\text { 1634-1662 y } \\
\text { solamente } \\
1700\end{array}$ & 2 \\
\hline Alberich & $1600-1677$ & 2 & Eiximeno & $\begin{array}{l}1600-1700 \\
1647-1653\end{array}$ & 3 & Museros & $\begin{array}{c}1590-1634 \text { y } \\
1638-. . .\end{array}$ & 11 \\
\hline Albiol & $1653-1700$ & 1 & Ferrer & $\begin{array}{c}\text { y } 1677- \\
1685\end{array}$ & 2 & Navarro & $1590-\ldots$ & 14 \\
\hline Alegre & $1600-1694$ & 5 & Figuerola & $\begin{array}{c}1590-1623 \\
1630-\ldots\end{array}$ & 12 & Pasqual & $\begin{array}{c}1590-1638 \text { y } \\
1653-\ldots\end{array}$ & 11 \\
\hline Amiguet & $1653-\ldots$ & 2 & Flors & $1600-1623$ & 1 & Pastor & $\begin{array}{c}\text { Solamente } \\
1700\end{array}$ & 1 \\
\hline Amposta & $1679-\ldots$ & 1 & Fores & $1623-1630$ & 1 & Pavia & $1623-1634$ & 1 \\
\hline Andreu & $\begin{array}{c}1590-1623 \\
1630-1634 \text { y }\end{array}$ & 3 & Gascó & $1623-1638$ & 9 & Planell & $1600-1623$ & 1 \\
\hline
\end{tabular}

${ }^{150}$ AHMC. Datos extraídos de la todas las insaculaciones realizadas desde 1597 hasta 1707 que se pueden consultar en el documento 8 del apéndice. 


\begin{tabular}{|c|c|c|c|c|c|c|c|c|}
\hline Anglés & $\begin{array}{c}\text { Solamente } \\
1700\end{array}$ & 1 & Giner & $1590-\ldots$ & 9 & Quevedo & $1623-1630$ & 1 \\
\hline Aragonés & $1662-1700$ & 1 & Gisbert & $1590-1623$ & 2 & Reboll & $\begin{array}{c}1638-1653 \text { y } \\
1677-\ldots\end{array}$ & 3 \\
\hline Avinent & $1638-\ldots$ & 6 & Godes & $1630-1638$ & 1 & Ribalta & $\begin{array}{c}1600-1623 \\
1630-\ldots\end{array}$ & 3 \\
\hline Batiste & $1638-1647$ & 1 & Gombau & $\begin{array}{c}1623-1630 \\
\text { y } 1647- \\
1662\end{array}$ & 2 & Ribes & $1600-1634$ & 1 \\
\hline Bernat & $1590-1600$ & 1 & Grañana & $1630-1653$ & 1 & Roig & $\begin{array}{c}1590- \\
1600,1638- \\
1677 \text { y } 1677-\end{array}$ & 4 \\
\hline Blasco & $1623-1638$ & 1 & Jover & $\begin{array}{l}1590-1634 \\
\text { у } 1638-\ldots\end{array}$ & 4 & Romeu & $\begin{array}{c}\cdots \\
1590-1600 \mathrm{y} \\
1638-1677\end{array}$ & 2 \\
\hline Boix & $\begin{array}{c}1630-1653 \text { y } \\
1677-1700\end{array}$ & 2 & Llansola & $1638-1694$ & 3 & Rubert & $1630-\ldots$ & 7 \\
\hline Bonet & $\begin{array}{c}1590-1623 \text { y } \\
1662-1677\end{array}$ & 3 & Lleó & $1623-1630$ & 1 & Safont & $1694-\ldots$ & 1 \\
\hline Bosch & $1590-1647$ & 3 & Llorens & $1630-1653$ & 2 & Salvador & $1623-1630$ & 2 \\
\hline Bou & $1623-1647$ & 2 & March & $1590-1653$ & 6 & Sanchís & $\begin{array}{c}1590-1666 \text { y } \\
1677-\ldots\end{array}$ & 6 \\
\hline Breva & $1686-\ldots$ & 4 & Marqués & $1653-1677$ & 2 & Segarra & $1623-1694$ & 5 \\
\hline Brunell & $1638-1677$ & 1 & Martí & $1600-1677$ & 5 & Serra & $1623-1647$ & 2 \\
\hline Calbo & $1662-1700$ & 1 & Mas & $1590-1647$ & 4 & Sisternés & $1623-1633$ & 1 \\
\hline Capero & $1623-1634$ & 2 & Mercer & $1653-1679$ & 1 & Sorrando & $\begin{array}{c}\text { Solamente } \\
1700\end{array}$ & 1 \\
\hline Casalís & $\begin{array}{c}1638-1647 \text { y } \\
1677-\ldots\end{array}$ & 2 & Micó & $1600-1623$ & 1 & Timor & $1677-1700$ & 1 \\
\hline Cases & $1677-\ldots$ & 1 & Miralles & $1590-1600$ & 1 & Tormo & $1634-1653$ & 2 \\
\hline Castell & $1590-\ldots$ & 16 & Molina & $1590-1623$ & 1 & Tosquella & $1677-\ldots$ & 1 \\
\hline Castellet & $\begin{array}{c}1630-1677 \text { y } \\
1685-\ldots\end{array}$ & 5 & Moliner & $1623-1662$ & 3 & Viciano & $1653-1662$ & 3 \\
\hline Català & $1662-1694$ & 1 & Molinos & $1600-1623$ & 1 & Vidal & $1600-1623$ & 1 \\
\hline Coll & $1600-1638$ & 1 & Morán & $1600-1623$ & 1 & Vilarroig & $1590-\ldots$ & 19 \\
\hline
\end{tabular}

Elaboración propia.

Era evidente que los datos nos iban a mostrar que el dominio de esta bolsa correspondería a las mismas familias que en las bolsas de jurado tercero y cuarto y podemos ver como la familia que más miembros tuvo fue los Vilarroig con diecinueve en 
todo el período objeto de nuestro estudio. En segundo lugar encontramos a los Castell con dieciséis miembros y también desde 1590 hasta el final. Después encontramos a los Navarro con catorce miembros durante todo el período y los Figuerola con doce representantes, los Museros y los Pasqual con once. Estas tres últimas familias no se perpetuaron en todo el periodo estudiado puesto que hubo años que no tuvieron participación en las bolsas.

No podemos olvidarnos de los Giner que con nueve representantes siguen extendiendo sus ramificaciones por todas las bolsas, y los Gascó que con el mismo número que la familia anterior certifica su presencia de una forma importante en la bolsa de acequieros al igual que ocurría en la almotacén, pese a no ser labradores enriquecidos puesto que no provienen de la bolsa de jurado tercero y cuarto.

Por tanto es evidente que el control de esta bolsa se sigue manteniendo entre las mismas familias que dominaban las de almotacén y jurados tercero y cuarto

\subsubsection{Bolsa de escribanos.}

Esta bolsa estaba integrada por notarios, ya que la función del escribano era ser notario del Consell.

Tabla 17: Insaculaciones bolsa de $\operatorname{escribanos}^{151}$ :

\begin{tabular}{|ccc|ccc|}
\hline Apellido & Periodo & Miembros & Apellido & Periodo & Miembros \\
\hline Andreu & $1634-1653$ & 1 & Martí & $1634-1685$ y 1700 & 2 \\
Arrufat & $1590-1623$ & 1 & Mas & $1600-1623$ & 1 \\
Beltrán & $1590-1623$ & 1 & Micó & $1590-1600$ & 1 \\
Bonet & $1677-\ldots$ & 1 & Moliner & $1590-1623$ & 1 \\
Bou & $1600-1653$ & 2 & Museros & $1694-\ldots$ & 1 \\
Breva & $1686-\ldots$ & 1 & Pascual & $1662-\ldots$ & 1 \\
Brunell & $1590-1623$ & 1 & Peris & $1590-1623$ & 1 \\
Capero & $1623-1634$ & 1 & Planell & $1630-1638$ & 1 \\
Cases & $1666-1700$ & 1 & Porta & $1638-1666$ & 1 \\
Castell & $1590-1600$ & 1 & Quevedo & $1623-1630$ & 1 \\
Castellet & $1630-1647$ & 1 & Roig & $1634-1638$ & 1
\end{tabular}

${ }^{151}$ AHMC. Datos extraídos de la todas las insaculaciones realizadas desde 1597 hasta 1707 que se pueden consultar en el documento 8 del apéndice. 


\begin{tabular}{|ccc|ccc|} 
Compte & $1666-1700$ & 1 & Romeu & $1634-1653$ & 1 \\
Ferrer & $1666-\ldots$ & 1 & Rubert & $1694-\ldots$ & 1 \\
Figuerola & $1679-1694$ & 1 & Salvador & $1600-1630$ & 1 \\
Folch & $1590-1630$ & 1 & Sanchís & $1677-\ldots$ & 1 \\
Gascó & $1590-1623$ & 1 & Serra & $1590-1623$ & 1 \\
Giner & $1600-1686$ & 3 & Traver & $1630-1638$ & 1 \\
Grau & $1666-1677$ & 1 & Vallés & $1623-1630$ & 1 \\
Jover & $1590-1630$ & 1 & Vidal & $1694-\ldots$ & 1 \\
Llorens & $1686-1694$ & 1 & & \\
\hline
\end{tabular}

Las conclusiones del análisis detallado de todas las insaculaciones nos muestran como no hubo el dominio de ninguna familia en cuánto a miembros puesto que son los Giner, como no, los que más tuvieron pero solo fueron tres, seguido por los Martí y los Bou con dos. Todas las demás solo tuvieron un miembro en esta bolsa, que recordemos tenía el límite establecido en el Privilegio de 1604 en diez.

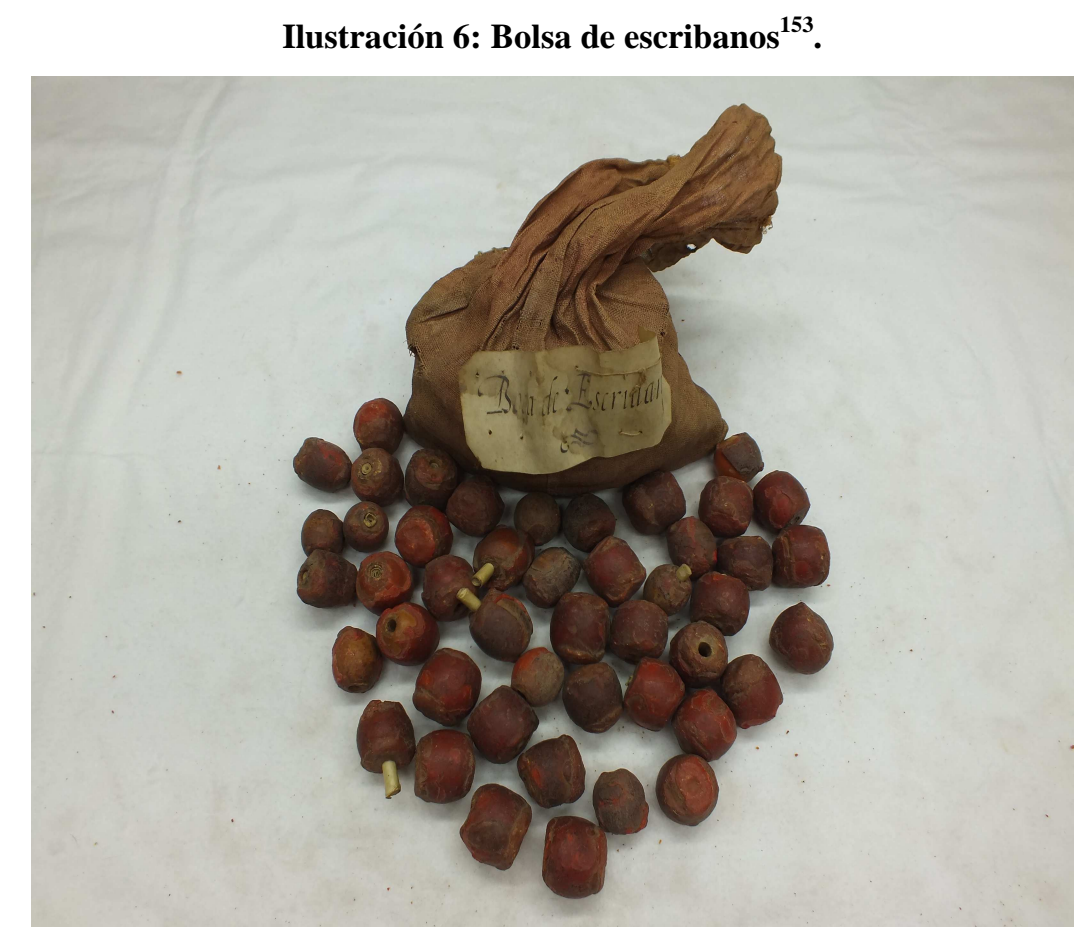

\footnotetext{
${ }^{152}$ En 1653 no hay insaculación y no sabemos el motivo. A partir de la insaculación de 1666 y hasta 1694 hay un nombre ilegible. En 1700 hay un nombre Vicent...que es ilegible el apellido.

153 AHMC. Fotografía realizada de la bolsa donde se introducían las cédulas o redolines de cera del escribano. Su estado está bastante deteriorado.
} 


\subsubsection{Bolsa de consejeros de mano mayor.}

La bolsa de consejeros de mano mayor incluía aquellas personas que estaban en la bolsa de jurado primero y jurado segundo, es decir los ciudadanos honrados, los doctores en leyes, los pintores, los apotecaris, los cirujanos, los doctores en medicina, los notarios y mercaderes.

Tabla 18: Insaculaciones bolsa de consejeros de mano mayor ${ }^{154}$ :

\begin{tabular}{|c|c|c|c|c|c|c|c|c|}
\hline Apellido & Periodo & Miembros & Apellido & Periodo & Miembros & Apellido & Periodo I & Miembros \\
\hline Agramunt & $\begin{array}{c}1590-1623 \text { y } \\
1630-1653\end{array}$ & 2 & Feliu & $1590-1638$ & 4 & Pardo & $1600-1623$ & 1 \\
\hline Alberich & $1638-1677$ & 2 & Ferrer & $\begin{array}{l}1590-1647 \\
\text { y } 1662-\ldots\end{array}$ & 4 & Pasqual & $1653-\ldots$ & 3 \\
\hline Albiol & $\begin{array}{c}1590- \\
1623,1634-1677 \\
\text { y } 1685-1694\end{array}$ & 5 & Figuerola & $1630-\ldots$ & 4 & Pauner & $1630-1677$ & 2 \\
\hline Alfaseri & $1590-1600$ & 1 & Folch & $1590-1630$ & 1 & Pavia & $1623-1634$ & 1 \\
\hline Amiguet & $1623-1677$ & 1 & Garces & $1685-\ldots$ & 1 & Pedro & $1600-1623$ & 1 \\
\hline Amposta & $1677-\ldots$ & 2 & Gascó & $1590-1653$ & 7 & Peris & $1590-1623$ & 1 \\
\hline Andreu & $1623-\ldots$ & 6 & Giner & $1590-\ldots$ & 12 & Planell & $1630-1647$ & 1 \\
\hline Anglés & $\begin{array}{c}\text { Solamente } 1700 \\
1590-\end{array}$ & 1 & Gombau & $1600-1662$ & 2 & Porta & $1638-1666$ & 1 \\
\hline Aragonés & $\begin{array}{c}1623,1630-1647 \\
\text { y } 1653-1700\end{array}$ & 1 & Grau & $1662-1677$ & 1 & Quevedo & $1623-1630$ & 1 \\
\hline Arrufat & $1590-1623$ & 4 & Jover & $\begin{array}{l}1590-1662 \\
\text { у } 1677-\ldots\end{array}$ & 8 & Roig & $\begin{array}{c}1634-1638 \\
y \\
\text { solamente } \\
1700 \\
1590-1600\end{array}$ & 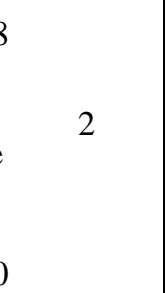 \\
\hline Avinent & $1685-1700$ & 1 & Lleó & $1600-1630$ & 1 & Romeu & $\begin{array}{c}\text { y } 1630- \\
1677\end{array}$ & 4 \\
\hline Beltran & $1590-1623$ & 1 & Llopis & $\begin{array}{c}\text { Solamente } \\
1700\end{array}$ & 1 & Rubert & $1685-\ldots$ & 1 \\
\hline Bernat & $1600-1634$ & 1 & Llorach & $1600-1623$ & 1 & Sabera & $1600-1630$ & 1 \\
\hline
\end{tabular}

\footnotetext{
${ }^{154}$ AHMC. Datos extraídos de la todas las insaculaciones realizadas desde 1597 hasta 1707 que se pueden consultar en el documento 8 del apéndice.
} 


\begin{tabular}{|c|c|c|c|c|c|c|c|c|}
\hline Blasco & $\begin{array}{c}1623-1638 \text { y } \\
1685-\ldots\end{array}$ & 2 & Llorens & $1685-1700$ & 3 & Safont & $1686-\ldots$ & 1 \\
\hline Bonaventura & $1623-1634$ & 1 & March & $\begin{array}{l}1600-1653 \\
\text { у } 1694-\ldots\end{array}$ & 5 & Salvador & $1623-1630$ & 1 \\
\hline Bonet & $\begin{array}{c}1623-1638 \text { y } \\
1677-\ldots\end{array}$ & 3 & Martí & 1590-... & 8 & Sanchís & $\begin{array}{c}1600- \\
1623, \\
1634-1638 \\
\text { y } 1666-. . .\end{array}$ & 4 \\
\hline Bosch & $1590-1630$ & 1 & Mas & $\begin{array}{l}1590.1623 \\
1662-1666 \\
\text { у } 1685-\ldots\end{array}$ & 4 & Segarra & $1694-\ldots$ & 1 \\
\hline Bou & $1600-1653$ & 2 & Mascaros & $1600-1623$ & 2 & Serra & $1590-1638$ & 5 \\
\hline Breva & $1679-\ldots$ & 2 & Mercer & $1653-1 \ldots$ & 3 & Sisternés & $1600-1634$ & 1 \\
\hline Brito & $1653-1662$ & 1 & Micó & $1590-1600$ & 1 & Sorrando & $1679-1685$ & 2 \\
\hline Brunell & $\begin{array}{c}1590-1623 y \\
1630-1677\end{array}$ & 4 & Moliner & $1590-1653$ & 4 & Sunyer & & 1 \\
\hline Capero & $\begin{array}{c}1600-1630 \text { y } \\
1634-1694\end{array}$ & 3 & Moreno & $1600-1623$ & 1 & Timor & $\begin{array}{c}1662-1666 \\
\text { y } 1677- \\
1700\end{array}$ & 2 \\
\hline Carnicer & $1600-1623$ & 1 & Muntanyés & $1694-\ldots$ & 1 & Tormo & $1634-1653$ & 1 \\
\hline Casalís & $1677-\ldots$ & 1 & Mur & $1638-1677$ & 1 & Tosquella & $1662-\ldots$ & 2 \\
\hline Cases & $1666-1700$ & 3 & Museros & $1653-\ldots$ & 4 & Traver & $1630-1638$ & 1 \\
\hline Castell & $\begin{array}{c}1590-1623 \\
1634-\ldots\end{array}$ & 3 & Navarro & $1600-1623$ & 1 & Vallés & $1623-1634$ & 1 \\
\hline Castellet & $1623-1677$ & 3 & Nicolau & $1623-1630$ & 1 & Vicent & $1630-1694$ & 1 \\
\hline Català & $1590-1623$ & 1 & Nuñez & $1647-1653$ & 1 & Viciano & $1679-\ldots$ & 1 \\
\hline Compte & $1662-1666$ & 1 & Orts & $1662-1666$ & 1 & Vidal & $\begin{array}{l}1653-1666 \\
\text { у } 1694-. . .\end{array}$ & 1 \\
\hline Fabregat & $1600-1623$ & 1 & Palanques & $1662-1677$ & 1 & Vilar & $\begin{array}{l}1638-1666 \\
\text { у } 1685-\ldots\end{array}$ & 2 \\
\hline
\end{tabular}

Los resultados del estudio de las diversas insaculaciones nos muestran como fueron los Giner los que más miembros tuvieron en la bolsa llegando a doce abarcando todo el periodo. Este aspecto no es nuevo y corrobora el dominio de esta familia en las bolsas relacionadas con ciudadanos honrados. En segundo lugar encontramos a los Martí con ocho representantes al igual que los Jover, con al diferencia que los primeros estuvieron en todo el periodo y los últimos hay un pequeño intervalo de quince años en

${ }^{155}$ En la insaculación de 1623 hay un nombre tachado ilegible y en la insaculación de 1662 incorporamos a Martí Castell, Cristòfol Castell y Félix Sisternés que se incorporaron a la bolsa en 1660. 
el que no están presentes. En cuarto lugar nos gustaría destacar a los Andreu que tuvieron seis miembros y que su entrada fue a partir de 1623 en esta bolsa.

No queremos extendernos más en nuestro análisis porque en los apartados siguientes podremos ver y estudiar qué familias ocuparon realmente los cargos una vez había entrado en las bolsas, y quiénes fueron las personas, lo cual nos permitirá ver si el haber sido elegido para formar parte de los sacos suponía el ocupar un cargo o no.

\subsubsection{Bolsa de consejeros de mano menor.}

Como ya hemos indicado anteriormente esta bolsa estaba formada por los labradores enriquecidos de la villa de Castellón y suponía el equilibro de poder en las instituciones castellonenses.

Tabla 19: Insaculaciones bolsa de consejeros de mano menor ${ }^{156}$ :

\begin{tabular}{|c|c|c|c|c|c|c|c|c|}
\hline Apellido & Periodo & Miembros & Apellido & Periodo & Miembros & Apellido & Periodo & Miembros \\
\hline Agramunt & $1600-1623$ & 1 & Ferrer & $\begin{array}{c}1630- \\
1638 \text { y } \\
1647- \\
1653\end{array}$ & 2 & Museros & $1590-\ldots$ & 10 \\
\hline Agullo & $1590-1630$ & 1 & Figuerola & $\begin{array}{c}1590- \\
1653 y \\
1662-. .\end{array}$ & 10 & Navarro & $1590-\ldots$ & 14 \\
\hline Alberich & $1600-1630$ & 1 & Flors & $\begin{array}{c}1600- \\
1623 \text { y } \\
1638- \\
1647\end{array}$ & 2 & Pasqual & $1590-\ldots$ & 12 \\
\hline Albiol & $\begin{array}{c}1623-1647 y \\
1653-1700\end{array}$ & 2 & Fores & $\begin{array}{l}1623- \\
1630\end{array}$ & 1 & Pastor & $\begin{array}{c}\text { Solamente } \\
1700\end{array}$ & 1 \\
\hline Alegre & $1590-1685$ & 6 & Giner & $\begin{array}{l}1590- \\
1666\end{array}$ & 5 & Planell & $1590-1623$ & 1 \\
\hline Amiguet & $\begin{array}{c}1634-1638 \text { y } \\
1653-\ldots\end{array}$ & 3 & Gisbert & $\begin{array}{l}1590- \\
1623\end{array}$ & 2 & Portolés & $1630-1638$ & 1 \\
\hline Andreu & $1590-1623$ & 1 & Godes & $\begin{array}{c}1630- \\
1638\end{array}$ & 1 & Reboll & $1630-1677$ & 5 \\
\hline Avinent & $1638-1700$ & 6 & Goterris & 1679- & 1 & Ribalta & $1600-\ldots$ & 4 \\
\hline
\end{tabular}

\footnotetext{
${ }^{156}$ AHMC. Datos extraídos de la todas las insaculaciones realizadas desde 1597 hasta 1707 que se pueden consultar en el documento 8 del apéndice.
} 


\begin{tabular}{|c|c|c|c|c|c|c|c|c|}
\hline Bernat & $1590-1600$ & 1 & Grañana & $\begin{array}{l}1685 \\
1630- \\
1653\end{array}$ & 1 & Ribes & $1600-1634$ & 1 \\
\hline Blasco & Solamente 1700 & 1 & Jover & $\begin{array}{l}1590- \\
1600\end{array}$ & 1 & Roig & $1600-\ldots$ & 3 \\
\hline Boix & $\begin{array}{c}1630-1653 \text { y } \\
1677-1700\end{array}$ & 2 & Llansola & $\begin{array}{l}1638- \\
1700\end{array}$ & 3 & Romeu & $1590-1600$ & 1 \\
\hline Bonet & $\begin{array}{c}1590-1623 y \\
1653-1677\end{array}$ & 4 & Llorens & $\begin{array}{l}1623- \\
1666\end{array}$ & 2 & Rubert & $\begin{array}{c}1623-1638 \\
1653-\ldots\end{array}$ & 5 \\
\hline Bosch & $1590-1638$ & & March & $\begin{array}{l}1590- \\
1647\end{array}$ & 2 & Sanchís & $1590-1677$ & 6 \\
\hline Breva & $1685-\ldots$ & 7 & Marqués & $\begin{array}{l}1590- \\
1677\end{array}$ & 2 & Segarra & $1600-1694$ & 5 \\
\hline Calbo & $1662-1700$ & 1 & Martí & $\begin{array}{l}1600- \\
1638\end{array}$ & 1 & Sunyer & $1623-1630$ & 1 \\
\hline Casalís & $\begin{array}{c}1630-1647 \text { y } \\
1666-. . .\end{array}$ & 2 & Mas & $\begin{array}{l}1590- \\
1647\end{array}$ & 4 & Tirado & $\begin{array}{c}\text { Solamente } \\
1700\end{array}$ & 1 \\
\hline Castell & $1590-\ldots$ & 18 & Micó & $\begin{array}{l}1590- \\
1623\end{array}$ & 1 & Tormo & $1634-1662$ & 1 \\
\hline Castellet & $1630-\ldots$ & 7 & Miralles & $\begin{array}{l}1590- \\
1600\end{array}$ & 1 & Vicent & $1638-1647$ & 1 \\
\hline Català & $1653-\ldots$ & 2 & Molina & $\begin{array}{l}1590- \\
1623\end{array}$ & 1 & Viciano & $1653-\ldots$ & 3 \\
\hline Coll & $1598-1638$ & 1 & Moliner & $\begin{array}{l}1630- \\
1662\end{array}$ & 2 & Vidal & $\begin{array}{c}1600-1623 y \\
1630-1638\end{array}$ & 2 \\
\hline Duenyes & $1630-1638$ & 2 & Molinos & $\begin{array}{l}1600- \\
1623\end{array}$ & 1 & Vilarroig & $1590-\ldots$ & 20 \\
\hline Eiximeno & $1600-1685$ & 3 & Morán & $\begin{array}{l}1600- \\
1623\end{array}$ & 1 & & & \\
\hline Esteve & $1638-1666$ & 1 & Muntanyés & $\begin{array}{l}1634- \\
1662\end{array}$ & 1 & & & \\
\hline
\end{tabular}

Elaboración propia $^{157}$.

La tabla nos muestra como familia con más representantes en esta bolsa a los Vilarroig con veinte miembros y durante todo el periodo, igual que lo obtenido en la de los jurados tercero y cuarto, es decir, el preámbulo de esta bolsa. A continuación tenemos a los Castell con dieciocho miembros, los Navarro con catorce, los Pasqual con doce y los Museros con diez. Todos ellos durante todo el período estudiado, es decir desde 1590 hasta 1707. Por tanto es evidente que el dominio en mano menor o de

${ }^{157}$ En 1666 hay un nombre tachado ilegible. 
labradores enriquecidos lo encontramos con los Vilarroig, los Castell, los Pasqual, los Navarro y los Museros. 


\section{El poder de las familias en los cargos municipales y en el Consell.}

En el procedimiento insaculatorio era fundamental para ser elegido haber entrado en las diferentes bolsas, sin embargo no era garantía de ocupar un cargo ya que además del azar, jugaba un papel fundamental la habilitación o inhabilitación para desempeñar el oficio. Este proceso se celebraba momentos antes de que el niño de nueve o diez años extrajera de las vasijas los redolines de cera con los nombres de los que se habían considerado podían optar al cargo, y cuando era extraído su nombre y había sido declarado inhábil no era propuesto para ocupar el cargo. Por ello era fundamental realizar un estudio de quiénes ocuparon realmente estos puestos y ver si eran las mismas familias que copaban las insaculaciones en las diferentes bolsas, de forma que las inhabilitaciones fueran un requisito de buen desempeño del oficio y no una red que filtrase a aquellos considerados "no idóneos" pero por intereses particulares y no por intereses del municipio.

\subsection{Cargos y familias.}

A continuación realizaremos una breve descripción de las familias que ocuparon cada uno de los cargos para posteriormente en las conclusiones realizar una comparación de estos datos con los que obtuvimos de las insaculaciones en las bolsas de los distintos oficios.

\subsubsection{Justicia.}

El justicia presidía el Consell de una forma más decorativa que efectiva centrándose sus funciones en la impartición de justicia. Sin embargo en muchas ocasiones intentaba acaparar más poder ${ }^{158}$.

\footnotetext{
${ }^{158}$ Arroyas Serrano, M. (1989): El Consell... op. cit., pp. 107. En plena crisis en el Consell de Castellón por la propuesta del jurado primero de intentar revocar el Privilegio de 1604, el justicia decide prohibir que se trate en dicha reunión tal propuesta lo que provoca el rechazo del Consell por apropiarse de poderes que no tiene.
} 
Este puesto era ocupado por miembros del brazo militar y miembros del brazo real alternando con una periodicidad de uno, dos, tres, cuatro o incluso cinco años en función de las personas hábiles que había en la bolsa de generosos o caballeros. En la siguiente tabla podemos observar la agrupación de las familias que ocuparon el cargo entre 1597 y 1707.

Tabla 20: Apellidos del justicia ${ }^{159}$ :

\begin{tabular}{|c|c|c|c|}
\hline Brazo Militar & $\begin{array}{l}\text { Número } \\
\text { de veces }\end{array}$ & Brazo Real & $\begin{array}{c}\text { Número de } \\
\text { veces }\end{array}$ \\
\hline Arrufat & 4 & Giner & 9 \\
\hline Reus & 4 & March & 8 \\
\hline Bou & 3 & Jover & 6 \\
\hline Igual & 3 & Andreu & 6 \\
\hline Ros & 3 & Martí & 5 \\
\hline $\begin{array}{l}\text { Bou de } \\
\text { Monsonis }\end{array}$ & 2 & Bonet & 4 \\
\hline Feliu & 2 & Brunell & 3 \\
\hline Mas & 2 & Castell & 3 \\
\hline Castell & 1 & Gombau & 3 \\
\hline Jover & 1 & Cases & 3 \\
\hline Miquel & 1 & Sorrando & 3 \\
\hline Miralles & 1 & Salvador & 2 \\
\hline Serra & 1 & Mas & 2 \\
\hline Sisternés & 1 & Gascó & 2 \\
\hline Ros de Ursins & 1 & Lleó & 2 \\
\hline & & Vicent & 2 \\
\hline & & Amiguet & 2 \\
\hline & & Museros & 2 \\
\hline & & Roig & 2 \\
\hline & & Alberich & 1 \\
\hline & & Alegre & 1 \\
\hline & & Avinent & 1 \\
\hline & & Bou & 1 \\
\hline & & Capero & 1 \\
\hline & & Casalís & 1 \\
\hline & & Figuerola & 1 \\
\hline & & Folch & 1 \\
\hline & & Mur & 1 \\
\hline & & Romeu & 1 \\
\hline & & Segarra & 1 \\
\hline & & Serra & 1 \\
\hline & & Sisternés & 1 \\
\hline & & Viciano & 1 \\
\hline & & Vilar & 1 \\
\hline
\end{tabular}

Elaboración propia.

En primer lugar y antes de analizar los resultados de la tabla, hemos de hacer mención de que en la villa de Castellón era casi inexistente la nobleza titulada ${ }^{160}$, sin

\footnotetext{
${ }^{159}$ AHMC. Elaborado a partir del listado de justicias recogido en la tabla 4 aportado anteriormente y que se ha extraído de las reuniones del Consell recogidas en el Judiciari.
} 
embargo existía un grupo en un escalón inferior en el que se engloban aquellos con el derecho al título de "Don" llamados generosos o caballeros y que eran considerados descendientes de aquellos que vinieron con la conquista del Reino de Valencia y/o llegaron inmediatamente después. Estas familias eran tal y cómo cita Gimeno Sanfeliu ${ }^{161}$ los Mas, los Igual, los Feliu, los Sisternés, los Castell o los Vallés. En el cuadro podemos observar como aparecen estas familias, pero no fueron las más relevantes a la hora de repetir en el cargo puesto que a la cabeza encontramos a los Arrufat o los Reus que lo ocuparon cuatro veces, seguidos de los Bou y los Igual con tres veces.

Es importante citar como los Arrufat desaparecen del cargo a partir de 1632, aspecto que nos deja entrever que su poder se centró en la primera parte de la centuria. El caso contrario lo encontramos en la familia de los Bou, que ocupará el cargo en la segunda mitad del s. XVII. Los Igual aparecen a partir de 1679, ya que obtienen la confirmación de su título a partir de las Cortés de $1645^{162}$.

En la bolsa de candidatos para ocupar el cargo de justicia del brazo real encontramos ciudadanos honrados, notarios, doctores en leyes, labradores, mercaderes, cirujanos, doctores en medicina, es decir que lo componían los miembros de las bolsas de jurado primero, segundo y tercero y cuarto.

La familia que más veces que desempeña el cargo de justicia del brazo real es la familia de los Giner ocupándolo en diversos años dentro de todo el período de nuestro estudio pero también tendrán una presencia relevante en el Consell ${ }^{163}$. Será a partir de la llegada de los Borbones cuando obtengan la Hidalguía de sangre ${ }^{164}$.

\footnotetext{
${ }^{160}$ Gimeno Sanfeliu, M.J. (1998): Patrimonio, ... op. cit. La autora explica que en la villa de Castellón en el s. XVII solo existían las baronías de Benicassim y de la Pobla que habían pertenecido a la misma familia y que después de su venta en 1620 se había disgregado en estos dos.

${ }^{161}$ Gimeno Sanfeliu, M.J. (1998): Patrimonio, ... op. cit., pp. 49.

162 Casey, J. (1980): “Tierra ...” op. cit., pp. 37.

163 Casey, J.(1980): “Tierra ...” op. cit., pp. 48. Los Giner no tuvieron el favor de las mercedes concedidas por los Austrias puesto que el Síndico en las Cortés de 1645 fue el abogado Jaime Giner que se opuso a la concesión del servicio y en 1702 eran todavía abogados y ciudadanos.

${ }^{164}$ Gimeno Sanfeliu, M.J. (1990): La Oligarquía... op. cit., pp. 130.
} 
A continuación encontramos a la familia March que lo ocupa ocho veces de las cuales, cinco se concentran entre 1685 y 1707 en la persona de Tomàs March. Es relevante este hecho puesto que como matizaremos después, fue esta persona un representante del mantenimiento en el poder, ya que lo vamos a encontrar en diversos puestos pero todos los años. Es el ejemplo del grupo cerrado que representaba entrar a formar parte de las bolsas y permanecer en el poder ostentando diferentes oficios así como perteneciendo al Consell. Esta familia obtendrá la hidalguía en el año $1767^{165}$.

Los Jover ocuparon el cargo durante seis años durante todo el período estudiado y, al contrario que las otras familias, no desembocó en la concesión de la hidalguía.

Sin embargo, es más relevante hacer mención a los Andreu y los Martí por su importancia posterior (ocuparon el cargo seis y cinco veces respectivamente). La familia de los Andreu centra su desempeño del oficio en Francesc Andreu en los últimos años del s. XVII y es utilizado como un mérito más para incorporarse a las familias nobles de Castellón con la hidalguía conseguida en 1756, así como su pertenencia desde muy antiguo al estatus de ciudadano ${ }^{166}$.

En cuánto a los Martí su presencia como justicia la encontramos hasta 1663 en las personas de Vicent Martí y Aleixandre Martí, pero se ha de hacer constatar el hecho de que Cosme Martí fue elegido baile en 1673 y ejerció el cargo hasta 1707, lo cual, pese a estar insaculado en todas las bolsas le inhabilitaba para ocupar el cargo. Esta familia aportará ambos aspectos, entre otros, para la obtención de la hidalguía en $1777^{167}$

En cuánto a qué grupo de las oligarquías ocupó más veces el puesto de justicia, teniendo en cuenta que en esta bolsa entraban un mayor número de insaculados de los ciudadanos honrados, doctores en leyes y doctores en medicina, para seguir a

\footnotetext{
${ }^{165}$ Gimeno Sanfeliu, M.J. (1990): La oligarquía... op. cit., pp. 193.

${ }^{166}$ Gimeno Sanfeliu, M.J.(1990): La oligarquía... op. cit., pp. 255.

${ }^{167}$ Gimeno Sanfeliu, M.J.(1990): La oligarquía... op. cit., pp. 238.
} 
continuación en número de los artistas y por último los labradores, hemos obtenido los resultados que certifican este hecho y que podemos ver en la siguiente tabla:

Tabla 21: Distribución del cargo de justicia según el grupo de la oligarquía ${ }^{168}$ :

\begin{tabular}{|c|c|c|}
\hline $\begin{array}{c}\text { Grupo de la oligarquía } \\
\text { municipal }\end{array}$ & $\begin{array}{c}\text { Número de veces que } \\
\text { ocupó el cargo }\end{array}$ & $\begin{array}{c}\text { Porcentaje respeto } \\
\text { al total }\end{array}$ \\
\hline Ciudadanos y doctores en leyes y & 48 & $44 \%$ \\
en medicina & 27 & $25 \%$ \\
Militares & 22 & $20 \%$ \\
Artistas & 12 & $11 \%$ \\
\hline
\end{tabular}

Elaboración propia.

Como era de esperar los ciudadanos honrados, doctores en medicina y en derecho ocupan casi la mitad de todo el período estudiado (44\%). Es pues evidente que en la ciudad de Castellón los llamados caballeros o generosos no eran las personas más relevantes a la hora de ocupar los cargos institucionales de la villa, e incluso podemos ver que los notarios, cirujanos, apotecaris, mercaderes y pintores tienen casi el mismo número de personas ocupando el cargo. En cuánto a los labradores quedan relegados a una parte marginal, pero si que nos sirve para poder refutar el argumento expuesto por Villamaría Gómez ${ }^{169}$, cuando especifica que el cargo de justicia solo está destinado a los ciudadanos y artistas. Con los datos que hemos analizado hemos comprobado como lo ocupan en sólo doce ocasiones pero ello implica que están insaculados en la consiguiente bolsa de justicia del brazo real ${ }^{170}$. Es más, podemos afirmar que en 1705 el justicia fue March Casalis que estaba insaculado en la bolsa de justicia del brazo real como llaurador. Esto lo podemos corroborar comprobando en el documento 8 del apéndice donde se transcriben todas las insaculaciones del periodo estudiado. Concretamente tendríamos que centrarnos en la de 1700 donde March Casalis está

168 AHMC. Elaborado a partir de los datos recopilados en la tabla 4 en la que se detallaban justicias. Ésta se ha obtenido con los datos recogidos en las diferentes reuniones del Consell y que se encuentran en el Judiciari entre 1597 y 1707. En los años que hay sustitución de justicia, bien por fallecimiento o por cese se han contado como dos diferentes ya que los datos interesantes para nosotros son las personas que van ocupando el cargo.

${ }^{169}$ Villamaría Gómez, S. (2014): Castellón de... op. cit., pp. 33.

${ }^{170}$ En el documento 8 del apéndice donde se detallan las insaculaciones del siglo XVII podemos ver como en la ampliación de 1668 se cita expresamente como entran en la bolsa de justicia del brazo real los labradores Antoni Castell y Josep Castell. Ocurre lo mismo en la insaculación de 1677. 
insaculado en la bolsa de justicia y evidentemente por su condición en la de mano menor.

Si analizamos la ocupación del cargo por personas concretas, obtenemos que de los ciento doce años estudiados, ocupan el cargo setenta y tres personas diferentes, y además hemos de tener en cuenta que los caballeros tenían un número reducido de miembros en sus bolsas por lo que era más fácil que repitieran, pero pese a ello no encontramos en este grupo oligárquico a las personas que ocupan el puesto más veces, ya que a nivel individual destacamos a Tomás March con cinco veces, Batiste Jover y Francesc Andreu con cuatro veces y Gaspar Joan Brunell, Vicent Martí, Felip Sorrando y Miquel Giner con tres. En los caballeros encontramos las tres presencias de Francesc Bou como las más destacadas.

\subsubsection{Jurado primero.}

Este cargo al igual que ocurría con el justicia y el almotacén era de alternancia entre el brazo militar y real. Anteriormente ya hemos explicado cuáles eran sus funciones y la importancia que tenía ostentarlo. A continuación podemos observar una tabla con las familias que lo ocuparon:

Tabla 22: Apellidos del jurado primero ${ }^{171}$ :

\begin{tabular}{|cc|cc|}
\hline Brazo Militar & $\begin{array}{c}\text { Número } \\
\text { de veces }\end{array}$ & Brazo Real & $\begin{array}{c}\text { Número } \\
\text { de veces }\end{array}$ \\
\hline Arrufat & 6 & Jover & 14 \\
Jordà & 4 & Figuerola & 11 \\
Sisternés & 3 & Giner & 11 \\
Castell & 2 & March & 10 \\
Jover & 2 & Serra & 7 \\
Miralles & 2 & Andreu & 6 \\
Morales & 2 & Martí & 5 \\
Reus & 2 & Brunell & 5 \\
Gombau & 1 & Capero & 4 \\
Igual & 1 & Gascó & 3 \\
Miquel & 1 & Vilar & 3 \\
Ros & 1 & Romeu & 3
\end{tabular}

\footnotetext{
${ }^{171}$ AHMC. Se ha elaborado con los datos obtenidos en las reuniones del Consell y recogidas en el Judiciari. Estos datos se habían presentado en la tabla 5 de jurados.

Incluimos en la tabla los jurados segundos de los años en que el jurado primero es elegido del brazo militar, ya que en esos años se toma de la bolsa de jurado primero del brazo real. Recordemos que esto ocurre para que haya representación de todas las bolsas, de forma que de la bolsa de jurados primeros de brazo real hay uno, de la bolsa de jurados segundos o artistas hay otro y de la bolsa de jurado tercero y cuarto uno más.
} 




Elaboración propia.

Continuando con el orden en el análisis realizado anteriormente, nos centramos en primer lugar en el brazo militar donde podemos observar como comparándolo con los datos del cuadro de justicias volvemos a encontrar a los Arrufat pero no encontramos a los Bou. Es llamativo de nuevo que los Arrufat ocupen el cargo de jurado primero en la primera mitad de la centuria y después desaparezcan, habiéndolo ocupado Gerony Arrufat en 1637, 1641, 1645 y 1649. El resto de familias serían las mismas que detentaban el puesto de justicia.

En la parte del brazo real volvemos a los Giner, los March, los Andreu (Francesc Andreu vuelve a ser uno de los más habituales) y los Jover, ya presentes en el cargo de justicia, pero aparecen nuevas familias como los Figuerola, de los cuales resaltamos al doctor en leyes Ignacio Figuerola y a Vicent Figuerola, ciudadano, porque lo ocuparon bastantes veces. En concreto el segundo seis veces y el primero tres veces. Esta familia se entronca en la primera mitad de siglo con los labradores enriquecidos ya que aparecen ejerciendo alguna vez cargos de esta bolsa. La prueba de este ascenso la tenemos en el caso del doctor Ignacio Figuerola (hijo de una familia de campesinos) ${ }^{172}$.

En el período de ciento siete años objeto de nuestro estudio encontramos a sesenta y dos personas diferentes entre las que destacan Batiste Jover que lo ocupa siete veces, Vicent Figuerola que lo ocupa seis veces, Gerony Arrufat cinco veces siendo del

172 Casey, J. (1980): “Tierra...” op. cit., pp. 38. 
brazo militar y March Antoni Jordà de este mismo brazo, Gaspar Brunell y Tomàs con cuatro veces cada uno.

\subsubsection{Jurado segundo.}

Este oficio se nutría de la bolsa llamada de los artistas en la que se incluían los cirujanos, médicos, apotecaris, mercaderes, notarios, y pintores. En la siguiente tabla se puede ver la agrupación por familias.

Tabla 23: Apellidos de los jurados segundos ${ }^{173}$ :

\begin{tabular}{|cc|cc|}
\hline Apellidos & $\begin{array}{c}\text { Número } \\
\text { de veces }\end{array}$ & Apellidos & $\begin{array}{c}\text { Número } \\
\text { de veces }\end{array}$ \\
\hline Amposta & 6 & Porta & 2 \\
Moliner & 5 & Sanchís & 2 \\
Alberich & 4 & Alegre & 1 \\
Martí & 4 & Beltrán & 1 \\
Amiguet & 3 & Bonaventura & 1 \\
Cases & 3 & Breva & 1 \\
Mercer & 3 & Capero & 1 \\
Rubert & 3 & Castell & 1 \\
Sorrando & 3 & Coll & 1 \\
Vicent & 3 & Compte & 1 \\
Andreu & 2 & Folch & 1 \\
Aragonés & 2 & Jover & 1 \\
Avinent & 2 & Llopis & 1 \\
Bonet & 2 & March & 1 \\
Castellet & 2 & Navarro & 1 \\
Ferrer & 2 & Palanques & 1 \\
Figuerola & 2 & Sabera & 1 \\
Giner & 2 & Safont & 1 \\
Mas & 2 & Salvador & 1 \\
Museros & 2 & Tosquella & 1 \\
Pasqual & 2 & & \\
\hline \multicolumn{2}{|l|}{} & Elaboración propia. & \\
\hline
\end{tabular}

Se puede observar como el abanico queda más abierto que en los oficios anteriores y que, aunque aparecen familias como los Martí, Andreu o Giner, ya no dominan el oficio puesto que en primer lugar encontramos a los Amposta o los Moliner, entre los que destacan dos cirujanos Josep Amposta o Batiste Moliner.

En todo el período objeto de nuestro estudio encontramos a setenta y una persona diferentes ocupando el cargo y la que destaca por haberlo ocupado más veces es Melchor Amiguet con cuatro veces.

\footnotetext{
${ }^{173}$ AHMC. Se ha elaborado la tabla a partir de los datos recogidos en la tabla 4 en que se recogían los nombres de los jurados segundos y que se había confeccionado con las reuniones del Consell reflejadas en el Judiciari. Recordamos que se han incluido los jurados terceros en los años que se elige jurado primero del brazo militar.
} 


\subsubsection{Jurado tercero y cuarto.}

Este oficio estaba ocupado por labradores, y a continuación podemos observar la tabla resumen de las familias que lo ocuparon:

Tabla 24: Apellidos de los jurados tercero y cuarto $^{174}$ :

\begin{tabular}{|lc|lc|}
\hline Apellidos & $\begin{array}{c}\text { Número } \\
\text { de veces }\end{array}$ & Apellidos & $\begin{array}{c}\text { Número } \\
\text { de veces }\end{array}$ \\
\hline Vilarroig & 25 & March & 3 \\
Castell & 15 & Reboll & 3 \\
Museros & 13 & Viciano & 3 \\
Alegre & 9 & Catala & 2 \\
Figuerola & 9 & Llansola & 2 \\
Navarro & 9 & Vicent & 2 \\
Pasqual & 9 & Agramunt & 1 \\
Segarra & 7 & Alberich & 1 \\
Amiguet & 6 & Albiol & 1 \\
Avinent & 6 & Amposta & 1 \\
Rubert & 6 & Blasco & 1 \\
Breva & 5 & Calbo & 1 \\
Casalís & 5 & Ferrer & 1 \\
Castellet & 5 & Folch & 1 \\
Eiximeno & 5 & Gasco & 1 \\
Llorens & 5 & Grañana & 1 \\
Bosch & 4 & Mas & 1 \\
Compte & 4 & Molina & 1 \\
Marques & 4 & Moliner & 1 \\
Martí & 4 & Ribes & 1 \\
Ribalta & 4 & Roig & 1 \\
Sanchís & 4 & Sabera & 1 \\
Bonet & 3 & Tormo & 1 \\
Bou & 3 & Traver & 1 \\
Brunell & 3 & Vallés & 1 \\
Giner & 3 & Vidal & 1 \\
Gisbert & 3 & Vilar & 1 \\
\hline
\end{tabular}

Elaboración propia.

El aspecto más relevante de las familias que ocuparon este oficio lo encontramos en la familia que encabeza la lista. Los Vilarroig fueron la familia predominante entre los jurados tercero y cuarto, estando muy entroncada con otras familias de labradores de la época. A su vez hemos de destacar a los Castell que también están entre los que más veces ocuparon y que a su vez ya aparecían entre el brazo de caballeros y generosos. Los Museros, Alegre o Navarro se encuentran entre esas familias de labradores que son habituales y que a lo largo de la centuria irán subiendo en el escalafón social.

\footnotetext{
${ }^{174}$ AHMC. Elaborada a partir del cuadro de jurados que se ha expuesto anteriormente y que se había obtenido de las reuniones del Consell reflejadas en el Judiciari entre 1597 y 1707.
} 
Hemos de hacer una mención a parte a los Figuerola porque confirman su presencia en este grupo social y que ya habíamos visto anteriormente y los Segarra que como explica Gimeno Sanfeliu ${ }^{175}$ son un claro ejemplo del ascenso de los ricos labradores (previo paso por el de ciudadanos a la hidalguía).

En todo el período objeto de nuestro estudio encontramos a setenta y cinco personas diferentes ocupando el cargo de jurado tercero mientras que en la de jurado cuarto encontramos hasta ochenta y cuatro personas diferentes. Las que más veces lo ocuparon son Mach Casalís y Macià Compte con cuatro en el de jurado tercero y en el de jurado cuarto tenemos a Miquel Vilarroig de Nicolau y a Batiste Llorens. Es significativa la diferencia de personas que ocupan uno u otro, ya que recordemos que tras el Privilegio de Felipe III los años que se extraía jurado primero del brazo militar, el jurado segundo era cubierto con las personas de los ciudadanos honrados, doctores en medicina y en leyes, el jurado tercero lo era con la bolsa de los artistas y el cuarto con la de labradores. Este hecho determina que los artistas a veces ocupen el cargo de jurado tercero mientras que el de jurado cuarto siempre lo ocupen los labradores, por tanto era más habitual que en el puesto de jurado cuarto fuese más dinámica la ocupación del cargo y entrasen más personas diferentes.

\subsubsection{Almotacén.}

Este oficio era extraído de forma alternativa cada tres, cuatro, cinco o seis años entre la bolsa de caballeros y generosos y brazo real, existiendo una bolsa específica para almotacén del brazo real.

El resumen de las personas que ocuparon el oficio lo podemos observar en la tabla siguiente:

Tabla 25: Apellidos del almotacén ${ }^{176}$ :

\begin{tabular}{|lc|lc|}
\hline \multicolumn{1}{|c}{ Brazo Militar } & $\begin{array}{c}\text { Número } \\
\text { de veces }\end{array}$ & Brazo Real & $\begin{array}{c}\text { Número de } \\
\text { veces }\end{array}$ \\
\hline Reus & 4 & Pasqual & 6 \\
Arrufat & 3 & Giner & 5 \\
Giner de Bou & 3 & Martí & 5
\end{tabular}

\footnotetext{
${ }^{175}$ Gimeno Sanfeliu, M.J. (1990): La oligarquía... op. cit., pp. 172-173.

${ }^{176}$ AHMC. Tabla elaborada a partir de los datos expuestos anteriormente en la relación de personas que ocuparon el cargo de almotacén y que se muestran en la tabla 6 y que se obtuvieron de las reuniones del Consell entre 1597 y 1707 recogidas en el Judiciari.
} 


\begin{tabular}{|c|c|c|c|}
\hline Miralles & 3 & Bonet & 4 \\
\hline Sisternés & 3 & Castell & 4 \\
\hline Igual & 2 & Figuerola & 4 \\
\hline Ros & 1 & Bou & 3 \\
\hline Gombau & 1 & Gascó & 3 \\
\hline Jordà & 1 & Jover & 3 \\
\hline Morales & 1 & Ribalta & 3 \\
\hline Vallés & 1 & Alberich & 2 \\
\hline Ros de Ursins & 1 & Amiguet & 2 \\
\hline Castell de Museros & 1 & Breva & 2 \\
\hline Castell & 1 & Moliner & 2 \\
\hline & & Salvador & 2 \\
\hline & & Sisternés & 2 \\
\hline & & Vilarroig & 2 \\
\hline & & Amposta & 1 \\
\hline & & Andreu & 1 \\
\hline & & Aragonés & 1 \\
\hline & & Blasco & 1 \\
\hline & & Brunell & 1 \\
\hline & & Casalís & 1 \\
\hline & & Cases & 1 \\
\hline & & Castellet & 1 \\
\hline & & Compte & 1 \\
\hline & & Eiximeno & 1 \\
\hline & & Ferrer & 1 \\
\hline & & Garcés & 1 \\
\hline & & Llansola & 1 \\
\hline & & Lleó & 1 \\
\hline & & March & 1 \\
\hline & & Mas & 1 \\
\hline & & Museros & 1 \\
\hline & & Navarro & 1 \\
\hline & & Rubert & 1 \\
\hline & & Segarra & 1 \\
\hline & & Serra & 1 \\
\hline & & Sorrando & 1 \\
\hline & & Vallés & 1 \\
\hline & & Vilar & 1 \\
\hline
\end{tabular}

Elaboración propia.

En el brazo militar encontramos las mismas presencias que en los oficios anteriores, estando en cabeza la familia Reus con cuatro veces y que lo ocupa tanto al principio como al final del s. XVII. Le siguen otras familias que ya hemos comentado antes como los Arrufat, que también desaparecen a partir de 1650 en este oficio, concentrando su poder en la primera mitad del s. XVII. Otras familias que ocupan un lugar destacado son los Miralles o los Sisternés, que son familias que ya nos han aparecido antes pero que es en este oficio donde ocupan más veces. En cuanto a los Giner su presencia se centra en la figura de Pere Giner de Bou que entra en la bolsa en la insaculación de 1647-1648, especificando su entrada en 1649 y manteniéndose hasta la de 1662. Es muy revelador este caso porque esta familia obtiene la hidalguía de sangre con los Borbones por la oposición al servicio de Felipe IV en las Cortes de 1645 
lo cual era un enfrentamiento con la casa de Austria, por tanto su presencia en la bolsa militar es en relación a la familia Bou y no Giner.

En el brazo real encontramos a los Pasqual como los que más veces lo ejercen, concretamente en la figura de Miquel Pasqual de Francesc que lo llega a ocupar cuatro veces de las seis, a continuación volvemos a encontrar familias habituales: los Giner y los Martí con cinco veces, los Bonet seguidamente con cuatro y después los Castell, los Figuerola y los Bou con tres.

Tabla 26: Distribución del cargo de almotacén según el grupo de la oligarquía que lo ocupaba ${ }^{177}$ :

\begin{tabular}{|c|c|c|}
\hline $\begin{array}{c}\text { Grupo de la oligarquía } \\
\text { municipal }\end{array}$ & $\begin{array}{c}\text { Número de veces que } \\
\text { ocupó el cargo }\end{array}$ & $\begin{array}{c}\text { Porcentaje respeto } \\
\text { al total }\end{array}$ \\
\hline $\begin{array}{c}\text { Ciudadanos y doctores en } \\
\text { leyes y en medicina }\end{array}$ & 26 & $25 \%$ \\
Militares & 27 & $26 \%$ \\
Artistas & 28 & $27 \%$ \\
Labradores & 22 & $22 \%$ \\
\hline
\end{tabular}

Elaboración propia.

Como podemos observar en la tabla 21, el desempeño de este oficio estuvo más repartido entre los grupos oligárquicos de poder de la villa castellonense, y es que prácticamente fue ocupado por el mismo porcentaje, alrededor del $25 \%$.

$\mathrm{Al}$ analizar de forma individual si hay concentración de desempeño en algunas personas tampoco obtenemos un predominio de nadie en particular, ya que en los ciento tres años que hemos estudiado, es ocupado por ochenta personas diferentes, por tanto el sistema parecía asegurar que no hubiese nadie anquilosado. De estas ochenta personas destacamos a Miquel Pasqual de Francesc con cuatro veces, llegando a ocuparlo dos años consecutivos o Fernando Miralles del brazo militar que también lo ocupó cuatro veces.

\subsubsection{Escribano del Consell.}

La escribanía del Consell se ejercía por un período de tres años tras el Privilegio de Felipe III de 1597 por lo que en la tabla adjunta se han englobado las familias por veces que lo ejercieron, es decir que se considera una vez los tres años que lo ejercen.

\footnotetext{
${ }^{177}$ Ibidem.
} 
Tabla 27: Apellidos del escribano ${ }^{178}$ :

\begin{tabular}{|c|c|}
\hline Apellido & $\begin{array}{c}\text { Número } \\
\text { de veces }\end{array}$ \\
\hline Martí & 5 \\
Giner & 4 \\
Casses & 3 \\
Tosquella & 3 \\
Bou & 2 \\
Breva & 2 \\
Capero & 2 \\
Castellet & 2 \\
Jover & 2 \\
Moliner & 2 \\
Museros & 2 \\
Andreu & 1 \\
Beltrán & 1 \\
Bonet & 1 \\
Compte & 1 \\
Figuerola & 1 \\
Porta & 1 \\
Quevedo & 1 \\
Romeu & 1 \\
Salvador & 1 \\
Vidal & 1 \\
\multicolumn{2}{|c|}{ Elaboración propia. }
\end{tabular}

Es importante destacar que Museros lo ejerce dos veces pero solo un año cada una, ya que la primera es por el fallecimiento de Macià Compte y la segunda es en 1707 ya que la llegada del ayuntamiento borbónico abandona el cargo.

Podemos observar como las familias que más veces lo ocupan siguen siendo los Martí o los Giner, aspecto que ya había ocurrido anteriormente en otros oficios. Y a nivel individual destacamos a Vicent Martí que lo ocupa en cuatro ocasiones, Pere Giner, Vicent Tosquella y Jaume Cases que lo ocupan tres veces.

\subsubsection{Consejeros del brazo militar.}

El Consell de Castellón estaba formado por treinta y seis miembros de los cuales dos eran consejeros del brazo militar y es reseñable que ocupaban el cargo directamente aquellos que habían sido justicia, jurado primero o almotacén en el año anterior. Esto implica que serán las mismas familias que hemos estudiado antes.

\footnotetext{
178 AHMC. Elaborada con los datos de la tabla anterior en la que se detallaban todas las personas que habían ocupado el cargo de escribano y que se recogían en la tabla 7. Estos datos se habían obtenido de las reuniones del Consell recogidas en el Judiciari entre 1597 y 1707.
} 
Con estos datos podemos obtener la siguiente tabla resumen por apellidos:

Tabla 28: Apellidos de los consejeros del brazo militar $^{179}$ :

\begin{tabular}{|c|c|}
\hline Apellido & $\begin{array}{c}\text { Número de } \\
\text { veces }\end{array}$ \\
\hline Reus & 32 \\
Arrufat & 20 \\
Ros & 16 \\
Sisternés & 16 \\
Miquel & 15 \\
Vallés & 15 \\
Mas & 13 \\
Igual & 12 \\
Morales & 11 \\
Bou & 10 \\
Jordà & 9 \\
Miralles & 8 \\
Castell & 7 \\
Giner & 6 \\
Jover & 6 \\
Feliu & 4 \\
Gombau & 3 \\
Castell de Museros & 3 \\
Serra & 2 \\
Ros de Ursins & 2 \\
Ripoll & 1 \\
Serra i Dols & 1 \\
Castell de Romeu & 1 \\
Bou de Monsonis & 1 \\
\hline Elaboracion propaa
\end{tabular}

Elaboración propia.

Es muy significativo como los Morales, los Arrufat y los Miquel desaparecen a partir de la segunda mitad del s. XVII. Caso contrario los Vallés, Igual, Serra, Bou, Mas ${ }^{180}$, que van a aparecer en la segunda mitad del citado siglo. Pere Giner Bou lo ocupa en los años 1650, 1651, 1652, 1653,1654 y 1656.

La familia de Reus ocupa muchas veces el cargo en la primera mitad del siglo pero después ya no es tan habitual, al igual que la familia de los Sisternés o de los Ros.

${ }^{179}$ AHMC. Datos obtenidos del listado de consejeros militares recogidos en la tabla 28 y que se habían recopialado revisando todas las reuniones del Consell reflejadas en el Judiciari entre 1597 y 1707.

${ }^{180}$ Gimeno Sanfeliu, M.J. (1998): Patrimonio,... op. cit. En esta obra nos explica como esta familia obtiene el título de caballero en 1652 por lo que es lógico que ocupen ese cargo a partir segunda mitad del siglo XVII. 


\subsubsection{Acequieros.}

Ya hemos explicado sus funciones anteriormente y como su desempeño no implicaba la pertenencia al Consell para el ejercicio siguiente. En la tabla anexa podemos observar las familias que lo ocuparon:

Tabla 29: Apellidos de los acequieros ${ }^{181}$ :

\begin{tabular}{|c|c|c|c|}
\hline Apellidos & $\begin{array}{l}\text { Número } \\
\text { de veces }\end{array}$ & Apellidos & $\begin{array}{l}\text { Número } \\
\text { de veces }\end{array}$ \\
\hline Vilarroig & 10 & Giner & 2 \\
\hline Rubert & 8 & Montanyes & 2 \\
\hline Castell & 7 & Ribalta & 2 \\
\hline Pasqual & 7 & Amposta & 1 \\
\hline Sanchís & 7 & Bosch & 1 \\
\hline Museros & 5 & Bou & 1 \\
\hline Eiximeno & 4 & Breva & 1 \\
\hline Navarro & 4 & Brunell & 1 \\
\hline Amiguet & 3 & Coll & 1 \\
\hline Avinent & 3 & Fores & 1 \\
\hline Mas & 3 & Gisbert & 1 \\
\hline Moliner & 3 & Llansola & 1 \\
\hline Segarra & 3 & March & 1 \\
\hline Alegre & 2 & Martí & 1 \\
\hline Boix & 2 & Roig & 1 \\
\hline Calbo & 2 & Romeu & 1 \\
\hline Casalís & 2 & Safont & 1 \\
\hline Castellet & 2 & Serra & 1 \\
\hline Català & 2 & Viciano & 1 \\
\hline Figuerola & 2 & & \\
\hline
\end{tabular}

La primera conclusión que extraemos es que las familias que más veces ocuparon el cargo provenían de la bolsa de labradores, como los Vilarroig, los Sanchís, los Rubert o los Pasqual. Es evidente que el interés por ejercer el poder en la acequia mayor podía ser de provecho para las familias de labradores enriquecidos. Ello queda patente con la presencia de los Vilarroig (que como habíamos analizado anteriormente son los que más veces ejercieron los cargos de jurado tercero, cuarto y las consejerías de mano menor). La presencia de los Castell indica en este cargo nos muestra como ésta familia se entronca con todos los oficios municipales.

\footnotetext{
${ }^{181}$ AHMC. Se ha obtenido con los datos de las personas que fueron acequieros y que se han presentado anteiormente en la tabla 8. El listado de las personas se había obtenido de la recopilación de reuniones del Consell que se encuentra en el Judiciari.
} 
Tabla 30: Distribución del cargo de acequieros según el grupo de la oligarquía que lo ocupaba ${ }^{182}$ :

\begin{tabular}{|c|c|c|}
\hline $\begin{array}{c}\text { Grupo de la oligarquía } \\
\text { municipal }\end{array}$ & $\begin{array}{c}\text { Número de veces que } \\
\text { ocupó el cargo }\end{array}$ & $\begin{array}{c}\text { Porcentaje respeto } \\
\text { al total }\end{array}$ \\
\hline Ciudadanos y doctores en leyes & $\mathbf{8}$ & $\mathbf{8 \%}$ \\
y en medicina & $\mathbf{9}$ & $\mathbf{9 \%}$ \\
Artistas & $\mathbf{8 6}$ & $\mathbf{8 3 \%}$ \\
\hline Labradores &
\end{tabular}

Elaboración propia.

La tabla muestra las consecuencias de la insaculación, es decir de cómo estaba compuesta la bolsa para ocupar este cargo. Evidentemente este oficio era muy deseado por los labradores enriquecidos y lo que podía suponer el control del riego de las aguas mayores de Castellón y eso se refleja en una bolsa compuesta en su mayoría por labradores, y por lo tanto a la hora de ocupar el puesto encontramos que son ellos con un $83 \%$ los que más veces ocupan el cargo.

En cuánto a alguna persona que ocupará el cargo de una forma sistemática, no encontramos una asiduidad relevante, siendo tres el máximo número de veces que lo ocupan Francesc Amiguet, Vicent Eiximeno, Gerony Rubert, Miquel Sanchís, Mateu Sanchís y Joan Vilarroig. Al igual que ocurre en los cargos de justicia y almotacén en los ciento tres años que hemos estudiado, han aparecido setenta y ocho personas diferentes.

\subsubsection{Síndicos.}

No era elegido por el proceso insaculatorio, sino que su elección se hace cuando se ha completado los miembros del Consell en la víspera de la Pascua de Pentecostés. Sin embargo su desempeño le otorgaba por oficio el cargo de consejero para el ejercicio siguiente, por tanto es relevante ver que familias lo ocuparon. A continuación se expone una tabla con los nombres de todos lo que ocuparon el cargo.

\footnotetext{
${ }^{182}$ AHMC. Elaborada con los datos que se muestran en la tabla 8 de las personas que ejercieron el oficio de acequieros. Recordemos que esa tabla se obtuvo de las reuniones del Consell de Castellón y que se recogían en el Judiciari.
} 
Tabla 31: Síndicos del Consell ${ }^{183}$ :

\begin{tabular}{|c|c|c|}
\hline Año & Síndico & Grupo de la oligarquía \\
\hline 1597 & Gabriel Agramunt & Llaurador \\
\hline 1598 & Francesc Jover menor & Notari \\
\hline 1599 & Bertomeu Mas & Llaurador \\
\hline 1600 & Antoni Joan Lleó & Ciutadà \\
\hline 1601 & Miquel Museros & Llaurador \\
\hline 1602 & Jaume Sabera & Mercader \\
\hline 1603 & & \\
\hline 1604 & Miquel Aragonés & Notari \\
\hline 1605 & Jaume Giner & Notari \\
\hline 1606 & Tomàs Moliner & Notari \\
\hline 1607 & Pau Capero & Notari \\
\hline 1608 & Cristòfol Sisternés & Ciutadà \\
\hline 1609 & Baltazar Gombau & Ciutadà \\
\hline 1610 & Francesc Joan Bou & Ciutadà \\
\hline 1611 & & \\
\hline 1612 & Melchor Salvador & Notari \\
\hline 1613 & Pere March & Ciutadà \\
\hline 1614 & Pere Figuerola & Llaurador \\
\hline 1615 & Francesc Mas & Llaurador \\
\hline 1616 & Pere Joan Martí & Ciutadà \\
\hline 1617 & & \\
\hline 1618 & & \\
\hline 1619 & & \\
\hline 1620 & Miquel Sanchís & Llaurador \\
\hline 1621 & Batiste Serra & Ciutadà \\
\hline 1622 & Bertomeu Giner & Doctor en medicina \\
\hline 1623 & Lluís Mas & Doctor en medicina \\
\hline 1624 & Miquel Alberich & Llaurador \\
\hline 1625 & Cristòfol Bou & Notari \\
\hline 1626 & Martí Giner & Notari \\
\hline 1627 & Gaspar Martí & Notari \\
\hline 1628 & Nicolau Figuerola & Doctor en dret \\
\hline 1629 & Gabriel Bonet & Notari \\
\hline 1630 & Agostí Agramunt Sisternés & Ciutadà \\
\hline 1631 & Pere Alegre & Llaurador \\
\hline 1632 & Cosme Feliu & Doctor en dret \\
\hline 1633 & Batiste Gascó & Doctor en dret \\
\hline 1634 & Nicolau Pauner & Ciutadà \\
\hline 1635 & Melchor Capero & Ciutadà \\
\hline 1636 & Jaume Jover & Ciutadà \\
\hline 1637 & Miquel Mur & Doctor en medicina \\
\hline 1638 & Vicent Martí & Notari \\
\hline 1639 & Francesc Bou & Ciutadà \\
\hline 1640 & Pere Roig & Notari \\
\hline 1641 & Jaume Castell & Mercader \\
\hline 1642 & Batiste Jover & Ciutadà \\
\hline 1643 & Jaume Giner & Doctor en dret \\
\hline 1644 & Gaspar Lluís Brunell & Ciutadà \\
\hline 1645 & Baltazar Gombau & Ciutadà \\
\hline 1646 & Josep Castell de Antoni & Llaurador \\
\hline 1647 & Vicent Castellet & Doctor en dret \\
\hline 1648 & Vicent Museros & Llaurador \\
\hline 1649 & Joan Andreu & Ciutadà \\
\hline 1650 & Batiste Llorens & Llaurador \\
\hline
\end{tabular}

183 AHMC. Elaborada con los datos obtenidos en las reuniones del Consell de Castellón entre 1597 y 1707 y que se están recopiladas en el Judiciari. 


\begin{tabular}{|c|c|c|}
\hline Año & Síndico & Grupo de la oligarquía \\
\hline 1651 & Andreu Castellet & Llaurador \\
\hline 1652 & Josep Segarra & Llaurador \\
\hline 1653 & Mateu Tormo & Llaurador \\
\hline 1654 & Jaume Andreu & Notari \\
\hline 1655 & Josep Alberich & Mercader \\
\hline 1656 & Tomàs Giner & Ciutadà \\
\hline 1657 & Vicent Martí & Notari \\
\hline 1658 & Vicent Pasqual & Notari \\
\hline 1659 & Andreu Ribalta & Llaurador \\
\hline 1660 & Vicent Marqués & Llaurador \\
\hline 1661 & Pere Museros/Martí Mas & Llaurador/Cavaller \\
\hline 1662 & Gerony Vidal & Doctor en medicina \\
\hline 1663 & Joan Museros & Ciutadà \\
\hline 1664 & Miquel Vilarroig & Llaurador \\
\hline 1665 & Vicent Tosquella & Ciutadà \\
\hline 1666 & Antoni Castell & Llaurador \\
\hline 1667 & Francesc Andreu & Ciutadà \\
\hline 1668 & Felip Sorrando & Mercader \\
\hline 1669 & Macià Compte & Notari \\
\hline 1670 & Jaume Viciano de Miquel & Llaurador \\
\hline 1671 & March Casalís & Llaurador \\
\hline 1672 & Miquel Llansola & Llaurador \\
\hline 1673 & Pere Roig de Jaume & Llaurador \\
\hline 1674 & Josep Avinent major & Llaurador \\
\hline 1675 & Francesc Mercer & Pintor \\
\hline 1676 & Miquel Pasqual de Francesc & Llaurador \\
\hline 1677 & Miquel Bonet & Notari \\
\hline 1678 & Pere Calbo & Llaurador \\
\hline 1679 & Vicent Ferrer & Notari \\
\hline 1680 & Josep Albiol & Llaurador \\
\hline 1681 & Pere Figuerola & Notari \\
\hline 1682 & Joan Timor & Doctor en dret \\
\hline 1683 & Gabriel Segarra de Josep & Llaurador \\
\hline 1684 & Jaume Breva de Vilarroig & Llaurador \\
\hline 1685 & Pere Museros & Notari \\
\hline 1686 & Gaspar Rubert & Notari \\
\hline 1687 & Miquel Vilarroig de Nicolau & Llaurador \\
\hline 1688 & Ignacio Figuerola & Doctor en dret \\
\hline 1689 & Josep Amposta & Cirurgià \\
\hline 1690 & Cristòfol Vilar & Doctor en dret \\
\hline 1691 & Tomàs March & Ciutadà \\
\hline 1692 & Ignacio Breva & Llaurador \\
\hline 1693 & Félix Vilarroig & Llaurador \\
\hline 1694 & Pasqual Avinent & Notari \\
\hline 1695 & Francesc Amiguet & Llaurador \\
\hline 1696 & Josep Segarra & Ciutadà \\
\hline 1697 & $\begin{array}{c}\text { Francesc Joan Cases/Joan } \\
\text { Montanyés }\end{array}$ & Doctor en dret/Notari \\
\hline 1698 & Batiste Jover & Ciutadà \\
\hline 1699 & Pere Mercer & Pintor \\
\hline 1700 & Miquel Pasqual de Miquel & Llaurador \\
\hline 1701 & Vicent Anglés & Doctor en medicina \\
\hline 1702 & Jaume Breva de Jaume & Llaurador \\
\hline 1703 & Josep Castell de Antoni & Llaurador \\
\hline 1704 & Tomàs Blasco & Llaurador \\
\hline 1705 & Josep Llopis & Notari \\
\hline 1706 & Joan Safont & Notari \\
\hline 1707 & Pere Breva & Notari \\
\hline
\end{tabular}




$$
\text { Elaboración propia }{ }^{184} \text {. }
$$

El único aspecto no habitual lo encontramos en 1661 en que el fallecimiento de Pere Museros provoca su sustitución por Martí Mas. Además en 1697 no se incluye a Francesc Joan Cases entre los consejeros y se cita a parte. Después por su enfermedad es sustituido por Joan Montanyés.

En cuánto a quiénes ocuparon el oficio de síndico del Consell encontramos hasta ciento una personas diferentes en los ciento siete años objeto de estudio ${ }^{185}$. Solo encontramos a Baltazar Gombau, Batiste Jover, Jaume Giner, Josep Castell de Antoni, Josep Segarra, Pere Figuerola, Pere Museros y Vicent Martí que lo ocupan dos veces, el resto lo ocupan una sola vez. Es llamativo que no hay ninguna persona que lo ocupe más de dos veces, lo que sigue demostrando la movilidad entre los diferentes puestos del Consell pero nadie perdura en un mismo oficio.

Tabla 32: Distribución del cargo de síndico según el grupo de la oligarquía ${ }^{186}$ :

\begin{tabular}{|c|c|c|}
\hline $\begin{array}{c}\text { Grupo de la oligarquía } \\
\text { municipal }\end{array}$ & $\begin{array}{c}\text { Número de veces que } \\
\text { ocupó el cargo }\end{array}$ & $\begin{array}{c}\text { Porcentaje respeto } \\
\text { al total }\end{array}$ \\
\hline $\begin{array}{c}\text { Ciudadanos y doctores en leyes } \\
\text { y en medicina }\end{array}$ & 37 & $\mathbf{3 4 \%}$ \\
Militares & 1 & $\mathbf{1 \%}$ \\
Artistas & 33 & $\mathbf{3 1 \%}$ \\
Labradores & 37 & \\
\hline
\end{tabular}

Con los resultados de la tabla podemos ver que el cargo se repatía de una forma bastante equitativa entres los tres grupos oligárquicos del brazo real, de forma que cada uno lo ocupa alrededor de un tercio de las veces. De forma anecdótica aparecen los militares que lo ocupan una vez en la persona de Martí Mas y es por el fallecimiento de Pere Museros. Esto parece indicar que el cargo de tesorero del Consell o síndico no era un cargo destinado a los caballeros o generosos.

En la tabla siguiente podemos ver las familias que lo ocuparon:

\footnotetext{
${ }^{184}$ Los años $1603,1611,1617,1618$ y 1619 no tenemos datos y los dejamos en blanco.

185 Hemos incluido a Martí Mas y Joan Montanyés porque aunque no lo ocuparon todo el año, es significativo que sean dos personas que no lo habían ocupado anteriormente.

${ }^{186}$ AHMC. Elaborado a partir de los datos recopilados en la tabla 20 en la que se detallaban justicias. Ésta se ha obtenido con los datos recogidos en las diferentes reuniones del Consell y que se encuentran en el Judiciari entre 1597 y 1707. En los años que hay sustitución de justicia, bien por fallecimiento o por cese se han contado como dos diferentes ya que los datos interesantes para nosotros son las personas que van ocupando el cargo.
} 
Tabla 33: Apellidos de los síndicos ${ }^{187}$ :

\begin{tabular}{|cc|cc|}
\hline Familia & $\begin{array}{c}\text { Número } \\
\text { de veces }\end{array}$ & Familia & $\begin{array}{c}\text { Número } \\
\text { de veces }\end{array}$ \\
\hline Giner & 5 & Calbo & 1 \\
Museros & 5 & Casalís & 1 \\
Breva & 4 & Cases & 1 \\
Castell & 4 & Compte & 1 \\
Figuerola & 4 & Feliu & 1 \\
Jover & 4 & Ferrer & 1 \\
Martí & 4 & Gascó & 1 \\
Andreu & 3 & Llansola & 1 \\
Bou & 3 & Lleó & 1 \\
March & 3 & Llopis & 1 \\
Mas & 3 & Llorens & 1 \\
Pasqual & 3 & Marqués & 1 \\
Segarra & 3 & Moliner & 1 \\
Vilarroig & 3 & Muntanyés & 1 \\
Agramunt & 2 & Mur & 1 \\
Alberich & 2 & Pauner & 1 \\
Avinent & 2 & Ribalta & 1 \\
Bonet & 2 & Rubert & 1 \\
Capero & 2 & Sabera & 1 \\
Castellet & 2 & Safont & 1 \\
Gombau & 2 & Salvador & 1 \\
Mercer & 2 & Sanchís & 1 \\
Roig & 2 & Serra & 1 \\
Albiol & 1 & Sisternés & 1 \\
Alegre & 1 & Sorrando & 1 \\
Amiguet & 1 & Timor & 1 \\
Amposta & 1 & Tormo & 1 \\
Angles & 1 & Tosquella & 1 \\
Aragonés & 1 & Viciano & 1 \\
Blasco & 1 & Vidal & 1 \\
Brunell & 1 & Vilar & 1 \\
\hline
\end{tabular}

Volvemos a encontrar las mismas familias como aquellas que más veces ocuparon el cargo, como los Giner, Breva, Museros y Castell, con la circunstancia especial de que los Breva aparecen al final del siglo XVII, muestra de la mayor poder político que ha adquirido esta familia.

\subsubsection{Consejeros de mano mayor.}

Recordemos que en esta bolsa se encontraban las personas de las mismas características que en las bolsas de jurados primero y segundo, es decir ciudadanos y artistas, entre los que encontramos doctores en leyes, notarios, doctores en medicina, cirujanos, apotecari, mercaderes y pintores.

\footnotetext{
187 AHMC. Elaborada con los datos expuestos anteriormente en la tabla anterior 32 y que se había confeccionado revisando las reuniones del Consell entre 1597 y 1707 y que se recogen el el Judiciari.
} 
Tabla 34: Apellidos de los consejeros de mano mayor ${ }^{188}$ :

\begin{tabular}{|c|c|c|c|}
\hline Apellido & $\begin{array}{l}\text { Número } \\
\text { de veces }\end{array}$ & Apellido & $\begin{array}{l}\text { Número } \\
\text { de veces }\end{array}$ \\
\hline Giner & 102 & Sabera & 12 \\
\hline Martí & 79 & Avinent & 9 \\
\hline Andreu & 74 & Blasco & 9 \\
\hline Figuerola & 67 & Segarra & 9 \\
\hline March & 62 & Sanchís & 8 \\
\hline Jover & 59 & Timor & 8 \\
\hline Moliner & 42 & Fabregat & 7 \\
\hline Gascó & 40 & Folch & 7 \\
\hline Bonet & 37 & Quevedo & 7 \\
\hline Museros & 34 & Roig & 7 \\
\hline Amposta & 32 & Tormo & 7 \\
\hline Mercer & 31 & Traver & 7 \\
\hline Cases & 29 & Llorens de Prima & 6 \\
\hline Serra & 29 & Agramunt & 5 \\
\hline Amiguet & 28 & Bernat & 5 \\
\hline Aragonés & 28 & Giner de Vilarroig & 5 \\
\hline Bou & 28 & Llopis & 5 \\
\hline Romeu & 28 & Mascarós & 5 \\
\hline Castell & 27 & Peris & 5 \\
\hline Ferrer & 27 & Planell & 5 \\
\hline Brunell & 26 & Beltrán & 4 \\
\hline Compte & 26 & Casalís & 4 \\
\hline Gombau & 26 & Grau & 4 \\
\hline Alberich & 25 & Llorens de Clavell & 4 \\
\hline Pasqual & 23 & Montanyés & 4 \\
\hline Tosquella & 23 & Vallés & 4 \\
\hline Breva & 22 & Albiol & 3 \\
\hline Vilar & 22 & Anglés & 3 \\
\hline Capero & 21 & Safont & 3 \\
\hline Mur & 21 & Arrufat & 2 \\
\hline Mas & 20 & Orts & 2 \\
\hline Salvador & 19 & Llorens & 2 \\
\hline Vicent & 18 & Palanques & 2 \\
\hline Viciano & 18 & Pauner & 2 \\
\hline Castellet & 17 & Pedro & 2 \\
\hline Lleó & 16 & Alegre & 1 \\
\hline Rubert & 16 & Bonaventura & 1 \\
\hline Sisternés & 15 & Gaspar & 1 \\
\hline Carnicer & 13 & Gisbert & 1 \\
\hline Porta & 13 & Llorach & 1 \\
\hline Sorrando & 13 & Llorens de Planell & 1 \\
\hline Vidal & 13 & Moreno & 1 \\
\hline Feliu & 12 & Pavia & 1 \\
\hline
\end{tabular}

Nota: En cursiva aquellas familias que solo tienen un representante.

Realizar meticulosamente el estudio de los consejeros de mano mayor es crucial, ya que eran quince lo cual suponía el $42,6 \%$ de los votos del Consell y recordemos que era en esta institución donde se habilitaba con habas blancas y negras para poder entrar

\footnotetext{
${ }^{188}$ AHMC. Se ha elaborado con los datos de la tabla 2 de consejeros de mano mayor y menor. Estos datos se habían obtenido de las reuniones del Consell recogidas en el Judiciari entre 1597 y 1707.
} 
en las bolsas. Por tanto, las familias presentes controlaban los accesos a la posibilidad de ser consejero, el acceso a las bolsas de insaculados y el nombramiento de los diferentes oficios. Era pues, el núcleo del poder de Castellón

Los resultados nos dejan una primera conclusión que nos llama poderosamente la atención, aunque sigue en la línea de los datos de los anteriores cuadros, y es que la familia que más veces tiene representante en el Consell son los Giner que suma 102 presencias. Esto nos podría llevar a pensar que formó parte del Consell durante todo el período estudiado ${ }^{189}$, sin embargo en algunos años estudiados a veces había dos o incluso tres personas relacionadas con la familia Giner. Pese a eso podemos asegurar que con este dato queda de manifiesto la relevancia a nivel del municipio de esta familia, que además ocupó otros cargos lo cual compensaría la presencia de dos o tres personas en el Consell.

Otras familias que van a ser muy influyentes en la villa de Castellón, como ya habíamos visto anteriormente, son los Martí, Andreu, Figuerola, Jover y March. Todos ellos entran a formar parte del Consell más de la mitad de años el período estudiado, es decir, más de 53 ocasiones. Por tanto los datos parecen indicarnos que continuamos con las mismas familias dominando la esfera política de Castellón. Sin embargo este análisis no estaría completo si no realizáramos un pequeño estudio a nivel individual de las personas que ocuparon los distintos cargos del municipio, y es que en la tabla anterior se ha marcado de forma especial aquellas familias en las que solo participo un miembro. Como observamos ${ }^{190}$ Melchor Amiguet, Macià Compte, Miquel de Mur, Vicent Tosquella son los únicos representantes de sus familias pero ocupan el cargo más de veinticinco veces, lo cual es una muestra de esta perpetuidad en el puesto dando cuenta de ser unas oligarquías cerradas. En un apartado posterior ampliaremos este análisis individual ya que tendremos en cuenta todos los puestos que ocuparon.

\footnotetext{
${ }^{189}$ Nuestro estudio comprende desde la aprobación del Privilegio de Felipe III en 1597 hasta 1707 con la introducción del Ayuntamiento borbónico, eso supone 111 años, si le descontamos aquellos de los que no hemos podido obtener datos que son cinco obtenemos 106 Consells.

${ }^{190}$ En la tabla 2 se aporta los componentes del Consell de todo el período y junto a la tabla comentada anteriormente se puede extraer los datos individuales.
} 
La suma total de familias que tuvieron algún representante en el Consell en la parte correspondiente a mano mayor asciende a 87 , lo cual no nos parece una cantidad muy grande ya que si utilizamos los datos de población que hemos aportado al principio en la introducción supone que las familias de mano mayor, que estaban formadas por notarios, doctores en leyes, cirujanos, apotecaris, doctores en medicina, pintores y mercaderes representan alrededor de un 5,2\% de la población ${ }^{191}$.

Evidentemente sería más conveniente realizar un análisis completo con las familias de mano menor o de labradores ya que con ello podríamos tener una visión global de las familias que conformaron el poder local. Por ello pasamos a ver los datos de la mano menor.

\subsubsection{Consejeros de mano menor.}

En esta bolsa se encontraban los labradores enriquecidos y como hemos comentado en el caso de los consejeros de mano mayor, forman parte de la institución que proveerá las bolsas y, por tanto, que marcará los límites del círculo de poder de la ciudad de Castellón. Como práctica habitual ocupan catorce puestos en el Consell y representan el 39\% de los votos. A continuación podemos observar las veces que ocuparon el cargo cada una de las familias.

Tabla 35: Apellidos de los consejeros de mano menor ${ }^{192}$ :

\begin{tabular}{|cc|cc|}
\hline Apellido & $\begin{array}{c}\text { Número de } \\
\text { veces que } \\
\text { aparece }\end{array}$ & Apellido & $\begin{array}{c}\text { Número de } \\
\text { veces que } \\
\text { aparece }\end{array}$ \\
\hline Vilarroig & 165 & Bosch & 12 \\
Pasqual & 107 & Llorens & 12 \\
Castell & 102 & March & 12 \\
Museros & 96 & Tormo & 11 \\
Navarro & 83 & Vidal & 11 \\
Avinent & 59 & Bonet & 10 \\
Segarra & 51 & Martí & 8
\end{tabular}

191 Para el cálculo de ese 5,2\% se ha tenido en cuenta el recuento poblacional de Campoflorido de 1712/1713, puesto que los datos obtenidos son de todo el período estudiado y eso implica que hay familias que aparecen y desaparecen y los datos son acumulativos, por tanto consideramos mas relevante tomar los datos poblacionales del último periodo que se aportan. Es evidente que el sesgo es muy importante y que el cálculo realizado es orientativo pero nos da una idea aproximada del porcentaje de familias representadas que en este caso sería de 87 de 1700.

${ }^{192}$ AHMC. Elaborada a partir de los las listas de consejeros de mano mayor y menor que se han detallado anteriormente en la tabla 2. Éstas se habían elaborado con los datos obtenidos en las reuniones del Consell de Castellón entre 1597 y 1707 y recogidas en el Judiciari. 


\begin{tabular}{|cl|cl|} 
Alegre & 45 & Planell & 8 \\
Mas & 38 & Ribes & 8 \\
Eiximeno & 37 & Ferrer & 6 \\
Sanchís & 37 & Grañana & 6 \\
Ribalta & 36 & Molinos & 6 \\
Castellet & 35 & Muntaynés & 6 \\
Rubert & 35 & Alberich & 5 \\
Figuerola & 32 & Blasco & 4 \\
Giner & 31 & Gisbert & 4 \\
Llansola & 30 & Molina & 4 \\
Breva & 26 & Pastor & 3 \\
Casalís & 25 & Pauner & 3 \\
Reboll & 25 & Tirado & 3 \\
Roig & 25 & Fores & 2 \\
Viciano & 25 & Monterde & 2 \\
Marqués & 21 & Morán & 2 \\
Calbo & 20 & Bou & 1 \\
Català & 16 & Capero & 1 \\
Amiguet & 15 & Duenyes & 1 \\
Albiol & 14 & Flors & 1 \\
Boix & 14 & Goterris & 1 \\
Coll & 14 & Jover & 1 \\
Moliner & 14 & Mico & 1 \\
Agramunt & 12 & Romeu & 1 \\
\hline & Elaracon & \\
\hline
\end{tabular}

Elaboración propia.

La tabla nos muestra unos datos que siguen en la línea marcada por los cargos de jurado tercero y cuarto y acequieros, y es el dominio de la familia Vilarroig. Esto nos puede llevar a pensar que siempre tuvo representación en el Consell, pero se debe tener en cuenta que en muchas ocasiones no habrá un solo miembro de la familia en la institución municipal. El número de veces que la familia tiene presencia supera con creces los ciento once años estudiados por lo que las posibilidades de mover los resortes de poder eran elevadas ya que al menos siempre había un consejero. A continuación encontramos a los Pasqual con ciento siete presencias, los Castell con ciento dos, los Museros con noventa y seis y los Navarro con ochenta y tres. Es decir las familias más arraigadas entre los labradores enriquecidos. A nivel individual podemos destacar a Andreu Castellet o Antoni Castell que ocuparon un asiento en el Consell más de veinte veces. Sin embargo no queremos extendernos mucho ya que en la tabla siguiente podemos observar el análisis global del Consell. 


\subsection{Perpetuidad en el poder a nivel individual.}

El número de miembros del Consell era de treinta y seis miembros que incluían el justicia, los cuatro jurados, dos consejeros de la bolsa militar, quince consejeros de la bolsa de mano mayor y catorce de la de mano menor. Algunos años aparecen excepciones porque ya no se encontraban personas hábiles en las bolsas e incluso algún año se excede el número. No obstante, la práctica habitual es que estuviera compuesto por treinta seis miembros lo cual implica que teniendo en cuenta el período estudiado supone ciento seis años por treinta seis miembros igual a 3816 puestos a cubrir, teniendo en cuenta el ajuste por los desfases del algunos años, estimamos que fueron alrededor de 3800 puestos.

A continuación observamos quiénes fueron los que ocuparon estos puestos y durante cuánto tiempo, analizando todos los componentes del Consell desde 1597 hasta 1707 y obtenemos que fueron alrededor de 430, es decir, ello implica que cada uno de ellos ocupó como término medio el asiento del Consell casi nueve veces. Esto nos deja entrever esa oligarquía municipal castellonense que monopoliza el poder y que se plasma en realidades más concretas cuando observamos a diferentes personas que llegaron ocupar un asiento en más de veinte ocasiones. Estas personas pertenecen en su mayoría a los ciudadanos y artistas, como ocurre en el Consell de Cent en Barcelona puesto que en los estudios de Danti i Riu ${ }^{193}$ se expone el caso de personas que ocuparon el cargo más de teinta años, de los cuales un $80 \%$ pertenecían a los ciudadanos y un $20 \%$ a los artistas.

Josep Alberich, Melchor Amiguet, Francesc Andreu, Joan Andreu,Gerony Arrufat, Josep Avinent, Miquel Bonet, Pere Breva, Gaspar Luis Brunell, Pere Calbo, March Casalís, Joan Cases, Antoni Castell, Jaume Castell, Andreu Castellet, Macià Compte, Vicent Ferrer, Ignacio Figuerola, Pere Figuerola, Vicent Figuerola ciudadano, Jaume Giner, Miquel Giner, Pere Giner, Tomàs Giner, Baltazar Gombau, Batiste Jover, Miquel Llansola, Tomàs March, Aleixandre Martí, Vicent Martí, Francesc Mas, Lluís Mas, Francesc Mercer, Batiste Moliner, Miquel Mur, Pere Museros, Vicent Museros,

\footnotetext{
${ }^{193}$ Danti i Riu, J. (2001): "El govern de la ciutat de Barcelona a l'època moderna: estabilitat institucional, dificultats financeres i relació amb el poder reial”. Cuaderns d'Història 5. Barcelona, pp. 131.
} 
Miquel Navarro de Gaspar, Vicent Pasqual, Andreu Ribalta, Miquel Romeu, Melchor Salvador, Josep Segarra, Cristòfol Sisternés, Felip Sorrando, Vicent Tosquella, Pere Joan Vicent, Martí Viciano o Francesc Vilarroig, todos ellos se sentaron en el órgano decisorio de la vida diaria castellonense en veinte o más ocasiones. Esto nos muestra el grado de control sobre los resortes de poder que ejercían las familias más bien situadas y que establecían unos mecanismos que desembocaban en que solamente alrededor del $7 \%$ de la población accediese al poder municipal ${ }^{194}$, y que se palpaba en mayor medida en los puestos de jurado primero, jurado segundo, consejeros de mano mayor y cuando eran estos los que ocupaban el cargo de almotacén o acequiero, pues era más individualizada la participación, pero también nos da una idea de personas que tuvieron mucho poder pese a ser originarios de familias con muy pocos miembros en la élite castellonense (como es el caso de Miquel Mur, ya que solo encontramos una familia con este apellido).

\subsection{Las mismas familias en el Consell de Castellón.}

Para finalizar este apartado era relevante realizar un análisis de forma global de todos los miembros que formaban parte del Consell de Castellón, o sea, de sus treinta y seis miembros, los veintinueve consejeros del brazo real, los dos consejeros del brazo militar, los cuatro jurados y el justicia: las personas que determinaron quién entraba en las bolsas de las insaculaciones con las votaciones de las habas blancas y negras, para después jugar una segunda baza si eran inhabilitados ${ }^{195}$, lo cual le confería todo el poder para ser el valuarte del poder político de la ciudad.

Evidentemente, no podemos negar que nuestros análisis tienen ciertas limitaciones mencionadas al principio de este trabajo, consistentes en la inexistencia de datos en algunos años concretos, pero creemos que no supone un inconveniente para las conclusiones que expondremos a posteriori. Además es un factor que se ha de tener en cuenta el hecho de que, en alguno de los años que se están estudiando, el número de

\footnotetext{
${ }^{194}$ Para el cálculo del porcentaje se han tenido en cuenta los datos poblacionales del final del siglo XVII, tanto los de la Real Pragmática de 1692 como los de Campoflorido.

195 Es muy importante tener en cuenta este aspecto porque como hemos visto anteriormente las inhabilitaciones que estipulaban los Privilegios a veces no eran cumplidas por el Consell.
} 
consejeros de mano mayor no fuese de quince o el de mano menor no fuese de catorce por falta de personas hábiles en las correspondientes bolsas.

Los datos obtenidos son los siguientes:

Tabla 36: Apellidos que ocuparon uno de los 36 puestos del Consell ${ }^{196}$ :

\begin{tabular}{|c|c|c|c|c|c|c|c|c|}
\hline Apellido & $\begin{array}{c}\mathbf{N}^{\mathbf{o}} \\
\text { años }\end{array}$ & $\begin{array}{c}\text { Más de un } \\
\text { consejero }\end{array}$ & Apellido & $\begin{array}{c}\mathbf{N}^{\mathbf{0}} \\
\text { años }\end{array}$ & $\begin{array}{l}\text { Más de un } \\
\text { consejero }\end{array}$ & Apellido & $\begin{array}{c}\mathbf{N}^{\mathbf{o}} \\
\text { años }\end{array}$ & $\begin{array}{l}\text { Más de un } \\
\text { consejero }\end{array}$ \\
\hline Giner & 104 & 39 & Compte & 30 & 0 & Folch & 9 & 0 \\
\hline Vilarroig & 95 & 61 & Ferrer & 30 & 3 & Miralles & 9 & 0 \\
\hline Museros & 87 & 45 & Serra & 30 & 11 & Ribes & 9 & 0 \\
\hline Figuerola & 84 & 38 & Breva & 29 & 16 & Timor & 9 & 0 \\
\hline Castell & 77 & 48 & Gascó & 27 & 9 & Garcés & 8 & 0 \\
\hline Jover & 77 & 12 & Llorens & 26 & 2 & Traver & 8 & 0 \\
\hline Navarro & 77 & 26 & Reboll & 26 & 2 & Fabregat & 7 & 0 \\
\hline Pasqual & 73 & 38 & Tosquella & 25 & 0 & Gisbert & 7 & 0 \\
\hline Martí & 71 & 26 & Vicent & 25 & 0 & Granyana & 7 & 0 \\
\hline Avinent & 66 & 14 & Vilar & 25 & 0 & Llopis & 6 & 0 \\
\hline March & 66 & 19 & Mercer & 24 & 0 & Quevedo & 6 & 0 \\
\hline Andreu & 62 & 25 & Marqués & 23 & 1 & Beltrán & 5 & 0 \\
\hline Segarra & 60 & 3 & Calbo & 22 & 0 & Mascarós & 5 & 0 \\
\hline Mas & 57 & 19 & Salvador & 22 & 0 & Molina & 5 & 0 \\
\hline Rubert & 54 & 12 & Feliu & 21 & 0 & Peris & 5 & 0 \\
\hline Bonet & 53 & 5 & Miquel & 21 & 2 & Bernat & 4 & 0 \\
\hline Amiguet & 52 & 3 & Mur & 21 & 0 & Grau & 4 & 0 \\
\hline Moliner & 52 & 14 & Vallés & 20 & 0 & Molinos & 4 & 0 \\
\hline Castellet & 51 & 13 & Ros & 19 & 0 & Angles & 3 & 0 \\
\hline Alegre & 46 & 11 & Sorrando & 19 & 0 & Palanques & 3 & 0 \\
\hline Bou & 45 & 3 & Vidal & 19 & 0 & Pastor & 3 & 0 \\
\hline Sanchís & 42 & 7 & Català & 18 & 0 & Pauner & 3 & 0 \\
\hline Aragones & 41 & 0 & Tormo & 18 & 0 & Pedro & 3 & 0 \\
\hline Eiximeno & 40 & 1 & Albiol & 17 & 0 & Tirado & 3 & 0 \\
\hline Amposta & 39 & 0 & Safont & 17 & 0 & Fores & 2 & 0 \\
\hline Brunell & 38 & 2 & Boix & 16 & 0 & Monterde & 2 & 0 \\
\hline Capero & 37 & 0 & Bosch & 16 & 0 & Moran & 2 & 0 \\
\hline Ribalta & 37 & 0 & Coll & 16 & 0 & Orts & 2 & 0 \\
\hline Roig & 36 & 0 & Lleó & 16 & 0 & Pavia & 2 & 0 \\
\hline Sisternés & 36 & 0 & Igual & 15 & 1 & Bonaventura & 1 & 0 \\
\hline Reus & 35 & 0 & Porta & 15 & 0 & Duenyes & 1 & 0 \\
\hline Alberich & 34 & 0 & Agramunt & 14 & 1 & Flors & 1 & 0 \\
\hline Cases & 34 & 3 & Sabera & 14 & 0 & Gaspar & 1 & 0 \\
\hline Gumbau & 34 & 2 & Blasco & 13 & 1 & Goterris & 1 & 0 \\
\hline Viciano & 34 & 10 & Planell & 13 & 0 & Llorach & 1 & 0 \\
\hline Llansola & 33 & 0 & Jordà & 12 & 0 & Mico & 1 & 0 \\
\hline
\end{tabular}

\footnotetext{
${ }^{196}$ AHMC. Elaborada a partir de los datos de todos los miembros del Consell y que se han ido explicando de forma individual según su oficio. En este caso se muestra de manera global y se ha podido realizar con todos los datos recopilados en las reuniones del Consell de Castellón enrte 1597 y 1707 y que se están registrados en el Judiciari.
} 


\begin{tabular}{|cll|cll|cll|} 
Romeu & 31 & 2 & Carnicer & 11 & 1 & Moreno & 1 & 0 \\
Arrufat & 30 & 3 & Morales & 11 & 0 & Ripoll & 1 & 0 \\
Casalís & 30 & 0 & Muntanyes & 10 & 0 & Tomàs & 1 & 0 \\
\hline
\end{tabular}

Elaboración propia.

Los datos obtenidos nos pueden dar una idea de un Consell claramente controlado por ciertas familias en las que destacamos a los Giner. Tuvieron un miembro al menos en ciento cuatro ocasiones, de las ciento seis analizadas, por tanto en el Consell podemos decir en sentido figurado que un asiento tenía el escudo de los Giner. Además en treinta y nueve de ellas tuvieron más de un miembro y recordemos que su presencia venía de la bolsa mayor.

La familia de los Vilarroig podemos decir que controlaba la mano menor, ya que era el origen de esta familia que al igual que ocurre con los Giner, también asegura su presencia en el Consell durante casi todo el período dados sus noventa y cinco años de los cuales sesenta y uno fueron con más de un miembro.

A continuación aparecen los Museros, Figuerola, Castell, Jover, Navarro, Pasqual, Martí, Avinent, March, Andreu y Segarra, todos ellos superando las cincuenta y ocho presencias que sería la mitad de años de los estudiado al igual que los Mas y los Rubert, Bonet Amiguet, Moliner y Castellet muy cercanos a ese 50\% y siempre con más de más de un miembro.

Los datos de la tabla nos muestran pues, que el número de familias que ocuparon un asiento en el Consell no fue muy reducido ya que treinta y seis lugares dejaban un amplio margen para entrar a formar parte de él, sin embargo se ha de tener en cuenta que encontramos muchas familias que solo tuvieron un miembro y con un participación anecdótica. Diremos pues, que es partir de las veinticinco presencias, cuando ya tenemos familias con muchos componentes y que podríamos hablar de saga de poder en la oligarquía municipal. Esto nos da una idea de que en Castellón pertenecer al Consell no parece tan complicado, pero mantenerse en él si que recae en manos de unos pocos que siempre están ahí de forma omnipresente y son realmente capaces de controlar el acceso al dominio de la institución foral. 
Ilustración 7: Plano de Castellón a finales s. XVI

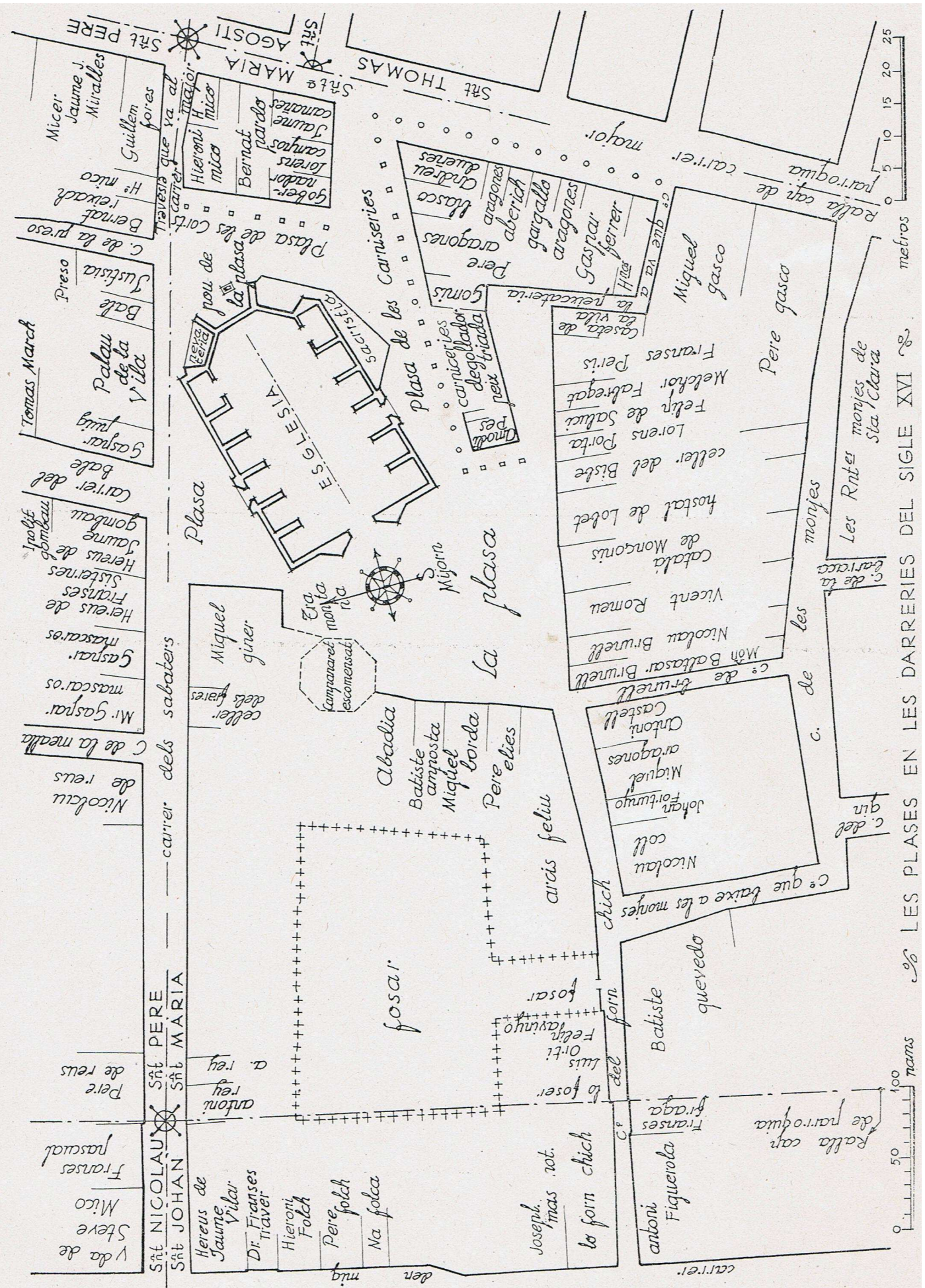

Esta imagen la hemos obtenido del libro de Vicente Traver Tomás “Antigüedades de Castellón de la Plana”, y en se pueden observar las viviendas de muchas de las familias que nos aparecen en nuestro estudio, así como el emplazamiento del Consell, denominado Palau de la Vila. ${ }^{197}$

${ }^{197}$ Traver Tomás, V. (1982): Antigüedades... op. cit. pp. 201. 


\section{La relación directa entre ser insaculado y el desempeño de un cargo en el Castellón del seiscientos.}

Cuando nos planteamos realizar un análisis de las personas que entraron a formar parte de las bolsas para ocupar los distintos cargos u oficios municipales, ya fuera el de justicia, jurados, acequiero, almotacén, escribano o consejero, queríamos ver si eran las mismas familias o no las que copaban estos sacos, lo cual podía demostrar la restricción de acceso a los órganos decisorios del municipio castellonense. Sin embargo, en nuestro trabajo también hemos obtenido quiénes fueron los que realmente ocuparon estos puestos, por lo que es ahora oportuno relacionarlo para ver si eran las mismas familias insaculadas y si eran unas pocas o no.

En el brazo militar los apellidos más veces insaculados eran los Reus, los Ros, los Castell y los Feliu con cinco veces, los Arrufat y los Bou con cuatro veces y los Miquel y Miralles con tres veces. Si después comparamos con quiénes ocuparon los cargos de justicia del brazo militar observamos la presencia de tres de ellos: los Bou, los Reus y los Arrufat. En el caso de jurado primero son los Arrufat, centrado en la persona de Gerony Arrufat (cuatro de las seis veces) y los Jordà en la persona de March Antoni Jordà. Mientras que en el cargo de almotacén del brazo militar volvemos a encontrar a los Reus, Arrufat y la novedad de los Giner, que centran la ocupación del oficio en la figura de Pere Giner de Bou. Si , a continuación, observamos las personas que ocuparon el cargo de consejeros militares, llegamos a la conclusión que prácticamente la totalidad de familias insaculadas ocuparon los cargos y solamente encontramos como excepción a Escorcia y Ladrón, Muñoz, Ripio y Vich, apellidos que no estuvieron presentes prácticamente en las insaculaciones sino de forma marginal, y de los cuales es importante destacar a modo de ejemplo a Don Luis Escorcia y Ladrón que pese a estar insaculado desde 1685 y estar emparentado con el que fuera lugarteniente de gobernador de la ciudad entre 1673 y 1677 no ocupó ningún cargo. En consecuencia, podemos afirmar, que en el brazo militar eran pocos los que se controlaban esta bolsa pero todos ellos tuvieron acceso a ocupar cargos en el municipio castellonense.

En el brazo real las consecuencias de relacionar la mayor presencia en las bolsas con la ocupación de los cargos nos llevan a una lógica aplastante, sobre todo cuando 
estudiamos los cargos de jurado primero, segundo, consejeros de mano mayor, y cuando el almotacén, justicia y acequiero lo ocupan personas de las bolsas de ciudadanos honrados, doctores en leyes y doctores en medicina. Concretamente, en la bolsa de justicia del brazo real habíamos obtenido que los apellidos que más se repetían eran, por este orden, los Giner, Jover, Castell, Martí, March, Serra, Figuerola y Gascó, y al ver los apellidos que más veces ocuparon el cargo obtenemos también los Giner, March, centrado en las personas de Tomàs March padre e hijo, Jover, Andreu y Martí.

Evidentemente no parece que las inhabilitaciones afectaran a los Giner, a los Jover o a los Martí, todos ellos con raíces en las bolsas de jurados primeros y segundos, es decir, de consejeros de mano mayor, mientras que los Castell con una presencia mayor en la bolsa de consejeros de mano menor o labradores, tuvieron un acceso más restringido. Encontramos, pues que, los Giner, Jover, Martí, Andreu o incluso los March fueron los miembros del Consell que ocuparon el puesto de justicia de una forma más habitual.

El cargo de jurado primero del brazo real nos muestra los resultados esperados, con los Giner de nuevo como la familia más veces insaculada. Consigue ocupar el cargo once veces, solo por detrás de los Jover que también eran de los que más veces fueron insaculados y que ocuparon el cargo en catorce ocasiones, por tanto seguimos encontrando la relación directa entre insaculación y desempeño del cargo. Ahora bien, hemos de hacer una mención especial a Tomàs March padre e hijo, puesto que vuelven a ocupar el cargo diez veces pese a tener pocas insaculaciones, o el caso de los Figuerola y su ascenso social, iniciándolo a principio de siglo cuando se movían en la bolsa de labradores o consejeros de mano menor hasta conseguir que Vicent Figuerola se situase como ciudadano honrado o el doctor en leyes, Ignacio Figuerola quién ocupó puestos relevantes finales del siglo XVII ${ }^{198}$. Hemos de hacer una mención especial a la familia Gascó que desempeñó algunos cargos como el de justicia dos veces en la persona de micer Bernat Gascó; el de almotacén dos veces en la persona de Cristòfol Gascó y otra en la de micer Bernat Gascó, y por último micer Batiste Gascó que ocupó

\footnotetext{
198 Casey, J. (1980): Tierra y ... op. cit. pp. 33. Como expresa el autor en este artículo el margen de separación entre los labradores enriquecidos y los ciudadanos honrados era muy corto y el ejemplo lo tenemos con la familia Figuerola.
} 
el cargo de jurado primero dos veces. Sin embargo, a partir de 1653 desaparecieron de las bolsas y de los puestos municipales.

Para el oficio de jurado segundo la relación entre insaculación y ocupación del cargo también se hace evidente puesto que encontramos a los Martí, los Moliner o los Giner entre los apellidos con más personas insaculadas. Aquí se repite el hecho de que volvemos a encontrarlos entre quienes tuvieron el cargo. Sin embargo, en este caso el desempeño de jurado segundo no esta tan focalizado sino que hay una mayor dispersión y aparece Josep Amposta, como la persona que más veces ocupó el cargo pese a que su familia no tenía más que dos personas insaculadas, por lo que nos da una idea del poder que pudo tener esta persona.

En el cargo de jurado tercero y cuarto encontramos que las familias con más personas insaculadas fueron los Vilarroig, los Castell, los Pasqual, los Museros, los Navarro y Figuerola, y fueron los mismos quiénes desempeñaron el cargo. Además se incorporan los Alegre que no estaban entre los más insaculados y los Segarra. Por tanto parece que entrar en las bolsas aseguraba ocupar un puesto tarde o temprano en ésta.

En las insaculaciones para el oficio de almotacén encontrábamos a los Giner, Gascó, Jover, Martí, Castell, Vilarroig, Figuerola y March encabezando el número de personas insaculadas y a su vez a los Giner y a los Jover los encontramos durante todo el período. Si seguimos la misma estrategia y observamos quiénes ocuparon el puesto realmente, sí que nos aparecen los Giner, Martí, Castell o Figuerola pero no es una relación tan directa ya que no están en primer lugar ni los Jover ni los Gascó. Ahora bien, los que ocupan el primer puesto son los Pasqual con seis veces desempeñando el cargo, de las cuales cuatro corresponden a la persona de Miquel Pasqual de Francesc. También aparece un apellido no muy común en los primeros puestos en las insaculaciones ni en los diversos oficios, los Bonet, que lo ocuparon cuatro veces. Por tanto, aunque los Pasqual o los Bonet no eran los apellidos más comunes en esta insaculación, sí que se puede afirmar que seguimos en la misma línea de dominio del oficio aquellas personas o apellidos que dominan la insaculación aunque no sea tan evidente como en otros cargos, puesto que incluso estos dos apellidos tuvieron hasta cuatro miembros en las insaculaciones y su período de estancia en las bolsas fue bastante amplio. 
El oficio de síndico del Consell era uno de los elegidos en el proceso de la Pascua de Pentecostés, por tanto no había bolsa ni se cubrían con el proceso de insaculación, sin embargo ya hemos comentado anteriormente su importancia porque su desempeño implicaba entrar a formar parte del Consell del ejercicio siguiente. Como es evidente encontramos como apellidos más comunes a los Giner, los Jover, los Castell, Museros y Figuerola, aunque fue un cargo en el que no hay un dominio claro sino que estuvo bastante bien repartido. Esto nos lleva a mantener nuestra línea de argumentación en la que podemos afirmar que ciertos apellidos y familias copaban los cargos de la villa de Castellón.

En el puesto de escribano del Consell ocurre lo mismo que en el de síndico y es que estuvo muy repartido, pero de nuevo encontramos a los Giner como los que más miembros tuvieron insaculados y junto a los Martí los que más veces ocuparon el puesto.

En las bolsas de acequiero los apellidos con más miembros fueron los Vilarroig, los Castell, los Navarro, los Figuerola. los Museros, los Pasqual, los Giner y los Gascó, destacando que los Vilarroig, Castell y los Navarro lo estuvieron durante todo el período objeto de estudio, lo que evidencia que los Vilarroig serán los que más veces desempeñarán el cargo, seguidos de los Rubert, Castell, Pasqual, Sanchís y Museros.

Estos datos nos muestran que son los mismos apellidos los que se insaculan con un mayor número de miembros y los que desempeñan el oficio excepto los Rubert y los Sanchís, dos familias bastante habituales entre los labradores enriquecidos. Es destacable, a su vez, como los Giner y los Gascó no ocupan el cargo en muchas ocasiones, pero hemos de tener en cuenta que era más apetecible para los labradores enriquecidos. En muchas ocasiones apellidos como los Giner o los Gascó estaba ocupando oficios reservados a ciudadanos honrados, doctores en leyes o en medicina.

En las bolsas de consejeros de mano mayor y menor la relación es totalmente directa, es decir aquellas familias o apellidos con más miembros en las bolsas fueron las que más veces ocuparon los puestos del Consell reservados para ellos. Concretamente en la mano mayor tenemos a los Giner, Martí, Jover y Andreu encabezando las familias 
con más miembros en las insaculaciones y si nos fijamos en las que más veces ocuparon los puestos aparecen los Giner, los Martí y los Andreu, además de los Figuerola, March, y los Gascó. Es decir, volvemos a encontrar los mismos apellidos.

En la bolsa de mano menor encabezan la lista con más número de personas insaculadas y durante todo el período los Vilarroig, los Castell, los Navarro, los Pasqual y los Museros, y son esos mismos apellidos los que ocuparon los cargos insaculados a este saco.

Parece evidente, por los datos recopilados, que la inhabilitación no actuaba como freno, puesto que, como norma general, aquellos apellidos o familias que copaban las insaculaciones en sus diferentes bolsas eran las que después ocupaban los distintos puestos y oficios de la villa de Castellón. En el brazo militar encontramos que los Reus y los Arrufat son los que más miembros tuvieron en las insaculaciones y los que más veces ocuparon los cargos de consejeros militares, almotacén, justicia o jurado primero cuando les correspondía. En la parte del brazo real hemos de distinguir a las familias que controlaban las bolsas de ciudadanos honrados, doctores en medicina, doctores en leyes, es decir, la de jurado primero. Son los Giner, Jover, Figuerola, March, Martí, Andreu, que después serán las que más veces ocuparán los cargos que les corresponden. En las de jurado segundo o bolsas de los artistas no hay una relación tan evidente entre la insaculación y las personas que van a ocupar los distintos cargos. Sin embargo sí que es muy claro que, tanto en los oficios de justicia, almotacén como en los consejeros de mano mayor, hay un dominio de las familias que vienen de los ciudadanos honrados, doctores en leyes y medicina, es decir, los Giner, Jover, Martí o Andreu, que eran los que más veces estaban insaculados.

En mano menor ocurre lo mismo ya que van a ser los Vilarroig, los Castell, los Navarro, los Pasqual o los Museros los que más veces se insaculan y los que después dominan los puestos de consejeros de mano menor, los de acequiero, los de justicia, los de almotacén o los de síndico.

Esto se pone de manifiesto cuando observamos la tabla 36 en la que hacemos un resumen final de las personas que ocuparon alguno de los treinta y seis puestos del Consell y los resultados vuelven a ser los mismos con las familias dominantes en los 
Giner, Vilarroig, los Museros, los Figuerola, los Castell, los Jover, los Navarro los Pasqual o los Martí, aquellos apellidos que ocupan todos los puestos en mayor medida y que tenían más miembros en las insaculaciones. 


\section{El ayuntamiento borbónico y la disyuntiva entre ruptura o continuación.}

La llegada de la nueva dinastía a la monarquía hispánica supuso un cambio drástico en la Corona de Aragón. El fin de la época foral suponía la sustitución de las instituciones propias de cada uno de los reinos que la formaban por las de la Corona de Castilla. El municipio castellano había estado vetado en su inicio para la nobleza, pero a partir del s. XIII y XIV se generaliza por la exigencia de requisitos como poseer una extensión de tierras, tener una casa en la población o poseer caballo y armas. Se va configurando un sistema municipal en el que la nobleza va copando los puestos relevantes favorecida por la debilidad de monarquía en la segunda mitad del s. XIV. La nobleza va adquiriendo cada vez más poder y va creando una red de influencias en todos los ámbitos, dejando muy poco margen a la burguesía, situación que hacía poco viable la entrada de mercaderes o menestrales en estos cargos de las villas y municipios.

La llegada de los primeros reyes Habsburgo a España, hará que se incremente la ocupación de estos puestos por las oligarquías aristocráticas. Carlos I y Felipe II van a utilizar la venta de oficios en los municipios para obtener ingresos para solventar las continuas bancarrotas. El abuso de la nobleza a la hora de ocupar estos cargos, que en muchos casos eran vitalicios y que conllevaban un control absoluto del municipio, ha sido visto por muchos autores como la causa de la decadencia del municipio castellano. Frente a estos abusos se va perfilando la necesidad de una intervención regia a través un oficial. La figura del corregidor creada por los Reyes Católicos, se consolidará como la herramienta municipal para controlar el funcionamiento de villas y ciudades. Es lógico pensar que la imposición de la nueva estructura institucional municipal vendrá determinada por estos parámetros. La figura del corregidor será la cabeza visible del nuevo ayuntamiento de la ciudad de la Plana. El primer cambio en la institución local se produce el 6 de octubre de 1707 en que los jurados pasan a denominarse regidores, y seguramente fueron ellos los encargados de marcar las pautas institucionales de la localidad, ya que no encontramos nueva reunión de ninguna institución municipal hasta 
diciembre de ese mismo año, estando compuesta por un teniente alcalde, cuatro regidores y veinticuatro consejeros ${ }^{199}$.

El 26 febrero de 1708 es el Comandante General de los Ejércitos, el caballero d'Asfeld el que designa un nuevo ayuntamiento en la ciudad de Castellón de forma temporal hasta que se consolida de forma definitiva en diciembre de 1709 bajo las órdenes del corregidor Don Josep Antonio de Valdenebro y Tapia. ${ }^{200}$ Este nuevo ayuntamiento temporal formado en 1708 mantenía a muchas familias que habían formado parte del Consell de Castellón, pero veremos a continuación como ocurre exactamente lo mismo en los años posteriores. Por tanto encontramos un gesto de continuidad y no una ruptura con la institución anterior, como guiño a las élites locales para intentar no soliviantarlas. La única excepción será la figura del Corregidor que será una persona ajena a los círculos de poder locales y vendrá nombrado desde el centro de la Península.

Seguidamente exponemos una relación de los corregidores de los primeros veinte años del ayuntamiento borbónico, entre (1710 y 1729) y vemos claramente como son familias llegadas de Castilla, puesto que estos apellidos no aparecían en la época foral.

Tabla 37: Relación de corregidores entre 1710-1729 ${ }^{201}$ :

\begin{tabular}{|ccc|}
\hline Corregidor & $\begin{array}{c}\text { Número } \\
\text { de veces }\end{array}$ & Período \\
\hline D. Francisco de Bustamante y Velasco & 8 & $1722-1729$ \\
D. Pedro Gajardo & 7 & $1715-1721$ \\
D. Joseph Ibáñez Cuevas & 5 & $1711-1715$ \\
D. Santiago Gonzáles de Escobedo & 2 & $1710-1711$ \\
\hline \multicolumn{2}{c}{ Elaboración propia. } \\
\hline
\end{tabular}

Elaboración propia.

Los corregidores del municipio castellonense entre 1710 y 1729 fueron cuatro diferentes pero ninguno de ellos pertenecía a las familias que habían controlado los cargos de responsabilidad local en la época foral.

\footnotetext{
199 En el documento 6 del apéndice se puede consultar los nombres de todos ellos.

200 En el documento 7 del apéndice se puede consultar el Decreto del caballero d'Asfeld.

201 AHMC. Elaborada a partir de los datos extraídos de las Actas Capitulares entre 1710 y 1729 que recogen las reuniones del nuevo ayuntamiento borbónico.
} 
Tabla 38: Relación de los regidores entre 1710-1729 ${ }^{202}$ :

\begin{tabular}{|ccc|ccc|}
\hline Regidor & $\begin{array}{c}\mathbf{N}^{\mathbf{0}} \mathbf{d e} \\
\text { veces }\end{array}$ & Período & Regidor & $\begin{array}{c}\mathbf{N}^{\mathbf{0}} \mathbf{d e} \\
\text { veces }\end{array}$ & Período \\
\hline $\begin{array}{c}\text { D. Josep Castell de } \\
\text { Museros }\end{array}$ & 20 & $1710-\ldots$ & Josep Figuerola & 7 & $1723-\ldots$ \\
D. Gerony Mas i Vallés & 20 & $1710-\ldots$ & $\begin{array}{c}\text { Doctor Tomàs Castell de } \\
\text { Alós }\end{array}$ & 7 & $1723-\ldots$ \\
Doctor Felip Roig & 20 & $1710-\ldots$ & $\begin{array}{c}\text { D. Geronimo Bou de } \\
\text { Monsonis }\end{array}$ & 6 & $1710-1715$ \\
Vicent Figuerola ciutadà & 20 & $1710-\ldots$ & Doctor Félix Poeta & 5 & $1710-1714$ \\
D. Mathias Igual i Borràs & 14 & $1710-1723$ & $\begin{array}{c}\text { Doctor Vicent Martí i } \\
\text { Castell }\end{array}$ & 2 & $1710-1711$ \\
$\begin{array}{c}\text { Doctor Jaime Giner } \\
\text { Jaume Andreu ciutadà }\end{array}$ & 14 & $\begin{array}{c}1710-1723 \\
1723-\ldots\end{array}$ & Don Basilio Giner & 1 & $1729-\ldots$ \\
\hline
\end{tabular}

Elaboración propia.

Sin embargo, cuando observamos quiénes ocuparon el cargo de regidores podemos ver que fueron las mismas familias que ya había sido los consejeros de la institución foral local. Volvemos a encontrar a los Castell, los Mas, los Figuerola, los Giner, los Igual, los Andreu, los Martí o los Bou, e incluso en muchos casos emparentados unos con otros como el caso de Josep Castell de Museros que engloba dos de las familias que más veces ocuparon asientos en el Consell, o el caso de Martí y Castell. La presencia de las familias oligárquicas en el poder de la institución local se mantenían con la nueva monarquía y esto aseguraba que las redes clientelares en la villa de Castellón se traspasarán de la antigua institución del Consell al recientemente creado ayuntamiento borbónico. No podemos obviar, la desaparición de algunas familias que en el último período de la época foral habían adquirido mucha fuerza como los Breva o los Vilarroig que se habían mantenido durante todo el período objeto de nuestro estudio, o los Navarro o los Pasqual que no aparecen tampoco en la relación de nombres del ayuntamiento. Ello no impidió pero el afianzamiento de algunas familias para volver a crear los círculos oportunos en el mantenimiento del equilibrio para los dos pilares del juego local-regnícola, que podían favorecer un reinado tranquilo y sin grandes sobresaltos, siempre y cuando las élites locales no se viesen muy afectadas.

En la escribanía del ayuntamiento encontramos a Amella, un nuevo apellido que no había aparecido anteriormente, pero a partir de 1723 lo ocupa Josep Ferrer, familia que ya había pasado por el Consell desde la bolsa de mano mayor.

\footnotetext{
${ }^{202}$ Ibidem.
} 
El secretariado del ayuntamiento lo ocupa durante todo el período Josep Llorens de Clavell, heredero de la época foral puesto que ya habíamos encontrado este apellido en diversos puestos del Consell en el siglo XVII. 


\section{La influencia regia en las instituciones locales de Castellón tras el Privilegio de Felipe III de 1597.}

Uno de los objetivos de este trabajo consiste en analizar la relación que tenía la villa de Castellón en la época foral con la monarquía, y concretamente si la situación jurídica de ser una villa de realengo implicaba una intervención real en los asuntos diarios de Castellón de la Plana y por supuesto en la injerencia en el nombramiento de los oficios del municipio. Evidentemente nuestro ámbito de estudio se centra entre 1597 y 1707, marcando como inicio la concesión del Privilegio de Felipe III hasta el final de la época foral.

Las autoridades reales en el Reino de Valencia eran: el Consejo de Aragón, el virrey, la Real Audiencia de Valencia, el gobernador general, los dos portanveus de éste con sus lugartenientes, los dos bailes generales y los bailes locales en las villas de realengo. Naturalmente el personal del que se nutrían estas instituciones mantenía estrechas relaciones de parentesco, clientelismo y hasta de vecindario con los representantes del poder en el municipio. Por eso actuarán como influyentes elementos de equilibrio en las relaciones entre las dos instancias de poder, posibilitando así el entendimiento entre la Corte y la periferia.

La intervención real la definimos aquí como las vías de actuación desarrolladas en el ámbito municipal por cualquiera de los oficiales y órganos de la administración real, y en concreto en el nuevo procedimiento de insaculación.

El proceso insaculatorio siempre se iniciaba con la concesión de un Privilegio u Ordinación, donde se establecía todas las características del sistema tales como los cargos que se cubrían con el sistema o los requisitos de las personas que entrarían a formar parte de las bolsas. De forma que las primeras listas las solía elaborar un Comisario Regio, teniendo en cuenta los grupos oligárquicos de la villa o municipio. Era entonces donde entraba el factor más relevante de la influencia regia, cuando se dictaminaba quién, a partir de ahí, se encargaría de cubrir o determinar qué nuevas personas iban a entrar en las bolsas, o como se iban a cubrir las bajas que se producían. 
Es en estos espacios donde se debe realizar un análisis profundo sobre esa convivencia entre el poder real y municipal, y si era un pulso para dominar o era un juego en el que mantener el equilibro suponía una victoria para ambos bandos, tanto para la autoridad monárquica por su confirmación, como para las élites locales por su mantenimiento.

Hemos de tener en cuenta que el Real Privilegio de 1597 en su capítulo número nueve deja claramente expresado: “... que faça la insaculació la vila, y no la Real Audiencia" ${ }^{203}$. Esto como se indica en el mismo capítulo, supone un cambio respecto a la Ordinación de Covarrubias de 1590 en el que la Insaculación correspondía a la Audiencia Real ${ }^{204}$.

Dejar el proceso de insaculación en manos de la villa implicaba que iban a ser las élites de la ciudad las que eligieran los miembros del Consell, y eso representaba que las decisiones más importantes de la ciudad vendrían determinadas desde éstas oligarquías municipales. Si analizamos las sucesivas insaculaciones que se produjeron en la villa de Castellón desde la obtención del Privilegio de Felipe III en 1597 (1598, 1600 con la ampliación posterior, 1623, 1630, 1634, 1638-1643, 1647-1648, 1653, 1660, 1662, 1666, 1668, 1677, 1679, 1685, 1694 y 1700) además de la confirmación del Privilegio de 1604 que limitaba el número de integrantes en las bolsas, se muestra como son los miembros del Consell quiénes promocionan y habilitan a las personas que formarán parte de ellas, por lo que es evidente que el círculo es bastante cerrado y no se deja mucho margen a la intervención regia. Sin embargo, reducir a la nulidad absoluta el papel de la monarquía en el proceso insaculatorio sería un craso error, puesto que en el proceso tenían voz y voto tanto el baile de la ciudad como el lugarteniente de portanveus de gobernador general de Castellón ${ }^{205}$, representantes de la monarquía en la

\footnotetext{
${ }^{203}$ Bernabé Gil, D. (2012): Privilegios... op. cit., pp. . Véase el documento 3 del apéndice, Real Privilegio de Felipe III.

${ }^{204}$ Bernabé Gil, D. (2012): Privilegios... op. cit., pp. 231-232. Véase el documento 2 del apéndice, la Ordinación de Covarrubias de 1590.

${ }^{205}$ En el Privilegio de 1604 donde se confirma el número de personas de cada una de las bolsas se cita que tanto el baile como el lloctinent de portanveus de Gobernador General de Castellón deben estar presentes en las insaculaciones ya que además de poseer las llaves de donse guardan las cajas con los nombres, deben votar para insacular a nuevos miembros.
} 
ciudad. Ahora bien, es evidente que dos votos frente al resto del Consell no suponía un poder importante, más bien podríamos decir que insignificante, además hemos de tener en cuenta que el cargo de baile recayó desde 1597 hasta 1658 en la familia Igual ocupante de cargos del brazo militar y por tanto perteneciente a las oligarquias municipales. Posteriormente, ejerció esta función hasta 1673 Francesc Bou, quién también era miembro de las altas esferas de poder castellonense. Finalmente desde 1673 hasta 1707 el cargo recayó en Cosme Martí, otro componente habitual de las bolsas del brazo real, que a su vez ocupó varias veces diversos oficios de la villa. Gracias a estos datos, podemos establecer que la influencia real a través del baile no debió ser muy importante ya que estarían más interesados los bailes en la pertenencia a la esfera de poder de las oligarquías municipales. Muchos autores han dado importancia a las peticiones que hicieron las villas de realengo en las Cortes de 1626 para que los bailes y lugartenientes de gobernador no tuvieran voto en las insaculaciones, lo que en algunos casos se consiguió ${ }^{206}$. En la confirmación de las Cortes de $1645^{207}$ se concede la petición del brazo real para que en las insaculaciones de todas las villas del Reino no tengan derecho a voto ni el baile ni el lugarteniente del gobernador. Sin embargo, más que de un patrón establecido podemos hablar de ambigüedad que no lo dejaban claro, y en el caso de Castellón siguieron participando en la elección de los candidatos a formar parte de las bolsas, o como el caso de Onteniente en que seguía participando el baile y en el caso de Játiva el Gobernador.

En cuánto a la presencia del lugarteniente de portanveus del gobernador en la villa de Castellón y su participación en el proceso insaculatorio sí que podríamos citarlo como de influencia real, ya que la mayoría de veces ocupaba el cargo una persona ajena a las familias que controlaban el poder en la ciudad, aunque un voto frente a treinta no suponía una intervención muy importante y además el asesor que actuaba como

\footnotetext{
${ }^{206}$ De Lario Ramírez, D. (1974): Cortes de... op. cit. En esta obra se pueden comprobar las peticiones de las villas de Penáguila y Bocairente que fueron aceptadas y que confirmaban la no participación de los bailes en las insaculaciones. Sin embargo en Castellón continuara la participación del baile y del lugarteniente de gobernador en las insaculaciones y por lo tanto con el derecho a voto.

${ }^{207}$ Guía Marín, Ll. (1984): “Cortes del reinado de Felipe IV, II. Cortes valencianas de 1645”, Revista Estudis. Monografía. Universitat de Valencia. En esta obra se puede consultar la petición que hace el brazo real y como la Corona acepta que los bailes locales y lugartenientes de gobernador dejen de tener voz y voto.
} 
subrogado si que pertenecía a estas oligarquías, como el Doctor Nicolau Figuerola nombrado en el año 1650 y cuyo nombramiento y juramento se recoge en el Llibre Vert $^{208}$.

Otro dato que nos da indicios de la nula intervención regia en la elección de cargos en el municipio castellonense es la no participación en la declaración de inhábiles en el momento de extracción de los oficios, puesto que primero se enumeraba la relación de personas inhábiles y después se llamaba a las cuatro personas que tenían la llave de la caja de insaculados: lugarteniente de portanveus de gobernador, baile, justicia y jurado primero. Por lo que si había votación para declarar hábil o no hábil con habas blancas o negras, ellos no intervenían porque no estaban en la sala. Y además la mayoría de veces no eran ellos los que estaban en las elecciones, ni el baile ni el gobernador se encontraban en la villa y en muchas ocasiones eran los subrogados lo que acudían a la elección de los oficios y estos también pertenecían a las oligarquías del municipio.

Por tanto la intervención real sobre promoción, insaculación y determinación de cargos se limitaba al poder que tenía la Real Audiencia de Valencia para revocar ciertas habilitaciones o inhabilitaciones, recurso este que fue empleado a menudo por personas de la villa que no consideraban justa su exclusión de algunas bolsas o su inhabilitación.

Esto nos muestra el interés de ciertas personas por entrar en estas oligarquías y no un intento de control de la institución regnícola para con el nombramiento de los cargos de la villa. El ejemplo más evidente lo encontramos con el pleito que llevaron a cabo los oficios mecánicos para poder entrar en las bolsas. Supuso la concesión por parte del monarca del Privilegio de 1626, después de sucesivas disputas con el Consejo de Aragón y el pago de una cantidad a la monarquía. Se citó en dicha concesión del rey la entrada en bolsas de estos oficios por un período de diez años, pero nunca llegó a cumplirse, ya que no fueron habilitados más que unos pocos que enseguida desaparecieron de las bolsas ${ }^{209}$. Es evidente que los resortes de poder de la villa

\footnotetext{
${ }^{208}$ AHMC. Llibre Vert ff. 25.

${ }^{209}$ AHMC. Llibre de les Insaculacions. En la insaculación de 1634 aparecen cinco personas de los oficios mecánicos pero ya no están incluidos en la de 1638 y 1643.
} 
consiguieron su propósito y no fueron desplazados del control de las bolsas. Evidentemente los que más se podían ver afectados por la entrada de los oficios mecánicos eran los labradores enriquecidos, quiénes por un lado copaban la bolsas de jurados tercero y cuarto y por otra la de consejeros de mano menor, saliendo victoriosos de esta contienda.

Es pues lógico pensar que la monarquía parecía más interesada en el buen funcionamiento de la villa, generado por un trato favorable a las peticiones de la corona de quiénes ostentaban el poder en Castellón y no por un control directo. Este margen posibilitaba que las élites del municipio no se viesen afectadas por las injerencias de la corona como en otras villas del Reino de Valencia como Valencia, Orihuela o Alicante. Hecho que veremos en un apartado posterior donde realizaremos una comparación del funcionamiento del proceso insaculatorio.

La Real Audiencia favoreció a determinadas personas, entre las que encontramos al mercader Jaume Blasco ${ }^{210}$; Gabriel Ferrer en 1612; Miquel Bonet en 1675; los doctores Vicente Martí y Cristòfol Vilar en 1680 o en 1694 Josep Museros y Joan Muntanyès $^{211}$. Favor que respondía, sobre todo, a intereses de particulares que no querían verse desplazados del núcleo del poder municipal. En otras villas, como Játiva, en la que en las primeras décadas del siglo XVII se realizaban insaculaciones o en Morella, podemos comprobar que la intervención real obedecía a otros motivos.

\footnotetext{
${ }^{210}$ Arroyas Serrano, M. (1989): El Consell... op. cit., pp. 189.

${ }^{211}$ Ibidem pp. 96, nota 102.
} 


\section{Castellón frente a otras villas de la Corona de Aragón: semejanzas y diferencias.}

\subsection{Villas del reino de Valencia.}

La ciudad de Valencia obtiene el primer Privilegio de insaculación con Felipe IV en 1633 en el que se dice que a partir de ese año la elección de justicias, jurados, racional, síndicos y almotacén se realizan mediante el sistema de insaculación ${ }^{212}$.

Se forman tres bolsas: una primera de ciudadanos que engloba aquellos que ya han ocupado el cargo de jurados, una segunda de ciudadanos que no lo han ocupado y una tercera de caballeros y generosos. Las vacantes serán provistas por el rey cada cuatro años.

A partir de aquí se decide por sorteo el justicia civil, criminal y almotacén, alternándose de las bolsas de ciudadanos y generosos. También por sorteo se eligen dos miembros de cada bolsa para jurados, es decir seis. Los síndicos de la cámara y del racionalato se eligen en el Consell y el del racional el rey, a partir de una terna extraída de la primera bolsa de ciudadanos. Como es evidente será el virrey el que sugiera a su majestad sobre las personas idóneas para cubrir las vacantes.

En 1646 se revoca el Privilegio de la insaculación por iniciativa del virrey, el conde de Oropesa. Esto supuso que algunas personas que habían quedado entre las élites con la implantación del sistema insaculatorio en 1633 quedaran fuera del poder lo que originó que empezarán a presionar para intentar recuperarlo.

Hasta 1648 las vacantes que se producían en la bolsa segunda de ciudadanos y la de generosos eran elegidas por el monarca de una lista de candidatos propuesta de forma conjunta por los jurados, el racional, el síndico y la consulta y veto del virrey. A partir de la citada fecha se reinstaura el Privilegio de insaculación al monarca ya que podía incluir en las bolsas a personas que no estaban propuestas. Muchas veces llegaban al monarca tres listas, la del virrey, la del racional y la de la ciudad. Clara intervención

${ }^{212}$ Felipo Orts, Á. 1996): Insaculación... op. cit., pp. 24. 
regia en el proceso por la introducción de personas no propuestas por el municipio a cambio de aceptar algunos propuestos por la villa de Valencia, proceso en el que queda muy claro el papel del racional como auténtico delegado real, a lo que hay que sumar que en este Privilegio las vacantes se rellenen anualmente ${ }^{213}$.

En este mismo estudio ${ }^{214}$ revela que para los cargos de síndicos del secreto y del racionalato, justicia civil y criminal y almotacén se sucedieron personas diferentes y no hay un claro dominio de familias.

Parece que en la ciudad de Valencia el proceso insaculatorio y el proceso de injerencia real no llevó al control de ciertas familias. La perpetuación en el poder fue impedida por el sistema insaculatorio, mostrando más que peso de las familias, el peso de personas en si mismas. Apoyan esta afirmación, los datos aportados por Felipo Orts en los que predominan las personas que lo ocuparon una o dos veces, para dejar patente la no creación de unas oligarquías en el poder urbano de los oficios, lo que conduce a hallar diferencias importantes con Castellón. Mientras que en la capital del Reino de Valencia la intervención regia es evidente (y además no se ve claramente una oligarquía), en el municipio de la Plana, sí que se detecta una repetición en la ocupación de los cargos tanto a nivel individual como familiar.

En la ciudad de Jijona, perteneciente a la Lugartenencia de Játiva, se implanta la insaculación en 1512 en el que se establecen la configuración de dos bolsas o sacos de mano mayor y menor. Del primero se extraen el jurado primero y el justicia y en años alternos el almotacén. Del saco menor los jurados segundo y tercero, el acequiero y años alternos el almotacén. Los consejeros son ocho insaculados de bolsa mano mayor y diez de mano menor, englobando la bolsa de mano mayor los oficios de mayor autoridad, elevándose a veinte con la incorporación de dos consejeros militares a partir de 1655. En la bolsa de mano mayor se insacularon 23 individuos y en la mano menor 38, más los anteriores 23 por lo que en total hace 61 vecinos. ${ }^{215}$

\footnotetext{
${ }^{213}$ La primera bolsa de ciudadanos se llenaba con los de la segunda que hubiesen ocupado el cargo de jurado.

${ }^{214}$ Felipo Orts, Á. (2004): Autoritarismo... op. cit.

${ }^{215}$ Bernabé Gil, D. (2001): "Insaculación, ...” op. cit.
} 
Encontramos descontento en cierta parte de la villa, puesto que se establece el carácter vitalicio de pertenencia a las bolsas y solo se puede renovar por bajas por fallecimiento, jubilación o emigración, y previo paso por la estancia en la bolsa de mano menor y después promoción a la de mano mayor. Tomaba especial relevancia quién iba a determinar la entrada en las bolsas y la promoción. En 1513 quedó en manos del justicia presente y el anterior, tres jurados actuales y tres anteriores y el escribano, es decir, en manos de las oligarquías municipales. Confirmado por $\mathrm{D}^{\mathrm{a}}$. Juana y Carlos I, no se ve modificado hasta 1590. En la segunda mitad del s. XVI las intervenciones de la Real Audiencia fueron más habituales al igual que en el resto del Reino. Suponían que aquellos rechazados pudieran entrar en el poder municipal por la vía de insaculaciones extraordinarias. Pero los problemas seguían surgiendo, elevándose quejas de que las insaculaciones seguían favoreciendo a las mismas familias que ya estaban en los resortes del poder jijonenco. El resultado fue la modificación del sistema insaculatorio introduciendo al baile local para determinar las personas insaculadas así como las promociones. Además se establecía el número de insaculados en 61 como se estableció al principio y no en 56 que era lo que se hacía en la práctica, quedando la bolsa de mano mayor en 38 y la de mano menor en 23 , sin existir la posibilidad de estar presente en las dos bolsas de forma simultánea. La administración real no puso ninguna objeción puesto que suponía intervención regia a través del baile ${ }^{216}$. Sin embargo, durante los primero años posteriores a la reforma del proceso insaculatorio nos encontramos con dos habilitaciones realizadas por mandato real: la de 1597 y la de 1606 . Hubo una nueva modificación en 1620 en el número de insaculados de las bolsas siendo 20 para mano mayor y 40 para mano menor. Mientras que a partir de 1635 se tiene documentación de la bolsa de caballeros o generosos.

La polémica por la intervención del baile, parecía resuelta en las Cortés de 1626 y 1645 pero en la práctica continuaban ejerciendo esa participación como ocurre en

\footnotetext{
${ }^{216}$ Recordemos que desde las cortes valencianas de 1604 se disponía la intervención de los bailes locales en las insaculaciones municipales. Ciscar Pallarés, E. (1979): "Las Cortes valencianas de Felipe III", Revista Estudis. Monografía. Universitat de Valencia. Sin embargo en las Cortés de 1626 algunas villas del reino consiguen que no intervengan. Lario Ramírez, D. (1973): Cortes... op. cit. En las Cortes de 1645 se vuelve a insistir en este tema pero el monarca no rechaza de forma tajante sino que para no agraviar permite a aquellos bailes que ocupan su cargo hasta que no cesen. Guía Marín, Ll. (1984): Cortes... op. cit.
} 
Jijona y sigue siendo un peso importante su voto puesto que aquí es muy reducida la cantidad de personas que eligen a los nuevos candidatos. Además interfiere en la habilitación de una forma relevante, aunque parece ser que intenta adecuarse a lo que decide la mayoría. Pero tal y como ocurre en Castellón la estrecha vinculación con determinadas familias de la oligarquía y su frecuente condición de antiguo insaculado actuaron como amortiguadores en esas potenciales tensiones entre administración municipal y la real. Finalmente comentar que la primera referencia a la existencia de una bolsa de caballeros o generosos es en 1635, cuyo número no debió sobrepasar las dos o tres personas y por tanto, según los fueros, les tocaba alternar en los cargos cada seis años. Es un caso similar al de Castellón. Se crea una oligarquía local que va a ser la que mueva los resortes de poder, y la que insacule, aunque con intervención regia en algunos casos a través de la Real Audiencia y otros, mediante oficiales reales. Pero no será determinante frente al papel del baile que también está vinculado a las élites urbanas de la villa.

En la ciudad de Alicante es Juan II de Aragón el que concede las primeras Ordenanzas para insacular en 1459, estableciendo dos sacos, uno mayor para cubrir los oficios de justicia y jurados y el saco menor para los oficios de almotacén y clavario, elaborando las primeras listas una comisión formada en su mayor parte por las oligarquías locales. Este sistema, se va implantar de forma definitiva con la concesión del Privilegio de 1502 de Fernando el Católico en el que mantenían las bases de las Ordenanzas de 1459 y en las que destacamos que el cargo de almotacén pasaba a cubrirse del saco mayor. La primera gran modificación la encontramos a principios del siglo XVII cuando Felipe III establece tres bolsas, una de caballeros o generosos, una de mano mayor y una de mano menor, estableciéndose en 1612 que hubiese cuatro jurados, dos de la bolsa de los caballeros y dos de la bolsa de los ciudadanos. En cuánto al racional hubo diversos cambios durante la centuria del diecisiete respecto a la influencia regia para nombrarlo, pero lo más destacado es que casi siempre fue un miembro de la bolsa de los caballeros. El Consell de la ciudad estaba formado por cuarenta miembros de los que dieciséis eran de la bolsa de los caballeros, el mismo número de mano mayor y ocho de mano menor. El escribano era un cargo de desIgnacioón real, mientras que el almotacén se elegía alternativamente entre los miembros de los caballeros y los de mano mayor. Finalmente comentar que el sobrecequiero, en un principio, era elegido entre los 
miembros de mano menor, para pasar a partir de principios del siglo XVII a alternar entre los caballeros y mano menor anualmente.

A partir de las conclusiones que extrae Alberola i Romà podemos deducir que en Alicante unas cuántas familias consiguieron afianzarse en el poder y que muchas veces no se respetaron los fueros puesto que miembros de la misma familia ocuparon el cargo de forma consecutiva, aspecto que ya habíamos comprobado que ocurría en Lleida y en Castellón. La intervención de la Real Audiencia fue muy relevante porque durante el s. XVII controló cada vez más las personas insaculadas, tenemos, por ejemplo, el caso de 1612, llegando a prohibir que no fuese insaculada persona alguna sin su permiso, o en 1687 cuando fueron insaculados ciudadanos de mano mayor que se les había otorgado el privilegio militar. Además hemos de hacer una mención muy importante al enorme peso que tuvo en la ciudad la bolsa de caballeros, copando algunos cargos importantes y puestos del Consell porque el procedimiento insaculatorio les daba un acceso prioritario, frente a otras villas como Castellón. Por tanto, encontramos diferencia con la villa de Alicante en que la intervención regia fue más clara y evidente, junto el peso de los caballeros o generosos, que en Castellón era mucho menor.

En Orihuela se concede el Privilegio de insaculación en 1459 en el que se establece que todos los cargos que se eligen por este procedimiento serán extraídos de tres bolsas, una del estamento de caballeros, una segunda de ciudadanos honrados o de mano mayor y una tercera de ciudadanos o de mano menor. Los dos justicias, cinco jurados y treinta y dos de los cuarenta consejeros del Consell se extraen de las dos primeras bolsas, y el resto de la última bolsa. Ésta estaría compuesta por los labradores enriquecidos, por lo que también estarían ampliamente representados en el municipio de Orihuela como ocurría en Castellón, desplazando totalmente a los oficios mecánicos. Es cierto, por lo que vemos en el dato que aporta Alberola Romà, que el $80 \%$ de los cargos eran ocupados por los ciudadanos honrados o caballeros ${ }^{217}$. En esta villa destacamos las posteriores reformas de $1569^{218}$ y 1625 en las que quedaba patente la intromisión real, que llega a su cenit con las insaculaciones por carta real a partir de 1669. Será este

\footnotetext{
217 Generalitat Valenciana, (1992) : Dels Furs ... op. cit., pp. 450.

218 Bernabé Gil, D. (1985/1986):“Centralismo y autonomía municipal en Orihuela: De Fernando el Católico al "Viraje Filipino"”. Revista de Historia Moderna nº12. Alicante, pp. 29-54.
} 
municipio otro en que el peso de la autoridad monárquica era mucho mayor que en Castellón. Las oligarquías municipales existieron copando la mayoría de los cargos pero fue la Corona la que fue ganando poder a finales del siglo XVII.

\subsection{Otras villas de la Corona de Aragón.}

En la ciudad de Barcelona se otorga el Privilegio de Insaculación en 1493 y se complementa en 1499 estableciendo cinco consellers nutridos de tres bolsas: una de ciudadanos y caballeros, otra de mercaderes y otra de artistas y menestrales. Se extraían tres de la primera, uno de la segunda y uno de la tercera alternándose anualmente hasta que a partir de 1652 se establece un sexto consejero. Los ciudadanos y caballeros ejercían un fuerte control sobre el resto de conserjerías urbanas, puesto que la suma de sus votos permitía aprobar por mayoría sus propuestas. La tercera bolsa englobaba a notarios, barberos, especieros, médicos y cirujanos y por los menestrales estaban los maestros de los gremios artesanos.

Estos eran asesorados por el Consell de Cent formado por 144 miembros o jurados, 48 de los cuales pertenecían a los ciudadanos, 32 para los mercaderes, 32 para los artistas y 32 menestrales, y dentro del cual existía el Trentenari, formado por 12 ciudadanos y 8 miembros de cada uno de los otros tres grupos y que era el encargado de elegir la comisión formada por doce jurados que se encargaría de elegir e inscribir a las personas insaculadas. El grupo de los doce jurados estaba formado por 3 ciudadanos ( 2 ciudadanos y 1 militar), 3 mercaderes, 3 artistas y 3 menestrales. Además se incorporaba a dos notarios y miembros de reserva por si faltaba alguien el día de la elección. Así pues era fundamental el papel que jugaba esta comisión insaculadora. Una vez en las bolsas era cuestión de tiempo conseguir ocupar un oficio municipal o ser conseller. Es palpable la similitud con Castellón. Desde la institución municipal se puede llegar a los resortes de poder de la villa. Sin embargo, parece mucho más complicado el acceso a la comisión en Barcelona lo que es bastante comprensible puesto que las dimensiones y la importancia económica son diferentes. Podemos afirmar que la influencia regia en uno u otro municipio fue distinta. Castellón fue consolidando su independencia del poder real tras la concesión del Privilegio de 1597. La intervención de la Real Audiencia vislumbraba cierta influencia regia, aunque no 
como tal sino como promoción de habitantes de la villa que sentían agraviados por no haber sido incluidos en las bolsas. En Barcelona se inicia el siglo XVII con la plena independencia del poder real para insacular, es decir, similar al municipio castellonense, pero esto se vio modificado a partir de 1652 y tras los hechos ocurridos en la década de los cuarenta, de forma que perdió el control sobre la insaculación que nunca recuperaría.

Nos encontramos en Barcelona con unas élites con lazos entre ellas y que no permitían el acceso a las distintas bolsas a personas que no fueran de la misma condición, aspecto muy similar en Castellón, puesto que las bolsas eran una puerta muy difícil de abrir para aquellos que no eran dignos de entrar en la época moderna, y el ejemplo más evidente lo vimos con los oficios mecánicos. Ahora bien la composición de estas élites difiere en este aspecto entre estas dos ciudades ya que en Barcelona los menestrales si que formaban parte de la élite de la villa, mientras que en Castellón no. Es el papel más rural de la ciudad de la Plana el que permite jugar un papel relevante a los labradores enriquecidos frente a una ciudad más comercial y mercantil en la que lo ocupan los mercaderes y menestrales, junto a ciudadanos honrados, militares y artistas. Pero el fondo de la cuestión sigue siendo el mismo, es decirla existencia de unos grupos oligárquicos en el poder municipal que se mantienen a través de la endogamia y clientelismo.

En Zaragoza existían cinco jurados que tenían el poder y existían cinco bolsas para los cinco cargos, desde el primero hasta el quinto. Todas las bolsas se nutrían de ciudadanos honrados de Zaragoza y la pertenencia a estas bolsas significaba formar parte de la flor y nata de la sociedad zaragozana. Las bolsas de jurados se nutrían de rentistas, abogados, notarios, médicos y procuradores. Normalmente los rentistas, abogados y mercaderes estaban en las tres primeras bolsas y los notarios tenían el techo en la tercera. También en esta ciudad era cuestión de tiempo e ir escalando en las bolsas, aunque había ciudadanos que, por su escasa parentela, por su profesión o riqueza no tenían como objetivo llegar muy alto como el caso de los notarios y médicos. Los mercaderes fueron desbancados del regimiento urbano ya que la Corona no veía con buenos ojos que los hombres de negocios controlaran los principales cargos urbanos. En la urbe zaragozana de los s. XVI y XVII no fue posible que un maestro artesano ocupara un cargo de jurado, hubieron de conformarse junto a labradores, pequeños comerciantes y tenderos con la participación en el gobierno urbano a través de las siete consejerías, 
más tarde cinco, a ellos reservadas en el conjunto de los 35 consejeros que integraban el Capítulo y Consejo. La Ordinación de 1561 hacía referencia a la prohibición de que los más importantes cargos municipales, sobre todo los jurados, pudieran recaer en los que hubieran tenido una tienda o realizado un oficio mecánico en un tiempo inmediatamente anterior.

El Capítulo y Consejo de Zaragoza era el organismo que adoptaba las decisiones municipales y estaba compuesto por 35 miembros. Decidían sobre las propuestas de los jurados que no votaban pero tenían voz y podían estar presentes. La mayoría de los miembros eran de los ciudadanos quedando siete para los gremios, comerciantes o labradores y reduciéndose más adelante a cinco.

El otro organismo urbano relevante era la Asamblea abierta que estaba formada al menos por cien vecinos, que no parece oponer mucha resistencia a las propuestas del Capítulo y Concejo, pero que debía ratificar las medidas tomadas por éste. En ella sí que podrían tener una representación importante los gremios, labradores y pequeños comerciantes. Por tanto, no parece incompatible la existencia de un poder en los jurados y en el Capítulo y Consejo (dominado por los ciudadanos honrados) y otro, en la Asamblea popular, que pudiera influir de alguna manera en el gobierno municipal.

En Zaragoza los ciudadanos estaban formados por mercaderes, notarios del número, abogados, médicos y procuradores. Para cubrir las vacantes que se producían había dos métodos el de insaculación y el de asunción. La insaculación se realizaba cada diez años y un grupo de ciudadanos confeccionaba las listas, en las que se señalaban el nuevo puesto que correspondía a los ya insaculados, eliminaban a las personas fallecidas desde la conformación de la matricula anterior e incluían a los nuevos ciudadanos, entre los que estaban los propios hijos. Después era supervisada por el Capítulo y Consejo municipal y elevada a la Corona que acaba por aprobarlas con algunos retoques.

El método de asunción consistía en el ascenso de los ciudadanos de las bolsas inferiores de jurado a las superiores y en el caso de la quinta en la admisión de una nueva persona. Para acceder a la ciudadanía honrada en Zaragoza la principal vía era la existencia de parentesco, y también se admitía a personas que ejercieran algún cargo 
floreciente como mercader, notario, abogado o con un título universitario que posibilitase un futuro prometedor como el de jurista. En el siglo XVII empieza a utilizarse el título "hijo de ciudadano" como uno de los valores principales para acceder a la ciudadanía e incluso podía ser el único, y disminuye también la admisión de mercaderes. Es muy importante hablar de la creciente importancia que adquirieron los abogados, ya que a medida que avanza el siglo XVI el número de miceres va avanzando y supera al número de mercaderes. Adelanta en prestigio a médicos y notarios, avance que fue posible por la existencia de puestos laborales en la capital de la Corona de Aragón debido a que numerosas instituciones que precisaban de ello, siendo la Corona la principal interesada por querer en la Administración a profesionales juristas. Esto originó cierta resistencia de las oligarquías urbanas, pero fue aceptada y entraron sin demasiadas reticencias en las bolsas del gobierno urbano. Encontramos en Zaragoza una oligarquía relativamente abierta, controlada por el patriciado urbano que disponía de unas vías precisas de acceso a sus filas. Se corrobora como entre el número de componentes aumentaba el número de abogados, profesión a la que no pusieron demasiados reparos a la hora de su admisión en las principales bolsas del gobierno municipal, como ocurre en Castellón donde la incorporación de una mayoría de notarios a lo largo del siglo XVII es bastante palpable. La oligarquía municipal en la villa de la Plana, como Zaragoza, tampoco incluyó a los oficios mecánicos y sí lo hizo con ciudadanos honrados, doctores en leyes, doctores en medicina, pintores, cirujanos, apotecaris, notarios, abogados y mercaderes y los labradores enriquecidos que serían similares a los rentistas zaragozanos. Sin embargo en Castellón sí se permitió la entrada de los caballeros o generosos mientras que en Zaragoza esto no ocurrió, puesto que encontramos un brazo nobiliario reacio al mundo urbano.

En cuánto a la influencia de la Corona en Zaragoza podemos observar como es mucho mayor que en Castellón ya que las listas elaboradas por los ciudadanos se elevaban a la monarquía que era quién determinaba si eran válidos para ser insaculados, aspecto que difiere con respecto a Castellón donde nunca tuvo ese margen de decisión.

En la Paería de Lleida encontramos al Consell General que sería el epicentro del poder local, es decir, similar al Consell de Castellón, existiendo cuatro bolsas, una de caballeros, otra de ciudadanos, (las dos juntas forman mano mayor), mano mediana y mano menor. El encargado de habilitar o cubrir las plazas vacantes era el Consell 
General y se inscribía en el Llibre de les Ànimes. Por supuesto al igual que ocurría en Castellón todo habilitado tenía que cumplir una serie de requisitos. La forma de presentarse para ser elegido cambió con la guerra dels segadors ya que antes podían presentarse ellos mismos o con recomendación de alguien de confianza del Consell General, pero después son los paheres los que eligen a los candidatos y que han de ser confirmados en el Consell General. En la primera bolsa se concentran los nobles y caballeros. En la segunda bolsa se incluyen ciudadanos honrados, médicos, doctores y licenciados en derecho civil y canónico. En la tercera bolsa notarios, mercaderes, apotecaris, cirujanos, bachilleres en derecho, y partir 1648 drogueros. Por último, en la cuarta bolsa encontramos a pageses y menestrales. Se elegía a cuatro Pahers o jurados, siendo el paher en cap de la bolsa primera, el segundo de la segunda, el tercero de la tercera y el cuarto de la cuarta.

El Consell General estaba formado por cincuenta miembros, de forma que había quince de mano mayor: siete caballeros y ocho ciudadanos; quince de mano mediana y quince más de mano menor, quedando cinco de las cofradías que incluía los gremios. La mano mediana incluía a los candidatos de la tercera bolsa de jurados mientras que la bolsa de mano menor encontramos los de la bolsa cuarta de Paher, es decir los pageses y menestrales. La estructura, pues, es muy similar a Castellón, con la diferencia de que en el municipio de la Plana solo hay dos manos, de que los caballeros no tienen tantos representantes (ya que la ciudad existen muy pocos caballeros o generosos) y de la presencia de los gremios en Castellón. Ya hemos explicado que no existió puesto que el intento de 1626 se quedó en eso, en un mero intento. En cuánto al poder para insacular en la villa de Lleida recaía en los cuatro Paheres o jurados por lo que era muy diferente al de Castellón y mucho menos “democrático”, de ahí que se instaurara el sistema de las matrículas que se hacía mediante supervisión del Consell, donde se votaban a los nuevos miembros y después los Paheres decidían a quién insacular. Esto cambió definitivamente en 1685 primero por Ordenanza y después por el Privilegio concedido por Carlos II, de forma que será a través del Consell General como se hagan las nuevas insaculaciones. 
La influencia regia tal y como explica Passola i Tejedor ${ }^{219}$ es inusual en el devenir diario de la villa, adoptando claramente el papel de suplicador la Pahería de Lleida cuando surgían disputas aunque no era lo habitual. Al repasar las actas municipales de la ciudad se puede observar que no había una preocupación por la Corona, ya que se consideraba que los asuntos propios de ella eran más de ámbito global o general. Así nos encontramos con una oligarquía leridana que tenían un pacto de facto con la monarquía y que permitía un equilibrio entre las dos partes, solo roto por las elevadas exigencias de las Cortés de 1626-1632 y la rebelión de 1640. Sin embargo los podemos citar como excepciones puesto que la restauración de los privilegios insaculatorios que volvían a favorecer a las élites municipales, volvían a reforzar ese sistema adecuado a la época en que cada uno sabía que papel debía jugar y el sistema insaculatorio era un fundamento más para legitimarlo. Por tanto, podemos ver esa similitud con el municipio de Castellón en el que la intervención regia es escasa a cambio de mantener el sistema de equilibrio acorde con la época moderna entre monarquía y élites urbanas.

\footnotetext{
219 Passola i Tejedor, A. (2001): "La élite municipal leridana bajo los Austrias". Revista de Historia Moderna. Anales de la Universidad de Alicante, nº19. Universidad de Alicante, pp. 79-81.
} 


\section{Conclusiones.}

Iniciamos este estudio planteando una serie de objetivos sobre la villa de Castellón en el seiscientos, una serie de propósitos tendentes a mejorar la comprensión del funcionamiento del municipio en una época marcada por las estructuras básicas del Antiguo Régimen y que hacían que la sociedad estuviese claramente delimitada en función de su pertenencia a un grupo u a otro. En este contexto era fundamental partir del correcto entendimiento del sistema insaculatorio que se implantó en la mayoría de los municipios de la Corona de Aragón al iniciarse la Edad Moderna y que se presentaba como una forma de control por parte de la monarquía de las instituciones que dirigían el funcionamiento de las distintas villas de realengo. Dentro de ellas incluimos a la ciudad de Castellón de la Plana, municipio de carácter rural sin tener una relevancia económica ni política especial como Valencia, Zaragoza o Barcelona, pero que según los historiadores de la época se consideraba una villa provechosa tal y como la define Escolano, “ preñez de su tierra" o " el rico estado en que hoy tienen (los naturales) a Castellón" ${ }^{220}$, y que era la capital de la zona norte del Reino de Valencia, es decir, de las tierras situadas al norte del riu Uxó, y era en este punto donde adquiría su importancia y que la hacía sede de un lugarteniente del gobernador.

Nuestro análisis se ha centrado en el funcionamiento del municipio en la época comprendida entre la aprobación del Privilegio de Felipe III que confirmaba el procedimiento insaculatorio en 1597 y el final de la época foral que lo eliminaba, con la introducción del ayuntamiento al estilo de Castilla que supuso el reinado de la nueva dinastía borbónica a partir de 1707. Para ello es fundamental desmenuzar las instituciones que administraban el día a día de la villa, y la principal es el Consell, la cual era la que dirigía los asuntos diarios y la encargada de tomar las decisiones sobre qué personas debían ocupar los distintos cargos y oficios del municipio. Además con la introducción de la insaculación va a ser desde donde se va a decidir quién entra en las distintas bolsas y quién no.

${ }^{220}$ Casey, J. (1980): “Tierra...” op. cit., pp. 2. 
La primera cuestión que nos planteábamos al inicio era si el funcionamiento del Consell de Castellón estaba suficientemente definido y si era correcto todo lo que había escrito la historiografía tradicional sobre él o eran necesarios hacer una serie de matizaciones para una mejor comprensión de la institución. La primera afirmación que tuvimos que corregir y que ha quedado suficientemente demostrada en el trabajo es la negación de la alternancia anual de los cargos de justicia, almotacén y jurado primero, entre el brazo militar y brazo real, puesto que esta alternancia dependía de las personas hábiles que hubieran en la bolsa del brazo militar. En Castellón prácticamente nunca fue anual. Esto ya lo había comentado Bernabé Gil para otras poblaciones del Reino de Valencia apoyándose como hemos hecho nosotros en los fueros, pero sobre la ciudad de Castellón había dudas por las palabras de Arroyas Serrano y debíamos dejarlo claro.

La segunda afirmación dudosa dentro de esta primera cuestión era la que hacía Arroyas Serrano, según la cual este vio incrementado el número de consejeros por la petición de Cortes de 1626, pasando de 36 a 39, porque se incorporaban dos consejeros más, uno de mano mayor y otro mano menor, así como el acequiero que había ejercido el año anterior. Para corroborarlo revisamos todas las reuniones del Consell entre 1597 y 1707. El análisis nos llevó a afirmar que no es cierta la suposición de Arroyas Serrano ya que la composición del Consell fue siempre de treinta y seis miembros, a excepción de aquellos años que por motivos extraordinarios había algún consejero más de mano menor o mayor o aquellos en que no había personas hábiles suficientes en las bolsas y ello implicaba que el número de consejeros fuese inferior a treinta y seis. Sin embargo, la práctica habitual eran quince de mano mayor y catorce de mano menor más dos consejeros del brazo militar, y los cuatro jurados y el justicia que en total sumaban treinta y seis consejeros, incluyendo en los consejeros de mano mayor, menor y militar aquellas personas que habían ocupado el año anterior uno de los cargos como el de justicia, jurados, síndico, almotacén o escribano que daba derecho a entrar como consejero de oficio, pero nunca se cita en las actas del Consell que lo hiciera el acequiero por haberlo sido el año anterior.

La tercera afirmación que había que aclarar para delimitar los entresijos de la institución municipal, era el papel que jugaban las inhabilitaciones familiares y las que no permitían ocupar el cargo de forma reiterada, y aquí encontramos argumentos para coincidir con lo enunciado por Arroyas Serrano que ya había expuesto como no siempre 
se cumplen, y nosotros lo hemos visto de una forma clara cuando observamos como consejeros que no pueden ocupar el cargo más de tres años, lo hacen hasta seis e incluso ocho, y que en un mismo año tenemos familiares en el Consell y que muchas veces pese a existir el fuero que lo prohíbe se decide votar con habas blancas y negras, es decir que sea la propia institución la que decida por encima de lo que se haya establecido en el fuero concedido por la Corona. Estamos ante una prueba manifiesta de cómo los intereses municipales de las oligarquías prevalecen aunque hayan sido ellas mismas las que solicitaran esas normas. Es importante aclarar que el incumplimiento de estas inhabilitaciones se fue diluyendo hacía el final de la centuria, donde ya tenemos a unas oligarquías plenamente asentadas, contrariamente a lo que ocurría al inicio del seiscientos en que el Privilegio se acababa de conceder y era necesario consolidarse en la élite de la ciudad, asimismo era una práctica más habitual entre los ciudadanos honrados, doctores en leyes y en medicina que formaban el grupo de nutría los consejeros de mano mayor y el jurado primero puesto que tuvo un comportamiento más endogámico y cerrado.

Resuelta esta primera cuestión, comenzábamos a plantearnos quiénes eran las personas que estaban en las bolsas y las que ocupaban los cargos y si eran las mismas familias, aspecto que resultaba de vital importancia para entender si la sociedad de la villa de Castellón se comportaba como la gran mayoría de las ciudades de la época moderna.

El estudio de las insaculaciones nos mostró un hecho relacionado con el límite establecido para los integrantes de las bolsas por el Privilegio de 1604 y que estaría en la línea de lo expuesto anteriormente sobre el menor incumplimiento de las habilitaciones hacía finales del seiscientos, y es que al principio del s. XVII es muy habitual incumplir estas condiciones, pero tal y como va pasando la centuria ya observamos unas élites plenamente consolidadas y con un mayor control de los resortes del poder y del procedimiento insaculatorio, por lo que los límites de la bolsa se van respetando asegurándose la presencia de las familias adecuadas.

En cuanto a la composición de las bolsas insaculadas, encontramos un hecho que vuelve a determinarnos el ámbito cerrado que éstas tenían y es que recordemos que los ciudadanos honrados, doctores en leyes y doctores en medicina nutrían las de mano 
mayor junto a los artistas, las de jurado primero y una parte mayoritaria en la de justicia, una parte de la de almotacén y una parte de la acequiero, pues cuando hemos comprobado todas ellas, nos encontramos que en cada insaculación están prácticamente los mismos nombres en todas las bolsas, alrededor del $75 \%$ de las personas insaculadas en la bolsa de jurado primero del brazo real vuelven a estar en mano mayor y por supuesto son los mismos que estarán entre los elegidos en la de almotacén y acequiero. Ocurre exactamente igual con la bolsa de jurados segundos o artistas que nutre junto con los ciudadanos la bolsa de consejeros de mano mayor. A su vez es similar lo que sucede en mano menor y la bolsa de jurados tercero y cuarto, pero no es de una forma tan acusada, puesto que entre los labradores enriquecidos había mucha más diversidad.

Si examinamos las familias que dominaron las distintas bolsas, hemos de partir de la distinción entre el brazo real y militar ya que la composición era diferente. En el brazo real a su vez hemos de distinguir entre los componentes de las bolsas relacionadas con los jurados primero, dónde hay un dominio de las familias Giner, Martí, Jover, Gascó $^{221}$, Feliu, Serra o el caso de los Figuerola que fueron escalando en la pirámide social pasando de los labradores enriquecidos a principio de siglo para consolidarse como ciudadanos y doctores en leyes en la segunda mitad. Las bolsas relacionadas con los jurados segundos o de los artistas estuvieron mucho más repartidas, quizás por la gran cantidad de notarios que existían en la villa, pero aún así siguen apareciendo en cabeza los Martí, Mas y Giner, aunque también son relevantes los Moliner, Museros y Mercer. Evidentemente la de escribanos será similar puesto que también se sitúan los notarios y pese a que hay mucha diversidad otra vez tenemos en cabeza a los Giner o los Martí. En las bolsas en que se introducen los labradores enriquecidos como son los jurados terceros y cuartos y las de mano menor y una parte de las de justicia, almotacén y acequiero hay cinco familias dominantes como son los Vilarroig, Castell, Navarro, Pasqual y Museros. Si contrastamos estos datos con los obtenidos con Sánchez Adell ${ }^{222}$, observamos como las familias de mano mayor tales como los Giner, los Jover, los Figuerola o los March eran pocas por lo que sí podríamos afirmar que nuestros resultados son válidos ya que controlaban cierta parte del Consell. En el caso de los

\footnotetext{
${ }^{221}$ Esta familia estuvo presente en la primera parte del seiscientos.

${ }^{222}$ Véase el estudio de las familias por apellidos realizado por Sánchez Adell en el documento 10 del apéndice.
} 
Martí esto es más difícil puesto que el número de familias con este apellido en Castellón se eleva según datos de Sánchez Adell ${ }^{223}$.

Cuando pasamos a contrastar quiénes dominaron las consejerías de mano menor y sus bolsas, encontramos a los Castell, Vilarroig, Museros, Pasqual y Navarro, y si recurrimos al estudio del mismo autor, encontramos estos apellidos con un número de familias no inferior diez, aspecto que puede debilitar más nuestras conclusiones, sin embargo hemos de tener en cuenta varias cosas. La primera es que ya hemos comentado anteriormente que la diversidad en los consejeros de mano menor y las bolsas relacionadas con ellos era mucho mayor, por lo que es más fácil que entrarán más familias en ellas. En segundo lugar en nuestro proceso de investigación se ha tenido en cuenta para agrupar los apellidos el seguimiento de las personas en las bolsas y la comprobación en protocolos notariales y, en tercer lugar, que la repetición de las mismas personas y su importancia a nivel individual corroboran su relevancia. Por tanto, teniendo en cuenta las limitaciones, podemos afirmar que los resultados explicados anteriormente son bastante ajustados a la realidad tal y como era en la época del seiscientos.

En el brazo militar el grupo de familias era mucho más reducido y encabezan las insaculaciones los Arrufat, Reus o Miquel, aunque dadas las pocas familias que existían sería difícil que no ocuparan un puesto en el Consell, aspecto que solo ocurrió con algunas familias cuyo apellido no está vinculado directamente a Castellón y que solo aparecieron en alguna insaculación.

Seguidamente comprobamos las familias qué ocupaban los puestos para los que se habían creado las bolsas y obtuvimos que en el caso del justicia, el cincuenta por cien de las veces lo ocuparon los ciudadanos, doctores en leyes y doctores en medicina, destacando los Giner, los Jover, los Andreu y los Martí y el caso especial de Tomás March que lo ocupó cinco veces en veintidós años o Francesc Andreu que lo ocupó cuatro veces. En el brazo militar tenemos en cabeza a los Arrufat, los Reus o los Igual, que también encabezan la ocupación del jurado primero. En el jurado primero de brazo real volvemos a encontrar a los Giner, los Andreu, los March y los Figuerola, en el

${ }^{223}$ Ibidem. 
jurado segundo o de los artistas volvemos a obtener que está más disperso y aparecen apellidos menos habituales como los Amposta, Moliner, Alberich, Amiguet aunque sí que tienen bastante presencia en esta bolsa seguidos de otros habituales como los Martí. Los jurados tercero y cuarto lo vuelven a copar los Vilarroig, Castell, Museros, Alegre o Navarro. El almotacén, en el brazo militar, los Arrufat y los Reus y en el brazo real los Pasqual, que vienen de la mano menor y destacamos a Miquel Pasqual de Francesc (que lo ocupa cuatro veces), los Giner o los Martí, es decir, otra vez las mismas familias. El escribano también ocupado por los Giner y los Martí muchas veces. Los acequieros, como la bolsa tiene más porcentaje de personas que provienen de la mano menor, está ocupado en su mayoría de veces por los Vilarroig, Sanchís, Pasqual y Francesc, y, a nivel individual, se reparte bastante puesto que la diversidad en la bolsa de los labradores es muy grande. Los consejeros militares están dominados por los Reus, Arrufat, Sisternés, Ros y Miquel, dominando la primera parte de la centuria los Arrufat o Miquel y apareciendo en la segunda los Vallés, Igual, Serra o Bou.

Los consejeros de mano mayor estaban dominados por los Giner, los Martí, Andreu, Figuerola, Jover y March y los consejeros de mano menor dominados por los Vilarroig, Pasqual, Castell, Navarro, y Museros.

Esta valoración global de las familias que formaban las bolsas de la insaculación así como cuáles de ellas ocuparon realmente los oficios o puestos tales como el justicia, jurados, consejeros, escribano, acequiero o almotacén, nos lleva a intentar averiguar la relación entre las insaculaciones y los cargos desempeñados y si habían sido las mismas familias o no las que lo ocuparon y si hubo un claro dominio de algunas familias que lo hiciera un sistema cerrado y útil para que las oligarquías se mantuvieran en el poder. Esto queda patente al comparar las familias que entraron en las respectivas bolsas y las que ocuparon los puestos, ya que son las mismas. En mano mayor fueron los Giner, los Jover, los Martí, los Andreu o los March mientras que en mano menor los Vilarroig, los Pasqual, los Castell, los Navarro o los Museros. En el brazo militar fueron los Arrufat o los Reus, pero el círculo era muy estrecho en la bolsa de los generosos o caballeros. Por tanto, las inhabilitaciones no servían de filtro para evitar que las mismas familias que dominaban las bolsas fueran después las que desempeñaban los cargos. 
Pese a la contundencia de los hechos, queríamos reforzar esta visión de una institución municipal controlada por un pequeño grupo de familias de la sociedad castellonense y para ello hay un dato muy relevante y es que sumando el número total de personas que ocuparon un asiento en el Consell y dividirlo por el número total de puestos que se debían cubrir en todo el período objeto de estudio obtenemos que cada uno lo ocupaba alrededor de nueve veces, o sea nueve años. Además hay cincuenta personas que lo ocuparon más de veinte veces e incluso personas como Miquel Mur, Melchor Amiguet, Macià Compte o Vicent Tosquella que no son de las familias más relevantes llegaron a ocupar el cargo más de veinticinco años. Esto nos muestra como además de las familias que siempre estaban en el Consell y que tenían mucho peso en la institución existieron algunas personas que a nivel individual también lo tuvieron. Una suma final nos deja bastante clara la existencia de una oligarquía municipal claramente cerrada en la que era difícil entrar si no se pertenecía a uno de los grupos de poder, y que utilizaba las relaciones endogámicas para tener más controlado el acceso a esos resortes de dominio que no querían abandonar y que habían conseguido con el tiempo. Se permitía a algunos miembros de bolsas inferiores pasar a ser de alguna bolsa superior pero lo realmente complicado era entrar en alguna de ellas.

La desaparición de las instituciones forales con el decreto de la abolición de los Fueros tras la derrota de la batalla de Almansa, supuso su sustitución por otras según el modelo de Castilla y en este caso para los municipios se instauró el ayuntamiento. En Castellón nos planteábamos si este cambio supuso que las viejas élites dirigentes fueran sustituidas con la llegada de los nuevos aires borbónicos. En Castilla se había creado una dualidad nobleza-corregidor, dejando los intereses de la población para intentar beneficiar a la aristocracia y a la corona. En el municipio castellonense encontramos durante los primeros años como las familias que habían ocupado los lugares relevantes en los oficios y en el Consell de la época foral van a ocupar los cargos de regidores. Al analizar los apellidos de los primeros ayuntamientos desde 1710 a 1729 volvemos a ver los mismos apellidos en los regidores, es decir Castell, Mas, Giner, Igual, Andreu, Martí o Bou, por tanto las mismas familias. No hay posibilidad de que entre muchas más, ya que el nuevo ayuntamiento sufre una reducción importante respecto al antiguo Consell, lo que hace que no exista la posibilidad de que haya tantas familias representadas. Muestra de esa pérdida de influencia es la desaparición de los Vilarroig, los Navarro, los Pasqual o los Breva que habían sido muy relevantes en la última parte de la época foral. 
El puesto de corregidor, en estos primeros años estudiados por nosotros, siempre quedará en manos de personas foráneas, no vinculadas a los apellidos tradicionales de Castellón. Son los regidores anteriormente citados los que presentarán su condición de ciudadanos inmemorial y obtendrán las hidalguías, aspecto muy bien estudiado por Gimeno Sanfeliu. Nos encontramos ante la nueva aristocracia aposentada en la villa de Castellón. Mientras en la cúspide del nuevo ayuntamiento borbónico se sitúa la figura del corregidor, llegado de fuera y afín a los intereses monárquicos.

El sistema foral ha sido desmantelado nominalmente y la representatividad del Consell de Castellón ha desaparecido, pero indirectamente el nuevo ayuntamiento mantiene el mismo juego de equilibrio de poder, élites locales frente a monarquía, donde los regidores junto a sus redes clientelares pasan a ser las élites locales y el corregidor el cargo de confianza del rey. Evidentemente esto supuso la expulsión del poder de algunos grupos socioeconómicos que no habían conseguido escalar hasta el primer puesto de ciudadanos como los labradores enriquecidos, pero había fuerzas oligárquicas que supieron mantenerse en el mando de la nueva institución.

Acorde con los tiempos del absolutismo de los nuevos monarcas borbónicos, encontramos una sociedad castellonense que ha seguido las pautas del Antiguo Régimen, primero con una institución municipal controlada por los grupos según su categoría socioeconómica más acorde con la época foral y con la llegada de Felipe de Anjou pasa a tener un carácter más aristocrático con las nuevas hidalguías.

A continuación nos preguntábamos si Castellón fue una villa independiente de la intromisión real a la hora de la insaculación o como la mayoría municipios del Reino de Valencia, fue manipulado este proceso por las instituciones regnícolas. Hemos de comenzar diciendo que la Ordinación de Covarrubias de 1590 establecía el poder para insacular a la Real Audiencia, pero que esto cambia con el Privilegio de 1597 y no se verá modificado en todo el siglo diecisiete, de forma que la insaculación en la villa de Castellón queda en manos del Consell y sí que podemos citar que la primera de ellas la realiza un comisario regio, a partir de aquí, por lo general, se va respetar las decisiones que se tomen a nivel local, como no ocurre en los otros municipios importantes del Reino de Valencia: Orihuela, Alicante o Valencia, en donde la Real Audiencia va a tener una papel fundamental llegando a insacular directamente, aspecto que nunca 
ocurrió en la ciudad de Castellón porque la función de esta institución de carácter real se centró en conseguir que algunos personajes del patriciado castellonense consiguiesen acceder a las bolsas, pero la independencia de la composición de las bolsas parece evidente. Ahora bien, esto no prueba una pérdida de autoridad por parte de la Corona en la villa de Castellón, pues a nuestro modo de ver los grupos oligárquicos del municipio eran conscientes que la existencia de ese equilibrio con la monarquía suponía conseguir mantener sus puestos de privilegio, sin intromisiones que pudieran desmantelar unos hilos y resortes de poder que permitían a un grupo más o menos cerrado controlar la villa de la Plana. Y ello se podía ver reforzado por la no presencia de una clase poderosa de caballeros o generosos con ansia de títulos que podía suponer para la Corona una mayor tranquilidad. Encontramos una prueba palpable en el papel que jugaron tanto el baile como el gobernador. En todo el período tuvieron voz y voto como se les había confirmado en el Privilegio de 1604. Ni las Cortes de 1626 ni las de 1645 se las quitaron de manera efectiva, ya que la ciudad no se vio muy preocupada por su intervención, puesto que los bailes siempre formaron parte de las oligarquías municipales y los sucesivos lugartenientes de gobernador representaban un voto en la insaculación.

Finalmente se planteaba la necesidad de realizar una comparación entre Castellón y otras villas del Reino de Valencia, así como de la Corona de Aragón. La primera comparación la establecemos con la ciudad de Valencia, capital del Reino, donde encontramos una intervención regia muy relevante centrada en dos ejes: la influencia directa sobre las insaculaciones y la no existencia de una oligarquía consolidada como en Castellón. En el caso de Jijona sí encontramos más similitudes con la villa de la Plana, porque la intervención regia se centra en el papel del baile con su voz y voto, aunque a veces algún comisario regio estableciera la orden de insacular. Sin embargo, a la hora del proceso nos encontramos con que es la villa la que realiza el proceso con la participación de la autoridad del rey en el municipio, pero muy vinculado a las oligarquías locales. Además también nos encontramos con unas élites que se consolidaron durante el s. XVII y que no quisieron perder este poder, así como una bolsa de caballeros o generosos muy poco numerosa como es la ciudad de la Plana.

Alicante fue una villa en que, al igual que en Castellón o Jijona, también se fueron formando unos grupos de poder que se establecieron en la pirámide de la 
dirección de las instituciones locales, pero aquí la intervención regía tomó más fuerza que en Castellón, llegando a ser la Real Audiencia la que tenía que dar el visto bueno en las insaculaciones a medida que se avanzaba el seiscientos, de forma que el proceso insaculatorio iba perdiendo su sentido. El papel de los caballeros fue muy importante ya que su porcentaje de participación era mucho más elevado que en Castellón. Para acabar nuestro estudio comparativo en el Reino de Valencia hemos elegido la villa de Orihuela, donde también encontramos grupos oligárquicos que se habían formado con el proceso insaculatorio y cuyo papel protagonista lo toman los ciudadanos, puesto que la mayoría de puestos fueron copados por ellos. Sin embargo, en el municipio no se logró el equilibrio monarquía-élites municipales, por lo que la intervención de la Real Audiencia fue muy habitual, llegando a insacular ella directamente en la última parte del seiscientos, aspecto que la aleja de lo que ocurría en la villa de Castellón.

Si observamos el comportamiento de otros municipios de la Corona de Aragón, también obtenemos conclusiones diferentes. El caso más parejo al de Castellón de los que hemos estudiado lo encontramos en Lleida donde a excepción de los problemas entre 1626-1632 o con la guerra dels segadors de 1640, quedaba muy claro que los encargados de insacular era las instituciones locales y se mantenía el respeto mutuo, de forma que determinar quién o quiénes debían dirigir la vida diaria de los ilerdenses quedaba en manos de ellos mismos. Además encontramos una oligarquía que está interesada en controlar esos accesos al poder y quiere lograr ese equilibrio monarquíamunicipio. Es en esta oligarquía donde encontramos la principal diferencia con Castellón ya que sí que entran en el juego del poder los oficios mecánicos.

Las otras dos villas que hemos utilizado para comparar con Castellón son Zaragoza y Barcelona. En cuanto a la primera hemos encontrado que las oligarquías urbanas que controlaban las instituciones locales en las más altas instancias eran los ciudadanos, dentro de los cuales en ningún caso se incluyeron ni los caballeros, ni los mercaderes ni los comerciantes. A estos se les dejaba participar de una manera significativa en la Asamblea que tenía más bien un carácter consultivo. Así pues la primera diferencia con Castellón la encontramos en este estrangulamiento a la hora de determinar quiénes formaban parte de estos grupos de poder en la ciudad de la Edad Moderna. Pero a su vez encontramos la diferencia de que siempre fue la Corona la que 
en última instancia, supervisaba las listas de personas que iban a incorporarse a las bolsas por el método de insaculación.

En el caso de Barcelona es más parecido a Castellón en cuanto que en sus inicios el poder para insacular queda en manos de una comisión de miembros del Consell de Cent, por tanto queda en manos del municipio, sin embargo, con el transcurso del s. XVII y con los diferentes hechos que ocurren en la ciudad, va perdiendo el poder para insacular, contrariamente a lo que ocurrió en Castellón que se fue consolidando. En relación a quiénes eran los grupos que consiguieron acaparar el poder municipal, confirmamos que ocurre como en el municipio de la Plana, puesto que son los ciudadanos los principales actores que estarán apoyados por los caballeros o generosos. Por el contrario, sí que van a entrar en el juego los mercaderes y menestrales, aspecto que no nos puede sorprender dadas las características de la ciudad y su importancia comercial y económica.

Por tanto es difícil establecer un paralelismo exacto con alguna de los casos analizados puesto que tomar como ejemplo a las ciudades de Barcelona, Zaragoza o Valencia conlleva un riego importante a la hora de equiparar la importancia de estas ciudades frente a Castellón. No podemos olvidar que las tres eran muy valiosas para la Corona y era evidente el interés regio por el control. Sin embargo, queremos ir más allá y buscar aspectos comunes que encontramos sobre todo en Barcelona pues lo habitual es que sea el Consell de Cent el que se encargue de la insaculación, es decir, que recaiga en manos de los propios habitantes de la ciudad ${ }^{224}$, y que sería muy similar al planteamiento que se da en Lérida, donde encontramos claras similitudes en el poder para habilitar y que se establece muy claro cual debe ser el papel de la Corona. Por tanto podemos hacer nuestras las palabras de Arroyas Serrano ${ }^{225}$ cuando afirma que Castellón se parece mucho más a los municipios catalanes, pese a esa pérdida de poder de Barcelona a finales de la época foral, que los del Reino de Aragón o del mismo Reino de Valencia, porque tal y como va avanzando el siglo XVII se va consolidando el

\footnotetext{
${ }^{224}$ Esta afirmación hay que entenderla en la época de la que estamos hablando en la que no se puede suponer que todos los habitantes elijan a sus representantes, ya que en una sociedad del Antiguo Régimen solo pueden gobernar la ciudad aquellos que se encuentran realmente preparados o que se consideran que lo están.

${ }^{225}$ Arroyas Serrano, M. (1989): El Consell...op. cit., pp. 68.
} 
sistema insaculatorio como autonomía local, pese a las intromisiones de la Real Audiencia pero más en la línea de resarcir a algún agraviado de las élites de la ciudad. Es aquí donde nos gustaría discrepar de las palabras de algunos autores cuando defienden que la supresión del municipio foral no se produjo con la llegada de los Borbones, sino que desde hacía tiempo había perdido su autonomía por el creciente aumento del control regio sobre las instituciones locales en las principales villas del Reino de Valencia por la intervención de comisarios u otras instituciones. Pese a que estamos en una época claramente tendente a la centralización del poder monárquico, queremos dejar patente nuestra visión de una doble dirección o de un poder con dos vertientes. La primera vertiente de un poder autoritario que se podía ejercer desde la Corona, en este caso desde la Monarquía Hispánica. La segunda vertiente que emergía desde las instituciones locales y permitía mantener ese equilibrio entre esos dos núcleos. Es por eso que en Castellón encontramos un sistema insaculatorio que sirvió como en muchos en otros casos para consolidar y depurar unas élites gobernantes adecuadas al Antiguo Régimen, tal y como defienden autores como Florensa y Soler ${ }^{226}$ o Alberola i Romà $^{227}$ con una clasificación en función de su jerarquía socio profesional. La ciudad de Castellón destacó por la preeminencia de los ciudadanos honrados, doctores en leyes, doctores en medicina situados en el escalafón más alto y que más influencia tuvieron en el gobierno municipal, seguidos de los caballeros o militares, artistas y labradores enriquecidos. Es evidente que convergían intereses muy diferentes que debían complementarse, los del municipio y los propios, aspecto que debería profundizarse más y que posiblemente le dediquemos un próximo estudio, pero el hecho más relevante es como en la ciudad de Castellón estos grupos de poder consiguieron asentarse manteniendo ese equilibro con la Corona para que su injerencia en los asuntos de la villa fuese mínima lo que permitió tender unos puentes magníficos para el mantenimiento en el poder con la llegada de los Borbones, e incluso presentando como

\footnotetext{
${ }^{226}$ Florensa i Soler, N. (1993): “La insaculació pactada: Barcelona 1640”. Pedralbes: Revista d'Història Moderna. (Ejemplar dedicado a les institucions Catalanes (segles XV-XVII)). Barcelona, pp. 447-456. En su artículo establece que el sistema insaculatorio en la ciudad de Barcelona conllevaba unos filtros para revisar los candidatos si cumplían los requisitos socio-profesionales.

227 Alberola i Romà, A. (1992): "Autoridad real y poder local. Reflexiones en tomo al desarrollo del procedimiento insaculatorio en los municipios valencianos durante la época foral moderna". Pedralbes. Revista d'Història Moderna, $\mathrm{n}^{\circ}$ vol. 12. Alicante. En su artículo habla de un claro proceso de depuración haciendo desaparecer los insaculados de dudosa procedencia.
} 
mérito para la obtención de los títulos de hidalguía la pertenencia a estas instituciones que ellos mismos se habían encargado de hacer a su medida. Hemos de recordar que este sistema insaculatorio permitió que existieran menos conflictos que cuando se utilizaba el de cooptación, muy habitual en la Baja Edad Media y que conllevaba a que la Corona tuviera que intervenir muy a menudo. El nuevo sistema insaculatorio favoreció que los linajes se asentarán en el poder con el apoyo implícito de la monarquía y Castellón es un claro ejemplo de ello, puesto que así la Corona lograba que estas élites colaboraran con la gobernabilidad y estabilidad del reino así como hacer frente a los servicios militares y monetarios que muchas veces se les exigió. Coincidimos en este punto con Passola i Tejedor ${ }^{228}$ en que no se puede generalizar en el enfrentamiento entre la Corona y las instituciones forales, como símbolo de la monarquía autoritaria. Es evidente que la época moderna se caracterizo por el incremento o reforzamiento de la autoridad de los Reyes Católicos primero y después de la casa de los Habsburgo, pero realizar una sistematización del enfrentamiento entre una monarquía centralizadora contra los diferentes reinos como base para un discurso nacionalista de buenos y malos nos parece exagerado y con falta de pruebas científicas.

La defensa del neoforalismo queda un poco debilitada cuando analizamos casos como el de la villa de Castellón, dónde siempre se tiene patente la autoridad real como referencia, pero no como un enemigo que intenta desvirtuar el funcionamiento de las instituciones locales, sino un amigo que quiere participar en el mismo sistema propio del Antiguo Régimen. Un sistema que mantiene una clara diferenciación en la sociedad de la época según la categoría socioeconómica, pero que no va a cambiar sustancialmente con la nueva dinastía borbónica y serán las mismas familias las que vuelvan a ocupar los cargos de regidores.

Sin embargo, no queremos generalizar nuestro caso ni para el resto de la Corona de Aragón, ni siquiera para el Reino de Valencia, puesto que es difícil establecer unos patrones homogéneos, aunque a veces podemos encontrar comportamientos similares en el Reino de Castilla o en otras partes de Europa. Es fundamental entender que la historia

\footnotetext{
${ }^{228}$ Passola i Tejedor, A. (2002): "Poder real y poder local: un pacto tácito". Congreso Internacional "Espacios de Poder: Cortes, ciudades y villas (s. XVI-XVIII)". Universidad Autónoma de Madrid. Madrid, pp. 45-71.
} 
no es un hilo continuo de acontecimientos, hay discontinuidades, retrocesos y todo ello a su vez conforma un fenómeno que se puede discutir, analizar, entender y que nos deja la puerta abierta para poder averiguar sus entresijos y sus porqués.

Castellón no es una excepción, es una villa que vivió el s. XVII como tantas otras dentro de un sistema de equilibrio de poder, un pacto tácito entre la monarquía autoritaria de la época y las clases dominantes de la ciudad. Élites sociales que perseguían sus propios intereses por encima de los del municipio, puesto que querían mantenerse en el poder, e incluso recurrían a la propia autoridad regia a través de Real Audiencia para poder entrar a formar parte de él. 


\section{Apéndice documental.}

\subsection{Documento 1: Privilegio dado por Juan de Navarra en 1446 a la villa de Castellón}

1446, mayo, 22. Valencia.

(AHMC. Privilegio de Insaculación).

(ARV. Chancillería Real, re. 269, ff. 47 ss.).

Ed. Francisco A. ROCA TRAVER: Ordenanzas municipales de Castellón de la Plana durante la Baja Edad Media. Instituto Alfonso el Magnánimo. Diputación Provincial de Valencia. Valencia. 1952, pp. 124-132. (Transcripción).

Ed. David BERNABÉ GIL: Privilegios de insaculación otorgados a municipios del Reino de Valencia en la Época Foral. Instituto Alicantino de Cultura Juan Gil-Albert y Diputación de Alicante. Alicante. 2012, pp. 205-223. (Transcripción).

En nom de nostre senyor, sia a tots manifest que nos en Joan, per la gràcia del Déu Rey de Navarra, Infanta e governador general de Aragó e de Sicilia, duc de Nemos e de Montblanch et Penyafiel, Compte de Ribagorça e senior de la ciutat de Balaguer, loctinent general del molt alt Senyor Rey, pare nostre mlt honrat. Atenenet e considerant que per experiència appar com moltes de les universitats de les ciutats e viles reals del present regne són constrenyides, en gran diminució, depauperació e dirruició, senyaladament, per causa de les discensions e discordies del habitadors de aquelles, les quals discòrdies principalment se demostren è exerciten en los officis e regiments de les dites civitats e viles, perco com cascú se treballa e esforça per a nantar e sublimar aquells ad qui té sa affectió, e per desanantar e derrerar als contraris de que los dits e altres inconvenients procehexen. E per aquesta rahó, lo señor Rey en dies passats veents, los grans inconvenients que el la Ciutat de Xativa se seguían per aquesta rahó, ordenà que lo Regiment de la dita ciutat fos fora de arbitrie e electió, puys que aquells en los quals haurie a recaure lo dit arbitre eren axí apassionats per lurs interessos e diferencies, que no podien egualment usar del dit arbitre è electió. E dona a la dita ciutat regiment vulgarment appellat de sacg, lo qual la experiència ha mostrat esser tan complit e bastant remey e provisió als dist inconvenients, que aprés, per exemple de aquell es estat estés e ampliat en altres moltes ciutats e viles del señor Rey, en les quals per semblants se és mostrant profitós e util, e per amor de açó, attenents com a 
supplicació de micer Nicholau Batle, missatger a les Corts e d'en Bernat Colomer notari, sindichs de la dita vila de Castelló, nos és stat suplicat quens plagués otorgar a la dita vila lo dit Regiment, e no res menys los habitadors e ciutadans de la Ciutat de València que son censalistes e creedors de la dita vila nos han de açó ab gran insistència suplicat, per lo gran interés que'ls va en lo ben avenir de la dita vila, així com és cert que pochs dies són passats que, ab llur gran dany e menyscapte hagueren a donar loch a la supportatió e comport de la dita vila per que no peris, així com estava en punt de perir, e totalment despoblat, e segons som informats per la maior part, per causa dels inconveninets e danys que a la dita vila en los temps passats són pervenguts e de present notoriament soté, per les passions que en obtenir e ocuparse los officis è regiment de aquella concorren. Per tal, nos, veents la dreta e bona intenció de tots los que açó volen e demanen, la qual molt loam, ab tenor de la present, deliberadament e de nostra certa scientia, haut acord e deliberació sobres les coses dejús scrites e ordenades ab nostre Sacre Consell, e encara demanants e convocats sobre aço en Manuel Raya, Johan Miquel, Pere Colomer, notari, Domingo Gascho, Miquel Arrufat, Llorenç Martorell, Guiamo Cvaller e Bernat Reboll, prohomen, vehins e habitadors de la dita vila, otorgam e donam a vosaltres, amats nostres,los justícia, jurats, consell e universitat de la dita vila de Castelló los capítols, stabliments è ordinacions infrasegüents:

\section{Forma dels sach i redolins}

Dels sachs dels homens de paratge à justícia, jurat è mustaçaf e que haja haver quatre milia souls valents.

Primerament, statuym è ordenam que sien fets tres sachs, en cascú dels quals sien meses en sengles redolins de cera de una mateyxa color, pes e forma, incluses cédules de pergamí hon sien scrits los noms, ço és en cascun albarà o redolí hun nom, dels homens de paratge que's trobaran en la dita vila, vehins e habitadors continuament o per la major part del any, ydóneos è sufficients, e que possehiran en aquella bens valents quatre milla souls, la hu del quals sachs sia intitulat sach per a justícia dels homens de paratge, l'altre per a offici de jurat, laltre per a offici de mustaçaf, e sia servada en lo traure dels dits redolins tal pràcticha o manera, ço és, quel any que per furs del Regne de València, segons lo nombre dels dits homens de paratge vehins e habitadors de la dita vila, lo justícia haura de ésser generós sia tret lo dit sach de la caxa hon lo consell de la dita vila serà ajustat, e del dit sach sia tret sens tot frau per hun infant, segons sos aspecte de deu anys, e per los jurats manat traure, hun redolí e sia mes en les mans del 
batle o de son loctinent, e per aquell sia ubert públicament, e aquell qui serà trobat nomenat en la cédula del dit redolí sia publicat per lo dit batle justícia de la dita vila per aquell any lladonchs següent. E així mateix, l'any que deurà ésser mes hun generós en jurat o en mustaçaf sia servada aquella matexa orde. Volem emperò e ordenam que feta la dita nominatió per lo batlle de aquell qui haurà nomenat o tret del sach o sachs de generosos per ésser justícia, jurat o mustaçaf, en continent sien tornats públicament per lo scrivà dins los dits redolins a cloure e tornen dins los sach o sachs d'on los hauran trets.

2. Del sachs dels vehins de la vila per a jurats e altres officis e per a consellers. ITTEM statuim e ordenam que los noms dels vehins dita vila, qui de present són en la dita vila àbils e sufficientes per offici de jurat primer de aquelal, sien scrits en sengles cèdules de pergamí e cada huna de aquelles inclusa en hun redolí de cera, los quals redolins sien de una matexa color, pes e forma, e sien meses en una bossa o sach, la qual, aprés que meses hi seran, sia tancada o tancat e segellada felment ab lo segell de la vila, e en aquella sien scrites de fora per títol o subscrites les paraules següents: sach de jurat primer. E per semblant manam volem que sien incluses cédules, hon sien los noms dels vehins hàbils e sufficients a offici de jurat segon, e aquelles meses en hun sach, lo qual sia intitulat sach de jurat segon. E altres redolins en que sien incluses cèdules hon sien los noms dels vehins hàbils e sufficients a offici de jurat ters e quart. E altres redolins en que sien incluses cèdules hon sien los noms dels vehins habils e sufficients al offici de clavari de dita vila, e aquelles mesos en altre sach, lo qual sia intitulat sach de clavari de la dita vila. E aprés altres redolins en que sien incluses cèdules hon sie los noms dels notaris habils e sufficients e de bona fama al offici de scrivà del consell de la dita vila, e aquells mesos en un sach, lo qual sia intitulat sach de scrivà de jurats i del consell de dita vila. E altres redolins en que sien incluses cèdules hon sien los noms dels vehins de la dita vila abils è sufficients per a ser consellers de la dita vila, e aquells mesos e inclusos en hun sac,h lo qual sia intitulat sach de consellers de la dita vila, E altres redolins en que sien incluses cèdules hon sien los noms dels vehins de la dita vila qui no seran generosos e que sien vists àbils e sufficients per a ésser mustaçaf de la dita vila, e aquells mesos en un sach, lo qual sia intitulat sach de mustaçaf de la dita vila. E altres resolins en que sien cèdules, hon sien los noms dels vehins de dita vila que no sien generosos e que seran trobats àbils e sufficients per a ésser justícia de la dita vila, e aquells mesos en hun sach, lo qual sia intitulat sach de justícia de dita vila. 
3. Del sach de missatgers e quels haya a traure lo jurat primer e de sachs de altres officis. ITTEM, perço com experiència ha mostrat en la dita vila e altres moltes universitats que alguns singulars de aquelles, per cobdícia de guanyar salaris e en altra manam per fer sos affers, se procuren missatgeries, ab color de les quals procuren grans despeses e càrrechs a les dites universitats, statuhim e ordenam que sia fet un sach intitulat sac de missatgers, en lo qual sien meses per via de cèdules e redolins en la forma desús dita los noms de aquells vehins e habitadors de la dita vila que seran vists ydòneos e sufficients per a les missatgeries que la dita vila sol e haurà menester fer. $\mathrm{E}$ quant serà cas en lo qual per lo consell de al dita vila, per la forma del capitol que açò parle, serà vist deure ésser tramés algun missatger, serà tret en la manera desús specifficada hun redolí o dos, si serà vist que dos missatgers degen ésser, e aquell o aquells presentats al jurat primer, lo qual de alli de continent e públicament haya a obrir lo dit redoli e publicar aquell o aquells que dins seran trobats per a la missatgería que ocorrera. E açó sia entés en qualsevol missatgería aceptat, solament en cas de Corts en lo qual perço com se deu més mirar en la disposició de la persona, volem que lo missatger qui deurà anar en Corts sia prés e elegit dels que seran en lo dit sach per veus del consell ab faues blaques e negres e la manera desús specifficada. E altres redolins en que sien incluses cèdules, hon sien los noms de aquells vehins abils e sufficients per ésser sagristans de la dita vila, e aquells mesos en sach lo qual sia intitulat sach de sagristans de la dita vila. E altres redolins en que sien incluses cédules, hon sien los noms de aquells vehins àbils e sufficients per ésser cequier de la dita vila, e aquells mesos en un sach lo qual sía intitulat sach de cequier de la dita vila, e altre redolins en que sien incluses cèdules, hon sien los noms de aquells vehins abils e sufficients per a èsser manobrer de dita vila, e aquells mesos en hun sach lo qual sía intitulat sach de manobrer de la dita vila.

4. Que en tots los redolins e en tots los sachs sía servada la caució e clasifficatió del jurat primer. Volem empero que tots temps, en lo fer de tots los dits redolins e aquells metre en los sachs e aquells tancar e sagellar, sien servades les caucions e clasifficatió en lo capítol que dispon del sach dels que deuen ésser assumpts à jurat primer contengudes.

5. Que los que són insaculats sien continuats en un llibre y mesos en redolins. 
Que los qui són en los oficis sien continuats en un libre, e de altra part sien mesos en redolins. E los noms dels vehins que segons dit és seran nomenats, e declarats als officis sobre dits, manam ésser mesos e continuats per lo scrivà de la vila en un libre, a açò specialment deputat, e a altra part en cèdulles de pergamí intercluses en redolins e aquelles meses en sos sachs per ell dit notari de la vila en la forma e manera desus ordenada.

6. Que los qui són en un sach de Jurat no sia en sach de altre jurat, però puxen èsser en altres sachs. ITTEM statuhim, ordenam e declaram que les tres bosses dessús mencionadas, hon són inclusos los noms dels vehins àbils è suficients per a jurat, sien així distintes entre si, que les persones que seran meses en la huna de aquelles no sien meses ni collocades en l'altra. Pero dels sachs dels jurats ni dels sachs dels altres officials entre sí no entenen que sia necessari ni expedient fer tal distinció. Ans volem que les persones que seran meses en la huna de aquelles bosses puxen ésser meses en l'altra o altres dels dits sachs per als officis als quals seran trobats àbils e sufficients.

\section{Caixa dels insaculats.}

Que sia feta caxa ab quatre panys e quí tendrà les claus de aquella. ITTEM, statuhim e ordenam que sia feyta una caxa, la qual tinga quate panys ab quatre claus la una diversa de la altra en manera que la una clau no pusca obrir la tancadura de la altra, e que una de aquestes claus tinga lo loctinent de governador o son subrogat. La altra lo batle de la dita vila o son loctinent, la altra lo justícia, la atra lo jurat primer. La qual caxa sia mesa en lo archiu lo quual és en la casa del consell o palau, la clau del qual archiu tinga lo scrivà del consell. E en la dita caxa sien fets tants caxons como hi ha sachs, o sien meses tantes capçes, e cascun caxó o capça sia mes hu dels sachs desús nomenats e cascun caxó o capça sia intitulat segons lo titol del sach que dins aquella serà mes, e de fora la caxa sien fetes les armes del señor Rey e de la vila.

8. Del jurament que hán a fer los que tinen les claus de la caxa e porten les claus quant menester sia sens difficultat. ITTEM statuym e ordenam que quant les claus de la dita caxa se acomanaran, qu'el loctinent de governador o son subrogat sia tengut jurar en poder del batle de la dita bila, e lo batle, justícia, jurat e scrivà en poder del dit loctinent eo subrogat, e prestar sagrament e homenatge de haverse bé e lealment en la guarda e custòdia de la dita caxa, e que per si ni per altre públicament o oculta no obriran ni obrir 
faran, ni consentiran o permetran que sia uberta la dita caxa, sinó en los casos e formes en les presents ordinacions contengudes e ordenades. E que cada ora, e quant la dita caxa segons tenor de les dites ordinacions abrirse deura, portaran les claus sens difficultat e dilació alguna per a obrir la dita caxa en la manera en les prsents ordinacions contenguda. E que directament o indirecta, públicament ni oculta no daran, faran, ni procuraran ni consentiran que sia feyt dayn, ni procurat impediment algú, per lo qual la dita caxa no sia uberta ab les dites claus en los casos e forma en les presents ordinacions compreses e ordenades. E si lo contrarí fahien, que pusca ésser procehit contra ells així com a trencadors de sagrament e homenatge, e execució de pena capital per esser torbadors de bon stament publich e privats de officis ad imperpetuum de la dita vila.

9. Dels que tenen les claus de la caxa si exiran de la vila, o son terme, a qui deuen acomanar les claus. ITTEM, sis sdevendrà lo dit loctinent de governador o subrogat absentarse de la dita vila, o son terme, per algun cas, ans que partexca de aquella sia tengut de acomanar la clau a altre qui romandrà subrogat per absència sua, presents los jurats de la dita vila, o la maior part, mijancant lo sagrament e homenatge en lo precedent capítol ordenat, la qual comanda lo dit subrogat sia tengut en si prendre e prestar lo dit sagrament e homenatge. Així mateix, sis sdevendra lo batle e justícia absentarse, sien tenguts en la manera desús dita acomanar les claus a sos Loctinents. E si lo jurat exiàa fora la vila o son terme, sia tengut comanar la dita clau al Jurat segon si serà en la dita vila, e si no y serà al hu dels altres jurats en la forma e manera desús dita, la qual volem sia comanada, present lo justícia e los altres jurats ab lo sagrament e homenatge desús expressats, ans que partesca de la dita vila. E si el scrivà se sdevendrà absentarse sia tengut comanar la clau del archiu al jurat segon o a un altre jurat que no tinga clan alguna en e per la forma desús dita. Es emperò nostra intenció que persona alguna no pusca tenir sino una clan de la dita caxa o archiu. E quant los dits absents o absent seran tornats a la dita vila, volem que les dites claus los sien tornades en la dita forma dins temps de tres dies.

10. Lo que han de vacar en officis. Que aquells qui son en algun offici no puxen haver algun affici dins un any, ne tornaran aquell que tendra fins passats dos anys. ITTEM, per quant a bon regiment de cosa pública pertany que los cárrechs e honors de aquella sien rahonablemtn entre los singulars de aquella distribuits, e la continuació de aquells 
en unes matexes persones porien dar a la universitat engendrar oys, enveges, e discòrdies, statuym e ordenam que aquell que serà mes en algun dels officis de justícia, jurat, scrivà e mustaçaf, clavari, sagristà, cequier o manobrer, no pusca en aquell tornar sinó que sien passats abans dos anys primer vinents aprés definit lo temps de sos offici, ni pusca obtenir algun altre offici dins un any aprés finit lo regiment del offici que haurà obtengut. Passat emperò un any pusca obtenir qualsevol offici si exira de aquells en los qual serà stat posat. Ni pusca en un mateix temps dos officis regir, ni lo conseller de un any pusca romandre ni tornar a ésser conseller sinó que per un any hara vacat de la dita consellería, però passat un any aprés qu'en sera exit si la sort lo i dona hi pusca tonar.

11. En quina manera se han a fer admissions de persones novament als officis e si de algú que sia conseller se ha apartat que haia aeixir del consell per a aquella vegada. Sperança havem em Déu de aquí avant la dita vila se serà prosperada augmentantse lo nombre dels vehins de aquella, encara les edats, facultats e virtuts de aquells, en tal manera que, ultra les personas que de present en los dits sachs per als dits officis collocam, se trobaran en lo temps sdevenidor persones noves, dignes e àbils als dits officis. E per tan,t volem provehir que la dita vila no sia frustada dels servicis de aquelles persones que últimament el poden servir, ni los vehins de aquella de les honors que la dita vila als ben merexents dona e acostuma distribuir. Estatuym e ordenam que sobre admissió de persones noves als dits officis, e encara mutació de officis e ascensió de grau de les persones que ja en los dits sachs se trobaran collocades, sia servada la forma seguent: És a saber, que tots aquells qui voldran ésser admesos novament als dits officis, o algú dels que ya seran admesos a altre offici o maior grau promoguts, pusca de dos en dos anys, aprés los dits dos anys passats dins los quals tota admissió e promoció de grau és prohibida, presentarse al jurat primer, present lo notari, lo disapte abans del diumenge de cuasimodo e aquell faça lo dilluns tantost següent convocar consell, en lo qual hagen a ésser tots los consellers sots pena de deu souls, extracció de concellers nous per absència de alguns ya extrets. E si algú se trobarà absent de la dita vila, o per altra urgent necessitat no's porà haver, que sia uberta la caxa e aqui tret lo sach dels consellers, e per un infant de deu anys sien trets tants conselleres del sach com hi falliran per aquella vegada tant solament, e puys, finit lo dit consell, sien tornats en los sach, los quals consellers qui seran trets en la forma dita volem que sien hauts per àbils a fer los dits actes, encara que no hagen vacat lo temps que per les presents ordinacions deuen vacar de hun any a altre abans de ésser Consellers. E així ajustat tot lo nombre 
dels consellers de aquell any, prestat primerament per aquells sagrament en poder del justícia de hauerse bé e lealment en donar sos vots en la admissió o promoció sobre dites, tota amor, odi, favor, temor, subornació e pregaries apart posades, solament havent sguart al bé e profit del comú de dita vila, e prestat axí mateix lo dit jurament sien fetes cèdules de pergamí, hon sien scrits los noms dels vehins que demanen novament ésser admesos als dits officis o promoguts à maior grau que dabans eren, e aquells qui seran competidors de un mateix offici e de pujament e de un grau en altre, si tals ni haurà e més de nombre que segons les presents ordinacions pusquen ésser admesos o promoguts, sien mesos en redolins de cera de un mateix pes, color e forma e aquells mesos en un bací ab aygua. E aprés, per un infant, segons son aspecto menor de deu anys, sia tret hu dels dits redolins e aquell per lo scrivà dels jurats ubert e públicament legit, e sia aprés per lo jurat primer intimiat als dits consellers la persona que serà eixida, e quin offici o grau és aquell a que vol o demana ésser admés, e aprés sien per lo notari del jurats donades a cascú dels consellers dos faues, la una blanca, l'altra negra, los quals consellers donen sos vots si deu la persona aquella ésser admesa o repulsa, posant curtament en un sach buyt, lo qual stiga penjat públicament en una taula en presència del dit Consell, la fava blanca lo que entendrà deure ésser admés, e la negra si entendrà deure ésser repellit. $\mathrm{E}$ après les dites faues per lo dit scrivà o notari sien buidades de la dita bosa en la dita taula públicament. E si seran trobades més blanques que negres sia admesa o promoguda al dit offici sobre lo qual los dits vots seran donats, e si seran més les negres sera hagut per repellit. E per aquesta manera, trahent redolins de hu en hu del dit bací, lo nombre de les persones que als officis o offici sobre que se votarà segons les presents ordinacions en aquell any poden ésser admesos. Lo qual nombre, haut son compliment, sia cesat de traure més redolins del dit bací, e aquell o aquells així admés o admesos, promogut o promoguts, sien scrits en sengles cèdules de pergamí e incluses en sengles redolins de cera en la forma sobredita, e aquells mesos en lo sach o sachs dels officis per als quals en la forma desús dita seran haguts per àbils e sufficients. Volem emperò que si serà conseller aquell qui deurà ésser admés o promogut, e per ell se haurà a votar que haia eixir del dit consell e en loch d'ell ne haya per aquella vegada ésser tret altre conseller, e aprés hi sia tornat, segons dit és Jesús, com no sia rahó que algú sia jutge en la sua propia cosa. E en la sobre dita manera, en la festa dita darrera de Pascua de Resurrectió, de dos en dos anys volem sien celebrades les dites admissions e promotions reputant lo temps de dos anys spay convenient per interposició entre una admisió e altra. 
12. Quantes persones o deuen ésser admeses a cascun offici. ITTEM, per tal que admissions de noves persones súbitament als supremos officis de la dita vila e promocions o ascensions de graus, moltes ensemps porien donar turbatió e impediment al bon stament de la cosa publica de la dita vila, e sia útil e expedient a aquella los sperts e aprovats regir e perverteixse el orde de rahó quants alguns volen ésser fets abans maestres que dexebles, statuim e ordenam sobre la admissió o promoció o ascensió de graus que sia servat l'orde seguent : És a saber, que aquell qui voldrà ésser collocat novament o promogut al offici de jurat, si aquest serà atrobat digne al dit offici, haia primerament ésser collocat en la bossa o sach de jurat terç, o quart, en lo qual sach no pusquen ésser collocats en un any mes de dos persones. E si algú voldrà ésser promogut o pujat del dita sach de jurat segon al primer jurat, no y pusca ésser pujat sinó que en lo sach de jurat segon haía aturat per dos anys contadors del dia que fonch mes avant. E si voldrà ésser promogut o pujat del dit sach de jurat terç o quart al segon, que no i pusca ésser pujat sinçó que haia aturat per dos anys en lo sach de jurat terç o quart del dia que fonc més avant. E en cada hu dels quals officis de jurat primer e segon no y pusca ésser promogut en un any sinó hu; axí mateix volem que al sach de mustaçaf no pusca ésser algú promogut o collocat de aquí avant, sinó que en lo sach de jurat segon haia ésser collocat e en aquell haia aturat per dons anys comptadors del dia que hi serà stat collocat, al qual sach de mustaçaf no pusca ésser promogut en un any sino hu. En cascú dels sachs de scrivà, clavari, sagristà e manobrer sia servada aqueta mateixa orde, que hagen a ésser collocats en los sachs de jurats o algú de aquells en aquella aturats per temps de dos anys del dia que y foren collocats avant comptadors, e si algú voldrà ésser promogut o collocat en lo sach de justícia que no y pusqua ésser admés sinó, que en lo sach de jurat segon haia a ésser collocat en aquell aturat per spay de dos anys comptadors del dia de la collocatió avant.

13. Del orde que's ha atenir en la evacuació dels sachs per donar compliment a aquells. E volem emperò, que si lo sach de primer jurat era així evacuat o disminuit de persones àbils e capaces al dit offici per mort o altra rahó, quel nombre de les persones en aquell stants fos tornat a nombre de dos o menys, que en tal cas pusca ésser dispensat en ésser admesos o promoguts al dit offici tants vehins que ab los que en lo dit sach atrobaran àbils sien almenys quatre. E semblant dispensació de aquesta volem sía feyta 
en la admissió e promoció de jurat segon, e al offici de justícia, e mustaçaf, e clavari, e scrivà, e manobrer. E si lo sach de scrivà vendrà en tal disminució o evacuació qu'el nombre del notaris en aquell stants àbils e sufficients vinga a hu per mort o altra rahó, que en tal cas pusca ésser dispensat en los altres notari a ésser admesos o promoguts que lo nombre ab lo que y serà baste almenys a dos. E si lo sach de jurat terç o quart vendrà a tal evacuació o disminució per mort o altra rahó que lo nombre dels vehins en aquell stants sia baxat a quatre, volem en aquell cas sia dispensat en ésser admesos o promoguts a lo dit sach o offici tants vehins que ab los que hi seran atrobats en lo dit sach àbils e capaces als dits officis que basten a nombre almenys de sis persones. Volem emperò que si algú dels dits sachs de jurats era axí evacuat, que los en aquell stans sien fets inàbils a aquell offici o per qualsevol causa que no's trobassen en aquell sach persones capaces en cascú dells, segons lo número desús ordenat que'en deuen ésser tret de cascun a aquell offici, que sia feta suplectió a aquell per trahimnet de redolí del sach de jurat a aquell subsegüent. E si serà tal desfalliment en lo sach de justicia, que sia feta suplectió o trahimnet de remolí del sach de jurat primer, e si de jurat segon, per suplecito o trahiment del redolí del sach de jurat terç e quart. E si en aquest sach de jurat terc e quart serà lo dit desfalliment, que si proveesqua en la forma o manera donada a les noves admissions e assumpcions de officis en lo capitol que comenta: Sperança hauen en Dèu.

14. En quina manera seran trets los redolins en les jornades de les elections e lo batle, justícia e jurat primer cascú quals redolins o quals officis ha nomenar. Ittem statuim e ordenam que la vespra de Cinquagesima, en la qual per furs e pràcticha del present Regne de València se deu fer electió de jurats, e en tots aquells altres dies que per los dits furs e pràticha, e ordinacions de la dita vila se ha a fer electió de justícia, mustaçaf, e scrivà de jurats, sagristà, cequier, manobrer, e qualsevol altre offici, lo qual per les presents ordinacions se haya a fer, los loctinent de governador o son subrogat, batle, justícia e jurats hagen a fer traure en presència de tot lo consell del archiu la caxa hon los dits sach seran mesos, e aquí sien per ells regonegudes les tanquadures si haurà fet algun frau. E après, tots los qui les dites claus tendran obren la dita caxa e traguen aquells sachs de justícia, jurats o de aquell offici que's haurà a publicar, e sien contats tots los redolins que en aquella seran públicament davant tot lo consell, e per un fadrí de deu anys poch més o meys e aprés sien per ell mateix tornats en lo dit sach e remanats, e aprés per ell mateix sia tret pera offici de justícia un redolí e aquell sia per lo dit fadri 
lliurat al batle, lo qual batle mostrades les mans e arromangades les manegues, sia tengut de obrir lo dit redolí e traure la cèdula que dins serà stada posada, e públicament sia per aquell legida e publicat aquell qui serà Justícia per aquell any següent de la vila de Castelló ab alta veu, que tots los qui seran en lo dit consell pusquen oyr. E aquí mateix liure la cèdula al scrivà, el scrivà faça públicament un altre redolí de cera de aquella color, pes e forma e aquell qui serà scrit en la dita cèdula sia tornat dins lo dit redoli inclus, e sia lo dit redoli tornat en lo dit sach e puys sia lo dit sach sagellat e mes en la dita caxa com de primer; e lo dia statuyt per fur o pràctica del Regne a fer jurats sia servada aquesta mateixa orde, que traguen la caxa del archiu e reconegudes les tancadures per los sobredits, sia treyt lo sach de jurat primer e per un fadrí de la dita edad publicament sien comptats los redolins e, aprés tornats en lo sach, ne sia tret hu per lo dit fadrí e mes en poder del batle que aquell redolí obra e traga la cèdula que dins serà scrita públicament davant tot lo consell, e lija aquell qui allí serà scrit per a jurat primer per al any següent e puys donat al scrivà que aquell cloga e meta en redolí de cera de aquella color, pes e forma del altre e en publich lo torn a segellar e torn en la dita caxa. E aquesta mateixa orde se tinga en lo jurat segon. E dels sachs de jurat terç e quart ne traga dos, los quals meta en poder del batle e aquells uberts faça com dels altres. E axí del mustaçaf e aquells officis que's pertany publicar al batle per son offici. E aquest mateix orde tinga lo justícia en lo offici de sagristà, cequier e aquells officis que's pertanyen publicar a ell. E lo jurat primer publique lo offici de manobrer e scrivà de Consell, e los altres que's pertanyeran publicar al consell los quals cascú, singula singulis referendo, tinguen, e serven l'orde que dit és desús en l'offici de justícia e jurat primer. Emperò l'any que per lo fur del Regne pertanyera la electió del offici de jurat als gentils homens, statuim e ordenam que vague lo offici de jurat segó, e que solament sia tret lo redolí de jurat primer, terç e quart; per quant ab lo dit generós e gentilhom será lo nombre de quatre.

15. Consellers. Que la vespra de Cinquagesima sien trets dels sachs de consellers trenta hu per consellers e lo jurament que han a fer. ITTEM, statuym e ordenam que la Vespra de Cinquagesima sia tret de la dita caxa, aprés feta la declaració del jurats, lo sach intitulat de consellers e de aquell per un infant segons son aspecte de deu anys, menejant primer lo sach, sien trets per trenta hu redolins e liurats al primer urat públicament, e per aquell sien deplegats e tretes les çedules que y seran scrites e legides públicament e ab veu alta los noms de aquells qui en les dites cèdules seran scrits, e per 
lo scrivà sien continuades en libre de consell e per al any següent, e puys sien tornats a cloure en los dits o altres redolins de cera de hun pes, color e forme e puys sien tornats en lo dit sach e sia segellat e tornat en la dita caxa e aquestes presten en poder del justícia lo jurament acostumat de bé e lealment haverse en la dita consellería a tota utilitat de la cosa pública, e de venir al consell tota ora que y sera demanats e oyran cridar o saben que's haurà a celebrar consell, si absents, no seran de la dita vila o no obtindran licència de tots los jurats ensemps, o de la maior part de aquells. E volem que puys sien presents al dit consell fins en nombre de vint e hu entre consellers, e los justícia, jurats, e clavari, mustaçaf e scrivà que darrerament hauran exercit los dits officis o la maior part part de aquells que pusquen celebrar consell, e valga tant com si tots hi eren presents. E fetes totes les dites sia tornada la dita caxa tanquada en lo dit archiu e los dits justícia, jurats e mustaçaf, clavari e scrivà que han a restar, axí com dit és per consellers hagen a fer lo jurament que los consellers son tenguts a fer.

16. Jurament dels consellers. Del jurament dels justícia, jurats e altres officials. E per semblant, lo justícia en lo dia de Nadal, e los jurats en lo dia de Cinquagesima e los altres qui publicats seran en los altres officis, cascun en los dies e temps per furs ordenats, presten e sien tenguts prestar lo jurament que per furs e privilegis del Regne e ordinacions de la vila són tenguts prestar en poder del batle e justícia, e de aquells a qui's pertany rebre la jura segon lo offici.

17. Clavari jurament. Del jurament del clavari e como ha executar la peyter e siser que és en la sua administració e lo clavari abans que ell, e de açó que resta en son poder que ha de fer. E lo clavari jur e faça sagrament que lo primer mes de decembre aprés serà stat posat en lo dit offici, executarà ab acabament tota la resta que lo clavari abans d'ell sera trobat tornador, e rebra e haurà rebut compte ab tot compliment del dit clavari, a ell en lo mes primer de Noembre aprés finit lo seu regiment executarà ab tot compliment lo peyter, e sisers maiors e del peix, e collector de la peyta que's pertany a rebre a ell lo compte e tornar la resta. E ell retrà lo compte de sa administració, e pagarà ab tot compliment al clavari après d'ell tot ço que serà vist tornador si muntarà tot en suma de mil souls, per tot lo mes de deembre apres seguent. E si muntara ames de suma de mil souls, que dins lo dit terme farà de aquells quitament dels censals carregats sobre la dita universitat a qui més gracia li fara. E si no complira les dites coses que encorrega la pena de perjur e perda lo salari, que per la administració del dit offici deurà haver, e 
sia privat a deu anys de tot offici o benefici, açó sens remissió e gràcia. E que en lo primer consell aprés la festa de Cinquagesma lo justicia, jurats e consell juren que no donaran empaig algú per que los sisers e peiters no sien exequtats, abans en lo que a ells se pertanyera en ésser als comptes e altres favors necessaries prestaran tot consell, favor e ajuda que mester serà per que en los dits terminis o abans los dits comptes sien rebuts, e los dits sisers, peyter e clavari del any passat sien exequtats, e lo quitament fer segons és dit, e si lo contrari faran que encorreguen la dita pena de perjurs, e perden los salaris que per los dits officis deuran hauer e sien privats a deu anys dels officis a beneficis de la dita vila.

18. Del salari que ha hauer los jurats en los missatgers. ITTEM, statuim e ordenam que lo jurats e altres officials hagen los salaris acostumats, e lo misatger en alguna misatgeria dins lo Regne de València no pusqua per nenguna manera haver més de cinh couls. E si yra fora lo dit Regne haia sis souls, e si serà Missatger en Corts generals e particular que haia a tenir cavalcadura e si nou farà que no haia més de tres souls se salari.

19. Quans ben han daver los insaculats Quants bens han haver valents los justícia, jurats e altres officials e los consellers. ITTEM, statuim e ordenam que los homens qui han a ésser assumptes en los officis de justicia, jurat, clavari, musataçaf, scrivà de jurats e sagristà hagen haver e posseyr clars bens valents quatre milia souls, e si no'ls hauran no y pusquen ésser admesos, e los consellers hagen haver clars dos milia souls.

20. Foraster casat ab filia de la vila haja de estar 5 anys y 10 lo que sera casat en qui no sera filla de la vila. Dels que no son naturals de la vila quant temps han a astar ans que hagen officis e quins bens han haver valents. E més, statuym e ordenam que algun home, que no sia natural de la vila no haia presa muller natural de la vila, no pusca ésser admés o assumpte a offici de justícia, jurat, musatacaf, clavari, sagristà o missatger si donchs no hauia deu milia souls valens clars, e que lo qui haurà presa muller natural de la vila haia habitat e contribuit en los càrrechs de aquella cinch anys aprés lo matrimoni. E lo qui no haura presa muller natural haia habitat e contribuit en los càrrech de la dita vila per deu anys contínuos, E que per a ésser conseller hagen cascú haver habitat e contribuyt per la meytat del temps desús dit, e que en Corts generals o particulars no pusca ésser missager sino home natural de la dita vila 
21. Impediments. Dels qui no poden ésser admesos a officis e qui l'ha a notificar al consell. E més, statuym e ordenam que los sisers o compradors de les sises maiors o del peix, e los collectors de les peytes e fermançes de aquells, ni home que sia deutor a la vila per alguna administració o altra qualsevol rahó, no pusqua ésser admés en algun dels dits officis, fins tant haia retut compte e pagada la resta que serà vist tornador e obtenguda diffinició del consell de la dita vila, ni home que sia en pleyt ab la vila, ni deutor al senyor Rey, ni denunciat de algun crim que no sia abolit o absolt, si emperò la denunciatió serà per crim evident o manifest aposada quatre mesos abans de la electió, e prosseguida continuament o que sia en bando manifest ab altre vehí de la dita vila no pusquen ésser rebuts en alguns officis de la dita vila. Volem emperò que sobre la clarifficació de aquests duotes per remoure tota la via de discòrdia sia servada tal orde, que en lo principi del consell abans de traure los redolins de que's deurà fer la electió al offici o officis, lo batle declare e sia tengut declarar públicament en consell qui són aquells qui són denunciats o són deutors al Rey per que no degen ésser rebuts. E ell e lo justícia digue aquells qui són denunciats o en bandositat, e lo jurat primer declare qui són los deutors a la vila o que pledegen ab aquella. E a quí si clarament constara al consell ésser impedits, sien haguts per inàbils a obtenir lo offici o officis que's deuen publicar. E si vendrà en dubte o disceptació que algú dels qui voldran ésser donats per inàbils per alguna de les coses dessús dites sia culpable o no en aquella inabilitat que li serà apposada, sien donades dues faues, una blanca e altra negra per lo escrivà a cascú conseller, e per ells meses secretament en un sach penjat publicament, e les blanques sien per los qui entendran deure a aquell no moure lo impediment e les negres per los qui entendran deureli obstar, e juren tots los consellers en poder del justícia que llealment votarà sobre lo dit feyt, tot ody, amor, sobomació, parentesch e altra rahó aparta posada solament a respecte del bé publich, e puys sien buydades les faves sobre la taula e comptades públicament e si seran més les blanques aquell impediment que serà stat posat a aquella persona o persones per lo batle, justícia o jurat no li moga a obtenir lo offici, si les negres seran més sia reppellit. E axí sia feta la dita clarifficatió abans de traure lo redolí. E si aprés tret lo redoli a algú serà posat algun impediment, puys tret serà no hoga abans sia publicat per al offici a que serà stat tret.

22. Impediments. Semblant del precedent dels que no poden esser a oflicis. ITTEM statuym ordenam que algu qui sera procurador de algun baró, cavaller, o prelat, o altre 
havent heretat tres llegues entom la dita vila, ni lo qui regira lo offici de subrogat, ni lo scrivă de les corts de la Govemació, del batle, ni del justicia, no pusca durant lo regiment de la dita subrogació, o procuració, o scrivanies de sus dites, ésser assumpt en algun dels dits ofñcis, abans si lo redolí de aquell, o aquells, serà stat tret sia tomat a cloure e tornat dins lo sach d'on serà tret, hon sia tret altre hon no sia algu dels dits impediments.

23. Quels jurats no puxen ser loctinents e que no's puxen donar licència a més de dos. ITTEM statuym e ordenam que algú dels jurats per alguna absència que faça, o altre ligíttim impediment que haia, no pusca fer loctinent, més que los altres hagen plenerament a exercer lo dit offici, axí com si tots fossen presents, emperò per proveyr que continuament haia en la dita vila qui regesca lo dit offici ab suffciència de número de persones, statuym e ordenam que los que seran assumps ab dit offici en la forma desús dita juren lo dia de Cinquagesma en poder del batle que no exiran de la dita vila, o ternens de aquella, sens haver licencia huns de altres, e que no donaran licència a més de dos en hun mateix temps, per que almenys s'en hagen a trobar continuament dos residens en la vila.

24. Sírıdico. Nominació de síndic per a alguna misatgeria. Que missatgeria no sia feta sens concòrdia de tot lo consell, e que no puxen ésser tramesos més de dos missatgers e com ha aportar memorial lo Missatger e que ha a fer. ITTEM, statuim e ordenam que alguna missatgeria, o missatgeries, no pusquen ésser fetes sens concòrdia de tot lo consell, o la maior part de aquell, e que per urgent necessitat que sia no pusquen esser tramesos més de dos missatgers, e aquestos s'en hagen aportar instructions de mà del scrívà, e signades de mà del jurat primer, de les coses per les quals seran tramesos. $\mathrm{E}$ hagen a notifficar al scrivà e al clavari lo dia e ora que partiran de la dita vila per anar a la dita missatgeria. E per semblant hagen a notificar al dit scrivà e fer scriure e al clavari lo dia e ora que tornaran de la dita missatgería, dins hun dia natural aprés que seran tomats. E hagen á fer relació als justícia, jurats e prohomens dins lo dit dia natural del que hauran fet en la dita missageria. E al primer Consell que's tendrà en públich consell. E si no compliran les dites coses que perden la meytat del salari de la dita missatgeria e sia adquisit al comú sens gràcia. 
25. Que no es puxa despachar albarà de major suma de la que no sia de ordes del concell. Quel scrívà no spache albarà sinó és manat per consell, e que sia signat de mà del jurat primer e que's faça registre de totes les letres. ITTEM, statuym e ordenam qu'el Scrivà no pusca spachar albarà de maior suma de cinch souls, sinó que sia provehit per tot lo consell e signat de mà del primer jurat. E que axí mateix sia tengut de registrar totes les letres, axí patens com secretes que seran trameses a qualsevol persona, o personas, per lo consell, o per los jurats, en nom de la vila, o jurats, e segellades ab lo segell de la vila, e si lo contrari farà que cometa crim de fals.

26. Que los jurats e clavari aprés finit son temps en lo primer consell notiffiquen que deu la vila e en quin punt és. ITTEM, statuym e ordenarn que los jurats e clavari en lo primer consell, aprés finit lo seu regíment, sien tenguts notificar e donar memorial als jurats e consell de aquell any començant tots los deutes que la vila deu e tots los qui són deguts a la vila, per manera que los qui novellament entren en regiment sapien lo stament en que la vila se trobara e donen rahó dels beneficis que en lo dia any per son regiment la vila haurà obtenguts.

27. El que serà tret a ofici o misatjeria la dega acceptar. Que aquell qui serà publicat a algun offici o misatgeria sia tengut acceptar ho, sots pena de vint morabatins. ITTEM, statuym e ordenam que quant algú serà publicat a algú offici e tret del redolí pera qualsevol offici, o missatgeria, que aquell offici o missatgeria sia tengut de acceptar, sots pena de vint morabatins, los quals sien adquisits al comú, e ultra sia tengut a tot lo dan que la vila sostendrà per la denegació que fara al dit offici, o missatgeria. Però que si haurà vacat en alguna missatgeria per spay de deu joms no pusca ésser forçat de altra missatgeria un mes aprés que serà tomat.

28. Que dels noms dels qui són en los sachs sia fet registre en un libre apart, e si la caixa era presa, o furtada, quin orde se deu tenir. ITTEM, per tal que en la electió de officials e en los altres actes que segons tenor de les presents ordinacios se deuen fer, per algunes persones malèvoles no sia feita, o procurada turbació, o empaig algú, e que no obstant tal empaig, o turbatió, les dites elections pusquen ésser deduides a degut effecte, statuim que los noms de aquelles persones que seran meses en los dits sachs sien scrites en lo Libre de la Vila per lo scrivà de aquella, designant lo nom de aquelles persones que són meses en cada un sach singularment. Así mateix se faça carta pública 
de aquelles, signada la qual lo dit notari continue en son protocol, e de la qual se meta un trasllat signat fe fahent en lo archiu de la dita vila. E volem e ordenam que si's sdevendrà en nengum temps la dita caixa ésser presa, amagada, empachada, cremada, o destroyda, o occupada per qualsevol jutge, jutges, o official, o privades persones, o per furt, roberia, avalot, o qualsevol altre cas, per impediment del qual la dita caixa no pusca ésser hauda e uberta libertament per ser los actes que fer se deuen, e aquell cas los noms de les persones que seran collocades en los dits sachs sien, de manament dels dits jurats e consellers, o de la maior partida d'ells, scrits en sengles cédules de pergamí per lo scrivà de la vila, públicament en consell, incluses cada una cèdula en son redolí de cera de una mateixa pes, color e forma, e los dits redolins sien mesos en altres sachs, rubricats, o intitulats, en la forma dels altres, cascú en aquell sach hon de primer era collocat. Dels quals sachs sien trets los redolíns pera fer los actes que fer se deuen, segons tenor de les presents ordinacions en la manera que desús és ordenada. Los quals actes hagen aquella mateixa valor que haurien si de la dita caixa los dits sachs fosen trets en la manera que desús és dita. E fets los dits actes sien tanquats e sagellats e mesos en la dita caixa, segons que los altres, e en lo dit archiu tomats.

29. Pare e fill, dos germans, dos cuñats no pugesen ser Jurats. Que dos propines parents en un mateix temps no pusquen ésser jurats. ITTEM, statuym e ordenam que en un mateix any pare e fill, ne dos germans, ne marits de dos germanes, ni sogre o gendre, no pusquen ésser jurats, abans si aprés que lo hu serà tret e publicat ne serà tret altre en que sia lo dit impediment, sia tomat en lo dit redolí e tornat en lo sach d'on serà stat tret, en sia tret altre.

30. Que si algú haurà un offici non puxe haver ne altre. E si algú serà ja posat en algun offici e aprés serà tret en altre offici, sia tomat en lo redolí e sien tret altre, com no sia rahó que per un mateix home sien regits dos officis.

\section{Que Ies ordinacions fetes per micer Giner Rabaça e en Guillem Serra sien servades} la hon no disponen les presents. ITTEM, statuym e ordenam que les ordinacions fetes en temps passat per micer Giner Rabaça e en Guillem Serra, comissaris per la Illustre Reyna dona Ehonor, loctinent general la donch, fetes e ordenades, sien servades sots incorrirnent de les penes alli aposades, tant emperò com seran vistes no contradir, o venir contra, a les presents ordinacions, o no seran libertats e drets del senyor Rey. 
32. De aquels que ses mulers per no pagar los deutes han repetir la dot, ne los qui han impretat guiatge no hagen officis ni sien admesos en aquells. ITTEM, statuim e ordenam que tots aquells dels quals les mullers, per no pagar los deutes que devien, o eren obligats, han repetides les dots o han del senyor Rey o Reyna o de nos obtengut carta de sobresehiment, o allongarnent, o guiatge de tres anys ençà, per no pagar los deutes que deuen, o són tenguts o obligats pagar, no puguen ésser admesos en los officis en les presents ordinacions expresats ni a missatgeries o conselleries del dit consell, tant com durara lo dit impediment.

33. Obligacions del escrivà. Quel scrivà sia tingut liurar en Io primer consell, aprés finit son temps, los actes continuats al scrivà novel. ITTEM statuym e ordenam que lo scriva del consell qui ara és, o per sdevenidor serà, sia tengut finit son any en lo primer consell que's celebrarà liurar tots e qualsevol actes que ell haurà rebut en lo seu any al scrivà que serà novament creat, continuats e notats stesarnent en son libre. E si açó no farà, que perda lo salari de tot l'any, del qual no li sia fins açó fet pagat cosa alguna, ni en lo cas quel deva perdre per la dita rahó li’n pusca ésser feta gràcia. E ultra açò sia compellit per lo loctinent de governador, o son subrogat, ab deguts remers a complir e de fer executar lo que dit és.

34. Del temps que han de començar les presents ordinacions. E volem e ordenam que los presents capítols e coses en aquells contengudes, se començen a praticar, e es tinguen e observen en la electió primer vinent faedora la vespra de Pentecostes primer següent en los officis de jurats, e altres que lo dit dia deuen ésser elegits, e de allí avant en tots los altres temps e actes dels quals per los dits capitols és dispost e ordenat, e duren per temps de deu anys primer següents. E aprés de passat lo dit temps, la revocació de aquells sia publicament notificada a veu de crida per la dita vila e lochs acostumats de aquella.

35. Salvetat a la vila en ses libertats. E per los presents capitols, e coses contengudes en aquells,no volem ni entenem en res derogar la dita vila en les facultats, e libertats que per furs e privilegis del present Regne e en altra manera li pertanyen sobre les elections dels officials ni en altra manera, ans volem aquells romanir illeses e ferms per a que, 
passat lo dit temps e revocat lo dit beneplàcit, la dita vila puga de aquells usar, axí com si'ls presents capítols, o actes que de aquells se seguiran fets no fosen.

36. Manament de servar les presents ordinacions. Les quals ordinacions, stabliments e capítols desús insertes e totes e sengles coses contengudes en aquells, vos manam que observets, acceptes, tingats e complescats ab les salvetats e reservacions desús expressades per lo temps dessús specifficat, e aprés tant com al senyor Rey plaurà axí com cosa molt útil, saludable, e expedient al servey del senyor Rey e ben avenir pau. tranquilitat e prosperitat de la dita vila. E que no façats ni permetats, o consentats ésser fet lo contrari, sots pena e indIgnacioó de la yra del senyor Rey, e de mil florins d'or de Aragó dels bens de cascú contrafaent havedors e aplicadors als cofrens de sa senyoria. Manams sots les dites penes als portantveus de nostre offici de govemador general, e als loctinents, o subrogats de aquells, batle general del Regne de Valencia e al batle de la dita vila, o altres qualsevol officials del senyor Rey e loctinents de aquells, als quals pertanyeran les coses dessús scrites, que res no façen, proveexquen, o enauten, contra les dites ordinacions, stabliments e capitols, ans que tota hora e quant per part de la dita vila, o de qualsevol dels singulars de aquella ne seran requests, los façen tenir e complir e observar inviolablement e proceexquen a execució de les dits penes, sens alguna venia e comport en los bens dels contrafahents, guardantse attentament de fer lo contrari. En testimoni de les quals coses manam ésser feta la present ab lo sagell del dit senyor Rey en pendent segellada. Dada en València a vint e dos dies del mes de maig en l'any de la Nativitat de nostre senyor Mil quatrecents quaranta e sis. E del Regne del dit senyor Rey de Sicilia deça far any dotze, e dels altres Regnes any trenta e hu. El Rey Johan: Dominus Rex Locumtenenty signata manis mihi Dominico Decho et viderunt eam Petrus de Bisulduvio, consevator generalis et Franciscus Masco, regii consiliari. De Bisuldubio conservator generalis Vidit Franciscus Masco, in diversorum locuntenety Valenti diu tertio.

Asi finis lo privilegi Senyor Rey Don Juan. (Anotación margen iziquierdo) 


\subsection{Documento 2: Proceso y Ordinaciones de 1590.}

1590, julio, 10. Valencia

Ed. Magín ARROYAS SERRANO: El Consell de Castellón en el siglo XVII. Diputación Provincial de Castellón. Castellón de la Plana. 1989, pp. 169-178 (Transcripción).

Ed. David BERNABÉ GIL: Privilegios de insaculación otorgados a municipios del Reino de Valencia en la Época Foral. Instituto Alicantino de Cultura Juan Gil-Albert y Diputación de Alicante. Alicante. 2012, pp. 225-240. (Transcripción).

Et pari modo, pro parte dicti Michaelis Jacobi Peris notarii dictae civitatis Valentiae, nomini síndici dictae villa de Castelló de la Plana, fuit coram nobis et in hoc S.S.R. Consilio Aragonum exhibita copia, cuiusdam Regiae sententiae latae per nostrum locumtenentem et capitaneum generalem et Regiam Audientiam dicti Regni Valentiae, die decimo tertio mensis januarii anni millesimi quingentesimi nonagesimi, circa observationem prae inserti privilegii et aliam copiam statutorum quae ordinavit et condidit Magnificus et dilectus consiliarius noster Licenciatus Didacus de Covarruvias, miles militae Beata Maria de Montesa et sancti Georgis de Alfama et regens Cancellarium in dicto nostro S.S.R. Aragonum Consilio tunc de Regia Audientia praedicti Regni Valentiae virtute praecalendate sententiae, et commisionis per lllustrem Marchione de Aytona tunc nostrorum locuntenentem et capitaneum generalem in dicto Valentiae Regno sibi atribute cuius data est in civitate Valentiae dio quinto mensis junii dicti anni millesimi quingentesirni nonagesimi, et dictarum sententiae commissionis et statutorum tenor talis est:

TÍtol de la insaculació

Inseculatio per als oflicis de la vila de Castelló de la Plana, ordinations y statuTs a aquella concernems, fetes e fets per lo molt magnifich Licenciado Diego de Covarruvias cavaller, altre dels molts magnifics doctors de la Real Audiència civil de la ciutat i Regne de Valentia y comissari real per a dit effecte per sa Excellència i dita Real Audiència elet y nomenat.

In dei nomine amen, anno a nativitate Domini millesimo quingentesimo nonagesimo, die vero intitulato duodecimo mensis Juliii. Lo molt magnífich Licentiado Diego de 
Covarruvias, cavaller, altres dels molts magnífichs doctors de la Real Audièntia Civil que's celebra en la ciutat y Regne de Valèntia, constihuit personalment en la present vila de Castelló. en virtud de una sentència real publicada per Francesc Pau Abreus, scrivà de manament, a tretze del mes de giner del present any, la qual és del serie i tenor inmediate següent:

Tenor de la Sentencia.

Attento quod Serenissimus Rex Joannes cum suo privilegio conceso justitiae, juratis, consilio et universitati dictae villae Castelionis Planictei, datti Valentiae die vigessimo secundo mensis maii anni millesimo quadrigentesimi quadragesirni sexti ad instanciam sindicorum dictae villae et pro bono publico illius, et pacis et concordiae vicinorum insaculationem concessit quod future illius officialium electiones fierent per nominorum inseculationem et globorum cere vulgo redolins vocatorum corum demque extrationem modo et forma contentis in dicto regio privilegio, quae forma creandi officiales ad regimen díctae villae fuit per multos annos in dicta villa obselvata. Attento praeterea quod et si dicti justicia, jurati et consilium dictae villae multis ab eius retio annis praeter missa dicta forma creandi offciales per extractionem ex dictis sacis, eos creaverint per arbitrium et electionem tamen considerantes quod ex dictis electionibus dictorum officialiu suscitate fuerunt multe et graves inimicitiae inter habitatores dictae villae. et quod sperantur sequi alie maiores et potenint sequi alia incommoda et scandala habito in dicta villa, consilio die vigessimo novembris anni proxime elapsi decreverunt ad vitanda dicta incommoda et alia grandivia futuras dictorurn officialium creationes per nominum inseculationem et eorundem extractionem fiere debere id quod fuit perdictum Michaelem Jacobum Peris, notarium Sindicum dictae villae supplicatum nobis et Regiae Audientiae, cum supplicatione posita die vigessima quarta dictorum mensis et anni. id circo et aliis conclusionem et deliberationem in Regio Consilio factam, insequendo pronunciamus, sentenciamus et praedictis justitiae, juratis et consilio dictae villae licentiam permisum et facultatem concedimus (durante nostra mera et libera voluntate) electiones officialium dictae villae facere per modum inseculationis et extractionis nominum personarum a saccis sine numeris, ln quibus nomina praedicta reponantur juxta formam seríem et tenorem dicti regii privilegii et arbitrium nostrum et Regiae Audientiae. Mandantes quod relatori huius cause fiat comissio qui accedens ad dictam vullam, dictas inseculationes faciat de personis qui 
concurrere habent ad dicta officia collocando unumquenque in illum sacuim et numenam et Iocumquem qualitas illius exposset, et prescribendo ordinem et formam servandum in dictis inseculationibus et extractionibus interponendo pro ut cum presenti interponimus in praedictis personarum seu nominum illarum inseculationibus, extractionibus et aliis omnibus super praemissis faciendis nunc protunc regiam auctoritatem pariter et decretum et denique neutram parlem in expensis condempnamus. Pasqual Rexens, Vidit Banyatos, Vidit Vives, Vidit Covarruvias, Vidit Auzina, Vidit Sen Joan, fisci patrimonii Advocatus. E.

Concessió a ell feta dattis en la ciutat de València en cinch dies del mes de Junii proxime passat, la qual és del tenor seguent:

Tenor de la comissió de Covarruvias.

DON PHELIPP, per la gràcia de Déu Rey de Castella, de Aragó, de Lleó, de les dos Sicilias, de Hierusalem, de Portugal, de Navarra, ettc.

E per sa Magestat, Don Francisco de Moncada, marqués de Ayatona, compte de Ossona, viscompte de Cabrera y de Bas, gran senescal de Aragó, loctinent y capità general en lo present Regne de Valèntia.

Al magnifich i amat conseller de sa Magestat micer Diego de Covarruvias, altre dels magnífichs doctors del Real Conçell civil, salud i real dilectió.

Per quant $a b$ real sentència en tretze dies del mes de giner propasat del present $\mathrm{i}$ corrent any, publicada en lo procés i causa que en la Real Audiència sea portat i tratat per i entre Miquel Hierony Sent Joan, nottari procurador de Llorens Sistemas, ciutadà, Gaspar Jover, doctor en medicina, i altres particulars de la villa de Castelló de la Plana, de una, i Miquel Jaume Peris, notari síndich de la universitat de dita vila e lo procurador patrimonial de sa Magestat de part altra, és estat pronunciat i declarat per les causes. rahons e motius en dita real sentència contenguts, donant e concedint licèntia permís $i$ facultat al justícia, jurats i consell de dita vila de Castelló, durant nostra mera i libera voluntat, per a que puixen fer e facen les elections dels officials de aquella per a el regiment de dita vila per modo de inseculació de redolins i extractió de noms i persones, 
juxta lo serie, forma e tenor del real privilegi per lo sereníssim Rey Don Joan als justícia, jurats, consell y universitat de dita vila concedit y otorgat, a vintidós de maig del anny mil quatrecents quarenta i sis, y a arbitre nostre i de la Real Audiència, manant per a dit effecte ésser vos despachades les presents, segons que dites coses en dita real sentència pus largament són contengudes. Perço, per deguda executió de dita real sentència, la qual en sa pública i auctèntica forma, apart de les presents, havem manat traure i liurar a instància e humil supplicació del dit Jaume Peris notari, en lo dit nom expressament, i de nostra certa scientia delliberadament consulta, e per la real autoridad vos diem, cometem i manam que ensemps ab un alguazir, notari i scrivà de dita causa $\mathrm{e}$ ministres de justícia necessaris y oportuns, vos conferixcau i aneu personalment a la dita vila de Castelló de la Plana i hon sia necessari i convinga, i allí constituhit i executat la dita real sentència fareu inseculació de redolins dels noms i persones que poden $\mathrm{i}$ dehuen concórrer als officis de dita vila i regiment de aquella, collocant a cascú en Ia bolsa, o sach, conforme la qualitat de cascuna de Ies persones que han de concórrer, ordenant i redigint en scrits l'orde i forma que de huy avant s'ha de guardar en les extractions fahedores de les persones que han de regir dita vila, interposant com interposam en dites elections per vos fahedores i en lo demés que acerca del que dit és ser convindra les nostres autoritat i decret reals ab les mateixes presents, per les quals diem i manam a universes e sengles officials dins lo dit present Regne constituhits e constituhidors, que sots pena de cinch cents florins de or de Aragó als reals cofres aplicadors i dels bens dels contrafaents exegidors, en fer effectuar i cumplir lo que dit és no us enpach, ni contradictió alguna facen, ans vos asisteixquen, i als manaments vestres com als nostres obtemperen tos temps que per Cort vostra manat serà.

Dattis en la ciutat de València en cinch dies del mes de juni del any mil cinchcents noranta.

Pasqual Rexens, Vidit Covarruvias, Vidit Sent Joan fisci patrimonii advocatus; in diversorum quinquagesimo tertio, foleo centesimo octuagesimo primo.

Essent primer plenament informat, precehint diligent examen de les persones ydònees i sufficients per als officis de la present vila, qualitat, experiència, intelligència i altres parts de aquelles, provehi feu i ordena a la inseculatió per als officis de la present vila en la forma i modo per los capítols inmediate seguents declaradora: 


\section{Ordinación de Covarrubias dada en 1590}

\section{Insaculació}

E primerament, de cavallers i generosos nomena per als oficis de justícia, jurat en cap, mustaçaf, consellers, de present à Pere de Reus, ettc. Los noms dels quals ordena i mana ésser continuats per lo scrivà de la sala de dita vila en un llibre per a d'açò especialment diputat, junctament ab les ordinations infrasegüents, e los mateixos noms, cascú per si scrits en cédules de pergamí i aquelles intercluses en redolins de cera vermella de un mateix pes i figura, e aquelles mesas en sos sachs en esta forma, ço és, los sobredits noms de generosos i cavallers en un sach intitulat sach de generosos i cavallers per als ofificis de justícia, jurat en cap, mostaçaf e consellers, de tal manera que lo dit sach en effecte serveixca de quatre sachs; e los noms de les persones del bras real inseculades per al officis de jurat en cap, per lo semblant, sien scrits en sengles cédules de pergamí, e cada una de aquelles inclusa en un redolí de cera vermella de un mateix pes e forma, e sien mesas en un altre sach intitulat sach de jurat primer del bras real. E axí mateix sien fets redolins en que sien incluses cédules hon sien los noms dels inseculats al offici de jurat segon, e aquelles posats en un altre sach intitulat de jurat segon. E altres redolins en que sien incluses cédules hon sien los noms dels inseculats per al offici de jurat tercer i quart, e aquells mesos en altre sach intitulat sach de tercer i quart. E altres redolins en que sien incluses cédules hon sien los noms dels notaris inseculats per al offici de scrivà, i aquells mesos en un sach intitulat sach de scrivà de jurats i consell, e altres redolins en que sien incluses hon sien los noms de les persones inseculades per al offici de mostaçaf $i$ aquelles mesas en un altre sach intitulat sach de mustaçaf. E altres redolins en que sien incluses cédules hon sien los noms de les persones insaculades per a justícia, e aquells mesas en un altre sach intitulat sach de justícia, e altres redolins en que sien incluses cédules hon sien los noms de les persones insaculades per a ésser cequiers de dita vila $\mathrm{i}$ aquelles meses en un sach intitulat sach de çequiers, e altres redolins en que sien incluses cédules hon sien los noms de les persones inseculades per a ésser consellers, axí de mà major com de mà menor, e aquells posats en altre sach que tinga dos compartiments, hu per als redolins de mà major i menor respective. Les quals boses eo sachs, aprés que posats i seran dits redolins, sien tancades i sagellades felment ab lo segell de dita vila.

Caixa dels insaculats i claus de aquella. 
Ittem statuys, ordena i mana que per custòdia i guarda de dits sachs sia feta una caixa ab quatre panys i claus, hon sien posats i tancats dits sahcs, los quals tinguen e ajen de tenir les persones nomenades en los seté capitol del real privilegi dels sachs otorgat per lo Serenissim Rey Don Juan, donat en València a ventidos dies del mes de maig del any Mil quatrecents quaranta sis, ço és, la una de aquelles lo batle de dita vila, o son loctinent, la altra lo loctinent de governador, o son subrogat, la altra lo justícia e altra los jurat en cap del bras real. La qual caixa sia mesa en lo archiu de la casa del consell de dita vila, la clau del qual archiu tinga lo escrivà del consell, los quals dits loctinent de governador, eo subrogat, batle eo son loctinent, justícia i jurat en cap hajen de jurar i juren quant s'els entreguen dites claus lo contengut en los capítols huit i nou del dit real privilegi, i en lo modo i forma en aquells contengut, los quals són del serie i tenor següent.

Comanda de claus i obligació dels que les tenen

ITTEM, statuim i ordenam que quant les claus de la dita caixa se acomanaran quel loctinent de governador, o son subrogat, sia tengut jurar en poder del batle de la dita vila, e lo batle, justícia, jurat e scrivà en poder del dit loctinent, eo subrogat, a prestar sagrament e homenatge de haverse bé e llealment en la guarda e custòdia de la dita caixa, e que per si ni per altre, públicament ni oculta, no obriran ni obrir faran ni concluiran, o permetran que sia uberta la dita caixa, sinó en los casos e formes en les presents ordinations contengudes i ordenades, e que cada hora e quant la dita caixa segons, tenor de les dites ordinacions, obrir se deurà, portaran les claus sen difficultat ni dilació alguna per a obrir la dita ciaxa en la manera en les presents ordinacions contenguda e que directament, o indirecta, públicament ni oculta, no daran, faran ni procuraran ni consentiran que sia feyt dany ni procurat impediment algú, per lo qual la dita caixa no sia uberta ab les dites claus, en los casos e forma en les presents ordinacions compreses e ordenades, e si lo contrari fahiren que pusca ésser procehit contra ells així com a trencadors de sagrament e homenatge, e executió de pena capital per ésser torbadors de bon stament públich, e privats de officis e beneficis ad imperpetuum de la dita vila.

ITTEM, si's devendrà lo dit loctinent de governador, o subrogat, absentarse de la dita vila o son terme, per algun cas, ans que parteixca de aquella sia tengut de acomanar la clau a altri qui romandrà subrogat per absència sua, presens los jurats de la dita vila, o la 
major part, mitjançant lo sagrament e homenatge en lo precedent capítol ordenat, la qual comanda lo dit subrogat sia tengut en si pendre e prestar lo dit sagrament e homentage, e axí mateix si's sdevendrà lo batle e justícia absentarse, sien tenguts en la manera desús dita acomanar les claus a sos loctinents, e si lo jurat eixirà fora de la vila, o son terme, sia tengut acomanar la dita clan al jurat segon, si serà en la dita vila, e si no i serà al hu dels altres jurats en la forma e manera desús dita, la qual volem sia acomanada present lo justícia e los altres jurats, ab lo sagrament e homentage desús expresats ans que parteixca de la dita vila, e si lo escrivà s'es devendrà absentarse sia tengut acomanar la clau del archiu al jurat segon, o a un altre jurat que no tinga clau alguna, en e per la forma desús dita, és emperò nostra intenció que persona alguna pusca tenir sino una clan de la dita caixa o archiu, e quant los dits absent, o absents seran tornats a la dita vila, volem que les dites claus los sien tornades en la dita forma.

Que no's faça insaculació sino per la Audiència Real

ITTEM, statuix, ordena i mana que les dites persones inseculades i no de altres algunes se fasen les extractions per a dits officis respective, sots decret de nulitat i de mil florins d'or dels bens dels contrafaents exegidors, si ya altra cosa per sa Magestat, o per son loctinent general Real Audiència no fos provehit, e per si cas pareixera al consell de dita vila en lo esdevenidor deurés fer algunes promocions dels inseculats en un sach e altre sach major, o de més preheminent offici, o ultra de les personas que de present estan inseculades en los dits sachs per als dits officis se trobaran en lo esdevenidor persones noves no impedides, dignes e àbils per a dits officis, o algú de dits sachs per mort de les persones en aquell inseculades, aut aliis, vendrà a tal evacuatió que sia necessari fer nova inseculatió de alguna, o de algunes persones, en qualsevol de dits casos statuix, ordena y mana dita promoció, o nova insaculatió, haverse de fer i que's fasa en lo modo i forma i de les persones per sa Magestat, o son loctinent general y Real Audiencia nomenadores e ordenadora, e no altra manera, per convenir així al bé comun de dita vila, sots decrets de nulitat e mil florins de or, applicadors ut supra e altres penes a arbitre de sa Excellència i Real Consell imposadores.

Forma de les extractions

ITTEM statuix, ordena i mana, que en la vespra de Pascua de Sperit Sant, en la qual per furs e pràctica del present Regne de Valèntia se deu fer electió de jurats, e en tots aquells altres dies que per los dits furs e practica e ordinations de la dita vila se ha a fer 
electió de justícia, mostaçaf, scrivà, cequier e concellers, se guarde en la extractió de aquelles i creació la forma,modo i manera satuida i ordenada en los capitols primer, catorze, quinze, e setze de dit real privilegi, a saber és que lo loctinent de governador, o son subrogat, batle, justícia i jurat manen fer traure en presèntia de tot lo consell la caixa de dits sachs, e los qui tendran les claus de aquella obren dita caixa e lo jurat en cap dels ciutadans traga aquell sach o sachs de aquell Office que se haurà a publicar, e sien contats tots los redolins que en aquells seran atrobats públicament davant tot lo consell, per un fadri de deu anys poch mes o menys, e per aquell mateix, posats en un basí ple de aigua, e aprés per el mateix sia tret per a offici de justícia un redolí, e per a offici de mustaçaf un altre, e per a offici de jurat en cap un altre, e per a offici de jurat segon un altre, e per a offici de jurat tercer y quart dos, e per a offici de scrivà un altre, e per a offici de cequier un altre, e aquel sia liurat al batle, o al justícia, o al jurat en cap, ad aquell que conforme al offici que se ha de publicar s'esguardarà, lo qual mostrades les mans sea arromangades les polaines, sia tengut de ubrir lo dit redoli e traure la cèdula que dins serà estada posada, e públicament sia per aquell legida e publicats aquells que seran Justícia, jurat, mostaçaf, çequier o escrivà per al any següent ab alta veu, que tots los que seran en lo dit consell ho pugen hoir, aqui mateix liure la çèdula al scrivà, lo qual farà públicament un altre redolí de çera, e aquell que serà scrit en la dita cèdula sia tornat dins lo dit redolí, e sia lo dit redoli tornat en lo sach e aprés sia lo dit sach segellat e mes en la dita caixa com de primer, e la caixa tancada e tornada en lo archiu.

Any de militars

E açò entés i declarat que lo any que, per lo fur vintihuit título de curia et baiulo in novis, pertanyera la electió de offici de justícia, mustaçaf e jurat en cap als cavallers, dit offici se traga del sach dels cavallers i generosos. E l'any que serà tret jurat en cap cavaller vaque lo offici de jurat segon, e solament sia tret en cap del bras real, tercer i quart, per quant ab lo dit generós i cavaller seran número de quatre.

Agraduació de jurats

I en la graduació del offici de jurat tercer i quart se guarde lo dispost en lo fur vintitres, en orde en los furs nous feyts en lo anys mil cinchcents huitanta cinch, ço és, que dels dos que seran extrets del dit sach sia jurat tercer lo que més voltes serà estat jurat, $\mathrm{i}$ en cas que nengú dels dos ho sia stat, sia jurat tercer lo major de aquells en edad; e lo mateix orde se guarde en la extractió de concellers, que és lo dispost en los consellers 
sobre dits officis, los quals sien i ajen de ser trenta hu en número, ço és, los quatre jurats vells, síndich vell i novell, justícia, mustacaf i scrivà vells, e los demés sien trets dels sachs de consellers, ço és, generosos cascun any, o cavallers, de la bosa o sach de generosos sia trobats hi seran no impedits, e los demés sien estrets dels sachs dels concellers, ço és, la mitad de concellers de mà major, e l'altra mitad de concellers de mà menor, e si no seran pares los que han de ser extrets, lo hu que ha de ser demés sia pres dels de mà major, tots los quals han de ser convocats $\mathrm{i}$ ab que sien presents vintihu i no menys se puixa tenir consell, i la determinació a los que la major part de aquells que entrevindrà en dit consell haurà resolt y determinat, los quals officials i consellers sien tenguts prestar lo jurament acostumat en poder de la persona a qui pertanyera, conforme als capítols quintze i setze del dit real privilegi.

\section{Officis de electió}

ITTEM statuix, ordena i mana que per quant en los officis de síndich, clavari, sacristà, manobrer y misatger apar no poderse comodament fer elections, o extractions, de persones idones y sufficients per via de inseculacions en sach i extractions de aquelles, anes convenir més al bé publich de dita vila i seguritat de les pecunies de aquella ferse en lo modo i manera que hui en dia se fan i creien persones per a dits officis. Per ço, ordena se crehen aquelles en lo sdevenidor en lo modo i manera acostumats fins a huy, $\mathrm{i}$ guardant acerca de dits officis lo que esta disposat en lo capítol del dit real privilegi respectant al offici de síndich, lo qual es del serie i tenor següent:

\section{Jurament i obligacions del syndich}

E lo clavari jur e fasa sagarament, per lo primer mes de dembre aprés serà stat posat en lo dit offici, executarà ab acabament tota la resta que lo clavari abans d'ell serà trobat tornador, e rebra e haurà rebut Compte, ab tot compliment del dit clavari a ell, en los primers de noembre aprés finit lo seu regiment, executarà ab tot compliment lo peiter e sisers mayors e del peix, en collector de la peyta que's pertany a rebre a ell lo Compte, e tornar la resta a ell retre lo compte de sa administració, e pagarà ab tot compliment al clavari aprés dell tot lo que serà vist tornador si muntara ne en suma de mil sous per tot lo mes de dembre aprés següent, i si muntara a més de summa mil sous que dins lo dit terme fasa de aquells quitament dels censals carregats sobre la dita universitat a qui més gràcia li farà, e si no cumplira les dites coses que encorrega la pena de perjur e perda lo salari que per la administració del dit offici devia haver, e sia privat a deu anys de tot 
offici e benefici, asó sens remissió e gràcia, e que en lo primer consell aprés la festa de Quinquagèsima lo justicia, jurats, y consell juren que no donaran empaig per algú per que los sisers e peiters no sien executats, abans en lo que a ells se pertanyera en ésser als Comptes e altres favors necessaries prestant tot consell, favor e ajuda que menester serà, per a que en los dits terminis, o abans, los dits comptes sien rebuts, e los dits sisers, peiters e clavari del any pasat sien executats, e lo quitament fet segons és dit, e si lo contrari faran que encorreguen la dita pena de perjurs e perden los salaris que per los dits officis deuran haver, e sien privats a deu anys dels officis e beneficis de la dita vila.

Dels Misatgers i ses obligacions

E lo que està ordenat en lo capítol veintiquatre de dit privilegi respectan los misatgers, lo qual és del serie i tenor següent: ITTEM statuhim e ordenam que alguna misatgeria, o misatgeries, nos pusquen ésser fetes sens concòrdia de tot lo consell, o la major part de aquell, e que per urgent necessitat que sie no pusquen ésser tramesos més de dos misatgers, e aquestos se'n ajen de portar instructions de mà del scrivà e firmades de mà del jurat primer de les coses per les quals seran tramesos, e ajen de notificar al scrivà e al clavari lo dia e hora que partiran de la dita vila per anar a la dita misatgeria, e per semblant ajen a notificar al dit scrivà e fer scriure e al Clavari lo dia e hora ques tornaran de la dita mitsageria dins un dia natural, e aprés que seran tornats e hajen a fer reclació als justícia, jurats e prohomes dins lo dit dia natural del que hauran fet en la dita misatgeria e al primer consell que's tendrà en públich consell, e si no cumpliran les dites coses que perden la meytat del salari de la dita Misatgeria e sia adquisit al comun sens gràcia.

\section{Vacació de officis}

ITTEM statuix, ordena y mana que aquell que haurà regit algú dels sobre dits officis de justícia, jurat, mustaçaf e clavari, síndich, segrestà e çequier, no puixa tenir ni tornar a regir el mateix offici sinó passats dos anys primer vinents aprés de finit lo temps de dit son offici, ni puixca en lo mateix temps regir dos officis, ni lo conseller puixa ésser conseller més de dos anys continuos, tots los quals officis duren i ajen de durar per temps de un any tan solament, excepto lo offici de scrivà que dure per temps de dos anys tan solament.

Qui no puguen ser officials en un mateix any. 
ITTEM statueix, ordena y mana que un mateix any pare e fill, ne dos germans, ne dos cuñats, ne marits de dos germanes, ni sogre ni gendre no puixen ésser jurats, ans si aprés que lo hu serà tret e publicat ixqués lo altre en lo qual sia lo dit impediment, tornat en lo dit redolí e tornat a posar en lo sach de hon sera estat tret e sia tret altre redolí.

Quins bens deguen tenir per a concórrer als officis

ITTEM statueix, ordena i mana que les persones que han ésser assumpts en los officis de justícia, jurat, musataçaf, síndich, clavari, scrivà, o sacristà, cequier haja haver i possehir clars bens valents vint milia sous, e si no'ls hauran que no i puixen ser admesos e los Consellers hajen de haver deu milia sous.

\section{Impediments per als officis}

ITTEM statuix, ordena i mana que no puxen ser admesos a dits officis los que seran impedits per algun just impediment, declarant ser justs impediment com ab lo present així los contenguts en los capítols vintihu, vintidos e tranta dos del dit Real Privilegi, com en los capítols vuité i nové del nou regiment de dita vila, és a saber, sisers, arrendadors de les sises majors, o del peix, o los collectors de les peytes, o fermances de aquells, ab esta modificació, que les dites fermances no sien inhàbils per a entrar en officis durant lo temps del arrendament de sises, colleta de peites, sinó tan solament finit lo dit arendament, o colecta, i en cas que dit siser o peiter sia deutor a la vila, e així mateix qualsevol deutor a la vila per resta de alguna administració, o altra qualsevol rahó, y la fermansa de aquell no puga ser admés a algú de dits officis si no pagada dita resta, declarant no ser legítima paga en aquestos lo que's fa per vi de carregament de censal, o per adosació, o transportatió o consIgnacioó de algun censal o debitori, ni home que sia en plet ab la vila, ni deutor a sa Magestat, ni denunciat del agun crim que no sia abolit, o absolt, ab tal que la denunciatió sia per crim evident o manifest, e no posada affectadament, ni home que sia en bando manifest ab altre veí de la dita vila, ni procurador ni advocat de algun baró, cavaller, o prelat, o altre havent heretat tres llegües en torn la dita vila ni encara si no tres anys aprés finida la dita procuratió y advocatió, ni lo que regira el offici de subrogat ni son assessor ni lo scrivà de les corts de la gobernació, del batlle ni del justícia, ni aquell que haurà fet pagament a sa muller, o a obtés carta de sobresehiment e longament, o guiatge per no pagar sos deutes, ni señor de Molí, pugar ser jurat, mustaçaf ni cequier, puga emperò ser justícia de dita vila,ni lo señor de bestiar no puga ser justicia, mas puga ser jurat i mustaçaf, ordenant que para la 
proposició e determinació de dits impediments se guarde lo dispost en lo dit capítol vintihú de dit real privilegi, lo qual és del serie i tenor següent. Comensant en lo versiculo volem emperò que sobre la clarificatió de aquestos dubtes per remoure tota via de discordia, sia servada tal orde sobre la clarificatió de aquestos duptes per remoure tota via de discordia, sia servada tal orde que en lo principio del consell, abans de traure los redolins de que's deurà fer la electió a offici, o officis, lo batle declare e sia tengut declarar públicament en consell qui són aquells quin són deutors al Rey, per que no deguen ésser rebuts, e ell e lo justícia diga aquells quin són denuntiats, o en bandositat, e lo jurat primer declare qui són los deutors a la vila, o que pledejen ab aquella, e aquí si clarament constarà al consell ésser impedits sien haguts per inhàbils a obtenir lo offici o officis, que's dehuen publicar, e si vendrà en dubte, o discrepatió, que algú dels que voldrà ésser donats per inhàbils per alguna de les sises desús dites sia culpable, o no, en aquella inhabilitat que li serà aposada, sien donades dues faves, un blanca e altra negra, per lo scrivà a cascun conseller e per ells mese secretament en un sach penjat, públicament, e les blanques sien per lo que entredran deure e aquell no aoure lo impediment, e les negres per los qui entendran deureli obstar, e juren tots los consellers en poder del justícia que lealment votaran sobre lo dit feit, tot hoy, amor, sobornació, parentesch e altra rahó apart posada, solament a respecte del bé públich, e puis sien buidades les faves sobre la taula comptades públicament, e si seran més les blanques aquell impediment que serà stat posat a aquella persona, o personas, per lo batle, justícia, o jurat no li noga a obtenir lo offici.

\section{Escrito en el margen del artículo anterior}

[Amo de moli no puge servir officis de Jurat, Mustasaf ni Sequier.]

[Amo de Bestiars no puga ser Justicia

[Forma de la terminació dels impediments]

Quant se faça la dita determinació

E si les negres seran més sia repellit així sia feta la dita clarificació abans de traure lo redolí, e si aprés tret lo redolí a algú serà posat algun impediment, puix tret serà no noga, abans sia publicat per al offici a que serà estat tret.

Qui deguen eixir del consell quant se vota 
Aço emperò ajustat que tots temps i quant se tratara de interesos de algú dels particulars que asistiran en dit consell, o de pare, fill, o germà, sogre, gendre o cunyat, aquell tal o tals, ajen de eixir fora de dit consell mentres que's vota dit impediment, e si aquell tal, o tals, seran concellers en lloch de aquell, o aquells, sien extrets del sach dels consellers tants quants seran los que hauran se'n hauran eixit, y aquells tals axí extrets sien consellers per a dit effecte tan solament, lo qual se fasa en los casos graves e coneguda del dit consell.

Ques guarden los capitols ací contenguts

ITTEM statuix, ordena i mana que lo dispost en los capitols vintitres, vintiquatre, vinticich, $i$ vintisis i trentatres de dit real privilegi se guarde i observe com en aquells està dispost, per convenir molt al bé comun de dita vila, sots pena de cent liures applicadores ut supra.

De lo que no està dispost en les presents ordinacions

ITTEM statuix, ordena i mana que les altres coses que per los presents capítols no seran ordenades ni provehides, sien fetes segons dit real privilegi, nou regiment, furs e privilegis usos i bons costums del present Regne i dita vila com deguen guardarse les presents Ordinacions.

com deguen guardarse les presents ordinacions

ITTEM statuix, ordena i mana que os presents capítols e coses en aquell contengudes se comencen a practicar, estiguen i observen en la electió primer vinent fahedora en lo present dia de hui en los officis de jurats e altres que deuran ésser elegits, e de alli avant en tots los altres temps e actes dels quals per los dits capitols és dipost i ordenat, e fins altra cosa per sa Magestat, o son Loctinent general i Real Audiència, sia provehit i ordenat, sots decret de nullitat e pena de Mil florins de or e altres penes aplicadores ut supra. Vidit Covarrubias.

Liurament de aquelles y publicació

Deinde auten dicto et eodem die intitulato duo decimo mensis de Juliy que iam dicto millesinmo quingentesimo nonagesimo. Les prop dites inseculatió, status i ordinacions de mananment del dit molt magnífich licenciado Diego de Covarrubias, cavaller 
comissari real, qui desús i en presentia de sa señoria, per mi Andreu Cristòfol de Rocafull, notario publich de la ciutat i Regne de València i altre dels scrivans de la dita Real Audiència en les causes civil, foren lectes ab alta e inteligible veu de la primera linea fins a la darrera, intimades i notificades als magnífichs Lorens Sisternés justícia, Narsis Feliu ciutadà, Joan Castell i Gaspar Brunell, notaris, jurats, Miquel Juan Català, mustaçaf, Joseph Mas, notari, syndich, Joan Geroni Folch notari, scrivà de la sala de la present vila de Castelló de la Plana i altre prohomens i consellers de dita vila, ajuntats i congregats en la sala eo palau de dita vila, hon se acostuma a juntar i tenir lo consell de dita vila, essent present en dita sala i consell los magnífichs Miquel Arrufat subrogat de loctinent de governador en la dita e present vila, e Gerony Egual, ciutadà batle de aquella, e llestes, intimades i notificades les dites inseculatió, status i ordinations, lo dit molt magnifich real comissari liura i entrega, com liura i entrega les dites quatre claus, ço és la una al dit magnífich subrogat, l'altra al dit magnífich batle, l'altra al dit magnífich justicia e l'altra al dit magnífich Narsis Feliu, jurat en cap de la dita e present vila, juxta lo serie y tenor de dit real privilegi y de les dites ordinacions, status, dins la qual caixa hi havia nou sachs de tela vermella, cascú de aquells intitulat ab son rètul de pergamí, és a saber lo hu intitulat sach de generosos i cavallers per a justícia, jurat en cap y mustaçaf, lo altre intitulat sach de jurat en cap del bras real, lo altre sach de jurat segon, lo altre de jurat tercer i quart, lo altre sach de scrivà, lo altre sach de Justícia, lo altre sach de mustaçaf, lo altre sach de çequier, e l'altre sach de consellers ab dos compartiments, lo hu de mà major i lo altre de mà menor, dins los quals estaven posats los redolins de cera vermella $\mathrm{i}$ en los dits redolins meses e incluses cèdules de pergamí $\mathrm{i}$ en aquells scrits los noms de respectivament de tots sobredits i nomenats respective perals dits officis, conforme lo orde contengunt i expressat en les dites insaculatió e ordinacions. Manant sa señoria, segons que mana a tots sobredits e sots les penes en los capítols de dites ordinacions i status contengudes i apposades, que així en la creació del offici de jurats en lo present dia de hui fahedora, com en totes les demés creations i extraccions de officis pera la present vila que de hui avant in eventum se's faran, guarde, observen, e tinguen ad unquem la forma, modo i orde en les dites ordinacions y status contenguts y expresats e justa la serie i tenor de aquells, e si e segons los dits capitols i en cascú de aquelles està dispost e ordenat fins altrà mèrit per sa Magestat, o son loctinent general i Real Audiència fos provehit i manat. De totes les quals coses lo dit molt magnífich comissari real mana a mi dit notari i scrivà, ne rebés i continuàs acte públich per haverne memòria en lo sdevenidor, e que les dites inseculació, ordinacions i 
statuts ac omnibus inde seguits ne done e liure copia auténtica $\mathrm{i}$ fe fahient als dits magnífichs justícia, jurats, consell i síndich de dita vila, per als effectes desús dits e així per mi dit notari, inseguint lo dit manament de totes les dites coses e sengles de aquelles, ne fonch revut e continuat acte públich en los lochs, dia, mes e any desús dits. Presents foren per testimonis atotes les dires coses los magnífichs Andres Stevan, alguazil de sa Magestat i Joan Perez, scrivent e habitador de la Ciutat de València, atrobat en la dita vila de Castelló de la Plana.

Preinserta copia in his precedentibus qum decim papiro foleis presenti comprehenso contenta sumpta fuit atque de prompta ab originali regestio processus cuiusdam in Regia Audientia quae in civitae Valentiae celebratur in causis civilibus ventihati Inter Laurentiun Sisternés, Gasparem Jover medicinae doctorem et alios particulares oppidi Castillionis Planiciei, ab una, et sindicum universitaris dicti oppidi partibus, ex altera, apud Franciscum Joanem Ortiz nottary dicti processus scribam recondito per me, Andream Christophorum de Rocafull notarium publicum Valentiae aliumque ex scribis dictae Regiae Audientiae, et ut eidem copie ab ómnibus et ubique terramque fides plenaria absque aliqua dubitaciones valeat adhiberi, non obstantibus supra positis in folio septimo pagina prima, ubi supra ponuntur haec verba e aquells mesos en un altres sach intitulat sach tercer y quart, et eadem pagina ubi supra ponitur tos temps et foleo duodecimo pagina prima statuheix, et non obstantibus etiam aliquibus lineatis, ideo ego dictus Rocafull notarius, hic me suscribo et meum quo in similibus auctenticandis uti consveni appono et de pingo sig (+) num.

Lo present tresllat de mà de altri en les present onze cartes sorites stat tret e treslladat dels libre e registres del govern de la vila de Castelló de la Plana, recondits en lo archiu de dita vila, per mi Francesc Jover notari, scrivà del consell e jurats de dita vila, e perque ad aquell fe i sia atribuhida i donada, yo dit notari i scrivà, ací meso tascrich i pose mon acostumat de art de notari sig (+) num 


\subsection{Documento 3: Petición y Privilegio de 1597.}

1597, diciembre, 17. Madrid.

Ed. Magín ARROYAS SERRANO: El Consell de Castellón en el siglo XVII. Diputación Provincial de Castellón. Castellón de la Plana. 1989, pp. 178-183 (Transcripción).

Ed. David BERNABÉ GIL: Privilegios de insaculación otorgados a municipios del Reino de Valencia en la Época Foral. Instituto Alicantino de Cultura Juan Gil-Albert y Diputación de Alicante. Alicante. 2012, pp. 241-250. (Transcripción).

Relació de la nova suplicació.

Et ultimo, idem Michael Jacobus Peris, dicto nomine sindici villae de Castelló de la Plana, quandam nobis in dicto nostro S.S.R. Aragonum Consilio obtuhit supplicationem aliquibus capitulis distinctam cumqua petiyt praeinsertum privilegium serenissimi Regis Joannis et statuta per dictum Magnificum Didacum Covarrubias ordinata, juxta praesentis temporis ocurrentiam et necessitatem interpretari juxta formula in praedicta supplicatione et capitulis iLluís contemtam quam supplicationem in fine cuisque capituli decretan jussimus et dictae supplicationis capitolorum et decretorum in illis appositorum tenor talis est:

Tenor de la Supplicació.

Señor. Miquel Jaume Peris, notari síndich de la vila de Castelló de la Plana diu que per la Real Audiència de València se donà i promulgà certa sentència, manant per aquella se guardàs un privilegi que lo Rey Don Joan de gloriosa memòria concedí a la dita vila sobre la electió e insaculació de justícia, jurat, mustassaf, çequier i demés officials i conselleres consernens al govern de la dita vila, i en la dita sentència se dona commissió al regent Covarruvias, que huy o és del Supremo Consell i eo tunc oidor de la dita Real Audiència, per a que ordenàs lo convenient a les dites elections, de modo que cessassen los inconvenients que llavos se prestaren a la dita Real Audiència, per a que ordenàs lo convenient a les dites elections, de modo que cessassen los inconvenients que llavos se presentaren a la dita Real Audiència, i davant lo commissari lo qual posant en execució lo que és tunc paregue convenientissim feu certes ordinacions, les quals sens dupte 
foren bastants i o eren llavors per al bon govern i regiment de la dita vila, però de llavors ensà, per coses que han succeehit, ha paregut tenir necessitat declaracions i enmiendes, per a que ab aquelles se puga conseguir lo fi pretés per la dita vila, que és acertar a que se eligesquen tals persones per a son govern, les quals sien celoses de la cosa pública y del servici de nostre senyor Déu y de Vostra Magestat, i a la pau i quietud dels vehins de ella, per al qual lo dit síndich representa a Vostra Magestat los capítols següents, en los quals representa los danys e inconvenients que offereixen i lo modo fàcil que tenen per a son remey, essent Vostra Magestat servit manarlos obeir.

\section{Confirmació del Privilegi del Rey don Joan en certa forma}

Plau a sa Magestat confirmar lo privilegi del sereníssim Rey Don Joan, en quant la vila ne està en possesió, conforme a la sentència de la Real Audiència de València, publicada en tretze del mes de giner del any mil cinchcents i noranta, i al orde i forma que donà en virtud d'ella lo relator de la causa en dotze del mes de juliol del dit any mil cinchcents noranta.

Quins bens han de tenir los que concurren als officis.

Primerament, diu que per ordinacions antigües i per la octava feta per lo dit regent, està dispost que los consellers hajen de tenir de açienda fins cinchcentes lliures reals de València, augmentan fins a dita cantitat los dos milia sous que ans estava ordenat per la dita antiga ordinació, i així mateix se augmenta a mil liures per dit regent la cantitat de açienda que han de tenir los demés officials que eren ans quatre milia sous, i encara que est augment fonch bastant, i o és ara per als naturals de la vila, pera la forma de esta liquidació se fan molts fraus, volent pasar en esta quantitat los dots de ses mullers i los bens vinclats i subjectes a restitució, i succehint lo cas per al qual se preten que los tals officials tinguen tal açienda, que és per mala administració i com esta no’s puga traure dels dits bens vinclats i les dots de les mullers són preferides, resta la dita vila sens la causió necessaria i en cas que succedís la dita mala administració, la dita vila restaria sens ninguna manera de obligació ne resguart, per lo qual pareix seria fàcil remey $\mathrm{i}$ encara necessari, añadint i declarant la dita octava declaració del dit regent de Covarrubias, manar que les dites cinchcents liures dels dits consellers i mil dels demés officials sia açienda propia deles tals persones, sens que en ella entre ni's puga computar dots de mullers, ni bens vinclats subjectes a restitutió, ni bens en los quals tan solament tinguen lo usufruyt de vida, i que tinguen les propietats i heretats que poxesen 
de liures de cens, recens e reponsió, o almenys de descompte de lo que respondran sobre les tal coses, heretats i possiesions per no acienda, de manera que les dites cinchcentes i mil liures respectivament poguessen ser bens liures en qualsevol cas i succés, i lo mateix se entenga de les persones forasteres que pretendan ser eletes, o asumptes als dits officis, en cas que puguen ser, que hajen de tenir en doble de açienda que los naturals, conforme al capítol vinté del dit privilegi. Plau a sa Magestat que's duplique la cantitat en los que seran originaris de la dita vila de Castelló de la Plana i que en los demés no’s innove ninguna cosa.

Que los consellers puguen ésser compellits a servir tres anys

ITTEM, lo dit syndich diu que conforme a les ordinacions i costum antiga de la dita vila, los consellers de ella que an servit dos anys lo dit offici no poden servir i ser compellits encara que sien trets per a d'aquella regirlo, de que succeix moltes vegades en la bosa de mà major no trobarse inseculades persones bastant per al número de consellers, sino son de les que ja tenen inmunitat per aver servit los dits dos anys conforme a la dita ordinació, i en tal cas és necessari acudir a la bosa de mà menor per a omplir lo dit número de consellers, i per que la differència que i ha en les dites bosses és posar en la de mà major les persones més intelligents i prátiques per al govern, i en la de mà menor les que no u són tant $\mathrm{i}$ de aquí naix entrar per consellers homens de poca experiència i pràctica per no elegir ni voler ser elets los que han servit dit offici dos anys i són trets de la dita bosa de mà major, lo que redunda en gran dany de la dita vila i grandíssim profit de ser regida per homens de molta pràctica i experiència. Per tant lo dit síndich supplica a Vostra Magestat sia servit manar que no obstant la dita ordinació i costum en contrari, que tos temps i quant serà necessari acudir a la bosa de mà menor a traure consellers per a omplir lo número dels que no i haurà en la de mà major per defecte de aver servit dos anys lo dit offici de conseller, que alló entés no obstant, puguen ser compellits a servir lo dit offici de consellers més anys los de la bosa de mà major, de manera que lo menys que ser puga se acudixca a la dita bosa de mà menor a traure consellers haventlos hi en la de mà major, encara que sien, com dit és, dels que hauran servit los dits dos anys, als quals puga compellir lo consell a haver de regir dit offici ab les penes que'ls pareixera i executarles. Plau a sa Magestat que pugen ser compellits a servir lo dit offici en fins a tant que'l hayen servit tres anys.

\section{4. pena dels Consellers que no venen al Consell}


ITTEM diu que moltes vegades succehix no tractarse los negocis en lo consell de dita vila en la punctualitat i resolució que convé per no acudir los consellers, encara que cridats à consell, i alguns tan tart que no's pot tractar ninguna cosa ninguna en les hores senyalades i los officials se estan en lo consell, o casa de dita vila, sols aguardant als dits consellers, i per no venir no se celebren los dits consells ni's pren resolutió en les coses convenients al bon govern de la dta vila com convé, lo que causa no tenir pena ninguna statuida contra los tals consellers. Per lo qual pareix seria convenient que'n tinguesen alguna, al menys de cinch sous per cada vegada que faltasen esent cridats more solito a dit consell e no vinguessen a la hora senyalada per a celebrar aquell, la qual pena se aplicàs al hospital de dita vila i se manàs als jurats que l'altre dia després inmediate següent del dit consell fesen executar irremisiblement la dita pena, consigatla a baciner del dit hospital. Plau a sa Magestat.

\section{Dins quin temps se pasen los contes, i es paguen los restes.}

ITTEM, diu que per lo capítol deset del privilegi del Rey Don Joan, que està insertat en lo capítol quint de les ordinacions del dit regent Covarrubias, està imposada pena al síndich de la dita vila que per tot lo mes de nohembre no haurà fet donar compte als clavaris de les sises i peytes de la dita vila, e o arrendadors de aquelles, i per tot lo mes de dehembre cobrat les restes i alcansos, i així mateix posa la mateixa pena de perdiment de salari i privació i suspensió de offici per deu anys als jurats que no hauran asistit a dits comptes, sent necessària sa asistència i donaran tot consell i ajuda per a que tinga effecte tot lo contengut en dit capítol i per a que, per lo desús dit, lo temps limitat al dit síndich són los mesos de nohembre i dehembre respectivament aprés de finit son any, dins dels quals par que los dits justícia i jurats no poden compellir al dit síndich a que complisca ab les dites ordinacions, puix té tot lo mes de dehembre per a complirles, i serà cosa molt fort que en lo mateix instant que se li acaba lo temps al dit síndich restàs encorreguda la pena als dits justícia i jurats que no han tengut temps ningú per a poder compellir a tal síndich. Per tant suplica que, restant les dites ordinacions en sa forsa i valor, en quant toca al dit síndich i se declare que los dits justícia i jurats sien obligats a fer lo que a ells tocara per tot lo mes de giner després inmediate següent, i fins que aquell sia passat, no encorreguen en les penes de dit capítol, i lo mateix diu en respecte del clavari dels forments, lo qual conforme a ordinació dela dita vila està obligat a pagar ab tot effecte sent la resta de trescentes lliures abaix per tot lo mes de setemebre, que los dits jurats pugen tenir sens incorriment de pena tot lo mes de octubre 
per a compellir als dits clavaris a pagar lo alcans i resta en la forma desús dita. Plau a sa Magestat

\section{Que lo offici de scrivà sia trienal}

ITTEM diu que per antiga costum lo scrivà dels jurats se mudava de tres en tres anys, fins tant que lo dit regent Covarrubias los reduhí à dos anys com apar per lo capítol sisé de les ordinacions, de que par resulta algún inconvenient al bé públich de la dita vila, per que elegintse com se eleig tos temps per al dit offici persona pública i entra nou en los papers de la dita vila i regiment de aquella, los quals ab lo discurs del temps se entenen bé i venés a ser señor de ells, lo que no's pot fer en menys de un any i essent dos lo que dura lo dit offici par que se li acaba al temps que podria ésser señor de dits papers. Per a remey del qual convendria almenys que per los tres anys antiga costum se exersís lo tal offici per una persona, per a que millor pugés exercirlo dit offici per al bé comú, en lo qual se emendex i corriexga lo dit capítol sisé de dites ordinacions de dit regent Covarrubias. Plau a sa Magestat.

7. ITTEM per lo capítol dehé de les dites ordinacions fonch declarat poder ser jurat los señor de bestiars, privant solament de poder ser justícia als qu'els tingués, lo que par ser de molt gran inconvenient, perquè los guardians i pastors dels tals bestiars, no tement la pena del dany, que fan ab dit bestiar, se atreveixen a ferlos grandíssimis en les parts vedades públiques i particulars, i resten sens lo castich condecent, i no se atreverien a fer dit dany sinó fos ab la confiansa que tenen del dit offici i puix, asò és benefici públich, se suplica a Vostra Magestat sia servit que sia i se extenga la dita prohibitió en lo dit offici de jurat i justícia. Sa Magestat mana que no's fassa novetat en assò de com stava abans.

8. Que si eixirà justícia del raval, sen entre en la vila dins quinze dies, se puga nominar loctinent per al arraval.

ITTEM diu que alguns vehins de la dita vila que viuen en los arravals, que estan inseculats en la bosa de justícia si hixen pera dit offici i són extrets, vivint fora los murs de la dita vila, és de gran inconvenients, tancantse los portals com se tanquen cada nit, que lo dit justícia reste fora, que succehintse alguna repentina necessitat no puga lo dit justícia acudir a ella ab la presteça necesaria, per lo qual est molt convenient se mane als dits tals que en continent com sien elets per al dit offici de justícia sen entren a viure 
dins dels murs de la dita vila, o almenys dins quinse dies, passats los quals sinó seran entrats se puga fer is fasa electió de nou de persona pera dit offici, restant lo tal elet primer privat del dit offici per al dit any. Plau a sa Magestat y dona facultat al justícia que nomene un loctinent que per lo menys residesca de nit en lo arrabal.

\section{Que faça la insaculació la vila, i no la Real Audiència}

ITTEM diu que per lo Privilegi del Rey Don Joan, de gloriosa memoria, foch concedit a la dita vila el insecular les persones per als officis de aquella, tos temps que faltàs número conveninet, lo qual privilegi en est cap fonch alterat per lo capítol tercer de les ordinacions del dit regent Covarrubias, reservant la dita inseculació al lloctinent i capità general i Real Audiència de València, de que han succehit grans inconvenients per que moltes persones pretenent ser inseculades als tals officis acudixen a la dita Real Audiència, i movent plet formal i fulminant procés ab lo síindich de la dita vila, de que naix averse de fer molts gastos i despeses a dita vila en la defensa dels dits pleits, i lo que més fort és, que com en la dita Real Audiència no's té tan entera noticia de la sufficiència de les tals persones ni's pot averiguar per prova extrínseca de testimonis lo que se enten de algunes, i seria ocasió que si se articulasen les faltes públicament se vendria a les armes i seria incendi de qüestions i differències i perturbar la pau tant necessaria, i com aço no's pot fer, naix major inconvenient que és, complint ab lo discedit i determinat en la Real Audiencia, averse de insecular homens no benemèrits ni intelligents, i exint aprés als officis és cert qu'els han de exercir ab molt dany de la cosa pública. Per a remey del qual se supplica a Vostra Magestat sia servit manar se guarde $\mathrm{i}$ observe lo dit privilegi, remeten al consell de la dita vila les dites inseculacions i promocions de una bosa a altra, sens empaig del dit capítol tercer se observe y guarde lo dispost en lo dit privilegi en lo conernent a dites coses. Plau a sa Magestat durant sa mera i libre voluntad.

10. Extractió de jurats, en anys de militars.

ITTEM diu que en lo any que confome al fur i al capítol quart de les ordinacions del regent Covarrubias sea de elegir jurat en cap del estament militar, aquell any cessa lo traure jurat de la bosa de jurats segons, traent de la bosa tercera lo tercer i quart jurat, i per que los de la dita bosa tercera són llaurados, los quals no asistixen ni poden asistir de oridinari en la dita vila, com poden i asistixen los de la segona bosa per ser artistas i homens que no van al camp a llaurar, i pareix molt menys inconvenient que cesse hu 
dels redolins de la tercera bosa que no lo de la segona, lo qual és i serà sens dupte més a propòsit per al regiment i govern de la dita vila, i així se supplica a Vostra Magestat sia servit manar emendar la dita ordinació quarta, declarant que lo any que serà jurat en cap militar, lo segon jurat sia de la primera bosa del stament secular, i lo tercer de la segona bosa i lo quart de la tercera. Plau a sa Magestat.

11. Que lo justícia puga dar llicència per marqueses i altres regocijos.

ITTEM. Així mateix diu que lo justícia de la dita vila, com a jutge ordinari de ella, tos temps acostumat y acostuma a dar llicència per a que, en lo temps de carnestoltes i en altres occasions de regozijo entre lo any, puguen los particulars de dita vila portar maixqueres i desfraçarse i regozijarse amb lo modestia i desència que convé, lo qual se ha usat i practicat sens ninguna contradictió ni la han feta los governadors de la dita vila fins lo que ara de present o és ne ha fet, pretenent que a ell tocaria lo haver de donar dites llicències $\mathrm{i}$ no al dit justícia, $\mathrm{i}$ encara que de dret ningun dupte tinga de que semblants llicències competeixquen al dit justicia, ab tot, no obstant dita pretenció, suplica a Vostra Magestat dit síndich sia servit manar, i en quant sia necessari donar i de nou concedir a la dita vila i justícia de aquella, privilegi per a poder dar i concedir en dites ocasions les dites licències per a dits disfreços i regocijos. Plau a sa Magestat

12.ITTEM diu, que és notori i de furs del Regne de València al justícia de la dita vila pertanyer la jurisdictió de totes causes civils i criminals de la dita vila i sa contribució, sens que havent comensat a coneixer d'elles per ninguna via lo governador de la dita vila li puga llevar causa ninguna que haja prevengut, per ser com és la jurisdictió del dit governador comulativa i no privativa, i pretenent lo contrari se sociten de cada dia molts plets en dany de la cosa pública, i lo temps que era just gastarse en expedir los pleits de les parts se gasta en competencies de jurisdictions, les quals se porten excusar contentanse lo dit governador en la que ste, sens voler perturbar la del dit justícia i desitjant resercar estos inconvenients la dita vila, e o lo dit síndich humilment supplica à Vostra Magestat sia servit manar al dit governador que no se entrometa en les causes criminals prevengudes per lo dit justícia, sinó en los casos ad aquell permesos per furs. Plau a sa Magestat que's guarden los furs, resecats tos abusos.

Nos vero volentes dictam villam Castilionis de la Plana favore prossegui praecedentematura deliberatione nostri S.S.R. Consili Aragonum ei illam insequendo 
tenore praesentis de nostra certa scientia et regia auctoritate, deliberate et consulto praesinsertum privilegium Serenissimi Regis Joannis quatenus est impossessione illus praedicta villa de Castelló de la Plana, iuxta praeinsertam sententiam per nostrum locumtenientem et capitaneum generalem et Regiam Audientiam Regni praedicti Valentiae, latam et publicatam dicto die decomotertio mensis jannuairi anni millesimo quingetessimi nonagessimi, et ordinem et forman prescriptam virtute illius perdictum magnificum et dilectum consiliarum nostrum et nostram Regiam Cancelleriam regentem in nostro S.S.R. Aragonum Consilio Didacum Covarruvias, cum suis praeinseri ordinationbus factis et conditos, die duodecimo mensis julii dicti anni millesi quingentesimi nonagesimi, cum declarationibus extensionibus et decretanionibusque per nos apponi mandatis infine cuislibet capituli praeinserte supplicationis per dictum Michaelem Jacobum Peris, notarium nobis et in hoc nostro S.S.R. Aragonum Consilio oblate, laudamus approbamus, ractificamus et confirmamos et quatemus opus est de novo concedimos. Hanc itaque conformationem, approbationem, ratificationem et laudationem et quatenus opus est novarum concessionem facimus dictae villae de Castelló de la Plana in perpetum, nostra mera et libera voluntate durante, sicut melius dici potest et intelligi ad dictae villae de Castelló de la Plana in perpetuum, nostra mera et libera voluntate durante, sicut melius dici potest et intelligi ad dictae villae de Castelló de la Plana sanum sincerum et meliorem intellectu, volentes et expresse decementes quod ab hinc inperpetuum (nostra mera et libera vountate durante) preadicta confirmatio, approbattio, laudatio et ratificatio et quanteus opus est nova concessio sit et esse debeat dictae villae de Castelló de la Plana stabilis realis valida atque firma nullumque in juditio aut ex na sentiat diminutions obiectum deffectus incommodum aut noxe cuius libet alterus detrimentum sed in suo semper robore et firmitate persistat.

SERENISSIMO propterea PHILIPPO Principi Asturiarum et Gerundae, ducique Calabriae et Montisalbi, filio primogenito nostro charisimo ac post foelices et longaenos dies nostros in omnibus Regnis et Dominus nostris (Deo propitio), inmediato haeredi et legitimo succesori obtentu dicimus eumique rogamos. Futuro vero nostro locumtnentiam et capitaneo generali, spectabili regenti locumtenenti et capitanium generalem, rexentí Cancellariam et docotoribus Regiae Audientiae, gerentibusque vices generalis gubernatoris et eorum locumtenetibus et ssessoribus, baiulis generalibus, magistro rationali, locumtenenti generalis thesauraii, advocatis, alguahirris, virgaiis, 
portariis, cieterisque denuum universis et singulis officialibus et subditis nostris mioribusque et minoribus in praefatos nostro Valentiae Regno constitutis et constinuendis, et eorem locantenentibusque et subrogatis pro prima et secunda jussionibus dicimus, praecipimus et jubemus ad incursum nostrae regiae indiganitionis et irae poenae que florenorum auri Aragonum mille nostris regiis inferendorum aerariis quod presentem nostram confirmationem, laudationem, approbationem et ratificationem et quantenus opus est dictorum capitulorum novam concessionem et decretum dictae villae de Castelló de la Plana, et omnia et singula in eis contenta ut superius expresum est in perpetuum (nostra mera et libera voluntate durante) teneant firmitier et observent tenenque et inviolabiliter observari faciant per quoscumque cauti secus agere fieri ve permittore racione aliqua sine causa si dictus Serenissimus Principes nobis morem genere cupit coeteii vero officiales et subditi nostri praedicti gratiam nostram charam habent et praeter irae et indignationis nostrae incursum poenam prae appositam cupiunt evitare incuius ser testimonium presentem fieri jussimus nostro Regio communi sigillo impendenti numita.

Datti in oppido nostro Madritae die decimo septimo mensis decembris anno a nativitate Domini millesimo quingentesimo nonagesimo septimo. Regnorurque nostrorum videlicet citerions Sícilae et Hierusalem quadragesimo quarto, Castellae autem Aragonum ulterioris Sicilae et alinorum quadragesimo secundo, Portugalie tamen decimo octavo.

Yo el Príncipe

Vidit Frigola, vicecancellarius, Vidit Frias, Vidit Covarrubias regens, Vidit Guardiola regens, Vidit Don Petrum Sans, fisci advocatus, Vidit Franquesa, procurator conservatore generalis, Vidit Baptista, rexens, Vidit Sans Flq Vidit Clavero, regens.

Dominus Rex et eius nomine Dominus Princeps mandavit mihi Petro Franquesa visa per Frigola vicecancellarius comitem generalem, Frias, Batista.

Covarrubias, Guardiola et Clavero regentes Cancellariam et don Petrum Sans fisci et patrimoniis advocatum 
In Diversorum Valentiae 27, $f .43$

Vuestra Magestad confirma a la villa de Castellón de la Plana un Privilegio del señor Rey Don Joan aqui inserto, en quanto esta en posesión del y es cerca el regimiento de la dicha villa, y de nuevo se han decretado algunos capítulos sobre lo mesmo, los quales se conceden para durante la Real Voluntad de Vuestra Majestad. 


\subsection{Documento 4: Privilegio real dado por Felipe III a la villa de Castellón, por el que se modifica la forma y el número de los que pueden ser insaculados en las bolsas para los oficios de gobierno del municipio.}

(AHMC. Variarum de Clavell. ff. 50-53).

Nos Philippus, Dei gratia Rex Castellae, Aragonum, Legionis, utriusque Cicilia, Hierusalem, Portugalia, Ungariae, Dalmaciae, Croaciae, Navarrae, Granata, Tolesti, Valentiae, Galisia, Maioricarum, Ispalis, Sardinia, Corduba, Corcisca, Murciae, Gienni, Algarby, Algehira, Gibraltr, Insularum Canarariae, nec non Indiarum orientalium et occidentalium, Insularum et térrea firmae mares oseani. Archiduchs Austriae. Dux Burgundiae, Bramantiae, Mediolani, Attenarum et Neopatriae. Comes Abspurgiy, Flandriae, Tirolis, Barcinonae, Rosilionis et Seritaniae. Marchio Oristani et Comes Goseani.

Cimper dilectum nominim Blatasarem Peris nottarium syndicum eb procuratorem villa nostra de Castelló de la Plana humilites presentata fuit quedam suppicatio, soupetitio inferius inserta quannon solm admissimus verumetiam decretari, eberepedisi jussimus provit infine iprius petitiony, et in calce eiusdem continiebus thenoris huius modi:

Señor, Baltasar Peris notari síndich i procurador de la vila de Castelló de la Plana supplicant diu que per lo sereníssim Rey Don Juan, ab real privilegi donat en la present ciutat de València en vintidos dies del mesde maig de l'any mil quatrecents quaranta sis, feu mercé i otorgà als justicia, jurats, concells e universitat de dita vila lo regiment de aquella, lo qual privilegi fons confirmat per la magestat del Rey Don Phelip, pare de vostra Magestat, ab privilegi donat a desset de de decembre del del any mil cinchcents noranta set, i entre altres capítols, establiments $\mathrm{i}$ ordinacions ques feren pera dit regiment e insaculació, foncs statuhit sobre la admisió a persones que yha en los dits sachs, se trobaran collocades, que tots aquells que volguessen ser admesos novament als dits officis, o algú dels que yha seran admessos a altre offici o machor grau promoguts, puga de dos en dos anys presentarse al jurat primer present lo notari lo disapte ans del diumenge de quasi modo, i servada la forma en dit privilegi contengudas si son trobats hàbils poden ser admesos novament als dits officis dos tan solament, i dels ya insaculats remoguts dos de cada grau i muntats a officis machors, $i$ en los novament admesos se ha 
de guardar esta forma: que primerament han de ser colocats an la boça de terç i quart; de les quals ordinacions redunden molt incovenients, i señaladament dos que impedeixen lo bon govern de la vila; lo primer és que com los insaculats en los officis menors aspiren a ser promoguts e insaculats en officis machors, en lo discurs del temps fent requesta de dos en dos anys són promoguts, i los sachs i boçes de dels officis machors se troben molt plenes, i faltes de persones les dels sachs inferiors; lo segon és que persones que conforme ses qualitats al principi fóren insaculats en los officis machors, i com los que novament volen ser insaculats han de ser posats i collocats en los officis de jurats terç i quart, i moltes vegades se es devé i pot succeyr sevantse la forma del dit privilegi que un mateix any eixiren los ciutadans, doctors en lleys i medicina a jurats ters y quart, y persones artistas y que no són de tanta qualitat a jurat primer i segon, per obviar als quals inconvenients, i altres, i pergi conve a la bona admnistració dels officis y del regiment de dita vila supplica lo dit síndich a Vostra Magestat li fasa merçe de donar i otorgar libera facultat y poder al justicia, jurats i concell i universitat, pera puguen inocular i promoure liberament ens dits sachs les persones quels pareixeran benemèrites $\mathrm{i}$ en les boçes que ses calitats requeriran, sens haverse de observar lo orde $\mathrm{i}$ forma contenguts en lo dit privilegi del rey Don Joan, i supplicant així mateix li fasa merçe de posar número cert en les boses i sachs de dits officis; ço és en la bosa de jurat en cap vint persones, en la de jurat segon altres vint, en la de ters i quart quaranta, en la de justicia trenta, en la de mustaçaf quaranta, en la de sequier cinquanta, $i$ en la de escrivà deu, i que havent dit número en dites boses no puga ser persona alguna novament insaculada ni promoguda en dits officis, perquè com los dits justicia, jurats i concell coneixen les persones part i qualitats de cada hu, posaran e insacularan a cada hu en lo offici, bosa i sach que convindrà a sa facultat i a la bona administració de dita vila i serà per aquella molt gran mercé, eb licet si.

Plau a sa Magestat, de concedirlos tot lo contengut en la present supplicació i petició, ab que en la insaculació fahdora assitixquen lo lochtinent de portanveus en la vila juntament ab lo batlle de aquella i no essent lo dit llochtinent lo batle asoles, i hajen de donar son vot quasiquidem petitione, eb suplicatione, et omnia et singula inea contenta, volenses dicta villa Castellionis de la Plana ab ómnibus ad quos spectet ab ómnibus inviolabiliter observari juxta forman et itenorem decretationis, eb respentionis nostra in calce dicta supplicationis apposita thenore presentis nostra carta curatis futuris tempore valiture eo nostra certa scientia deliberate, eb consultó regiaque auctoritate nostra 
petionem eb supplicationem preinsertam juxta decretationis, eb respensionis nemine infine dicta supplicationis apposita tenores perpertuo concedimos, consetimus, assentimus, et liberaliter elargimur nostregi huius modi concesiimii, consensus assensus, et elargitionis munimine seu presidi roboramus, et validamus auctoritatemqui nostram e inde interperimus pariber et decretum futuro propetera locum tenenti, eb capitaneo generali nostro inprefatoValentiae regno, nobilibus, magnifics dilectisque consiliaris, eb fidelibus nostris regenti cancellariam, et doctoribus nostre Regia Audiencia gerentibus vices nostri generalis gubernatoris, bailo generali, magistro racionali, advocabis y procuratoribus fiscalibus, justicias, juratis, alguaziriis, vergariis, portariis ceterisqui demum universis eb singulis officialibus, eb subditis nostris impredicho nostro Valentia Regno constitutis, et constituhendis, presentibus et futuris, eb forum militet dicimus, precipimus, et jubemus eadem nostra Regia auctoritate, et incursum nostre indigantionis, et ire florennorum auri Aragonum quingentorim nostris inderendorum erariis quatenus forma, et thenore presentis, et pre inserta petitionis, et supplicationis decretationis, et respensionii infine eiusdem facte per ebs et unum quemque forum diliginter attentis prosi et forum milibet provet ad unum quemque eorum spectavit preinsertam petitionem, et suplicantionem, et omnia et singula inea contenta juxta thenorem seriem, et continentiam decretiationis, et respontionis nicalce eiusdem apposita preadicta villae de Castelló de la Planaperpetuo teneant firmiter, et observet tenerigi et observati faciant in concusse per quos deceat. Itaque omni dubio contradictione et sinistra interpretatione, cessantigus predicta villa Castellonis de la Plana gaudeat et gaudere possit et valeat fructu, et obilitate prefatarum gratiarum per nos eidem concessarum ub superius perpetionem, suplicationem, decretionem, et respontionem predictas apparet et non contrafaciant imeveniant, si gratiam nostram charam habent penamgi pre apositam cupuint nos subire, in cuius rei testimonim presentem fieri jussimus nostre huius locum tenentiae sigillo cum comune nostre Regiae Aragonum cancellariae improinpbre non estet im pedenti munitam. Datis in civitate Valentiae die decimo octavo mensi februarii anno a nattivitate domini milesimo sexcentésimo quarto, Regnorum autem nostrorum anno septimo.

Yo el Rey

Vidit Covarrubias, vicecancellarius regens, vidit doctor R. Sans, locumetenens generali thesaurarii, vidi Franquesa, conservatoris generalis. 
Dominus Rex mandavit mihi dominico orbis. Vista per Covarrubias vicecancellarium, doctor R. Sans locumtenens generalis tesaurii et Franquesa conservatoris generalem.

Tomó la razón el conservatoris. In diversorum locum tenentia XX, generalis Franquesa. Vuestra Magestad concede y decreta la suplication aqui incerta a la villa de Castellón de la Plana para el buen gobierno de ella.

Assido vista por la Audiencia y con su parecer decretada. 


\subsection{Documento 5: Texto del Caballero D'Asfeld}

(AHMC. Judiciari. 1707-1708-1709-1710. 26 de Febrero de 1708).

\section{COMENDADOR DE LA ORDEN DE SAN LUIS.}

Theniente General de los Exercitos de ambas Coronas, Comandante de los Reynos de Valencia y Murcia, y de las Fronteras de Castilla.

Por la presente y en virtud de la especial orden que tenemos del Excelentísimo señor mariscal duque de Berwick y Liria para la aprobación de la Justicias que en este tiempo se deben elegir al pie de Castilla. Elegimos y nombramos por Alcaldes ordinarios de la villa de Castellón de la plana a Don Josep Castell de Museros, Y a Josep Segarra, Por regidores a Don Jerónimo Bou de Monsonis, Don Matias Egual, Don Antonio Gombau, Don Geronimo Mas, Don Manuel Vallés al Doctor Félix Sisternés caballero, al Doctor Jaume Giner, al Doctor Vicente Martí, al Doctor Félix Roig, al Doctor Félix Porta, al Don Basilio Giner Y a Jayme Pasqual. Por Agualcil mayor a Josep Llopis, Por alcaldes de la hermandad a Vicente Figuerola, Y a Roque Escuder Y por Escribano del ayuntamiento a Pedro Vidal, para que lo usen y ejerzan por espacio de un año mas o menos tiempo el que a su Majestad bien visto fuese arreglándose en el Juramento. En el Gobierno en las banas Y en la administración de Justicia a las leyes de Castilla para lo cual mandamos expedir la presente firmada de nuestra mano sellada con el sello de nuestras armas y refrendada por (...)(...)Dado en Castellón de la Plana Y febrero a 26 de usos.

el cavallero D'asfeld 


\subsection{Documento 6: Extracto del libro de Ayuntamientos y Concejos de la Villa de Castellón de la Plana del ano 1707 y 1708, 1709 y 1710.}

(AHMC. Judiciari. 1707-1708-1709-1710. Sesión del Ayuntamiento de 16 de diciembre de 1707).

A los dies y seis dias del mes de de desiembre de mil sieteccientos y siete años fue juntado y congregado Ayuntamiento y concejo en la sala de la presente Villa de Castellón de la plana haviendo pecedido convocación hecha a voz de pregón por Pedro Valero nuncio y pregonero publico de dita villa por los lugares acostumbrados de aquella echa en lo dia de hoy ante mi Pedro Vidal escribano de dicho Ayuntamiento en el qual asistieron y fueron presentes los siguientes:

Teniente de Alcalde: Josep Segarra ciudadano

Regidores: Tomàs March de Bustamante ciudadano, Gaspar Rubert notario, Domingo Vilarroig y Jaume Breva.

Consejeros: Don Macià Igual Borras, Bautista Jover ciudadano, Joan Andreu doctor en derecho, Félix Roig doctor en derecho, Vicent Tosquella doctor en derecho, Pedro Breva escribano, Josep Amposta cirujano, Felip Breva escribano, Joan Safont escribano, Josep Llorens de Clavell escribano, Josep Llopis escribano, Miquel Navarro de Gaspar, Miquel Vilarroig de Nicolau, Josep Fuster major, Ignacio Breva, Josep Pasqual de Francisco, Josep Castell de Antoni, Baltazar Avinent, Andrés Ribalta, Félix Tirado, Josep Castell de Gerony, Pedro Museros de Castell, Josep Vilarroig y Miquel Pasqual menor. 


\subsection{Documento 7: Ejemplo de nombramiento de justicia y asesor de justicia.}

(AHMC. Judiciari. 1620-1623. Sesión del Consell de 22 de diciembre de 1622).

Die xxii mensis decembris

\section{Anno MDCXXII}

fonch convocats y congregats Consell en la sala del palau de la present vila de Castello de (....) i provisió de Miquel Giner ciutadà Justicia de dita vila, de Micer Joan Batiste Gascó doctor en drets, Jaume Castellet notari, Miquel Alberich jurats de dita vila i veus mija de Jaume Grases nuncio i trompeta publich de la present vila per a la present hora en la qual asistiren les persones següents:

Justicia : Miquel Giner ciutadà

Jurats : Micer Joan Batiste Gascó, Miquel Alberich y Jaume Castellet

Consellers :Pere Morales cavaller, Batiste Serra ciutadá, Baltazar Gombau ciutadà, Lluís Mas doctor en medicina, Gerony Quevedo notari, Francesc Jover notari, Martí Giner notari, Jaume Blasco mercader, Melchor Salvador notari, Cristòfol Bou notari, Antoni Joan Lleó ciutadà, Pere March ciutadà, Francesc Mas, Francesc Vilarroig, Miquel Lluch de Sanchís, Mateu Sanchís, Andreu March, Miquel Rubert, Miquel Pasqual, Nicolau Alegre, Joan Bosch, Gabriel Segarra, Pere Marqués i Gabriel Ferrer.

Ajuntats e congregats tots los desus dits fonch proposats pero lo dit Micer Joan Batiste Gascó doctor en drets Jurat de la present vila de Castelló que en semblant dia que hui conforme furs i privilegis del present regne de Valencia se acostuma a fer electió i extractió de justicia per al any primer vinent de MDCXXIII que (...) de fer dita electió i extractió de justicia del bras real se mantenen tot les forals dispositions del present regne per les ordinations ussos i bons costums de dita vila guardant los impediments acostumats de la present vila de Castelló.

E proseguint anant segons estat proposat per lo dit Jurat fonch votat per lo dit Consell ne (...) discrepant e que es fasa electió i extractió de persona abil per a justicia del any 
primer vinent (...) en tot los furs i privilegis del present regne ordinations ussos i bons costums de la present vila conforme se acostuma.

E axi en continent per mi Pau Capero escrivà dels Jurats e Concell foren legides en publich Conselle $\mathrm{i}$ ab veu alta e intelligible dites ordinations que tratten dels impediments se deuen guardar en semblants elections enomenades les persones de una en una que estan inseculades en lo sach e bosa de justicia del bras real. Foren atrobades (...) insaculades les persones següents: Miquel Giner ciutadà, Cristòfol Sisternés ciutadà, Micer Tomàs March, Gaspar Gombau, Gerony Folch notari, Micer Miquel Moliner, Melchor Salvador, Antoni Joan Lleó ciutadà, Pere March, Bertomeu Giner Doctor en medicina, Micer Bernat Gascó, Micer Batiste Gascó, Pere Joan Martí, Baltazar Gombau, Francesc Joan Bou notari, Cosme Martí ciutadà, Pau Capero, Batiste Vallés, Micer Jaume Bonet, Gerony Quevedo notari, Lluís Mas doctor en medicina, Macià Gascó, Miquel Aragonés, Francesc Mas, Pere Museros. Los impediments generalment de totes les dites persones nomenant aquí es (...) abil o no foren atrobades per impedides les persones següents Miquel Giner per trobarse Justicia, Cristòfol Sisternés deudor, Gaspar Gombau portar pleit en la vila restar extraregnum, Gerony Folch per portar pleit en la vila i denunciat, Micer Miquel Moliner estar denunciat, Bertomeu Giner ser sindich, Micer Batiste Gascó jurat per lo Joan Martí portar pleit en la vila i deudor, Baltazar Gombau clavari, Cosme Martí per ser tresorer, Pau Capero escrivà, Batiste Vallés arrendador, Micer Jaume Bonet asesor, Francesc Mas no (...), Miquel Aragonés jubilat, Macià Gascó arrendador de les carniceries. Que totes les dites persones impedides (...) sumarse (...) estan abils les demes non persones impediment algun per al dit offici de Justicia per al any primer vinent de MDCXXIII. E fet lo dit (...) i abilitació fonch per lo dit Consell provehit que lo dit doctor Giner sindich de la present Vila de Castelló anas Francesc (..Reus..) cavaller de subrogat governador e Gerony Igual ciutadà Batlle per sa Magestat de la present vila per a que vinguesen ab les claus tenen per a obrir la caixa dels sachs e boses de les persones que estan insaculades per als oficis de la present vila, los quals en contirent vinguere a dit Concell i asesntats en son lloch. E tretas per Gabriel Mancana Macer e verguer dels dist Jurats la dita caixa i posarla aquella sobre lo taulell que esta davant dels oficials de dita vila aquella foch uberta en publich Consell per los dits subrogat, batle, justicia i jurat en cap fonch tret lo sach intitulat sach de Justicia del bras real lo qual fonch trobat tancat clos i segellat ab lo sagell de la vila. Lo qual pres per mi dit notari escriva fonch ubert i buydats los redolins 
que en dit sach estan damunt de dit taulell foren contats per mi dit escrivà trobats en aquell vinti set redolins i posats en un basi mig de aigua $i$ tapats ab una tovallola $i$ Jaume Bonet infant de set anys poc mes o menys asentantse primer posat lo bras dret en dit basi tragué un redoli que posa aquell en mans del dit Jurat en cap y aquell tragué lo albaranet que dins aquell stava i donat per lo dit Jurat en mans del dit balle fou elegit lo nm de Cosme Martí ciutadà major de dies i per ser mort ne fou per dit infant tret altre de dit basi y donat en mans del dit jurat aquell tragué lo albaranet que dins aquell estava i donat en mans del dit Batlle fou legit lo nom de Joan Batiste Vallés notari i per ser un dels impedits lo dit Infant ne tragué altre redolí del dit basi i donat en mans del dit Jurat aquell trague lo albaranet que dins aquell estava i donat en mans del dit Balle fou llegit lo nom de Anthoni Joan Leó ciutadà i com fos un dels abils per lo dit Concell lo dit Batlle en nom i beus de sa Magestat ab altaveu dis pleno concilio que nomena com de fet nomena al dit Anthoni Joan Lleó ciutadà Justicia de la dita vila per a l'any primer vinent de MDCXXIII e feta la dita extractió i nominació forent restituhits en dit sach vint y sis reolins sagellat per mi dit notari i escrivà fou per los dits jurats restituhit i posat dins la duta caixa i tancada aquella per los dits clauers i fou per llos dits Gabriel Mancan restituida dins lo archiu i posada en lo armari i los (...) estar presents foren testimonis a dites coses los dits Gabriel Mancana i Jaume (...) macers dels dits jurats.

E feta la dita electió de Justicia fonch proposat per lo dit Jurat qye ne semblant dia de huy se sol acostuma a fer nominació i electió de assessor de Justicia conforme als furs i privilegis del present regne ordinations e practiques e bons costums de la dita vila per a l'any primer vinent que (...) (...) dita electió de assessor i encontinent soren escrits per mi dit escrivà los noms de les persones per dites nomenades per lo dit escrivà per a concorrer al dit carec de assessor que fou lo doctor march, lo doctor Micer Bernat Gascó, lo doctor Micer Nicolau Figuerola, Micer Fulgenci Mascarós, Micer Cosme Feliu. Sa vots segrets com se acostuma foren votats i acabats de votar per tots los dits consellers compta per mi dit escrivà los vots que tenien quiscu fou atrobat (...) lo dit Micer Nicolau Figuerola tenint setze vots i los dits Micer Bernat Gascó sis vots y los dits Micer Fulgenci Mascarós set vots de manera que havent tengut més vots lo dit Micer Nicolau Figuerola que los demés que han concorregut fou feta electió de asesor del dit Justicia per al dit anys primer vinent de la persona del dit Micer Nicolau Figuerola. 


\subsection{Documento 8: Transcripción insaculaciones.}

\section{$\underline{\text { Insaculación } 1590}$}

(AHMC. Llibre de les Insaculacions, ff. 38-41).

Primerament de cavallers i generosos nomenats per als officis de Justicia, Jurat en cap, Mustassaf i consellers de la ciutat : Pere Reus i Micer Cristòfol Miralles.

E de vehins de dita vila del bras real es a saber per al offici de jurat en cap: (Doctor) Cosme Feliu, (nombre tachado) Pere Gascó, Cosme Martí, Lluís Agramunt, Narcís Feliu, Miquel Giner, Melchor Serra, Llorens Sisternés, Gaspar Jover doctor(obiit), Martí Arrufat notari, Francesc Jover notari, Miquel Gascó notari, Micer Gerony Jover, Miquel Jaume Serra i Micer Tomàs Martí.

E per al offici de Jurat segon: Miquel Serra notari, Baltazar Peris notari, Gaspar Brunell notari, Nicolau Brunell de Gaspar, Domingo Beltran notari, Joan Castell notari, (nombre tachado)Guillem Fores notari, Miguel Aragonés notari, Josep Mas notari, Guillem Alfaseri cirurgià, Vicent (...) Jubilat per lo Consell, Gerony(....) obiit (nombre tachado), Tomàs Moliner cirurgià, Bertomeu Moliner notari i Joan Gerony Folch notari.

E per al offici de Jurat tercer i quart: Joan Andreu llaurador, Pere Mas llaurador, Francesc Navarro de Antoni, Miquel Jover, Jaume Alegre, Francesc Navarro major, Miquel Pasqual (obiit)(nombre tachado), Pere Figuerola de Joan, Pere Navarro de Antoni, Bertomeu Mas de Jaume, Francesc Pasqual (obiit)(nombre tachado), Joan Miralles de Pere jubilat, Jaume Bonet, Pere Bosch (obiit), Nicolau Alegre de Jaume, Joan Figuerola de Joan, Pere Vilarroig de Antoni (obiit), Nicolau Giner de Joan (obiit) (nombre tachado), (nombre tachado), Francesc Romeu de Bertomeu (jubilat), Pere Gisbert (obiit), Joan Sanchís de Joan, Jaume Bernat de Vicent, Jaume Micó, Miquel Giner de Nicolau (obiit), Miquel Museros, Joan Agulló (pagament), Joan Vilarroig i Batiste Gisbert. 
E per al offici de Justicia : Cosme Feliu, Pere Francesc Albiol, Cosme Martí, Pere Gasco (obiit) (nombre tachado), Narcís Feliu, Miquel Giner, Melchor Serra, Llorens Sisternés, Gaspar Jover de Romeu(obiit)(nombre tachado), Joan Batiste Pasqual (obiit)doctor en medicina(tachado), Martí Arrufat notari, Miquel Serra notari, Baltzar Peris notari, Joan Castell notari, Gaspar Brunell notari, Guillem Forés (obiit)(nombre tachado) fora, Francesc Jover notari, Miquel Gascó notari, Domingo Beltran notari, Bertomeu Moliner notari, Pere Bosch (obiit), Francesc Romeu (jubilat), Miquel Jaume Serra, Micer Gerony Jover i Micer Tomàs March.

E per al offici de Mustassaf:Don Cosme Feliu, Pere Gascó(obiit), Cosme Martí, Lluís Agramunt de Sisternés, Doctor Narcís Feliu (obiit), Miquel Giner, Melchor Serra, Llorens Sisternés, Gaspar Jover Doctor en medicina, Pere Aragonés (obiit) (nombre tachado) Joan Castell notari, Miguel Serra notari, Guillem Fores notari (obiit) (nombre tachado), Gaspar Brunell notari, Miquel Gascó notari, Francesc Jover notari, Guillem Alfaseri cirurgià jubilat, Domingo Beltrán notari, Josep Mas notari, Vicent Romeu, Baltazar Peris notari, Tomàs Moliner cirurgià, Bertomeu Moliner notari, Joan Gerony Folch, Joan Batiste Cases (nombre tachado)fora, March Arrufat notari, Francesc (....) (obiit) (nombre tachado), Jaume Bonet, Pere Bosch (obiit), Joan Figuerola de Joan, Francesc Romeu de Bertomeu (jubilat), Bertomeu Bonet de Pere, Joan Vilarroig (jubilat), Miquel Joan (....), Micer Gerony Jover i Micer Tomàs March.

$\underline{E}$ per al offici de scrivà de la sala : Miquel Serra notari, Francesc Jover notari, Miquel Gascó notari, Joan Castell notari jubilat, Baltazar Peris notari, Domingo Beltrán notari, Gaspar Brunell notari, Gerony Miró notari (obiit), Martí Arrufat notari, Bertomeu Moliner notari i Joan Gerony Folch notari.

Per al offici de Cequier: Joan Andreu llaurador, Pere Figuerola de Joan, Francesc Navarro de Joan, Bertomeu Mas, Jaume Alegre, Miquel Pasqual (obiit), Joan Miralles de Pere (jubilat), Pere Navarro de Antoni, Pere Bosch de Miquel (jubilat), Francesc Pasqual de Joan(obiit), Joan Figuerola de Joan, Jaume Bonet, Nicolau Giner de Joan (obiit), Nicolau Alegre de Jaume, Bertomeu Giner de Nicolau, Pere Vilarroig major(obiit), Pere Gisbert (obiit), Francesc Romeu de Bertomeu (obiit), Jaume Bernat (jubilat), Bertomeu Bonet de Pere, Miquel Giner de Nicolau (obiit), Joan Sanchís, Joan Figuerola de Francesc, Miquel Museros, Joan Bosch menor de Pere,Domingo Molina, 
Andreu Pasqual (obiit), Joan Giner de Nicolau, Antoni Castell de Joan(obiit), Miquel Navarro, Pere March de (...) (obiit), Pere March, Miguel Jaume Jover, Francesc Navarro major, Joan Vilarroig i Batiste Gisbert.


tachado), Cosme Martí, Lluís Agramunt de Sisternés (obiit), Narcís Feliu (obiit), Miquel Giner, Melchor Serra (obiit), Joan Batiste Pasqual doctor en medicina(obiit) (nombre tachado), Gaspar Jover (obiit) (nombre tachado) doctor en medicina, Pere Aragonés (obiit), March Arrufat notari (obiit)Francesc Jover notari, Miquel Serra notari (obiit), Nicolau Brunell (obiit), Miquel Gascó notari, Miquel Aragones notari, Gaspar Brunell notari, Guillem Alfaseri sirurgià, Domingo Beltran notari(obiit), Gerony Micó (obiit) notari (nombre tachado), Josep Mas notari, Miquel Andreu (obiit) notari (nombre tachado), Vicent Romeu (obiit) (jubilat), Bertomeu Moliner (notari), Baltazar Peris (obiit) notari, Joan Gerony Folch (notari), Tomàs Moliner cirurgià, Micer Gerony Jover, Joan Castell (obiit) notari, Micer Tomàs March, Miquel Joan Catala notari, Miquel Jaume Serra i Pere Francesc Albiol.

\section{E de mà menor}

Joan Andreu llaurador, Pere March, Francesc Navarro de Antoni, Miquel Jaume Jover(obiit) Jaume Alegre(obiit), Francesc Navarro major de Francesc, Miquel Pasqual(obiit), Pere Figuerola de Joan, Pere Navarro de Antoni(obiit), Bertomeu Mas de Jaume, Francesc Pasqual de Joan(obiit), Joan Miralles de Pere(Jubilat i tret), Pere Bosch de Miquel (obiit), Jaume Bonet, Joan Figuerola de Joan, Nicolau Alegre de Joan, Nicolau Giner de Joan(obiit)(nombre tachado), Pere Vilarroig major de Antoni(obii), Bertomeu Giner de Nicolau, Francesc Romeu de Bertomeu(obiit), Pere Gisbert(obiit), Jaume Bernat de Vicent(jubilat), Bertomeu Bonet de Nicolau, Miquel Giner de Nicolau(obiit) Joan Sanchís de Joan, Joan Agulló(pagament), Jaume Micó de Breva, Joan Figuerola de Francesc, Miquel Museros, Joan Bosch menor de Pere, Miquel Planell(obiit), Joan Giner de Nicolau, Domingo Molina, Pere March(obiit)(nombre tachado), Andreu Pasqual (obiit)Joan Vilarroig, Antoni Castell de Francesc(obiit), Batiste Gisbert i Miquel Navarro. 


\section{Insaculación 1598}

(AHMC. Judiciari. 1596-1599. Sesión del Consell de 23 de abril de 1598).

De la bossa o sach de cavallers: Micer Cristòfol Miralles cavaller doctor en dret, Pere de Reus cavaller, Nicolau de Reus cavaller, Pere Miguel cavaller i Gerony Miquel cavaller.

De la bossa o sach de Jurat en cap : Narcís Feliu, Melchor Serra, March Arrufat notari, Miquel Jaume Serra, Miquel Giner, Llorens Sisternés, Micer Gerony Jover, Micer Tomàs March, Antoni Joan Lleó, Joan Bernat, Francesc Jover menor, Antoni Pedro, Cristòfol de Sisternés, Nicolau Feliu i Cristòfol Gascó.

De la bossa o sach de Jurat segon: Gaspar Brunell notari, Josep Mas notari, Joan Vilarroig major, Baltazar Peris notari, Nicolau Brunell, Joan Castell notari, Guillem Alfagueri, Tomàs Moliner, Bertomeu Moliner notari, Jaume Sabera i Miquel Carnicer. Dels que foren atrobats inseculats en dit sach de jurat segon ni hagué dos que tingueren més faves negres que blanques los quals foren los següents: Miquel Navarro i Agostí Llorach.

De la bossa o sach de jurat tercer o quart: Francesc Navarro de Antoni, Jaume Alegre, Pere Navarro de Antoni, Pere Mas, Francesc Navarro de Francesc, Bertomeu Mas, Jaume Bonet, Nicolau Alegre, Francesc Romeu, Bertomeu Bonet, Joan Sanchís, Jaume Micó de Sisternés, Miquel Museros, Pere Bosch de Miquel, Joan Figuerola de Joan, Bertomeu Giner, Batiste Gisbert, Miguel Sanchís, Antoni Figuerola, Pere Pasqual, Andreu Figuerola, Martí Castell, Miquel Flors, Pere Vilarroig, Gabriel Agramunt, Joan Vilarroig de Bertomeu, Miquel Pasqual i Agostí Molinos.

De la bossa o sach de consellers de mà major: Joan Ferrer. De la mateixa boça Miquel Joan Català tingué més faves negres que blanques. A continuación serían de mano menor(suposición). Nicolau Coll, Joan Boses, Miquel Planell, Domingo Molina, Miquel Navarro, Joan Figuerola de Francesc, Joan Bosch de Pere, Joan Giner de Nicolau. Del qual sach ni hagué un que tingué mes faves negres que blanques lo qual fonch Martí Avinent menor. 


\section{Insaculación 1600}

(AHMC. Llibre de les Insaculacions. ff. 44-46).

Any 1600

Memorial de les persones que són estades atrobades inseculades i abils per a poder correr als oficis de la vila en lo any MDC

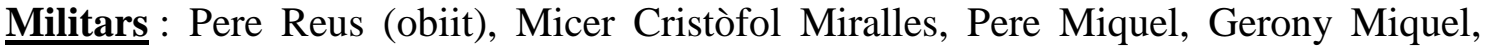
Nicolau de Reus. Anotados en letras muy pequeñas: Mateu Ros, Pere Morales, Martí Arrufat i Gerony Arrufat.

Bras Real per a Jurats en Cap: Cosme Feliu, Cosme Martí, Lluís Agramunt (nombre tachado) (obiit), Narcís Feliu (nombre tachado) (obiit), Melchor Serra (nombre tachado) (obiit), March Arrufat (nombre tachado) (obiit), Se intuye un nombre más pero está cortado el papel y no se puede ver, Pere Francesc Albiol, Gaspar Gombau, Jaume (nombre tachado que no se puede ver) (obiit), Doctor Miquel Jaume Serra (obiit), Miquel Giner, Llorens Sisternés (obiit), Francesc Jover notari, Micer Gerony Jover, Micer Tomàs March, Bernat Pardo (nombre tachado) (obiit), Micer Gaspar Mascarós, Antoni Lleó, Francesc Jover Lleó, Antoni Pedro (nombre tachado) (obiit), Cristòfol Sisternés, Joan Bernat (nombre tachado) (obiit) i Cristòfol Gascó (obiit).

Per a Jurats Segon: Miquel Serra notari(nombre tachado) (obiit), Gaspar Brunell notari, Gerony Folch, Domingo Beltrán notari, Josep Mas notari, Tomàs Moliner, Baltazar Peris(nombre tachado)(obiit), Jaume Giner notari, Joan Castell notari(nombre tachado) (obiit), Pau Capero, Miquel Aragonés, Bertomeu Moliner notari, Melchor Salvador notari, Miquel Mas notari, Francesc Joan Bou notari, Miquel Carnicer, Joan Moreno (nombre tachado) (obiit), Miquel Navarro (obiit), Antoin Fabreo (no se entiende), Jaume Sabera i Agostí Llorach.

Jurats Tercer: Joan Andreu, Francesc Navarro de Antoni, Pere Navarro (nombre tachado) (obiit), Pere Mas, (nombre tachado que no se puede leer), (nombre tachado que no se puede leer), Miquel Jaume Jover(nombre tachado) (obiit), Francesc Navarro(nombre tachado) (obiit), Pere Figuerola de Joan, Bertomeu Mas (obiit), Jaume Bonet, Bertomeu Bonet, Joan Sanchís, Nicolau Alegre (nombre tachado) (obiit), Jaume Micó (nombre tachado) (obiit), Miquel Museros (obiit), Joan Vilarroig major, Joan 
Figuerola de Joan, Bertomeu Giner, Batiste Gisbert (obiit), Pere Museros, Andreu Pasqual, Martí Castell, Pere Vilarroig, Gabriel Agramunt, Miquel Pasqual, Agostí Molinos (obiit), Joan Bosch major (nombre tachado) i Joan Agulló.

Per al ofici de Justicia: Cosme Feliu (nombre tachado) (obiit), Cosme Martí, Narcís Feliu, Melchor Serra (nombre tachado), March Arrufat (nombre tachado), Baltazar Peris (nombre tachado), Pere Francesc Albiol, Gaspar Brunell, Francesc Jover notari, Domingo Beltrán (obiit), Bertomeu Bonet, Miquel Jaume Serra, Micer Tomàs March, Lluís Agramunt (obiit), Miquel Giner, Llorens Sisternés, Miquel Serra (nombre tachado), Joan Castell (nombre tachado), Bertomeu Moliner, Micer Gerony Jover, Bernat Pardo (nombre tachado) (obiit), Micer Gaspar Mascarós (obiit), Antoni Lleó, Joan Ferrer (obiit), Francesc Jover menor, Antoni Pedro (nombre tachado) (obiit), Cristòfol Sisternés, Joan Bernat (obiit), Cristòfol Gascó (obiit), Joan Giner (obiit), Miquel Mas (obiit), Antoni Lleó, Joan Ferrer (obiit), Francesc Jover menor (obiit), Antoni Pedro (nombre tachado) (obiit), Cristòfol Sisternés, Joan Bernat (obiit), Cristòfol Gascó (obiit), Miquel Navarro (obiit), Gaspar Pere Granyena i Jaume Giner notari.

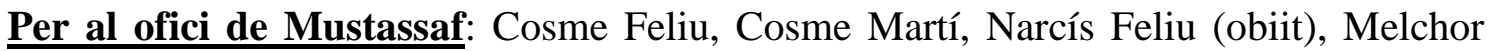
Serra (obiit), había un nombre escrito pero se ha quemado el final de la hoja. Pere Francesc Albiol, Joan Castell (obiit), Francesc Jover notari, Domingo Beltrán notari, Tomàs Moliner (obiit), March Arrufat (obiit), Jaume Bonet, Joan Figuerola de Joan, Bertomeu Bonet, Batiste Gisbert (obiit), Miquel Jaume Serra (obiit), Lluís Agramunt (obiit), Miquel Giner, Llorens Sisternés (obiit), Gaspar Pere Granyena, Miquel Serra (obiit), Josep Mas, Baltazar Peris (obiit), Bertomeu Moliner (obiit), Joan Vilarroig (jubilat), Micer Gerony Jover, Micer Tomàs March (nombre tachado), Micer Gaspar Mascaròs (obiit), Bernat Pardo (obiit), Antoni Lleó, Joan Ferrer (obiit), Francesc Jover menor(obiit), Antoni Pedro (obiit), Cristòfol Sisternés, Joan Bernat (obiit), Cristòfol Gascó (obiit), Miquel Navarro (obiit), Francesc Joan Bou, Melchor Salvador, Miquel Mas (obiit), Baltazar Gombau, Jaume March (obiit), Gaspar Vicent Gombau, Jaume Giner, Jaume Sabera, Joan Sanchís, Joan Giner i Gabriel Segarra de Josep.

Per al ofici de sequier: Joan Andreu, Francesc Navarro de Antoni, Pere Navarro (obiit), Jaume Bonet, Nicolau Alegre, Bertomeu Bonet, Joan Sanchís, Jaume Micó (obiit), Miquel Museros, Domingo Molina, Miquel Navarro, Pere Mas, Miquel Jaume Jover, 
Francesc Navarro de Francesc, Joan Vilarroig, Batiste Gisbert, Pere Figuerola de Joan, Bertomeu Mas, Joan Figuerola de Joan, Joan Bosch menor de Pere, Joan Giner, Nicolau Coll, Pere Museros, Andreu Pasqual, Miquel Sanchís, Andreu Figuerola (obiit), Martí Castell (obiit), Miquel Flors major (Jubilat), Pere Vilarroig, Gabriel Agramunt, Joan Vilarroig de Agramunt, Miquel Pasqual, Agostí Molinos (obiit), Miquel Planell, Francesc Alegre, Miquel Alberich, Lluís Mas de Pere, Antoni Pastor, Antoni Ribes, Gerony Vidal, Monserrat Martí, Antoni Navarro, Jaume Roig major, Miquel Planell, Francesc Mas, Berenguer Castell, Pere Marqués, (nombre tachado que no se puede leer), Antoni (...), Pere Eiximeno, Joan (Morán) i Pere Ribalta.

Consellers de mà maior: Cosme Feliu (nombre tachado), Cosme Martí, Narcís Feliu, Melchor Serra (nombre tachado), March Arrufat (nombre tachado), Miquel Serra (nombre tachado), Gaspar Brunell, Domingo Beltrán, Josep Mas, Baltazar Peris (nombre tachado), Tomàs Moliner, Joan Castell (nombre tachado), Miquel Joan Català (nombre tachado), Miquel Jaume Serra, Lluís Agramunt, Francesc Jover notari, Pere Francesc Albiol, Miquel Aragonés, Bertomeu Moliner, Joan Gerony Folch, Micer Gerony Jover, Micer Tomàs March, Micer Gaspar Mascarós, Bernat Pardo (nombre tachado), Antoni Lleó, Joan Ferrer, Francesc Jover menor, Antoni Pedro (nombre tachado), Cristòfol Sisternés, Joan Bernat, Cristòfol Gascó, Miquel Navarro (nombre tachado), Francesc Joan Bou, Melchor Salvador, Miquel Mas, Jaume Sabera, Miquel Carnicer i Agostí Llorach.

Consellers de mà menor: Joan Andreu, Francesc Navarro de Antoni, Pere Navarro (nombre tachado) (obiit), Pere Mas, Francesc Navarro major (nombre tachado) (obiit), Pere Figuerola, Bertomeu Mas, Jaume Bonet, Nicolau Alegre, Bertomeu Bonet, Joan Sanchís, Jaume Micó(nombre tachado) (obiit), Miquel Museros, Domingo Molina, Miquel Navarro, Joan Figuerola de Joan, Bertomeu Giner, Joan Figuerola de Francesc, Joan Bosch menor de Pere (nombre tachado)(obiit), Joan Giner de Nicolau, Joan Vilarroig de Joan, Batiste Gisbert, Nicolau Coll, Pere Museros, Andreu Pasqual, Miquel Sanchís, Antoni Figuerola (nombre tachado) (obiit), Andreu Figuerola, Martí Castell, Miquel Flors major (nombre tachado), Pere Vilarroig, Gabriel Agramunt, Joan Vilarroig de Bertomeu, Miquel Pasqual i Agostí Molinos. 
Per al ofici de escrivà de la Sala: Miquel Serra notari, Miquel Gascó notari, Baltazar Peris (nombre tachado) (obiit), Gaspar Brunell notari, Marc Arrufat notari(nombre tachado) (obiit), Joan Gerony Folch notari, Francesc Jover notari, Domingo Beltrán notari (obiit), Bertomeu Moliner notari (obiit), Melchor Salvador notari, Miquel Mas notari (obiit), Francesc Joan Bou notari i Jaume Giner notari.

Jurat tercer i quart: Domingo Moliner (nombre tachado) (obiit), Miquel Navarro, Miquel Sanchís, Nicolau Coll, Joan Giner (obiit), Joan Figuerola de Francesc, Miquel Planell, Francesc Alegre, Miquel Alberich, Lluís Mas, Antoni Pastor (obiit), Antoni Ribes i Gerony Vidal.

Consellers nou de mà menor requiera: Miquel Planell, Francesc Alegre, (A...) Alberich, Lluís Mas, Antoni Pastor, Antoni Ribes, Gerony Vidal, Monserrat Martí, Antoni Navarro, Jaume Roig major (obiit), Francesc Mas, Berenguer Castell (obiit), Pere Marqués, Jaume Bonet Segarra, Antoni Castell, Pere Eiximeno, Joan Morán (obiit), Pere Ribalta (anotación a la izquierda que no entiendo), Joan Bosch i Gabriel Segarra.

Consellers de mà major: Baltazar Gombau, Jaume March, Gaspar Gombau, Jaume Giner notari, Pau Capero notari, Joan Moreno cirurgià, Antoni Fabregat cirurgià, Pere (.....),Joan Sanchís i Joan Giner. 


\section{Insaculación 1623}

(AHMC. Judiciari. 1621-1625. Sesión del Consell del 5 de septiembre de 1623).

Die V mensis septembris anno

a nostre senor MDCXIII

Inseguint una aprovisió conciliar feta per lo concell de la dita vila de Castelló de (...) (...), proposat per Francesc de Reus cavaller subrogat de lloctinent de portantveus de General Governador de la ciutat i regne de Valencia(...) (...), Gerony Igual, ciutadà Balle per sa Magestat en la present vila de Castelló de la Plana, Pere March ciutadà subdelegat de Antoni Joan Lleó ciutadà, Justicia de la Vila de Castelló, Micer Jaume Bonet de (...), Pere Joan Vicent sirurjià, Antoni Ribes i Joan Bosch jurats de la dita vila de Castelló en lo present any. Congregats i ajuntats en lo palau de la casa de la dita vila e convocat mi Francesc Joan Bou, scrivà de dita sala, uberta la caixa dels noms de les persones habilitades per a officis e (...) de la vila de Castelló, foren mesis e posades en los sachs de la caixa les persones següents: en la bossa de militars: Nicolau de Reus, Mateu Ros major, Pere Morales, Gerony Arrufat, Joan Arrufat, Pere Arrufat, Francesc de Reus, March Mascarós menor, Pere Miquel i Mateu Miralles.

Los abilitats per a offici de justicia: Gaspar Vicent Gombau, Miquel Giner ciutadà, Baltazar Gombau, Pau Capero notari, Cristòfol de Sisternés, Micer Bernat Gascó, Micer Jaume Bonet, Melchor Salvador notari, Micer Miquel Moliner, Macià Gascó, Micer Tomàs March, Joan Gerony Folch, Francesc Joan Bou notari, Micer Batiste Gascó, Pere Joan Martí ciutadà, Salvador Lluís Mas, Francesc Mas labrador, Cosme Martí ciutadà, Pere Museros labrador, Gerony Quevedo notari, Martí Giner notari, Nicolau Serra ciutadà, Joan Baptiste Vallés, Antoni Joan Lleó ciutadà, Lo Doctor Bernat Berenguer, Pere March ciutadà, Gaspar Serra ciutadà, Salvador Gerony Jover, Lluís Mas llaurador i Miquel Alberich no se posa per lo pleit. Essent testimonis a estes coses Jaume Fons i Jaume Grases nuncio.

A lo offici de jurat en cap: Miquel Giner ciutadà (insac.), Gaspar Vicent Gombau (insac.), Baltazar Gombau (insac.), Cristòfol de Sisternés (insac.), Macià Gascó (insac.), Micer Miquel Moliner, Lo doctor Bertomeu Giner, Pere Joan March ciutadà, Lluís Andreu ciutadà, Micer Tomàs March, Antoni Joan Lleó ciutadà, Cosme Martí ciutadà, Pere March ciutadà, Micer Bernat Gascó ciutadà, Micer Jaume Bonet, Micer Batiste 
Gascó, Lo doctor Lluís Mas, Nicolau Serra ciutadà, Lo doctor Gerony Jover i Micer Pere Nicolau Figuerola.

Al offici jurat segon: Joan Gerony Folch notari (obiit), Melchor Salvador notari, Llorens Gascó notari, Gerony Quevedo notari, Pere Joan Vicent cirurgià, Jaume Blasco mercader, Martí Giner notari, Francesc Jover de Sunyer notari, Gaspar Moliner cirurgià, Jaume Castellet notari, Gabriel Ferrer mercader, Gabriel Bonet, Pau Pavia mercader, Gaspar Martí Serer, Pau Capero notari, Luis Cristòfol Bou notari, Francesc Joan Bou notari, Ventura Pasqual, Joan Baptiste Vallés notari i Gregori Sabera. No se posen redolons per lo pleit ab Melchor Amiguet.

Als officis de jurat tercer e quart : Miquel Museros, Miquel Ventura Pasqual, Miquel Pasqual, Pere Museros de Narcís, Andreu Pasqual, Nicolau Coll, Antoni Castell, Francesc Mas, Francesc Alegre, Pere Eiximeno, Miquel Vilarroig, Joan Vilarroig de Bertomeu, Francesc Vilarroig, Nicolau Alegre, Jaume Alegre, Andreu March, Miquel Lluch Sanchís, Miquel Sanchís de Joan, Mateu Sanchís, Monserrat Martí, Gabriel Segarra, Batiste Lorens, Miquel Rubert, Joan Vilarroig de Pere, Francesc Castell de Berenguer, Miquel Castell de Antoni, Gaspar Navarro, Cosme Segarra, Berenguer Ribalta, Joan Giner de Joan, Antoni Ribes, Joan Bosch, Miquel Navarro, Pere Museros, Pere Marqués, Lluís Mas, Miquel Alberich, Martí Castell, Pere Alegre i Joan Agulló.

Al offici de mustassaf : Joan Gerony Folch notari, Miquel Giner ciutadà, Micer Tomàs March, Antoni Joan Lleó ciutadà, Francesc Joan Bou notari, Baltazar Gombau ciutadà, Pere March ciutadà, Lo doctor Bertomeu Giner, Micer Batiste Gascó, Micer Bernat Gascó, Pau Capero notari, Batiste Serra ciutadà, Lo doctor Lluís Mas, Pere Joan Vicent sirurgià, Batiste Vallés notari, Jaume Blasco mercader, Gaspar Gombau ciutadà, Martí Giner notari, Micer Miquel Moliner, Cristòfol Sisternés ciutadà, Melchor Salvador, Micer Jaume Bonet, Miquel Vicent Pasqual llaurador, Macià Gascó, Pere Joan Martí ciutadà, Cosme Martí ciutadà, Llorens Gascó notari, Francesc Jover de de Sunyer notari, Andreu Pasqual, Nicolau Serra ciutadà, Micer Nicolau Figuerola, Lluís Andreu ciutadà, Gabriel Bonet, Luis Cristòfol Bou notari, Francesc Mas llaurador, Miquel Sanchís llaurador, Francesc Alegre llaurador, Pere Eiximeno llaurador, Andreu March llaurador i Lluís Mas llaurador. Die VI mensis septembris DCXXIII. 
Foren posats per al offici de cequier los noms de les persones següents : Nicolau Coll, Pere Museros de Pere, Francesc Mas, Antoni Castell, Lluís Mas, Baltazar Gombau ciutadà, Miquel Giner ciutadà, Gabriel Segarra ciutadà, Francesc Joan Bou notari, Miquel Navarro, Miquel Museros, Joan Vilarroig de Bertomeu, Francesc Alegre, Miquel Alberich, Antoni Ribes, Monserrat Martí, Pere Marqués, Pere Eiximeno, Antoni Joan Lleó ciutadà, Pere March ciutadà, Pere Museros de Narcís, Cristòfol de Sisternés ciutadà, Gaspar Gombau ciutadà, Macià Gascó, Melchor Salvador notari, Pere Joan March, Miquel Lluch Sanchís, Lluís Salvador ciutadà, Batiste Serra, Miquel Sanchís de Joan, Miquel Rubert, Miquel Pasqual, Andreu Pasqual, Nicolau Serra ciutadà, Gerony Jover ciutadà, Francesc Jover de Sunyer notari, Pau Capero notari, Cosme Martí ciutadà, Jaume Blasco mercader, Batiste Moliner cirurgià, Martí Giner notari, Nicolau Alegre, Pau Pavia mercader, Joan Bosch de Joan, Francesc Vilarroig, Miquel Vicent Pasqual, Jaume Alegre, Miquel Fores, Gerony Quevedo notari, Pere Vilarroig Jubilat, (mort) Antoni Navarro (mort) i (...) Joan Ber(...) Batiste (...) llaurador de Castelló.

Die X mensis may anno MDCXXIII los dits Francesc de Reus cavaller subrogat de governador, Macià Igual ciutadà, Pere Arrufat cavaller justicia, Jaume Bonet doctor en dret Antoni Ribes i Joan Bosch jurats de la vila de Castelló. Lluís Mas síndich de la dita vila en convocat a Francesc Joan Bou notari escrivà de la sala expresura (...)in proseguint les provisió conciliam feta ací (...) (...) posaren en redolins per al govern de la dita vila les persones següents:

Primer per al offici de scrivà de la sala del Consell : Joan Gerony Folch, Francesc Joan Bou, Melchor Salvador, Pau Capero, Joan Baptiste Vallés, Francesc Jover de Sunyer, Gerony Quevedo i Martí Giner.

Proseguint als conceler de la dita vila de Castelló. Els noms de aquelles foren posats en redolins les persones següents:

Concellers de ma maior : Antoni Joan Lleó, Miquel Giner, Gaspar Gombau, Baltazar Gombau, Cristòfol Sisternés, Cosme Martí, Macià Gascó, Pere Joan Martí, Pere March, Lluís Andreu, Nicolau Serra, Micer Tomàs March, Micer Miquel Moliner, Micer Bernat Gascó, Micer Jaume Bonet, Micer Joan Batiste Gascó, Batiste Serra, Micer Nicolau Figuerola, Lo doctor Bertomeu Giner, Lo doctor Lluís Mas, Gerony Jover doctor, (obiit) Joan Gerony Folch, Melchor Salvador, Francesc Joan Bou, Pau Capero, Joan Batiste 
Vallés, Gerony Quevedo, Llorens Gascó, Francesc Joan de Sunyer, Martí Giner, Cristòfol Bou, Jaume Castellet, Miquel Pasqual Ventura, Pere Joan Bosch, Batiste Moliner, Jaume Blasco, Pau Pavia, Gabriel Ferrer, Gabriel Bonet, Melchor Amiguet, Gaspar Martí, Gerony Jover i Joan Gerony Folch. Cristòfol Bou notari i Jaume Fons verguers de Castelló.

Los consellers de mà menor de la vila de Castelló : Pere Museros, Miquel Forés, Pere Sunyer de Narcís, Miquel Museros, Miquel Pasqual, Andreu Pasqual, Miquel Vicent Pasqual, Nicolau Coll, Antoni Castell, Antoni Ribes, Francesc Mas, Lluís Mas, Miquel Alberich, Francesc Alegre, Pere Eximeno, Miquel Vilarroig, Nicolau Alegre, Jaume Alegre, Andreu March, Miquel Lluch Sanchís, Miquel Sanchís de Joan, Monserrat Martí, Joan Bosch, Gabriel Segarra, Batiste Llorens, Mateu Sanchís, Francesc Vilarroig, Pere Marqués, Miquel Rubert, Joan Vilarroig de Bertomeu, Joan Vilarroig de Pere, Martí Castell, Francesc Castell de Berenguer, Miquel Castell de Antoni, Gaspar Navarro, Pere Alegre, Cosme Segarra, Berenguer Ribalta, Joan Giner, Joan Agulló i (obiit) Miquel Navarro. (...) Jaume Fons i Gabriel Macana verguers de jurat de la vila de Castelló. 


\section{Insaculación 1630}

(AHMC. Llibre de les Insaculacions. ff. 66-69).

Memorial de les persones que estan insaculades per al govern de la vila de Castelló, així de les persones que estan insaculades com les que se li han insaculat en lo any de MDCXXX en set(...) del mes de gener.

\section{Insaculació de l'any MDCXXX}

1630

Bossa Militars: 1. Gaspar Vich de Gombau, 2. Mateu Ros (obiit), 3. Pere Morales (obiit), 4. Joan Arrufat (obiit), 5. Pere Reus (obiit), 6. Francesc Reus (obiit), 7. Gerony Arrufat (obiit), 8. Gaspar Vich de Gombau i 9. Mateu Ros (obiit).

Bossa de Jurat en cap del Bras Real: 1. Dionís Jover Doctor (obiit), 2. Lluch Andreu (obiit), 3. Micer Batiste Gascó, 4. Macià Gascó (obiit), 5. Micer Bernat Gascó (obiit), 6. Pere Joan Martí (obiit), 7. Micer Miquel Moliner (obiit), 8. Doctor Cristòfol Sisternés (obiit), 9. Bertomeu Giner Doctor (obiit), 10. Cosme Martí (obiit), 11. Micer Nicolau Figuerola (obiit), 12. Nicolau Serra, 13. Batiste Serra, 14. Micer Fulgenci Mascarós (obiit), 15. Francesc Romeu (obiit), 16. Agostí Agramunt, 17. Micer Cosme Feliu, 18. Micer March Antoni Feliu (obiit), 19. Gerony Feliu (obiit) i 20. Batiste Vallés (obiit).

Bossa segona lo sach de jurat segon: 1. Gabriel Bonet, 2. Pau Capero notari (obiit), 3. Pau Pavia (obiit), 4. Melchor Amiguet, 5. Cristòfol Bou, 6. Jaume Castellet notari, 7. Miquel Bonaventura Pasqual (obiit), 8. Pere Joan Vicent, 9. Jaume Blasco, 10. Batiste Moliner, 11. Gabriel Ferrer, 12. Gaspar Martí, 13. Joan Martí notari (obiit), 14. Batiste Traver notari (obiit), 15. Jaume Andreu notari, 16. Joan Planell (obiit) i 17. Pere Giner notari.

Bossa lo sach de Jurat tercer i quart: 1. Miquel Pasqual (obiit), 2. Pere Eiximeno (obiit), 3. Batiste Llorens, 4. Cosme Segarra, 5. Miquel Lluch Sanchís (obiit), 6. Nicolau Coll, 7. Martí Castell, 8. Pere Marqués, 9. Francesc Castell, 10. Joan Vilarroig de Bertomeu (obiit), 11. Francesc Alegre, 12. Mateu Sanchís, 13. Nicolau Alegre(obiit), 14. Miquel Castell, 15. Miquel Vicent Pasqual(obiit), 16. Pere Museros de Narcís(obiit), 17. Monserrat Martí (obiit), 18. Pere Alegre, 19. Francesc Mas, 20. Jaume Alegre (obiit), 21. Antoni Ribes (obiit), 22. Andreu March(obiit), 23. Joan Bosch (obiit), 24. 
Joan Vilarroig de Pere, 25. Lluís Mas, 26. Antoni Castell, 27. Francesc Vilarroig (obiit), 28. Berenguer Ribalta, 29. Miquel Rubert (obiit), 30. Gaspar Navarro (obiit), 31. Joan Giner (obiit), 32. Francesc Pasqual (obiit), 33. Baltazar Avinent, 34. Monserrat Museros, 35. Miquel Giner, 36. Cosme Vidal, 37. Cosme Reboll, 38. March Casalís, 39. Joan Vilarroig de Miquel i 40. Joan Navarro de Miquel.

Bossa de Justicia: 1. Macià Gascó (obiit), 2. Doctor Bertomeu Giner (obiit), 3. Cosme Martí (obiit), 4. Micer Miquel Moliner(obiit), 5. Nicolau Serra, 6. Pau Capero (obiit), 7. Lluís Mas, 8. Baltazar Serra, 9. Doctor Dionís Jover (obiit), 10. Joan Batiste Vallés(obiit), 11. Micer Bernat Gascó (obiit), 12. Micer Joan Batiste Gascó (obiit), 13. Cristòfol de Sisternés, 14. Pere Joan Martí (obiit), 15. (nombre tachado), 16. Gabriel Bonet, 17. Lluís Cristòfol Bou, 18. Miquel Bonaventura Pasqual (obiit), 19. Pere Alegre, 20. Micer Cosme Feliu, 21. Gaspar Joan Brunell (obiit), 22. Francesc Alegre, 23. Francesc Bou, 24. Francesc Romeu (obiit), 25. Micer Fulgenci Mascarós (obiit), 26. Nicolau Pauner (obiit), 27. Micer Nicolau Figuerola, 28. Jaume Aragonés (obiit), 29. Melchor Amiguet i 30. Pere Joan Vicent.

Bossa lo sach de Mustassaf : 1 . Miquel Vicent de Pasqual (obiit), 2. Nicolau Serra, 3. Gabriel Bonet, 4. Jaume Blasco, 5. Pere Joan Vicent, 6. Pau Capero (obiit), 7. Lluch Andreu (obiit), 8. Pere Eximeno, 9. Micer Miquel Moliner (obiit), 10. Cosme Martí, 11. Lluís Mas, 12. Micer Joan Batiste Gascó, 13. Joan Batiste Vallés (obiit), 14. Francesc Alegre (obiit), 15. Cristòfol Sisternés (obiit), 16. Pere Joan Martí (obiit), 17. Francesc Mas, 18. Cristofol Bou (notari), 19. Micer Nicolau Figuerola (obiit), 20. Micer Bernat Gascó (obiit), 21. Doctor Bertomeu Giner, 22. Batiste Serra, 23. Miquel Lluch Sanchís (obiit), 24. Macià Gascó (obiit), 25. Andreu March, 26. Martí Castell, 27. Batiste Moliner, 28. Gaspar Martí, 29. Melchor Amiguet, 30. Francesc Romeu, 31. Francesc Bou, 32. Micer Fulgenci Mascarós, 33. Micer March Antoni Feliu, 34. Jaume Aragonés, 35. Joan Bernat, 36. Gabriel Ferrer, 37. Jaume Castellet, 38. Pau Pavia (obiit), 39. Gerony Feliu (obiit) i 40. Doctor Dionís Jover (obiit).

Bossa lo sach de Cequier: 1. Francesc Mas, 2. Lluch Andreu (obiit), 3. Antoni Ribes (obiit), 4. Pere Eiximeno (obiit), 5. Pere Joan Martí(obiit), 6. Lluís Mas, 7. Pau Capero (obiit), 8. Francesc Vilarroig (obiit), 9. Jaume Blasco, 10. Francesc Alegre(obiit), 11. Miquel Rubert(obiit), 12. Joan Bosch (obiit), 13. Nicolau Serra, 14. Miquel Lluch 
Sanchís (obiit), 15. Pere Marqués (obiit), 16. Cristòfol Sisternés, 17. Pere Museros de Narcís(obiit), 18. Pau Pavia(obiit), 19. Antoni Castell, 20. Miquel Pasqual, 21. Nicolau Coll, 22. Cosme Martí (obiit), 23. Monserrat Martí (obiit), 24. Jaume Alegre (obiit), 25. Joan Vilarroig de Bertomeu (obiit), 26. Macià Gascó (obiit), 27. Nicolau Alegre (obiit), 28. Batiste Moliner, 29. Batiste Serra, 30. Miquel Bonavetura de Pasqual (obiit), 31. Francesc Moliner, 32. Cosme Segarra, 33. Mateu Sanchís, 34. Pere Alegre, 35. Batiste Llorens, 36. Antoni Navarro (obiit), 37. Andreu March, 38. Francesc Castell de Francesc, 39. Joan Navarro, 40. Joan Granyana, 41. Pere Castellet, 42. Miquel Castell de Antoni, 43. Berenguer Ribalta, 44. Jaume Rubert, 45. Miquel Boix, 46. Pere Figuerola, 47. Joan Godes (obiit), 48. Gaspar Navarro (obiit), 49. Francesc Castell de Berenguer (obiit) i 50. Martí Castell.

Bossa lo sach de escrivans: 1. Pau Capero notari (obiit), 2. Cristòfol Bou notari, 3. Pere Giner notari, 4. Jaume Castellet notari, 5. Joan Batiste Traver notari (obiit) i 6. Joan Planell notari (obiit).

Bossa lo sach de consellers de mà major: 1. Pau Capero notari (obiit), 2. Micer Miquel Moliner, 3. Melchor Amiguet, 4. Micer Joan Batiste Gascó, 5. Macià Gascó, 6. Micer Nicolau Figuerola, 7. Cosme Martí, 8. Batiste Moliner, 9. Pere Joan Martí, 10. Jaume Blasco, 11. Doctor Bertomeu Giner (obiit), 12. Gabriel Ferrer, 13. Doctor Dionís Jover (obiit), 14. Miquel Bonaventura Pasqual (obiit), 15. Nicolau Serra, 16. Cristòfol Sisternés, 17. Cristòfol Bou notari, 18. Micer Bernat Gascó, 19. Batiste Serra, 20. Jaume Castellet notari, 21. Pere Joan Vicent, 22. Lluch Andreu (obiit), 23. Gaspar Martí, 24. Joan Batiste Vallés (obiit), 25. Gabriel Bonet, 26. Pau Pavia (obiit), 27. Micer Fulgenci Mascaros, 28. Francesc Romeu, 29. Agostí Agramunt, 30. Micer Cosme Feliu, 31. Micer March Antoni Feliu (obiit), 32. Gerony Feliu (obiit), 33. Jaume Aragonés, 34. Francesc Bou, 35. Nicolau Pauner, 36. Gaspar Joan Brunell, 37. Joan Bernat, 38. Pere Giner, 39. Joan Planell, 40. Joan Martí, 41. Batiste Traver notari i 42. Jaume Andreu notari.

Bossa lo sach de consellers de mà menor: 1. Gaspar Navarro, 2. Joan Bosch de Joan, 3. Pere Lleonart espardenyer (nombre tachado) (obiit), 4. Antoni Castell, 5. Miquel Castell, 6. Miquel Vicent Pasqual, 7. Francesc Alegre, 8. Joan Ferrer Teixidor, 9. Francesc Mas, 10. Joan Giner (nombre tachado) (obiit), 11. Pere Eiximeno, 12. Cosme 
Segarra, 13. Mateu Sanchís, 14. Andreu March, 15. Berenguer Ribalta, 16. Pere Marqués, 17. Pere Museros de Narcís, 18. Monserrat Martí, 19. Miquel Pasqual, 20. Antoni Ribes, 21. Nicolau Coll, 22. Nicolau Alegre, 23. Jaume Alegre de Jaume, 24. Miquel Lluch Sanchís, 25. Andreu Duenyes Sastre (obiit), 26. Martí Castell, 27. Joan Vilarroig de Bertomeu, 28. Miquel Rubert, 29. Francesc Castell de Berenguer, 30. Joan Vilarroig de Pere, 31. Francesc Vilarroig de Pere, 32. Pere Alegre, 33. Batiste Llorens, 34. Lluís Mas, 35. Francesc Pasqual, 36. Baltazar Avinet, 37. Monserrat Museros, 38. Miquel Giner, 39. Cosme Vidal, 40. Cosme Reboll, 41. March Casalís, 42. Joan Vilarroig de Miquel, 43. Joan Navarro, 44. Francesc Moliner, 45. Antoni Navarro, 46. Francesc Castell de Francesc, 47. Joan Granyena, 48. Jaume Rubert, 49. Pere Castellet, 50. Miquel Boix, 51. Pere Figuerola, 52. Joan Godes i 53. Antoni Portolés. 


\section{Insaculación de 1634}

(AHMC. Llibre de les Insaculacions. ff.70-72).

Insaculación en lo any de 1634

Bossa de Militars: 1. Gerony Arrufat, 2. Francesc Reus, 3. Pere Morales (obiit), 4. Pere de Reus, 5. Cristòfol Sisternés, 6. Bernat Ros, 7. Jaume Miquel (obiit) i 8. Francesc Sisternés.

Bossa lo sach de Jurat en cap del bras real: Batiste Serra, 2. Nicolau Serra, 3. Micer Miquel Moliner (obiit), 4. Micer Nicolau Figuerola (obiit), 5. Pere Joan Martí (obiit), 6. Agostí Agramunt, 7. Micer Cosme Feliu (obiit), 8. Micer Joan Batiste Gascó, 9. Cosme Martí (obiit), 10. Micer Bernat Gascó (obiit), 11. Macià Gascó (obiit), 12. Francesc Bou, 13. Nicolau Pauner (obiit), 14. Jaume Aragonés (obiit), 15. Vicent Albiol, 16. Jaume Jover, 17. Melchor Capero, 18. Miquel Romeu, 19. Gaspar Lluís Brunell, 20. Gaspar Joan Brunell (obiit).

Bossa segona lo sach de Jurat segon 1. Pere Giner notari, 2. Jaume Blasco, 3. Cristòfol Bou notari, 4. Joan Planell notari (obiit), 5. Joan Martí notari (obiit), 6. Jaume Andreu notari, 7. Gabriel Bonet, 8. Melchor Amiguet, 9. Batiste Moliner, 10. Batiste Traver notari (obiit), 11. Gabriel Ferrer, 12. Pere Joan Vicent, 13. Gaspar Martí, 14. Jaume Castellet notari, 15. Lluís Mas, 16. Pere Romeu notari, 17. Vicent Martí notari, 18. Salvador Martí, 19. Jaume March i 20. Jaume Castell mercader.

Bossa lo sach de Jurat tercer i quart: 1. Miquel Lluch Sanchís (obiit), 2. Miquel Castell, 3. Mateu Sanchís, 4. Monserrat Museros, 5. Baltazar Avinent, 6. Joan Navarro de Miquel, 7. Francesc Mas, 8. Miquel Vicent Pasqual (obiit), 9. Joan Vilarroig de Miquel, 10. Gaspar Navarro (obiit), 11. Andreu March, 12. Miquel Rubert (obiit), 13. Pere Eximeno (obiit), 14. March Casalís, 15. Pere Alegre, 16. Cosme Reboll, 17. Joan Bosch de Joan (obiit), 18. Francesc Vilarroig (obiit), 19. Martí Castell, 20. Miquel Pasqual (obiit), 21. Nicolau Alegre (obiit), 22. Miquel Giner, 23. Francesc Castell de Berenguer (obiit), 24. Antoni Castell, 25. Cosme Segarra, 26. Monserrat Martí (obiit), 27. Joan Vilarroig de Pere, 28. Cosme Vidal (obiit), 29. Francesc Pasqual (obiit), 30. Nicolau Coll, 31. Berenguer Ribalta, 32. Pere Marqués (obiit), 33. Francesc Alegre 
(obiit), 34. Batiste Llorens major, 35. Pere Castellet, 36. Francesc Moliner, 37. Joan Granyana (obiit) i 38. Batiste Llorens menor.

Bossa de Justicia: 1. Pere Joan Vicent cirurgià, 2. Melchor Amiguet apotecari, 3. Micer Nicolau Figuerola (obiit), 4. Gaspar Joan Brunell (obiit), 5. Nicolau Pauner, 6. Nicolau Serra, 7. Micer Miquel Moliner (obiit), 8. Cosme Martí (obiit), 9. Lluís March, 10. Francescc March, 11. Batiste Serra, 12. Gabriel Bonet, 13. Macià Gascó (obiit), 14. Francesc Bou, 15. Jaume Aragonés (obiit), 16. Pere Alegre, 17. Lluís Cristòfol Bou notari, 18. Micer Bernat Gascó (obiit), 19. Micer Cosme Feliu (obiit), 20. Pere Joan Martí (obiit), 21. Francesc Alegre (obiit), 22. Micer Joan Batiste Gascó, 23. Agostí Agramunt, 24. Miquel Mur Doctor en Medicina, 25. Jaume Jover, 26. Gaspar Lluís Brunell, 27. Batiste Jover, 28. Pere Giner notari, 29. Gabriel Ferrer i 30. Gaspar Martí.

Bossa lo sach de Mustassaf: 1. Pere Eiximeno (obiit), 2. Gaspar Martí, 3. Francesc Bou, 4. Batiste Moliner, 5. Francesc Mas, 6. Jaume Blasco (obiit), 7. Andreu March, 8. Micer Nicolau Figuerola (obiit), 9. Pere Juan Vicent, 10. Cosme Martí (obiit), 11. Micer Bernat Gascó (obiit), 12. Nicolau Serra, 13. Jaume Aragonés, 14. Miquel Pascual Vicent (obiit), 15. Gabriel Ferrer, 16. Cristòfol Bou, 17. Francesc Alegre (obiit), 18. Lluís Mas, 19. Pere Joan Martí (obiit), 20. Melchor Amiguet, 21. Gabriel Bonet, 22. Jaume Castellet notari, 23. Batiste Serra, 24. Martí Castell, 25. Micer Joan Batiste Gascó, 26. Miquel Lluch Sanchís (obiit), 27. Macià Gascó (obiit), 28. Micer Miquel Moliner (obiit), 29. Agostí Agramunt, 30. Jaume Jover, 31. Gaspar Joan Brunell (obiit), 32. Micer Cosme Feliu (noble), 33. Vicent Albiol, 34. Nicolau Pauner (obiit), 35. Melchor Capero, 36. Gaspar Lluís Brunell, 37. Joan Batiste Jover notari (obiit), 38. Joan Planell notari (obiit) i 39. Jaume Andreu notari.

Bossa de Cequier: 1. Andreu March, 2. Pere Figuerola (obiit), 3. Francesc Moliner, 4. Gaspar Navarro (obiit), 5. Miquel Vicent Pasqual (obiit), 6. Jaume Rubert (obiit), 7. Antoni Navarro (obiit), 8. Lluís March, 9. Francesc Castell de Berenguer (obiit), 10. Joan Godes (obiit), 11. Francesc Castell de Francesc, 12. Pere Castellet, 13. Miquel Boix (obiit), 14. Nicolau Coll, 15. Mateu Sanchís, 16. Miquel Castellet de Antoni, 17. Nicolau Serra, 18. Joan Granyena, 19. Monserrat Martí (obiit), 20. Pere Alegre, 21. Francesc Vilarroig (obiit), 22. Martí Castell, 23. Joan Navarro, 24. Cosme Segarra, 25. Batiste Moliner, 26. Berenguer Ribalta, 27. Miquel Lluch Sanchís (obiit), 28. Francesc 
Alegre (obiit), 29. Francesc March, 30. Nicolau Alegre (obiit), 31. Joan Bosch (obiit), 32. Jaume Blasco (obiit), 33. Batiste Serra, 34. Pere Marqués (obiit), 35. Macià Gascó (obiit), 36. Miquel Rubert (obiit), 37. Pere Eiximeno (obiit), 38. Batiste Llorens major, 39. Cosme Martí, 40. Pere Joan March (obiit), 41. Antoni Castell, 42. Miquel Pasqual (obiit), 43. Francesc Bou, 44. Joan Tormo, 45. Guillem Sanchís notari (obiit), 46. Jaume Muntanyés, 47. Mateu Tormo, 48. Bertomeu Navarro i 49. Cristòfol Castellet.

Bossa lo sach de escrivans: 1. Cristòfol Bou notari, 2. Pere Giner notari, 3. Joan Batiste Traver notari (obiit), 4. Joan Planell notari (obiit), 5. Jaume Castellet notari, 6. Jaume Andreu notari, 7. Pere Roig notari (obiit), 8. Vicent Martí notari i 9. Pere Romeu notari.

Bossa lo sach de consellers de mà major: 1. Jaume Castellet notari, 2. Nicolau Serra, 3. Pere Giner notari, 4. Joan Batiste Traver notari, 5. Batiste Moliner, 6. Jaume Aragonés (obiit), 7. Gabriel Bonet, 8. Micer Cosme Feliu (obiit), 9. Micer Joan Batiste Gascó, 10. Agostí Agramunt, 11. Francesc Bou, 12. Micer Bernat Gascó (obiit), 13. Jaume Blasco, 14. Batiste Serra, 15. Macià Gascó (obiit), 16. Cristòfol Bou notari, 17. Jaume Andreu notari, 18. Micer Miquel Moliner, 19. Pere Joan Vicent, 20. Melchor Amiguet, 21. Nicolau Pauner (obiit), 22. Cosme Martí (obiit), 23. Pere Juan Martí (obiit), 24. Joan Martí notari, 25. Gaspar Juan Brunell (obiit), 26. Micer Nicolau Figuerola (obiit), 27. Gabriel Ferrer, 28. Gaspar Martí, 29. Joan Planell notari (obiit), 30. Vicent Albiol, 31. Jaume Jover, 32. Melchor Capero, 33. Gaspar Lluís Brunell, 34. Miquel Romeu, 35. Lluís March, 36. Pere Romeu notari, 37. Vicent Martí, 38. Salvador Martí Cases, 39. Jaume March, 40. Jaume Castell mercader, 41. Miquel March Doctor en medicina, 42. Batiste Jover, 43. Joan Tormo, 44. Guillem Sanchís notari (obiit) i 45. Pere Roig notari.

Bossa lo sach de consellers de mà menor: 1. Joan Godes (obiit), 2. Francesc Moliner, 3. Gaspar Navarro (obiit), 4. Jaume Castell de Francesc, 5. Francesc Mas, 6. Martí Castell, 7. Miquel Giner, 8. Berenguer Ribalta, 9. Miquel Rubert (obiit), 10. Pere Castellet, 11. Cosme Vidal (obiit), 12. Joan Navarro, 13. Monserrat Museros, 14. Batiste Llorens major, 15. Pere Figuerola, 16. Nicolau Coll, 17. Pere Alegre, 18. Miquel Luch Sanchís (obiit), 19. Miquel Pasqual (obiit), 20. Joan Granyena, 21. Pere Eiximeno (obiit), 22. Andreu March, 23. Antoni Navarro, 24. Francesc Alegre (obiit), 25. Antoni Castell, 26. Baltazar Avinent, 27. March Casalís, 28. Jaume Rubert (obiit), 29. Nicolau 
Alegre, 30. Mateu Sanchís, 31. Francesc Pasqual (obiit), 32. Miquel Castell, 33. Francesc Castell de Berenguer (obiit), 34. Joan Vilarroig de Miquel, 35. Miquel Boix (obiit), 36. Cosme Reboll, 37. Pere Marqués, 38. Joan Bosch de Joan (obiit), 39. Joan Vilarroig de Pere, 40. Cosme Segarra, 41. Miquel Vicent Pasqual (obiit), 42. Francesc Vilarroig, 43. Batiste Llorens menor, 44. Jaume Muntanyés, 45. Mateu Tormo, 46. Bertomeu Navarro, 47. Cristòfol Castellet, 48. Andreu Duenyes sastre, 49. Joan Ferrer teixidor, 50. Antoni Portolés corder, 51. Vicent Amiguet espardenyer (obiit), 52. Joan Duenyes sabater i 53. Monserrat Martí (obiit). 


\section{Insaculación de 1638 y 1643}

(AHMC. Llibre de les Insaculacions. ff.74-77).

Insaculats en lo any 1638 i 1643 i los que estaven insaculats

Bossa de Militars: 1. Don Cristòfol Sisternés, 2. Pere Reus, 3. Gerony Arrufat, 4. Josep Reus, 5. Don Bernat Ros (noble), 6. Don Francesc Sisternés, 7. Nicolau Serra, 8. Don Joan Ros i 9. Francesc Josep Bou.

Bossa lo sach de Jurat en cap del Bras Real de ciutadans: 1. Batiste Serra notari, 2. Agostí Agramunt, 3. Jaume Jover, 4. Gaspar Brunell, 5. (nombre tachado no se puede ver) Albiol, 6. Melchor Capero, 7. Miquel Romeu, 8. Francesc Josep Bou, 9. Micer Joan Batiste Gascó, 10. Batiste Jover, 11. Doctor Micer Miquel Mur, 12. Joan Andreu, 13. Micer Vicent Vilar, 14. Lluís Giner, 15. Miquel Vicent Gascó, 16. Francesc Albiol, 17. Baltazar Gombau, 18. Micer Francesc Giner, 19. Lluís Pauner i 20. Micer Vicent Castellet.

Bossa segona lo sach de jurat segon: 1. Pere Giner notari, 2. Cristòfol Bou notari, 3. Jaume Andreu notari, 4. Melchor Amiguet, 5. Batiste Moliner, 6. Gabriel Ferrer, 7. Pere Joan Vicent, 8. Gaspar Martí, 9. Jaume Castellet notari, 10. Pere Romeu notari, 11. Lluís Mas, 12. Vicent Martí, 13. Salvador Martí, 14. Jaume March, 15. Jaume Esteve mercader, 16. Vicent Porta notari i 17. Miquel Alberich.

Bossa lo sach de jurat tercer i quart: 1. Miquel Castell de Antoni, 2. Mateu Sanchís, 3. Monserrat Museros, 4. Baltazar Avinent major, 5. Joan Navarro de Miquel, 6. Francesc Mas, 7. Joan Vilarroig de Miquel, 8. Andreu March, 9. March Casalís major, 10. Pere Alegre, 11. Cosme Reboll, 12. Martí Castell, 13. Miquel Giner, 14. Cosme Segarra, 15. Joan Vilarroig de Pere, 16. Berenguer Ribalta, 17. Batiste Llorens major, 18. Pere Castellet, 19. Francesc Moliner, 20. Joan Granyena, 21. Batiste Llorens menor, 22. Francesc Castell de Francesc, 23. Mateu Tormo, 24. Jaume Muntanyés, 25. Bertomeu Navarro, 26. Cristòfol Castellet, 27. Miquel Sanchís de Miquel, 28. Vicent Museros, 29. Vicent Figuerola, 30. Miquel Llansola, 31. Josep Castell de Antoni, 32. Andreu Pasqual de Francesc, 33. Josep ..... de Miquel, 34. March Casalís menor, 35. Joan Flors, 36. Miquel Castellet de Berenguer, 37. Baltazar Avinent menor, 38. Vicent Marqués, 39. Pere Vilarroig de Berenguer i 40. Joan Marqués. 
Bossa lo sach de Justicia: 1. Pere Joan Vicent, 2. Melchor Amiguet, 3. Lluís Mas, 4. Francesc Mas (obiit), 5. Batiste Serra, 6. Francesc Bou, 7. Pere Alegre, 8. Cristòfol Bou, 9. Micer Batiste Gascó, 10. Agostí Agramunt, 11. Micer Vicent Vilar, 12. Lluís Giner, 13. Micer Jaume Giner, 14. Micer Vicent Castellet, 15. Doctor Miquel Mur, 16. Gaspar Lluís Brunell, 17. Jaume Jover, 18. Batiste Jover, 19. Pere Giner, 20. Gabriel Sisternés, 21. Gaspar Martí, 22. Miquel Romeu, 23. Melchor Capero, 24. Joan Andreu, 25. Miquel Vicent Gascó, 26. Baltazar Gombau, 27. Lluís Pauner, 28. Miquel Castell de Antoni i 29. Francesc Albiol.

Bossa lo sach de Mustassaf: 1. Gaspar Martí, 2. Francesc Bou, 3. Batiste Moliner, 4. Francesc Mas, 5. Andreu March, 6. Pere Joan Vicent, 7. Gabriel Ferrer, 8. Cristòfol Bou, 9. Melchor Amiguet, 10. Lluís March, 11. Batiste Serra, 12. Jaume Castellet notari, 13. Martí Castell, 14. Micer Joan Batiste de Gaspar, 15. Agostí Agramunt, 16. Jaume Jover, 17. Vicent Albiol, 18. Melchor Capero, 19. Gaspar Lluís Brunell, 20. Jaume Andreu notari, 21. Miquel Romeu, 22. Pere Giner notari, 23. Vicent Martí notari, 24. Batiste Jover, 25. Doctor Miquel Mur, 26. Joan Andreu, 27. Micer Vicent Vilar, 28. Lluís Giner, 29. Baltazar Gombau, 30. Miquel Vicent Gascó, 31. Micer Francesc Giner, 32. Lluís Pauner, 33. Pere Alegre, 34. Berenguer Ribalta, 35. Mateu Sanchís, 36. Micer Vicent Castellet, 37. Joan Vilarroig de Miquel i 38. Francesc Albiol.

Bossa lo sach de Cequier: 1. Andreu March, 2. Francesc Moliner, 3. Lluís March, 4. Francesc Castell de Francesc (obiit), 5. Pere Castellet (obiit), 6. Mateu Sanchís, 7. Miquel Castellet de Antoni, 8. Joan Granyana, 9. Pere Alegre (obiit), 10. Martí Castell (obiit), 11. Cosme Segarra (obiit), 12. Joan Navarro, 13. Batiste Moliner, 14. Berenguer Ribalta, 15. Francesc Mas (obiit), 16. Batiste Serra (obiit), 17. Batiste Llorens, 18. Francesc Bou cavaller, 19. Joan Tormo, 20. Jaume Muntanyés, 21. Bertomeu Navarro, 22. Cristòfol Castellet, 23. Melchor Capero, 24. Jaume Jover, 25. Gaspar Brunell, 26. Miquel Romeu, 27. Salvador Martí, 28. Baltazar Avinent major, 29. Joan Vilarroig de Pere, 30. Miquel Giner, 31. March Casalís major, 32. Monserrat Museros, 33. Cosme Reboll, 34. Joan Vilarroig de Miquel, 35. Andreu Castellet, 36. Batiste Llorens menor, 37. Francesc Llansola, 38. Nicolau Moliner de Francesc, 39. Agostí Reboll, 40. Miquel Roig, 41. Joan Castell de Miquel, 42. Andreu Vicent (obiit), 43. Jaume Roig, 44. Josep 
Segarra, 45. Gaspar Eiximeno, 46. Joan Navarro de Joan, 47. Francesc Figuerola i 48. Pere Navarro de Joan.

Bossa lo sach de escrivans: 1 . Cristòfol Bou notari, 2. Pere Romeu notari, 3. Pere Giner notari, 4. Jaume Castellet notari, 5. Vicent Porta notari, 6. Vicent Martí notari i 7. Jaume Andreu notari.

Bossa lo sach de consellers de mà major: 1. Batiste Serra, 2. Agostí Agramunt, 3. Micer Joan Batiste Gascó, 4. Francesc Bou, 5. Bueno Albiol, 6. Jaume Jover, 7. Melchor Capero, 8. Miquel Romeu, 9. Gaspar Lluís Brunell, 10. Batiste Jover, 11. Joan Andreu, 12. Miquel Mur Doctor. 13. Micer Vicent Vilar, 14. Lluís Giner, 15. Miquel Vicent Gascó, 16. Baltazar Gombau, 17. Micer Jaume Giner, 18. Lluís Pauner, 19. Micer Vicent Castellet, 20. Pere Giner, 21. Cristòfol Bou, 22. Jaume Andeu, 23. Melchor Amiguet, 24. Batiste Moliner, 25. Gabriel Ferrer, 26. Pere Joan Vicent, 27. Gaspar Martí, 28. Francesc Castellet notari, 29. Lluís Mas, 30. Pere Romeu, 31. Vicent Martí, 32. Salvador Martí, 33. Jaume March, 34. Jaume Castell, 35. Vicent Porta, 36. Miquel Alberich, 37. Josep Alberich, 38. Joan Tormo i 39. Francesc Albiol.

Bossa lo sach de Consellers de mà menor: 1. Miquel Castell de Antoni, 2. Mateu Sanchís, 3. Monserrat Museros, 4. Baltazar Avinent major, 5. Joan Navarro de Miquel, 6. Francesc Mas, 7. Joan Vilarroig de Miquel, 8. Andreu Mas, 9. March Casalís major, 10. Pere Alegre, 11. Cosme Reboll, 12. Martí Castell, 13. Miquel Giner, 14. Cosme Segarra, 15. Joan Vilarroig de Pere, 16. Berenguer Reboll, 17. Batiste Llorens major, 18. Pere Castellet, 19. Francesc Moliner, 20. Joan Granyana, 21. Batiste Llorens menor, 22. Francesc Castell de Francesc, 23. Mateu Tormo, 24. Jaume Montanyés, 25. Bertomeu Navarro, 26. Cristòfol Castellet, 27. Miquel Sanchís de Miquel, 28. Vicent Museros (nombre tachado), 29. Vicent Figuerola, 30. Miquel Llansola, 31. Andreu Pasqual de Josep, 32. Josep Castell de Antoni, 33. Josep Esteve de Miquel, 34. March Casalís menor, 35. Joan Flors, 36. Miquel Castell de Berenguer, 37. Baltazar Avinent menor, 38. Vicent Marqués, 39. Pere Vilarroig de Berenguer, 40. Andreu Castellet, 41. Francesc Llansola, 42. Nicolau Moliner de Francesc, 43. Joan Navarro de Francesc, 44. Gaspar Eiximeno, 45. Josep Segarra, 46. Jaume Roig, 47. Miquel Roig, 48. Francesc Figuerola, 49. Agostí Reboll, 50. Joan Castell de Miquel, 51. Andreu Vicent i 52. Pere Navarro de Joan. 


\section{Insaculaciones de 1647 y 1648}

(AHMC. Llibre de les Insaculacions. ff. 78-80).

[Anotación en el margen izquierdo] A 13 de maig 1647 i 27 de mars de 1648

Les persones insaculades en les Boces del Govern de la vila de Castelló de la Plana i las que se insacularen en los Anys MDCXXXXVII i Mil DCXXXXVIII són los següents:

Bossa de Militars: 1. Gerony Arrufat, 2. Cristòfol Sisternés, 3. Pere Reus, 4. Nicolau Serra, 5. Don Francesc Sisternés, 6. Don Joan Ros, 7. Josep Reus, 8. Don Francesc Bou i 9. Pere Giner entra en lo any 1649. [Anotación en el margen izquierdo] Vidi A la fi desta Insaculació Cristòfol Castell, Félix Sisternés i Martí Mas.

Bossa de Jurat en Cap del Bras Real: 1. Agostí Agramunt Sisternés (obiit), 2. Vicent Albiol, 3. Miquel de Mur Doctor, 4. Batiste Jover (obiit), 5. Melchor Capero, 6. Micer Vicent Vilar, 7. Joan Andreu, 8. Micer Vicent Castellet, 9. Baltazar Gombau, 10. Micer Jaume Giner, 11. Gaspar Brunell, 12. Lluís Giner (obiit), 13. Miquel Romeu, 14. Miquel Vicent Gascó (obiit), 15. Lluís Pauner, 16. Tomàs Giner, 17. Micer Nicolau Figuerola, 18. Doctor Miquel Birto (obiit), 19. Micer Miquel Giner (obiit) i 20. (tachado no se puede ver quién es).

Bossa segona de Jurats: 1. Cristòfol Bou notari (obiit), 2. Pere Giner notari, 3. Pere Joan Vicent (obiit), 4. Batiste Moliner (obiit), 5. Jaume Andreu, 6. Vicent Martí, 7. Pere Romeo (obiit), 8. Salvador Martí (obiit), 9. Jaume Castell, 10. Gaspar Martí, 11. Josep Albiol, 12. Jaume March (obiit), 13. Miquel Alberich (obiit), 14. Vicent Porta notari, 15. Melchor Amiguet i 16. Melchor Amposta. Quatre llocs restaren buits dita segona boça.

Bossa tercera i quarta de jurats: 1 . Jaume Montanyés, 2. Josep Castell de Antoni, 3. Miquel Giner, 4. Josep Esteve de Miquel, 5. Cosme Reboll (obiit), 6. Batiste Llorens menor, 7. Joan Granyana (obiit), 8. Joan Marqués (obiit), 9. Miquel Llansola, 10. Berenguer Ribalta (obiit), 11. Pere Vilarroig de Bertomeu, 12. Joan Vilarroig de Miquel (obiit), 13. Miquel Castell de Antoni, 14. Francesc Moliner, 15. Baltazar Avinent major (obiit), 16. Mateu Tormo, 17. Baltazar Avinent menor (obiit), 18. Vicent Museros, 19. Vicent Figuerola, 20. Joan Vilarroig de Pau (obiit), 21. Batiste Llorens de Pau (obiit), 22. Vicent Marqués, 23. Mateu Sanchís (obiit), 24. Andreu March (obiit), 25. Joan 
Navarro de Miquel (obiit), 26. Miquel Sanchís de Miquel, 27. Francesc Figuerola, 28. Monserrat Museros, 29. Josep Segarra, 30. Gaspar Eiximeno, 31. Joan Castell de Miquel (Cavaller), 32. Francesc Llansola (obiit), 33. Agostí Reboll (obiit), 34. Joan Navarro de Joan, 35. Pere Navarro, 36. Miquel Boix (obiit), 37. Francesc Pasqual de Francesc, 38. Andreu Castellet i 39. Jaume Roig . Cristòfol Castellet obiit. No es posà en redolí.

Bossa de Justicia del Bras Real: 1. Baltazar Gombau, 2. Lluís Giner ciutadà (obiit), 3. Pere Giner notari, 4. Melchor Amiguet, 5. Batiste Jover, 6. Lluís Pauner, 7. Gaspar Martí, 8. Joan Andreu, 9. Pere Joan Vicent (obiit), 10. Cristòfol Bou notari (obiit), 11. Agostí Agramunt Sisternés (obiit), 12. Miquel Castell Antoni (cavaller), 13. Micer Vicent Vilar, 14. Miquel Vicent Gascó (obiit), 15. Melchor Capero (obiit), 16. Gaspar Brunell, 17. Miquel Romeu, 18. Doctor Miquel Mur, 19. Micer Vicent Castellet, 20. Micer Jaume Giner, 21. Tomàs Giner, 22. Micer Nicolau Figuerola, 23. Doctor Miquel Brito (tachado) (obiit), 24. Vicent Martí notari, 25. Melario Nuñez (obiit), 26. Josep Castell de Antoni, 27. Batiste Moliner (obiit), 28. Andreu March (obiit), 29. Vicent Museros, 30. Micer Miquel Giner (obiit).

Bossa de Mustassaf del Bras Real: 1. Miquel Romeu, 2. Lluís Giner (obiit), 3. Melchor Capero (obiit), 4. Vicent Albiol, 5. Pere Giner, 6. Vicent Martí, 7. Gaspar Martí, 8. Joan Vilarroig de Miquel (obiit), 9. Agostí Agramunt Sisternés (obiit), 10. Baltazar Gombau, 11. Joan Andreu, 12. Miquel Vicent Gascó (obiit), 13. Andreu March (obiit), 14. Lluís Pauner, 15. Pere Joan Vicent (obiit), 16. Micer Jaume Giner, 17. Mateu Sanchís (obiit), 18. Batiste Jover, 19. Jaume Andreu notari, 20. Batiste Moliner (obiit), 21. Micer Vicent Castellet, 22. Cristòfol Bou notari (obiit), 23. Berenguer Ribalta (obiit) 24. Micer Vicent Vilar, 25. Doctor Miquel Mur, 26. Melchor Amiguet, 27. Tomàs Giner, 28. Micer Nicolau Figuerola, 29. Josep Alberich, 30. Salvador Martí (obiit), 31. Vicent Porta notari, 32. Pere Romeu notari (obiit), 33. Joan Vilarroig de Pere (obiit), 34. Cosme Reboll (obiit), 35. Miquel Giner, 36. Doctor Miquel Birto (obiit), 37. Melario Nuñez (obiit), 38. Micer Miquel Giner (obiit), 39. Miquel Castell de Antoni (obiit) i 40. Gaspar Brunell.

Bossa de Sequier: 1. Gaspar Eiximeno, 2. Joan Granyana (obiit), 3. Berenguer Ribalta (obiit), 4. Miquel Castell Antoni (cavaller), 5. Batiste Llorens major (obiit), 6. Miquel 
Romeo, 7. Jaume Muntanyés (obiit), 8. Nicolau Moliner de Francesc (obiit), 9. Mateu Sanchís (obiit), 10. Baltazar Avinent major (obiit), 11. Miquel Giner, 12. Monserrat Museros, 13. Josep Segarra, 14. Francesc Moliner, 15. Batiste Llorens Muñoz, 16. Joan Tormo (obiit), 17. Andreu Castellet, 18. Agostí Reboll (obiit), 19. Mateu Tormo, 20. Miquel Boix, 21. Melchor Capero (obiit), 22. Joan Vilarroig de Pere (obiit), 23. Joan Vilarroig de Miquel (obiit), 24. Andreu March (obiit), 25. Cosme Reboll (obiit), 26. Pere Navarro de Joan, 27. Joan Navarro major, 28. Joan Navarro menor, 29. Salvador Martí (obiit), 30. Gaspar Brunell, 31. Joan Castell de Miquel (cavaller), 32. Francesc Figuerola (obiit), 33. Batiste Moliner (obiit), 34. Francesc Llansola (obiit), 35. Jaume Roig, 36. Baltazar Gombau, 37. Joan Andreu, 38. Miquel Alberich (obiit), 39. Josep Castell de Antoni, 40. Pere Vilarroig de Bertomeu, 41. Miquel Sanchís, 42. Baltazar Avinent menor (obiit), 43. Vicent Figuerola, 44. Josep Castell de Francesc, 45. Francesc Alegre, 46. Josep Avinent, 47. Pere Reboll (obiit), 48. Miquel Llansola, 49. Jaume Ferrer de Jaume i 50. Batiste Jover (obiit).

Bossa de escrivans: 1. Cristòfol Bou notari (obiit), 2. Pere Giner notari, 3. Jaume Andreu notari, 4. Vicent Martí notari, 5. Pere Romeu notari (obiit) i 6. Vicent Porta notari.

Bossa de Consellers de Mà Major: 1. Joan Andreu, 2. Melchor Capero (obiit), 3. Pere Romeu notari (obiit), 4. Vicent Albiol, 5. Batiste Jover, 6. Vicent Martí notari, 7. Agostí Agramunt Sisternés (obiit), 8. Joan Tormo (obiit), 9. Cristòfol Bou notari (obiit), 10. Micer Vicent Vilar, 11. Miquel Vicent Gascó (obiit), 12. Batiste Moliner (obiit), 13. Gaspar Martí, 14. Josep Alberich, 15. Gaspar Brunell, 16. Doctor Miquel Mur, 17. Lluís Pauner, 18. Salvador Martí, 19. Lluís Giner (obiit), 20. Vicent Porta notari, 21. Jaume Andreu notari, 22. Jaume Castell, 23. Pere Giner notari, 24. Micer Vicent Castellet, 25. Baltazar Gombau, 26. Melchor Amiguet, 27. Miquel Romeu, 28. Micer Jaume Giner, 29. Pere Joan Vicent (obiit), 30. Jaume March, 31. Miquel Alberich (obiit), 32. Tomàs Giner, 33. Micer Miquel Giner, 34. Doctor Miquel Brito (obiit), 35. Doctor Nicolau Figuerola, 36. Melario Nuñez (obiit) i 37. Melchor Amposta.

Consellers de mà menor: 1. Francesc Moliner, 2. Joan Vilarroig de Pere, 3. Gaspar Eiximeno, 4. Joan Castell de Miquel, 5. Miquel Giner, 6. Joan Granyana, 7. Miquel Sanchís, 8. Andreu March, 9. Josep Castell de Antoni, 10. Batiste Llorens menor, 11. 
Berenguer Ribalta, 12. Cosme Reboll, 13. Agostí Reboll, 14. Jaume Roig, 15. Vicent Figuerola, 16. Mateu Tormo, 17. Baltazar Avinent menor, 18. Jaume Montanyés, 19. Miquel Llansola, 20. Pere Vilarroig de Bertomeu, 21. Batiste Llorens major, 22. Miquel Castell de Andreu, 23. Mateu Sanchís major, 24. Monserrat Museros, 25. Miquel Boix, 26. Josep Esteve de Miquel, 27. Joan Vilarroig de Miquel, 28. Francesc Llansola, 29. Pere Navarro de Joan, 30. Joan Navarro de Joan, 31. Vicent Marqués, 32. Vicent Museros, 33. Nicolau Moliner de Francesc, 34. Baltazar Avinent menor, 35. Josep Segarra, 36. Andreu Castellet, 37. Joan Marqués, 38. Francesc Figuerola, 39. Joan Navarro major, 40. Josep Castell de Francesc, 41. Josep Avinent, 42. Francesc Alegre, 43. Pere Reboll, 44. Francesc Pasqual de Joan i 45. Jaume Ferrer de Cosme 


\section{Insaculación 1653}

(AHMC. Llibre de les Insaculacions. ff. 81-84).

Copia de les persones que estan insaculades per als oficis de la present vila en la renovació dels sachs feta a XIIII i XVI de....MDCLIIII per.... la insaculació feta per los oficials i consellers en lo mes de Mars del any MDCLIII.

Bossa de Militars: 1. Don Francesc Bou, 2. Don Joan Bou, 3. Josep Reus, Pere Giner (nombre tachado) (obiit), 5. Miquel Castell (nombre tachado) (obiit), 6. Pere Serra i Dols, 7. Basilio Reus, 8. Joan Castell, 9. March Antoni Jordà i 10. Gerony Mas. [Anotación margen izquierdo] En 7 de gener de 1660 foren insaculats Cristòfol Castell, Martí Mas Félix Sisternés.

Bossa de Jurat en Cap de Bras Real: 1. Joan Andreu ciutadà, 2. Gaspar Brunell, 3. Micer Vicent Castellet, 4. Jaume Giner (nombre tachado) (obiit), 5. Micer Vicent Vilar, 6. Micer Nicolau Figuerola, 7. Batiste Jover ciutadà (obiit), 8. Miquel Romeu ciutadà, 9. Miquel Mur Doctor en medicina, 10. Baltazar Gombau ciutadà (nombre tachado) (obiit), 11. Tomàs Giner ciutadà, 12. Lluís Pauner ciutadà, 13. Dionís Aragonés ciutadà, 14. Vicent Figuerola ciutadà, 15. Gerony Vidal doctor, 16. Micer Joan Cases i 17. Dionís Aragonés ciutadà. Restaren tres llochs vacuos.

Bossa de Jurat segon : 1. Jaume Andreu notari (obiit), 2. Pere Giner notari, 3. Vicent Martí notari, 4. Vicent Porta notari, 5. Melchor Amiguet, 6. Melchor Amposta, 7. Josep Alberich, 8. Jaume Castell mercader, 9. Gaspar Martí (nombre tachado) (obiit), 10. Vicent Pasqual notari, 11. Francesc Mercer menor, 12. Alexandre Martí i 13. Pere Museros cirurgià. Restaren set llochs vacuos de Jurat de esta boça.

Bossa de Jurat tercer y quart: 1. Mateu Tormo (nombre tachado) (llaurador) (obiit), 2. Batiste Llorens (nombre tachado) (obiit), 3. Joan Navarro de Joan, 4. Francesc Moliner (nombre tachado) (obiit), 5. Monserrat Museros (nombre tachado) (obiit), 6. Miquel Giner, 7. Gaspar Eiximeno, 8. Vicent Museros, 9. Miquel Sanchís, 10. Miquel Llansola major, 11. Vicent Figuerola (llaurador), 12. Francesc Pasqual de Joan, 13. Josep Segarra (nombre tachado) (obiit), 14. Josep Esteve de Miquel, 15. Andreu Castellet, 16. Pere Vilarroig, 17. Pere Navarro, 18. Jaume Roig, 19. Josep Castell 
d'Antoni, 20. Vicent Marqués, 21. Jaume Montanyés (nombre tachado) (obiit), 22. Josep Castell de Francesc, 23. Francesc Alegre, 24. Josep Avinent, 25. Josep Vilarroig major, 26. Andreu Ribalta, 27. March Castellet (nombre tachado) (obiit), 28. Miquel Vilarroig gendre de Viciano, 29. Pere Castell gendre de Granyana (nombre tachado) (obiit), 30. Pere Castell gendre Martí (nombre tachado) (obiit), 31. Pere Bonet, 32. Vicent Eiximeno, 33. Gerony Reboll, 34. Josep Rubert, 35. Miquel Vilarroig gendre de Castell, 36. Miquel Català i 37. Pere Segarra de Cosme. I restaven tres llochs vacuos. Per haverse mort del dia de la Insaculació, hasta el dia de la Insaculació que són Joan Navarro major, Nicolau Moliner i Miquel Boix.

Bossa de Justicia del Bras Real: 1. Joan Andreu ciutadà, 2. Miquel Romeu ciutadà, 3. Micer Nicolau Figuerola, 4. Gaspar Brunell, 5. Baltazar Gombau (nombre tachado) (obiit), 6. Micer Vicent Vilar, 7. Micer Jaume Giner (nombre tachado)(obiit), 8. Melchor Amiguet, 9. Pere Giner notari, 10. Vicent Martí notari, 11. Batiste Jover ciutadà (nombre tachado) (obiit), 12. Vicent Museros llaurador, 13. Lluís Pauner cirurgià, 14. Micer Vicent Castellet, 15. Gaspar Martí mercader (nombre tachado) (obiit), 16. Josep Castell de Antoni, 17. Miquel de Mur Doctor, 18. Vicent Figuerola ciutadà, 19. Dionís Aragonés ciutadà, 20. Micer Joan Cases, 21. Gerony Vidal Doctor, 22. Jaume Andreu notari (nombre tachado) (obiit), 23. Alexandre Martí, 24. Jaume Castell Doctor en medicina, 25. Vicent Figuerola llaurador, 26. Miquel Giner llaurador i 27. Tomàs Giner ciutadà. Restaven tres llochs vacuos per no per no haver-hi habilitats dels ciutadans.

Bossa de Mustasaf del Bras Real: 1. Micer Vicent Vilar, 2. Micer Vicent Castellet, 3. Jaume Andreu notari (nombre tachado) (obiit), 4. Melchor Amiguet (...Joseph...), 5. Gaspar Brunell ciutadà, 6. Josep Alberich mercader, 7. Gaspar Moliner mercader (nombre tachado) (obiit), 8. Micer Jaume Giner (nombre tachado) (obiit), 9. Pere Giner notari, 10. Batiste Jover ciutadà (nombre tachado) (obiit), 11. Miquel Romeu ciutadà, 12. Joan Andreu ciutadà, 13. Miquel Mur Doctor, 14. Micer Nicolau Figuerola, 15. Tomàs Giner, 16. Vicent Martí notari, 17. Miquel Giner llaurador, 18. Baltazar Gombau (nombre tachado) (obiit), 19. Lluís Pauner cirurgià, 20. Vicent Porta notari, 21. Vicent Albiol, 22. Vicent Figuerola ciutadà, 23. Gerony Aragonés ciutadà, 24. Micer Joan Cases, 25. Gerony Vidal Doctor, 26. Jaume Castell mercader, 27. Melchor Amposta, 28. Vicent Pasqual notari, 29. Alexandre Martí mercader, 30. Francesc Mercer menor, 31. 
Joan Navarro de Joan, 32. Josep Castell d'Antoni, 33. Mateu Tormo (obiit), 34. Jaume Roig, 35. Vicent Museros, 36. Batiste Llorens (nombre tachado) (obiit) i 37. Josep Segarra (nombre tachado) (obiit). Restaven vacuos tres llochs.

Bossa de Sequiers: 1. Miquel Giner, 2. Monserrat Museros (nombre tachado) (obiit). 3. Josep Castell de Francesc, 4. Miquel Romeu ciutadà, 5. Jaume Montanyés (nombre tachado) (obiit), 6. Francesc Moliner (nombre tachado) (obiit), 7. Vicent Figuerola llaurador, 8. Joan Andreu ciutadà, 9. Josep Segarra (nombre tachado) (obiit), 10. Miquel Llansola major, 11. Pere Navarro de Joan, 12. Gaspar Eiximeno, 13. Andreu Castellet, 14. Mateu Tormo (nombre tachado) (obiit), 15. Batiste Jover ciutadà (nombre tachado) (obiit), 16. Batiste Llorens (nombre tachado) (obiit), 17. Pere Vilarroig, 18. Jaume Vilarroig, 19. Baltazar Gombau (nombre tachado) (obiit), 20. Gaspar Brunell, 21. Francesc Alegre, 22. Josep Castell de Antoni, 23. Joan Navarro de Joan, 24. Josep Avinent, 25. Miquel Sanchís, 26. Josep Alberich mercader, 27. Tomàs Giner ciutadà, 28. Josep Castell mercader, 29. Alexandre Martí mercader, 30. Vicent Museros, 31. Vicent Marqués, 32. Francesc Pasqual de Joan, 33. Andreu Pasqual de Andreu, 34. Martí Viciano, 35. Pere Castell gendre de Granyana (nombre tachado) (obiit), 36. Pere Castell gendre de Martí (nombre tachado) (obiit), 37. Vicent Eiximeno, 38. Andreu Ribalta, 39. Vicent Rubert, 40. Josep Vilarroig major, 41. Miquel Llansola de Miquel, 42. Miquel Vilarroig gendre de Viciano , 43. Vicent Castellet de Cristòfol, 44. Josep Albiol i 45. Francesc Amiguet. Restaven cinc llochs vacuos, 3 de la boça segona i 2 de la tercera i quarta.

Consellers de mà major (no están numerados) : Micer Vicent Castellet, Vicent Martí notari, Gaspar Brunell, Baltazar Gombau (nombre tachado) (obiit), Lluís Pauner, Joan Andreu, Micer Vicent Vilar, Melchor Amposta, Melchor Amiguet, Micer Nicolau Figuerola, Gaspar Martí (nombre t achado) (obiit), Tomàs Giner, Vicent Albiol, Batiste Jover (nombre tachado) (obiit), Jaume Castell, Josep Andreu notari (obiit), Pere Giner notari, Miquel Romeu, Vicent Porta, Micer Jaume Giner (nombre tachado) (obiit), Doctor Miquel Mur, Josep Alberich, Dionís Aragonés, Vicent Figuerola ciutadà, Micer Joan Cases, Doctor Gerony Vidal, Vicent Pasqual notari, Aleixandre Martí, Francesc Merce menor i Pere Museros cirurgià. 
Consellers de mà menor: Josep Avinent, Monserrat Museros (nombre tachado) (obiit), Vicent Marqués, Joan Navarro, Miquel Giner, Mateu Tormo (nombre tachado) (obiit), Francesc Pasqual de Joan, Vicent Museros, Vicent Figuerola llaurador, Batiste Llorens (nombre tachado) (obiit), Francesc Moliner (nombre tachado) (obiit), Francesc Alegre, Miquel Sanchís, Josep Castell de Francesc, Andreu Castellet, Gaspar Eiximeno, Pere Vilarroig, Jaume Montanyés (nombre tachado) (obiit), Jaume Roig, Josep Segarra (obiit), Pere Navarro, Josep Castellet Antoni, Miquel Llansola major, Josep Esteve de Miquel, Josep Vilarroig major, Andreu Ribalta, March Castellet (nombre tachado) (obiit), Miquel Vilarroig de Viciano, Pere Castell gendre de Gombau (nombre tachado) (obiit), Pere Castell gendre de Martí (nombre tachado) (obiit), Pere Bonet, Vicent Eiximeno, Gerony Reboll, Josep Rubert major, Miquel Vilarroig gendre de Castell, Miquel Català, Pere Segarra de Cosme, Andreu Pasqual de Andreu, Martí Viciano, Vicent Rubert, Miquel Llansola menor, Vicent Castellet, Josep Albiol i Francesc Amiguet. En VII de novhembre MDCLX foren insaculats en la boça de militars Cristòfol Castell cavaller (obiit), Félix Sisternés cavaller i Martí Mas cavaller. 


\section{Insaculación de 1662}

(AHMC. Llibre de les Insaculacions. ff. 86-90).

1662

Los Insaculats al Govern de la Vila de Castelló de la Plana, així vells com de la última Insaculació que s'ha fet en XXVII de Mars fins IV de Abril de MDCXII són los següients:

Bossa de Cavallers i Generosos i los nobles que s'han Insaculat al Govern novament en la dita última Insaculació en la dita Boça sens prelació, sinó segons sa Edat i Antiguitat de oficis són los següents: 1. Francesc Bou de Monsonís cavaller .(obiit), 2. Joan Ros de Ursins. cavaller (obiit), 3. Josep Reus cavaller (obiit), 4. Pere Serra cavaller (obiit), 5. Basilio Reus cavaller, 6. Joan Castell cavaller (obiit), 7. March Antoni Jordà cavaller (obiit), 8. Gerony Mas cavaller (obiit), 9. Cristòfol Castell cavaller, 10. Martí Mas cavaller, 11. Don Félix Sisternés cavaller, 12. Don Cosme Feliu, 13. Don Narcís Feliu (obiit), 14. Don Miquel Vallés (obiit), 15. Don Josep Igual, 16. Don Felip Jover. Doctor en Dret, 17. Don Carlos Jover, 18. Don Fernando Miralles, 19. Don Bernardo Ros i 20. Joan Ros de Ursins. cavaller (obiit).

Bossa de Jurat en cap del Bras Real: 1. Gaspar Brunell cirugià (obiit), 2. Joan Andreu (obiit), 3. Micer Vicent Tosquella (obiit), 4. Micer Vicent Vilar (obiit), 5. Micer Nicolau Figuerola, 6. Miquel Romeu (obiit), 7. Doctor Miquel Mur (obiit), 8. Vicent Albiol (obiit), 9. Tomàs Giner, 10. Lluís Pauner (obiit), 11. Dionís Aragonés, 12. Vicent Figuerola ciutadà, 13. Gerony Vidal Doctor (obiit), 14. Micer Joan Cases, 15. Doctor Melchor Calbo, 16. Tomàs Capero (obiit), 17. Doctor Batiste Orts (obiit) i 18. Francesc Andreu ciutadà.

Bossa Segona de Artistes de Jurat: 1. Pere Giner notari, 2. Vicent Martí notari, 3. Melchor Amiguet, 4. Vicent Porta notari, 5. Melchor Amposta sirurgià, 6. Josep Alberich mercader, 7. Jaume Castell mercader, 8. Vicent Pasqual notari, 9. Francesc Mercer pintor, 10. Alexandre Martí, 11. Pere Museros cirurgià, 12. (nombre tachado que no se ve nada), 13. Francesc Mas notari (obiit), 14. Pere Joan Vicent notari, 15. Francesc Timor notari (obiit), 16. Pere Palanques notari, 17. Francesc Grau notari (obiit), 18. Macià Conte notari i 19. Vicent Ferrer notari. Resta un lloch vacuo de Jurat. 
Bossa de Jurat 3 i 4: 1. Joan Navarro de Joan, 2. Miquel Giner, 3. Gaspar Eiximeno, 4. Vicent Museros, 5. Miquel Sanchís, 6. Miquel Llansola major (jubilat), 7. Vicent Figuerola llaurador, 8. Francesc Pasqual de Joan, 9. Josep Esteve de Miquel, 10. Pere Vilarroig, 11. Andreu Castellet, 12. Pere Navarro, 13. Jaume Roig, 14. Josep Castell de Antoni, 15. Vicent Marqués, 16. Josep Castell de Francesc, 17. Francesc Alegre, 18. Josep Avinent major, 19. Josep Vilarroig major, 20. Andreu Ribalta, 21. Miquel Vilarroig gendre Viciano, 22. Pere Bonet de Batiste, 23. Vicent Eiximeno, 24. Gerony Reboll, 25. Josep Rubert, 26. Miquel Vilarroig gendre de Castell, 27. Miquel Català, 28. Pere Segarra de Cosme, 29. Vicent Rubert, 30. Miquel Llansola de Miquel menor, 31. Vicent Castellet de Cristòfol, 32. Josep Albiol, 33. Pere Museros de Vicent, 34. Antoni Castell de Josep, 35. Joan Museros de Monserrat, 36. Francesc Figuerola de Vicent, 37. Miquel Navarro de Gaspar, 38. Miquel Pasqual de Francesc i 39. Josep Avinent de Baltazar menor.

Bossa de Justicia del Bras Real : 1. Joan Andreu ciutadà, 2. Miquel Romeu ciutadà, 3. Micer Nicolau Figuerola, 4. Gaspar Lluís Brunell, 5. Micer Vicent Vilar, 6. Melchor Amiguet, 7. Pere Giner notari Jubilat, 8. Vicent Martí notari, 9. Vicent Museros llaurador, 10. Lluís Pauner cirurgià, 11. Micer Vicent Castellet, 12. Josep Castell de Antoni, 13. Lo doctor Miquel Mur, 14. Vicent Figuerola ciutadà, 15. Dionís Aragonés, 16. Micer Joan Cases, 17. Gerony Vidal Doctor, 18. Alexandre Martí, 19. Jaume Castell mercader Jubilat, 20. Vicent Figuerola llaurador, 21. Miquel Giner llaurador Jubilat, 22. Tomàs Giner ciutadà, 23. Lo Doctor Melchor Calbo, 24. Tomàs Capero ciutadà, 25. Micer Batiste Orts, 26. Francesc Andreu ciutadà, 27. Vicent Pasqual notari i 28. Vicent Porta notari. Restaren dos llochs vacuos de la Boça dels ciutadans.

Bossa de ciutadàns del Bras Real de Mustassaf: 1. Micer Vicent Vilar, 2. Micer Vicent Castellet, 3. Melchor Amiguet, 4. Gaspar Brunell ciutadà, 5. Vicent Martí notari, 6. Josep Alberich mercader, 7. Pere Giner notari, 8. Miquel Romeu ciuatadà, 9. Joan Andreu ciutadà, 10. Miquel Mur Doctor, 11. Micer Nicolau Figuerola, 12. Tomàs Giner, 13. Miquel Giner, 14. Lluís Pauner, 15. Vicent Porta notari, 16. (nombre tachado que no se ve nada), 17. Vicent Figuerola ciutadà, 18. Dionís Aragonés, 19. Micer Joan Cases, 20. Gerony Vidal Doctor, 21. Jaume Castell mercader, 22. Melchor Amposta, 23. Vicent Pasqual notari, 24. Alexandre Martí, 25. Francesc Mercer pintor, 26. Joan Navarro de Joan, 27. Josep Castell de Antoni, 28. Jaume Roig, 29. Vicent Museros, 30. 
Don Melchor Calbo, 31. Tomàs Capero ciutadà, 32. Micer Batiste Orts, 33. Francesc Andreu ciutadà, 34. Pere Museros cirurgià, 35. Miquel Sanchís, 36. Pere Vilarroig i 37. Gaspar Eiximeno. Restaren tres llochs vacuos, dos dels ciutadàns i hu dels Artistas.

Bossa de Sequiers: 1. Josep Castell de Francesc, 2. Miquel de Romeu, 3. Vicent Figuerola llaurador, 4. Joan Andreu ciutadà, 5. Miquel Giner, 6. Miquel Llansola major Jubilat, 7. Pere Navarro de Joan, 8. Gaspar Eiximeno, 9. Andreu Castellet, 10. Pere Vilarroig, 11. Jaume Roig, 12. Gaspar Brunell, 13. Francesc Alegre, 14. Josep Castell de Antoni, 15. Joan Navarro, 16. Josep Avinent major de Baltazar, 17. Miquel Sanchís, 18. Josep Alberich, 19. Tomàs Giner, 20. Jaume Castell jubilat, 21. Alexandre Martí, 22. Vicent Museros, 23. Vicent Marqués, 24. Francesc Pasqual de Joan, 25. Andreu Pasqual de Andreu, 26. Martí Viciano, 27. Vicent Eiximeno, 28. Andreu Ribalta, 29. Vicent Rubert, 30. Josep Vilarroig major, 31. Miquel Llansola de Miguel menor, 32. Miguel Vilarroig gendre Viciano, 33. Vicent Castellet de Cristófol, 34. Josep Albiol, 35. Francesc Amiguet, 36. Vicent Figuerola ciutadà, 37. Dionís Aragonés ciutadà, 38. Francesc Viciano major, 39. Vicent Pasqual notari, 40. Pere Museros cirurgià, 41. Francesc Mercer, 42. Pere Bonet de Batiste, 43. Josep Rubert major, 44. Miquel Català, 45. Miquel Vilarroig gendre de Castell, 46. Pere Segarra, 47. Gerony Rubert major, 48. Josep Vilarroig de Josep, 49. Pere Calbo i 50. Joan Pasqual de Joan.

Bossa de Consellers de Mà major: 1. Micer Vicent Castellet, 2. Vicent Martí notari, 3. Gaspar Brunell ciutadà, 4. Lluís Pauner ciutadà, 5. Joan Andreu ciutadà, 6. Micer Vicent Vilar, 7. Melchor Amposta, 8. Melchor Amiguet, 9. Doctor Nicolau Figuerola, 10. Tomàs Giner cirurgià, 11. (nombre tachado que no se ve) ciutadà, 12. Jaume Castell mercader, 13. Pere Giner notari, 14. Miquel Romeu ciutadà, 15. Vicent Porta notari, 16. Pere Josep Albiol ciutadà, 17. Doctor Miquel Mur, 18. Josep Alberich mercader, 19. Dionís Aragonés ciutadà, 20. Vicent Figuerola ciutadà , 21. Micer Joan Cases, 22. Doctor Gerony Vidal, 23. Vicent Pasqual notari, 24. Alexandre Martí, 25. Francesc Mercer, 26. Pere Museros cirurjià, 27. Doctor Melchor Calbo, 28. Tomàs Capero ciutadà, 29. Doctor Batiste Orts, 30. Francesc Andreu ciutadà, 31. Vicent Tosquella ciutadà, 32. Francesc Mas notari, 33. Pere Joan Vicent notari, 34. Francesc Timor notari, 35. Pere Palanques notari, 36. Francesc Grau notari, 37. Macià Compte notari i 38. Vicent Ferrer notari. 
Consellers de Mà menor: 1 . Josep Avinent llaurador, 2. Vicent Marqués llaurador, 3. Joan Navarro, 4. Miquel Giner, 5. Francesc Pasqual de Joan, 6. Vicent Museros, 7. Vicent Figuerola llaurador, 8. Francesc Alegre, 9. Miquel Sanchís, 10. Josep Castell de Francesc, 11. Andreu Castellet, 12. Gaspar Eiximeno, 13. Pere Vilarroig, 14. Jaume Roig, 15. Pere Navarro, 16. Josep Castell de Antoni, 17. Miquel Llansola major, 18. Josep Esteve de Miquel, 19. Josep Vilarroig major, 20. Andreu Ribalta, 21. Miquel Vilarroig gendre Viciano, 22. Pere Bonet de Batiste, 23. Vicent Eiximeno, 24. Gerony Reboll, 25. Josep Rubert major, 26. Miquel Vilarroig gendre de Castell, 27. Miquel Català, 28. Pere Segarra de Cosme, 29. Andreu Pasqual de Andreu, 30. Martí Viciano, 31. Vicent Rubert, 32. Miquel Lansola menor, 33. Vicent Castellet, 34. Josep Albiol, 35. Francesc Amiguet, 36. Pere Museros de Vicent, 37. Antoni Castell de Josep, 38. Joan Museros de Monserrat, 39. Francesc Figuerola de Vicent, 40. Miquel Navarro de Gaspar, 41. Miquel Pasqual de Francesc, 42. Josep Avinent menor de Baltazar, 43. Francesc Viciano major, 44. Gerony Rubert, 45. Josep Vilarroig de Josep, 46. Pere Calbo, 47. Joan Pasqual de Joan i 48. Gabriel Segarra de Josep.

Bossa de Escrivans: 1. Pere Giner notari, 2. Vicent Martí notari, 3. Vicent Porta notari i 4. Vicent Pasqual notari.

Finis 


\section{Insaculación de $1662\left(2^{\mathrm{a}}\right.$ parte $)$}

(AHMC. Llibre de les Insaculacions. ff. 91-93).

Die XXVIII de Aprillis MDCLVI se juntaren los subrrogat de Governador, Batlle, Justicia, 4 jurats i los 8 elets de les 4 boses per a posar en redolins els vells Insaculats i nous del govern de la present Vila.

1. Militars. En primer lloc de la Bossa de Militars: 1. Francesc Bou de Monsonís, 2. Joan Ros de Ursins cavaller, 3. Josep Reus cavaller, 4. Pere Serra. cavaller, 5. Basilio Reus cavaller, 6. Joan Castell cavaller, 7. March Antoni Jordà cavaller, 8. Gerony Mas cavaller, 9. Cristòfol Castell cavaller, 10. Martí Mas, 11. Don Félix Sisternés, 12. Don Cosme Feliu, 13. Don Miquel Vallés, 14. Don Narcís Feliu, 15. Don Josep Igual, 16. Don Felip Jover, 17. Don Carlos Jover,18. Don Fernando Miralles i 19. Don Bernardo Ros.

Bossa 1 de Jurat en cap del Bras Real o ciutadà: 1. Gaspar Brunell, 2. Joan Andreu, 3. Micer Vicent Tosquella, 4. Micer Vicent Vilar, 5. Micer Nicolau Figuerola, 6. Miquel Romeu (obiit), 7. Doctor Miquel Mur, 8. Vicent Albiol, 9. Tomàs Giner, 10. Lluís Pauner, 11. Dionís Aragonés, 12. Vicent Figuerola, 13. Doctor Gerony Vidal, 14. Micer Joan Cases, 15. Doctor Melchor Calbo, 16. Tomàs Capero, 17. Doctor Batiste Orts i 18. Francesc Andreu ciutadà.

Bossa Segona de Artistes de Jurat: 1. Doctor Pere Giner, 2. Vicent Martí, 3. Melchor Amiguet, 4. Vicent Porta, 5. Melchor Amposta, 6. Josep Alberich, 7. Jaume Castell, 8. Vicent Pasqual, 9. Francesc Mercer, 10. Alexandre Martí, 11. Pere Museros, 12. (nombre tachado que no se ve nada), 13. Francesc Mas notari, 14. Pere Joan Vicent notari, 15. Francesc Timor notari, 16. Pere Palanques notari, 17. Francesc Grau notari, 18. Macià Compte notari i 19. Vicent Ferrer notari.

Bossa de Jurat 3 i 4 : 1.Joan Navarro de Joan, 2. Miquel Giner, 3. Gaspar Eiximeno, 4. Vicent Museros, 5. Miquel Sanchís, 6. Miquel Llansola major, 7. Vicent Figuerola llaurador, 8. Francesc Pasqual de Joan, 9. Josep Esteve de Miquel, 10. Pere Vilarroig, 11. Andreu Castellet, 12. Pere Navarro, 13. Jaume Roig, 14. Josep Castell de Antoni, 15. Vicent Marqués, 16. Josep Castell de Francesc, 17. Francesc Alegre, 18. Josep Avinent major de Baltazar, 19. Josep Vilarroig major, 20. Andreu Ribalta, 21. Miquel Vilarroig gendre de Viciano, 22. Pere Bonet de Batiste, 23. Vicent Eiximeno, 24. 
Gerony Reboll, 25. Josep Rubert, 26. Miquel Vilarroig gendre de Castell, 27. Miquel Català, 28. Pere Segarra de Cosme, 29. Vicent Rubert, 30. Vicent Castellet de Cristòfol, 31. Josep Albiol, 32. Pere Museros de Vicent, 33. Antoni Castell de Josep, 34. Joan Museros de Monserrat, 35. Francesc Figuerola de Vicent, 36. Miquel Navarro de Gaspar, 37. Miquel Pasqual de Francesc, 38. Josep Avinent de Baltazar menor, 39. Gabriel Segarra de Josep i 40. Miquel Llansola de Miquel menor.

Bossa de Justicia del Bras Real: 1. Joan Andreu ciutadà, 2. Miquel Romeu ciutadà, 3. Micer Nicolau Figuerola, 4. Gaspar Brunell, 5. Micer Vicent Vilar, 6. Melchor Amiguet, 7. Pere Giner notari Jubilat, 8. Vicent Martí notari, 9. Vicent Museros llaurador, 10. Lluís Pauner, 11. Micer Vicent Castellet, 12. Josep Castell de Antoni llaurador, 13. Lo Doctor Miquel Mur, 14. Vicent Figuerola ciutadà, 15. Dionís Aragonés, 16. Micer Joan Cases, 17. Gerony Vidal Doctor, 18. Alexandre Martí, 19. Jaume Castell mercader Jubilat, 20. Vicent Figuerola llaurador, 21. Miquel Giner llaurador jubilat, 22. Tomàs Giner, 23. Doctor Melchor Calbo, 24. Tomàs Capero sirurgià, 25. Micer Batiste Orts, 26. Francesc Andreu ciutadà, 27. Vicent Pasqual notari i 28. Vicent Porta notari.

Bossa de Mustassaf: 1. Micer Vicent Vilar, 2. Micer Vicent Castellet, 3. Melchor Amiguet, 4. Gaspar Brunell, 5. Vicent Martí notari, 6. Josep Alberich mercader, 7. Pere Giner notari, 8. Miquel Romeu, 9. Joan Andreu, 10. Miquel Mur Doctor, 11. Micer Nicolau Figuerola, 12. Tomàs Giner, 13. Miquel Giner llaurador, 14. Lluís Pauner, 15. Vicent Porta notari, 16. Vicent Albiol, 17. Vicent Figuerola ciutadà, 18. Dionís Aragonés, 19. Micer Joan Cases, 20. Gerony Vidal Doctor, 21. Jaume Castell, 22. Melchor Amposta, 23. Vicent Pasqual notari, 24. (Se han saltado en la lista este número), 25. Alexandre Martí, 26. Francesc Mercer, 27. Joan Navarro de Joan, 28. Josep Castell de Antoni, 29. Jaume Roig, 30. Vicent Museros, 31. Doctor Melchor Calbo, 32. Tomàs Capero, 33. Micer Batiste Orts, 34. Francesc Andreu cirurgià, 35. Pere Museros cirurgià, 36. Miquel Sanchís i 37. Pere Vilarroig. (Este último no tiene número) Gaspar Eiximeno.

Bossa de Sequiers: 1 . Josep Castell de Francesc, 2. Miquel de Romeu, 3. Vicent Figuerola llaurador, 4. Joan Andreu ciutadà, 5. Miquel Giner, 6. Miquel Llansola major, 7. Pere Navarro de Joan, 8. Gaspar Eiximeno, 9. Andreu Castellet, 10. Pere Vilarroig, 
11. Jaume Roig, 12. Gaspar Brunell, 13. Francesc Alegre, 14. Josep Castell de Antoni, 15. Joan Navarro de Joan, 16. Josep Avinent major de Baltazar, 17. Miquel Sanchís, 18. Josep Alberich, 19. Tomàs Giner, 20. Jaume Castell, 21. Alexandre Martí, 22. Vicent Museros, 23. Vicent Marqués, 24. Francesc Pasqual de Joan, 25. Andreu Pasqual de Andreu, 26. Martí Viciano, 27. Vicent Eiximeno, 28. Andreu Ribalta, 29. Vicent Rubert, 30. Josep Vilarroig major, 31. Miquel Llansola de Miguel menor, 32. Miguel Vilarroig gendre de Viciano, 33. Vicent Castellet, 34. Josep Albiol, 35. Francesc Amiguet, 36. Vicent Figuerola ciutadà, 37. Francesc Viciano major, 38. Dionís Aragonés, 39. Vicent Pasqual notari, 40. Pere Museros cirurgià, 41. Francesc Mercer, 42. Pere Bonet de Batiste, 43. Josep Rubert major, 44. Miquel Català, 45. Miquel Vilarroig de Castell, 46. Pere Segarra, 47. Gerony Rubert major, 48. Josep Vilarroig de Josep menor, 49. Joan Pasqual de Joan i 50. Pere Calbo.

Bossa de Escrivans: 1. Pere Giner notari, 2. Vicent Porta, 3. Vicent Pasqual i 4. Vicent Martí.

Bossa de Consellers de Mà major: 1 . Micer Vicent Castellet, 2. Vicent Martí notari, 3. Gaspar Brunell, 4. Lluís Pauner, 5. Joan Andreu ciutadà, 6. Micer Vicent Vilar, 7. Melchor Amposta, 8. Melchor Amiguet, 9. Micer Nicolau Figuerola, 10. Tomàs Giner cirurgià, 11. Vicent Albiol, 12. Jaume Castell mercader, 13. Pere Giner notari, 14. Miquel Romeu, 15. Vicent Porta notari, 16. Doctor Miquel Mur, 17. Josep Alberich, 18. Dionís Aragonés, 19. Vicent Figuerola ciutadà, 20. Micer Joan Cases, 21. Gerony Vidal Doctor, 22. Vicent Pasqual notari, 23. Alexandre Martí, 24. Francesc Mercer, 25. Pere Museros, 26. Doctor Melchor Calbo, 27. Tomàs Capero, 28. Doctor Batiste Orts, 29. Francesc Andreu ciutadà, 30. Vicent Tosquella ciutadà, 31. Francesc Mas notari, 32. Pere Joan Vicent notari, 33. Francesc Timor notari, 34. Pere Palanques notari, 35. Francesc Grau notari, 36. Macià Compte notari i 37. Vicent Ferrer notari.

Consellers de Mà menor: 1. Josep Avinent major, 2. Vicent Marqués, 3. Joan Navarro, 4. Miquel Giner, 5. Francesc Pasqual de Joan, 6. Vicent Museros, 7. Vicent Figuerola. llaurador, 8. Francesc Alegre, 9. Miquel Sanchís, 10. Josep Castell de Francesc, 11. Andreu Castellet, 12. Gaspar Eiximeno, 13. Pere Vilarroig, 14. Jaume Roig, 15. Pere Navarro, 16. Josep Castell de Antoni, 17. Miquel Llansola major, 18. Josep Esteve de Miquel, 19. Josep Vilarroig major, 20. Andreu Ribalta, 21. Miquel Vilarroig gendre 
Viciano, 22. Pere Bonet, 23. Vicent Eiximeno, 24. Gerony Reboll, 25. Josep Rubert major, 26. Miquel Vilarroig de Castell, 27. Miquel Català, 28. Pere Segarra de Cosme, 29. Andreu Pasqual de Andreu, 30. Martí Viciano, 31. Vicent Rubert, 32. Miquel Lansola menor, 33. Vicent Castellet, 34. Josep Albiol, 35. Francesc Amiguet, 36. Pere Museros de Vicent, 37. Antoni Castell de Josep, 38. Joan Museros de Monserrat, 39. Francesc Figuerola de Vicent, 40. Miquel Navarro de Gaspar, 41. Miquel Pasqual de Francesc, 42. Josep Avinent menor de Baltazar, 43. Francesc Viciano major, 44. Gerony Rubert, 45. Josep Vilarroig de Josep, 46. Pere Calbo, 47. Joan Pasqual de Joan i 48. Gabriel Segarra de Josep. 


\section{Insaculación 1666}

(AHMC. Llibre de les Insaculacions. ff. 95-99).

1666. Los insaculats al Govern de Castelló de la Plana així vells com en la última Insaculació que s'ha fet en 10 i en 11 de Abril 1666 són los següents:

Bossa dels Militars: 1. Francesc Bou de Monsonís cavaller, 2. Joan Ros de Ursins cavaller (obiit), 3. Josep Ros cavaller (nombre tachado) (obiit), 4. Pere Serra i Dols cavaller, 5. Basilio de Reus cavaller, 6. Joan Castell cavaller, 7. March Antoni Jordà cavaller, 8. Gerony Mas cavaller, 9. Cristòfol Castell cavaller, 10. Martí Mas cavaller, 11. Don Félix Sisternés cavaller, 12. Don Narcís Feliu cavaller (nombre tachado), 13. Don Miquel Vallés (nombre tachado) (obiit), 14. Don Josep Igual, 15. Don Felip Jover, 16. Don Carlos Jover, 17. Don Fernando Miralles, 18. Don Bernardo Ros (obiit) i 19. Don Josep Feliu (obiit).

Bossa de Jurat en Cap del Bras Real o ciutadans: 1. Gaspar Brunell ciutadà (obiit), 2. Joan Andreu ciutadà (obiit), 3. Doctor Vicent Castellet (obiit), 4. Doctor Nicolau Figuerola, 5. Miquel Romeu ciutadà jubilat (obiit), 6. Doctor Miquel Mur (obiit), 7. Tomàs Giner ciutadà, 8. Luis Pauner ciutadà (obiit), 9. Dionís Aragonés ciutadà, 10. Vicent Figuerola ciutadà, 11. Doctor Joan Cases, 12. Doctor Melchor Calbo, 13. Tomàs Capero ciutadà, 14. Francesc Andreu ciutadà i 15. Cosme Martí ciutadà. Restaren vacuos cinc llochs de Jurat en Cap o ciutadans.

Bossa Segona de Artistes de Jurat: 1. Pere Giner notari jubilat, 2. Vicent Martí notari, 3. Vicent Porta notari (obiit), 4. Josep Alberich mercader (obiit), 5. Jaume Castell jubilat (obiit), 6. Vicent Pasqual notari impedit, 7. Francesc Mercer pintor, 8. Alexandre Martí notari (obiit), 9. Pere Museros cirurgià, 10. (nombre tachado que no se ve nada), 11. Pere Joan Vicent notari, 12. Pere Palanques notari, 13. Francesc Grau notari (obiit), 14. Macià Conte notari, 15. Vicent Ferrer notari, 16. Jaume Cases notari, 17. Miquel Sanchís notari, 18. Felip Sorrando mercader i 19. Pere Josep Albiol (nombre tachado). Quedà dos llochs vacuos.

Bossa tercera i quarta de Jurat: 1 . Joan Navarro de Joan (obiit), 2. Gaspar Eiximeno, 3. Vicent Museros, 4. Vicent Figuerola llaurador (obiit), 5. Francesc Pasqual de Joan, 6. Pere Vilarroig (obiit), 7. Pere Navarro, 8. Vicent Marqués (obiit), 9. Josep Castell de 
Francesc, 10. Francesc Alegre (obiit), 11. Josep Avinent major, 12. Josep Vilarroig major, 13. Andreu Ribalta, 14. Miquel Vilarroig gendre de Breva, 15. Pere Bonet de Batiste (obiit), 16. Vicent Eiximeno, 17. Gerony Reboll (obiit), 18. Josep Rubert, 19. Miquel Vilarroig gendre de Castell, 20. Miquel Català, 21. Pere Segarra de Cosme, 22. Vicent Rubert (obiit), 23. Miquel Llansola de Miquel menor, 24. Vicent Castellet de Cristòfol, 25. Josep Albiol (nombre tachado), 26. Antoni Castell de Josep, 27. Joan Museros de Monserrat, 28. Francesc Figuerola de Vicent, 29. Miquel Navarro de Gaspar, 30. Miquel Pasqual de Francesc, 31. Josep Avinent de Baltazar menor, 32. Gabriel Segarra de Josep, 33. Gerony Rubert major, 34. Martí Viciano (obiit), 35. Joan Pasqual (obiit), 36. Pere Calbo, 37. Pere Roig de Jaume, 38. March Casalís, 39. Jaume Viciano de Miquel, 40. Gerony Alegre i 41. Pere Albiol (nombre tachado).

Bossa de Justicia del Bras Real: 1. Dionís Aragonés ciutadà, 2. Doctor Joan Cases notari, 3. Alexandre Martí notari (obiit), 4. Jaume Castell jubilat (obiit), 5. Vicent Figuerola llaurador (obiit), 6. Joan Andreu ciutadà, 7. Tomàs Giner ciutadà, 8. Doctor Melchor Calbo, 9. Tomàs Capero ciutadà (obiit), 10. Francesc Andreu ciutadà, 11. Vicent Pasqual notari, 12. Vicent Porta notari (obiit), 13. Cosme Martí ciutadà, 14. Josep Castell de Francesc (obiit), 15. Antoni Castell de Josep, 16. Josep Alberich (obiit) i 17. Pere Josep Albiol ciutadà. Resten quatre llochs vacuos de la boça dels ciutadans.

Bossa de Mustassaf: 1. Doctor Vicent Castellet (obiit), 2. Gaspar Brunell ciutadà (obiit), 3. Vicent Martí notari (obiit), 4. Josep Alberich (obiit), 5. Pere Giner notari jubilat, 6. Miquel Romeu ciutadà jubilat (obiit), 7. Joan Andreu ciutadà (obiit), 8. Doctor Miquel Mur (obiit), 9. Doctor Nicolau Figuerola, 10. Tomàs Giner ciutadà, 11. Lluís Pauner ciutadà (obiit), 12. Vicent Porta notari (obiit), 13. Vicent Figuerola ciutadà, 14. Dionís Aragonés, 15. Doctor Joan Cases, 16. Jaume Castell jubilat (obiit), 17. Vicent Pasqual notari, 18. Alexandre Martí notari (obiit), 19. Francesc Mercer pintor, 20. Joan Navarro de Joan (obiit), 21. Vicent Museros, 22. Doctor Melchor Calbo, 23. Tomàs Capero ciutadà (obiit), 24. Francesc Andreu ciutadà, 25. Pere Museros cirurgià, 26. Pere Vilarroig (obiit), 27. Gaspar Eiximeno, 28. Cosme Martí ciutadà, 29. Vicent Tosquella notari, 30. Macià Compte notari, 31. Jaume Cases notari, 32. Vicent Marqués (obiit), 33. Andreu Ribalta, 34. Miquel Llansola menor i 35. Miquel Vilarroig de Breva. Vaquen cinch llochs de la Bossa dels ciutadans. 
Bossa de Sequiers: 1. Josep Castell de Francesc (obiit), 2. Miquel de Romeu ciutadà (obiit), 3. Vicent Figuerola llaurador (obiit), 4. Joan Andreu ciutadà, 5. Pere Navarro de Joan, 6. Gaspar Eiximeno, 7. Pere Vilarroig (obiit), 8. Gaspar Brunell ciutadà (obiit), 9. Francesc Alegre (obiit), 10. Joan Navarro de Joan (obiit), 11. Josep Avinent major, 12. Josep Alberich (obiit), 13. Tomàs Giner ciutadà impedit a dit ofici, 14. Jaume Castell jubilat (obiit), 15. Aleixandre Martí, 16. Vicent Museros jubilat, 17. Vicent Marqués (obiit), 18. Francesc Pasqual de Joan, 19. Andreu Pasqual de Andreu, 20. Martí Viciano (obiit), 21. Vicent Eiximeno, 22. Andreu Ribalta, 23. Vicent Rubert (obiit), 24. Josep Vilarroig major, 25. Miquel Llansola menor, 26. Miguel Vilarroig gendre de Breva, 27. Josep Albiol, 28. Francesc Amiguet jubilat, 29. Vicent Figuerola ciutadà, 30. Dionís Aragonés, 31. Vicent Pasqual notari, 32. Pere Museros cirurgià, 33. Francesc Mercer pintor, 34. Pere Bonet de Batiste (obiit), 35. Josep Rubert major, 36. Miquel Català, 37. Miquel Vilarroig gendre de Castell, 38. Pere Segarra, 39. Gerony Rubert major (obiit), 40. Josep Vilarroig de Josep (obiit), 41. Pere Calbo, 42. Joan Pasqual de Joan (obiit), 43. Antoni Castell de Josep, 44. Miquel Navarro de Gaspar, 45. Pere Museros de Vicent, 46. Josep Avinent menor, 47. Francesc Figuerola de Vicent, 48. Gabriel Segarra de Josep, 49. Joan Museros de Monserrat i 50. Miquel Pasqual de Francesc.

Bossa de Escrivans: 1. Pere Giner notari jubilat, 2. Vicent Martí notari (obiit), 3. Vicent Porta (obiit), 4. Vicent Pasqual notari. 5. Alexandre Martí notari (obiit), 6. (nombre tachado que no se ve), 7. Macià Compte notari, 8. Francesc Grau notari (obiit), 9. Vicent Ferrer notari i 10. Jaume Cases notari.

Bossa de Consellers de Mà major: 1. Doctor Vicent Castellet (cambia el Micer por el Doctor), 2. Doctor Miquel Mur, 3. Gaspar Brunell ciutadà, 4. Vicent Martí notari, 5. Lluís Pauner ciutadà, 6. Joan Andreu ciutadà, 7. Doctor Nicolau Figuerola, 8. Tomàs Giner ciutadà, 9. Jaume Castell jubilat, 10. Pere Giner notari, 11. Miquel Romeu ciutadà, 12. Vicent Porta notari, 13. Josep Alberich, 14. Dionís Aragonés ciutadà, 15. Vicent Figuerola ciutadà, 16. Doctor Joan Cases, 17. Vicent Pasqual notari, 18. Alexandre Martí notari, 19. Francesc Mercer, 20. Pere Museros cirurgià, 21. Doctor Melchor Calbo, 22. Tomàs Capero ciutadà, 23. Francesc Andreu ciutadà, 24. Vicent Tosquella ciutadà, 25. Pere Joan Vicent notari, 26. Pere Palanques notari, 27. Francesc Grau notari, 28. Macià Conte notari, 29. Vicent Ferrer notari, 30. Cosme Martí ciutadà, 
31. Jaume Cases notari, 32. Miquel Sanchís notari, 33. Felip Sorrando mercader i 34. Pere Josep Albiol.

Consellers de Mà menor: 1. Josep Avinent major, 2. Vicent Marqués, 3. Joan Navarro, 4. Francesc Pasqual de Joan, 5. Vicent Museros, 6. Vicent Figuerola llaurador, 7. Francesc Alegre, 8. Josep Castell de Francesc, 9. Gaspar Eiximeno, 10. Pere Vilarroig, 11. Pere Navarro, 12. Josep Vilarroig major, 13. Andreu Ribalta, 14. Miquel Vilarroig gendre de Breva, 15. Pere Bonet, 16. Vicent Eiximeno, 17. Gerony Reboll, 18. Josep Rubert major, 19. Miquel Vilarroig gendre de Castell, 20. Miquel Català, 21. Pere Segarra de Cosme, 22. Andreu Pasqual de Andreu, 23. Martí Viciano, 24. Vicent Rubert, 25. Miquel Llansola menor, 26. (nombre tachado que no se ve). 27. Francesc Amiguet, 28. Pere Museros de Vicent, 29. Antoni Castell de Josep, 30. Joan Museros de Monserrat, 31. Francesc Figuerola de Vicent, 32. Miquel Navarro de Gaspar, 33. Miquel Pasqual de Francesc, 34. Josep Avinent menor, 35. Gerony Rubert, 36. Josep Vilarroig de Josep, 37. Pere Calbo, 38. Joan Pasqual de Joan, 39. Gabriel Segarra de Josep, 40. Pere Roig de Jaume, 41. March Casalís, 42. Jaume Viciano de Miquel i 43. Gerony Alegre.

\section{Die IIII Mensis May Anno ana... Doni MDCLXVIII}

Don Arsis Feliu subrogat de Governador Francesc Joseph Bou de Monsonis cavaller Batlle per Sa Majestat de la present vila de Castelló de la Plana. Joan Casses Doctor en Dret, Justicia de la dita vila i Thomas Capero ciutadà Jurat en cap en presència $\mathrm{i}$ asistència de Vicent Pasqual notari, i Vicent Museros llaurador, Jurats de dita vila. Feliu Sisternés cavaller, Gaspar Brunell i Joan Andreu, Pere Giner notari, Antoni Castell llaurador i Francesc Andreu ciutadà, Síndichs per execucció de la delliberació del Consell de dita Vila feta en XI de Abril. Posat per a reconèixer les boces del Govern i posar en aquells als nous Insaculats en la damunt dita Insaculació congregats i juntats en la çala del Palau de dita Vila. Manaven traure a un verguer la caixa dels insaculats on están les boces del Govern recondida en lo Archiu de Palau de dita vila i dits subrogat Balle, Justicia i Jurat en cap obriren dita caixa $i$ en primer lloch lo sach de cavallers $i$ generosos i posaren en dit sach de nou redolins que són los antecedement nominats. I en la Boça de Jurat en cap del Bras real posaren quinze redolins dins los quals se posaren los quinze persones Insaculades en dit ofici de Jurat de super mensionats. I su..........ment en la Boça Segona dels Artistes de Jurat segon se posaren dihuit 
redolins ab los noms en pergamí de super mencionats. I en la Boça de tercera i quarta de Jurat se posaren quaranta redolins, en los quals estan los noms de les quaranta persones Insaculades en dita boça a dit ofici de Jurat també de super específicada.

I en la Boça de Justicia se posaren vintsis redolins i en ells los Insacultas a dit ofici de Justicia quedant quatre llochs vacuos de la boça dels ciutadans. I en la boça de Mustasaf se posaren trenta sinch redolins en les quales se posaren los noms de les trenta sinch persones insaculades a dit ofici con vaguen sinch llochs dels ciutadans. I en la Boça de cequier se posaren cinquanta redolins en los quals se posaren los noms de les cinquanta Insaculats en dit ofici de super mencionats. I en la boça dels escrivans se posaren deu redolins de les deu persones Insaculades a dit ofici de escrivans. I en la boça de consellers de mà major se posaren trenta i tres redolins en los quals se posaren los noms dels trenta i tres persones Insaculades a conselleres de ma major i ultimament se posaren en la Boça de consellers de ma menor quaranta tres redolins de les quaranta i tres persones Insaculades als dits oficis en dita Boça. Les quals Boces en presència dels desus dits, per mi Vicent Martí escrivà fosen closes i segellades i per dit Jurat en cap tornades en dita Caixa i per dits subrogat Balle, Justicía, i Jurat tornades a tancar (.........) Premissis carta pública la qual (....) (....) Castelló i en dita çala del Palau (...)

Presents foren per testimonis a dites coses Pere Joan Gornis i Jaume Fortuny macers de dits Jurats de Castelló (....)

R. Vicentius Martí notari 


\section{AMPLIACIÓN DE 1668}

(AHMC. Judiciari. Sesión del Consell de 10 de abril de 1668).

Bossa militar: Don Josep Feliu.

Bossa de jurat primer: Cosme Martí ciutadà.

Bossa segona dels artistes: Jaume Cases notari, Miquel Sanchís notari i Felip Sorrando mercader.

Bossa tercera i quarta de jurats: Gerony Rubert, Martí Viciano, Joan Pasqual, Pere Calbo, Pere Roig de Jaume, March Casalís, Jaume Viciano de Miquel i Gerony Alegre.

Bossa Justicia: Cosme Martí ciutadà(bossa ciutadans), Josep Alberich (bossa segona dels artistes), Antoni Castell(bossa llauradors) i Josep Castell(bossa llauradors).

Bossa Mustassaf: Cosme Martí, Vicent Tosquella, Macià Compte, Jaume Cases, Vicent Marqués i Andreu Ribalta, Miquel Llansola i Miquel Vilarroig.

Bossa Cequiers: Antoni Castell, Miquel Navarro, Pere Museros, Josep Avinent, Francesc Figuerola, Gabriel Segarra, Joan Museros i Miquel Pasqual de Francesc.

Bossa Escribans: Aleixandre Martí, Vicent Tosquella, Macià Compte, Vicent Ferrer, Jaume Cases i Francesc Grau. 


\section{INSACULACIÓN DE 1677}

(AHMC. Llibre de les Insaculacions. ff. 100-104).

1677

Los Insaculats en lo Govern de la Vila de Castelló de la Plana com en la última Insaculació de 18 de Mars MDCXXLV i altres jornades següents i los altres certs impediments en lo dia de huy Contant XXVIII dies del mes de Janer MDCLXXVII són los següents:

Bossa dels Militars: 1 . Francesc Bou de Monsonís cavaller, 2. Pere Serra i Dols cavaller, 3. Basilio Reus cavaller, 4. Joan Castell cavaller (obiit), 5. Gerony Mas cavaller, 6. Cristòfol Castell cavaller, 7. Martí Mas cavaller, 8. Don Félix Sisternés cavaller, 9. Don Josep Igual, 10. Don Felip Jover, 11. Don Carlos Jover, 12. Don Fernando Miralles, 13. Don Bernado Ros, 14. Gerony Bou. Cavaller i 15. Don Macià Igual.

Bossa de Jurat en cap del Bras Real: 1. Doctor Nicolau Figuerola, 2. Tomàs Giner ciutadà, 3. Dionís Aragones ciutadà, 4. Vicent Figuerola ciutadà, 5. Doctor Francesc Joan Cases, 6. Doctor Melchor Calvo, 7. Francesc Andreu ciutadà, 8. Cosme Martí ciutadà, 9. Doctor Francesc Ferrer, 10. Doctor Josep Casalís, 11. Doctor Joan Timor i 12. Batiste Jover ciutadà. I restaren huit llochs vacuos.

Bossa Segona de Artistes de Jurat: 1. Pere Giner notari, 2. Vicent Pasqual notari, 3. (aparece un nombre tachado que no se puede leer), 4. Pere Joan Vicent notari, 5. Macià Compte notari, 6. Vicent Ferrer notari, 7. Jaume Casses notari, 8. Miquel Sanchís notari, 9. Pere Figuerola notari, 10. Francesc Mercer pintor (obiit), 11. Pere Museros cirurgià (obiit), 12. Felip Sorrando mercader, 13. Tomàs Mercer pintor, 14. Josep Amposta cirurgià i 15. Miquel Bonet notari. I restaren en dita Boça cinch llochs vacuos.

Bossa tercera i quarta de jurats: 1. Gaspar Eiximeno (obiit), 2. Vicent Museros, 3. Francesc Pasqual de Joan (obiit), 4. Pere Navarro de Joan, 5. Josep Avinent major, 6. Josep Vilarroig major, 7. Andreu Ribalta, 8. Miquel Vilarroig de Batiste (obiit), 9. Vicent Eiximeno, 10. Josep Rubert, 11. Miquel Vilarroig de Castell jubilat, 12. Miquel Català, 13. Pere Segarra, 14. Miquel Llansola de Miquel, 15. (nombre tachado que no se puede ver), 16. Pere Museros de Vicent, 17. Antoni Castell de Josep, 18. Joan 
Museros de Monserrat, 19. Francesc Figuerola de Vicent, 20. Miquel Navarro de Gaspar, 21. Miquel Pascual de Francesc, 22. Josep Avinent de Baltazar menor, 23. Gabriel Segarra de Josep, 24. Pere Calbo, 25. Pere Roig de Jaime, 26. March Casalís, 27. Jaime Viciano de Miquel, 28. Gerony Alegre (obiit), 29. Gerony Castell, 30. Miquel Boix de Miquel, 31. Miquel Vilarroig de Nicolau i 32. Pere Reboll. Restaren vacuos llochs en dita boça.

Bossa de Justicia del bras real o ciutadans: 1. Doctor Nicolau Figuerola, 2. Pere Giner notari, 3. Vicent Museros llaurador, 4. Vicent Figuerola ciutadà, 5. Dionís Aragonés ciutadà, 6. Doctor Francesc Joan Cases, 7. Tomàs Giner ciutadà, 8. Doctor Melchor Calbo, 9. Vicent Pasqual notari, 10. Cosme Martí ciutadà, 11. Francescc Andreu ciutadà, 12. Antoni Castell llaurador, 13. Doctor Francesc Ferrer, 14. Doctor Josep Casalís, 15. Doctor Joan Timor, 16. Vicent Tosquella, 17. Jaume Cases notari, 18. Miquel Sanchís notari, 19. Felip Sorrando mercader, 20. Joan Museros de Monserrat, 21. Pere Roig de Jaume i 22. Batiste Jover ciutadà. Restaren llochs vacuos de la Bossa dels ciutadans.

Bossa de Mustasaf del Bras Real: 1. Pere Giner notari, 2. Doctor Nicolau Figuerola, 3. Tomàs Giner ciutadà, 4. Vicent Figuerola ciutadà, 5. Dionís Aragones ciutadà, 6. Doctor Francesc Joan Cases, 7. Vicent Pascual notari, 8. Francesc Mercer pintor (obiit), 9. Vicent Museros, 10. Doctor Melchor Calbo, 11. Francesc Andreu ciutadà, 12. Pere Museros cirurgià, 13. Gaspar Eiximeno, 14. Cosme Martí ciutadà, 15. Vicent Tosquella, 16. Macià Compte notari, 17. Jaume Cases notari, 18. Andreu Ribalta, 19. Miquel Llansola, 20. Miquel Vilarroig de Batiste (obiit), 21. Doctor Francesc Ferrer, 22. Doctor Joan Timor, 23. Doctor Josep Casalís, 24. Vicent Ferrer notari, 25. Miquel Sanchís notari, 26. Felip Sorrando mercader, 27. Pere Navarro, 28. Vicent Eiximeno, 29. Miquel Pascual de Francesc, 30. Batiste Jover ciutadà i 31. Pere Figuerola notari. Restaren nou llochs vacuos Boça dels ciutadans.

Bossa de Cequier: 1. Pere Navarro, 2. Gaspar Eiximeno (obiit), 3. Josep Avinent major, 4. Tomàs Giner ciutadà, 5. Vicent Museros, 6. Francesc Pasqual de Joan (obiit), 7. Andreu Pascual de Andreu (obiit), 8. Vicent Eiximeno, 9. Andreu Ribalta, 10. Josep Vilarroig major, 11. Miquel Llansola, 12. Miquel Vilarroig de Batiste, 13. Josep Albiol, 14. Francesc Amiguet, 15. Vicent Figuerola ciutadà, 16. Dionís Aragones ciutadà, 17. 
Vicent Pasqual notari, 18. Pere Museros cirurgià, 19. Francesc Mercer pintor, 20. Josep Rubert major, 21. Miquel Català, 22. Miquel Vilarroig de Castell, 23. Pere Segarra, 24. Pere Calbo, 25. Miquel Navarro de Gaspar, 26. Pere Museros de Vicent, 27. Josep Avinent menor, 28. Francesc Figuerola de Vicent, 29. Gabriel Segarra de Josep, 30. Joan Museros de Monserrat, 31. Miquel Pasqual de Francesc, 33. Francesc Andreu ciutadà, 34. Doctor Francesc Ferrer, 35. Doctor Joan Timor, 36. Doctor Josep Casalís, 37. Vicent Tosquella, 38. Macià Compte notari, 39. Jaume Cases notari, 40. Miquel Sanchís notari, 41. Pere Roig de Jaume, 42. March Casalís, 43. Jaume Viciano de Miquel, 44. Gerony Alegre, 45. Gerony Castell, 46. Miquel Boix de Miquel, 47. Miquel Vilarroig de Nicolau, 48. Domingo de Vilaroig, 49. Pere Reboll i 50. Batiste Jover ciutadà.

Bossa de Escrivans: 1.Pere Giner notari, 2. Vicent Pascual notari, 3. (nombre que aperece tachado y no se puede ver), 4. Macià Compte notari, 5. Vicent Ferrer notari, 6. Jaume Cases notari, 7. Miquel Sanchís notari i 8. Miquel Bonet notari. En esta Boça va quedar dos llochs.

Bossa de Consellers de mà major: 1. Doctor Nicolau Figuerola, 2. Tomàs Giner ciutadà, 3. Pere Giner notari, 4. Dionís Aragones ciutadà, 5. Vicent Figuerola ciutadà, 6. Doctor Francesc Juan Cases, 7. Vicent Pasqual notari, 8. Francesc Mercer pintor, 9. Pere Museros cirurgià, 10. Doctor Melchor Calbo, 11. Francesc Andreu ciutadà, 12. Vicent Tosquella ciutadà, 13. Pere Joan Vicent notari, 14. Macià Compte notari, 15. Vicent Ferrer notari, 16. Cosme Martí ciutadà, 17. Jaume Cases notari, 18. Miquel Sanchís notari, 19. Felip Sorrando mercader, 20. Doctor Francesc Ferrer, 21. Doctor Joan Timor, 22. Doctor Josep Casalís, 23. Pere Figuerola notari, 24. Tomàs Mercer pintor, 25. Josep Amposta cirurgià, 26. Batiste Jover ciutadà i 27. Miquel Bonet notari.

Bossa de Consellers de mà menor: 1. Josep Avinent major, 2. Francesc Pasqual de Joan (obiit), 3. Vicent Museros, 4. Gaspar Eiximeno, 5. Pere Navarro de Joan, 6. Josep Vilarroig major, 7. Andreu Ribalta, 8. Miquel Vilarroig de Batiste, 9. Vicent Eiximeno, 10. Josep Rubert major, 11. Miquel Vilarroig de Castell, 12. Miquel Català, 13. Pere Segarra de Cosme, 14. Andreu Pasqual major, 15. Miquel Llansola menor, 16. Josep Albiol, 17. Francesc Amiguet, 18. Miquel Vilarroig de Batiste, 19. Pere Museros de Vicent, 20. Antoni Castell, 21. Joan Museros de Monserrat, 22. Francesc Figuerola de 
Vicent, 23. Miquel Navarro de Gaspar, 24. Miquel Pasqual de Francesc, 25. Josep Avinent menor, 26. Pere Calbo, 27. Gabriel Segarra de Josep, 28. Pere Roig de Jaume, 29. March Casalís, 30. Jaume Viciano de Miquel, 31. Gerony Alegre, 32. Gerony Castell, 33. Miquel Boix de Miquel, 34. Miquel Vilarroig de Nicolau, 35. Domingo Vilarroig i 36. Pere Reboll.

\section{Die VIIII Mensis January Anno (........) MDCLXXVII}

Don Joan Escorcia i Ladrón cavaller del hàbit de nostra de Montesa i de sant Jordi de Alfama, Governador de la present Vila de Castelló de la Plana; Cosme Martí ciutadà Batlle per Sa Majestat de dita present vila, Francesc Bou de Monsonís cavaller i Justícia de dita Vila, Vicent Figuerola ciutadà, Jaume Casses notari, Pere Segarra i Miquel Vilarroig de Castell llauradors, Jurats de dita vila. En presència i assistència de Basilio de Reus, March Antoni Jordà cavallers, Dionís Aragonés ciutadà, Pere Giner notari, Antoni Castell i Pere Calbo llaurador i Miquel Pasqual de Francesc, llaurador Síndich de dita vila, en execucció de la deliberació conciliar feta en XXIII dies del mes de mars de l'any de MDCLXXV per a reconèixer les bosses del govern i possar en aquelles als nous insaculats en la damunt dita insaculació. Congregats i juntats en la Sala del Palau de dita vila maneren traure al verguer la caixa dels Insaculats hon estan les bosses del govern, recondida en lo Archiu de Palau de dita Vila i dits Governador, Batle, Justícia i Jurat en cap de la dita boça, ab les claus que tenen encomanades obriren aquelles i en primer lloch lo sach dels cavallers i generosos i posaren en dit sach setze redolins que són los antecedentment escrits. I en la boça del Jurat en Cap del Bras Real posaren dotze redolins, los quals se possaren los noms de dotze persones Insaculades a dit ofici de Jurat de super mencionades. I succesivament en la boça segona de Artites per al ofici de Jurat segon se possaren quinze redolins ab los noms supra mencionats; I en la Boça Tercera i quarta de Jurat se possaren trenta i tres redolins en los quals estaven los noms de trenta $\mathrm{i}$ tres persones supramencionades insacualdes en dita boça de Jurat també de super especificades. I en la borça de Justicia foren possats vint i dos redolins i en elles los noms dels Insaculats per al dit ofici de Justicia, quedant huit llochs vacuos de la Boça dels ciutadans, i en la Boça de Mustassaf de Bras Real se posaren trenta un redolins, en los quals se possaren los noms de trenta una persones Insaculades per al dit ofici com vaquen deu llochs dels ciutadans, i en la Boça de sequier foren possats cinquanta redolins en los quals se posaren los noms de les cinquanta insaculats per al dit ofici de supermencionats. I en la boça de escrivans de la vila se possaren huyt redolins 
de les deu persones insaculades al dit offici de escrivans. I en la boça de ConSeller de mà major se posaren vinti set redolins, en los quals se possaren los noms de vinti set persones insaculades a Consellers de mà major i ultimament foren possats en la boça de Consellers de mà menor, trenta cinch redolins de les trenta $\mathrm{i}$ cinch persones insaculades als officis de dita vila suparamencionades, de les quals cosses, havent possat dites boçes en sachs los dits officials i prohoms per mi Vicent Tosquella notari, scrivà de dita vila, foren closes i segellades i per dit Jurat en cap tornades en dita caixa i per dits Governador, Batlle, Justicia i Jurat tornat a tancar i posar los sachs en dita caixa i tornada en on sol estar requerint de premisis Carta Pública la qual (....) en Castelló de la Plana i en dita Sala del Palau.

Presents foren per testimonis Jaume Fortuny Abaixador i Baltazar Naturil teixidor delli de dita vila habi(...)

R. Vicentius Martí notari 


\section{Insaculación 1679}

(AHMC. Llibre de les Insaculacions. ff. 106-109).

Los insaculats al govern de la Vila de Castelló de la Plana, així en les antecedents Insaculacions com en la última que se ha fet en XXVI, XXVII, XXVIII y XXVIIII de abril de l'any de MDCLXXVIIII són los següents:

Bossa dels Militars: 1. Francesc Bou de Monsonís. Cavaller (obiit), 2. Pere Serra i Dols cavaller (obiit), 3. Basilio Reus cavaller, 4. March Antoni Jordà cavaller, 5. Gerony Mas cavaller, 6. Cristòfol Castell cavaller, 7. Martí Mas cavaller, 8. Don Félix Sisternés cavaller, 9. Don Josep Igual, 10. Don Felip Jover, 11. Don Carlos Jover, 12. Don Fernando Miralles, 13. Don Bernat Ros, 14. Gerony Bou cavaller, 15. Don Macià Igual, 16. Don Nicolau Muñoz de Casalduch (obiit), 17. Don Jaume Vallés, 18. Don Francesc Feliu, 19. Don Antoni Gombau i 20. Felip Mas cavaller (obiit).

Bossa de jurat en cap del brac reial: 1. Doctor Nicolau Figuerola (obiit), 2. Tomàs Giner ciutadà, 3. Doctor Francesc Joan Cases, 4. Dionís Aragones ciutadà, 5. Vicent Figuerola ciutadà, 6. Doctor Melchor Calvo, 7. Francesc Andreu ciutadà, 8. Cosme Martí ciutadà, 9. Doctor Francesc Ferrer (obiit), 10. Doctor Josep Casalís, 11. Doctor Joan Timor, 12. Batiste Jover ciutadà, 13. Doctor Pere Giner de Vilarroig, 14. Tomàs March ciutadà, 15. Doctor Ignacio Figuerola, 16. Doctor Martí Viciano i 17. Doctor Jaume Giner. Restaven vacuos en dita borsa de jurat en cap del bras real al tres llocs.

Bossa Segona de Artistes de Jurat: 1. Pere Giner notari (obiit), 2. Vicent Pasqual notari, 3. (aparece un nombre tachado que no se puede leer, 4. Pere Joan Vicent notari (ausent), 5. Macia Compte notari, 6. Vicent Ferrer notari, 7. Jaume Cases notari, 8. Miquel Sanchís notari, 9. Pere Figuerola notari, 10. Felip Sorrando mercader, 11. Tomàs Mercer pintor (obiit), 12. Josep Amposta cirurgià, 13. Miquel Bonet notari, 14. Pere Breva notari i 15. Felip Breva notari. Quedaven cinc llocs vacuos en dita segona borsa de artistes de jurat, dic cinc llocs.

Bossa tercera i quarta de jurats: 1 . Vicent Museros (obiit), 2. Pere Navarro de Joan. Jubilat, 3. Josep Avinent major (obiit), 4. Josep Vilarroig major (obiit), 5. Andreu Ribalta, 6. Vicent Eiximeno, 7. Josep Rubert major jubilat, 8. Miquel Vilarroig de 
Castell jubilat, 9. Miquel Català de Pere, 10. Pere Segarra (obiit), 11. Miquel Llansola de Miquel, 12. Josep Albiol major, 13. Pere Museros de Vicent, 14. Antoni Castell, 15. Joan Museros de Monserrat, 16. Francesc Figuerola de Vicent, 17. Miquel Navarro de Gaspar, 18. Miquel Pasqual de Francesc, 19. Josep Avinent menor, 20. Gabriel Segarra de Josep, 21. Pere Calbo, 22. Pere Roig de Jaime, 23. March Casalís, 24. Jaume Viciano de Miquel, 25.Gerony Castell, 26. Miquel Boix de Miquel, 27. Miquel Vilarroig de Nicolau, 28. Domingo Vilarroig, 29. Pere Reboll (obiit), 30. Francesc Amiguet menor, 31. Josep Vilarroig de Jaume, 32. Miquel Navarro de Antoni, 33. Josep Museros de Vicent, 34. Josep Goterris (obiit), 35. Josep Rubert menor, 36. Andreu Castellet, 37. Félix Vilarroig, 38. Agostí Reboll, 39. Francesc Vilarroig i 40. Jaume Breva gendre de Vilaroig.

Bossa de Justicia del bras real: 1. Doctor Nicolau Figuerola (obiit), 2. Pere Giner (obiit), 3. Vicent Museros (obiit), 4. Vicent Figuerola ciutadà, 5. Dionís Aragonés ciutadà, 6. Doctor Francesc Joan Cases, 7. Tomàs Giner ciutadà impedit a tot, 8. Doctor Melchor Calbo, 9. Vicent Pasqual notari, 10. Cosme Martí, ciutadà 11. Francesc Andreu ciutadà, 12. Pere Roig de Jaume, 13. Antoni Castell, 14. Doctor Francesc Ferrer (obiit), 15. Josep Casalís, 16. Doctor Joan Timor, 17. Vicent Tosquella, 18. Jaume Cases notari, 19. Miquel Sanchís notari, 20. Felip Sorrando mercader (obiit), 21. Joan Museros de Monserrat, 22. Batiste Jover ciutadà, 23. Doctor Pere Giner de Vilarroig, 24. Tomàs March ciutadà, 25. Doctor Ignacio Figuerola, 26. Doctor Martí Viciano, 27. Doctor Jaume Giner, 28. Doctor Macià Compte notari i 29. Doctor Josep Amposta cirurgià. Queda un lloc vacuo de la borsa dels ciutadans de justicia.

Bossa de Mustasaf del bras real: 1. Pere Giner notari (obiit), 2. Doctor Nicolau Figuerola, 3. Tomàs Giner ciutadà impedit a tot, 4. Vicent Figuerola ciutadà, 5. Dionís Aragonés ciutadà, 6. Doctor Francesc Joan Cases, 7. Vicent Pascual notari, 8. Vicent Museros (obiit), 9. Doctor Melchor Calbo, 10. Francesc Andreu ciutadà, 11. Cosme Martí ciutadà, 12. Vicent Tosquella ciutadà, 13. Macià Compte notari, 14. Jaume Cases notari, 15. Andreu Ribalta, 16. Miquel Llansola, 17. Doctor Francesc Ferrer (obiit), 18. Doctor Joan Timor, 19. Doctor Josep Casalís, 20. Vicent Ferrer notari, 21. Miquel Sanchís notari, 22. Felip Sorrando mercader (obiit), 23. Pere Navarro de Joan jubilat, 24. Vicent Ferrer notari, 25. Vicent Eximeno, 26. Miquel Pascual de Francesc, 27. Batiste Jover ciutadà, 28. Pere Figuerola notari, 29. Doctor Pere Giner de Vilarroig, 30. 
Tomàs March ciutadà, 31. Doctor Ignacio de Figuerola, 32. Doctor Martí Viciano, 33. Doctor Jaume Giner, 34. Miquel Bonet notari, 35. Josep Amposta cirurgià, 36. Tomàs Mercer pintor (obiit), 37. Jaume Viciano de Miquel i 38. Antoni Castell. Quedaven tres llocs vacuos en dita borsa de Mustassaf en ciutadans.

Bossa de Cequier: 1. Pere Navarro de Joan jubilat, 2. Josep Avinent major (obiit), 3. Tomàs Giner ciutadà (impedit), 4. Vicent Museros (obiit), 5. Andreu Pasqual de Andreu (obiit), 6. Vicent Eximeno jubilat, 7. Andreu Ribalta, 8. Josep Vilarroig major(obiit), 9. Miquel Llansola de Miquel, 10. Josep Albiol jubilat, 11. Francesc Amiguet machor, 12. Vicent Figuerola ciutadà jubilat, 13. Dionís Aragonés ciutadà, 14. Vicent Pasqual notari, 15. Josep Rubert Major jubilat, 16. Miquel Catala de Pere, 17. Miquel Vilarroig de Castell jubilat, 18. Pere Segarra (obiit), 19. Pere Calbo, 20. Antoni Castell, 21. Miquel Navarro de Gaspar, 22. Pere Museros de Vicent (obiit), 23. Josep Avinent menor, 24. Francesc Figuerola de Vicent, 25. Gabriel Segarra de Josep, 26. Joan Museros de Monserrat, 27. Miquel Pasqual de Francesc, 28. Francesc Andreu ciutadà, 29. Francesc Ferrer Doctor (obiit), 30. Joan Timor Doctor, 31. Josep Casalís Doctor. 32. Vicent Tosquella jubilat, 33. Macià Compte notari, 34. Jaume Cases notari, 35. Miquel Sanchís notari, 36. Pere Roig de Jaume, 37. Marc Casalís, 38. Jaume Viciano de Miquel, 39. Gerony Castell, 40. Miquel Boix de Miquel, 41. Miquel Vilarroig de Nicolau, 42. Domingo de Vilaroig, 43. Pere Reboll (obiit), 44. Batiste Jover ciutadà, 45. Pere Giner de Vilaroig, 46. Pere Figuerola notari jubilat, 47. Francesc Amiguet menor, 48. Agostí Reboll, 49. Felip Sorrando mercader (obiit), 50. Josep Amposta cirurgià i 51. Agostí Reboll.

Bossa de Escrivans: $1 . P e r e$ Giner notari (obiit), 2. Vicent Pasqual notari, 3. (nombre que aperece tachado y no se puede ver), 4. Macià compte notari, 5. Vicent Ferrer notari, 6. Jaume Cases notari, 7. Miquel Sanchís notari, 8. Miquel Bonet notari i 9. Pere Figuerola notari. Queda un lloc vacuo en la dita borsa de escrivans.

Bossa de Consellers de mà major: 1. Nicolau Figuerola Doctor (obiit), 2. Tomàs Giner ciutadà, 3. Pere Giner notari (obiit), 4. Dionís Aragones ciutadà, 5. Vicent Figuerola ciutadà, 6. Francesc Joan Cases Doctor, 7. Vicent Pasqual notari, 8. Melchor Calbo Doctor, 9. Francesc Andreu ciutadà, 10. Vicent Tosquella ciutadà, 11. Pere Joan Vicent notari, 12. Macià Compte notari, 13. Vicent Ferrer notari, 14. Cosme Martí 
ciutadà, 15. Jaume Cases notari, 16. Miquel Sanchís notari, 17. Miquel Sorrando mercader (obiit), 18. Doctor Francesc Ferrer (obiit), 19. Doctor Joan Timor, 20. Doctor Josep Casalís, 21. Pere Figuerola notari, 22. Tomàs Mercer pintor (obiit), 23. Josep Amposta cirurgià, 24. Batiste Jover ciutadà, 25. Miquel Bonet notari, 26. Doctor Pere Giner de Vilarroig (obiit), 27. Tomàs March ciutadà, 28. Doctor Ignacio Figuerola, 29. Doctor Martí Viciano, 30. Doctor Jaume Giner, 31. Pere Breva notari, 32. Felip Breva notari.

Bossa de Consellers de mà menor: 1. Josep Avinent major (obiit), 2. Vicent Museros (obiit), 3. Pere Navarro de Joan jubilat, 4. Josep Vilarroig major (obiit), 5. Andreu Ribalta, 6. Vicent Eximeno, 7. Josep Rubert major jubilat, 8. Miquel Vilarroig de Castell jubilat, 9. Miquel Català de Pere, 10. Pere Segarra (obiit), 11. Andreu Pasqual jubilat (obiit), 12. Miquel Llansola, 13. Josep Albiol major, 14. Francesc Amiguet major jubilat, 15. Pere Museros de Vicent (obiit), 16. Antoni Castell, 17. Joan Museros de Monserrat, 18. Francesc Figuerola de Vicent (obiit), 19. Miquel Navarro de Gaspar, 20. Miquel Pasqual de Francesc, 21. Josep Avinent menor, 22. Pere Calbo, 23. Gabriel Segarra de Josep, 24. Pere Roig de Jaume, 25. March Casalís, 26. Jaume Viciano de Miquel, 27. Gerony Castell, 28. Miquel Boix de Miquel, 29. Miquel Vilarroig de Nicolau, 30. Domingo Vilarroig, 31. Pere Reboll (obiit), 32. Francesc Amiguet menor (obiit), 33. Josep Vilarroig de Jaume, 34. Josep Museros de Vicent, 35. Josep Goterris (obiit), 36. Josep Rubert de Josep, 37. Andreu Castellet, 38. Félix Vilarroig, Agostí Reboll, Francesc Vilaroig i Jaume Breva de Vilaroig.

Die $V^{\mathrm{o}}$ mensis may Anni a (...naq...) Ani MDCLXXIIII 1679

Don Jaume Borras Arnal Brusca Cañizar de Cenil, Senyor del llocs d'Ortells i Varó de Pauls del orde i milicia de nostra senyora de Montesa i Sant Jordi d'Alfama, lloctinent del portantveus de general gobernador de la ciutat i Regne de València en la vila i governació de Castelló de la Plana dexa lo riu d'Uixo. Cosme Martí ciutadà, Baile per Sa Majestat de dita (...present...) vila, Don Josep Igual, Justicia de la mateixa vila, Francesc Andreu ciutadà, jurat en cap en presència i asistència de Vicent Tosquella notari, també jurat de dita vila, de Don Carlos Jover, Cristòfol Castell cavaller, Batiste Jover ciutadà, Josep Casalís Doctor en drets, Felip Sorrando mercader, Miquel Bonet notari, Pere Navarro de Joan, Antoni Castell Pons i de Pere Calbo los síndics ordinari de 
dita present vila per execució de la delliberació del Consell feta a XXVIIII del mes de Abril. (..Lo passat...) per a reconèixer les borses del govern i posar en aquelles als novament insaculats en la damunt dixa insaculació feta en XXVI, XXVII, XVIII i XXVIIII de dit mes de abril ajuntats i congregats en la sala del Palau de dita vila, manaren traure a un verguer la caixa dels insaculats on estan les dites borses del govern (...) en lo arxiu de dita sala, Palau de la present vila y dits Governador, Batle, Justicia i Jurat en cap obriren dita caixa ab les quatre claus que aquelles respectives tenen, i tragueren la borsa en sacs de militars i generosos i posaren en dits sacs vint redolins que són los noms de les antecedentment nomenades vint persones. En la borsa dels jurats en cap del bras real posaren desset redolins, dins los quals se posaren escrits en pergamins les dessets persones insaculades al dit ofici de jurat (...). Después en la segona borsa de artistes de jurat segon se posaren quinze redolins ab los noms escrits en pergamí de les quinze persones (...) mencionades. En la borsa tercera i quarta de jurat se posaren quaranta redolins en los quals estan escrits en pergamí los noms de les quaranta persones supra mencionades insaculades a dit ofici. En la borsa de Justicia del bras real se posaren vint i nou redolins i en ells de pergamí escrits los noms, de les persones insaculades a dit ofici de justicia quedant un lloch vacuo dels ciutadans.

En la borsa de Mustassaf de dit bras real se posaren trenta i set redolins, en los quals se posaren escrits en pergamí los noms de les trenta i set persones insaculades a dit ofici de Mustassaf com vacuen tres llochs dels ciutadans. En la borsa de cequier se posaren cinquanta redolins $\mathrm{i}$ en ells en pergamins escrits los noms de les cinquanta persones insaculades a dit ofici se super escrites (...).

En la borsa de escrivans se posaren nou redolins i en ells escrits en pergamins los noms de les nou persones insaculades a dit ofici supra (...notades...)

En la borsa de consellers de mà machor se posaren trenta i dos redolins en los quals se escorgueren los noms de les trenta dos persones insaculades a consellers de mà machor supra $(\ldots)$

I ultimament en la borsa de consellers de mà menor se possaren quarant un redolins i en ells escrits en pergamí les noms de les quaranta una persones insaculades a conseller de mà menor. Les quals borses en presència dels desus dits oficials i prohoms per mi Jaume Cases notari escrivà de la sala jurats i concell de dita vila, foren closes i segellades i per lo dit jurat en cap tornades en dixa caixa i per dit governador, Batle, Justicia i Jurat en cap (...foren...) tancada ab les claus que aquells respective tenen. 
Requerint de (...premissis...) carta pública et la qual (...) Castelló de la Plana en la Sala del Palau (...)

(...) foren per testimonis a dites coses Agostí de la Cuenca subsindics i Baltazar Martíns Verguer de dits jurats i de dita Vila vehins i labradors. Receipt Jacobus Cases notari er Scriba an lo Jurator et consily emis dita villa. 


\section{Insaculación 1685}

(AHMC. Llibre de les Insaculacions. ff. 111-114).

Los insaculats al govern de la Vila de Castelló de la Plana, així en les antecedents insaculacions com en la última que s'ha fet en XVIIII, X, XI,XII i XIII d'abril de l'any de MDCLXXXV son los següents:

\Anotación en el margen izquierdo: Se concluhí en XXVII de nobembre de MDCLXXXVI]

Bossa dels Militars: 1. Basilio Reus cavaller, 2. March Antoni Jordà cavaller (obiit), 3. Gerony Mas cavaller (obiit), 4. Cristòfol Castell cavaller, 5. Martí Mas cavaller, 6. Don Josep Igual, 7. Don Carlos Jover, 8. Don Felip Jover, 9. Don Fernando Miralles, 10. Don Bernat Ros (obiit), 11. Gerony Bou cavaller, 12. Don Macià Igual, , 13. Don Jaume Vallés, 14. Don Francesc Feliu, 15. Don Antoni Gombau, 16. Don Baltazar Ripio (obiit), 17. Don Gerony Vallés, 18. Don Josep Castell Museros cavaller, 19. Don Joachim Gombau i 20. Don Luis Escorcia y Ladrón.

Bossa de jurat en cap del brac reial : 1. Tomàs Giner ciutadà, 2. Doctor Francesc Joan Cases, 3. Dionís Aragones ciutadà, 4. Vicent Figuerola ciutadà, 5. Doctor Melchor Calvo, 6. Francesc Andreu ciutadà, 7. Cosme Martí ciutadà, 8. Doctor Josep Casalís, 9. Doctor Joan Timor, 10. Batiste Jover ciutadà, 11. Doctor Pere Giner de Vilarroig, 12. Tomàs March ciutadà, 13. Doctor en dret Ignacio Figuerola, 14. Doctor en medicina Martí Viciano 15. Doctor en dret Jaume Giner, 16. Miquel Garcés Doctor en medicina, 17. Pere Giner de Bou Doctor en Dret, 18. Vicent Martí Doctor en Dret, 19. Cristòfol Vilar Doctor en Dret i 20. Josep Castell Planell Doctor en Dret. No quedà ningun lloc vacio en dita borsa.

Bossa Segona de Artistes de Jurat : 1.Vicent Pasqual notari, 2. Vicent Ferrer notari 3. (aparece un nombre tachado que no se puede leer), 4. Pere Joan Vicent notari (ausent i provehit son puesto), 5. Macià Compte notari, 6. Jaume Cases notari, 7. Miquel Sanchís notari, 8. Felip Sorrando mercader, 9. Pere Figuerola notari, 10. Miquel Bonet notari, 11. Josep Amposta cirurgià, 12. Pere Breva notari, 13. Felip Breva notari, 14. Josep Llorens notari renúncia, 15. Pasqual Avinent notari, 16. Francesc Mercer Pintor, 17. Gaspar Rubert notari, 18. Pere Museros notari, 19. Vicent Llorens apotecari (obiit) i 20. Josep Blasco notari. No quedà ningun puesto per a cobrir en dita borsa. 
Bossa tercera i quarta de jurats: 1. Pere Navarro de Joan. Jubilat, 2. Andreu Ribalta, 3. Vicent Eiximeno, 4. Josep Rubert major, 5. Miquel Vilarroig de Castell, 6. Miquel Català de Pere, 7. Miquel Llansola de Miquel, 8. Josep Albiol major, 9. Pere Museros de Vicent, 10. Antoni Castell, 11. Joan Museros de Monserrat, 12. Francesc Figuerola de Vicent, 13. Miquel Navarro de Gaspar, 14. Miquel Pasqual de Francesc, 15. Josep Avinent menor, 16. Gabriel Segarra de Josep, 17. Pere Calbo, 18. Pere Roig de Jaime, 19. March Casalís, 20.Gerony Castell, 21. Miquel Boix de Miquel, 22. Miquel Vilarroig de Nicolau, 23. Domingo Vilarroig, 24. Pere Reboll (obiit), 25. Francesc Amiguet menor, 26. Josep Vilarroig de Jaume, 27. Miquel Navarro de Antoni, 28. Josep Museros de Vicent, 29. Josep Rubert menor, 30. Andreu Castellet, 31. Félix Vilarroig, 32. Agostí Reboll, 33. Francesc Vilarroig 34. Jaume Breva gendre de Vilaroig, 35. Miquel Avinent de Josep, 36. Joan Vilarroig de Miquel, 37. Vicent Pascual de Miquel, 38. Joan Museros de Joan i 39. Jaume Viciano de Miquel. Queda un lloc per provehir de jurat de dita borsa.

Bossa de consellers de mà major: 1. Tomàs Giner ciutadà, 2. Francesc Joan Cases Doctor en Dret, 3. Dionís Aragones ciutadà , 4. Vicent Figuerola ciutadà, 5.Vicent Pasqual notari, 6. Melchor Calbo Doctor en Dret, 7. Francesc Andreu ciutadà, 8. Vicent Tosquella ciutadà, 9. Pere Joan Vicent notari, 10. Macià Compte notari, 11. Vicent Ferrer notari, 12. Cosme Martí ciutadà, 13. Jaume Cases notari, 14. Miquel Sanchís notari, 15. Miquel Sorrando mercader (obiit), 16. Doctor en dret Joan Timor, 17. Doctor en dret Josep Casalís, 18. Pere Figuerola notari, 19. Josep Amposta cirurgià, 20. Batiste Jover ciutadà, 21. Miquel Bonet notari, 22. Doctor en dret Pere Giner de Vilarroig, 23. Tomàs March ciutadà, 24. Doctor en dret Ignacio Figuerola, 25. Doctor en medicina Martí Viciano, 26. Pere Breva notari, 27. Felip Breva notari, 28. Jaume Giner Doctor en Dret, 29. Miquel Garcés Doctor en medicina, 30. Pere Giner de Bou Doctor en Dret, 31. Vicent Martí Doctor en Dret, 32. Cristòfol Vilar Doctor en Dret, 33. Josep Castell de Planell. Doctor en Dret, 34. Josep Llorens notari, 35. Pasqual Avinent notari, 36. Francesc Mercer pintor, 37. Gaspar Rubert notari, 38. Pere Museros notari, 39. Vicent Llorens apotecari i 40. Josep Blasco notari.

Bossa de Consellers de mà menor: 1. Pere Navarro de Joan, 2. Andreu Ribalta, 3. Vicent Eximeno, 4. Josep Rubert major, 5. Miquel Vilarroig de Castell jubilat, 6. 
Miquel Català de Pere, 7. Miquel Llansola, 8. Josep Albiol major, 9. Francesc Amiguet major jubilat, 10. Pere Museros de Vicent (obiit), 11. Antoni Castell, 12. Joan Museros de Monserrat, 13. Francesc Figuerola de Vicent (obiit), 14. Miquel Navarro de Gaspar, 15. Miquel Pasqual de Francesc,16. Josep Avinent menor, 17. Pere Calbo, 18. Gabriel Segarra de Josep, 19. Pere Roig de Jaume, 20. March Casalís, 21. Jaume Viciano de Miquel, 22. Gerony Castell, 23. Miquel Boix de Miquel, 24. Miquel Vilarroig de Nicolau, 25. Domingo Vilarroig, 26. Francesc Amiguet menor, 27. Josep Vilarroig de Jaume, 28. Josep Museros de Vicent, 29. Josep Rubert menor, 30. Andreu Castellet, 31. Félix Vilarroig, 32.Agostí Reboll, 33.Francesc Vilaroig, 34.Jaume Breva de Vilaroig, 35. Joan Breva, 36. Miquel Avinent de Josep, 37. Joan Vilarroig de Miquel, 38. Vicent Pasqual de Miquel i 39. Joan Museros de Joan.

Die primo mensis augusti ano a (...) MDCLXXXV

Martí Mas cavaller i subrogat del Lloctinent del portantveus de general governador de la ciutat i regne de València en la present vila i governació de Castelló, Cosme Martí ciutadà Baile per sa magestat de dita vila, Felip Sorrando mercader Justicia de la mateixa vila, Batiste Jover jurat en cap en presència i asistència de Macià Compte notari i Pere Roig de Jaume los jurats de dita Vila, de Basilio Reus Cavaller, Don Jaume Valles, Dionís Aragones, Francesc Andreu ciutadans, Vicent Ferrer, Vicent Tosquella notaris. Joan Museros de Monserrat, Pere Calbo llaurador i de Jaume Breva de Vilarroig Sindics ordinaris de dita vila, per execució de la provició conciliar feta en lo dia de huy per a reconeixer les borses de govern i possar en aquells als novaments insaculats en la damunt dita insaculació feta en VIIII, X, XI, XII i XIII dies del mes de abril pro passat. Apuntats i congregats en lo Palau de dita Vila manaren traure a un verguer la caixa de insaculats on estan les dites borses del govern (...reundida...) en lo archiu de dit palau i dits subrrogats, Batle, Justicia i Jurat en cap obriren dita caixa ab les quatre claus que aquells respective tenen i tragueren la bolsa en sacs que tenen de militars i generosos $\mathrm{i}$ posaren en dits sacs vint redolins que són los noms de les antecedentment nomenades vint persones.

En la borsa de Jurat en cap del bras real posaren escrits en pergamí los noms de les vint persones insaculades al dit ofici de jurat en cap del bras real supra mencionades. Después en la segona bolsa en sacs de artistes de Jurat segon se posaren vint redolins ab 
los noms escrits en pergamí de les vint persones insaculades a dit offici de Jurat segon de super expressades.

En la tercera i quarta bolsa de Jurat se posaren trenta nou redolins en los quals estan escrits en pergamins los noms de les trenta nou persones insaculades a dit ofici de Jurat tercer i quart supra mencionades, quedant un lloch vacuo de dit ofici de Jurat de dita Bolsa. En la Bolsa de Conseller de mà machor se posaren quaranta redolins en los quals se possaren escrites en pergamí les quaranta persones insaculades a dit ofici de conseller de mà major (..saperin..) notades. I ultimament en la bolsa de conseller de mÀ menor se posaren trenta nou redolins i en ells escrits en pergamí los noms de les trenta nou persones insaculades a dit ofici de conseller de ma menor de super expressades. Les quals bolses en presència dels dits officials i prohoms per mi Jaume Cases, notari escrivà de la Sala de Jurats i Consell de dita vila foren closes i segellades i per lo dit Jurat en cap tornades en dita caixa, i per lo dits subrogat, Batle, Justicia, i Jurat en cap foren tancada ab les claus que aquells respective tenen quedant per a reconeixer les bolses de Justicia, Mustassaf del bras Real, cequier i d'escrivans per a quant se declare lo pleit (...suiitat...) per la Real Audiència de Valencia, per certes persones de dita vila que pretenen estan habilitades per a els oficis de Justicia i Mustassaf en la damunt dita insaculació. Requerint los de sus dits (...depremiresxen...) los rebut (...) publics lo qual per mi dit Jaume Cases notari escrivà, los fons rebut en lo dit Palau de la present vila de Castelló de la Plana los dia mes e anys de sus dits.

(....) foren per testimonis a dites coses Jaume Fortuny i Baltasar Martíns verguers de dits Jurats i de dita vila de Castelló de la Plana vehins i establits. Receipt Jacobus Cases notari Scriba an lo Juratorum et concily dicta vila. 


\section{Insaculación 1686}

(AHMC. Llibre de les Insaculacions. ff. 115-119).

Anotación en el margen izquierdo: [Esta insaculación és la conclusió de la que escomensa en l'any 1685 en VIIII de abril per raó del pleit que es sucità.]

Los insaculats per el govern de la present vila de Castell de la Plana. Així en les antecedents insaculacions com en la última que escomensà i feu en VIIII, X, XI, XII i XIII del mes de Abril de l'any de MDCLXXXVI en virtud d'una Real Sentència donada en la Real Audiència de València, sots audició del Magnífic Donato Sanchez del Castellar, oïdor de la cuasa i litigi que es portava sobre dita insaculació, entre parts de la present vila i dels Doctors Vicent Martí i Cristòfol Vilar d'una i certs particulars de la mateixa vila, d'altra publicada per Josep Llorens de Saboya cavaller escrivà, demanant XVII de octubre de dit any MDCLXXXVI son els següents:

Bossa segona de Artistes de Jurat segon: 1.Vicent Pasqual notari, 2. Vicent Ferrer notari 3. (aparece un nombre tachado que no se puede leer), 4. Pere Joan Vicent notari, 5. Macià Compte notari, 6. Jaume Cases notari, 7. Miquel Sanchís notari, 8. Pere Figuerola notari, 9. Miquel Bonet notari, 10. Josep Amposta cirurgià, 11. Pere Breva notari, 12. Felip Breva notari, 13. Josep Llorens notari renúncia, 14. Pasqual Avinent notari, 15. Francesc Mercer Pintor, 16. Gaspar Rubert notari, 17. Pere Museros notari, 18. Vicent Llorens apotecari (obiit), 19. Josep Blasco notari i 20. Joan Safont notari. No queda ningun lloc vacuo en dita borsa.

Bossa tercera i quarta de jurat: 1 . Pere Navarro de Joan (obiit), 2. Andreu Ribalta llaurador, 3. Vicent Eiximeno llaurador, 4. Josep Rubert major llaurador (obiit), 5. Miquel Vilarroig de Castell llaurador jubilat, 6. Miquel Català de Pere llaurador jubilat, 7. Miquel Llansola major llaurador, 8. Josep Albiol major llaurador, 9. Antoni Castell llaurador, 10. Joan Museros de Monserrat llaurador, 11. Francesc Figuerola de Vicent llaurador (obbit), 12. Miquel Navarro de Gaspar llaurador, 13. Miquel Pasqual de Francesc llaurador, 14. Josep Avinent menor llaurador, 15. Gabriel Segarra de Josep llaurador (obiit), 16. Pere Calbo llaurador, 17. Jaume Viciano de Miquel llaurador, 18. Pere Roig de Jaume llaurador, 19. March Casalís llaurador, 20.Gerony Castell llaurador, 21. Miquel Boix de Miquel llaurador, 22. Miquel Vilarroig de Nicolau llaurador, 23. Domingo Vilarroig llaurador, 24. Francesc Amiguet menor llaurador, 25. Josep Vilarroig de Jaume llaurador, 26. Miquel Navarro de Antoni llaurador, 27. Josep 
Museros de Vicent llaurador, 28. Josep Rubert menor llaurador, 29. Andreu Castellet llaurador,30. Félix Vilarroig llaurador,31. Agostí Reboll llaurador,32. Francesc Vilarroig llaurador 33. Jaume Breva gendre de Vilaroig llaurador, 34. Joan Breva llaurador, 35. Miquel Avinent de Josep llaurador, 36. Joan Vilarroig de Miquel llaurador, 37. Vicent Pascual de Miquel llaurador, 38. Joan Museros de Joan llaurador, 39. Josep Pascual de Francesc llaurador i 40. Ignacio Breva. No queda ningun per proveir en dita borsa.

Bossa de Justicia del Bras Real: 1. Vicent Figuerola ciutadà, 2. Dionís Aragonés ciutadà, 3. Doctor Francesc Joan Cases, 4. Tomàs Giner ciutadà (obiit), 5. Doctor Melchor Calbo (obiit), 6. Vicent Pasqual notari, 7. Cosme Martí ciutadà, 8. Francescc Andreu ciutadà, 9. Pere Roig de Jaume llaurador, 10. Antoni Castell llaurador, 11. Doctor Josep Casalís, 12. Doctor Joan Timor, 13. Vicent Tosquella, 14. Jaume Cases notari, 15. Miquel Sanchís notari, 16. Joan Museros de Monserrat, 17. Batiste Jover ciutadà, 18. Doctor Pere Giner de Vilarroig, 19. Tomàs March ciutadà, 20. Doctor Ignacio Figuerola, 21. Doctor Martí Viciano, 22. Doctor Jaume Giner, 23. Doctor Macià Compte notari, 24. Doctor Josep Amposta cirurgià, 25. Doctor Vicent Martí, 26. Doctor Pere Giner de Bou, 27. Doctor Cristòfol Vilar, 28. Pere Figuerola notari (obiit), 29. Pasqual Avinent notari i 30. Pere Calbo.

Bossa de Mustassaf del bras real: 1. Tomàs Giner ciutadà (obiit), 2. Vicent Figuerola ciutadà, 3. Dionís Aragones ciutadà, 4. Doctor Francesc Joan Cases, 5. Vicent Pasqual notari, 6. Doctor Melchor Calbo, 7. Francesc Andreu ciutadà, 8. Cosme Martí ciutadà, 9. Vicent Tosquella, 10. Macià Compte notari, 11. Jaume Cases notari, 12.Andreu Ribalta, 13. Miquel Llansola, 14. Doctor Joan Timor, 15. Doctor Josep Casalís, 16. Vicent Ferrer notari jubilat (obiit), 17. Miquel Sanchís notari, 18. Pere Navarro de Joan (obiit), 19. Vicent Eiximeno, 20. Miquel Pasqual de Francesc, 21. Antoni Castell, 22. Batiste Jover ciutadà, 23. Pere Figuerola notari (obiit), 24. Tomàs March ciutadà, 25. Doctor Ignacio de Figuerola, 26. Doctor Martí Viciano, 27. Doctor Jaume Giner, 28. Miquel Bonet notari, 29. Josep Amposta cirurgià, 30. Jaume Viciano de Miquel, 31. Doctor Pere Giner de Vilarroig, 32. Doctor Miguel Garcés, 33. Doctor Pere Giner de Bou, 34. Doctor Vicent Martí, 35. Doctor Cristòfol Vilar, 36. Doctor Josep Castell de Planell, 37. Pere Breva notari, 38. Felip Breva notari, 39. Gabriel Segarra de Josep (obiit) i 40. Gaspar Rubert notari. 
Bossa de Cequier: 1. Pere Navarro de Joan (obiit), 2. Tomàs Giner ciutadà (obiit), 3. Vicent Eiximeno jubilat, 4. Andreu Ribalta, 5. Miquel Lansola, 6. Josep Albiol machor jubilat, 7. Francesc Amiguet major (obiit), 8. Vicent Figuerola ciutadà jubilat (obiit), 9. Dionís Aragonés ciutadà, 10. Vicent Pasqual notari, 11. Josep Rubert major jubilat (obiit), 12. Miquel Català de Pere (obiit), 13. Miquel Vilarroig de Castell jubilat, 14. Pere Calbo, 15. Antoni Castell, 16. Miquel Navarro de Gaspar, 17. Josep Avinent menor, 18. Francesc Figuerola de Vicent (obiit), 19. Gabriel Segarra de Josep (obiit), 20. Joan Museros de Monserrat, 21. Miquel Pasqual de Francesc, 22. Francesc Andreu ciutadà, 23. Doctor Joan Timor, 24. Doctor Josep Casalís, 25. Vicent Tosquella, 26. Macià Compte notari, 27. Jaume Cases notari, 28. Miquel Sanchís notari, 29. Pere Roig de Jaume, 30. March Casalís, 31. Jaume Viciano de Miquel, 32. Gerony Castell, 33. Miquel Boix de Miquel, 34. Miquel Vilarroig de Nicolau, 35. Domingo Vilarroig, 36. Batiste Jover ciutadà, 37. Doctor Pere Giner Vilarroig (obiit), 38. Pere Figuerola notari. Jubilat (obiit), 39. Francesc Amiguet menor, 40. Agusti Reboll, 41. Josep Amposta cirurgià, 42. Gaspar Rubert notari, 43. Pasqual Avinent notari, 44. Jaume Breva de Vilarroig, 45. Francesc Vilarroig, 46. Andreu Castellet, 47. Josep Rubert menor, 48. Josep Museros de Vicent, 49. Félix Vilarroig i 50. Miquel Navarro de Antoni.

Bossa de Escrivans: 1. Vicent Pasqual notari, 2. (nombre tachado que no se puede leer), 3. Macià Compte notari, 4. Vicent Ferrer notari, 5. Jaume Cases notari, 6. Miquel Sanchís notari, 7. Miquel Bonet notari, 8. Pere Figuerola notari, 9. Josep Llorens de Prima notari (renuncia al art), 10. Pere Breva notari, 11. Vicent Pasqual notari i 12. (nombre tachado que no se puede leer).

Bossa de Consellers de mà major: 1. Tomàs Giner ciutadà (obiit), 2. Francesc Joan Cases Doctor en Dret, 3. Dionís Aragones ciutadà , 4. Vicent Figuerola ciutadà, 5.Vicent Pasqual notari, 6. Melchor Calbo Doctor en Dret (obiit), 7. Francesc Andreu ciutadà, 8. Vicent Tosquella ciutadà, 9. Pere Joan Vicent notari (ausent), 10. Macià Compte notari, 11. Vicent Ferrer notari, 12. Cosme Martí ciutadà, 13. Jaume Cases notari, 14. Miquel Sanchís notari, 15. Doctor en dret Joan Timor, 16. Doctor en dret Josep Casalís, 17. Pere Figuerola notari (obiit), 18. Josep Amposta cirurgià, 19. Batiste Jover ciutadà, 20. Miquel Bonet notari, 22. Doctor en dret Pere Giner de Vilarroig (obiit), 22. Tomàs March ciutadà, 23. Doctor en dret Ignacio Figuerola, 24. Doctor en 
medicina Martí Viciano, 25. Pere Breva notari, 26. Felip Breva notari, 27. Jaume Giner Doctor en Dret, 28. Miquel Garcés Doctor en medicina, 29. Pere Giner de Bou Doctor en Dret, 30. Vicent Martí Doctor en Dret, 31. Cristòfol Vilar Doctor en Dret, 32. Josep Castell de Planell Doctor en Dret, 33. Josep Llorens notari, 34. Pasqual Avinent notari, 35. Francesc Mercer pintor, 36. Gaspar Rubert notari, 37. Pere Museros notari, 38. Vicent Llorens apotecari (obiit), 39. Josep Blasco notari, 40. Joan Safont notari i 41. Pere Albiol.

Bossa de Consellers de mà menor: 1 . Pere Navarro de Joan (obiit), 2. Andreu Ribalta, 3. Vicent Eximeno, 4. Josep Rubert major (obiit), 5. Miquel Vilarroig de Castell jubilat, 6. Miquel Català de Pere (obiit), 7. Miquel Llansola, 8. Josep Albiol major, 9. Francesc Amiguet major jubilat, 10. Antoni Castell, 11. Joan Museros de Monserrat, 12. Francesc Figuerola de Vicent (obiit), 13. Miquel Navarro de Gaspar, 14. Miquel Pasqual de Francesc,15. Josep Avinent menor, 16. Pere Calbo, 17. Gabriel Segarra de Josep, 18. Pere Roig de Jaume, 19. March Casalís, 20. Miquel Boix de Miquel, 21. Miquel Vilarroig de Nicolau, 22. Domingo Vilarroig, 23. Francesc Amiguet menor, 24. Josep Vilarroig de Jaume, 25. Josep Museros de Vicent, 26. Josep Rubert menor, 27. Andreu Castellet, 28. Félix Vilarroig, 29.Agostí Reboll, 30.Francesc Vilaroig, 31.Jaume Breva de Vilaroig, 32. Joan Breva, 33. Miquel Avinent de Josep, 34. Joan Vilarroig de Miquel, 35. Vicent Pasqual de Miquel, 36. Joan Museros de Joan, 37. Josep Pasqual de Francesc, 38. Ignacio Breva, 39. Joan Vilarroig de Miquel i 40. Vicent Pasqual de Miquel.

Don Jaime Borras Arnal Bresca Cañisar de (...cuil...) senyor dels llochs de Ortells i Varò de Pauls, cavaller de la orde i milicia de nostra senyora de Montesa i Sant Jordi de Alfama, Lloctinent de Portantveus de general governador de la ciutat i regne de València, en la present vila de Castelló de la Plana dexa lo Riu d'Uxò, Cosme Martí ciutadà Batle per sa magestat de dita present vila, Vicent Martí Doctor en drets, Jurat en cap i regent lo offici de Justicia per mort de Felip Sorrando Mercader Justicia que era dita vila en lo present i corrent any en presència i asistència de Francesc Mercer Pintor i dorador Joan Museros de Monserrat i Francesc Amiguet menor de dies, Lavradors Jurats de dita vila, de Don Baltazar Ripoll, Don Joachim Gombau, Francesc Andreu, Batiste Jover ciutadans, Macià Compte, Jaume Casses notari, Pere Roig de Jaume i March Casalís de Lavradors Prohoms i de Gaspar Rubert notari sindic ordinari de dita 
vila, per execució de la provisió conciliar feta en lo dia de aui per a reconeixer les bolses del govern respecte dels de jurat segon,tercer i quart, de Justicia, de Mustassaf del bras real, de cequier, de escrivans i de consellers de mà major i menor i posar en aquelles als novament insaculats en la damunt dita insaculació, feta en lo dia d'ahir i en la que es feu y començà en VIIII, X, XI, XII y XIII dies del mes de Abril de l'any MDCLXXXV la qual se proseguí i finí en lo dia d'ahir en virtut i per execució d'una Real Sentència donada en la Real Audiència de la ciutat i present Renge de Valencia, sots audició i examen dels Magnifics Donato Sanchez del Castellar DDRC oïdor de la causa i litigi que es seguí sobre dita Insaculació entre de la present vila i dels Doctors Vicent Martí i Cristòfol Vilar de una i serta particulars de dita vila, d'altra justificada per Josep Llorens de Saboya cavaller escrivà de manament en XVII d'octubre, però passat ajuntats i congregats en la sala del palau de dita vila i manaren traure a un verguer la caixa dels insaculats on estan les bolses de govern (...recondida...) en lo Arxiu de dit Palau i dits Gobernador, Batle, Jurat en cap, que per regir la vara de justicia tenia dos claus, obriren dita caixa ab les quatre claus que aquells respective tenen i tragueren la bolsa e los sacs insaculats, Bolsa segona de Artistes de Jurat, i posaren en aquella vint redolins que són los noms de les antecedenment nomenades vint persones ab cèdules de pergamí. En la tercera i quarta borsa de jurat se posaren quaranta redolins, en los quals estan escrits en seda de pergamí los noms de les quaranta persones insaculades a dit offici de jurat tercer i quart supra mencionades. En la bolsa de Justicia del braç real se posaren trenta redolins $\mathrm{i}$ en ells escrits en seda de pergamí los noms de les trenta persones insaculades a dit offici de Justicia; e la bolsa de Mustassaf del dit Braç Real se posaren quaranta redolins en los quals se posaren escrits en pergamí los noms de les quaranta persones insaculades a dit offici de Mustassaf. En la bolsa de cequier se posaren cinquanta redolins i en ells escrits en pergamí los noms de les cinquanta persones insaculades a dit offici de cequier de (...suspres...). En la bolsa de escrivans se posaren deu redolins i en ells escrits en pergamí los noms de les deu persones insaculades a dit offici supra notades. En la bolsa de concellers de mà major se posaren quaranta redolins en los quals se escrigueren en pergamí los noms de les quaranta persones insaculades a dit offici de concellers de super (...insaculades...).

I ultimament en la bolsa de conseller de mà menor se posaren quaranta redolins i en ells escrits en pergamí los noms de les quaranta persones insaculades a consellers de mà menor. 
Les quals bolses en presència dels desus dits officials i prohoms, per mi Pere Figuerola notari escrivà de la Sala de Jurats i Consell de dita vila fosen closes i segellades, per lo dit jurat en cap foren tornades en dita caixa i per los dits governadors, Batle i Jurat en cap en este nom i de Regent la vara de Justicia per mort de Felip Sorrando Justicia de dita vila, fonc tancada ab les claus que aquelles respective. Requerint de premisis com pública la qual és costum en Castelló de la Plana en la Sala del Palau.

Presents foren testimonis a dites cosses Jaume Fortuna i Baltasar Martíns verguers de dit Jurat i de dita Vila de Castelló de la Plana, vehins i habitants. Recepeit Pietrus Figuerola notari escrivà an lo juratorum et concily $(\ldots)(\ldots)$ Villa. 


\section{Insaculación 1694}

(AHMC. Llibre de les Insaculacions. ff. 120-122).

Los insaculats per al govern de la present vila de Castelló de la Plana, avui en les antecedents insaculacions com en la última que escomençà el VIII i VIIII d'abril de l'any MDCLXXXXIII, la qual s'ha proseguit i finit en VII i VIII de Maig de l'any MDCLXXXX en virtut d' una Real Sentència donada en la Real Audiència de la ciutat de Valencia, sots audició del Noble Don Manuel Mercader, Doctor del Real Concell, oidor de la causa litigi, que es portava per dita Audiencia sobre Insaculació entre parts de la present Vila i del Doctor Josep Museros i Joan Muntanés notari d'una sens particulars de dita Vila de part altra publicada per Vicente de Saboya generós escrivà de manament d'en XX del mes de decembre del any MDCLXXXXIIII.

Bossa dels militars: 1. Basilio Reus (obiit), 2. Martí Mas, 3. Don Josep Igual, 4. Don Felip Jover, 5. Don Fernando Miralles, 6. Gerony Bou, 7. Don Macià Igual, 8. Don Jaume Vallés, 9. Don Antoni Gombau, 10. Don Gerony Vallés, 11. Don Josep Castell de Museros gendre, 12. Don Joachim Gombau, 13. Don Luis Escorcia y Ladron, 14. Don Vicent Feliu i Sisternés i Josep Castell de Romeu (obiit).

Bossa de Jurat en cap de Bras Real: 1 . Francesc Joan Cases Doctor Dret, 2. Dionís Aragones ciutadà, 3. Vicent Figuerola ciutadà, 4. Francesc Andreu ciutadà, 5. Cosme Martí. ciutadà, 6. Josep Casalís Doctor Dret, 7. Joan Timor Doctor Dret, 8. Batiste Jover ciutadà, 9. Tomàs March ciutadà, 10. Ignacio Figuerola Doctor Dret, 11. Martí Viciano Doctor medicina, 12. Jaume Giner Doctor Dret, 13. Miquel Garcés Doctor medicina, 14. Pere Giner de Bou Doctor Dret, 15. Vicent Martí. Doctor Dret, 16. Cristòfol Vilar Doctor Dret, 17. Josep Castell de Planell Doctor Dret, 18. Jacint March Doctor Dret, 19. Josep Segarra ciutadà i 20. Josep Museros Doctor medicina.

Bossa segona de Artistes de Jurat segon: 1. Vicent Pasqual notari, 2. Vicent Ferrer notari, 3. (nombre tachado que no se puede leer), 4. Macià Compte notari (obiit), 5. Jaume Cases notari (obiit), 6. Miquel Sanchís notari, 7. Miquel Bonet notari, 8. Pere Breva notari, 9. Josep Amposta sirurjià, 10. Felip Breva notari, 11. Pasqual Avinent notari, 12. Francesc Mercer pintor (obiit), 13. Gaspar Rubert notari, 14. Pere Museros notari, 15. Josep Blasco notari, 16. Joan Safont notari, 17. Aleixandre Martí notari, 18. 
Pere Mercer pintor, 19. Joan Montanyés notari i 20. Pere Vidal notari. No quedà ningun lloch vacant en dita bolsa.

Bossa de Jurat tercera i cuarta: 1. Andreu Ribalta (obiit), 2. Vicent Eiximeno (obiit), 3. Miquel Vilarroig de Castell (obiit), 4. Miquel Llansola major (obiit), 5. Josep Albiol major (obiit), 6. Antoni Castell, 7. Joan Museros de Monserrat, 8. Miquel Navarro de Gaspar, 9. Miquel Pasqual de Francesc, 10. Josep Avinent menor, 11. Pere Calbo (obiit), 12. Jaume Viciano de Miquel, 13. Pere Roig de Jaume, 14. March Casalís, 15. Gerony Castell, 16. Miquel Boix de Miquel, 17. Miquel Vilarroig de Nicolau, 18. Domingo Vilarroig, 19. Francesc Amiguet de Francesc, 20. Josep Vilarroig de Jaume, 21. Miquel Navarro de Antoni, 22. Josep Museros de Vicent, 23. Josep Rubert de Josep, 24. Andreu Castellet, 25. Félix Vilarroig, 26. Agostí Reboll, 27. Francesc Vilarroig, 28. Jaume Breva de Vilarroig, 29. Joan Breva, 30. Miquel Avinent de Josep, 31. Joan Vilarroig de Miquel, 32. Vicent Pasqual de Miquel, 33. Joan Museros de Joan, 34. Josep Pasqual de Francesc, 35. Ignacio Breva, 36. Jaume Breva de Jaume, 37. Jaume Català, 38. Baltazar Avinent, 39. Vicent Figuerola de Francesc i 40. Josep Castell de Antoni.

Bossa de Justicia del Bras Real: 1. Vicent Figuerola ciutadà, 2. Dionís Aragonés ciutadà (obiit), 3. Francesc Joan Cases Doctor Dret, 4. Vicent Pasqual notari, 5. Cosme Martí ciutadà, 6. Francescc Andreu ciutadà, 7. Pere Roig de Jaume, 8. Antoni Castell, 9. Don Josep Casalís Doctor en Dret, 10. Joan Timor Doctor en Dret, 11. Vicent Tosquella ciutadà, 12. Jaume Cases notari (obiit), 13. Miquel Sanchís notari, 14. Joan Museros de Monserrat, 15. Batiste Jover ciutadà, 16. Tomàs March ciutadà, 17. Ignacio Figuerola, 18. Martí Viciano Doctor en medicina, 19. Jaume Giner Doctor en dret, 20. Macià Compte notari (obiit), 21. Josep Amposta cirurgià, 22. Vicent Martí Doctor en Dret, 23. Pere Giner de Bou Doctor Dret, 24. Cristòfol Vilar Doctor en Dret, 25. Pasqual Avinent notari (obiit), 26. Pere Calbo (obiit), 27. Miquel Garcés Doctor en medicina (obiit), 28. Jacinto March Doctor en Dret, 29. Josep Segarra ciutadà i 30. Francesc Mercer pintor (obiit). No quedà ningun lloch vacuo en dita bolsa per a proveir.

Bossa de Mustassaf del Bras Real: 1.Vicent Figuerola ciutadà, 2. Dionís Aragonés ciutadà (obiit), 3. Francesc Joan Cases Doctor en Dret (obiit), 4. Vicent Pascual notari, 5. Francesc Andreu ciutadà, 6. Cosme Martí ciutadà, 7. Vicent Tosquella notari, 8. Macià Compte notari (obiit), 9. Jaume Cases notari (obiit), 10. Andreu Ribalta (obiit), 
11. Miquel Llansola (obiit), 12. Joan Timor. Doctor en Dret. renúncia, 13. Josep Casalís, 14. Vicent Ferrer notari, 15. Miquel Sanchís notari, 16. Vicent Eiximeno (obiit), 17. Miquel Pascual de Francesc, 18. Antoni Castell, 19. Batiste Jover ciutadà, 20. Tomàs March ciutadà, 21. Ignacio de Figuerola Doctor Dret, 22. Martí Viciano (Doctor Medicina), 23. Jaume Giner. Doctor en Dret, 24. Miquel Bonet notari, 25. Josep Amposta cirurgià. 26. Jaume Viciano de Miquel, 27. Miguel Garcés Doctor en Dret, 28. Pere Giner de Bou Doctor Dret, 29. Vicent Martí Doctor en Dret, 30. Josep Amposta cirurgià, 31. Josep Castell Planell Doctor Dret, 32. Pere Breva notari, 33. Felip Breva notari, 34. Gaspar Rubert notari, 35. Jacinto March Doctor en Dret, 36. Josep Segarra ciutadà, 37. Josep Museros Doctor en medicina. (obiit), 38. Pasqual Avinent notari (obiit), 39. March Casalís (obiit) i 40. Jaume Breva de Vilaroig. No queda ningun lloch per a proveir en la dita bolsa.

Bossa de Cequier: 1. Vicent Eiximeno (obiit), 2. Andreu Ribalta (obiit), 3. Miquel Lansola (obiit), 4. Josep Albiol major (obiit), 5. Vicent Figuerola ciutadà, 6. Dionís Aragonés ciutadà (obiit), 7. Vicent Pascual notari, 8. Miquel Vilarroig de Castell (obiit), 9. Pere Calbo (obiit), 10. Antoni Castell, 11. Miquel Navarro de Gaspar, 12. Josep Avinent de Baltasar, 13. Joan Museros de Moncerrat, 14. Miquel Pasqual de Francesc, 15. Francesc Andreu ciutadà, 16. Joan Timor Doctor en Dret. Renúncia, 17. Josep Casalís Doctor en Dret, 18. Vicent Tosquella notari, 19. Macià Compte notari (obiit), 20. Jaume Cases notari (obiit), 21. Miquel Sanchís notari, 22. Pere Roig de Jaume, 23. March Casalís, 24. Jaume Viciano de Miquel, 25. Gerony Castell, 26. Miquel Boix de Miquel (obiit), 27. Miquel Vilarroig de Nicolau, 28. Domingo Vilarroig, 29. Batiste Jover ciutadà, 30. Francesc Amiguet menor, 31. Agostí Reboll, 32. Josep Amposta cirurgià, 33. Gaspar Rubert notari, 34. Pasqual Avinent notari (obiit), 35. Jaume Breva de Vilarroig, 36. Francesc Vilarroig, 37. Andreu Castellet, 38. Josep Rubert de Josep, 39. Josep Museros de Vicent, 40. Félix Vilarroig, 41. Miquel Navarro de Antoni, 42. Jacint March Doctor en Dret, 43. Josep Segarra ciutadà, 44. Josep Vilarroig de Josep, 45. Joan Breva, 46. Miquel Avinent de Josep, 47. Josep Pasqual de Francesc, 48. Vicent Pasqual de Miquel, 49. Ignacio Breva i 50. Joan Safont notari.

Bossa de Escrivans: 1. Vicent Pasqual notari, 2. (nombre que aperece tachado y no se puede leer), 3. Macià Compte notari (obiit), 4. Vicent Ferrer notari, 5. Jaume Cases 
notari (obiit), 6. Miquel Sanchís notari, 7. Miquel Bonet notari, 8. Pere Breva notari, 9. Pere Museros notari i 10. Gaspar Rubert notari.

Bossa de Concellers de mà major: 1.Francesc Joan Cases Doctor en Dret (obiit), 2. Dionís Aragonés ciutadà (obiit), 3. Vicent Figuerola ciutadà, 4. Vicent Pasqual notari, 5. Francesc Andreu ciutadà, 6. Vicent Tosquella, 7. Macià Compte notari (obiit), 8. Vicent Ferrer notari, 9. Cosme Martí ciutadà, 10. Jaume Cases notari (obiit), 11. Miquel Sanchís notari, 12. Joan Timor Doctor en Dret. Renúncia, 13. Josep Casalís. Doctor en Dret, 14. Josep Amposta cirurgià, 15. Batiste Jover ciutadà, 16. Miquel Bonet notari, 17. Tomàs March ciutadà, 18. Ignacio Figuerola Doctor en Dret, 19. Martí Viciano Doctor en Medicina, 20. Pere Breva notari, 21. Felip Breva notari, 22. Jaume Giner Doctor en Dret, 23. Miquel Garcés Doctor en Medicina (obiit), 24. Pere Giner de Bou Doctor en Dret, 25. Vicent Martí Doctor en Dret, 26. Cristòfol Vilar. Doctor en Dret, 27. Josep Castell de Planell Doctor en Dret, 28. Pasqual Avinent notari (obiit), 29. Francesc Mercer pintor (obiit), 30. Gaspar Rubert notari, 31. Pere Museros notari, 32. Josep Blasco notari, 33. Joan Safont notari, 34. Jacint March Doctor en Dret, 35. Josep Segarra ciutadà, 36. Josep Museros. Doctor Medicina, 37. Aleixandre Martí notari, 38. Pere Mercer pintor, 39. Joan Montanyés notari i 40. Pere Vidal notari.

Bossa de Consellers de mà menor: 1. Andreu Ribalta (obiit), 2. Vicent Eiximeno (obiit), 3. Miquel Vilarroig de Castell (obiit), 4. Miquel Llansola, 5. Josep Albiol major (obiit), 6. Antoni Castell, 7. Joan Museros de Monserrat, 8. Miquel Navarro de Gaspar, 9. Miquel Pasqual de Francesc, 10. Josep Avinent Baltazar, 11. Pere Calbo (obiit), 12, Pere Roig de Jaume, 13. March Casalís, 14. Jaume Viciano de Miquel, 15. Gerony Castell, 16. Miquel Boix de Miquel (obiit), 17. Miquel Vilarroig de Nicolau, 18. Domingo Vilarroig, 19. Francesc Amiguet, 20. Josep Vilarroig de Jaume, 21. Josep Rubert de Josep, 22. Andreu Castellet, 23. Miquel Navarro de Antoni, 24. Josep Museros de Vicent, 25. Félix Vilarroig, 26. Agostí Reboll, 27. Francesc Vilarroig, 28. Jaume Breva de Vilarroig, 29. Joan Breva, 30. Miquel Avinent de Josep, 31. Joan Vilarroig de Miquel (obiit), 32. Vicent Pasqual de Miquel, 33. Joan Museros de Joan, 34. Josep Pasqual de Francesc, 35. Ignacio Breva, 36. Jaume Breva de Francesc, 37. Jaume Català (obiit), 38. Baltazar Avinent, 39. Vicent Figuerola de Francesc i 40. Josep Castell de Antoni. 
Die $\mathrm{x}$ mensis may anno (...) de MDCLXXXXV

Don Andreu Monserrat Ciurana Crespí de Valldaura, Lloctinent de Portantveus de general governador en la present vila i gobernacio de Castello de la Plana, Cosme Martí ciutadà Batle per sa Magestat de dita vila, Tomàs March ciutadà Justicia, Don Miquel Garcés Jurat en cap en ausènsia de Juseph Amposta cirurjià també Jurat, de Don Jusep Igual, de Don Martí Mas, Batiste Jover ciutadà, de Francesc Cases, i Miquel Bonet notari y de Pere Museros notari e sindic de dita vila, per execució de la deliberació conciliar feta en VIII dels corrents per a reconèixer les bolses i posar en aquelles als novament insaculats en la dita insaculació feta en VIII i VIIII d'abril de l'any MDCLXXXXIII. VII y VIII dels corrents ajuntats i congregats en la Sala del Palau de dita vila manaren traure a un verguer la caixa dels insaculats hon estan les dites bolses del govern (...recondida...) en lo archiu de la Sala de dita Vila i dits Governador, Batle, Justicia i Jurat en cap obriren dita caixa ab les quatre claus que aquells respective tenen i tragueren la bolsa en sach de militars i generosos i posaren en dith sach quinze redolins que són los noms de les antecedents nomenades quinse persones. En la bolsa de Jurat en cap del bras real, posaren vint redolins dins los quals se posaren escrits en pergamí les vint persones insaculades als dits officis de Jurat supra anotades. Después en la segona bolsa de artistes de jurat segon se posaren vint redolins ab los noms escrits en pergamí de les vint persones de super mencionades. En la bolsa tercera i quarta de jurat se posaren quaranta redolins en los quals estan escrits en pergamí los noms de les quaranta persones supramencionades i insaculades a dit offici. En la bolsa de Justicia del bras real se posaren trenta redolins i en ells escrits en pergamí los noms de les persones insaculades a dit offici de Justicia. En la bolsa Mustasaf de dit bras real se posaren quaranta redolins en los quals se escrigueren en pergamí de les quaranta persones insaculades a dit offici de Mustassaf. En la bolsa de Cequier se posaren sinquanta redolins y en ells escrits en pergamí los noms de les sinquanta persones insaculades a dit offici de superescrites. En la bolsa de esrivans deu redolins en ells escrits en pergamí los noms de les deu persones insaculades a dit offici supra escrites. En la bolsa de consellers de mà major quaranta redolins i en ells escrits en pergamí los noms de les quaranta persones insaculades a dit offici de super escrites. En la bolsa de consellers de mà menor se posaren quaranta redolins $\mathrm{i}$ en ells escrits en pergamí los noms de les quaranta persones insaculades a conseller de mà menor superius escrites. Les quals bolses en presència de sus dits officials i prohoms per mi Pere Breva notari escrivà de la 
Sala foren closes i segellades per lo dit Jurat en cap tornades en dita caixa y per los dits Governador, Batle, Justicia y Jurat en cap fonch tancada ab les claus que aquells respectives tenen, requerint de premisis Carta Pública esa la qual esa Actum en Castelló de la Plana en la Sala del Consell de dita vila esa.

Junts foren per testimonis a dites coses Josep Blanco Submich i Baltazar Martíns verguers de dits jurats i de dita Vila de Castello vehins i habitadors. Recepit Petrus Breva notari et escriba Auto jurotarum et concily dita Vila. 


\section{Insaculación 1700}

(AHMC. Llibre de les Insaculacions. ff. 124-128).

Insaculació 1700

Los insaculats al Govern de dita Vila de Castelló de la Plana. Així en les antecedents insaculacions com en la última que s'ha fet en vint i hu, vint i dos, vint i cinch del corrent mes de maig del any de la Nativitat del Nostre Senyor Deu Jesuchrist de MDCC són los següents:

Bossa de Militars: 1. Don Martí Mas (obiit), 2. Don Felip Jover (obiit), 3. Don Fernando Miralles (obiit), 4. Gerony Bou generós (obiit), 5. Don Macià Igual (obiit), 6.

Don Jaume Vallés (obiit), 7. Don Antoni Gombau (obiit), 8. Don Gerony Vallés (obiit), 9. Josep Castell de Museros generòs, 10. Don Joachim Gombau (obiit), 11. Don Lluís Escorcia y Ladrón (obiit) i 12. Don Vicent Feliu i Sisternés, 13. Don Cosme Feliu.

Bossa de Jurat en cap del Bras Real: 1. Vicent Figuerola ciutadà (obiit), 2. Francesc Andreu ciutadà (obiit), 3. Cosme Martí ciutadà (obiit), 4. Doctor Josep Casalís ciutadà (obiit), 5. Batiste Jover ciutadà (obiit), 6. Tomàs March ciutadà, 7. Doctor Ignacio Figuerola (obiit), 8. Martí Viciano Doctor en Medicina, 9. Doctor Jaume Giner, 10. Doctor Pere Giner de Bou (obiit), 11. Doctor Vicent Martí, 12. Doctor Cristòfol Vilar (obiit), 13. Doctor Josep Castell Planell (obiit), 14. Doctor Jacinto March (obiit), 15. Josep Segarra ciutadà (obiit), 16. Doctor Vicent Anglès (obiit), 17. Doctor Félix Roig, 18. Doctor Joan Andreu, 19. Doctor Vicent Tosquella i 20. Doctor Joan Sanchís (obiit).

Bossa Segona de Jurat dita de Artistas: 1. Vicent Pasqual notari(obiit), 2. Vicent Ferrer notari(obiit), 3. (tachado el nombre y no se puede leer), 4. Miquel Sanchís notari(obiit), 5. Miquel Bonet notari(obiit), 6. Josep Amposta cirurgià(obiit), 7. Pere Breva notari, 8. Felip Breva notari(obiit), 9. Gaspar Rubert notari, 10. Pere Museros notari, 11. Josep Blasco notari(obiit), 12. Joan Safont notari, 13. Aleixandre Martí notari(obiit), 14. Pere Mercer pintor(obiit), 15. Joan Montanyés notari, 16. Pere Vidal notari(obiit), 17. Josep Llorens de Planell notari, 18. Jaume Pasqual notari, 19. Josep Llopis notari i 20. Severino Museros notari capellà. 
Bossa de Jurat $3^{\text {a }}$ y $4^{\text {a }}$ : 1. Antoni Castell (obiit), 2. Joan Museros de Monserrat (obiit), 3. Miquel Navarro de Gaspar (obiit), 4. Miquel Pasqual de Francesc (obiit), 5. Josep Avinent de Baltasar (obiit), 6. Jaume Viciano de Miquel (obiit), 7. Pere Roig de Jaume (obiit), 8. March Casalís (obiit), 9. Gerony Castell (obiit), 10. Miquel Vilarroig de Nicolau (obiit), 11. Domingo Vilarroig (obiit), 12. Francesc Amiguet (obiit), 13. Josep Vilarroig de Jaume (obiit), 14. Miquel Navarro de Antoni (obiit), 15. Josep Museros de Vicent (obiit), 16. Josep Rubert (obiit), 17. Andreu Castellet (obiit), 18. Félix Vilarroig (obiit), 19. Agostí Reboll (obiit), 20. Francesc Vilarroig (obiit), 21. Jaume Breva de Vilarroig (obiit), 22. Joan Breva (obiit), 23. Miquel Avinent de Josep (obiit), 24. Vicent Pasqual de Miquel, 25. Joan Museros de Joan (obiit), 26. Josep Pasqual de Francesc (obiit), 27. Ignacio Breva (obiit), 28. Jaume Breva de Jaume (obiit), 29. Baltazar Avinent, 30. Vicent Figuerola de Francesc, 31. Josep Castell de Antoni (obiit), 32. Félix Tirado (obiit), 33. Josep Castell de Gerony (obiit), 34. Andreu Ribalta (obiit), 35. Tomàs Blasco, 36. Pere Museros de Pere, 37. Josep Breva, 38. Tomàs Breva, 39. Miquel Pasqual de Miquel i 40. Josep Vilarroig de Miquel.

Bossa de Justicia del Bras Real : 1. Vicent Figuerola ciutadà (obiit), 2. Vicent Pasqual notari (obiit), 3. Cosme Martí ciutadà (obiit), 4. Francesc Andreu ciutadà (obiit), 5. Pere Roig de Jaume (obiit), 6. Antoni Castell(obiit), 7. Doctor Josep Casalís (obiit), 8. Vicent Tosquella(obiit), 9. Miquel Sanchís notari (obiit), 10. Joan Museros de Monserrat(obiit), 11. Batiste Jover ciutadà(obiit), 12. Tomàs March ciutadà (obiit), 13. Doctor Ignacio Figuerola (obiit), 14. Martí Viciano Doctor en Medicina (obiit), 15. Doctor Jaume Giner, 16. Josep Amposta cirugià (obiit), 17. Doctor Vicent Martí, 18. Doctor Pere Giner de Bou (obiit), 19. Doctor Cristòfol Vilar (obiit), 20. Doctor Jacinto March (obiit), 21. Josep Segarra ciutadà (obiit), 22. Doctor Vicent Anglés (obiit), 23. Doctor Félix Roig, 24. Doctor Joan Andreu, 25. Doctor Vicent Tosquella, 26. Pere Mercer pintor (obiit), 27. Miquel Bonet notari (obiit), 28. Gaspar Rubert notari, 29. Joan Montanyés notari i 30. March Casalís (obiit).

Bossa de Mustassaf del Bras Real: 1. Vicent Figuerola ciutadà (obiit), 2. Vicent Pasqual notari(obiit), 3. Francesc Andreu ciutadà(obiit), 4. Cosme Martí ciutadà (obiit), 5. Vicent Tosquella(obiit), 6. Doctor Josep Casalís(obiit), 7. Vicent Ferrer notari (obiit), 8. Miquel Sanchís notari (obiit), 9. Miquel Pasqual de Francesc (obiit), 10. Antoni Castell(obiit), 11. Batiste Jover ciutadà (obiit), 12. Tomàs March ciutadà(obiit), 13. 
Doctor Ignacio Figuerola (obiit), 14. Martí Viciano Doctor en Medicina (obiit), 15. Doctor Jaume Giner (obiit), 16. Miquel Bonet notari(obiit), 17. Josep Amposta cirurgíà (obiit), 18. Jaume Viciano de Miquel(obiit), 19. Doctor Pere Viciano de Bou (obiit), 20. Doctor Vicent Martí, 21. Doctor Cristòfol Vilar (obiit), 22. Doctor Castell de Planell (obiit), 23. Pere Breva, 24. Felip Breva (obiit), 25. Gaspar Rubert, 26. Doctor Jacinto March (obiit), 27. Josep Segarra ciutadà, 28. March Casalís (obiit), 29. Jaume Breva de Vilarroig (obiit), 30. Doctor Vicent Anglés (obiit), 31. Doctor Félix Roig, 32. Doctor Joan Andreu, 33. Doctor Vicent Tosquella, 34. Doctor Joan Sanchís (obiit), 35. Joan Safont notari, 36. Pere Mercer pintor (obiit), 37. Josep Blasco notari (obiit), 38. Miquel Navarro de Gaspar (obiit), 39. Miquel Vilarroig de Nicolau (obiit) i 40. Vicent Figuerola de Francesc.

Bossa de Cequier: 1. Vicent Figuerola ciutadà (obiit), 2. Vicent Pasqual notari (obiit), 3. Antoni Castell (obiit), 4. Miquel Navarro de Gaspar (obiit), 5. Josep Avinent de Baltazar (obiit), 6. Joan Museros de Monserrat (obiit), 7. Miquel Pasqual de Francesc (obiit), 8. Francesc Andreu ciutadà (obiit), 9. Doctor Josep Casalís (obiit), 10. Vicent Tosquella (obiit), 11. Miquel Sanchís notari (obiit), 12. Pere Roig de Jaume (obiit), 13. March Casalís (obiit), 14. Jaume Viciano de Miquel (obiit), 15. Gerony Castell (obiit), 16. Miquel Vilarroig de Nicolau, 17. Domingo Vilarroig (obiit), 18. Batiste Jover ciutadà (obiit), 19. Francesc Amiguet (obiit), 20. Agostí Reboll (obiit), 21. Josep Amposta cirurgià (obiit), 22. Gaspar Rubert notari, 23. Jaume Breva de Vilarroig (obiit), 24. Francesc Vilarroig (obiit), 25. Andreu Castellet (obiit), 26. Josep Rubert (obiit), 27. Josep Museros de Vicent (obiit), 28. Félix Vilarroig (obiit), 29. Miquel Navarro de Antoni (obiit), 30. Doctor Jacinto March (obiit), 31. Josep Segarra ciutadà (obiit), 32. Josep Vilarroig de Jaume (obiit), 33. Joan Breva, 34. Miquel Avinent (obiit), 35. Josep Pasqual de Francesc (obiit), 36. Vicent Pasqual de Miquel, 37. Ignacio Breva (obiit), 38. Joan Safont notari, 39. Doctor Vicent Anglés, 40. Doctor Félix Roig, 41. Doctor Joan Sanchís (obiit), 42. Pere Museros notari, 43. Joan Montanyés notari, 44. Jaume Pasqual notari, 45. Jaume Breva de Jaume (obiit), 46. Josep Castell de Antoni, 47. Baltazar Avinent , 48. Vicent Figuerola de Francesc, 49. Andreu Ribalta (obiit) i 50. Pere Museros de Pere.

Bossa de Escrivans: 1.Vicent Pasqual notari (obiit), 2. Vicent (el apellido no se ve porque esta tachado) notari (obiit), 3. Vicent Ferrer notari (obiit), 4. Miquel Sanchís 
notari (obiit), 5. Miquel Bonet notari (obiit), 6. Pere Breva notari, 7. Pere Museros notari, 8. Gaspar Rubert notari, 9. Aleixandre Martí notari i 10. Pere Vidal notari (obiit).

Bossa de Consellers de Ma major: 1. Vicent Figuerola ciutadà (obiit), 2. Vicent Pasqual notari (obiit), 3. Francesc Andreu ciutadà (obiit), 4. Vicent Tosquella ciutadà (obiit), 5. Vicent Ferrer notari (obiit), 6. Cosme Martí ciutadà (obiit), 7. Miquel Sanchís notari (obiit), 8. Doctor Josep Casalís, 9. Josep Amposta cirurgià, 10. Batiste Jover ciutadà, 11. Miquel Bonet notari, 12. Tomàs March ciutadà, 13. Doctor Ignacio Figuerola (obiit), 14. Martí Viciano Doctor en Medicina (obiit), 15. Pere Breva notari, 16. Felip Breva notari, 17. Doctor Jaume Giner, 18. Doctor Pere Giner de Bou, 19. Doctor Vicent Martí, 20. Doctor Cristòfol Vilar (obiit), 21. Doctor Josep Castell de Planell, 22. Gaspar Rubert notari, 23. Pere Museros notari, 24. Josep Blasco notari (obiit), 25. Joan Safont notari, 26. Doctor Jacinto March, 27. Josep Segarra ciutadà (obiit), 28. Aleixandre Martí ciutadà, 29. Pere Mercer pintor, 30. Joan Montanyés notari, 31. Pere Vidal notari (obiit), 32. Doctor Vicent Anglés, 33. Doctor Félix Roig, 34. Doctor Joan Andreu, 35. Doctor Vicent Tosquella, 36. Doctor Joan Sanchís, 37. Josep Llorens de Planell notari, 38. Jaume Pasqual notari, 39. Josep Llopis notari i 40. Severino Museros notari.

Bossa de Concellers de Mà menor: 1. Antoni Castell, 2. Joan Museros de Monserrat (obiit), 3. Miquel Navarro de Gaspar, 4. Miquel Pasqual de Francesc, 5. Josep Avinent de Baltazar (obiit), 6. Pere Roig de Jaume (obiit), 7. March Casalís (obiit), 8. Jaume Viciano de Miquel (obiit), 9. Gerony Castell (obiit), 10. Miquel Vilarroig de Nicolau, 11. Domingo Vilarroig, 12. Francesc Amiguet (obiit), 13. Josep Vilarroig de Jaume (obiit), 14. Josep Rubert (obiit), 15. Andreu Castellet, 16. Miquel Navarro de Antoni (obiit), 17. Josep Museros de Vicent, 18. Félix Vilarroig (obiit), 19. Agostí Reboll, 20. Francesc Vilarroig (obiit), 21. Jaume Breva de Vilarroig (obiit), 22. Joan Breva, 23. Miquel Avinent (obiit), 24. Vicent Pasqual de Miquel, 25. Joan Museros de Joan, 26. Josep Pasqual de Francesc (obiit), 27. Ignacio Breva, 28. Jaume Breva de Jaume, 29. Baltazar Avinent, 30. Vicent Figuerola de Francesc, 31. Josep Castell de Antoni, 32. Félix Tirado, 33. Josep Castell de Gerony, 34. Antoni Ribalta, 35. Tomàs Blasco, 36. Pere Museros de Pere, 37. Josep Breva, 38. Tomàs Breva, 39. Miquel Pasqual de Miquel i 40. Josep Vilarroig de Josep. 
Die XXVI Mensis May Anno an(....) Annis MDCC

Don Andreu Monserrat i Siurana Crespi del Valldaurar Lloctinent de Portantveus de General Governador de la Ciutat i Regne de (Vallat) en la present Vila i Governació de Castelló de la Plana. Cosme Martí ciutadà Batllé per sa majestat en dita present vila, Joseph Segarra ciutadà Justicia, Don Macià Igual i Borras, Doctor Ignacio Figuerola, Aleixandre Martí notari i Joseph Museros de Monserrat, los jurats de dita vila i en presencia de Don Fernando Miralles, Don Gerona Vallés.

Militars: 1. Josep Castell de Museros, 2. Don Vicent Feliu i Sisternés i Don Cosme Feliu.

Ciutadans 20: Tomàs March (nombre tachado), Doctor Jaume Giner, Doctor Vicent Martí, Doctor Josep Castell (nombre tachado), Doctor Vicent Anglés (nombre tachado), Doctor Félix Roig, Doctor Joan Andreu i Doctor Vicent Tosquella.

Artistes 20: Pere Breva, Gaspar Rubert, Pere Museros, Joan Safont, Aleixandre Martí (nombre tachado), Joan Montanyés, Josep Llorens, Jaume Pasqual, Josep Llopis.

Llaurador $3^{\text {a }}$ y $\mathbf{4}^{\text {aa: }}$ Miquel Vilarroig, Joan Breva (nombre tachado), Vicent Pasqual, Baltazar Avinent, Vicent Figuerola, Josep Castell de Antoni (nombre tachado), Tomàs Blasco i Pere Museros.

Justicia 30: Tomàs March (nombre tachado), Doctor Jaume Giner, Doctor Vicent Martí, Doctor Vicent Anglés (nombre tachado), Doctor Félix Roig, Doctor Joan Andreu, Doctor Vicent Tosquella, Gaspar Rubert i Joan Montanyés.

Mustassaf 40: Tomàs March (nombre tachado), Doctor Jaume Giner, Doctor Vicent Martí, Doctor Josep Castell (nombre tachado), Pere Breva, Gaspar Rubert, Doctor Vicent Anglés (nombre tachado), Doctor Félix Roig, Doctor Joan Andreu, Doctor Vicent Tosquella, Joan Safont, Miquel Vilarroig i Vicent Figuerola.

Cequier 50: Miquel Vilarroig, Gaspar Rubert, Joan Breva (nombre tachado), Vicent Pasqual, Doctor Vicent Anglés (nombre tachado), (hoja rota y no se puede ver el nombre), Doctor Félix Roig, Pere Museros, Joan Montanyés, Jaume Pasqual, Josep 
Castell (nombre tachado), Baltazar Avinent, Vicent Figuerola de Francesc i Pere Museros de Pere.

Escrivans 10: Pere Breva, Pere Museros, Gaspar Rubert i Aleixandre Martí (nombre tachado). 


\subsection{Documento 9: Familias en Castellón entre 1588 y 1769.}

Tabla 39: Miembros de las familias en Castellón entre 1588 y $1769^{229}$.

\begin{tabular}{|c|c|c|c|c|c|}
\hline Familia & 1588 & 1769 & Familia & 1588 & 1769 \\
\hline Agramunt & 4 & 6 & Llorens & 2 & 21 \\
\hline Alberich & 8 & 0 & March & 3 & 2 \\
\hline Albiol & 3 & 8 & Marco & 0 & 12 \\
\hline Alegre & 3 & 7 & Marí & 1 & 20 \\
\hline Amiguet & 15 & 6 & Martí & 12 & 16 \\
\hline Amposta & 6 & 4 & Martínez & 1 & 16 \\
\hline Andreu & 5 & 3 & Melià & 1 & 14 \\
\hline Aragonés & 3 & 0 & Miralles & 5 & 26 \\
\hline Arrufat & 4 & 10 & Molina & 6 & 3 \\
\hline Avinent & 7 & 16 & Moliner & 5 & 13 \\
\hline Balaguer & 11 & 16 & Molinos & 6 & 12 \\
\hline Beltrán & 5 & 14 & Monroig & 1 & 13 \\
\hline Bernat & 10 & 14 & Monserrat & 2 & 1 \\
\hline Blasco & 4 & 19 & Montanyés & 6 & 14 \\
\hline Boix & 4 & 23 & Mur & 0 & 1 \\
\hline Bosch & 7 & 9 & Museros & 13 & 11 \\
\hline Brunell & 3 & 0 & Navarro & 7 & 27 \\
\hline Calbo & $*$ & $*$ & Nebot & 1 & 32 \\
\hline Camanyes & 1 & 15 & Nicolau & 5 & 4 \\
\hline Capero & $* *$ & $* *$ & Pasqual & 11 & 49 \\
\hline Castell & 27 & 37 & Pastor & 10 & 9 \\
\hline Castellet & 4 & 3 & Peris & 12 & 28 \\
\hline Caudet & 2 & 15 & Ramos & 1 & 24 \\
\hline Climent & 1 & 10 & Reboll & 0 & 6 \\
\hline Coll & 4 & 2 & Ripollés & 3 & 22 \\
\hline Domènech & 3 & 9 & Roca & 3 & 10 \\
\hline Eiximeno & 4 & 7 & Roig & 4 & 18 \\
\hline Escoin & 1 & 12 & Ros & 1 & 8 \\
\hline Escuder & 3 & 12 & Rovira & 0 & 12 \\
\hline Esteve & 3 & 14 & Ruiz & 1 & 12 \\
\hline Estellés & 4 & 11 & Salazar & 0 & 13 \\
\hline Fabregat & 4 & 33 & Sales & 1 & 19 \\
\hline Feliu & 3 & 0 & Salvador & 4 & 10 \\
\hline Ferrandis & 3 & 17 & Sanç & 5 & 19 \\
\hline Ferrer & 18 & 20 & Sanchís & 8 & 10 \\
\hline Figuerola & 8 & 2 & Segura & 1 & 10 \\
\hline Flors & 8 & 4 & Sidro & 0 & 12 \\
\hline Folch & 2 & 4 & Sisternés & 3 & 0 \\
\hline Font & 7 & 11 & Serra & 8 & 0 \\
\hline Gascó & 9 & 1 & Soler & 1 & 17 \\
\hline García & 2 & 22 & Tirado & 2 & 36 \\
\hline Gargallo & 3 & 15 & Torrent & 5 & 12 \\
\hline Gil & 3 & 10 & Torres & 2 & 18 \\
\hline Giner & 9 & 7 & Tosquella & 3 & 1 \\
\hline Gombau & 4 & 2 & Vallés & 0 & 15 \\
\hline Gómez & 0 & 36 & Viciano & 12 & 24 \\
\hline Ibañez & 0 & 9 & Vidal & 4 & 3 \\
\hline Igual & 5 & 13 & Vilarroig & 9 & 18 \\
\hline Jover & 7 & 0 & Vicent & 8 & 19 \\
\hline Llansola & 7 & 4 & Vives & 1 & 14 \\
\hline López & 0 & 12 & & & \\
\hline Llopis & 4 & 14 & & & \\
\hline
\end{tabular}

*Los Calbo tuvieron en el periodo intermedio una familia pero al final no hay ninguno.

** Los Capero tuvieron tres familias en el período intermedio pero al final no hay ninguno.

${ }^{229}$ Sánchez Adell, J. (1965): Cognoms castellonencs de 1588 i 1769. Butlletí de la Societat Castellonenca de Cultura. Quadern IV. Octubre-Desembre de 1965. Castelló de la Plana, pp. 205-230. El cuadro se ha elaborado a partir de los datos que aporta el autor en la referida obra. 


\subsection{Documento 10: Relación de asesores de justicia ${ }^{230}$.}

\section{Tabla 40: Relación de asesores de justicia:}

\begin{tabular}{|cc|}
\hline Año & Nombres \\
\hline $\mathbf{1 5 9 8}$ & Tomàs March \\
$\mathbf{1 5 9 9}$ & Gerony Jover \\
$\mathbf{1 6 0 0}$ & Gerony Jover \\
$\mathbf{1 6 0 1}$ & Cristòfol Miralles \\
$\mathbf{1 6 0 2}$ & Tomàs March \\
$\mathbf{1 6 0 3}$ & \\
$\mathbf{1 6 0 4}$ & \\
$\mathbf{1 6 0 5}$ & Vicent Estany \\
$\mathbf{1 6 0 6}$ & Tomàs March \\
$\mathbf{1 6 0 7}$ & \\
$\mathbf{1 6 0 8}$ & Vicent Estany \\
$\mathbf{1 6 0 9}$ & Gerony Jover \\
$\mathbf{1 6 1 0}$ & Gerony Micó \\
$\mathbf{1 6 1 1}$ & Tomàs March \\
$\mathbf{1 6 1 2}$ & \\
$\mathbf{1 6 1 3}$ & Tomàs March \\
$\mathbf{1 6 1 4}$ & Miquel Moliner \\
$\mathbf{1 6 1 5}$ & Jaume Bonet \\
$\mathbf{1 6 1 6}$ & Tomàs March \\
$\mathbf{1 6 1 7}$ & Miquel Moliner \\
$\mathbf{1 6 1 8}$ & \\
$\mathbf{1 6 1 9}$ & \\
$\mathbf{1 6 2 0}$ & \\
$\mathbf{1 6 2 1}$ & Batiste Gascó \\
$\mathbf{1 6 2 2}$ & Jaume Bonet \\
$\mathbf{1 6 2 3}$ & Nicolau Figuerola \\
$\mathbf{1 6 2 4}$ & Tomàs March \\
$\mathbf{1 6 2 5}$ & (...) Gascó \\
$\mathbf{1 6 2 6}$ & Bernabeu Giner \\
$\mathbf{1 6 2 7}$ & Tomàs March \\
$\mathbf{1 6 2 8}$ & Batiste Gascó \\
$\mathbf{1 6 2 9}$ & Fulgenci Mascarós \\
$\mathbf{1 6 3 0}$ & Nicolau Figuerola \\
$\mathbf{1 6 3 1}$ & Joan Batiste Gascó \\
$\mathbf{1 6 3 2}$ & Miquel Moliner \\
$\mathbf{1 6 3 3}$ & Nicolau Figuerola \\
$\mathbf{1 6 3 4}$ & Micer Bernat Gascó \\
$\mathbf{1 6 3 5}$ & Joan Batiste Gascó \\
$\mathbf{1 6 3 6}$ & Nicolau Figuerola \\
$\mathbf{1 6 3 7}$ & Cosme Feliu \\
$\mathbf{1 6 3 9}$ & Nicolau Arrufat \\
& Jaume Giner \\
\hline
\end{tabular}

${ }^{230}$ AHMC. Judiciari. Elaborada a partir de la reuniones del Consell entre 1597 y 1707 . No tenemos datos de $\operatorname{los}$ años 1603, 1604, 1607, 1612, 1618, 1619 y 1620. La elección de asesor se hace en diciembre después de haber extraído al justicia entre una terna que propone el Consell y el que obtiene más votos es elegido asesor. En 1625 es ilegible el nombre por el papel y la caligrafía pero podemos suponer que será Batiste Gascó. En el año 1642 por la caligrafía es ilegible pero lo lógico es pensar que será Jaume Giner. Cuando se refiere a Doctor quiere decir Doctor en leyes. El asesor para el año 1677 se elige en enero de es mismo año por el pleito que había en la Real Audiencia y que afectó también a otros cargos electos. 


\begin{tabular}{|c|c|}
\hline 1640 & Joan Batiste Gascó \\
\hline 1641 & Nicolau Figuerola \\
\hline 1642 & Jaume $(\ldots)$ \\
\hline 1643 & Vicent Vilar \\
\hline 1644 & Nicolau Figuerola \\
\hline 1645 & Jaume Giner \\
\hline 1646 & Josep Casalís \\
\hline 1647 & Vicent Vilar \\
\hline 1648 & Miquel Giner \\
\hline 1649 & Vicent Castellet \\
\hline 1650 & Vicent Vilar \\
\hline 1651 & Jaume Giner \\
\hline 1652 & Jaume Giner \\
\hline 1653 & Cosme Feliu \\
\hline 1654 & Joan Cases \\
\hline 1655 & Jaume Giner \\
\hline 1656 & Melchor Calbo \\
\hline 1657 & Joan Cases \\
\hline 1658 & Jaume Giner \\
\hline 1659 & Melchor Calbo \\
\hline 1660 & Francesc Ferrer \\
\hline 1661 & Batiste Orts \\
\hline 1662 & Melchor Calbo \\
\hline 1663 & Francesc Ferrer \\
\hline 1664 & Felip Jover \\
\hline 1665 & Joan Cases \\
\hline 1666 & Francesc Ferrer \\
\hline 1667 & Josep Miralles \\
\hline 1668 & Felip Jover \\
\hline 1669 & Ignacio Vives \\
\hline 1670 & Joan Cases \\
\hline 1671 & Josep Casalís \\
\hline 1672 & Ignacio Vives \\
\hline 1673 & Francesc Joan Cases \\
\hline 1674 & Joan Timor \\
\hline 1675 & Joan Timor \\
\hline 1676 & Josep Casalís \\
\hline 1677 & Jaume Giner \\
\hline 1678 & Ignacio Figuerola \\
\hline 1679 & Francesc Ferrer \\
\hline 1680 & Joan Timor \\
\hline 1681 & Pere Giner \\
\hline 1682 & Ignacio Figuerola \\
\hline 1683 & Josep Castell \\
\hline 1684 & Vicent Ferrer \\
\hline 1685 & Gerony Vallés \\
\hline 1686 & Gerony Vallés \\
\hline 1687 & Pere Giner de Bou \\
\hline 1688 & Cristòfol Vilar \\
\hline 1689 & Vicent Anglés \\
\hline 1690 & Vicent Ferrer \\
\hline 1691 & Joan Andreu \\
\hline 1692 & Miquel Falcó \\
\hline 1693 & Vicent Anglés \\
\hline 1694 & Cristofol Vilar \\
\hline 1695 & Miquel Falcó \\
\hline 1696 & Vicent Anglés \\
\hline 1697 & Félix Porta \\
\hline 1698 & Félix Sisternés \\
\hline 1699 & Joan Marsal \\
\hline
\end{tabular}




\begin{tabular}{|lc|}
\hline $\mathbf{1 7 0 0}$ & Vicent Anglés \\
$\mathbf{1 7 0 1}$ & Cristòfol Vilar \\
$\mathbf{1 7 0 2}$ & Félix Porta \\
$\mathbf{1 7 0 3}$ & Félix Sisternés \\
$\mathbf{1 7 0 4}$ & Vicent Tormo \\
$\mathbf{1 7 0 5}$ & Joan Marsal \\
$\mathbf{1 7 0 6}$ & Vicent Ferrer \\
$\mathbf{1 7 0 7}$ & Felip Català \\
\hline
\end{tabular}




\section{Relación de tablas.}

Tabla 1: Censos de población de diversos autores: 53

Tabla 2: Consejeros de mano mayor y menor entre 1597 y 1707: 72

Tabla 3: Consejeros militares en la ciudad de Castellón entre 1597 y 1707: 89

Tabla 4: Justicias de la ciudad de Castellón entre 1597 y 1707: 100

Tabla 5: Jurados de la ciudad de Castellón entre 1597 y 1707: .................................... 106

Tabla 6: Almotacén de la ciudad de Castellón entre 1597 y 1707: ............................... 111

Tabla 7: Escribanos de la ciudad de Castellón entre 1597 y 1707: .............................. 114

Tabla 8:Acequieros de la ciudad de Castellón entre 1597 y 1707: .............................. 116

Tabla 9: Las insaculaciones y el número de personas insaculadas: ............................ 125

Tabla 10: Insaculaciones bolsa generosos o caballeros:.............................................. 128

Tabla 11: Insaculaciones bolsa de justicia del brazo real:......................................... 130

Tabla 12: Insaculaciones bolsa de jurado primero del brazo real................................ 132

Tabla 13: Insaculaciones bolsa de jurado segundo del brazo real:............................. 134

Tabla 14: Insaculaciones bolsa de jurado terceros y cuarto del brazo real: .................. 136

Tabla 15: Insaculaciones bolsa de almotacén del brazo real:..................................... 139



Tabla 17: Insaculaciones bolsa de escribanos: ........................................................ 143

Tabla 18: Insaculaciones bolsa de consejeros de mano mayor: .................................. 145

Tabla 19: Insaculaciones bolsa de consejeros de mano menor: .................................. 147



Tabla 21: Distribución del cargo de justicia según el grupo de la oligarquía: .............. 154

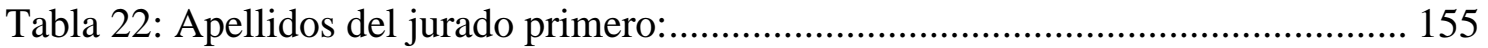

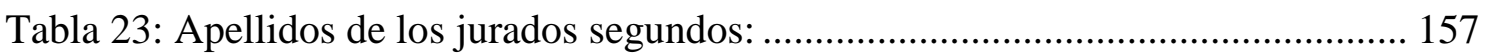



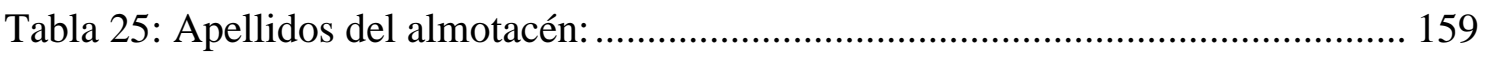

Tabla 26: Distribución del cargo de almotacén según el grupo de la oligarquía que lo

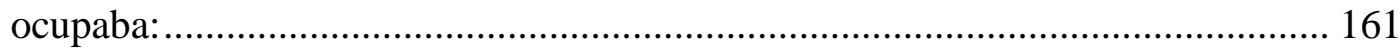

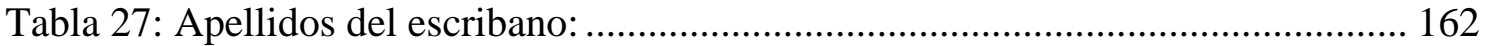

Tabla 28: Apellidos de los consejeros del brazo militar: ........................................... 163

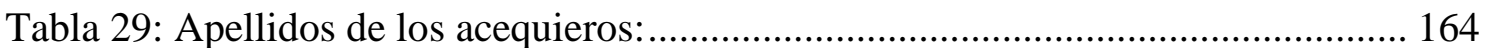

Tabla 30: Distribución del cargo de acequieros según el grupo de la oligarquía que lo ocupaba: 




Tabla 32: Distribución del cargo de síndico según el grupo de la oligarquía: .............. 168



Tabla 34: Apellidos de los consejeros de mano mayor: .............................................. 170

Tabla 35: Apellidos de los consejeros de mano menor: ............................................... 172

Tabla 36: Apellidos que ocuparon uno de los 36 puestos del Consell: ........................ 176

Tabla 37: Relación de corregidores entre 1710-1729: ................................................ 186

Tabla 38: Relación de los regidores entre 1710-1729:.............................................. 187

Tabla 39: Miembros de las familias en Castellón entre 1588 y 1769. .......................... 350

Tabla 40: Relación de asesores de justicia: ................................................................ 351 


\section{Relación de ilustraciones.}

Ilustración 1: Redolines de cera de la insaculación.......................................................... 61

Ilustración 2: Simulación del edificio del antiguo Consell de Castellón: ....................... 63



Ilustración 4: Jurado primero de la villa de Castellón .................................................. 105

Ilustración 5: Bolsa de jurado tercero y cuarto........................................................... 138



Ilustración 7: Plano de Castellón a finales s. XVI...................................................... 178 